\title{
RIVOLTE URBANE E RIVOLTE CONTADINE NELL'EUROPA DEL TRECENTO
}

Un confronto

a cura di

Giuliano Pinto

Monique Bourin

Giovanni Cherubini 
Biblioteca di Storia

$-6-$ 


\title{
Centro di Studi sulla Civiltà Comunale \\ Dipartimento di Studi storici e geografici Università degli Studi di Firenze
}

\author{
Comitato Scientificio \\ Giovanni Cherubini (Direttore) \\ Anna Benvenuti \\ Franco Cardini \\ Paolo Grossi \\ Francesca Klein \\ Jean-Claude Marie Vigueur \\ Enrica Neri \\ Giuliano Pinto \\ Andrea Zorzi
}

Volumi pubblicati

A. Zorzi (a cura di), La civiltà comunale italiana nella storiografia internazionale M. Bourin, G. Cherubini, G. Pinto (a cura di), Rivolte urbane e rivolte contadine nell'Europa del Trecento. Un confronto 


\title{
Rivolte urbane e rivolte contadine nell'Europa del Trecento \\ Un confronto
}

\author{
a cura di \\ Monique Bourin \\ Giovanni Cherubini \\ Giuliano Pinto
}

Firenze University Press

2008 
Rivolte urbane e rivolte contadine nell'Europa del Trecento : un confronto : atti del convegno internazionale di studi (Firenze, 30 marzo - 1 aprile 2006) / a cura di Monique Bourin, Giovanni Cherubini, Giuliano Pinto. - Firenze University Press, 2008. (Biblioteca di storia ; 6)

http://digital.casalini.it/9788884538833

ISBN 978-88-8453-883-3 (online)

ISBN 978-88-8453-882-6 (print)

940.1072 (ed. 20)

Medioevo - Storiografia

In copertina: Biblioteca Medicea Laurenziana, Firenze, ms. Tempi 3, c. 79r Su concessione del Ministero per i Beni e le Attività Culturali È vietata ogni ulteriore riproduzione con qualsiasi mezzo.

Impaginazione: $\mathrm{A} \& \mathrm{D}$

Progetto grafico di Alberto Pizarro Fernández

(C) 2008 Firenze University Press

Università degli Studi di Firenze

Firenze University Press

Borgo Albizi, 28, 50122 Firenze, Italy

http://www.fupress.com/

Printed in Italy 


\section{SOMMARIO}

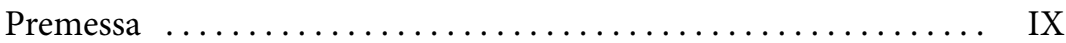

Samuel K. Cohn, Jr.

La peculiarità degli Inglesi e le rivolte del tardo Medioevo $\ldots$. Marc Boone

Le comté de Flandre dans le long XIV ${ }^{\mathrm{e}}$ siècle: une société

urbanisée face aux crises du bas Moyen Age

Monique Bourin

Les révoltes dans la France du XIV ${ }^{\mathrm{e}}$ siècle: traditions

historiographiques et nouvelles recherches $\ldots \ldots \ldots \ldots \ldots$.

Hipólito Rafael Oliva Herrer

Révoltes et conflits sociaux dans la Couronne de Castille

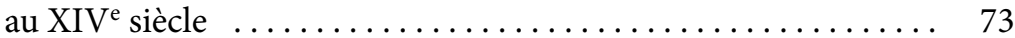

Giovanni Cherubini

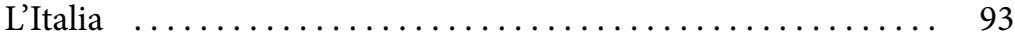

Pierre Monnet

Les révoltes urbaines en Allemagne au XIV ${ }^{\mathrm{e}}$ siècle:

un état de la question $\ldots \ldots \ldots \ldots \ldots \ldots \ldots \ldots \ldots \ldots \ldots$

Alessandro Barbero

Una rivolta antinobiliare nel Piemonte trecentesco:

il Tuchinaggio del Canavese $\ldots \ldots \ldots \ldots \ldots \ldots \ldots \ldots \ldots . \ldots \ldots$

Paolo Grillo

Rivolte antiviscontee a Milano e nelle campagne fra XIII

e XIV secolo .................................. 197

Rinaldo Comba

Boschi e alpeggi fra certosini e contadini nell'Italia

centro-settentrionale: fine XII secolo-inizi XV

Valeria Braidi

Le rivolte del pane: Bologna 1311 ................. 251

Franco Franceschi

I 'Ciompi' a Firenze, Siena e Perugia ............... 277 
Francesco Panero

Signori e servi: una conflittualità permanente .......... 305 Giulia Barone

Le componenti religiose delle rivolte $\ldots \ldots \ldots \ldots \ldots \ldots \ldots 323$ Giuliano Pinto

Congiuntura economica, conflitti sociali, rivolte $\ldots \ldots \ldots \ldots 337$ Jean-Claude Maire Vigueur

Le rivolte cittadine contro i "tiranni" $\ldots \ldots \ldots \ldots \ldots \ldots \ldots . \ldots 35$ Andrea Zorzi

Politiche giudiziarie e ordine pubblico $\ldots \ldots \ldots \ldots \ldots \ldots . \ldots 381$

Indice dei nomi e dei luoghi $\ldots \ldots \ldots \ldots \ldots \ldots \ldots \ldots \ldots \ldots \ldots$ 


\section{PREMESSA}

L'idea di organizzare un convegno sulle rivolte urbane e rurali del XIV secolo in una prospettiva europea è maturata alcuni anni fa in occasione di un incontro e di uno scambio di opinioni tra Monique Bourin, Giovanni Cherubini e il sottoscritto. Non era un'idea peregrina, perché tutti e tre avevamo fatto i conti, nelle nostre ricerche, anche se con approcci diversi, con le rivolte e i conflitti sociali del basso Medioevo. Ci parve opportuno riprendere una tematica che aveva conosciuto un certo oblio negli ultimi decenni rispetto alla straordinaria fortuna di cui aveva goduto soprattutto negli anni ' 60 e '70 del secolo scorso, salvo una ripresa di interesse proprio in questi ultimissimi anni, ma in contesti assai diversi. Naturalmente a questa attenzione così mutevole nel tempo non erano e non sono affatto estranee le vicende politiche, sociali, culturali della contemporaneità.

Abbiamo deciso di preparare il convegno seguendo tre diverse forme di analisi all'interno di un taglio cronologico che fa riferimento al Trecento, un periodo interessato da rivolte che investirono un po' tutte le realtà europee. Ma si deve intendere un Trecento largo, che va dagli ultimi decenni del XIII secolo sino ai primi del XV, secondo una cronologia indicata a suo tempo nel celebre volume del 1970 Ongles bleus, Jacques et Ciompi di Michel Mollat e Philippe Wolff. Abbiamo pensato innanzi tutto a una serie di relazioni 'geografiche' relative alle principali aree dell'Occidente europeo (Inghilterra, Francia, Paesi Bassi, Germania, Penisola iberica), in modo che si potesse fare il punto sullo stato degli studi, sulla cronologia delle rivolte, sulle diverse tipologie. E insieme che si evidenziassero le 'novitä' nel contesto sociale, economico, politico che in qualche misura furono alla base dei diversi sommovimenti. Poi l'analisi di casi circoscritti o di episodi ben precisi, tutti relativi alla penisola italiana; ma non si è trattato di una scelta: era prevista almeno una relazione relativa all'Oltralpe. Infine alcuni approfondimenti tematici che cercassero di evidenziare tratti comuni (se ce ne sono stati) alle rivolte, oppure il diverso peso di alcune spiegazioni avanzate dai diversi studiosi che si sono misurati con esse. Alle nostre sollecitazioni hanno risposto positivamente studiosi provenienti da numerose università, italiane e straniere. 
Il progetto è stato fatto proprio dal Comitato scientifico del Centro di studi sulla civiltà comunale (CESC) dell'Università degli studi di Firenze, e ha ottenuto l'appoggio della Deputazione di storia patria per la Toscana (memore dei Ciompi e dei lavori che ai Ciompi dedicarono in diverso modo, in tempi diversi, due dei suoi più prestigiosi presidenti: Niccolò Rodolico ed Ernesto Sestan) e dell'Archivio di Stato di Firenze, dove si è svolta una delle tre giornate di lavoro. Un sostegno economico è arrivato dall'Università degli studi di Firenze e soprattutto dall'Ente Cassa di Risparmio di Firenze. A tutte queste istituzioni, e poi alle persone che concretamente al loro interno hanno preso a cuore l'iniziativa, va il nostro ringraziamento.

Un ringraziamento particolare poi è dovuto a quanti si sono impegnati nella pubblicazione degli atti: Domenico Andergassen ha eseguito con pazienza l'uniformazione, tutt'altro che facile, e l'impaginazione dei testi; a Claudia Tripodi, già impegnata nella segreteria del convegno, si deve un'attenta revisione delle bozze e la curatela dell'indice.

Giuliano Pinto 


\author{
SAMUel K. CoHn, JR.
}

\title{
LA PECULIARITÀ DEGLI INGLESI \\ E LE RIVOLTE DEL TARDO MEDIOEVO*
}

Le generalizzazioni relative alle rivolte sociali del tardo medioevo sono basate principalmente su tre o quattro rivolte meglio studiate, e soprattutto sulla rivolta contadina inglese del 1381. A partire da queste rivolte $\mathrm{e}$ da altre del periodo "pre-industriale», storici e sociologi distinsero le rivolte moderne da quelle pre-industriali. Conclusero che i leaders di quelle rivolte contadine ed urbane non provenivano dai ranghi degli artigiani e dei contadini, e spesso erano chierici; anche le donne partecipavano alle rivolte; l'ideologia dei rivoltosi riguardava principi religiosi; i ribelli popolari avevano sacro timore e reverenza per i reali, il Papa, l'Imperatore ed altri signori ereditari, e distinguevano fra il «bravo re» e i suoi cattivi consiglieri; le rivolte popolari erano rare e per la maggiore parte vennero schiacciate. ${ }^{1}$

In un libro appena pubblicato presso la Harvard University Press, ho raccolto un campione di 1112 esempi di proteste popolari, a partire dal 1200 circa fino al $1425 .^{2}$ Sulla loro base ho concluso che le generalizzazioni basate sui modelli sociologici e sulle rivolte meglio studiate del medioevo, e soprattutto la rivolta contadina inglese del 1381, sono fuorvianti. Per esempio, gli storici continuano a ritenere che le rivolte medioevali piú frequenti ed importanti fossero quelle dei contadini e non le rivolte urbane, e per questa ragione si sono concentrati irresistibil-

* Desidero ringraziare il Dott. Guido Alfani e il Professor Matthew Strickland per l'assistenza e le consulenze datemi nella preparazione di questo saggio.

${ }^{1}$ Si vedano al riguardo libri a carattere generale come B. Guenée, L'Occident aux $X I V^{e}$ et $X V^{e}$ siècles, $6^{\mathrm{e}}$ ed., Presses universitaires de France, Paris 1998 ( $1^{\mathrm{e}}$ ed., 1971), ma anche testi che si concentrano sulla storia delle rivolte popolari, inclusivi di esempi ulteriori, come G. Fourquin, Les soulèvements populaires au Moyen Age, Presses universitaires de France, Paris 1972; G. Mollat e P. Wolff, Ongles bleus, Jacques et Ciompi: les révolutions populaires en Europe aux XIV et XVe siècles, Calman-Lévy, Paris 1970; e R. Comba, Rivolte e ribellioni fra tre e quattrocento, in La storia: I grandi problemi, a cura di N. Tranfaglia e M. Firpo, Utet,Torino 1988, vol. II, parte 2, pp. 673-91.

2 S. Cohn, Lust for Liberty: The Politics of Social Revolt in Medieval Europe, 12001425, Italy, France and Flanders, Harvard University Press, Cambridge Ma. 2006. 
mente sulle prime a scapito delle seconde. ${ }^{3}$ In effetti, dei cinque movimenti meglio studiati - le due rivolte fiamminghe della prima parte del Trecento, la Jacquerie del 1358, gli Hussiti ed il tumulto dei Ciompi solo uno (i Ciompi) fu esclusivamente urbano. Tuttavia, le fonti disponibili per Italia, Francia e Fiandre raccontano un'altra storia: 60 rivolte (ovvero meno del $6 \%$ ) possono essere considerate contadine, e in questo computo sono considerate contadine anche le rivolte che intrecciano il popolo delle città con ribelli della campagna, come le rivolte delle Fiandre del primo Trecento. Per di più, solo dieci di tali conflitti videro i contadini in lotta con i loro signori. ${ }^{4}$

Inoltre, altre caratteristiche delle rivolte popolari del Medioevo non possono essere generalizzate a partire da questo pugno di rivolte e specialmente non dall'esperienza inglese. Le descrizioni delle rivolte dimostrano che la borghesia, la nobiltà e soprattutto i chierici furono raramente i leaders dei tumulti popolari del tardo Medioevo, nonostante le cronache siano state scritte per la maggiore parte da membri delle élites che non avevano simpatia per i ribelli. I chierici, ad esempio, occupano posizioni di leadership in appena 27 dei 1112 movimenti, e la maggior parte di questi erano movimenti ereticali. ${ }^{5}$ Inoltre, quando i mercanti od i nobili appaiono nelle rivolte popolari continentali, di solito dirigono i loro clan coalizzandosi con gli artigiani, che hanno i loro propri leaders, come si può vedere in almeno cinque rivolte senesi contro il governo dei Nove tra 1317 e $1355 .{ }^{6}$ Lo stesso schieramento di gruppi e classi indipendenti si riscontra nel tumulto piú famoso (1355), quando il governo dei Nove venne finalmente estromesso dal potere; in questo caso, però, la presenza del popolo minuto ebbe maggior evidenza. ${ }^{7}$

${ }^{3}$ Si veda R. Hilton, Popular Movements in England at the End of the Fourteenth Century, in Hilton, Class Conflict and the Crisis of Feudalism: Essays in Medieval Social History, Hambledon Press, London 1983, pp. 157-158.

${ }^{4}$ Cohn, Lust for Liberty cit., pp. 25-52.

${ }^{5}$ Cohn, Lust for Liberty cit., pp. 111-112.

${ }^{6}$ Cohn, Lust for Liberty cit., pp. 120-122. Per le descrizione degli eventi quale riportata dalle cronache, si veda Cronaca senese di autore anonimo della metà del secolo XIV dall'anno 1202 al 1362, con aggiunte... fino 1391, in Cronache senesi, ed. A. Lisini e F. Iacometti, Rerum Italicarum Scriptores, XVI, parte 6.1, Zanichelli, Bologna 1939, p. 114; Cronaca senese attribuita ad Agnola di Tura del Grasso detta la cronaca maggiore, in Cronache senesi, pp. 371-373, 375-80, e 494, e Frammento di cronaca senese di anonimo (1313-1320), in Cronache senesi, p. 172.

${ }^{7}$ Cronaca senese di Donato di Neri, in Cronache senesi, pp. 577-579, e M. Villani, Cronica con la continuazione di Filippo Villani, ed. G. Porta, 2 vol., Fondazione Pietro Bembo, Parma 1995, pp. 655-656 e 679-680. 
Piú spesso, le cronache descrivono leaders provenienti dai ranghi dei contadini e degli operai, come il marinaio Piero Capurro, che diresse un ammutinamento per domandare il salario arretrato dovuto dai Doria di Genova. In seguito, Capurro organizzò rivolte di villani contro il comune genovese nel $1339 .{ }^{8}$ Un altro esempio poco noto è la rivolta dei «senza braghe» - domestici ed apprendisti - che nel 1289 accusarono il podestà di Bologna di corruzione, attaccarono il suo palazzo, lo cacciarono fuori della città, e forzarono la città stessa a scegliere un nuovo podestà gradito al popolo minuto. ${ }^{9}$

In secondo luogo, le rivolte per la carenza di grano o cibo erano straordinariamente rare; ${ }^{10}$ in terzo luogo (ancora contro i modelli delle rivolte preindustriali) le donne non furono presenti tra i leaders di quegli incidenti ed inoltre parteciparono raramente alle rivolte popolari, indipendentemente dalle loro caratteristiche. Questa mancanza di donne tra i ribelli non risulta semplicemente dalla cecità dei cronisti di fronte all'agire delle donne nella storia. Piuttosto, le donne sono spesso descritte in queste fonti come persone in lutto, partecipanti ai movimenti religiosi, ed anche nel ruolo di sostenitirici e partecipanti ad azioni militari volte a proteggere la loro comunità. I fondi archivistici conservano ancor meno tracce, rispetto alle cronache, di un ruolo delle donne nelle rivolte sociali. Nelle sentenze e inchieste criminali di Firenze, per esempio, si possono trovare i nomi di piú di mille ribelli per vari tumulti dal 1342 al 1400; però non ho trovato neppure un singolo nome femminile (benché alcune appaiano negli elenchi dei contro-rivoltosi che si opposero al governo dei Ciompi e poi a quello delle Arti Minori). ${ }^{11}$

In quarto luogo, i popolani nelle loro insurrezioni dell'Europa continentale dimostravano raramente reverenza o timore sacro per la regalità o per i sovrani ereditari (dove non vi era la corona). Inoltre, questi ribelli non trasferivano il loro furore sui consiglieri del re, neppure in Francia nel 1380, dopo che i consiglieri di Carlo VI - i suoi zii - ebbero ripulito la tesoreria reale di tutto ciò che potevano portar via. Invece, le menu peuple di Parigi considerava il re responsabile e lottava per bloccare tutti gli aumenti delle tasse reali di cui Carlo aveva disperatamente bisogno per proteggere la Francia contro gli Inglesi. Come Michel Pintoin, il cronista del re, ripeté da una rivolta all'altra durante questo periodo travagliato, i plebei si comportavano senza «decoro» di fronte al loro re, avanzando le loro istanze

\footnotetext{
${ }^{8}$ Cohn, Lust for Liberty cit., p. 124.

${ }^{9}$ Cohn, Lust for Liberty cit., p. 91.

${ }^{10}$ Cohn, Lust for Liberty cit., pp. 70-72, 108-109, e 130-132.

${ }^{11}$ Cohn, Lust for Liberty cit., pp. 130-135.
} 
con minacce invece che con suppliche e parole rispettose e, quando non potevano accusarlo direttamente, attaccavano gli ebrei sotto la sua protezione come espediente per insultare l'autorità reale. ${ }^{12}$

Per le città-stato dell'Italia centrale e settentrionale, il rispetto per la regalità non era generalmente una possibilità. Nondimeno, i papi e gli imperatori spesso ne dominavano la politica. Certamente, i ribelli popolari ogni tanto rivolsero delle suppliche all'uno o all'altro di questi super-poteri; però nella maggior parte dei casi tali suppliche erano finalizzate solamente a minacciare l'autorità dell'altro, come si vede spesso nella storia tardo-medievale del popolo romano: si opponevano al papa con l'aiuto imperiale, $\mathrm{e}$ ogni tanto riuscivano a cacciarlo da Roma. ${ }^{13}$ Altresì, alcune città-stato possedevano governanti la cui autorità era ereditaria, come a Viterbo dove i Prefetti di Vico avevano diritti signorili. Però non tenevano costoro in gran rispetto. Ad esempio, il 17 marzo 1387 il popolo tumultuò e costrinse il Prefetto a nascondersi; lo trovò e lo trascinò nella piazza centrale di Viterbo dove di fronte alla folla riunita lo umiliò ritualmente, premendone la bocca nell'ano del suo cavallo favorito. La notte, lo buttò fuori dalla città nudo $\mathrm{e}$ chiuso in una bara, poi uccise il suo figlio illegittimo, che in precedenza aveva assassinato il padre di uno dei capitani ribelli. Lo scuoiò vivo e diede la sua carne in pasto a dei cani affamati. ${ }^{14}$

Infine, le aperte azioni collettive del popolo minuto nel tardo Medioevo in Europa continentale non erano così rare, né così suicide, come il politologo James C. Scott ha recentemente sostenuto per le rivolte preindustriali in generale. ${ }^{15}$ Inoltre, queste rivolte continentali non erano così effimere come ad esempio la rivolta contadina inglese del 1381, che a Londra durò solamente per tre giorni. Benché alcune rivolte come la Jacquerie del 1358 o l'attacco contro i condottieri bretoni di Cesena nel 1377 venissero represse brutalmente, il 70 per cento delle rivolte popolari che ho rintracciato nelle cronache e nelle ricordanze (726 su 1012) si esaurì senza repressione, oppure si concluse col successo dei ribelli. ${ }^{16}$

${ }^{12}$ Chronique du religieux de Saint-Denys, a cura di M. Bellaguet, Collection de Documents inédits sur l'histoire de France, 6 vols. De l'imprimerie de Crapelet, Paris 1839-42, I, pp. 44-53; e Cohn, Lust for Liberty cit., pp. 137 e 290.

${ }^{13}$ Cohn, Lust for Liberty cit., p. 77.

${ }^{14}$ Cohn, Lust for Liberty cit., pp. 140-141.

${ }^{15} \mathrm{~J}$. Scott, Domination and the Art of Resistance: Hidden Transcripts. Yale University Press, New Haven 1990; e principalmente Id., Weapons of the Weak: Everyday forms of Peasant Resistance. Yale University Press, New Haven 1985.

${ }^{16}$ Cohn, Lust for Liberty cit., pp. 147-156. 
Fino a che punto l'esperienza inglese si accorda con i risultati trovati sul continente? Primo, le rivolte per il grano erano rare, ancor piú nell'Inghilterra che nell'Europa continentale. Finora, gli storici inglesi hanno sostenuto che non ve ne furono fino al Cinquecento; tuttavia recentemente un tumulto contro i mercanti di grano è stato trovato per Bristol nel $1347 .{ }^{17} \mathrm{Vi}$ sono inoltre casi più antichi che probabilmente vale la pena di citare. Ad esempio, durante la grande carestia del 1315-16 una nave genovese piena di grano venne assaltata dalla folla a Sandwich. Chi fossero precisamente i partecipanti di questo tumulto non é chiaro. ${ }^{18}$ Nondimeno, esempi del genere sono molto rari nella storia inglese medioevale, forse ancor più che in Francia $\mathrm{o}$ in Italia. ${ }^{19}$

Per quanto riguarda altre caratteristiche, l'esperienza inglese è ben diversa da quella del continente. Sebbene le donne inglesi non si unissero alle rivolte dovute alla mancanza di grano, svolsero una parte importante nei ranghi degli insorti durante la rivolta contadina del 1381, come risulta dai registri dei tribunali, dalle ricostruzioni letterarie, ed anche (benché obliquamente) dalle cronache. Inoltre, e in contrasto con l'esperienza continentale, le donne compaiono anche tra i leaders del 1381. La principale tra loro fu Johanna Ferrour: assieme al marito diresse gli insorti del Kent che bruciarono il Palazzo di Savoia il 13 luglio, ed il giorno seguente diresse l'esecuzione, nella Torre di Londra, dei principali e più stretti consiglieri di Riccardo II, ovvero l'arcivescovo Simon Sudbury ed il camerlengo reale Robert Hales. Inoltre, donne appaiono negli elenchi degli atti criminali e nella letteratura immaginaria come partecipanti e leaders delle rivolte, per lo meno nel $1381 .^{20}$

${ }^{17}$ B. Sharp, The Food Riots of 1347 and the Medieval Moral Economy, in Moral Economy and Popular Protest: Crowds, conflict and authority, a cura di A. Randall ed A. Charlesworth, Macmillan, Basingstoke 2000, pp. 33-54.

${ }^{18}$ M. Prestwich, The Three Edwards: War and State in England 1272-1377, Methuen and Co., Ltd, London 1980, p. 248. Purtroppo, il libro non cita la fonte in cui si trova notizia di questo incidente.

${ }^{19}$ Per questi esempi continentali, si veda Cohn, Lust for Liberty cit., pp. 70-72, 108109, 130-132.

${ }^{20}$ S. Federico, The Imaginary Society: Women in 1381, «Journal of British Studies», 40 (2001), pp. 159-183. Il ruolo di Johanna Ferrour é analizzato in A. Réville, Le soulèvement des travailleurs d'Angleterre en 1381, Picard, Paris 1898. Tuttavia, nella letteratura piú recente di R. Hilton, R. Faith, C. Dyer, S. Rigby (English Society in the Later Middle Ages: Class, Status and Gender, Mcmillan, Basingstoke, 1995), ed in collezioni dedicate alle rivolte dei contadini inglesi, come The English Rising of 1381, a cura di R. Hilton e T. Ashton, Cambridge University Press, Cambridge 1984, Ferrour non é menzionata, nonostante l'importanza e l'influenza assunta dalla storia delle donne negli ultimi trent’anni. 
Per altri aspetti, la leadership della rivolta inglese del 1381 diverge dalle tendenze prevalenti sul continente, soprattutto per quanto riguarda la seconda parte del Trecento. Senza dubbio, leaders come Wat Tyler ed il tintore di Norfolk, Geoffrey Lister, provenivano da famiglie di artigiani; tuttavia la leadership della rivolta inglese era ben diversa per due aspetti cruciali: primo, i chierici erano un pilastro della leadership della rivolta inglese, e non soltanto per quanto riguarda due dei capitani piú famosi, John Ball e John Wrawe: Rodney Hilton ha identificato almeno venti chierici tra i leaders della rivolta, provenienti principalmente dallo strato piú basso della gerarchia parrocchiale. ${ }^{21}$ Inoltre, Hilton ha ribadito l'importanza della predicazione popolare durante la rivolte, che trasmetteva idee precorritrici di quelle dei Lollardi. ${ }^{22}$

Secondo, per i tumulti urbani del periodo della rivolta contadina del 1381 - che avvennero a York, Scarborough, Beverley, Cambridge, St Albans e Bury St Edmunds - la leadership non attinse dagli artigiani o dal popolo minuto, ma fu costituita piuttosto da persone che possedevano già posti nei principali consigli dei governi urbani: erano priori (aldermen) e balivi e provenivano spesso da antiche famiglie. ${ }^{23} \mathrm{~A}$ partire da queste posizioni d'autorità, i leaders poterono attrarre artigiani ed altri appartenenti a ceti meno privilegati. In qualche caso, ad esempio in quello di Simon de Quixlay di York, poco o niente li differenziava dalle vecchie famiglie signorili che sostenevano la corona e le nuove tasse reali degli anni 1370, che il popolo trovava pesanti ed ingiuste. Inoltre, a Cambridge, per attaccare i collegi ed opporsi ai privilegi degli studiosi, il popolo grasso costituì una lega con $\mathrm{i}$ contadini ribelli, guidata da due grandi possidenti, John Hanchach e Geoffry Cobbe. In seguito, diresse gli assalti ai manieri a nord della città. ${ }^{24}$

Infine, la rivolta urbana di Londra unì i rustici del Kent e dell'Essex con il popolo della città, ed il consenso ad aprire le porte di Londra ai rustici pare sia stato dato per ordine di alcuni priori (o perlomeno dell' alderman

${ }^{21}$ R. Hilton, Bond Men Made Free: Medieval Peasant Movements and the English rising of 1381, Methuen \& Co Ltd, London 1973, pp. 207-213.

22 R. Hilton, Inherent and derived ideology in the English Rising of 1381, in Campagnes médiévales: l'homme et son espace, études offertes à Robert Fossier, a cura di E. Mornet, Publications de la Sorbonne, Paris 1995, pp. 399-405; e Id., Popular Movements in England cit., p. 164.

${ }^{23}$ Per le rivolte in queste città e nei paesi fuori Londra, si veda R. Dobson, The Peasants' Revolt of 1381, $2^{\circ}$ ed., Macmillan, London 1983, pp. 269-300; Id, The Risings in York, Beverley, and Scarborough, in The English Rising of 1381 cit., pp. 112-142; C. Liddy, Urban Conflict in Late Fourteenth-Century England: The Case of York in 13801381, «English Historical Review», CXVIII, 2003, pp. 1-32.

${ }^{24} \mathrm{Si}$ vedano i Rotuli Parliamentorum, riguardanti la rivolte di Cambridge, in Dobson, The Peasants' Revolt of 1381 cit., pp. 239-242. 
John Horn). Non è chiaro se Horn o gli altri priori del governo londinese fossero i leaders dei tumulti urbani iniziali, però secondo le inchieste dei magistrati superstiti (gli «sheriffs»), il membro del popolo grasso Horn, e non il popolo o popolo minuto, negoziò con i contadini offrendo promesse d'amicizia, assistenza, cibo e altro se fossero entrati in città. ${ }^{25}$

Così come per la leadership, anche l'ideologia sottostante alla rivolta contadina era diversa da quella delle rivolte continentali, specialmente dopo la Peste Nera. In aggiunta al fatto che la religione giocava un ruolo molto più rilevante, i ribelli a Mile End ed in altri luoghi fuori Londra come St Albans dimostravano rispetto e sacro timore per il loro re, il giovane Riccardo che aveva all'epoca soltanto quattordici anni. Nel resoconto piú dettagliato degli avvenimenti del 1381 - quello della «Cronaca dell'Anonimalle» ${ }^{26}$ - le domande dei ribelli di Mile End erano fondate su due principi: il primo riguardava l'autorità secolare; il secondo, quella religiosa. A nome dei rustici, Tyler pretese che non vi fossero più servi $\mathrm{e}$ glebe in Inghilterra; il dominio signorile doveva scomparire. Però, questa richiesta non includeva il re ed il suo dominio, che i ribelli rifiutarono di toccare. In secondo luogo, i ribelli pretesero che i beni della Chiesa non fossero lasciati nelle mani dei religiosi, né dei preti; allo stesso tempo, però, chiesero che ai chierici venissero garantiti adeguati mezzi di sostentamento. Quindi l'attacco contro la Chiesa era focalizzato contro i ranghi più alti della gerarchia ecclesiastica: «vi deve essere un unico vescovo in tutta l'Inghilterra». ${ }^{27}$ Dalla peste nera fino agli Hussiti della prima parte del Quattrocento, non sono a conoscenza di altre richieste di ribelli popolari che fossero concentrate sul mondo religioso, $o$ in cui venisse presa di mira la proprietà dei grandi prelati, o si minacciasse la gerarchia religiosa. ${ }^{28}$

In marcato contrasto con la profonda irriverenza di fronte alla regalità spesso dimostrata dai ribelli continentali, le speranze dei ribelli inglesi riposavano nell'intervento del loro re, e la loro ribellione era plasmata sulla

${ }^{25}$ Si veda le due inchieste dinanzi al tribunale degli «Sheriffs» il 4 ed il 20 Novembre, 1382, il London Letter Book H, e la discussione di questi documenti in Dobson, The Peasants' Revolt of 1381 cit., pp. 208-226.

${ }^{26}$ Questo è il giudizio di Dobson, The Peasants' Revolt of 1381 cit., p. 155: «In any attempt to collect evidence for the course of events in London between 13 and 15 June pride of place must inevitably be given to the account of the author of the Anonimalle Chronicle».

${ }^{27}$ Dobson, The Peasants' Revolt of 1381 cit., pp. 164-165.

${ }^{28}$ Senza dubbio, con le proteste degli Hussiti dal 1409 in poi, la minaccia alla gerarchia della chiesa diventerà uno dei punti focali delle rivolte popolari. Per gli Hussiti, si veda ad esempio T. Fudge, The Magnificent Ride: The First Reformation in Hussite Bohemia, Ashgate, Aldershot 1998. 
distinzione fra il «bravo re» ed i suoi cattivi consiglieri. I popolani inglesi del 1381 vedevano se stessi come i soldati del re e si attribuivano il compito di salvarlo e proteggerlo dai suoi consiglieri, i traditori dell'Inghilterra. ${ }^{29}$ Eccettuata l'esecuzione di 35 fiammighi o piú a Londra, i loro assalti colpirono la proprietà e le persone degli avvocati e dei consiglieri del re, definiti come i traditori dell'Inghilterra e causa del suo malgoverno. Secondo l'Anomimalle Chronicle, prima dell'assemblea di Mile End, il popolo («commons»):

Fece gridare per tutta la città che ogni avvocato, ogni uomo della Cancelleria e dello Scacchiere e chiunque potesse scrivere un'ordinanza o una lettera doveva essere decapitato dove si trovava. ${ }^{30}$

Primo fra tutti questi cattivi consiglieri vi era John of Guant, duca di Lancaster. Già nel periodo del «Buon Parlamento» del 1376 la folla in tumulto aveva attaccato il suo palazzo principale, chiamato Palazzo di Savoia, capovolgendo il suo stemma nobiliare come segno del tradimento. Ancora nel 1381, il primo bersaglio dei ribelli, anche prima dell'entrata dei contadini dal Kent, fu il Palazzo di Savoia. ${ }^{31}$ In aggiunta a quest'assalto del 13 di giugno, i ribelli distrussero il maniero di John of Guant a Highbury, l'ospedale di San Giovanni a Clerkenwell di cui era signore e piú lontano, a Cambridge, il bersaglio principale fu il collegio del Corpus Christi, poiché era stato fondato dal traditore in persona, John Guant. ${ }^{32}$ Per contrasto, i ribelli sventolarono il gonfalone del re nei loro attacchi contro le forze dei consiglieri e, per dimostrare il loro affetto per il sovrano, il popolo ed i contadini a Londra ed a St Albans gli offrirono le insegne di San Giorgio. ${ }^{33} \mathrm{Nel}$ loro zelo di deridere e screditare i contadini ribelli, i cronisti si accanirono contro una sola persona che si era mostrata irrispettosa dinanzi al re - Wat Tyler. Tuttavia, il suo crimine d'arroganza e la sua mancanza di rispetto appare modesta al confronto delle azioni contro i signori ereditari nel continente. Il rozzo Wat Tyler osò bere un boccale d'acqua e dopo pulirsi la

${ }^{29}$ E. Fryde, The Great Revolt of 1381, The Historical Association, n. 100, Historical Association, London 1981, p. 18; e C. Dyer, Making a Living in the Middle Ages: The people of Britain 850-1520, New Haven 2002, p. 288.

${ }^{30}$ Dobson, The Peasants' Revolt of 1381 cit., p. 160.

${ }^{31}$ Prestwich, The Three Edwards cit., p. 288. Curiosamente, questo primo attacco del popolo londinese contro John of Guant è raramente citato dagli storici della guerra contadina del 1381.

${ }^{32}$ Dobson, The Peasants' Revolt of 1381 cit. (Anonimalle Chronicle), pp. 156, 158, e (Rolls of Parliament, 13-7 June 1381), 240.

${ }^{33}$ Dobson, The Peasants' Revolt of 1381 cit. (Walsingham, Historia Anglicana), p. 274.

${ }^{34}$ Dobson, The Peasants' Revolt of 1381 cit. (Anonimalle Chronicle), p. 165. 
bocca con la birra alla presenza del re; ${ }^{34}$ senza dubbio questa mancanza di rispetto era lontana dall'insulto fatto dai Viterbesi al loro Prefetto.

Infine, le rivolte popolari inglesi sembrano molto meno frequenti che sul continente, nonostante il fatto che per piú di un secolo gli studiosi inglesi abbiano rastrellato fondi ricchi come i registri delle signorie («manorial rolls») per trovare traccia di rivolte (perlomeno quelle dei contadini). Nondimeno, trovarono pochi esempi di azioni collettive oltre a casi di riluttanza ad obbedire, rifiuto di pagare gli affitti dovuti e altre azioni piuttosto passive e confinate a singole signorie, almeno fino agli anni '70, quando a causa dei testatici («poll taxes») iniziò un periodo turbolento. Nel 1377 le proteste coinvolsero almeno quaranta villaggi in Wiltshire, Surrey, Sussex, e Devon in cui i contadini si rifiutarono di lavorare i campi dei lori signori. ${ }^{35}$ Prima di tale episodio, non sono note agli storici ondate di protesta capaci di estendersi oltre singoli ambiti signorili. ${ }^{36}$ Si possono citare solo incidenti quali quello del 1350 quando i contadini («villeins») dell'abbazia di Meaux (vicino a Beverley nell'East Riding, Yorkshire) si ribellarono contro i monaci perchè non rispondevano adeguatamente alle nuove condizioni economiche sviluppatesi dopo la Peste Nera. Secondo Michael Prestwich questo tumulto «presaged the great explosion of the Peasants' Revolt of 1381». Però, a differenza del 1381, quando le rivolte avrebbero coperto larga parte dell'isola britannica, dallo Yorkshire al Winchester, nel 1350 il tumulto riguardava un singolo signore, almeno a quanto risulta dai fondi esaminati finora.

Alcuni studiosi, pertanto, asseriscono che la rivolta contadina del 1381 segnò uno spartiacque che stimolò un brusco aumento delle ribellioni contadine per il resto del Medioevo ed anche in seguito. Tuttavia, questi studiosi possono indentificare pochi incidenti di questo tipo tra il 1381 e la fine del Quattrocento: la ribellione di Cade nel 1450 e una rivolta in Cornovaglia nel $1497 ;{ }^{37}$ altri aggiungono una rivolta contro le tasse nello Yorkshire del $1489 ;{ }^{38}$ altri ancora inclusero i movimenti che ebbero luogo

${ }^{35}$ R. Faith, The 'Great Rumour' of 1377 and Peasant Ideology, in The English Rising cit., pp. 43-83; G. Harriss, Shaping the Nation: England 1360-1461, Clarendon Press, Oxford 2005, pp. 227-229; e E. Hallam, Domesday Book through nine centuries, Thames and Hudson, London 1986, pp. 102-104.

${ }^{36}$ D. Carpenter, English peasants in politics 1258-1267, «Past \& Present», no. 136 (1992), pp. 3-42, dimostra l'importanza dei contadini nella politica inglese del Duecento; questi movimenti, tuttavia, erano parte della lotta dei 'barons' contro il regno, guidati per la maggiore parte dai baroni stessi.

${ }^{37}$ Fryde, The Great Revolt of 1381 cit., p. 7.

38 J. Whittle and Rigby, England: Popular Politics and Social Conflict, in A Companion to Britain in the Later Middle Ages, a cura di Rigby, Blackwell Publishers, Oxford 2003, pp. 69-70. 
nello Yorkshire e nel Cheshire negli anni 1391-3, nell'Essex e nel Cheshire nel 1400, e nel Cheshire ed a York nel $1403 .{ }^{39}$ Queste ultime, però, sembra siano state rivolte di soldati rimasti senza lavoro, e non rivolte contadine. Altri ancora hanno indicato le rivolte in Galles del 1400-1409 come «una ribellione contadina». ${ }^{40}$ Invece, secondo R. R. Davies, erano originariamente rivolte della nobiltà («gentry») contro il regno inglese, nel corso delle quali Owain Glyn Dŵr venne proclamato principe, e diventarono, nel corso di nove anni, «una rivolta nazionale»: non essendo mai un conflitto di classe o una sommossa contadina. ${ }^{41}$

Grazie alla nuova versione «on-line» dei Parliamentary Rolls medievali a partire dai regni di Edoardo I fino ad Enrico VII, una ricerca per parole-chiave quali «rivolt», «seditio», «riot», ed altre simili produce un elenco di piú di 95 risultati. ${ }^{42}$ Bisogna però guardarli con maggior attenzione. Senz'altro l'elenco corrisponde a poche rivolte popolari: molti risultati si riferiscono alle stesse rivolte; in altri casi l'uso di queste espressioni non indica l'esistenza di azioni collettive; in altri ancora si tratta di leggi probabilmente stimolate da incidenti particolari, nel cui testo però è assente ogni riferimento ad eventi specifici. Ma uno sguardo preliminare suggerisce una forte concentrazione di questi eventi e dell'uso di queste parole durante il regno di Riccardo II, subito prima della rivolta contadina del 1381 e durante quello stesso anno. Sulla base di questi risultati, la rivolta contadina del 1381 non appare affatto come lo spartiacque che portò ad una nuova epoca di disordine rurale nell'Inghilterra. Di quindici atti riguardanti tumulti popolari trovati in questo fondo, dieci hanno attinenza con i tumulti del 1381. Questi atti e petizioni continuarono fino all'aprile 1384, con una petizione dell'abate di Bury St. Edmunds che si lagnò della distruzione del monastero perpetrata dai ribelli del 1381 e supplicò il re di non rinnovare i privilegi ai cittadini di Bury. ${ }^{43}$ Dopo questa petizione non vi è un'altra petizione o legge che riguarda tumulti

${ }^{39}$ Piú tardi, Fryde, Peasant rebellion and discontents, in The Agrarian History of England and Wales, III: 1348-1500, a cura di E. Miller, Cambridge University Press, Cambridge 1991, pp. 797-808.

${ }^{40}$ Dyer, Making a Living in the Middle Ages cit., pp. 291-292,

${ }^{41}$ R. Davies, The Age of Conquest: Wales 1063-1415, Oxford University Press, Oxford 1987, pp. 443-459, e Id., The Revolt of Owain Glyn Dwr, Oxford University Press, Oxford 1995.

${ }^{42}$ The Parliament Rolls of Medieval England, 1275-1504, a cura di C. Given-Wilson, The National Archives: The History of Parliament Trust, Scholarly Digital Editions, Boydell and Brewer, Leicester 2005.

${ }^{43}$ The Parliament Rolls, Richard II, iii, 170. In uno di questi atti, (Richard II, iii100, no. 17) il Parlamento riconobbe anche che le cause del tumulto derivavano dagli ufficiali locali «qi sont come rois en paiis, qe droit ne loye est a poy fait a nully, et la povre commune est de temps en temps a tiel guyse pilez et destruitz...». 
o proteste popolari fino allo «Statute of Riots» di Enrico IV, nel $1411 .{ }^{44} \mathrm{Vi}$ sono insomma piú atti inerenti tumulti popolari negli anni immediatamente precedenti la rivolta contadina del 1381, vale a dire dal 1376 al 1381, che nei cent' anni successivi. ${ }^{45}$ La mancanza di conflitti nelle campagne (ed anche nelle città) durante gli ultimi decenni del Trecento ed i primi del Quattrocento, è spiegabile almeno in parte col mutamento delle condizioni di vita e dei rapporti sociali. In una generazione sola (c. 13801430), la posizione dei contadini nelle tenute («manors») si era trasformata, con la scomparsa delle obbligazioni servili: il «villaneage» era ormai un fantasma di se stesso. ${ }^{46}$ Un aumento dei salari reali e delle dimensioni dei patrimoni ne migliorava il tenore di vita, rendendolo irriconoscibile. ${ }^{47}$ In secondo luogo, quest'elenco derivato dai Parliamentary Rolls, insieme a riferimenti sparsi reperibili nella letteratura generale inerente la storia medievale inglese, solleva dubbi per quanto riguarda la tesi di Rodney Hilton ed altri, ovvero che nell' Inghilterra le rivolte contadine fossero molto più importanti e più numerose di quelle urbane. Eppure, gli storici inglesi non hanno ancora studiato le rivolte urbane con la stessa attenzione che dedicano, da un secolo o più, a quelle rurali. Non solo la cosiddetta «rivolta contadina» del 1381 mostra una lunga serie di tumulti urbani che attraversano l'Inghilterra, da Winchester ad ovest fino a York nel nord est; città come Norwick, Bristol e Londra mostrano una lunga storia di proteste popolari a partire dal Duecento, con grande varietà di azioni collettive. Così come il tumulto degli operai dell'industria tessile a Winchester nel giugno 1381, la maggior parte di queste rivolte non è ancora stata oggetto di studi adeguati. ${ }^{48}$

Non vi sono esami sistematici, né descrizioni ampie di tumulti urbani, neppure per singole città. Ad esempio, in un recente studio sulla storia me-

${ }^{44}$ The Parliament Rolls, Henry V, 1411, Appendix e 1414, iv, 25.

${ }^{45}$ Senza dubbio, vi furono molti conflitti sociali che non emergono nelle petizioni e leggi promulgate dal Parlamento. Per esempio, contestazioni di 'mediocres et inferiores' contro consigli oligarchici continuarano a Lincoln dal 1375 al 1390; per questi ed altri esempi del Quattrocento, si veda G. Harriss, Shaping the Nation. England 1360-1461, Oxford U.P. 2005, pp. 291-293; e P. Maddern, Violence and social order: East Anglia 14221442, Clarendon Press, Oxford 1992.

${ }^{46}$ Harriss, Shaping the Nation, p. 234.

${ }^{47}$ Harriss, Shaping the Nation, pp. 234-242; e C. Dyer, Standards of living in the later Middle Ages: Social change in England c.1200-1520, Cambridge University Press, Cambridge 1989, pp. 158-177; ed Id. Work Ethics in the Fourteenth Century, in The Problem of labour in Fourteenth-Century England, a cura di J. Bothwell, P. Goldberg, e W. Ormrod, Woodbridge, York Medieval Press, Suffolk 2000, pp. 21-41

${ }^{48}$ Dobson, The Peasants' Revolt of 1381 cit., p. 44, elenca una «urban rising, apparently led by cloth-workers, late June?», ma non cita un documento o fondo per questa sommossa. 
dievale di Londra, le proteste popolari non figurano, nonostante l'ampio spazio dedicato all'organizzazione delle arti e delle loro confraternite religiose. ${ }^{49}$ In contrasto con l'attenzione fiamminga alle rivolte popolari nei centri urbani, le proteste di William FitzOsbert («Longbeard») negli ultimi anni dell'XI secolo contro le tasse sproporzionate imposte ai poveri di Londra occupano al massimo una pagina o due negli studi recenti sulla città, nonostante i cronisti raccontino che i suoi seguaci raggiunsero il numero di 52.000. Anche se questa cifra è certamente esagerata, FitzOsbert divenne ben noto durante il suo tempo e nei secoli successivi come «il primo demagogo di Londra». Inoltre, dopo la sua morte violenta, quando i suoi nemici bruciarono la chiesa di St. Mary-le-Bow dove si era rifugiato, il luogo della sua esecuzione divenne un reliquario popolare.$^{50}$ Pertanto, la storia di FitzOsbert appare molto simile a quello di Henri de Dinant, sessant'anni dopo a Liegi, ma in rapporto alla fama di cui gode Henri, FitzOsbert rimane quasi sconosciuto alla storiografia inglese: entrambi erano traditori della loro classe, entrambi erano famosi nel loro secolo per la loro eloquenza e il potere di stimolare la folla, entrambi protestavano contro le tasse ed altre forme d'ingiustizia contro i poveri della città. ${ }^{51}$

Un'occhiata agli studi generali della storia medioevale inglese rivela altri esempi di proteste popolari urbane. L'ultimo decennio dell'undicesimo secolo fu turbolento anche per altri borghi e città oltre a Londra. A Lincoln e York, nel 1190, cittadini e signori dei rispettivi contadi furono a capo di movimenti che coinvolsero membri del popolo, i quali attaccarono gli ebrei per cancellare i propri debiti. ${ }^{52}$ Altri esempi risalgono al Duecento: negli anni 1250 circa, $i$ «burgesses of the lesser commune» di Oxford protesta-

${ }^{49}$ C. Barron, London in the Later Middle Ages: Government and People 1200-1500, Oxford University Press, Oxford 2004, pp. 199-234; non viene dedicato spazio alcuno ai conflitti minori di popolo e artigiani, e una sola frase è dedicata alla rivolta del 1381 (p. 155). D'altra parte, G. Williams, Medieval London: From Commune to Capital, University of London Historical Series, no. IX, The Athlone Press, London 1963, presta piú attenzione al soggetto delle proteste popolari nella storia medievale londinese.

${ }^{50}$ Si veda C. Brooke, London 800-1216: The Shaping of a City, Secker \& Warburg, London 1975, pp. 48-49; E. Miller e J. Hatcher, Medieval England: Towns, Commerce and Crafts 1086-1348, Longman, London 1995, p. 284; e Williams, Medieval London cit., p. 4.

${ }^{51}$ G. Kurth, La Cité de Liège au Moyen-Age, 3 vols., A. Dewit, Brussels 1909-1910, I, pp. 179-215; Id., Henri de Dinant et la démocratie liégeoise, "Academie royale des Sciences des Lettres et de Beaux-arts de Belgigue: Bulletins de la classe des lettres», 1908, pp. 384-410.

${ }^{52}$ Miller e Hatcher, Medieval England cit., p. 388; e R. Dobson, The Jews of medieval York and the massacre of March 1190, St. Anthony's Press, York 1974; A History of Yorkshire: The City of York, a cura di P. Tillott, Institute of Historical Research, London 1961, p. 47. 
rono contro i 'grandi' e il sistema di tassazione, che (affermarono) imponeva loro una rata doppia rispetto a quella pagata dai grandi. ${ }^{53}$ Altre similari rivolte dei poveri contro i ricchi a causa delle tasse si verificarono a Grimbsy (1258), Northampton (1276), Gloucester (1290), e Cambridge (1291).$^{54}$ Le tasse non erano l'unica causa di tumulti popolari nelle città medievali inglesi. Come nel continente, le minacce ai diritti e ai privilegi di autogoverno urbano provocarono proteste ed atti di violenza, come nel 1326, quando il re Edoardo II provò a limitare i diritti del governo della città di Londra. Il popolo attaccò uno degli uomini del re, il vescovo Stapledon di Essex (il camerlengo reale), lo tirò giù dal suo cavallo, e lo decapitò con un coltello da macellaio (secondo Williams, era un coltello per pane). Dopo questo fatto, il re fu costretto a scappare da Londra al Galles con i suoi detestati consiglieri, i Despensers. ${ }^{55}$

Inoltre, nelle città e nei borghi dell'Inghilterra, ebbero luogo rivolte piuttosto simili alle proteste del popolo italiano nel Duecento e Trecento. Per esempio, prima della Pasqua del 1264 a Bury St. Edmunds, una città posta sotto il controllo della grande abbazia di St. Edmund, i giovani del borgo insorsero contro l'abbazia per estendere i diritti dei cittadini nel governo della città. I giovani formarono un'arte (gilda juvenum), presero le porte della città, elessero i loro propri priori («aldermen and bailiffs»), ruppero le porte dell'abbazia e scagliarono frecce dentro il cortile. ${ }^{56}$ Conflitti e vertenze fra il popolo di Bury ed il loro signore (l'abate ed il convento) continuarono, per quanto riguarda i diritti di governo della città dal Duecento alla fine del Medioevo, ${ }^{57}$ come nel 1327, quando i ribelli vennero puniti molto piú aspramente che nel 1264: diciannove popolani finirono impiccati; una multa gigantesca di 140.000 sterline venne imposta al popolo («burgesses») e, nel corso dell'anno successivo, la città perse tutti i suoi diritti comunali. ${ }^{58}$

Nello stesso periodo lo scontro fra Earl Simon de Montfort ed il re Enrico III provocò altri conflitti in altre città: nel settembre 1264, studenti e altri giovani della città di Oxford si ricongiunsero con altri rivoltosi fuori

${ }^{53}$ Miller e Hatcher, Medieval England cit., p. 359.

${ }^{54}$ Miller e Hatcher, Medieval England cit., p. 359.

${ }^{55}$ Prestwich, The Three Edwards cit., p. 97; Barron, London in the Later Middle Ages cit., pp. 26-27; e Williams, Medieval London cit., pp. 295-297.

${ }_{56}$ F. Powicke, King Henry III and the Lord Edward: The Community of the realm in the Thirteenth Century, 2 volumi, Clarendon Press, Oxford 1947, II, pp. 449-450.

${ }^{57}$ Si veda R. Gottfried, Bury St. Edmunds and the urban crisis. 1290-1539, Princeton University Press, Princeton 1982.

${ }^{58}$ H. Davis, The Commune of Bury St. Edmunds, 1264, «English Historical Review» XXIV (1909), p. 315. 
della città e con gli Ebrei che erano appena arrivati fuggendo alla persecuzione a Londra ed altrove. Insieme, formarono assemblee e società illegali. ${ }^{59}$ Tuttavia, il più importante di questi tumulti ebbe luogo a Londra, quando il sindaco di Londra e i suoi priori dovettero cedere alla forza della folla ammassata fuori della cattedrale di St. Paul e concessero per la prima volta agli artigiani e alle arti minori («mysteries») il diritto di partecipare al governo. Peraltro, il popolaccio («the lowest orders») saccheggiò le case degli stranieri e attaccò gli Ebrei. ${ }^{60}$ Infine, anche le assemblee e le proteste a contenuto economico da parte di operai ed artigiani non erano assenti dalle città medievali inglesi, come nel 1349, quando i fornai ed altri lavoranti vennero accusati di tenere assemblee illegali e di cospirare per innalzare i propri salari. ${ }^{61}$

Senz'altro, un esame delle fonti narrative inglesi (per non dire nulla di quelle archivistiche) potrebbe aggiungere molti altri esempi di proteste popolari urbane. Si tratta senza dubbio di un tema trascurato. Per il momento comunque, possiamo indicare solo qualche esempio. Uno dei più coloriti incidenti, che riguardò una protesta urbana, ebbe luogo nel 1223, dopo una gara di lotta fra la casa dell'abate di Westminster e giovani cittadini di Londra. I Londinesi persero, e per questo motivo il popolo di Londra scelse un nuovo sindaco e la mattina successiva fece un'assemblea e marciò sotto la bandiera della città contro l'abate, attaccò il suo siniscalco e depredò alcuni suoi beni. A causa di ciò, l'abate rivolse una petizione al re e, sentendo questa notizia, i Londinesi circondarono il palazzo dell'abate «come le api» (secondo la descrizione degli Annali di Dunstable). I ribelli presero 12 dei cavalli dell'abate ed assaltarono i suoi servitori. Il giudice supremo («justiciar») del re richiese al sindaco ed ai capi della città di fare un'inchiesta per identificare i capi del tumulto. Dopo di che, i Londinesi si sollevarono ancora e, questa volta, il re entrò nel conflitto, depose il nuovo sindaco, nominò un proprio uomo al suo posto, prese 60 ostaggi, e minacciò $i$ Londinesi di procedere a numerose esecuzioni. Infine, i baroni negoziarono una pace fra il re ed il popolo, che venne multato «di molte migliaia di marchi». ${ }^{62}$ Può quindi darsi che questo incidente sia all'origine di un'altra peculiarità inglese, gli hooligan tifosi di calcio. A differenza delle lotte dei pugni senesi nel 1319 e nel 1324, che cominciarono come competizioni sportive fra i terzieri della città, ma sfociarono in rivolte politiche contro il

${ }^{59}$ F. Powicke, King Henry III cit., pp. 450, 786-787.

${ }^{60}$ Powicke, King Henry III cit., pp. 446-447.

${ }^{61}$ Prestwich, The Three Edwards cit., p. 261.

${ }^{62}$ W. Robieson, The Growth of Parliament and the War with Scotland, 1216-1307, G. Bell, London 1914, pp. 9-10. 
governo dei Nove, ${ }^{63}$ questo tumulto inglese seguito ad una gara di lotta non si sviluppò in una direzione politica e non presentò i tratti di una protesta sociale contro i privilegi dell'abate o della sua abbazia, né contro il re. Solo l'orgoglio dei Londinesi, che avevano perso malamente, appare essere in gioco.

Ad ogni modo, anche dopo una ricerca approfondita nelle ricche fonti archivistiche e nelle cronache, credo che il confronto fra l'Inghilterra ed il continente non varierà di molto da quanto appena visto. Anche se tutte le 90 petizioni e statuti contenenti parole chiave legate alle rivolte indicheranno effettivamente casi di rivolte popolari (e devo dire che questo non accadrà), ammonterebbero comunque a meno della metà delle rivolte popolari che ho trovato per Parigi o per Firenze considerando un periodo piú limitato e avvalendomi solo di fonti narrative.

Questa scarsità di rivolte popolari in Inghilterra mostra un'altra peculiarità degli Inglesi, che a prima vista non sembra sostenere la tesi di Alan Macfarlane, secondo cui la storia del popolo e dei contadini inglesi si distingue da tutti gli altri Paesi perché nell'isola la consapevolezza dell'individualismo avrebbe raggiunto un livello piú avanzato che altrove nel Medioevo, e le cui origini potrebbero essere fatte rialire fino ai tempi degli Anglo-Sassoni. ${ }^{64} \mathrm{Al}$ contrario, per quanto riguarda l'esperienza delle proteste popolari, gli Inglesi risultano meno «avanzati» del popolo continentale, avendo meno potere e meno consapevolezza nel minacciare i poteri signorili e le gerarchie delle loro città. D'altra parte, però, questa mancanza di proteste potrebbe essere un altro segno dello sviluppo precoce dello stato inglese e del potere della sua monarchia centrale.

${ }^{63}$ Cronaca senese di autore anomino cit., pp. 127-128; Frammento di cronaca senese, cit., p. 172; Cronaca di Agnolo di Tura, cit., pp. 375-380 e 416-417; Cohn, Popular Protest in Late Medieval Europe, Manchester Medieval Sources, Manchester University Press, Manchester 2004, pp. 62-64; Id., Lust for Liberty cit., p. 120.

${ }^{64}$ A. Macfarlane, The origins of English individualism: the family, property and social transition, Blackwell, Oxford 1978. 

MARC BOONE ${ }^{1}$

LE COMTÉ DE FLANDRE DANS LE LONG XIV ${ }^{\mathrm{e}}$ SIÈCLE:
UNE SOCIÉTÉ URBANISÉE FACE AUX CRISES DU BAS MOYEN AGE

\section{Les révoltes médiévales: un champ de recherches miné?}

Les révoltes et rébellions urbaines et des campagnes ont frappé l'imagination de générations d'historiens. Il s'agit en effet d'actes de grande ampleur, présents de façon spectaculaire dans les récits des contemporains qui les ont souvent décrits avec passion, en prenant facilement partie pour l'un ou l'autre groupe dans la plupart des cas en les condamnant, car aux yeux d'auteurs membres de l'église, les mouvements en question portaient atteinte à l'ordre social et donc à l'ordre voulu par Dieu. L'engagement dans la description, présent au moment où se sont déroulés les faits même, est resté dans les écrits des historiens, dits modernes.

Au XIX ${ }^{\mathrm{e}}$ siècle, des auteurs romantiques, Kervyn de Lettenhove pour la Flandre, ou encore Jules Michelet pour la France ont abondamment écrit sur les Arteveldes, les Etienne Marcel et autres Jacques, moteurs des mouvements collectifs dans un XIV siècle plus que perturbé.

Mais également les historiens académiques de renom se sont manifestés dans ce débat dès que l'histoire s'est développée et s'est consolidée comme science. A Bruxelles, par exemple, Léon Vanderkindere (1842-

${ }^{1}$ Avant d'avoir été soumis au public à Florence lors du colloque sur les révoltes le 30 mars 2006, le texte de cette contribution a profité des remarques formulées à l'occasion d'un colloque organisé par le SFB (Sonderforschungsbereich) 584 'Das Politische als Kommunikationsraum in der Geschichte' (Université de Bielefeld et ZiF) les 20 et 21 février 2006, intitulé 'Gewalt im politischen Raum' (la violence en politique), je remercie mon collègue Neithard Bulst de Bielefeld de ses observations. Avant de préparer le texte pour la publication, il a également soutenu une des leçons données à l'ULB (Université Libre de Bruxelles) dans le contexte d'une chaire Francqui au titre belge que j'ai eu l'honneur d'y avoir occupé en 2006 sur le thème général de 'Emergence d'une modernité civique: la société urbaine des anciens PaysBas'. Que les collègues bruxellois, en premier lieu Claire Billen et Jean-Pierre Devroey soient donc à juste titre remerciés de leurs remarques judicieuses, tout comme ceux et celles présents lors du colloque de Florence. Elodie Lecuppre-Desjardin (Université Lille III, université Charles-de-Gaulle) a bien voulu relire le texte, qu'elle en soit vivement remerciée. 
1906) professeur à l'université libre de Bruxelles publia en 1879 son 'Le siècle des Artevelde. Etudes sur la civilisation morale et politique de la Flandre et du Brabant' œuvre qui laisse mesurer la distance parcourue depuis Kervyn de Lettenhove ou encore Henri Conscience (auteur romantique qui dans un de ses romans 'Jacques d'Artevelde. Le tribun de Gand' publié en 1849 s'était également attaqué à la figure des Artevelde). Henri Pirenne dira du livre de Vanderkindere en comparant les Artevelde de ce dernier à ceux de Kervyn de Lettenhove: 'Ces grandes figures (les Artevelde) passionnèrent Vanderkindere. Libéral, il voyait dans les deux capitaines gantois les partisans de la liberté contre la tyrannie des princes féodaux, en même temps que ses théories ethnographiques lui faisaient apparaître en eux les représentants de la race germanique aux prises avec le 'despotisme latin' venant de France (...) Une conviction passionnée s'y révèle d'un bout à l'autre; on sent que l'auteur prend parti dans les conflits qu'il raconte, qu'il plaide pro domo'.2 Henri Pirenne lui même n'échappe pas à un tel constat, j'y reviendrai.

Une semblable coloration idéologique est restée de mise au $\mathrm{XX}^{\mathrm{e}}$ siècle. Deux tentatives de décrire et d'expliquer les vagues de révoltes qui ont secoué le monde médiéval au bas moyen âge, encore souvent présentées comme les seules synthèses disponibles aujourd'hui, sont par exemple clairement marquées par 'mai 68' et la situation française. Il s'agit de deux livres de synthèse, le premier écrit par Michel Mollat et Philippe Wolff en 1970, le deuxième par Guy Fourquin en $1972 .{ }^{3}$ La prise de position idéologique est la plus claire chez Fourquin qui s'efforce de rejeter même l'emploi du terme révolution (auquel il préfère soulèvement) afin de mieux pouvoir réfuter l'application des recettes marxistes à l'histoire médiévale. ${ }^{4}$ Fourquin consacre la deuxième moitié de son livre à une typologie des soulèvements: il distingue ainsi trois grandes familles: les mouvements messianiques - l'attente messianique et le millénarisme sont déterminants; les soulèvements marqués par un désir ardent de mobilité sociale - l'accent

${ }^{2}$ H. Pirenne, Notice sur Léon Vanderkindere, membre de l'Académie: sa vie et ses travaux, "Annuaire de l'Académie royale de Belgique», 74, 1908, pp. 98-99 (voir également http://digistore.bib.ulb.ac.be/2006/a744323_000_f.pdf)

${ }^{3} \mathrm{M}$. Mollat, Ph. Wolff, Ongles bleus, Jacques et Ciompi. Les révolutions populaires en Europe aux XIV et XV siècles, Calmann-Levy, Paris 1970 et G. Fourquin, Les soulèvements populaires au moyen âge, PUF, Paris 1972.

${ }^{4}$ Fourquin, Les soulèvements populaires cit., pp. 5-7 (introduction) notons que le livre de Fourquin est publié dans une série 'l'historien' auprès des PUF (presses universitaires de France) dirigée par Roland Mousnier lui même auteur d'un livre sur 'les fureurs paysannes' en 1967 et pivot d'un débat qui faisait rage en histoire sociale à ce moment, voir une évaluation et contextualisation dans F. Cosandey éd., Dire et vivre l'ordre social en France sous l'ancien regime, Paris 2005 (EHESS, recherches d'histoire et de sciences sociales, 105), pp. 10-23. 
mis sur le combat entre élites traduit une forte influence de sociologues italiens (tels Mosca ou Vilfredo Pareto) de l'entre deux guerres; les soulèvements liés à la conjoncture économique avec un classement interne entre fureurs paysannes et commotions urbaines (le choix des mots reste révélateur!).

Mollat et Wolff confessent également dès la première page de leur introduction l'embarras ressenti lors du choix d'un titre ou plutôt d'un soustitre: si 'populaires' ne leur posait guère problème, 'révolution' le faisait davantage. Leur tentative de synthèse (couronnée par un succès international, surtout après la traduction en anglaise du livre) a le mérite de ne pas vouloir à tout prix réduire tous les mouvements à une typologie axée sur les motivations supposées des acteurs. ${ }^{5}$ Ainsi ont-ils attaché une grande valeur au phénomène d'influence mutuelle, au schéma chronologique, parce que la façon dont se sont déroulés les mouvements a souvent été déterminante pour leur nature, ils se sont auto-nourris et témoignent souvent d'une grande conscience historique. Autre élément sur lequel ils ont à juste titre attiré l'attention: le rôle grandissant de l'appareil d'Etat. Un paragraphe de leur conclusion ne commence pas par hasard par la remarque suivante: 'L'envahissement de la société par l'Etat, telle est en effet l'une des causes des luttes sociales.' ${ }^{6}$

Le même rôle essentiel réservé à l'Etat faisait irruption dans les écrits de sociologues historisants. Parmi eux, une des voix les plus écoutées est sans doute celle du sociologue américain Charles Tilly (maintenant à Columbia university) qui, après avoir écrit une thèse sur la révolte de la Vendée (1964), s'est attaqué à l'étude systématique des mouvements collectifs, d'où l'idée de répertoire de rébellion, la fameuse 'resource mobilisation theory.' L'important c'est que Tilly ne limite pas l'effort de recherche à une reconstruction minutieuse des événements, ni à formuler une possible relation causale avec l'économie, les structures sociales etc., mais qu'il considère les rébellions et révolutions comme faisant partie intégrante de processus plus larges. Parmi ces derniers en premier lieu: l'avènement d'un système économique, le développement du capitalisme et la genèse d'une construction Etatique en Europe, phénomènes qui se sont manifestés plus ou moins conjointement vers la fin du Moyen Age et au début des temps dits modernes. Nul étonnement donc à ce que les idées en la matière de Tilly fu-

\footnotetext{
${ }^{5} \mathrm{M}$. Mollat, $\mathrm{Ph}$. Wolff, The popular revolutions of the late Middle Ages, Londres, 1973 (Great revolution series 6).

${ }^{6}$ Mollat-Wolff, Ongles bleus, Jacques et Ciompi cit., p. 283.

${ }^{7}$ Voir Ch. Tilly, From mobilization to revolution, Reading 1978 et plus général Ch. Tilly, European revolutions 1492-1992, Oxford Cambridge (Mass.) 1993.
} 
rent une des sources d'inspiration pour le grand programme de recherche lancé à partir de l'année 1987 par la Fondation Européenne de la science (ESF), «les origines de l'Etat moderne en Europe, $\mathrm{XII}^{\mathrm{e}}$-XVIII ${ }^{\mathrm{e}}$ siècles» dont la direction générale fut confiée à Wim Blockmans et à Jean-Philippe Genet. ${ }^{8}$ On notera une fois de plus le synchronisme avec l'actualité du développement de la société: le grand questionnaire sur la genèse de l'Etat moderne arrivait au moment où l'on discutait de l'élargissement de l'union européenne et où l'on cherchait des réponses aux effets de la chute des régimes communistes en Europe de l'Est, ce qui posait la question d'un retour éventuel vers d'autres constructions politiques et donc mettait leur genèse et nature au cœur du débat.

Dans le contexte du programme ESF les rébellions ont trouvé la place qui leur revenait dans une des six collections d'études auquel le programme a donné lieu, celui baptisé 'résistance, représentation et communauté' sous la direction de Peter Blickle. ${ }^{9}$ Blickle, lui même auteur d'une œuvre théorique considérable sur le Kommunalismus, et l'équipe autour de lui regarde les soulèvements sans les isoler d'un contexte politique plus large. ${ }^{10}$ Etudier les résistances ensemble avec la représentation signifie que les révoltes sont

${ }^{8}$ Des considérations générales et plus ponctuelles concernant le programme dans: J.-Ph. Genet (éd.), L'Etat moderne: genèse. Bilans et perspectives. Actes du colloque tenu au CNRS à Paris les 19-20 septembre 1989, Paris, ed. CNRS, 1990; W. Blockmans, J.-Ph. Genet (éds.), Visions sur le développement des Etats Européens. Théories et historiographies de l'Etat moderne. Actes du colloque organisé par la Fondation Européenne de la Science et l'Ecole Française de Rome, Rome 18-31 mars 1990, Rome 1993 (Collection de l'Ecole Française de Rome 171).

${ }^{9}$ P. Blickle, Résistance, représentation et communauté, PUF, Paris 1998 (ESF, 'les origines de l'Etat moderne en Europe, XII $-X V I I I^{e}$ siècle').

${ }^{10}$ P. Blickle, Kommunalismus. Skizzen einer gesellschaftlichen Organisationsform, Munich 2000, 2 tomes. Suivant cette théorie le corps politique de la commune (par là on entend communautés urbaines et des campagnes et qui donc transcende l'opposition entre villes et villages chère à l'historiographie traditionnelle) prend naissance en Europe occidentale sans être une création de l'État. Elle naît d'une association volontaire et s'incarne dans une organisation institutionnelle comprenant deux pôles: une assemblée des membres pouvant statuer et les organes représentatifs qui en sont l'émanation. Elle est donc une pierre angulaire du processus de construction du politique au cours d'une période que les historiens ont trop volontiers taxée de féodale (14 fin $18^{\mathrm{e}}$ siècle). Pour Blickle le communalisme peut prendre place à côté des concepts comme 'féodalisme', 'absolutisme' ou 'parlementarisme', bref les 'poids lourds conceptuels' ('Elefantenbegriffe') de la pensée politique et de la science historique. Le communalisme s'impose à partir du $14^{\mathrm{e}}$ siècle comme une conquête du troisième Etat, celui des laboratores, unis par un désir d'améliorer leurs conditions de vie et de travail et de préserver le bien commun (Gemeinnutz opposé au Eigennutz des princes et seigneurs). Vu sous cette angle les communes sont l'antithèse du pouvoir de type monarchique, d'où un nombre impressionnant de conflits, de soulèvements. 
considérées comme des moments de courts-circuits dans un processus de négociations politiques ou encore comme un épisode où la préférence pour l'utilisation d'une violence ouverte (souvent maitrisée et dosée) prend la place d'un dialogue traditionnel. Là on rejoint le 'history from below' l'histoire vu d'en bas, donc du point de vu de ceux et celles qui la subissent, chère également à Tilly et à son étude du répertoire de rébellions.

\section{Le comté de Flandre: terre de traditions de rébellions?}

En 1988 Wim Blockmans a qualifié la remarquable tradition des rébellions de toutes sortes survenues dans les anciens Pays-Bas et qui ont façonné la relation entre gouvernants et gouvernés à long terme, pour aboutir vers la fin du $\mathrm{XVI}^{\mathrm{e}}$ siècle et dans le courant du XVII ${ }^{\mathrm{e}}$ siècle à la fondation d'une vraie République dominée par des élites marchandes, la République des Provinces-Unies, comme 'la grande tradition' des rébellions essentiellement urbaines. ${ }^{11}$ Quelques années plus tard en 1995, avec mon co-auteur de l'époque Maarten Prak, j'ai attiré l'attention sur la dynamique engendrée par cette grande tradition qui était constamment nourrie par ce que nous avons appelé à l'époque la 'petite tradition', celle qui donnait expression aux soulèvements urbains, aux manifestations violentes et confrontations entre groupes sociaux à l'intérieur d'une ville. ${ }^{12} \mathrm{Or}$, dans toutes ses considérations, il apparaît clairement que le XIV ${ }^{\mathrm{e}}$ siècle était celui au cours duquel le processus s'est mis en route après une série d'expériences collectives et d'essais.

Pour le cadre géographique: en parlant de la Flandre, je désigne bien sûr la principauté connue pendant ce longue $\mathrm{XIV}^{\mathrm{e}}$ siècle comme le comté de Flandre, fief tenu de la couronne de France, gouverné par une dynastie comtale elle aussi d'origine et de culture française, les Dampierre. Vers la

${ }^{11} \mathrm{~W}$. Blockmans, Alternatives to monarchical centralisation: the great tradition of revolt in Flanders and Brabant, in H. Koenigsberger (ed.), Republiken und Republikanismus im Europa des frühen Neuzeit (Schriften des historischen Kollegs, Kolloquien 11), Munich,1988, pp. 145-154. En qualifiant les révoltes de cette façon il élaborait une analyse développée auparavant: W. Blockmans, Revolutionaire mechanismen in Vlaanderen van de 13de tot de 16de eeuw, "Tijdschrift voor sociale wetenschappen", 18, 1974 , pp. 123-140. Finalement il a livré une approche synthétique de la problématique dans une synthèse sur l'échelle européenne: W. Blockmans, L'impact des villes sur l'édification de l'Etat: trois territoires différents des Pays-Bas $d u X I V^{e}$ au XVI ${ }^{e}$ siècle, in $\mathrm{P}$. Blickle (éd.), Résistance, représentation et communauté cit., pp. 340-358.

${ }^{12}$ M. Boone, M. Prak, Rulers, patricians and burghers: the Great and the Little Traditions of Urban Revolt in the Low Countries, in K. Davids, J. Lucassen (ed.), A miracle mirrored. The Dutch Republic in European Perspective, Cambridge University Press, Cambridge 1995, pp. 106-113. 
fin du XIV ${ }^{\mathrm{e}}$ siècle, le comté fut incorporé dans l'héritage des ducs de Bourgogne. Il devient dès lors un élément essentiel de cette construction étatique de premier ordre des $\mathrm{XV}^{\mathrm{e}}-\mathrm{XVI}^{\mathrm{e}}$ siècle, l'Etat bourguignon et plus tard habsbourgeois dans les Pays-Bas.

La Flandre et les expériences accumulées en son sein ont a plusieurs reprises inspiré des pratiques dans les autres principautés urbanisées des anciens Pays-Bas, en premier lieu le duché de Brabant et les principautés ecclésiastiques de Liège et d'Utrecht.

Dans ce qui suit je propose de traiter ensemble la 'grande et la petite' tradition des soulèvements protestataires et rébellions politiques qu'a connus la Flandre dans le long XIV ${ }^{e}$ siècle, en l'insérant dans une approche inspirée par les théories sociales concernant les 'actions collectives' auxquelles je viens de faire allusion. Il est donc important de déterminer le caractère des actions collectives flamandes et de démontrer les processus et répertoires mises en œuvre. Or, la grande majorité des sources contemporaines qui nous informent sur la nature et le déroulement des révoltes sont fortement engagées et évoquent une vision plus que partisane. Elles émanent en effet soit d'auteurs ecclésiastiques souvent peu enclins à comprendre les motivations des rebelles, soit d'autorités princières, citadines parfois, chargées d'organiser la répression après avoir maté les révoltes. L'historien a donc besoin d'essayer de pénétrer dans ce que James Scott a qualifié de 'hidden transcript', le discours souvent sous-jacent des rebelles caché derrière le discours dominant des pouvoirs en place, à l'aide d'un questionnaire emprunté aux sciences sociales et à l'analyse de discours. ${ }^{13}$

Les révoltes urbaines et paysannes de la Flandre médiévale ont également été mobilisées dans les combats politiques et idéologiques des XIX ${ }^{\mathrm{e}}$ et $\mathrm{XX}^{\mathrm{e}}$ siècles, au moment où le développement d'une science historique allait de pair avec un débat politique qui se nourrissait tout naturellement d'une histoire nationale redécouverte, mobilisatrice et légitimatrice. Le contraire aurait surpris. Là également l'historien actuel se doit de contextualiser sa lecture des prédécesseurs, et d'être attentif aux changements parfois subtils des tonalités et des traditions historiographiques. Un auteur hautement important pour le sujet en question, comme Henri Pirenne, change par exemple considérablement de ton lorsqu'il s'agit de juger de façon très positive l'action des hommes de métiers flamands et leur apport dans la lutte pour l'autonomie du comté face au roi de France Philippe le Bel au début du XIV ${ }^{\mathrm{e}}$ siècle d'une part, ou d'autre part de

${ }^{13}$ J.C. Scott, Domination and the art of resistance. Hidden transcripts, New HavenLondres 1990. 
condamner les mêmes membres des métiers comme une force d'inertie sociale et de retardement face à l'action unificatrice des ducs de Bourgogne, dans laquelle il salue les premiers pas vers la constitution de sa Belgique libérale tant aimée. ${ }^{14}$

\section{Le comté de Flandre à l’aube du long XIV esiècle: des villes en ébullition}

Les données démographiques disponibles à partir du milieu du XIV siècle nous montrent un comté de Flandre dominé dans la partie dite 'Flandre flamingante' par trois grandes villes (Gand avec environ 64.000, Bruges environ 45.000 et Ypres 28.000 habitants). ${ }^{15}$ On y ajoutera, en Flandre française, (les châtellenies de Lille, Douai et Orchies, sous la domination directe de la couronne de France entre 1312 et 1369) deux grandes villes: Lille et Douai; et en Artois, aussi deux grandes villes: SaintOmer et Arras, dont la population aurait pu se situer dans un ordre de grandeur de 20 à 30.000 habitants au début du XIV siècle et qui faisaient partie intégrante du comté de Flandre jusqu'à la fin du XII ${ }^{\mathrm{e}}$ siècle. ${ }^{16} \mathrm{~A}$ côté des 'grandes' villes citées, se dessine un réseau de quelque 50 petites villes ou villes moyennes comptant moins de 10.000 habitants ( 7 entre 5 et $10.000,11$ entre 2 et 5.000, 14 entre 1.000 et 2.000 , le reste en dessous de 1.000). Cette forte population urbaine occupait une superficie restreinte, le fait démographique révélateur étant la densité urbaine exceptionnelle: 77,9 habitants par $\mathrm{km}^{2}$ ou un degré d'urbanisation de $36 \%$ de la population totale (seul le comté voisin de Hollande faisait mieux avec $45 \%)^{17}$.

${ }^{14}$ Voir, avec d'abondantes références aux textes de Pirenne, M. Boone, Les métiers dans les villes flamandes au bas moyen âge (XIV e-XVI ${ }^{e}$ siècles): images normatives, réalités socio-politiques et économiques, in P. Lambrechts, J.-P. Sosson (éd.), Les métiers au moyen âge. Aspects économiques et sociaux, Actes du Colloque International de Louvainla-Neuve, 7-9 octobre 1993, Louvain-la-Neuve 1994 (Université Catholique de Louvain, Publications de l'Institut d'Etudes Médiévales, Textes, Etudes, Congrès, vol. 15), pp. 1-2. Sur Pirenne, M.Boone, 'L'automne du Moyen Age': Johan Huizinga et Henri Pirenne ou 'plusieurs vérités pour la même chose', in P. Moreno, G. Palumbo (éd.) 'L'automne du Moyen Age. Textes, iconographie, philologie. Journées pour Alberto Varvaro (chaire Francqui au titre étranger 2003-2004, Liège-Genève, Droz, (Bibliothèque de la Faculté de Philosophie et Lettres de l'Université de Liège), sous presse.

${ }^{15}$ Voir W. Prevenier, La démographie des villes du comté de Flandre aux XIV et XV siècles. Etat de question. Essai d'interprétation, «Revue du Nord», LXV, 1983, pp. 255-258.

${ }^{16}$ Voir les données chiffrées (discutables) chez A. Derville, Le nombre d'habitants des villes de l'Artois et de la Flandre Wallonne (1300-1450), «Revue du Nord», LXV, 1983, pp. 277-299.

17 Voir les données et des références utiles à une littérature abondante chez W. Prevenier, J.-P. Sosson, M. Boone, Le réseau urbain en Flandre (XIII ${ }^{e}-X I X^{e}$ siècle): composantes et dynamique, dans Actes du $15^{e}$ colloque international 'Le réseau urbain en Belgique dans une perspective historique (1350-1850). Une approche statistique et dyna- 
Economiquement, les grandes villes flamandes combinaient le rôle de centres réputés de production textile (aussi bien les produits de haut de gamme que les textiles plus courants) avec celui plus passif de marché d'échange pour colonies de marchands étrangers. ${ }^{18}$ Par sa situation géopolitique sur l'embouchure de quelques grandes rivières navigables de l'Europe du NordOuest (Escaut, Meuse et Rhin) la Flandre et les principautés voisines qui partagèrent progressivement le même sort, se situaient sur un carrefour commercial entre l'Angleterre, la Rhénanie, le bassin parisien et l'Europe du Nord (où s'activait la Hanse germanique). Dès les environ de 1280 le lien direct avec l'autre pôle majeur de l'Europe urbaine, l'Italie du Nord et du centre ne se faisait désormais plus exclusivement à travers les activités commerciales concentrées aux foires de Champagne, mais grâce à un contact maritime direct par l'intermédiaire du port de Bruges (et de ses avant-ports situés dans l'estuaire du Zwin). Bruges connut dès le XIV siècle l'apogée de son rôle de centre commercial de première importance. ${ }^{19}$ Le commerce international se nourrissait des activités industrielles d'une masse importante d'artisans et de gens de métiers à l'œuvre dans les grandes et moyennes villes de Flandre (dont les deux grandes villes Gand et Ypres passaient pour des centres majeurs de l'industrie drapière) mais également d'une agriculture 'industrialisée' à la fois par la production de produits de base pour l'industrie textile (colorants, lin) et par les activités de préparation et

mique, Spa, 4-6 sept. 1990, Bruxelles 1992 (Crédit communal, collection histoire, série in- $\left.8^{\circ}, \mathrm{n}^{\circ} 86\right)$, pp. 160-162. Sur le réseau urbain flamand P. Stabel, Dwarfs among giants. The flemish urban network in the late Middle Ages, Garant ed., Leuven-Apeldoorn 1997. Une comparaison des données démographiques en Italie du Nord et du Centre en dans les anciens Pays-Bas aura sa place dans E. Crouzet-Pavan, E. Lecuppre-Desjardin (éd.), Villes de Flandre et d'Italie: les enseignements d'une comparaison, Brepols Turnhout (Studies in European Urban History series 12) 2008 (contributions de P. Stabel et de G. Pinto).

${ }^{18}$ Des points de vue récents sur l'importance de la draperie classique et la présence d'une draperie plus légère déjà au XIII ${ }^{\mathrm{e}}$ siècle se retrouvent chez P. Chorley, The cloth exports of Flanders and northern France during the thirteenth century: a luxury trade?, «Economic history review», XL, 1987, pp. 349-379, et J.H. Munro, Industrial transformations in the north-west European textile trades, c. 1290 - c. 1340: economic progress or economic crisis?, in B.M.S. Campbell (éd.), Before the Black Death. Studies in the 'crisis' of the early fourteenth century, Manchester-New York 1991, pp. 110-148. Des approches ponctuelles se retrouvent dans M. Boone, W. Prevenier (édd.), La draperie ancienne des Pays-Bas: débouchés et stratégies de survie (14 $14^{e}-16^{e}$ siècles). Actes du colloque tenu à Gand le 28 avril 1992, Garant ed., Leuven-Apeldoorn 1993, passim. Une synthèse récente qui place la draperie flamande dans son contexte européen: R. Holbach, Frühformen von Verlag und Grossbetrieb in der gewerblichen Produktion (13.16. Jahrhundert), F. Steiner Verlag, Stuttgart 1994 (Vierteljahrschrift für Sozial- und Wirtschaftsgeschichte. Beihefte 110), pp. 51-78.

${ }^{19}$ Voir en dernier lieu (car là aussi la littérature est devenue abondante): J. Murray, Bruges, cradle of capitalism, 1280-1390, Cambridge university press, Cambridge 2005. 
de finition qui trouvaient leur raison d'être dans la même industrie textile. ${ }^{20}$ Mais c'est à l'intérieur des villes que les oppositions et contradictions entre groupes sociaux constituaient une base de possibles revendications et d'affrontements à la fois sociaux et politiques.

Les villes étaient en effet sous le contrôle d'une élite politique restreinte du type 'patriciat urbain', caractérisée dans le XIII' siècle, quand son action devient perceptible, par une mainmise presque absolue sur l'économie et sur l'immobilier, par un monopole sur le pouvoir politique et par un contrôle sans contre-pouvoir sur les finances urbaines. ${ }^{21}$ Ces élites urbaines étaient parvenues à prendre en main les villes et à partager le pouvoir au niveau du comté en collaborant avec le pouvoir princier mis en place par les dynasties qui se succédaient à la tête du comté, principauté de nature féodale tenue en grande partie du roi de France, dans une moindre mesure pour une partie du territoire flamand situé outre Escaut de l'empereur. Dans la grande crise du pouvoir comtal des années 1127-1128 qui mena finalement à l'arrivée au pouvoir de la dynastie des comtes dits d'Alsace, les grandes villes flamandes, Gand et Bruges avaient connu leur variante du mouvement 'communal' si typique pour un grand nombre de villes dans l'entre Seine et Rhin. ${ }^{22}$ Les villes en sortaient renforcées sur le

20 Sur le développement de l'agriculture: E. Thoen, A commercial survival economy' in evolution. The Flemish countryside and the transition to capitalism (middle ages-19 $9^{\text {th }}$ century), in P. Hoppenbrouwers, J.L. Van Zanden (éd.), Peasants into farmers? The transformation of rural economy and society in the Low Countries (middle ages-19 $9^{\text {th }}$ century) in light of the Brenner debate, Brepols, Turnhout 2001, pp 105-111.

${ }^{21}$ La notion même de patriciat est contestée: voir l'attaque en règle d'A. Derville, Les élites urbaines en Flandre et en Artois, in Les élites urbaines au Moyen Âge. XXVII ${ }^{\mathrm{e}}$ congrès de la Société des Historiens Médiévistes de l'Enseignement Supérieur Public (Rome, mai 1996), PUF, Paris (publications de la Sorbonne, Série histoire ancienne et médiévale 46), pp.119-135. La notion même est entrée dans le vocabulaire historique, surtout depuis qu'elle était mise en avant dans J. Lestoquoy, Aux origines de la bourgeoisie: les villes de Flandre et d'Italie sous le gouvernement des patriciens (XI ${ }^{e}$ $X V^{e}$ siècles), PUF, Paris 1952. Appliquée au XIII ${ }^{\mathrm{e}}$ siècle, elle reste toutefois acceptée et acceptable, voir l'étude classique d'un cas célèbre, Gand: F. Blockmans, Het Gentsche stadspatriciaat tot omstreeks 1302, De Sikkel, Antwerpen-'s Gravenhage 1938, (Rijksuniversiteit te Gent, werken uitgegeven door de fac. Letteren en wijsbegeerte, 85), passim.

${ }^{22} \mathrm{~K}$. Schulz, Denn sie lieben die Freiheit so sehr... Kommunale Aufstände und Entstehung des europäischen Bürgertums im Hochmittelalter, Darmstadt, 1992. Sur le moment communal: A. Rigaudière, Kommune. II Frankreich, «Lexikon des Mittelalters», V, München, 1991, col.1287-1289; O. Guyotjeannin, 1060-1285, in Ph. Contamine (ed.), Le Moyen Âge. Le roi, l'église, les grands, le peuple 481-1514, Le Seuil, Paris 2002 (Histoire de la France politique), pp. 199-202. Des mouvements similaires ont été signalés dans les communautés rurales: O.G. Oexle, Die Kultur der Rebellion. Schwureinung und Verschwörung im früh- und hochmittelalterlichen Okzident, in M.Th. Fögen ed. Ordnung und Aufruhr im Mittelalter. Historische und juristische Studien zur Rebellion (Ius com- 
plan politique: désormais le principe selon lequel elles pouvaient juger le prince et son action à l'aune de la défense du 'bien public' semblait acquis, tout comme son corollaire, le droit de procéder à la réfutation et à l'abnégation d'un prince qui ne respectait pas ses engagements et devoirs moraux vis-à-vis de ses sujets. ${ }^{23} \mathrm{Ce}$ principe fondamental, articulant la relation entre gouvernants et gouvernés sur la base d'un contrat avec des devoirs et des obligations des deux côtés allait refaire surface dans le courant des révoltes urbaines du XIV ${ }^{\mathrm{e}}$ siècle. Il est graduellement entré dans la culture politique et une version précoce se retrouve dans le préambule d'une charte-loi ('keure') octroyée à la ville de Gand par la veuve du comte Philippe d'Alsace en 1191, la reine Mathilde. ${ }^{24}$ L'idée d'un contrôle des gouvernants par les gouvernés était formulée au XII ${ }^{\mathrm{e}}$ siècle, mais allait connaître un avenir radieux, puisqu'après avoir été développé dans le courant des soulèvements des $\mathrm{XIV}^{\mathrm{e}}$ et $\mathrm{XV}^{\mathrm{e}}$ siècles elle a été la source d'inspiration directe de l'acte de déchéance de 1581 par lequel les Etats Généraux des Pays-Bas ont déclaré ne plus vouloir reconnaitre Philippe II roi d'Espagne comme leur roi légitime. ${ }^{25}$

Face au pouvoir comtal, entre les mains des comtesses Jeanne et Marguerite de Constantinople (1212-1278), affaibli par une première défaite de grandes conséquences face à la France (Bouvines, 1214) les villes allaient se poser en pouvoir alternatif. C'est l'époque de l'action des 'scabini Flandriae' (les échevins de la Flandre, émanation du pouvoir urbain au niveau de la principauté) soutenue par une caste de patriciens urbains socialement homogène.

Toutefois, dès les premières manifestations du retournement de la conjoncture économique vers les années 1270-1280, les antagonismes présents dans la société flamande s'accentuèrent: à l'intérieur des villes,

mune. Sonderhefte. Studien zur Europäischen Rechtsgeschichte 70), Frankfurt am Main 1995, pp. 120-122.

${ }^{23}$ C'est ce qui ressort du texte fondamental de Galbert de Bruges (dont on dispose désormais d'une nouvelle édition remplaçant celle de Pirenne): Galbertus notarius Brugensis, De multro, traditione et occisione gloriosi Karoli comitis Flandriarum, Brepols, Turnhout 1994 (Corpus Christianorum, continuatio mediaevalis CXXXI, éd. J. Rider).

${ }^{24}$ W. Prevenier, De oorkonden der graven van Vlaanderen (1191-aanvang 1206). II. Uitgave, KCG, Brussel 1964, p. 12 (art.1): «Oppidani Gandenses fideles debent esse principi suo et amici pre omnibus, quos mundus habet, principibus, quamdiu iuste et rationabiliter eos tractare voluerit».

${ }^{25}$ J'ai élaboré cette généalogie idéologique dans une contribution The Dutch Revolt and the medieval tradition of urban dissent lors de la conférence tenue à Los Angeles (EU) Williams Andrews Clark Library, Conference 'The political culture of the revolt of the Netherlands, 1566-1648', les 7-8 octobre 2005 ( (Journal of Early Modern History» 11, 2007, pp. 351-375). 
l'industrie drapière connaissait les premières difficultés structurelles d'où une montée des confrontations entre divers groupes: drapiers (entrepreneurs) contre salariés, tisserands contre foulons etc. Au niveau de la ville, le monopole de pouvoir des patriciens et plus précisément leur gestion financière et leur mainmise sur la justice et la politique en général fut contesté par des groupes divers: gens de métiers, artisans et groupes moyens, mais également par le prolétariat et les masses salariées présentes dans les grandes industries drapières. Les contemporains réduisaient aisément les oppositions - la pensée manichéenne très présente dans l'Europe médiévale y trouve une application - dans une juxtaposition entre deux groupes 'majores' et 'meliores' vis-à-vis des 'ille de communitate' ou encore en langue vernaculaire 'le commun' vis-à-vis des 'boins de la ville. ${ }^{26}$ Finalement au niveau de la principauté, l'interdépendance des finances urbaines et des finances princières provoquait des coalitions de groupes à l'intérieur des villes avec le pouvoir comtal, lui-même sous pression constante du pouvoir royal français. Dès qu'une approche chiffrée des revenus comtaux flamands devient possible (pour le règne de la comtesse Marguerite de Constantinople, 1244-1278), il est clair que l'apport des aides des cinq grandes villes de l'époque (Gand, Bruges, Ypres, Lille et Douai) pouvait monter à au moins un quart du total des revenus dont pouvait disposer la comtesse. ${ }^{27}$ D'où, par conséquent, l'intérêt grandissant des comtes à se mêler de ce qui se passait à l'intérieur des villes et à s'engager comme partenaire dans la lutte intestine des villes.

Faire de la politique, s'engager en économie vers 1280 en Flandre c'était en quelque sorte danser sur un volcan...

\section{Le long XIV siècle flamand}

\subsection{Les aléas d'une conjoncture changeante (1280-1312): grande politique et menus intérêts ${ }^{28}$}

Vers 1280 la période des affrontements qui allèrent crescendo tout au long du XIV e siècle démarrait. Déjà en 1245 un premier mouvement de

${ }^{26}$ Voyez sur la terminologie W. Prevenier, Conscience et perception de la condition sociale chez les gens du commun dans les anciens Pays-Bas des XIII et XIV ${ }^{e}$ siècles, in $\mathrm{P}$. Boglione, R. Delort, Cl. Gauvard (ed.), Le petit peuple dans l'occident médiéval. Terminologies, perceptions, réalités, Actes du congrès de Montréal 1999, Paris 2002, pp. 180-185, avec un grand nombre d'exemples du vocabulaire utilisé.

${ }^{27}$ T. Luyckx, De grafelijke financiële bestuursinstellingen en het grafelijk patrimonium in Vlaanderen tijdens de regering van Margareta van Constantinopel (1244-1278), Bruxelles 1961, pp. 247-252, 256-257.

${ }^{28}$ L'exposé qui suit fera référence aux travaux, études, éditions de sources qui nous 
grève ('takehans') se manifestait à Douai, ville industrielle touchée de nouveau en 1276. En 1252 et 1274 les ouvriers du textile à Gand rejoignaient le mouvement. Mais ce fut en 1280 , et dans les années qui ont suivi, qu'un mouvement généralisé, une vague de protestations sociales et politiques a touché le comté et les régions limitrophes. La liste est impressionnante: Provins en Champagne en 1279, Tournai en 1279-81, Douai, Bruges, Ypres, Gand, Saint-Omer et Arras en 1280, Damme, Lille, Cambrai, Arras, Bruxelles, Liège et Saint-Trond en 1285, Rouen en 1281 et 1292, Laon en 1295, Calais en 1298, Saint-Quentin en 1293. Durant les deux dernières décennies du XIII ${ }^{\mathrm{e}}$ siècle le territoire flamand-picard semble avoir été atteint par une véritable épidémie de mouvements sociaux. L'effet d'imitation et de contagion n’a évidemment pas échappé aux contemporains. Dans les faits, les mouvements d'environ 1280 naissaient de la conjonction d'exigences socio-économiques, salariales surtout et d'un mécontentement politique général dirigé en premier lieu contre les élites dirigeantes et inspiré par la situation fiscale et la gestion des finances urbaines. Quant au déroulement des 'troubles' il fait songer davantage à un mélange de manifestations carnavalesques, d'actes de violence banale sur la voie publique et de règlements de comptes politiques de caractère rituel. Les noms flamands donnés à ce genre de manifestations sont d'ailleurs significatifs, à Ypres la 'cockerulle' de 1280 ou à Bruges la 'moerlemaaie' de la même année signifient respectivement 'marcher en désordre dans les rues' et 'participer à un cortège relevant du charivari, en agitant les bras dans tous les sens. ${ }^{29}$ Difficile de voir dans ces mouvements une 'révolution' comme le veut une certaine tradition historiographique depuis que Henri Pirenne a attribué cette qualification aux deux mouvements en questions. Dans la plupart des mouvements urbains de ces années on note également que certaines parties de l'élite au pouvoir réussissaient régulièrement à rallier à leur cause de grands

ont inspiré des approches plus élaborées se retrouvent dans les travaux récents de mes étudiants qui ont abordé le sujet: R. Verbruggen, Geweld in Vlaanderen. Macht en onderdrukking in de Vlaamse steden tijdens de veertiende eeuw, Bruges, uitgeverij Marc vande Wiele, 2005 et J. Dumolyn, J. Haemers, Patterns of urban rebellion in medieval Flanders, «Journal of Medieval History» 31, 2005, pp. 369-393; J. Dumolyn, The legal repression of revolts in late medieval Flanders, «Revue d'histoire du droit», LXVIII, 2000, pp. 479-521.

${ }^{29}$ Voir sur ces mouvements, avec référence à la littérature ancienne, M. Boone, Social Conflicts in the cloth industry of Ypres (late $13^{\text {th }}$-early $14^{\text {th }}$ centuries). The 'Cockerulle' reconsidered, in M. Dewilde, A. Ervynck, A. Wielemans, Ypres and the Medieval Cloth Industry in Flanders. Archaeological and historical contributions. Ieper en de middeleeuwse lakennijverheid in Vlaanderen. Archeologische en historische bijdragen, Asse-Zellik, (Archeologie in Vlaanderen, monografie 2), 1999, pp. 147-155. Voir également A.A. Bardoel, The Urban uprising at Bruges, 1280-81. Some new findings about the rebels and partisans, «Revue Belge de Philologie et d'histoire», 72, 1994, pp. 761-791. 
groupes du 'commun' et à les employer comme troupes de choc dans des règlements de comptes internes avec d'autres patriciens. Des contrastes de classe objectifs existaient mais ne conduisaient pas toujours - en fait rarement - à une formation de partis nettement délimités par cette ligne de rupture. D'autres formes de solidarité qui obéissaient à une logique familiale ou professionnelle, parfois également à des formes de vie en commun, contrariaient ce schéma. En d'autres termes, il ne s'agissait pas dans ces deux dernières décennies du XIII ${ }^{\mathrm{e}}$ siècle d'une quelconque forme de manifestation très organisée et collective de mécontentement politique et sociale, mais plutôt d'une atmosphère 'pré-révolutionnaire' diffuse. L'intervention du pouvoir comtal après chacune de ces révoltes prouve toutefois que la gravité des motifs socio-économiques de toutes ces manifestations était effectivement prise au sérieux.

Pour le comte, la tentation d'utiliser ce moment de faiblesse interne des élites patriciennes à l'intérieur des villes fut en effet grande. Les Dampierre ont bien décodé les occasions qui ainsi se présentaient et ont essayé d'éliminer, en s'appuyant sur le pouvoir des frustrés de la politique urbaine (groupes moyens, artisans mais également familles de l'élite exclues du patriciat fermé), le contre pouvoir des élites traditionnelles, le seul à ce jour là capable de se poser comme alternative pour le pouvoir comtal. Dans cette logique, le comte de Flandre devint l'allié objectif du 'commun' des villes. A l'autre bout de la hiérarchie urbaine, l'élite traditionnelle du patriciat se trouvait du coup l'allié de circonstance du roi de France, dès le moment, vers 1300, où ce dernier trouvait opportun de se mêler directement des affaires du comté. Le processus de formation de partis politiques basée sur une opposition particulière entre groupes sociaux s'en trouvait renforcé. Ces partis politiques se nommaient et se reconnaissaient désormais en faisant référence aux armes du comte pour le commun (le lion, d'où le mot 'klauwaerts' référant aux griffes, klauwen en flamand, du lion) ou aux armes du roi pour le patriciat (la fleur de lys, d'où 'léliaerts' référant au mot flamand pour lys: lelie). Pour le roi de France, l'occasion d'en finir avec un énième pouvoir féodal régional, en l'occurrence le comte de Flandre, fut trop belle. Le combat juridico-politique autour de la situation de l'échevinat gantois classique, les soi-disant XXXIX, est à ce titre exemplaire. Mais en prenant en considération les particularités locales, une confrontation similaire se préparait aussi bien à Bruges qu'à Ypres, dans les années qui ont suivi les 'cockerulle' et 'moerlemaaie' des années 1280. Elle se traduisait graduellement, après interventions du Parlement de Paris et des légistes au service du roi, par un combat autour du contrôle des finances urbaines, donc sur la façon dont le pouvoir en place à l'intérieur 
des villes utilisait le produit fiscal. Une confrontation qui autorisait aussi bien de mobiliser des notions politiques et morales comme celle du 'bien commun', que de faire référence au mal être tangible provoqué par la fixation presqu'exclusive sur une fiscalité urbaine indirecte. Arme tactique redoutable mais à double tranchant, il suffisait que le roi Philippe le Bel ayant écarté les Dampierre règne directement sur le comté de Flandre pour qu'il se trouve en personne confronté au mécontentement fiscal de ses nouveaux sujets flamands, comme cela s'était manifesté lors de sa joyeuse entrée à Gand au mois de mai 1301 ou, comme cela résonnait dans les événements à Bruges quelques jours plus tard. ${ }^{30}$

A Bruges, un nouvel élément faisait son apparition qui allait marquer les événements ultérieurs de ce $\mathrm{XIV}^{\mathrm{e}}$ siècle flamand plus que mouvementé: l'action d'un meneur politique, en l'occurrence le tisserand Pieter de Coninc, figure peu spectaculaire, de petite taille, mais doué d'un grand talent oratoire. Il est, avec son compagnon le boucher Jan Breydel (les compères se trouvent actuellement ensemble sur un socle soutenant une statue typique du romantisme historique du XIX ${ }^{\mathrm{e}}$ siècle sur la place du marché à Bruges) la variante flamande du type de meneur qui s'impose dans bon nombre de révoltes urbaines du XIV ${ }^{\mathrm{e}}$ siècle. A titre de comparaison, l'on pense automatiquement aux Arteveldes gantois, mais aussi à Etienne Marcel et plus tard à Caboche à Paris, les 'tyrans urbains' en Allemagne, Cola di Rienzo à Rome, Wat Tylor et John Ball à Londres...

La polarisation politique et l'ingérence de forces politiques et militaires extérieures à la Flandre, ont fait qu'une fois les ambitions de la royauté française affichées, elles provoquèrent une réaction vive de la part de l'Angleterre, partenaire économique de la Flandre (et importante source d'approvisionnement en laine, la matière première par excellence pour l'industrie textile flamande). Les révoltes urbaines de la Flandre de la fin du $\mathrm{XIII}^{\mathrm{e}}$ et du début du XIV ${ }^{\mathrm{e}}$ siècle se greffaient donc sur un conflit politique de premier ordre sur l'échiquier politique européen, celui entre les royautés françaises et anglaises, les deux 'états' les plus développés du moment. En Flandre, devenu le champ de bataille de puissances étrangères, ce développement ne tardait pas à renforcer le caractère violent des confrontations et à augmenter l'expérience militaire acquise dans les faits par les milices urbaines et artisanales. L'apogée provisoire de ce développement se soldait en effet par une victoire à la fois spectaculaire et imprévue des mi-

${ }^{30}$ Voir le récit d'un franciscain gantois anonyme: F. Funck-Brentano, Annales Gandenses. Nouvelle édition, Picard, Paris 1896, p. 13. Il existe du texte en question une traduction anglaise (qui reprit l'édition Funck-Brentano): H. Johnstone, Annals of Ghent, London 1951. 
lices flamandes sur l'ost royal français dans la bataille dite 'des éperons d'or' ou bataille de Courtrai le 11 juillet $1302 .{ }^{31}$

Dans l'immédiat les résultats les plus importants de cette série de confrontations furent d'une importance capitale pour les développements ultérieurs:

- la percée définitive des corps de métiers à côté des élites politiques des grandes villes. Puisque les mêmes villes ont réussi à mettre la main sur la représentation officielle des sujets flamands auprès des autorités princières, cette percée devint réalité aussi parmi les élites des institutions 'parlementaires' (réunions des Etats, très vite dominés par le Tiers Etat en Flandre, le champ d'action des grandes villes ou Membres de Flandre: Gand, Bruges, Ypres et le district rural du Franc de Bruges) $)^{32}$;

- la sauvegarde de l'indépendance politique du comté de Flandre face à la royauté, mais avec une conséquence de taille: désormais le roi de France se trouvait toujours près de la frontière, prêt à se mêler aux affaires flamandes entre autre pour prêter main forte au comte à chaque fois que celui-ci se trouvait en difficulté;

- le développement d'une fiscalité étatique digne de ce nom, suite à la victoire que les légistes de Philippe le Bel obtinrent autour de la table des négociations et mise en application à partir de 1312 (traité de Pontoise). Finalement, le comte se voyait doté d'un droit fiscal sur ses propres sujets (le 'Transport de Flandre' base de la fiscalité princière jusque vers la fin de l'Ancien Régime), le roi mettait en compensation la main sur les trois châtellenies de la Flandre française (Lille, Douai, Orchies) dans les années 1312-1369. Le retour des trois châtellenies devenait automatiquement un des leitmotiv de la politique flamande au $\mathrm{XIV}^{\mathrm{e}}$ siècle, jusqu'à ce qu'en 1369 elles soient à nouveau réunies au comté, suite au mariage bourguignon de l'héritière du comté, la princesse Marguerite de Male. ${ }^{33}$

${ }^{31}$ La lecture sur ce conflit est une fois de plus très abondante, je renvoie à la synthèse d'histoire politique et sociale que j'ai écrit à l'occasion du $700^{\mathrm{e}}$ commémoration de la bataille, M. Boone, Une société urbanisée sous tension. Le comté de Flandre vers 1302, in R.C. Van Caenegem, 1302. Le désastre de Courtrai. Mythe et réalité de la bataille des Eperons d'or, Fonds Mercator, Anvers 2002, pp. 27-77.

${ }^{32}$ Sur les institutions dites représentatives en Flandre: M. Boone, 'In den beginne was het woord'. De vroege groei van 'parlementen' in de middeleeuwse vorstendommen der Nederlanden, «Bijdragen en Mededelingen betreffende de Geschiedenis der Nederlanden», 120, afl.3, 2005, pp. 338-361.

${ }^{33}$ Le développement d'une fiscalité d'État directe allait devenir un casse-tête important pour les princes des anciens Pays-Bas, le point de départ formé aux alentours de 1300 
- sur le plan de l'organisation des manifestations collectives, les années autour de 1300 avaient permis aux participants, avant tout les gens de métier, de bien roder les stratégies collectives: grèves, occupations de lieux stratégiques dans les villes (marchés, campaniles), manipulation du décor acoustique, etc. qui étaient appelés à un retour en force dans les décennies et siècles à venir. ${ }^{34}$ Dans la vision chère à Charles Tilly un 'répertoire de rébellion' digne de ce nom, s'était graduellement développé; en même temps une 'Widerstandstradition' comme l'a baptisée Peter Blickle se mettait également en place, dans les années à venir de nouvelles générations d'artisans flamands allaient se souvenir des actes et gestes des ancêtres des années $1300 .^{35}$

\subsection{Le rêve de l'État urbain (1312-1360)}

Après la phase d'émancipation bourgeoise et corporative à l'intérieur des villes et d'émancipation 'nationale' sur l'échiquier européen, une phase d'un apparent chaos politique s'installait en Flandre. Les manifestations de la crise économique se faisant ressentir de façon plus cruelle qu'avant. La famine de 1316, par exemple, semble avoir causé une mortalité d'environ $10 \%$ de la population dans des villes comme Bruges et Ypres. L'impact en était en tout cas renforcé considérablement par les effets de la répression fiscale d'après Courtrai. ${ }^{36} \mathrm{La}$ fiscalité installée suite au traité de paix d'Athis-

par l'élaboration d'une fiscalité de répartition le 'Transport' allait toutefois pour des siècles a venir servir de base, voir M. Boone, Les ducs, les villes et l'argent des contribuables: le rêve d'un impôt princier permanent en Flandre à l'époque bourguignonne, in $\mathrm{Ph}$. Contamine, J. Kerhervé, A. Rigaudière (éd.), L'impôt au moyen âge. L'impôt public et le prélèvement seigneurial en France, fin XII début XVI siècle. II. Les espaces fiscaux, Colloque tenu à Bercy les 14,15 et 16 juin 2000, Comité pour l'Histoire Economique et Financière de la France, Paris 2002, pp. 323-341. Sur la diplomatie autour de la question des trois châtellenies de la Flandre dite française, on consultera toujours F. Quicke, Les Pays-Bas à la veille de la période bourguignonne (1356-1384): contribution à l'histoire politique et diplomatique de l'Europe occidentale dans la seconde moitié du XIVe siècle, Bruxelles 1947.

${ }^{34}$ Une référence directe à une source précise s'impose: F. Funck-Brentano (éd.), Annales Gandenses cit., source narrative écrite par un minorite anonyme gantois, témoin oculaire qui manifeste un intérêt particulier aux prises de positions et aux sentiments du 'commun' de sa ville et nous livre un témoignage saisissant des moyens d'action utilisés. Sur cette chronique voir M. Boone, Der anonyme Minorit von Gent Annales Gandenses, in V. Reinhardt (éd.), Hauptwerke der Geschichtsschreibung, Stuttgart 1997 (Kröners Taschenausgabe Band 435), pp. 14-17.

${ }^{35}$ Concernant les écrits de Tilly voir supra note 7. Concernant la notion de 'Widerstandstradition': P. Blickle, Unruhen in der ständischen Gesellschaft 1300-1800, Munich 1988.

${ }^{36}$ Sur les famines, phénomène qui s'est manifesté sur une échelle européenne voir W.C. Jordan, The great famine. Northern Europe in the early fourteenth century, Princeton 1996, pp. 141-148. À partir des années 1348-50 la Flandre fut, plus que l'on 
sur-Orge (1305) n'était mise en application que par les comtes de Flandre, les Dampierre, qu’à partir de 1312 (traité de paix de Pontoise) ce qui causait une rupture définitive dans la coalition entre comte et commun.

Les tensions sociales et politiques ne cessèrent plus. Des révoltes se succédaient: rien que dans la décennie suivant 1302 à Gand en 1304, 1311 et 1313, à Ypres en 1303-1304, à Bruges en 1309-10, à Aardenburg en 130911, la liste semble interminable. Les partis qui s'opposaient n'étaient plus constitués suivant les lignes de rupture du XIII ${ }^{\mathrm{e}}$ et début du XIV ${ }^{\mathrm{e}}$ siècle (commun contre grands, artisans contre patriciens). Désormais la tension explosait entre gens de métier. A l'intérieur du secteur dominant de la draperie, entre tisserands et foulons par exemple. Pour la seule ville de Gand, on a compté pour la période allant de 1311 à 1375 pas moins de treize confrontations violentes entre ces deux grands corps de métier de l'industrie textile. Prenant en compte qui avait gagné la dernière confrontation souvent très sanglante, les contemporains parlaient d'un 'mercredi néfaste' (4 août 1311), d'un 'lundi néfaste' (2 mai 1345, défaite des foulons) ou d'un 'mardi faste' (13 janvier 1349 défaite des tisserands) marquant ainsi des explosions de violence entrées dans la mémoire collective, appelée à former l'esprit de corps des métiers en question. Entre 1349 et 1359 le 'mardi faste' fut commémoré chaque année le mardi après l'épiphanie en sonnant les cloches de la ville et en jouant des trompettes. ${ }^{37}$ Le retour au pouvoir des tisserands en 1359 sonna - bien évidemment - le glas de ces commémorations.

Les milices urbaines exportaient la terreur et la violence aussi à l'extérieur des remparts: sous les tensions économiques, les grandes villes drapantes avaient obtenu des privilèges qui les autorisaient à contrôler l'économie des arrières-pays en éliminant plus particulièrement la concur-

ne l'a accepté généralement, touché par des épidémies de peste successives: un état de la question chez W. P. Blockmans, The social and economic effects of plague in the Low Countries 1349-1500, «Revue Belge de Philologie et d'Histoire», 58, 1980, pp. 835-863.

${ }^{37}$ Le paysage sonore des villes médiévales reste un champ de recherche encore mal exploité, voir des inspirations chez D. Lett, N. Offenstadt (éd.), Haro! Noël! Oyé! Pratiques du cri au Moyen Âge, Paris 2003 (Histoire ancienne et médiévale 75), passim. Pour la période plus récente (l'époque bourguignonne et habsbourgeoise) l'impact de l'oralité et de la sonorité sur les expressions de la vie publique dans les villes est plus évidente et se laisse mieux mesurer, voir E. Lecuppre-Desjardin, La ville des cérémonies. Essai sur la communication politique dans les anciens Pays-Bas bourguignons, Brepols, Turnhout 2004, (Studies in European Urban History, 4), pp. 165-197. En ce qui concerne les révoltes, le mot même de 'crieur' était devenu synonyme pour celui qui participait activement à une rébellion: J. Dumolyn, Marginalen of radicalen? Het vertoog over de 'roepers en krijsers' tijdens stedelijke opstanden, voornamelijk in het laatmiddeleeuwse Vlaanderen, «Tijdschrift voor sociale en economische geschiedenis», 2, 2005, pp. 29-53. 
rence de l'industrie dans les campagnes. Et bientôt, Gantois et Yprois organisèrent des raids afin d'obtenir manu militari la cession de toute activité drapante dans le plat pays ou dans les petites villes soumises (Ypres par exemple vis-à-vis de Poperinge). Cette politique de vouloir à tout prix dominer l'arrière pays direct a finalement mené à l'installation dans les faits et les pratiques des 'quartiers', une division territoriale du comté de Flandre qui accordait à chacune des grandes villes le contrôle d'une partie du territoire environnant. ${ }^{38}$ Domination qui se manifestait sur le terrain de l'organisation militaire, la levée des impôts et la juridiction (par la pratique du 'chef de sens': les échevins de la grande ville qui donnaient un avis plus ou moins incontournable aux échevins des petites villes et des châtellenies de leur quartier). Nous ne disposons pas d'une charte formelle établissant les quartiers. Comme un grand nombre d'institutions médiévales, ils ont pris forme 'spontanément', formalisant des rapports de force et des défenses d'intérêts bien spécifiques. Ils n’en étaient pas moins une partie de la réalité qu'on devait prendre en compte. Cette domination dans les faits, et à l'aide d'une violence collective institutionnalisée, fait son apparition pendant la période dite d'Artevelde.

Cette période, que nous traiterons plus amplement dans ce qui suit, sonne comme un écho à la grande révolte dite de la 'Flandre maritime' des années 1323-1328. Ce mouvement, connu comme le soulèvement de la Flandre maritime de 1323-1328, dénomination consacrée par Henri Pirenne, s'inscrivait mal dans la grande tradition des rébellions flamandes où dominaient les révoltes urbaines. ${ }^{39}$ Mais l'explosion à première vue exceptionnelle d'une violence plus ou moins aveugle a promu ce soulèvement

${ }^{38}$ Sur les Quartiers voir D. Nicholas, Town and countryside: social, economic, and political tensions in fourteenth-century Flanders, Bruges 1971 (Rijksuniversiteit te Gent, werken uitgegeven door de faculteit der Letteren en wijsbegeerte, 152), pp. 152-172; W.P. Blockmans, De volksvertegenwoordiging in Vlaanderen in de overgang van middeleeuwen naar nieuwe tijden (1384-1506), Brussel 1978 (Verhandelingen van de Koninklijke Academie voor Wetenschappen, Letteren en Schone Kunsten van België, Klasse der Letteren, jg. XL, nr. 90) pp. 107-127; M. Boone, Gent en de Bourgondische hertogen, ca. 1384 - ca. 1455. Een sociaal-politieke studie van een staatsvormingsproces, Brussel, 1990, (Verhandelingen van de koninklijke academie voor wetenschappen, letteren en schone kunsten van België, Klasse der Letteren, jaargang 52, 1990, nr. 133), pp. 191-198. Pour le Brabant où une évolution comparable se dessinait, voir R. Van Uytven, Imperialisme of zelfverdediging: de extra-stedelijke rechtsmacht van Leuven, «Bijdragen tot de geschiedenis» (La ville en Brabant, quatrième colloque, Bruxelles 2930 mars 1974), 58, 1975, pp. 7-71 (avec résumé français).

${ }^{39}$ Voir l'édition de sources majeure: H. Pirenne, Le soulèvement de la Flandre maritime de 1323-1328. Documents inédits publiés avec une introduction, CRH, Bruxelles 1900 dont l'introduction a été reprise grandement dans son Histoire de Belgique, t. 2 (3 ed.), Bruxelles 1922, pp. 75-100. 
au premier rang des grandes révoltes paysannes de l'Europe du XIV $\mathrm{X}^{\mathrm{e}}$ siècle à côté de la révolte des paysans anglais de 1381 et de la Jacquerie française de $1358 .{ }^{40}$ L'importance de la protestation paysanne n'est pas à nier, toutefois: le mouvement a duré très longtemps comparé aux autres révoltes paysannes qui traditionnellement sont marquées par l'effet 'feu de paille' et s'est graduellement développé en un vaste mouvement de contestation du pouvoir comtal, après qu'à côté des grandes villes telles Bruges et Ypres, les tisserands gantois et des bourgeois de villes secondaires, Courtrai par exemple, eussent aussi rejoint le mouvement. ${ }^{41}$

Dans le courant de la révolte un pas décisif fut franchi: l'autorité comtale en soi restait en place, mais le comte, le jeune Louis de Nevers (13221348) assistait à une perte de la fidélité dynastique chez un nombre considérable de ses sujets, qui lui préféraient son oncle et rival, Robert de Cassel. Nommé régent de la Flandre pendant que Louis était le prisonnier des rebelles, Robert de Cassel devait toutefois accepter qu'une partie non négligeable du comté (Gand et son quartier, grosso modo la partie orientale englobant les vallées de l'Escaut et de la Lys) échappait à son pouvoir. Cette partie loyale se mit sous la direction d'un autre membre de la dynastie des Dampierre, Jean de Namur, grand-oncle du comte Louis, qui posait comme régent alternatif à Robert de Cassel. Bientôt les deux camps allaient s'affronter, tournant la révolte en guerre civile. Dans la foulée de leurs actions militaires, les insurgés ont nommé leurs fonctionnaires au lieu des baillis comtaux et ont réussi à soumettre à leur contrôle une partie considérable de 'l'appareil de l'Etat'. Le monopole sur l'exercice de la violence à travers l'appareil judiciaire semblait vaciller, par pour la dernière fois dans la Flandre médiévale d'ailleurs. Dès qu'il eut regagné sa liberté, (le $1^{\text {er }}$ décembre 1325), le comte Louis de Nevers chercha et trouva un soutien chez son suzerain, le roi de France, Charles IV. Ce dernier, alarmé par la tournure des événements et par la radicalisation du mouvement des paysans n’avait jusque là pas été avare des moyens déployés: outre une mobilisation morale et institutionnelle, l'ingérence de la papauté (le pape Français Jean

${ }^{40}$ Notamment dans une des rares tentatives d'histoire comparative des années précédant 1968: F.W.N. Hugenholtz, Drie boerenopstanden uit de veertiende eeuw: Vlaanderen 1323-1328, Frankrijk 1358, Engeland 1381, Haarlem 1949.

${ }^{41}$ Sur ce mouvement exceptionnel la littérature est abondante, à côte d'une édition de sources majeure de Pirenne (voir note 39 ) l'on doit de signaler le livre de W. H. TeBrake, A plague of insurrection.Popular politics and peasant revolts in Flanders, 13231328, University of Pennsylvania Press, Philadelphia 1993, passim et celui de J. Sabbe, Vlaanderen in opstand 1323-1328. Nikolaas Zannekin, Zeger Janszone en Willem de Deken, Bruges 1992. La révolte de la Flandre maritime continue à susciter également un intérêt local et inspiré, dernier témoin en date: s.n., Herenboer Nicolaas Zannekin opstandelingenleider, Veurne 2004. 
XXII avait fait proclamer l'interdit sur la Flandre rebelle), et la menace d'une intervention militaire massive de l'ost royal forçaient les insurgés à accepter une négociation (menant à la paix provisoire d'Arques du 19 avril 1326). L'amende considérable exigée par le comte et le retour en force des baillis et receveurs comtaux menaient cependant une fois de plus au blocage de la situation, avec une ultime confrontation militaire comme issue: dans la bataille de Cassel (23 août 1328) l'armée du nouveau roi de France, Philippe VI, écrasait l'armée des paysans insurgés.

Une répression exemplaire allait s'abattre sur la Flandre. Cette vague de répression, avec son nombre impressionnant d'exécutions, d'exils forcés et de prise d'otages (1000 Yprois et 500 Brugeois furent exigés par le roi de France en 1328, les listes conservées confirment que comme on pouvait s'y attendre les métiers de la draperie étaient visés avant tout), des confiscations en masse, une amende battant tous les records et finalement une révision des privilèges urbains, dépassait de loin tout ce qu'on avait connu jusque là. ${ }^{42} \mathrm{Il}$ ne fait pas de doute que du côté des autorités comtales et royales chargées d'organiser et d'appliquer cette répression, la violence institutionnelle sous forme de vengeance juridique organisée fut considérablement renforcée et augmentée. A côté de cela, une autre vengeance, celle des bandes armées visant à terroriser la population et à venger la défaite humiliante infligée à une armée féodale en 1302 s'ajoutait aux malheurs. Ces violences aux visages multiples comptent pour beaucoup dans l'effervescence et le recours 'facile' à une solution violente dans la période qui allait suivre et que semble caractériser profondément le XIV ${ }^{\mathrm{e}}$ siècle flamand en général.

Si la répression visait la masse des insurgés, quelques cas méritaient apparemment d'être traités séparément. Ainsi, l'ancien maire de Bruges et figure emblématique de la révolte, Willem de Deken, était jugé et condamné devant le Parlement de Paris (14-22 décembre 1328) et finalement exécuté de façon cruelle à la veille de Noël, l'ancien meneur de paysans Zegher Janszone jugé et condamné à Bruges le suivait dans la mort en février 1329. Son exécution après l'avoir mené nu par la ville, marqué au fer rouge aux coins des rues et finalement mis sur la roue et décapité, traduisait clairement l'intention de choquer le public et d'inculquer une attitude plus soumise à ceux qui y assistaient. Un certain tourisme judiciaire se développait: des gens venaient de Gand et de Lille ou encore de Malines en Brabant

${ }^{42}$ Une énumération chez Sabbe, Vlaanderen in opstand cit., pp. 77-85; voir dans un contexte politique et idéologique plus ample Dumolyn, The legal repression cit., pp. 498499, 507, 517. 
pour assister aux exécutions de rebelles à Ypres. ${ }^{43}$ La violence des rebelles tant décriée fut ainsi répétée et imitée pour une cause jugée supérieure. Le chef de l'accusation de Willem de Deken à Paris l'accusait d'avoir 'esmeu tout le commun de Flandres'. ${ }^{44}$ Dans la foulée l'on reprochait aux insurgés et à De Deken en particulier d'avoir porté atteinte à la souveraineté royale et donc d'être coupable du crime de lèse majesté. Cette dernière accusation était fondée sur le fait établi que Willem de Deken s'était tourné vers le roi d'Angleterre, espérant recevoir un soutien militaire de ce côté, forcé en partie par les multiples liens économiques qui liaient la Flandre au royaume d'Angleterre. Finalement, De Deken était accusé d'avoir proposé encore en 1328 au roi d'Angleterre, le jeune Edouard III, de le faire reconnaître comme roi de France par les communes flamandes, misant sur la rivalité et les susceptibilités grandissantes en ce début du conflit mieux connu sous le nom de la 'guerre de cent ans. ${ }^{45}$

Une configuration très semblable, mais d'une portée plus sérieuse allait se reproduire seulement douze ans plus tard. Le 26 janvier 1340 sur le marché du Vendredi à Gand, les communes des grandes villes flamandes, en présence du duc de Brabant Jean III et des représentants des villes de Brabant, acclamaient le même Edouard III comme roi de France. Cela se faisait sous le patronage du nouvel homme fort de Gand et par extension de la Flandre, Jacques d'Artevelde. Le 28 décembre 1337, celui-ci était arrivé au pouvoir dans la ville de Gand, touchée par la politique économique (blocus des exportations anglaises de laine, et les représailles françaises qui ont suivi) et lassée de la politique pro-française du comte Louis de Nevers. ${ }^{46}$ A la tête d'une grande coalition entre bourgeoisie, tisserands, menus métiers et foulons, un espèce de 'front populaire' Artevelde avait gagné le

${ }^{43}$ TeBrake, A plague of insurrection cit., p. 123.

${ }^{44}$ L.H. Stein, Les conséquences de la bataille de Cassel pour la ville de Bruges et la mort de Guillaume de Deken, son ancien bourgmestre, «Bulletin de la Commission royale d'histoire» 68, 1899, p. 655 et les corrections apportées par R. C. Van Caenegem, Nota over de terechtstelling van Willem de Deken te Parijs in 1328, «Handelingen van het genootschap voor Geschiedenis 'société d'émulation' te Brugge», 90, 1953, pp. 140-41.

${ }^{45}$ Voir à cet égard $\mathrm{H}$. Pirenne, La première tentative faite pour reconnaître Edouard III d'Angleterre comme roi de France (1328), "Annales de la Société d'Histoire et d'archéologie de Gand», 5, 1902, pp. 7-11; Sabbe, Vlaanderen in opstand cit., p. 64.

${ }^{46}$ Sur l'épisode Van Artevelde dans l'histoire de la ville de Gand voir W. Prevenier, M. Boone, Le rêve d'un État urbain (quatorzième et quinzième siècles), dans J. Decavele (éd.), Gand. Apologie d'une ville rebelle. Histoire, art, culture, Fonds Mercator, Anvers 1989, pp. 85-86. Concernant la famille des Artevelde à Gand au XIV ${ }^{\mathrm{e}}$ siècle, une vision partisane mais originale mettant l'accent sur les aspects de violence issue d'une volonté de vengeance non limitée: D. Nicholas, The Van Arteveldes of Ghent. The varieties of vendetta and the hero in history, Leiden, New York 1988. 
contrôle des affaires gantoises, et jouait ouvertement la carte anglaise. Le pouvoir comtal fut maintenu en principe mais le comte légitime ayant fui une fois de plus vers la France, c'était un financier italien, Simon de Mirabello, lié par son mariage à la dynastie comtale qui se voyait doté des pouvoirs de régent. ${ }^{47}$ En plus: d'Artevelde réussissait là où Willem de Deken avait échoué douze ans plus tôt. Il arrivait en effet à faire venir le roi d'Angleterre en personne avec sa cour et son armée, et pouvait donc jouer à la fois la carte du respect pour les formes politiques (les villes ne se proclamaient pas en république mais juraient d'obéir dorénavant un autre roi de France, l'anglais Edouard III) et celle de l'établissement d'un partage de pouvoir entre les villes (chacune d'elles regagnant son quartier). La voie pour l'établissement d'un réseau de 'villes-Etats' comme cela fut le cas dans l'Italie du Nord et du centre semblait toute tracée: en vérité, les possibilités économiques et financières des villes flamandes n'étaient pas à la hauteur d'une telle ambition. ${ }^{48}$ Comparé aux réalités toscanes et nord-italiennes, tout se jouait en Flandre sur un territoire beaucoup plus réduit et plus ouvert aux ingérences militaires et autres venant de l'étranger. Finalement, le manque de solidarité interurbaine et la tradition de tensions internes à chaque ville, bloquaient un développement ultérieur des aspirations pré-républicaines. Les idées étaient toutefois formulées. Si ceux qui les avaient propagées ne survécurent guère à l'initiative - Jacques d'Artevelde trouvait la mort le 17 juillet 1345 dans un complot des tisserands gantois - les motivations et options politiques allaient poursuivre leur chemin et servir comme source d'inspiration pour les mouvements ultérieurs. Lors de la grande révolte des Pays-Bas contre Philippe II d'Espagne au XVI siècle, des textes de l'époque d'Artevelde ont été réimprimés (avec un nombre impressionnant d'autres textes) et mis à contribution pour soutenir l'effort politique de l'instant. Il s'agissait notamment de l'alliance du 3 décembre 1339 entre les villes de Flandre et de Brabant pour mettre sur pied un contrôle effectif de leurs princes respectifs, inspirée directement par Van Artevelde ${ }^{49}$ Les motivations de Van Artevelde et de ses partisans ne ca-

${ }^{47}$ Dans les années qui précèdent la famille des Mirabello avait tissé un réseau d'influences et d'intérêts dans les Pays-Bas, voir D. Kusman, Jean de Mirabello dit van Haelen (ca. 1280-1333). Haute finance et Lombards en Brabant dans le premier tiers du $X I V^{e}$ siècle, «Revue Belge de philologie et d'histoire», 77, 1999, pp. 843-931.

${ }^{48}$ Voir la comparaison systématique entre villes de Flandre et d'Italie: CrouzetPavan, Lecuppre-Desjardin ed., Villes de Flandre et d'Italie cit., considérations autour de la politique par M. Boone et J. Cl. Maire-Vigueur.

${ }^{49}$ Boone, Prak Rulers, patricians and burghers cit. pp. 106-113 et Boone, The Dutch Revolt cit.. Voir également W.P. Blockmans, Du contrat féodal à la souveraineté du peuple. Les précédents de la déchéance du Philippe II dans les Pays-Bas (1581), in Assemblee di Stati e istituzioni rappresentative nelle storia del pensiero politico moderno (secoli XV- 
chaient pas les intérêts des élites corporatives au pouvoir dans les villes, ni la conscience que la défense des ses intérêts dépassait les frontières des anciennes principautés: considerant et entendant ke les boines gens des deux pays de Brabant et de Flandres sont tenu l'un a l'autre par linage et par alliance et aussi par voisinage sans moyen (...) et pour chou ke chil deus pays sont plein de communauté de peuple ki soutenir ne se peuvent sans marcandise. ${ }^{50}$

Pour les forces politiques à l'étranger, les villes flamandes et les chefs des rébellions devenaient entre temps les points de référence en matière de 'désordres urbains'. Quand, vers 1370-74, le conseiller du roi de France Charles V, Nicolas Oresme écrivait ses commentaires sur l'éthique d'Aristote, Jacques d'Artevelde fut pour lui la référence quand il s'agissait d'illustrer la conduite d'un meneur d'une révolte urbaine. ${ }^{51}$ Un écho direct se faisait entendre encore en 1358, quand Etienne Marcel lança un appel pour un soutien militaire à Gand, appel révélateur de la réputation récalcitrante bien méritée de la classe populaire gantoise. Aussi en 1380 à Paris, à Rouen et dans d'autres villes françaises touchées par une vague insurrectionnelle, le cri de ralliement était 'vive Gand'. ${ }^{52}$

Par les expériences accumulées, les villes évoluaient et l'action politique prenait de plus en plus le visage d'une lutte entre corps politiques établis, plutôt que d'une confrontation violente entre groupes d'intérêt. Ainsi, vers 1360-70, dans la plupart des villes flamandes une division des mandats politiques et de l'influence politique entre divers corps de métiers, souvent regroupés dans des 'membres', s'opérait. ${ }^{53}$ Le fait même que les corps de métier

XX), Atti del convegno internazionale Perugia 16-18 settembre 1982, «Annali della facoltà di scienze politiche 1982-1983», 19, Materiali di storia 7, Rimini 1983, pp. 135-150. Nous ne disposons toujours pas d'une édition moderne digne de ce nom du fameux traité d'Artevelde, voir P. Avonds, Beschouwingen over het ontstaan en de evolutie van het samenhorigheidsbesef in de Nederlanden (14 $\left.4^{d e}-19^{d e} e e u w\right)$, in Cultuurgeschiedenis in de Nederlanden van de Renaissance naar de Romantiek. Liber amicorum J. Andriessen, A. Keersmakers, P. Lenders, Garant, Leuven-Amersfoort 1986, pp. 45-58.

${ }^{50}$ Cité par H. Van Werveke, Jacob van Artevelde, Den Haag 1982 (réédition d'un texte datant de 1963), p. 49.

${ }^{51}$ J. Lusignan, Lire, indexer, gloser: Nicole Oresme et la 'politique' d'Aristote, in: C. Bourlet, A. Dufour (éd.), L'écrit dans la société médiévale. Divers aspects de sa pratique $d u X I^{e}$ au XV siècle. Textes en hommage à Lucie Fossier, Paris 1991, p. 178: 'demagogue est qui par adulation ou flaterie demeine le menu peuple à sa volonté et qui les emeut a rebellion contre les princes ou le prince. Et tel fu un en Flandres appellé Jaques d'Artevele'.

${ }^{52}$ Mollat, Wolff, Ongles bleues, Jacques et Ciompi cit., p. 167.

${ }^{53}$ Un aperçu pour les grandes villes Gand, Bruges et Ypres chez Blockmans, De volksvertegenwoordiging in Vlaanderen cit. pp. 72-80. Pour Bruges voir J. Mertens, 
étaient entrés dans les bancs d'échevins leur ouvrait également l'accès à la pratique juridique, ils apprenaient donc également à se servir d'un certain exercice de la violence institutionnelle leur permettant de régler les conflits par le jeu des mesures répressives (amendes, bannissements, condamnations morales, voire peines physiques et exécutions).$^{54}$ Cette redistribution du pouvoir allait de pair avec des fortes perturbations démographiques. Contrairement à ce qu'on a longtemps soutenu, le comté fut bel et bien touché par la peste noire et les épidémies d'écho qui ont suivirent, et les relations sociales et politiques subirent également les effet d'une redistribution des richesses individuelles, un nombre grandissant des gens de métiers actifs à l'intérieur des institutions avait acquis un bien être social, parfois précaire mais très réel pour ceux qui étaient arrivés à se glisser dans les cadres corporatifs relativement protégés. ${ }^{55} \mathrm{La}$ nature des confrontations politiques qui allaient suivre en fut touchée: une lutte de classe pour la survie même des intéressés encore caractéristique pour les confrontations au début du $\mathrm{XIV}^{\mathrm{e}}$ siècle, laissait la place à une défense d'intérêts bien définis (privilèges artisanaux et avantages fiscaux). L'ennemi principal ne se trouvait plus en premier lieu dans l'enceinte de la ville, il venait de l'extérieur: c'étaient le prince et ses administrateurs.

\subsection{La fin du XIV e siècle (1360-1384): les villes flamandes face au pouvoir bourguignon}

Tout comme autour de 1280, les années autour de 1380 ont vu les esprits s'échauffer et la tension politique monter un peu partout en Europe, à Florence, dans les grandes villes de France, dans les villes hanséates, en Angleterre et en Flandre où une fois de plus Gand prit l'initiative. Cette

Woelingen te Brugge tussen 1359 en 1361, in: Album Carlos Wyffels, Bruxelles, 1987, pp. 325-330; pour Gand Boone, Gent en de Bourgondische hertogen cit., passim.

${ }^{54}$ J'ai pu mesurer la façon dont les corps de métiers ont usé de ce pouvoir juridique, à l'aide de l'exemple gantois: $\mathrm{M}$. Boone, Les gens de métiers à l'époque corporative à Gand et les litiges professionnels (14 $4^{\text {ième }}-15^{\text {ième }}$ siècles), in M. Boone, M. Prak (édd.), Status individuels, statuts corporatifs et statuts judiciaires dans les villes européennes (moyen âge et temps modernes), Actes du colloque tenu à Gand les 12-14 octobre 1995. Individual, corporate and judicial status in European cities (late middle ages and early modern period), Proceedings of the colloquium Ghent, October $12^{\text {th }}-14^{\text {th }} 1995$, Garant, LeuvenApeldoorn 1996, pp. 23-47.

${ }^{55}$ Blockmans, The social and economic effects of plague cit. pp. 835-863 et E. Thoen, I. Devos, Pest in de Zuidelijke Nederlanden tijdens de Middeleeuwen en de Moderne Tijden. Een status quaestionis over de ziekte in haar sociaal-economische context, in La peste aux Pays-Bas: considérations médico-historiques 650 ans après la Peste Noire. Symposium Histoire des sciences médicales, Bruxelles 21 mars 1998 (Academia Regia Belgica Medicinae, Dissertationes series historica DSH 7), Bruxelles 1999, pp 19-43. 
nouvelle vague de manifestations d'inquiétudes collectives et de rébellion a, bien sûr, retenu l'attention des générations d'historiens. Ces sont les fameuses 'années révolutionnaires' (d'après l'expression de Mollat et Wolff) des paysans anglais, des Ciompi florentins et des rebelles gantois. ${ }^{56}$ Des facteurs structurels, mais également individuels ont lié les événements des années 1380 aux 'rébellions' précédentes. A Gand, dans une première phase (prenant fin sur le champ de bataille de Westrozebeke le 27 novembre 1382) personne d'autre que le fils Van Artevelde, Philippe, s'était mis à la tête du mouvement. Quant aux causes qui ont poussé Gand en 1379 à s'insurger, c'est-à-dire l'accord marqué par le comte (Louis de Male) pour le creusement d'un canal de jonction entre Bruges et la Lys (contournant l'étape de blé gantois et offrant ainsi un avantage économique à Bruges) et l'assassinat par la milice gantoise des 'Chaperons Blancs' du bailli comtal après que ce dernier eut arrêté un membre de la milice sans l'accord préalable des échevins gantois, elles illustrent la volonté de la ville de maintenir son autonomie à l'égard du pouvoir central et donc comtal. Elles soulignent également l'intérêt privé et semi-public des corporations au pouvoir (bateliers, marchands de céréales) dans la ville. L'élément d'une confrontation entre grandes villes, au début du conflit Gand et Bruges se sont affrontées autour de la question du contrôle du commerce interne, mettait hors service les mécanismes habituels de contrôle de conflits à l'intérieur, impliquant un dialogue au sein des organisations représentatives, les Membres de Flandre.

Pour soutenir leur mouvement, les Gantois eurent recours aux recettes éprouvées et héritées de l'époque d'Artevelde père: l'anglophilie politique et le front des villes contre le comte. La seule manifestation de soutien effectif du côté anglais se limita à l'expédition militaire de 1383 sous le commandement de l'évêque de Norwich présentée - schisme de l'Eglise oblige - comme une croisade urbaniste contre la Flandre supposée fidèle au pape français d'Avignon. ${ }^{57}$ L'épisode se termina par le siège d'Ypres par les

${ }^{56}$ Voir la qualification chez Mollat, Wolff, Ongles bleues, Jacques et Ciompi cit. pp. 139-142 pour un tableau synoptique, à compléter par A. Stella, La révolte des Ciompi. Les hommes, les lieux, le travail, Éditions de l'EHESS, Paris 1993; pour la Flandre: Dumolyn, Haemers, Patterns of urban rebellion cit. p. 378 (pour les références en détail).

${ }^{57}$ En vérité il faut le souligner, la population flamande et son compte Louis de Male restaient des partisans militants pour la cause du pape de Rome, ce n'était que le gendre et successeur probable du comte, le duc de Bourgogne Philippe le Hardi qui, étant prince de fleur de lys, soutenait la cause du pape à Avignon. En vérité donc la croisade anglaise n'était autre qu'une tantième entreprise dans le contexte de la guerre de Cent Ans, visant à ouvrir de nouveau un front au Nord. Sur les effets du schisme sur la po- 
Anglais et leurs alliés gantois, ajoutant ainsi à la confusion mentale et sociale et à la généralisation de la violence. Le front interurbain aussi y contribuait: les tisserands radicaux perdaient vite leur emprise sur les événements à Bruges et Ypres ils pouvaient se maintenir seulement à Gand en resserrant les rangs autour du fils Van Artevelde. Celui-ci opta finalement pour une sortie militaire en mai 1382. Les Gantois infligèrent une défaite aux Brugeois et aux troupes du comte, qui comme son père en 1328, ne pouvait que chercher refuge auprès de son suzerain français, Charles VI en l'occurrence. Une nouvelle intervention militaire française écrasant les rebelles à Westrozebeke en novembre 1382 sauva les apparences pour le comte de Flandre, mais ne réussit pas à maîtriser la ville de Gand. Les troupes françaises au service du duc de Bourgogne ne pouvant pas forcer une victoire définitive, elles se livraient à des actes de vengeance chargés de symboles: la ville de Courtrai fut prise comme cible et avant tout la chapelle où les Flamands tenaient en trophée les insignes militaires et éperons trouvés sur le champ de bataille de 1302. Témoignage concret et toujours visible de cette opération punitive: le transfert vers Dijon de la cloche de la ville de Courtrai. Le 'Jaquemart' sonne depuis 1383 dans la capitale bourguignonne.

Quand finalement, le 18 décembre 1385, une paix fut négociée et signée à Tournai, le dernier comte de Flandre de la maison des Dampierre mort en janvier1384, avait été remplacé par son gendre, le premier duc de Bourgogne appartenant à la maison royale des Valois, Philippe le Hardi. Dans la paix de Tournai le duc se contentait de miser sur l'établissement d'une paix nécessaire pour faire fructifier de nouveau son héritage flamand, les problèmes de cohabitation entre pouvoir central et contre-pouvoir aux mains des grandes villes ne furent toutefois pas résolus et continuèrent à nourrir une série de confrontations. ${ }^{58}$

L'établissement progressif du pouvoir bourguignon, prenant appui sur le fonctionnement d'institutions établies sur le modèle français familier au duc Philippe, frère cadet du roi Charles V, changea considérablement les re-

litique à l'intérieur des villes où la question continuait encore pour des années à chauffer les esprits voir Boone, Gent en de Bourgondische hertogen, ca. 1384 - ca. 1455 cit., pp. 207-209.

${ }^{58}$ Concernant les ducs de Bourgogne, la littérature est plus qu'abondante, quelques grandes synthèses disponibles en français méritent d'être signalées: W. Prevenier, W. Blockmans, Les Pays-Bas bourguignons, Fonds Mercator, Anvers 1983, et W. Prevenier (éd.), Le prince et le peuple.Images de la société du temps des ducs de Bourgogne 13841530, Fonds Mercator, Anvers 1998; B. Schnerb, L'Etat bourguignon 1363-1477, Perrin, Paris 1999. Voir également la collection 'Burgundica' chez l'éditeur Brepols (dirigé par J.-M. Cauchies). 
lations avec les villes. Une fois le pouvoir ducal libéré de l'imbroglio politique français, les ducs, avant tout Philippe le Bon, pouvaient induire les communes de Flandre dans une énième rébellion, sachant qu'en fin de compte leurs réserves de pouvoir dépassaient de loin celles qu'une seule ville pouvait mobiliser. C'est ce qui se passait en 1436-38 avec Bruges, en 1449-53 avec Gand. ${ }^{59}$ La réponse des villes s'alignait sur les expériences acquises tout au long du XIV ${ }^{\mathrm{e}}$ siècle, gagées essentiellement sur la mobilisation et sur une organisation répondant à la logique des institutions corporatives.$^{60}$ Un recours à la violence maîtrisée et ajustée aux besoins concrets et ponctuels en était un des éléments essentiels. ${ }^{61}$ Parmi ces moyens tactiques il faut mentionner, les grèves (souvent dans la formule d'une sortie collective), l'occupation armée d'une place politiquement symbolique (la formule dit du 'wapeninghe'), l'utilisation des signaux acoustiques et autres disponibles pour communiquer un message politique, les pratiques de parlementer et de négocier, mais aussi le recours à une pratique de la justice (contrôle des officiers ducaux, jugement des responsables politiques) qui en soi traduit une prise de conscience bien développée. ${ }^{62}$ L'analyse par Jelle Haemers du 'wapeninghe' le décrit comme une utilisation très ritualisée de la violence collective, visant à exprimer une série de revendications sachant que tôt ou tard on passerait à la table des négociations.

On est loin du mot de Chateaubriand appliqué par l'historien Victor Fris (1877-1925, archiviste de la ville de Gand et élève de Pirenne) au sujet

${ }^{59}$ Voir les études de fond par mes deux collaborateurs: J. Dumolyn, De Brugse opstand van 1436-1438, UGA, Courtrai 1997 (Anciens pays et assemblées d'Etats, CI), et J. Haemers, De Gentse opstand (1449-1453). De strijd tussen rivaliserende netwerken om het stedelijk kapitaal, UGA, Courtrai 2004 (Anciens pays et assemblées d'Etats, CV).

${ }^{60}$ Sur le fonctionnement des institutions corporatives (corps de métiers, confraternités, guildes d'arbalétriers, chambres de rhétorique et autres) voir M. Boone, «Les anciennes démocraties des Pays-Bas?». Les corporations flamandes au bas Moyen Age (XIV ${ }^{e}-X V I^{e}$ siècles): intérêts économiques, enjeux politiques et identités urbaines, in Atti dello XX Convegno internazionale di studi 'Tra economia e politica: le Corporazioni nell'Europa medievale', Centro Italiano di studi di storia et d'arte, Pistoia 2007. Une collection d'essais complète ce tableau: M. Prak, C. Lis, J. Lucassen, H. Soly (éd.), Craft guilds in the early modern Low Countries. Work, power, and representation, Ashgate, Aldershot 2006.

${ }^{61} \mathrm{M}$. Boone, 'Armes, courses, assemblées et commocions'. Les gens de métiers et l'usage de la violence dans la société urbaine flamande à la fin du moyen âge, "Revue du Nord», 87, 2005, pp. 7-33.

${ }^{62}$ Sur ces tactiques urbaines, voir M. Boone, Urban space and political conflict in Late Medieval Flanders, «Journal of Interdisciplinary History», XXXII, 2002, pp. 621640. 
des révoltés gantois du $\mathrm{XV}^{\mathrm{e}}$ siècle 'ils tendaient sans cesse à s'insurger, sans autre raison qu'une impossibilité dêtre paisibles.$^{63}$ Une façon de voir qui non seulement trahit une difficulté de décoder et de comprendre les expressions des sentiments et émotions collectifs, mais qui reprend dans les grandes lignes les a priori des contemporains, chroniqueurs officiels en premier lieu, pour qui les 'gens du commun' n'étaient pas en mesure de s'exprimer, voir de comprendre la politique. ${ }^{64}$ L'exécution du chancelier Hugonet et de l'homme fort du régime bourguignon Guy de Brimeu à Gand en 1477 était une manifestation par excellence de cette différence fondamentale dans la perception. ${ }^{65}$ Or, c'est au contraire notamment dans l'élaboration et le développement progressif d'une vraie culture politique, soutenue par une compréhension lucide des intérêts collectifs, que se situe l'apport fondamental, résultat des expériences douloureuses accumulées dans le courant $\mathrm{du} \mathrm{XIV}^{\mathrm{e}}$ siècle flamand. Notamment dès la grande révolte gantoise de 1379-85 résonnent des échos remplis de moralisme et de considérations autour de la notion de 'bien public', mieux servi par les citadins en révolte que par un prince avide et mal conseillé. Dans ce cas précis cette idéologie urbaine est rendue explicite dans le poème la 'Pucelle de Gand', qu'un poète flamand Boudin van de Lore a composé pendant la révolte et dont le vers initial donne le ton: 'suver leven ende vri gaet voor gout, voer dierbaer stene - une existence sans tache et libre passe avant l'or et les pierres précieuses. $^{66}$

${ }^{63} \mathrm{~J}$. Haemers, A moody community? Emotion and ritual in late medieval urban revolts, in E. Lecuppre-Desjardin, A.-L. Van Bruaene (éd.), Emotions in the heart of the City (14 ${ }^{\text {th }}-16^{\text {th }}$ century). Les emotions au Coeur de la ville (XIV ${ }^{e}-X V I^{e}$ siècle), Brepols, Turnhout 2005, (Studies in European Urban History, 1100-1800, 5), p. 63 (citation) et sur la wapeninghe: pp. 71-80.

${ }^{64}$ Voir l'incompréhension chez un auteur avisé comme Philippe de Commynes, dont la descendance flamande aurait pu faire supposer une plus grande ouverture d'esprit pour les prises de position des élites urbaines et corporatives: J. Blanchard, Commynes l'Européen. L'invention du politique, Genève 1996, pp. 250-251: la notion adoptée par Commynes est celle de 'bestialité qui se résume par une tendance à la division et donc à la violence interne, à l'autre bout du spectre de valeurs se situent bien sûr l'unité, la raison, la modération, toutes absentes chez les membres de communes flamandes aux yeux de Commynes.

${ }^{65}$ Et dont les termes ont été reprises également par les historiens du XIX ${ }^{\mathrm{e}}$ siècle: voir une évaluation chez M. Boone, La justice en spectacle. La justice urbaine en Flandre et la crise du pouvoir «bourguignon» (1477-1488), «Revue Historique», CCCVIII, 2003/1, pp. 43-65.

${ }^{66}$ La vierge en question allait servir littéralement comme symbôle de la communauté urbaine en soi, voir (avec réproductions) W. Prevenier, M. Boone, Les villes des Pays-Bas méridionaux au Bas Moyen Age: identité urbaine et solidarités corporatives, «Bulletin du Crédit Communal», 47, 1993, p. 40. En soi, la vierge comme symbole de 


\section{Conclusions}

Le XIV ${ }^{\mathrm{e}}$ siècle flamand, et les multiples rébellions qui l'ont scandé, ont frappé de stupéfaction et d'indignation nombre d'observateurs contemporains, souvent encore issus des milieux ecclésiastiques et donc, à quelques exceptions près, peu enclins à la compréhension d'une série d'actes qui se lisaient comme une perturbation de l'ordre social, cautionné par l'ordre divin. Les événements ont bien sûr retenu l'attention d'une histoire science naissante au XIX ${ }^{\mathrm{e}}$ siècle, mais là également les préoccupations et les choix idéologiques des historiens ont souvent coloré la fresque du XIV ${ }^{e}$ siècle réalisée à cette époque. Illustration des craintes bourgeoises envers les masses dangereuses pour les uns, manifestation des premiers pas vers une libération bourgeoise face aux forces de l'église et des princes pour les autres, ou encore affirmation précoce d'un sentiment flamand national: les grands courants idéologiques des $\mathrm{XIX}^{\mathrm{e}}-\mathrm{XX}^{\mathrm{e}}$ siècles ont reconnu dans les faits et gestes des ancêtres du XIV ${ }^{\mathrm{e}}$ siècle les ferments de leurs propres batailles politiques. Une reconnaissance qui n'a pas uniquement fait surface dans la production littéraire et historique, mais a également trouvé son expression dans les domaines des arts appliqués (architecture, monuments, peinture) et de l'urbanisme (statues, noms des rues, cortèges et commémorations consacrant l'espace urbain comme lieu de mémoire).$^{67} \mathrm{Ce}$ fut finalement grâce aux apports d'une histoire structuraliste qu'une relecture

la communauté urbaine n'est bien sûr pas une invention flamande, voir les exemples italiens ou allemands chez K. Schreiner, Maria Patrona. La sainte vierge comme figure symbolique des villes, territoires et nations à la fin du moyen âge et au début des temps modernes, in R. Babel, J.-M. Moeglin (éd.), Identité régionale et conscience nationale en France et en Allemagne du Moyen Âge à l'époque moderne. Actes du colloque organisé par l'université Paris XII, l'Institut universitaire de France et l'Institut Historique Allemand à Paris 6-8 octobre 1993, Thorbecke, Sigmaringen 1997 (Beihefte der Francia 39), pp. 133-153.

${ }^{67}$ La littérature est à nouveau abondante et très diversifiée; citons parmi d'autres possibles approches, pour l'épisode la mieux connue et étudiée autour de 1302 et la bataille des éperons d'or, J. Tollebeek, Le culte de la bataille des Eperons d'or de la fin du XVIII au XX ${ }^{e}$ siècle, in R.C. Van Caenegem (éd.), 1302. Le désastre de Courtrai. Mythe et réalité de la bataille des Eperons d'or, Fonds Mercator, Anvers 2002, pp. 195-239, 292 294 (pour une bibliographie sur le genre); plus général A. Morelli (réd.), Les grands mythes de l'histoire de Belgique, de Flandre et de Wallonie, Bruxelles 1995 (entre autres sur Van Artevelde); V. Lambert, De guldensporenslag van fait-divers tot ankerpunt van de Vlaamse identiteit (1302-1838): de natievormende functionaliteit van historiografische mythen, «Bijdragen en Mededelingen betreffende de Geschiedenis der Nederlanden», 115, 2000, pp. 365-391. Concernant Jacques d'Artevelde: G. Deneckere, De resurrectie van Jacob van Artevelde in de 19de-eeuwse Gentse arbeidersbeweging. Over het verlangen naar 'de Grote Man', "Handelingen der Maatschappij voor Geschiedenis en Oudheidkunde te Gent», L, 1996, pp. 155-187. 
du XIV ${ }^{\mathrm{e}}$ siècle est devenue possible. Un questionnaire influencé grandement par les sciences sociales a permis de juger à leur juste mesure les éléments déterminants qui aident à expliquer le parcours assez singulier des villes flamandes au XIV ${ }^{\mathrm{e}}$ siècle, car la dominance de l'élément urbain dans une écrasante majorité des rébellions est indéniable. Même la seule grande révolte dite 'de la Flandre maritime' qui, entre 1323-1329, a mobilisé une population agraire dans l'Ouest du comté, a finalement été liée à une révolte de la ville de Bruges et c'est précisément ce lien avec la tradition urbaine qui aide à expliquer sa durée très longue comparée aux semblables événements ruraux dans d'autres parties de l'Europe.

Parmi ces éléments déterminants je crois qu'il me faut signaler en premier lieu:

- La concentration d'un grand nombre de grandes villes sur un territoire relativement restreint, donc le facteur déterminant reste une urbanisation intense (environ $33 \%$ de la population de la Flandre étant urbaine), vecteur d'une possibilité accrue de communication politique; c'est ce qui a aidé à forger un mouvement presque incessant, repris facilement par les nouvelles générations et qui a donc contribué à l'impression déjà très présente chez les observateurs contemporains de vagues de contamination, voire d'imitation répétées.

- L'ancrage social à l'intérieur des villes dans une culture politique (mais également religieuse et économique) corporatiste. L'arrivée au pouvoir réellement exercé à partir de 1302 par les corps de métiers a fait d'eux les fers de lance et également les organisations qui ont constitué, organisé et transmis la mémoire concernant les rébellions précédentes. Loin d'avoir été limité à un effet de 'feu de paille' les rébellions flamandes se sont dès leur avènement inscrites dans une tradition entretenue et essentielle pour ce qui suit. Les violences à première vue irrationnelles peuvent dès lors être décodées dans un grand nombre de cas précis comme donnant voix à une série de revendications, bref comme des affirmations et des prises de positions politiques.

- La situation du comté de Flandre aux carrefours de l'Europe du NordOuest et les multiples liens économiques et culturels avec les principautés et nations voisines a inévitablement conduit les événements politiques à l'intérieur du comté à être repris et incorporés dans des conflits de plus grande envergure (pour le $\mathrm{XIV}^{\mathrm{e}}$ siècle en premier lieu le conflit opposant les royautés françaises et anglaises), ce qui a son tour a influencé la nature du débat politique dans lequel les questions essentielles des rapports entre gouvernants et gouvernés, la nature des relations et contrats politiques ont été à l'ordre du jour. Dans ce sens les expériences du XIV ${ }^{\mathrm{e}}$ siècle flamand ont grandement contribué à fa- 
çonner une culture politique entretenue et importante pour l'histoire ultérieure des Pays-Bas.

Sur le terrain, les princes des maisons de Bourgogne et de Habsbourg ont aux cours des $\mathrm{XV}^{\mathrm{e}}$ et $\mathrm{XVI}^{\mathrm{e}}$ siècles gagné la bataille pour le monopole de l'usage de la violence, également à l'intérieur des villes. Quand en 1540, Charles Quint a imposé un nouvel ordre politique à sa ville natale, Gand, il le faisait en pleine conscience qu'une telle intervention communiquait aux autres villes des Pays-Bas (et dans les autres parties de l'Europe dont il était l'empereur ou le roi ou 'simplement' le prince) le message que désormais l'époque des grandes communes médiévales en Espagne, en Allemagne, aux Pays-Bas était arrivée à son terme. ${ }^{68}$ En agissant de la sorte il prenait soin d'ôter aux corps de métiers tous les outils qu'ils avaient façonnés, durant les deux siècles précédents afin de leur permettre d'user de la violence ou de la menace d'y avoir recours: bannières, cortèges, droit de s'assembler, maisons, organisations propres, droit d'élire leurs gouvernants et représentants. ${ }^{69}$ Quinze ans plus tard, l'empereur abdiquait à Bruxelles, dans une séance semi-publique en face des représentants de l'Etat composite qu'étaient devenus les Pays-Bas bourguignons. A peine quelques années plus tard, son fils et successeur, Philippe II d'Espagne, faisait face à un soulèvement inspiré par la grande tradition des révoltes médiévales. Le mouvement connu dans l'histoire des Pays-Bas comme la révolte (de Opstand avec majuscule) fut nourri bien sûr par la grande question religieuse du moment et par les appétits fiscaux de l'État, aboutissant à l'établissement d'une république, celle des Provinces Unies, point d'orgue des expériences accumulées par des générations de 'gens du commun' des villes des Pays-Bas. ${ }^{70}$

${ }^{68}$ Voir les considérations de W. te Brake, Charles $V$ and his contentious subjects, in M. Boone, M. Demoor (éd.), Charles V in Context: the Making of a European Identity, VUBpress, Bruxelles 2003, pp. 125-145.

${ }^{69}$ Voir l'énumération et l'évaluation de l'arsenal répressif mis à l'oeuvre par Charles Quint voir M. Boone, 'Le dict mal s'est espandu comme peste fatale. Karel V en Gent, stedelijke identiteit en staatsgeweld, "Handelingen der Maatschappij voor Geschiedenis en Oudheidkunde te Gent», LIII, 2000, pp. 29-61.

${ }^{70}$ Voir pour l'idéologie politique M. Van Gelderen, The political thought of the Dutch Revolt 1555-1590, Cambridge University press, Cambridge 1992; et les essais de A. Duke, Reformation and Revolt in the Low Countries, London 2003 et les actes du colloque de Los Angeles 2005 cité à la note 25. 



\section{LES RÉVOLTES DANS LA FRANCE DU XIV SIÈCLE: TRADITIONS HISTORIOGRAPHIQUES ET NOUVELLES RECHERCHES}

Les révoltes du XIV ${ }^{\mathrm{e}}$ siècle ont été un thème finalement peu présent dans les 25 dernières années de l'historiographie française. ${ }^{1}$ Les livres de synthèse et les manuels récents font une place brève aux révoltes et développent les principales, c'est-à-dire les Jacques et la révolte d'Etienne Marcel, et le cycle des années 1378-82, essentiellement la Harelle, les Tuchins et les Maillotins. Cette orientation tient pour une part à l'éclairage induit par deux ouvrages majeurs, anciens, écrits dans la vingtaine d'années qui encadrent 1900, celui de Siméon Luce sur la jacquerie ${ }^{2}$ et celui de Léon Mirot sur les insurrections urbaines au début du règne de Charles $\mathrm{VI}^{3}$. Et à l'attention particulière portée, comme il est classique en France, aux révoltes parisiennes. Il y a encore peu de temps on avait l'impression que «tout était dit». Pourtant la thèse de Vincent Challet ${ }^{4}$ consacrée aux Tuchins et encore inédite et les découvertes récentes de Ghislain Brunel montrent justement que tout n'est pas dit et que l'historiographie française n'est pas morte à ce sujet. En outre, alors que se préparait ce colloque, était sous presse l'ouvrage central de Samuel Cohn ${ }^{5}$, Lust for liberty.

${ }^{1}$ Un contre-exemple, le livre d'A. Stella, La révolte des Ciompi, Les hommes, les lieux, le travail, EHESS, Paris 1993; ce n'est pas vraiment un contre-exemple puisque auteur et sujet sont italiens, mais le livre a soulevé un intérêt certain parmi les historiens français. Le volume du congrès du CTHS Violence et contestation, $114^{\mathrm{e}}$ congrès des sociétés savantes, Paris 1989, fait aussi partie des rares ouvrages récents consacrés en France à ce thème.

${ }^{2}$ S. Luce, Histoire de la jacquerie, $2^{\text {eme }}$ édition, Paris 1894.

${ }^{3}$ L. Mirot, Les insurrections urbaines au début du règne de Charles VI (1380-1383), Paris 1905, reed. Champion 1974.

${ }^{4} \mathrm{~V}$. Challet, Mundare et auferre malas erbas: la révolte des Tuchins en Languedoc (1381-1384), thèse soutenue en 2002 devant l'université de Paris1; Atelier de reproduction des thèses 2004; en attendant la publication de cet ouvrage majeur, se référer $\grave{a}$ La révolte des Tuchins: banditisme social ou sociabilité villageoise, «Médiévales» XXXIV, 1998, 101-112; G. Brunel, Les hommes de corps du chapitre cathédral de Laon (12001460): continuité et crises de la servitude dans une seigneurie ecclésiastique, dans Forms of Servitude in Northern and Central Europe, M. Bourin e P. Freedman eds, Brepols, Turnhout 2005, pp. 131-178. 
Le livre de synthèse publié par Mollat et Wolff, Ongles bleus, Jacques et Ciompi en 1970 a durablement influencé l'historiographie, et la publication en écho des Soulèvements populaires au Moyen Age de Guy Fourquin en 1972 a contribué à situer le débat dans des perspectives larges, européennes et comparatiste, mais aussi dans des combats idéologiques de l'après $68 .{ }^{6}$ Robert Fossier fait encore travailler quelques étudiants sur le sujet à la fin des années 70 . C'est à cette date, en 1982, que Bernard Chevalier, en même temps qu'il donne ses Bonnes villes de France ${ }^{7}$ publie dans la «Revue historique» une excellente synthèse, la seule consacrée à l'ensemble des révoltes françaises urbaines et à elles seules: je m’en suis beaucoup inspirée ${ }^{8}$. Dans les années 80 , l'intérêt est retombé.

Bien entendu, dans tous ces ouvrages, les révoltes du XIV ${ }^{\mathrm{e}}$ siècle sont situées par ces auteurs dans un contexte économique et politique bien particulier:

- l'insécurité de la guerre de Cent Ans et des bandes armées qui parcourent la France,

- les troubles politiques dus à la succession des Capétiens directs et aux rivalités entre les Valois et Charles de Navarre,

- les besoins fiscaux du roi,

- une politique oligarchique des villes. Le contexte urbain est essentiel puisque la plupart des révoltes sont urbaines et ne s'étendent pas aux campagnes environnantes. Le milieu urbain est d'ailleurs au cœur des réflexions de $\mathrm{B}$. Chevalier puisque son article est intitulé "Corporations, conflits politiques et paix sociale aux $\mathrm{XIV}^{\mathrm{e}}$ et $\mathrm{XV}^{\mathrm{e}}$ s.»,

- la retombée de la prospérité et l'arrivée des crises économiques de la fin du Moyen Age, admise sans que soient, en général, appréciées finement les différences locales.

Parmi les nombreuses difficultés que pose la confection d'un rapport de synthèse sur les révoltes du $\mathrm{XIV}^{\mathrm{e}}$ siècle français ${ }^{9}$, l'une des premières et

${ }^{5}$ S. K. Cohn, Lust of Liberty, The politics of social revolt in medieval Europe 12001425, Harvard University, Cambridge Ma. 2006, avait été précédé de Popular Protest in Late Medieval Europe, Manchester 2004.

${ }^{6} \mathrm{M}$. Mollat et P. Wolff, Ongles bleus, Jacques et Ciompi; les révolutions populaires en Europe aux XIV et $X V^{e}$ siècles, Calmann-Lévy, Paris 1970; G. Fourquin, Les soulèvements populaires au Moyen Age, PUF, Paris 1972.

${ }^{7}$ B. Chevalier, Les bonnes villes de France, Aubier-Montaigne, Paris 1982.

${ }^{8}$ B. Chevalier, Corporations, conflits politiques et paix sociale, "Revue historique», 1982, t. 543, pp. 18-44; reed. Les bonnes villes, l'État et la société dans la France de la fin $d u X V^{e}$ siècle, Paradigme, Orléans 1995.

${ }^{9}$ Il est difficile de définir le cadre juste pour un rapport consacré aux révoltes françaises. Faut-il y inclure ou non les Flandres? Le choix est fait par les organisateurs du 
des plus graves est d'arriver à avoir une vue suffisamment complète de la multiplicité des émeutes dont beaucoup furent limitées. Faire une liste fournie est difficile; faire une liste exhaustive impossible, tant sont nombreux les tensions et les petits effrois. Samuel Cohn a ainsi repéré très récemment dans le Trésor des Chartes une grave rébellion des paysans du Laonnois ${ }^{10}$ en 1338, qu'au même moment Ghislain Brunel éclairait d'un jour particulier, grâce à l'attention qu'il a portée à un livre de serfs du chapitre cathédral de Laon, conservé aux Archives Nationales. ${ }^{11}$ La liste est faite avec précision par Mollat et Wolff pour les années cruciales entre avril 1378 et la paix de Tournai en décembre 1385. B. Chevalier constate encore en 1982 que la liste complète n'est pas dressée et se demande si l'entreprise mérite d'être tentée. En fait, une telle entreprise a l'avantage de contraindre à se poser une question, dès lors qu'on va au-delà des «grandes» révoltes: qu'est-ce que les contemporains considéraient comme une révolte? Au dessous de quel seuil de gravité un soulèvement fait partie des émotions habituelles et ne mérite pas punition ou tout simplement mention?

Le poids des sources est donc lourd dans la connaissance et l'appréciation des révoltes. Les historiens ont travaillé principalement à partir des chroniques, parmi lesquelles au premier rang, Froissart. Or à l'exception des pages écrites par le carme Jean de Venette, elles sont très défavorables aux révoltes. Bernard Guenée fait remarquer que le Religieux de Saint Denis, Michel Pintoin ${ }^{12}$ évoque à de nombreuses reprises le mécontentement ou l'indignation: quatre fois sur cinq, il s'agit de celle des puissants et du roi au premier chef. En revanche, les lettres de rémis$\operatorname{sion}^{13}$ qui comprennent une supplique exposant les faits apportent une vision complémentaire, à l'évidence de manière à faciliter l'exercice de la grâce royale. Les informations les plus profondes proviennent des procès; celui qu'a retrouvé Vincent Challet à propos des Tuchins lui a permis de

colloque; il est judicieux car dans la perspective de ce colloque, les révoltes flamandes méritent un sort spécifique. Pour le reste, il m’a paru logique de choisir la limite d'Empire et de m'en tenir au royaume de France et non à la France actuelle, en incluant Lyon toutefois.

${ }^{10}$ Lust of liberty cit., pp. 28, 31, 51.

${ }^{11} \mathrm{G}$. Brunel, Les hommes de corps du chapitre cathédral de Laon, cité à la note 4 .

${ }_{12}$ B. Guénée, L'opinion publique à la fin du Moyen Age, d'après la chronique de Charles VI du Religieux de Saint-Denis, Paris 2002.

${ }^{13}$ Les lettres de rémission sont des actes de la chancellerie par lequel le roi octroie son pardon à la suite d'un crime ou d'un délit, arrêtant le cours ordinaire de la justice. Elles ont été remarquablement utilisées par Claude Gauvard, De grace especial. Crime état et société en France à la fin du Moyen Age, Paris 1991. 
reconsidérer complètement l'image que les lettres de rémission avaient apportée. ${ }^{14}$ Encore faut-il une recherche minutieuse et locale pour découvrir de telles sources.

A travers les chroniques, la cause est entendue: les révoltes sont celles des menus contre les gros. La version autorisée des évènements fait ressortir l'initiative et la responsabilité des travailleurs et passe sous silence la participation des gens d'état. Le menu peuple a été soumis au désordre mental, la deablie comme le dit Froissart.

Comme l'a judicieusement fait Claude Gauvard, il convient de poser d'emblée la question du lien entre crime et révolte. Au moment où les juristes comme Bartole et Balde définissent la haute trahison, fait-elle remarquer, il en est rarement fait mention pour les révoltés, qui sont décrits comme des "crimineux», des malfaiteurs en proie au démon et non comme des rebelles. Les lettres de rémission qui suivent les révoltes de 1382-85 sont demandées essentiellement pour des vols ou des crimes. Le fait est surprenant si on le rapproche de la constatation faite par Bernard Guenée ${ }^{15}$ qu'au seuil du XV $\mathrm{XV}^{\mathrm{e}}$ siècle, l'insulte la plus commune est celle de traître. Différences de sources ou d'époque? La perception de la violence politique est une question à approfondir.

\section{Chronologie}

Lorsqu'ils traitent d'un long XIV ${ }^{\mathrm{e}}$ siècle, les historiens français définissent en général trois périodes:

- une première qui perdure jusqu'au milieu des années 50 , marquée par une multitude de révoltes localisées et brèves,

- une seconde période qui s'étend de 1357 aux années 80 où la France est secouée par deux graves et longs cycles de révoltes,

- puis un retour à des révoltes de moins grande ampleur.

Rappelons rapidement les grandes lignes des deux cycles de révolte qui ont tellement retenu l'attention des historiens et sont les mieux connues ${ }^{16}$.

${ }^{14}$ Cf note 4. L'ouvrage antérieur est celui de Marcelin Boudet, qui concernait, il est vrai, surtout les Tuchins du Massif Central, La jacquerie des Tuchins, 1363-1384, Riom 1895.

${ }^{15}$ Cf note 12 .

${ }^{16}$ Pour ces évènements, voir notamment deux articles de Raymond Cazelles, Les mouvements révolutionnaires du milieu du XIV siècle et le cycle de l'action politique, "Revue historique», CCXXVIII, 1962, pp. 279-312 et Etienne Marcel au sein de la haute bourgeoisie d'affaires, «Journal des Savants», 1965, pp. 413-428. 
Le cycle de 1355-58:

Entre 1355 et 58, la contestation prend trois formes: la fréquente réunion des Etats, la révolte parisienne d'Etienne Marcel et la jacquerie. Cette contestation est orchestrée par le parti de Charles de Navarre qui ne reconnaît pas la royauté des Valois et elle est soutenue par le développement de l'idée selon laquelle la souveraineté est à la communauté du Royaume, le roi n’en étant que le dépositaire. Pour voter les subsides nécessaire à la guerre, les réunions d'Etats s'accélèrent, en Langue d'oil et Languedoc. Le peuple de Paris dans l'hiver 56-57 appuie les demandes de réforme formulées par les Etats, qui aboutissent à la grande ordonnance du 3 mars 1357.

Parallèlement, et pour la première fois, a-t-on longtemps pensé, les campagnes entrent en révolte dans une riche région agricole au Nord de Paris, le Beauvaisis et de là rapidement en quelques jours jusqu'en Normandie et dans le Nord de la Bourgogne. Ce sont des incidents entre des paysans et des hommes d'armes qui l'ont fait jaillir. La nouvelle était lancée de clocher en clocher; les jacques auraient été jusqu'à cinq à six mille, selon Jean de Venette. Un chef charismatique, Guillaume Carle, doté sans doute d'une expérience de la guerre et de sens stratégique. Quelques hauts faits, comme la prise du château d'Ermenonville le 7 juin 1358. Des violences extrêmes, largement rapportées, contre des familles seigneuriales, mais les troupes des Jacques, ces hommes sans armures «autre que de bâtons ferrés et de couteaux» tombent à la bataille de Mello contre Charles de Navarre. Le feu de paille, selon l'expression de Michel Mollat, s'éteint. Il a duré un bon mois.

Quelques temps plus tôt, la jonction s'est faite entre Charles de Navarre et Etienne Marcel, le prévôt des marchands, un grand bourgeois qui s'est éloigné de ses proches et de son milieu et bénéficie d'une grande faveur auprès des Parisiens. Etienne Marcel a incontestablement un projet de réformes du royaume qu' il souhaite faire partager à d'autres villes; il est en relation avec Ypres et les Flamands. Il s'appuie sur le peuple de Paris endetté et peu favorable à la réévaluation de la monnaie et des troupes aristocratiques massées derrière Charles dont l'intérêt est inverse. Il tente aussi de s'allier avec les Jacques, que Charles de Navarre a massacrés plus tard. La quadrature du cercle! Le 22 février, il a laissé la foule parisienne mettre à mort deux maréchaux du roi, mais sauvé le Dauphin. Quelques semaines plus tard, son alliance avec les Jaques fait peur et les liens avec Charles de Navarre et les Anglais achèvent de le discréditer. Il est assassiné par l'un de ses cousins le 31 juillet.

Déjà la contestation, anormalement longue, s'éteint.

Les évènements parisiens, ville et campagnes, retiennent l'attention, mais de mars 56 à juin 1358, Arras, Toulouse, Rouen, Amiens et Laon ont participé à cette vague d'émeutes. 
Le cycle de 1378-1383:

La seconde vague d'insurrections françaises suit celle des Ciompi, est contemporaine de l'insurrection de Gand et précède de peu la révolte anglaise. Elle se déroule en plusieurs phases; les premières manifestations sont celles des Tuchins, qui ont lieu dans le Centre et le Midi dès avril 1378. Elles perdurent jusqu'en 1383. Les travaux que vient de lui consacrer Vincent Challet justifient que je développe plus loin cet exemple. Puis viennent à l'automne 1380, les villes du bassin Parisien qui refusent de payer les impôts quels qu' ils soient, au lendemain de la mort de Charles V qui, dans son testament avait aboli les fouages. De fait l'ensemble des impôts est aboli en novembre 1380, situation intenable. Lorsque sont demandées une aide indirecte et une gabelle du sel en janvier 1382, l'insurrection se généralise, Rouen d'abord, puis les Maillotins de Paris où toute la rive droite tombe aux mains des insurgés et le roi se réfugie à Vincennes. De mars à l'automne les révoltes se succèdent: partout, dans des dizaines de villes normandes, en Champagne et en Picardie la grève de l'impôt s'organisait. Le calme ne revint qu'après la bataille de Roosebeke et la répression fut sauvage.

A dire vrai, il n'est pas si simple de fixer une date d'entrée dans la première période, dont les prémices remontent, en Normandie et dans les villes du Nord, au milieu du XIII ${ }^{\mathrm{e}}$ siècle. Et surtout si l'on oppose le mouvement apparemment chaotique des révoltes de la première phase aux grandes conjonctions d'émeutes de la deuxième, on est troublé par des vagues, moins longues et moins graves certes, mais pourtant bien marquées dès 1280 et de nouveau vers 1330-35.

Quant au seuil entre les périodes 2 et 3, il est difficile à établir: au temps de la querelle des Armagnacs et des Bourguignons, entre 1412 et 1422, les événements parisiens, l'émeute cabochienne en 1413 et celle de 1418, mettent Paris sur le devant de la scène, ${ }^{17}$ avec des centaines de victimes, mais l'agitation est présente presque partout entre 1417 et 1419, peut-être en grande partie due aux agissements des Bourguignons. Les révoltes françaises de ces années-là sont-elles si différentes de celles qui se sont déroulées quarante ans plus tôt?

Si on la compare au reste de l'Europe, cette chronologie n'a rien d'original; le point de départ de cette période agitée est un peu plus tardif qu'en Flandre ou en Italie, me semble-t-il. Les moments de paroxysme ne diffèrent guère. Mais les années 1357-1377 semblent plus calmes en France qu'en Italie ou même qu'en Angleterre. Les incidents ruraux sont peu nombreux ou mal connus; Mollat et Wolff attribuent le calme d'une vingtaine

${ }^{17}$ A. Coville, Les Cabochiens et l'ordonnance de 1413, Paris 1888. 
d'années après 1357, à la différence de la Toscane, à la peste de 1361 et à l'abattement qui la suivit. Ce retour de peste fut-il plus violent en France?

Bernard Chevalier reste d'ailleurs très prudent et parle de «chronologie vaporeuse» ${ }^{18}$.

\section{Les difficultés d'une chrono-typologie}

Fondant leur analyse sur cette périodisation, Mollat et Wolff ont construit une chrono-typologie. Ils distinguent:

- une première époque intitulée "les moyens contre les grands», qu'ils caractérisent comme celles de la révolution démocratique,

- ensuite les révoltes de la misère, qu'ils font commencer dès le début du $\mathrm{XIV}^{\mathrm{e}}$ siècle à Paris, où la famine surexcite les haines sociales, qui s'aggravent encore dans un monde ébranlé par la Peste,

- les années révolutionnaires qui ébranlent presque toute l'Europe occidentale (1378-1382),

- enfin, après un temps d'accalmie lié à la violence de la répression, une période où se mêlent des conflits politiques et conflits sociaux. Dans leur perspective européenne, ils vont jusqu'aux révoltes hussites qu'ils considèrent comme d'un type nouveau.

Révoltes de la misère, années révolutionnaires, ces qualificatifs sont-ils confirmés par les quelques études récentes?

A dire vrai, au cours de ce long siècle, coexistent toutes les formes de révolte. Sans doute parce que même si une évolution politique et économique se dessine à l'échelle du royaume, les différences régionales et locales demeurent encore dominantes. Et la pertinence du royaume comme cadre de l'étude des révoltes a ses limites. Cette échelle d'analyse induit des perspectives trompeuses. A la chrono-typologie il faut ajouter une géo-typologie.

\section{Localisation des révoltes}

La localisation des révoltes est une pièce à verser au dossier de l'interrogation sur les causes des révoltes, car il est une France de la sédition et une France que la guerre et les malheurs traversent, mais qui ne se révolte pas.

Pendant ce long siècle, certaines villes ont eu un profil particulièrement agité. Parmi les championnes de l'émeute Provins ${ }^{19}$ et Rouen, Lyon, Béziers

${ }^{18}$ Les bonnes villes de France cit., p. 300.

${ }^{19}$ Sur Provins, voir notamment le mémoire de maîtrise de Louise Richard, Les émeutes à Provins vers 1280, soutenu à la Sorbonne sous la direction de Michel Mollat en 1969. 
et Carcassonne. A Provins, six révoltes avant 1354, à Rouen aussi. Paris de l'émeute de 1307 à celle de 1418 a connu des évènements particulièrement graves. Il y a sans doute des profils plus contestataires que d'autres, même à courte distance. Caen beaucoup moins séditieuse que Rouen par exemple, mais il est vrai qu'elles n'ont ni la même population ni le même niveau d'activité économique. Pourquoi Provins plus que les autres villes champenoises? Pourquoi Béziers plus que Nîmes? Si certaines régions offrent des disparités peu explicables entre des villes comparables et voisines, il en est au contraire où les mêmes causes semblent bien produire les mêmes effets: les deux petites villes voisines, dans le Forez, que sont Montbrison et SaintGalmier se révoltent à deux ans de distance en 1308 et $1310 .{ }^{20}$

Ces histoires divergentes ou parallèles posent évidemment la question de la contagion, à petite et à plus longue distance. Mollat et Wolff sont sceptiques. Ils pensent plus à des raisons concomitantes qu'à des liens organisés, même si on sait les échanges de lettres entre Etienne Marcel et d'autres villes ${ }^{21}$. La contagion est décrite pour les villages de la jacquerie. Les insurgés d'Amiens en 82 criaient «Vive Gand, vive Paris». Claude Gauvard cite l'exemple d'Attichy où la population résiste au roi par solidarité avec ceux de Gand qui étaient alliés avec ceux de Paris et ceux de la ville de Rouen ${ }^{22}$. L'exemple de Clermont-l'Hérault, connu par la lettre de rémission accordée à son seigneur, est également clair: les révoltés y auraient crié faciamus sicut illi de Montepessulano et de Claromonte. ${ }^{23}$ On sait la vitesse à laquelle se répandent les peurs. Ne peut-on imaginer que la grève des impôts décidée ici est connue là et crée un précédent tentant, mais risqué?

Contagion ou pas, les révoltes repassent par les mêmes chemins. La géographie en est la même au long de la période. Les formes, les raisons, les circonstances, l'intensité peuvent être différentes d'une période à l'autre.Elle épargne l'Aquitaine au sens très large: de la Loire au Toulousain. Pour l'essentiel elle touche de la Normandie au Midi toulousain en passant par la Picardie et l'Ile de France, la Champagne, le Lyonnais et le Forez et

${ }^{20}$ E. Perroy, Une émeute fiscale à Montbrison sous Philippe le Bel, «Bull. Diana»1939, reed. Études d'histoire médiévale, Publications de la Sorbonne, Paris 1979 pp. 131-140; E. Fournial, Les villes et l'économie d'échange en Forez aux XII et XIV $V^{e}$ s., Les Presses du Palais Royal, Paris 1967, pp. 192-93.

${ }^{21}$ R. Cazelles, Etienne Marcel, champion de l'unité française, Tallandier, Paris 1984

${ }^{22}$ C. Gauvard, De grâce especial cit., note 12, p. 565; et l'exemple de l'accord acquis en Parlement en 1385 après les commotions «qui ont agité Arques, Saint-Omer et SaintBertin»; il évoque les bannis venus de Flandre pour inciter les tisserands et le commun «à faire commotion et sédition».

${ }^{23}$ Il s'agit de Clermont en Auvergne (Devic et Vaissette, Histoire Générale de Languedoc, Privat, Toulouse 1872-1904, t. X, col 1632-1639). 
tout le Midi languedocien. Les raisons de cette répartition en semblent assez claires. Ce n'est pas exactement l'importance démographique, mais la densité de l'urbanisation qui semble compter: dans les zones urbanisées, même de petites villes se soulèvent, pourtant moins peuplées que les principales villes des régions peu urbanisées. Même les révoltes de cultivateurs et de ruraux, jacquerie, Tuchins, vignerons d'Auxerre appartiennent (à l'exception de la partie du Massif Central qui a connu le Tuchinat) à des régions de forte densité rurale, d'agriculture productive et de villes développées. C'est un élément essentiel à porter au dossier des révoltes du $\mathrm{XIV}^{\mathrm{e}}$ siècle.

\section{4. À la recherche des caractéristiques des révoltes}

On ne dira jamais assez l'originalité de chaque révolte; néanmoins la simultanéité et la proximité des raisons invoquées entraînent à chercher les motifs et circonstances qui meuvent le peuple.

Il faut faire la part des choses dans le déroulement des évènements entre des tensions et des agitations sans crime ni effusion de sang et de longues et violentes séditions. ${ }^{24}$

Il faut également faire apparaître, aussi nettement qu'il est possible, qui sont les cibles des violences et quels sont les objectifs avoués des émeutiers. A quel type de biens s'en prennent les insurgés? Aux hôtels de l'oligarchie urbaine, aux bâtiments symboles du pouvoir ou à tout ce qui se trouve sur leur chemin.

Il faut enfin tenter d'établir qui sont les acteurs en distinguant villes et campagnes, élites paysannes et moyenne bourgeoisie urbaine, salariés des bons métiers et salariés à l'emploi précaire.

\section{Déjà au temps de Beaumanoir}

Il n'est pas sûr que la France, comme le reste de l'Occident, soit entrée en commotion seulement après 1300 . On sait bien la précocité des takehans des Flandres. Le témoignage de Philippe de Beaumanoir, écrit entre 1280 et 83 , est là pour montrer que les phénomènes décrits pour le $\mathrm{XIV}^{\mathrm{e}}$ siècle sont déjà sensibles du moins dans le Nord de la France et du moins à un esprit aussi acéré et lucide.

Dans les coutumes de Clermont en Beauvaisis, il évoque les haines «qui

${ }^{24}$ Bernard Chevalier, dans Les bonnes villes, fait soigneusement la part, à partir des sources, entre l'émotion, mouvement de foule tumultueux hors norme, qui résulte d'un «effroy» et la révolte ou rébellion (p. 299). 
meuvent l'un lignage contre l’autre» mais il écrit aussi au $\$ 1520^{25}$ : nous avons vu moult débat es bonnes villes des uns contre les autres, si comme des pauvres contre les riches ou des riches même les uns contre les autres... Les raisons qu'il avance sont l'impossibilité de se mettre d'accord sur le choix d'un maire ou les dissensions sur l'usage des revenus de la ville. Il met en avant au paragraphe suivant que les pauvres et les moyens n'ont aucun moyen de participer à l'administration de la ville, que les jurés désignent leurs frères et leurs neveux pour leur succéder et que quand le commun demande des comptes, la réponse fournie est qu'il se les ont donnés les uns aux autres. Au $\$ 1525$ il indique que la mauvaise répartition des tailles est souvent cause du mécontentement. Pour autant, dans un autre chapitre, Philippe de Beaumanoir n'est pas tendre avec les coalitions des travailleurs: il y a alliance contre le commun profit lorsque certaine manière de gens jurent... qu'ils ne travailleront plus à prix aussi bas qu'auparavant, augmentent ce prix de leur propre autorité, s'entendent pour ne pas travailler à moins et établissent entre eux des peines ou des menaces contre les compagnons qui n'observeront pas cette alliance. Ces alliances sont contre le bien public et il faut emprisonner les meneurs et ne les libérer que contre paiement de l'amende pour rupture de la paix publique. ${ }^{26}$ Les «contens», comme écrit Beaumanoir, c'est-à-dire les conflits, sont donc analysés déjà comme grèves des travailleurs, protestation des pauvres contre les riches, mais aussi luttes des riches entre eux. Les oppositions sont multiples et souvent enchevêtrées. Les thèmes majeurs des agitations du XIV siècle, partage du pouvoir, juste répartition des charges fiscales et organisation du travail, sont déjà là. Il se peut que les sources se fassent ensuite plus abondantes pour nous faire connaître les révoltes. Néanmoins le fait semble avéré: si les principaux sujets de tension étaient déjà présents dans la deuxième moitié du XIII ${ }^{\mathrm{e}}$ siècle, les «débas» se sont envenimés par la suite, et s'expriment au XIV ${ }^{\mathrm{e}}$ siècle par des émeutes plus ou moins longues. Pourquoi?

\section{Les scenarii}

Comment des tensions et «débas» explose la révolte? L'atmosphère est lourde de peurs diverses, sur lesquelles nous reviendrons. Des rumeurs circulent, conversations privées. Eclate un cri, un haro. Le plus célèbre est celui

${ }^{25}$ nous avons veu moult de débas es bonnes villes des uns contre les autres si comme des povres contre les riches ou de riches meismes les uns contre les autres: si comme quant il ne peuent accorder a fere maieur ou procureeurs ou avocats ou si comme quant li un metent sus as autres qu'il n'ont pas fet des reçoites de la vile ce qu'ils doivent. Ed. AM Salmon, Paris 1900, reed. 1970, p. 267.

${ }^{26}$ Cité par Mollat-Wolff, Ongles bleus cit., p. 46 dans cette version modernisée; $\$ 884$ p. 446 de l'édition Salmon. 
de la marchande des quatre saisons en friction avec un receveur des aides, à Paris en $1380^{27}$. On sonne le tocsin; alors le peuple s'assemble en armes, comme il convient au son du tocsin. Les discussions sont désormais sur la place publique. Souvent, ce rassemblement bruyant se disperse sans émeute. On sait bien que pour passer de l'émoi à l'émeute, il est nécessaire (mais sans doute pas suffisant) qu' il y ait à la tête du mouvement des gens qui se connaissent et ont une certaine habitude d'agir ensemble, tisserands, foulons, bouchers. Et qu'on trouve un chef, rarement un menu, presque toujours un notable. De fait le plus souvent la révolte est soutenue, par contrainte ou par choix, par une partie des notables, de ceux qu'on désigne par l'expression «gens d'état». La foule grossit, femmes et enfants s'y adjoignent et toute une population émotive et qui n'a rien à perdre. On s'en prend aux biens, hôtels des plus riches ou des plus puissants saccagés, parfois pillés. Parfois aux personnes: violences, effusion de sang, puis vient le temps des ripailles et la fête. ${ }^{28}$ En général les notables ont alors déjà rompu avec les émeutiers. L'émeute est une subversion temporaire de l'ordre dans la France du XIV ${ }^{\mathrm{e}}$ siècle, ce n'est pas une révolution.

Vient alors la répression. Deux cas de figure, le premier plus fréquent que le second. Les pendus et les bannis sont de pauvres hères; mais parfois aussi des chefs de métier, des hommes qui ne sont pas sans importance. Ce n'est pas la justice qui passe. Le prince exige «des victimes expiatoires, frappe toute la collectivité de lourdes amendes, supprime le corps de ville qui n’a pas joué son rôle». ${ }^{29}$ Ensuite, souvent assez vite, vient la réconciliation et la grâce. L'amende payée, la paix est retrouvée et le prince reçoit l'amour de ses sujets. Tel est le schéma languedocien après les révoltes urbaines et celle des Tuchins, entre 1374 et 1383 . Exécutions publiques ou à la sauvette, on ne sait. En tous cas les campagnes sont pleines de pendus; les nobles orchestrent la répression et exécutent les anciens tuchins, le duc de Berry confisque les biens. Les autorités consulaires usent de la répression pour clore le cycle des révoltes, là où elles s'en étaient pris aux élites urbaines. Certains Tuchins fuient. L'immense majorité revient à la vie normale. Vient la rémission en 1383, puis, six ans plus tard, le voyage de Charles VI en Languedoc: après avoir remis les arrérages, remplacé le duc de Berry par des réformateurs, le roi passe Noël à Toulouse. ${ }^{30}$

${ }^{27}$ Ibid. p. 172.

${ }^{28}$ Parmi d'innombrables exemples de épisodes festifs, on citera les Tuchins, qui à peine maîtres de Bagnols-sur-Cèze, se répandent dans les lupanars et les tavernes pour jouer aux dés et s'enivrer. Ils marient même l'un de leurs chefs et consomment dans un grand festin une bonne partie de leur butin.

${ }^{29}$ B. Chevalier, Les bonnes villes cit., p. 291.

${ }^{30}$ Voir la thèse de V. Challet, cit., note 4, 5 ème partie. 


\section{Le faible poids de la prédication}

A l'origine de ces scenarii, on ne trouvera guère de mouvement d'exaltation religieuse. Il y a bien, en 1320, le périple des Pastoureaux, ces jeunes venus du Nord de la France, qui avaient laissé «les bêtes es patis et s'en allaient sans saluer père et mère». Il s'achève misérablement dans la région de Toulouse: c'est un archaïsme qui n'a pas d'équivalent à cette époque. Les thèmes égalitaires chrétiens, attestés pour la révolte des paysans anglais, sont probablement présents. Ils sont en tous cas attestés dans des révoltes postérieures en Velay et Forez, au début du règne de Charles $\mathrm{VII}^{31}$. Néanmoins, ni Savonarole ni Jean Huss parmi les chefs des révoltés, ruraux ou urbains dans la France du XIV ${ }^{\mathrm{e}}$ siècle.

On pourrait rattacher à des motifs religieux l'agitation qui règne dans les villes languedociennes entre 1300 et 1305, surtout à Carcassonne et qui se terminent par la pendaison de bourgeois de Carcassonne et de Limoux; les harangues fougueuses du Franciscain Bernard Délicieux y ont très largement participé, mais il s'agit de rébellion contre l'Inquisition. ${ }^{32}$ Les deux principales émeutes sont tournées contre le couvent des Dominicains et la sinistre prison du Mur.

En revanche, beaucoup d'émeutes ont de très forts relents d'antisémitisme, de celle des Pastoureaux jusqu'aux diverses émeutes parisiennes en passant par le pogrom de Chinon. L'émeute du 14novembre 1380 à Paris commence par une protestation antifiscale et mais aboutit au pillage des maisons d'une quarantaine de juifs, à la mort d'un rabbin et à la soustraction d'enfants juifs à leurs parents pour les faire baptiser. ${ }^{33}$

\section{La lutte contre la seigneurie et la hantise de la servitude}

La lutte contre la seigneurie n'est en revanche pas absente des mouvements de révolte.

Dans les première années du XIV $\mathrm{V}^{\mathrm{e}}$ siècle, certains sont encore de type communal $^{34}$, parfois sanglants: c'est le cas de la révolte de Châteauneuf-

${ }^{31}$ Cité par Mollat et Wolff, Ongles bleus cit., p. 240.

${ }^{32}$ B. Hauréau, Bernard Délicieux et l'inquisition albigeoise 1300-1320, Hachette, Paris 1877, reed. Loubatières, Toulouse 1992.

${ }^{33}$ Claude Gauvard, De grâce especial cit., cite une lettre de rémission de 1385 qui se rapporte à des évènements contemporains des pillages et mises à mort de Juifs parisiens, événements qui ont conduit au pillage des biens de deux juifs de Montereau, et auxquels ont participé cinq officiers de la ville (p. 564, note 154).

${ }^{34}$ Dans son ouvrage consacré au Carnaval de Romans, (Paris 1979), Emmanuel le Roy Ladurie a distingué jadis les commotions «médiévales» où le conflit se noue entre 
les-Tours en 1305 où sous couvert de confrérie les émeutiers ont «fait des monopoles et usurpé le nom de commune». A Calais en 1298, à Beauvais en 1305 aussi, à Saint Quentin en 1311 il s'agit bien encore d'affaires communales $^{35}$. La rébellion de Saint-Malo, en 1308 est peut-être la plus célèbre car elle est le seul évènement connu de ce type en Bretagne, mais sans effusion de sang; dressée contre l'évêque et le chapitre, elle vient du refus seigneurial d'engager des travaux de fortification ${ }^{36}$. Ce n'est pas le poids financier de la seigneurie qui est à l'origine de l'exaspération, mais l'absence d'autonomie de la ville, ou plutôt le refus exprimé par l'évêque et le chapitre d'engager des travaux de défense, afin d'assurer la protection des sujets. La crainte que l'autorité requise ne sait pas apaiser est une des constantes émotives du XIV ${ }^{e}$ siècle. La forme qu'elle revêt dans ce cas, l'exigence d'une autonomie communale, peut être considérée comme archaïque, si l'on reprend les critères élaborés par E. Le Roy Ladurie en 1979. Critères sans doute caricaturaux, mais qui ont leur sens dans la perspective d'une mort annoncée de la société féodale dans la plupart des villes françaises au XIV siècle.

En revanche, le temps est loin où les villes se battaient pour limiter le poids de la seigneurie banale et les atteintes à la liberté des personnes. Dans les campagnes, il en va un peu autrement. On sait bien les violences de la jacquerie, «ainsi ces gens, assemblés sans chef, brûlaient et volaient tout et tuaient gentilshommes et nobles dames et leurs enfants», écrit Jean de Venette. ${ }^{37}$ Les Jacques s'en sont pris aux châteaux, où s'entassent des privilèges indus: il se peut que les défaites successives de l'ost aient montré que les seigneurs ne sont plus les protecteurs qu'ils devraient être. Les accusations contre les nobles portent plus sur leur trahison que sur l'injustice des taxes seigneuriales. La jacquerie commence par une altercation avec des gens d'armes, dans un climat d'énervement, sans préméditation; l'organisation vient ensuite. A coup sûr, son extension montre des sentiments largement partagés. La même grande peur en somme qu’à Saint Malo, dans le contexte rapproché de la guerre. Révolte de la misère, la jacquerie? Quoi qu'on en ait dit, pas plus que les autres agitations rurales de la période. Les régions touchées sont riches, peut-être moins riches que dans un passé récent. Mais on sait aussi qu'il n'y avait pas que de pauvres paysans instables

autorité seigneuriale et communautés rurales ou urbaines et commotions «classiques» où l'adversaire reconnu par les communautés est le prince ou plutôt ceux qui lèvent l'impôt pour lui.

${ }^{35}$ Cité par B. Chevalier, Corporations cit., p. 28 et Les bonnes villes cit., p. 282.

${ }^{36}$ J.P. Leguay, H. Martin, Fastes et malheurs de la Bretagne ducale 1213-1532, Ouest France, Rennes 1982, p. 53.

${ }^{37}$ Cité par Mollat et Wolff, Ongles bleus cit., p. 124. 
parmi les Jacques: les Grandes chroniques citent aussi de riches hommes et des bourgeois et les assemblées dans les villages écoutaient des notables paysans. Qu'allaient faire les Jacques à Compiègne et à Meaux, pour y assaillir le marché? L'ouverture des marchés, céréaliers notamment, est sans doute génératrice d'une autre forme d'incertitude que la guerre. Cinquante ans plus tard, dans la deuxième décennie du $\mathrm{XV}^{\mathrm{e}}$ siècle, dans un contexte de guerre civile la même région connaît des évènements très comparables, moins célèbres, peut-être plus diffus, secousses sporadiques ${ }^{38}$. Pérennité des craintes et des refus?

Mais les découvertes récentes de Ghislain Brunel ${ }^{39}$ interdisent de trop amenuiser le poids de la colère sociale. Le servage qu'on croyait presque disparu au XIV $\mathrm{X}^{\mathrm{e}}$ siècle, en dehors des régions où il se généralise comme la Champagne, certaines seigneuries berrichonnes ou, hors du royaume, la Franche Comté ou la Savoie survit dans des poches au statut insupportable. Il y eut une révolte servile dans la région de Laon en 1338, exactement vingt ans avant la jacquerie. Non pas exactement dans la même région, car celle-ci durement matée en 1338 ne bougea pas en 1358. G. Brunel a récemment exhumé aux Archives Nationales le Livre des serfs du chapitre cathédral de Laon. Ce document rédigé en 1406 par un seul scribe, long de $125 \mathrm{f}^{\circ}$, analyse les actes conservés par les archives du chapitre concernant les serfs; quelques actes originaux le complètent ou le recoupent. L'exploitation de ce livre des serfs a permis à $\mathrm{G}$. Brunel une étude très neuve sur le servage dans le Nord du Bassin Parisien; il y montre que les seuls actes de manumissions individuels ont rapporté au chapitre entre 1330 et 1340 la somme colossale de 12000 livres, non négligeable au moment où les chanoines se sont engagés à payer au roi 20000 livres pour ratifier la suppression de la commune de Laon. Dès 1280, des désobéissances et des «conspirations» sont mentionnées. Les communes, rurales et urbaines, offraient encore un recours; leur suppression progressive entre 1323 et 1331 (Laon) le ferment. Les conspirations se font plus fortes. A partir de 1337, les tailles ne sont plus payées. Entre mars et juillet 1338, la situation s'envenime. Quand vinrent les gens du chapitre, «a son de cloche se assamblerent et armerent et les assaillirent et villenerent... criant à haute voix 'a mort'»... Fuite des gens du chapitre; bris du sceau royal. Les documents royaux évaluent à 40.000 le nombre des insurgés; en fait 24 villages avaient participé au mouvement, cinq à six mille personnes. La répression est ra-

${ }^{38}$ Le Religieux de Saint-Denis s'en fait l'écho: «foulaient aux pieds toute crainte de Dieu et des hommes, ne songent qu'à piller et mettent tout à feu et à sang, sous prétexte de tirer vengeance de l'injustice commise à leur égard».

${ }^{39} \mathrm{G}$. Brunel, Les hommes de corps du chapitre cathédral de Laon cit., note 4 . 
pide: 9 hommes, issus de 7 villages différents, sont exécutés, et six femmes marquées au fer rouge (flétries sur les joues). Aussitôt les reconnaissances serviles reprennent. Mais le roi cherche une solution au conflit en 1340 (deux ans plus tard) «pour toujours nourrir bonne paix entre (ses) sujets»; les biens sont rendus, les procès annulés. La miséricorde après le sang. Les statuts personnels sont totalement confirmés, mais l'arbitraire judiciaire du chapitre, les citations à Laon, est régulé: il y aura désormais lettres patentes et délai de quatre jours pour comparaître. Le mouvement est resté limité, semble-t-il, à la seigneurie capitulaire. Il n'en est pas moins le signe d'exaspération latente des paysans et du recours nécessaire à la violence pour faire évoluer leur condition juridique et financière. Peut-on les interpréter comme le rattrapage violent d'une évolution qui s'est faite ailleurs de manière plus progressive? En tous cas la servitude (on le verra encore plus loin) reste une hantise ${ }^{40}$

\section{Les revendications des travailleurs}

A l'autre extrémité du champ des relations sociales, l'organisation du travail est une autre des multiples sources d'affrontements. Elle concerne évidemment surtout la ville, mais parfois aussi les campagnes et pas exclusivement le travail artisanal. Ainsi le mouvement des vignerons d'Auxerre en $1393^{41}$. A la fois propriétaires de quelques ceps et salariés, ce n'était pas tant la valeur des salaires que la durée du travail qui les agita. A dire vrai, le mouvement commence par une plainte des employeurs, qui se plaignent de leurs salariés: «engraissés en leur richesse» ils passent à chaque repas très grand délai». Révélant leur capacité d’organisation, les vignerons avaient avancé collectivement l'heure à laquelle ils quittaient le travail; les cris qui résonnent de vigne à vigne leur permettent de se coordonner. Ils trouvent écho auprès des villages voisins qui entrent dans le mouvement et tentent même d'étendre leur protestation aux autres métiers. Les vignerons sont soupçonnés de «faire et émouvoir une manière de jaquerie et mailleterie» Ils ont certainement d'excellents conseils qui leur permettent de faire évoquer l'affaire par le Parlement et l'argumentation présentée, qui renvoie d'ailleurs à leur statut de libre, confirmant la permanence de la référence au servage, a des accents sublimes «le terroir d'Auxerre est très fort et dur...

${ }^{40}$ Dans l'analyse de l'accord, cité par Claude Gauvard, Corporations cit., p. 565, accord conclu en Parlement en 1385 après les soulèvements des villes du Nord (Arques, Saint-Omer, Saint-Bertin), figure la mention des paroles prononcées par deux meneurs qui firent refuser la fourniture d'un char au seigneur d'Attichy pour participer au voyage de Flandres avec Charles VI: ils avaient peur de nouvelles «servitudes.

${ }^{41}$ Cf. Mollat et Wolff, Ongles bleus cit., p. 244 et sq. 
Bien qu'ils soient pauvres gens, toutefois ils sont des hommes et l'on ne doit pas exiger d'eux telle peine et tel travail comme on ferait d'un bœuf ou d'un cheval». On trouva un compromis.

Il en va souvent plus tumultueusement encore des conflits analogues dans les villes. Ils sont attestés dès la fin du XIII ${ }^{\mathrm{e}}$ siècle, tout particulièrement dans les milieux du textile. On sait souvent indirectement, par les interdictions qui en sont faites, les alliances et coalitions de ouvriers contre les donneurs d'ouvrage. Mais le plus souvent c'est parce que les autorités municipales soutiennent ouvertement les patrons (ce qu' ils sont aussi) que la contestation se porte contre elles. Notamment parce que ce sont les cloches qui signalent la fin de la journée de travail et que l'heure en est décidée par le conseil. Ces bouffées de violences sont rarement durables, rarement sanglantes. Il peut arriver que ce soit l'allongement de la durée de la journée qui déclenche l'émeute, comme à Provins en 1281, $1315 \mathrm{ou}$ $1324^{42}$. Il est probable aussi que, sans aggravation, la situation paraisse insupportable; c'était peut-être le cas dans les très nombreux conflits normands de la première moitié du siècle. A Paris et à Saint-Denis dans les années 1320 aussi chez les foulons: les maîtres reprochent aux ouvriers des accords visant à retarder l'heure de prise du travail; les valets reprochent aux maitres de prendre trop d'apprentis ${ }^{43}$. La situation complexe et variée des maitres des métiers dans le processus de production, les diversités des niveaux de revenus au sein du même métier ainsi que la hiérarchie de fortune et de prestige des métiers entre eux achèvent d'obscurcir la compréhension que nous avons des conflits. Bien souvent d'ailleurs les conflits du travail recoupent ceux de la révolte contre l'oligarchie municipale et les luttes entre grands et petits métiers.

${ }^{42}$ En 1281, à l'annonce de nouveaux impôts levés par le nouveau comte Edmond de Lancastre et le roi de France pour reconquérir la Navarre, l'ensemble de la population provinoise se mutine: 6000 personnes selon les sources. Peu auparavant une nouvelle "grande coutume» a augmenté les droits sur le commerce de draps. Pour éviter ce surcroît d'imposition, le maire, Guillaume Pentecôte décide de retarder d'une heure la fin de la journée de travail. La foule des ouvriers s'amasse, fait sonner le tocsin et se dirige vers l'hôtel de ville, ancien palais des comtes de Champagne. Ils enfoncent la porte, errent à la recherche du maire, le bastonnent et le piétinent, puis saccagent le palais. De là se dirigent vers les maisons de quelques échevins, et finissent la journée en beuveries. Tel est du moins le récit. Une chronique anonyme décrit la violente répression qui s'ensuivit, mutilation et pendaisons, exercées par Edmond de Lancastre, qui bannit 52 personnes: presque le tiers est ouvrier du textile. Cf. Louise Richard, Les émeutes à Provins cit. Dès le mois d'août vint la grâce qui coûta plus de 400 livres à la ville.

${ }^{43}$ Mollat et Wolff, Ongles bleus cit. p. 96. 


\section{Les émeutes de la cherté}

De ces émeutes issues du monde du travail, on peut rapprocher celles liées à la cherté. Il semble que ce soit les mêmes couches urbaines qui s'émeuvent. Telle semble avoir été la cause de plusieurs des révoltes de Provins, notamment en 1316, 1330 et 1348. Néanmoins les disettes ne paraissent pas avoir été souvent le moteur de ces commotions sociales dans la France du XIV ${ }^{\mathrm{e}}$ siècle et les chertés plus que les disettes.

C'est peut-être la peur de manquer qui soulevait les foules, dont l'existence quotidienne était de toutes façons difficile. Le récit de la rébellion d'Orléans en 1343 en fournit un exemple. Les grandes chroniques de France $^{44}$ rapportent l'aide que le roi voulut organiser à partir des bons pays d'Orléans, de Beauce et de Gâtinais pour secourir la Bourgogne où les vivres manquaient. ${ }^{45}$ Les clercs étudiants, qui s'étaient déjà révoltés à plusieurs reprises et notamment en 1284 contre la levée d'un subside pour payer la guerre d'Aragon, remuèrent «les bourgeois et le commun»; «ils disaient que les marchés seraient amenuisés et vidés», ils allèrent aux bateaux qui s'apprêtaient à porter le blé en Bourgogne, s'en saisirent et le vendirent; la phase suivante fut de briser les portes et de se répandre dans les villages voisins. La répression vint, pendaison sur le champ de tous ceux qui furent dénoncés par le prévôt. «Peu après, la révolte cessa». De cet épisode on retiendra, outre le milieu estudiantin comme fauteur de troubles, des caractéristiques essentielles: l'irritation de voir ses propres ressources, de nourriture ou d'argent, utilisées pour autrui et le danger, déjà signalé, ressenti devant le commerce des blés.

Jusqu'à un certain point, on pourrait aussi rattacher à ce type de sentiment la révolte de 1307 à Paris. Ce sont ici les remuements monétaires qui mirent le feu aux poudres: une dévaluation annoncée de près de $40 \%$ qui fit monter les prix et notamment les loyers. Les artisans s'en prirent au maître de la monnaie, Etienne Barbette et à ses biens, puis au roi réfugié hors de Paris, au Temple où il est assiégé. La ville reprise, 28 maîtres de métiers furent pendus puisque les responsables étaient en fait inconnus. Être injustement lésé par l'autorité qui gouverne aveuglément, telle est l'une de la colère populaire.

${ }^{44}$ Grandes chroniques de France, ed. J. Viard, Paris 1937, t. 9 p. 237-239; cité par Sources d'histoire médiévale, ed. G Brunel, E. Lalou, Larousse, Paris 1992, pp. 762-63

${ }^{45}$ S. K. Cohn, Lust cit., p. 67 sq. 


\section{Gouvernement municipal et fiscalité}

Colère contre l'injuste répartition des impôts, due à l'injuste répartition des pouvoirs. Si bien des raisons diverses et parfois conjuguées expliquent l'irruption de quelques unes des révoltes françaises, c'est bien la colère fiscale qui en a mu le plus grand nombre, partout et pendant toute la période. Que les deux phénomènes, oligarchie municipale et gestion financière, soient liés ne fait doute pour personne. B. Chevalier a décrit, quelle que soit l'apparence des statuts de la ville, cette «poignée d'hommes habitués à se rencontrer pour préparer toutes les décisions à prendre..., cette sorte de conseil municipal informel (qui) rassemble les vrais décideurs» et constitue le «cerveau du corps de ville». ${ }^{46}$ Une oligarchie dépensière, qui choisit en général, plus encore dans la France du Nord, une fiscalité indirecte pour financer ses décisions. Cette oligarchie municipale suscite une méfiance qui peut vite se muer en tumulte ou révolte, surtout si se profile, nous l'avons vu, une modification du régime du travail ou la levée d'un nouveau subside royal. Mais il ne semble pas que la désignation d'un nouveau maire ou de nouveaux consuls ait jamais mis le feu aux poudres. Bien que l'assemblée du peuple ait à ratifier, dans nombre de villes, le choix fait par les sortants. Certains maires sont impopulaires et leur désignation, comme celle de Guillaume Pentecôte à Provins en 1280, fait monter la tension, mais elle n'est pas l'élément déclenchant à proprement parler.

Le plus souvent c'est un nouvel impôt royal qui allume l'incendie. Il est toujours ressenti comme une charge extraordinaire, à justifier. Et lorsque les Tuchins sont maîtres de Bagnols-sur-Cèze, ils font cesser les levées d'impôts et particulièrement la gabelle du sel. ${ }^{47}$

De fait cette charge extraordinaire pèse sur les menus d'une manière qu'ils jugent injuste. Ainsi dans la France du Midi, les tailles, la plus lourde des impositions, ont suscité des tensions dès le milieu du XIII ${ }^{\mathrm{e}}$ siècle quel que soit leur destinataire. Comment les asseoir? ${ }^{48}$ Par feu et livre réclament les «populaires»; lorsque ce premier pas est acquis, on demande une assiette non plus selon une estimation sommaire des fortunes mais selon une évaluation précise. La révolte est déjà sanglante à Cahors en 1268; la répression pend et bannit. Mais la solution fait son chemin: les conseillers d'Alphonse de Poitiers l'imposent pour toutes les dépenses importantes. Le système des échelles prévaut dans la plupart des grandes villes au cours

${ }^{46}$ Les bonnes villes cit., p. 206.

${ }^{47} \mathrm{~V}$. Challet, Mundare cit., note 4.

${ }^{48}$ Albert Rigaudière, Les origines médiévales de l'impôt sur la fortune, dans L'impôt au Moyen Age. L'impôt public et le prélèvement seigneurial, Colloque tenu à Bercy 14-16 juin 2000, Ph. Contamine, J. Kerhervé, A. Rigaudière ed., Paris, 2002, 3 vol. pp. 227-287 
du XIII ${ }^{\mathrm{e}}$ siècle, à Montpellier d'abord, puis à Nîmes en 1272, à Lodève en 1301, à Béziers peu après; il prévoyait l'élection des consuls par des groupes de métiers, les échelles. Inutile de préciser que toutes les précautions sont prises pour que les consuls ne viennent pas des échelles les plus bas$\operatorname{ses}^{49}$. Les conquêtes des «menus» sont minces au cours du XIII ${ }^{\mathrm{e}}$ siècle; elles ne sont pas inexistantes. Mais au cours du XIV ${ }^{\mathrm{e}}$ siècle elles deviennent de plus en plus difficiles à maintenir ou accroître. Prenons l'exemple de Carcassonne, sans doute une sorte d'extrême parmi les villes méridionales parce que la pression des populaires qui s'exerce partout, y a sans doute obtenu moins de concessions qu'ailleurs. Le temps de Bernard Délicieux où régnait une relative unanimité n'est plus. Lorsque la ville doit payer l'amende due par tout le Languedoc à cause de la révolte des Tuchins, la levée se fait avec une extrême difficulté. Le procureur du roi a même accusé les consuls, trésoriers et estimeurs de ne pas rendre de comptes, d'avoir détourné à leur profit l'argent commun, et d'avoir oppressé les «pauvres». ${ }^{50}$ L'agitation devient émeute en 1413 lorsqu'on apprend que le duc de Berry retrouve ses fonctions de lieutenant du roi. ${ }^{51}$ Pourquoi ce mécanisme se grippe-t-il par lequel les menus acceptaient d'être représentés par les membres d'un petit nombre de famille et parvenaient, certes au prix de contestations et de refus parfois violents, à imposer à l'oligarchie municipale une amorce de démocratie urbaine et de proportionnalité fiscale? C’est sans doute un espoir désormais sans cesse déçu.

Au refus des aides royales, il y a aussi une autre raison: l'incertitude de leur destination. Si les aides étaient à coup sûr destinées à payer des hommes d'armes pour défendre le pays contre les compagnies, le paiement en eût été mieux accepté. Les Tuchins languedociens viennent d'un pays qui a payé, au duc d'Anjou et au duc de Berry, lieutenants du roi en Languedoc, des sommes considérables pour la guerre et a l'impression d'être bien mal défendu par les armées royales. ${ }^{52}$

${ }^{49} \mathrm{P}$. Wolff, Réflexions sur l'histoire médiévale de Carcassonne, dans Carcassonne et sa région, Actes des XLI et XXIV congrès de la Fed. Hist. Languedoc méditerranéen et Roussillon, Carcassonne 1970, pp. 135-146, notamment p. 145; Id., Les luttes sociales dans le Midi français, dans Regards sur le Midi médiéval, Privat, Toulouse 1978; pp. 7789, reprise des «Annales ESC», n 4, oct-dec 1947, pp. 443-454.

${ }^{50}$ Mollat-Wolff, Ongles bleus cit., p. 229.

${ }^{51}$ Toutefois les consuls et les bourgeois participent aussi à l'émeute et par la suite, disent avoir été contraints de s'allier au peuple pour mieux le contrôle et le désarmer. Les 35 décapités sont en effet travailleurs agricoles, ouvriers du textile et artisans, mais aussi 3 bouchers et 3 marchands (Mollat-Wolff, Ongles bleus cit., pp. 236-237).

${ }^{52}$ Vincent Challet (cit. note 4 ) a bien mis en lumière la méfiance, puis la défiance des populations. 


\section{Des révoltes largement politiques}

Rumeurs ou effrois se calment ou s'enveniment. Les conditions d'exercice du pouvoir politique ont joué un grand rôle dans le devenir des commotions du XIV ${ }^{\mathrm{e}}$ siècle. Mollesse ou dureté excessives ne rétablissent pas la confiance. Dans l'ensemble les officiers royaux ont assez bien su lâcher du lest ou comprendre les agitations, pour mieux reprendre la situation ensuite. Jean de Picquigny, enquêteur-réformateur pour le roi sut entendre, trop peut-être, les fureurs des Carcassonnais contre l'Inquisition..$^{53} \mathrm{Il}$ en est d'autres exemples.

Les plus longues des révoltes semblent avoir été entretenues par des pouvoirs rivaux. Il n'est pas surprenant que la querelle des Armagnacs et des Bourguignons et la situation politique qui a suivi le traité de Troyes en 1420 aient fourni un terrain d'accompagnement aux révoltes parisiennes, normandes ou méridionales. Charles le Mauvais en 1357, Gaston Phoebus pour les Tuchins ne sont pas étrangers à la force des insurrections. La vacance du pouvoir aussi: la Champagne des années 1280 est dans ce cas.

\section{Les révoltés du XIV ${ }^{e}$ siècle, «une nuée de vers»?}

Au terme de cette revue des révoltes françaises du XIV ${ }^{\mathrm{e}}$ siècle, il est temps de revenir sur l'image misérable qui fut la leur au Moyen Age, et qui a fortement influencé les historiens modernes et même récents. J'y reviendrai en suivant Vincent Challet et sa magnifique révision de ce que furent les Tuchins en Languedoc; un précédent historiographe les voyait comme des marginaux. ${ }^{54}$ Le mouvement, plus précoce et plus bref dans la partie toulousaine du Languedoc, dura plus de 3 ans dans la sénéchaussée de Beaucaire, jusqu'en 1393 en Rouergue. A en juger par le petit nombre de feux qui furent exemptés de l'amende pour participation au Tuchinat, le mouvement fut généralisé.

Le Religieux de Saint-Denis, l'un des rares chroniqueurs a avoir parlé de cette révolte lointaine, matée sans panache, peu digne d'être écrite, les décrit ainsi: «des bandes de misérables à la vie désordonnée, avaient surgi comme une nuée de vers». ${ }^{55}$ Les Tuchins porteraient leur nom de leur vie

${ }^{53}$ B. Hauréau, Bernard Délicieux cit., p. 14 sq.

${ }^{54}$ M. Boudet, La jacquerie des Tuchins, Paris 1895. Qu'il étudie surtout le mouvement en Limousin et Auvergne ne change pas fondamentalement cet aspect de la question.

${ }^{55}$ Sane multitudo maxima abjectissimorum virorum, qui ob inconditos mores tuchini dicebantur, ubique in illis partibus, velut inquieti vermes, inopine eruperant. Religieux de Saint-Denis, Chronique du règne de Charles VI, L.F. Bellaguet ed., Paris 1862, t.1, p. 307; reed CTHS, Paris 1994. La traduction est celle de Vincent Challet. 
dans la touche, ces landes désertées par la culture. Pourtant, les observations fines faites par Vincent Challet, les montrent habitant au cœur de leur village, bien intégrés dans un réseau de solidarité: l'un de leur chef se marie dans l'église paroissiale et la majorité de la communauté villageoise est invitée au repas de noces. Marginaux, ils ne deviennent qu'après leur défaite, lorsque certains passent le Rhône, et s'engagent dans les compagnies provençales. Le Religieux de Saint-Denis les décrit minablement armés de vieux arcs, d'épées rouillées et de bâtons. Là encore, les témoignages des lettres de rémission ne vont pas dans ce sens: ce sont des cavaliers, vêtus d'une jaque blanche, serrée par un cordon rouge qui entrent en ordre, bannières déployées, dans Bagnols-sur-Cèze qu'ils viennent de conquérir. Ils ont perdu, certes, le seul combat en rase campagne, celui d'Uchaud, mais ils excellaient à se former rapidement pour des coups de mains et à se fondre tout aussi vite dans la population. Il est bien probable qu'en Languedoc comme en Auvergne, après la chevauchée du Prince Noir en 1355 et les fréquents passages des grandes compagnies, l'auto-défense des communautés est devenu une nécessité à laquelle répond l'organisation du tuchinat. Il y a une dimension patriotique au tuchinat. ${ }^{56}$

La plupart des historiens ont soigneusement insisté sur la différence qui séparait les tuchins des révoltes urbaines contemporaines: villes contre campagnes. A y regarder de plus près, Vincent Challet montre au contraire que les villes, de Saint-Flour à Nîmes et à Toulouse, sont accueillantes aux tuchins: ils y mettent leur butin en sécurité et s'y approvisionnent. Ils aident Narbonne dans sa guerre contre le vicomte. Il y a plus: une véritable connivence entre les villes et les tuchins. Les villes s'aident des tuchins pour la garde des remparts: les brigands sont en fait chargés de la sécurité du territoire! Vincent Challet pense que le soutien des oligarchies urbaines aux tuchins est aussi manière de canaliser la violence des paysans et des artisans hors de la ville. De fait, dans la partie centrale, Béziers et Clermont l'Hérault, les révoltes sociales sont violentes; or les sources ne parlent pour ainsi dire pas des tuchins. Et la fréquence des révoltes urbaines en Languedoc, depuis 1374 (Castenaudary), les violences qui se sont exercées contre les consuls (mis à mort à Béziers ${ }^{57}$ ) mettent les élites urbaines dans l'angoisse. L'obsession de ces violences peut expliquer l'attitude des gouvernements urbains.

\footnotetext{
${ }^{56}$ Sur ce point voir l'article de P. Charbonnier, Qui furent les Tuchins? dans Violence et contestation au Moyen Age, CTHS, Paris 1990, pp. 235-247.

${ }^{57}$ L.-J. Thomas, La sédition du 8 septembre 1381 à Béziers et la légende de Bernard Pourquier, «Bull. soc. Arch. Béziers», 1930, XLVII, pp. 5-40.
} 
En tous cas Vincent Challet propose que loin d'être le fait de marginaux, le tuchinat représente une forme extrême de la sociabilité méridionale. Le procès que Pons Biordon, cet anobli récent, receveur de la gabelle, acquéreur du château d'Aiguèze, intente contre les syndics de Bagnols sur Cèze met en scène le réseau de sociabilité organisé dans un rayon d'une trentaine de $\mathrm{km}$ autour de la bourgade. ${ }^{58}$ Les tuchins se sont emparés du grenier à sel de Pont-Saint-Esprit et ont mis à sac le château de Pons Biordon. Celui-ci accuse les syndics de complicité. Défilent de nombreux témoins et l'on voit notamment raconter que le blé, qui avait été entassé par Pons Biordon dans son château, reprit grâce aux tuchins le chemin des villages environnants. Marginaux rebelles? En tous cas, le vicomte de Turenne les considère comme des interlocuteurs à prendre en considération. Et ils ont des conseils avisés. Ce n'est qu'à la fin du mouvement que le pouvoir royal arrive à les harceler, à les couper de leur environnement social et à faire basculer les élites urbaines.

$\mathrm{Au}$ cœur des révoltes françaises du XIV $\mathrm{X}^{\mathrm{e}}$ siècle, je placerai donc des peurs diverses, peurs qui ont tendu, parfois à les rompre, les sentiments. Parfois celui de toute une ville ou de toute une région, tous milieux confondus. Plus souvent celui des menus. Les émeutes de Montpellier ${ }^{59}$ et de Béziers, deux villes proches, deux dates proches (1379 et 1381), le meurtre des officiers royaux dans l'une, emmenée par les consuls, le meurtre des consuls dans l'autre, autant dire qu'il est indispensable de prendre en compte l'importance des situations locales. Les «vieilles» révoltes serviles et les «nouveaux» conflits du travail voisinent dans ce paysage multiple.

A coup sûr le refus de la fiscalité constitue un ferment de violence, dans ce royaume où les dépenses somptuaires de certains princes et les mécomptes des guerres n'incitent pas à concevoir le royaume comme cadre politique de référence. La fidélité au roi certes, même s'il est mal conseillé, mais le patriotisme se vit à une échelle plus étroite. Parfois même très étroite, si l'on prend en compte les rivalités intenses entre villes voisines et même entre villages voisins qui constituent l'une des composantes majeures de l'espace politique.

Le désarroi semble profond, la colère contre une élite qui ne joue pas son rôle d'intermédiaire entre l'État et lui. ${ }^{60} \mathrm{Il}$ se peut aussi que même si les

${ }^{58}$ Vincent Challet qui a édité les actes du procès en annexe à sa thèse attire l'attention sur le fait qu'une partie en est perdue et qu'il ne reste que les témoins cités à comparaître par les syndics, donc les témoins à décharge.

${ }_{59}$ A. Germain, Une émeute populaire sous Charles $V$, «Académie des Sciences et des Lettres de Montpellier», 1847, pp. 39-66; S.K. Cohn, Lust cit., note 5, p. 98.

${ }^{60}$ B. Chevalier, Corporations cit., note 8, p. 37. 
révoltes ne semblent pas hors du tissu des solidarités, une partie des troupes de ces commotions urbaines soient nourries par une émigration rurale récente. Il se peut aussi que dans les villes comme dans les campagnes, il y ait une sorte d'incompréhension d'une évolution qui entame l'économie traditionnelle en faisant pénétrer plus profond les transactions financières, le crédit, les nouveautés, l'adaptation au marché.

Je finirai en laissant la parole à Michel Pintoin, le Religieux de SaintDenis, qui évoque la multiplicité des causes pour la révolte parisienne de 1380: le passage de la joie, due à l'avènement de Charles VI au mécontentement à cause du joug pesant des impôts; mais aussi un désir ardent de nouveautés, enfin une sorte de désarticulation du tissu social, discordes entre les générations (les jeunes et les vieux), entre les milieux (les grands, summi, et les petits, infimi). ${ }^{61}$

${ }^{61}$ B. Guenée, L'opinion publique à la fin du Moyen Age cit., note 12, p. 58. 



\section{Hipólito Rafael Oliva Herrer}

\section{RÉVOLTES ET CONFLITS SOCIAUX DANS LA COURONNE DE CASTILLE AU XIV ${ }^{\mathrm{e}}$ SIËCLE}

\section{Le processus de formation des Hermandades Générales}

D'une manière similaire au reste de l'Europe Occidentale, le XIV siècle a provoqué une augmentation des tensions sociales dans la Couronne de la Castille. S'il fallut attendre le $\mathrm{XV}^{\mathrm{e}}$ siècle pour trouver une révolte d'une extension semblable à celle de la Jacquerie ou du soulèvement Anglais en 1381, le contraste avec les régions de l'Europe du Nord n'est pas si grand. L'historiographie a en effet démontré l'existence d'une atmosphère générale de conflit social dans la Couronne de la Castille au Bas Moyen Âge, laquelle aboutit à un certain nombre de révoltes, bien que restreintes à une échelle locale. ${ }^{1}$

La toile de fond de cette crise, dont les manifestations commencèrent à être ressenties dès la deuxième moitié du XIII ${ }^{e}$, est constituée par le blocage du processus d'expansion territoriale de la Couronne de la Castille, la contraction démographique et la baisse du revenu seigneurial... C'est précisément dans la réaction aristocratique à l'affaiblissement de ses revenus que nous pouvons trouver l'un des facteurs d'intensification des tensions sociales. Les expédients utilisés par la noblesse pour reproduire sa domination sur le corps social sont variés: réapparition de formes de prélèvement déjà oubliées, usurpations et pratiques de violence désignés dans la documentation sous le terme de malfetrías, et enfin participation à la fiscalité d'État, par le biais du transfert des juridictions et des impôts. ${ }^{2}$

* Cet article a été rédigé dans le cadre du projet de recherche Espacio público, opinión y crítica política a fines de la Edad Media (HUM 2007-65750), financé par le Ministerio de Edución y Ciencia.

${ }^{1}$ Le tournant de l'historiographie sur le sujet est marqué par les travaux de Julio Valdeón, notamment J. Valdeón Baruque, Los conflictos sociales en el reino de Castilla en los siglos XIV y XV. Madrid 1975.

${ }^{2} \mathrm{~J}$. Valdeón Varuque, Reflexiones sobre la crisis bajomedieval en Castilla. La crisis del siglo XIV en Castilla, «En la España Medieval», 5, 1984, pp. 1047-1057 y La crisis del siglo XIV en la Corona de Castilla, Homenaje a Marcelo Vigil Pascual: la historia en el contexto de las ciencias humanas y sociales. Madrid 1989, pp. 217-236. 
Le deuxième facteur, qui n'est pas nécessairement contradictoire avec le premier, est le progrès du processus de centralisation du pouvoir monarchique. Si les révoltes antiseigneuriales ont contribué à renforcer le pouvoir de référence du roi, il est vrai également que les classes populaires cherchaient à imposer au roi un programme politique de nature plus contractuel, visant à contrôler ses prérogatives et à transférer une partie de son pouvoir à l'ensemble des villes.

La perspective chronologique du long XIV ${ }^{\mathrm{e}}$ siècle choisie pour ce colloque permet d'aborder quelques questions plus en détail. L'introduction de la notion de conflit dans le titre de mon exposé n'a rien d'innocent et je voudrais profiter de la souplesse de ce concept pour évoquer le phénomène des Hermandades Generales. Certes, l'action collective liée aux Hermandades n’a pas dégénéré en rébellion ouverte, mais le mouvement me semble comparable à d'autres émeutes contemporaines, la révolte des Tuchins par exemple, telle qu'elle a été étudiée par Vincent Challet. L'apparition des Hermandades Generales se produisit entre 1282 et 1325: il ne s'agit certes pas de la première occurrence d'associations assermentées sous le nom de Hermandad. En revanche, la véritable nouveauté réside dans la formation de grandes confédérations de villes aux buts strictement politiques.

Nous devons replacer la mise en fonctionnement de la Hermandad générale dans le contexte de la guerre civile qui se produisit après la révolte de l'infant Don Sancho contre le roi légitime, son père Alphonse X, en 1282. L'infant essaiera d'exploiter le mécontentement généralisé provoqué par le processus de centralisation politique, d'uniformisation juridique et de déploiement de l'appareil fiscal mené par son père. ${ }^{3}$

Au moment du soulèvement, se produisit une floraison de confédérations de divers genres afin d'appuyer la cause de l'infant D. Sancho: des confédérations nobiliaires, des confédérations de certains nobles avec quelques conseils municipaux...

Cependant, ce qui nous intéresse c'est le processus de formation des Hermandades Générales. ${ }^{4}$ Il s'agissait de fédérations réunissant un nombre

${ }^{3}$ Voir notemment à ce sujet M. González Jiménez, Alfonso X el sabio. Barcelona 1994, pp. 342-371.

${ }^{4}$ La bibliographie sur les Hermandades est très large. Les travaux generaux les plus relevants sont les suivantes: M. González Mínguez, Aproximación al estudio del movimiento Hermandino en Castilla y León, «Medievalismo», 1 et 2, pp. 35-55 et 29-53; Contribución al estudio de las Hermandades durante el reinado de Fernando IV de Castilla. Vitoria, 1974 et Poder y conflictos sociales. una visión desde la Historia del movimiento hermandino castellano, dans Conflicto, violencia y criminalidad en Europa y América. Bilbao 2004. J. M. Minguez, Las Hermandades Generales de los concejos de Castilla, dans Concejos y ciudades en la Edad Media Hispánica. II Congreso de Estudios Medievales. Madrid 1990, pp. 537-567. L. Suarez Fernandez, Evolución histórica de las Hermandades 
important des conseils municipaux ('concejos') du royaume. Certains nobles en faisaient également partie, mais ce dernier aspect ne doit pas nous abuser: le programme politique de la Hermandad obéit aux intérêts des conseils municipaux et se trouve dicté par ceux-ci.

La constitution de la Hermandad General commença par la formation de Hermandades regroupées par unités géopolitiques. La première dont nous avons connaissance est la Hermandad General de la Galice et du Léon. Quelques jours plus tard, fut instaurée la Hermandad de la Castille, composée de 65 conseils municipaux, qui devait fusionner avec la précédente. Quelques jours plus tard, la Hermandad d'Andalousie, ou de la frontière, fut aussi constituée. L'ensemble des Hermandades instituées par royaume finit par se regrouper et par aboutir à une organisation unifiée. ${ }^{5}$

Les différentes chartes de constitution des Hermandades présentent une certaine dépendance formelle et une coïncidence d'intérêts, qui montrent clairement qu'elles surgirent en vue de l'accomplissement des mêmes objectifs. En termes généraux, cette affirmation vaut aussi pour les futures confédérations de concejos et l'on peut même dire que les principes fédérateurs du programme Hermandino se trouvent déjà reflétés dans les premières chartes de Hermandad.

Il est certain que l'appui à l'infant Don Sancho obéissait au rejet de la politique centralisatrice d'Alfonso $\mathrm{X}^{6}{ }^{6} \mathrm{Il}$ en résulte que la première revendication était précisément la sauvegarde des fueros et libertades, c'est-à-dire le rejet du progrès d'un droit unifié sur le droit coutumier et les chartes de franchise locales; le refus de l'intervention de la justice royale dans la résolution des conflits à l'échelle locale; et enfin le refus de se soumettre à une fiscalité qui ne serait pas régulée par les corps législatifs locaux. ${ }^{7}$

Deuxièmement, la Hermandad s'organisa avec un compromis de défense et une assistance mutuelle des conseils municipaux qui essayèrent de contribuer à la restauration de l'ordre public. Elle posa de façon spécifique

castellanas, "Cuadernos de Historia de España», XVI (1951), pp. 5-78. Alvarez De Morales, A., Las Hermandades, expresión del movimiento comunitario en España. Valladolid 1974. Asenjo Gonzalez, M., Ciudades y Hermandades en la Corona de Castilla. Aproximación sociopolítica, «Anuario de Estudios Medievales», no 27 (1997), pp. 103146. Plus especifiques sont les études de J. I Ruiz De La Peña, La Hermandad leonesa de 1313, León Medieval. León 1978, pp. 141-164 et Garcia Fernandez, M. La Hermandad General de Andalucía durante la minoría de Alfonso XI de Castilla (1212-1325), «Historia, Instituciones, Documentos», 12, 1985, pp. 351-375. Pour un aperçu bibliographique plus profond on pourra se rapporter aux travaux de Cesar González Mínguez.

${ }^{5}$ C. Gonzalez Minguez, Aproximación al estudio del movimiento Hermandino, II, pp. 29-34.

${ }^{6}$ Cf. M. González Jiménez, Alfonso X el sabio cit., pp. 373-392.

${ }^{7}$ J. M. Minguez, Las Hermandades Generales de los concejos de Castilla cit., pp. 549-550. 
le problème de la réponse à apporter aux violences nobiliaires et alla jusqu'à légitimer l'autodéfense armée face aux agressions des nobles. ${ }^{8}$

En outre, les accords de constitution de la Hermandad General démontrent une nette volonté de subordonner les intérêts de la noblesse à ceux de l'ensemble des villes: par exemple, au moyen d'une disposition qui cherche à garantir que les offices les plus élevés de l'administration territoriale (mérinos et adelantados) soient réservés aux représentants des villes. ${ }^{9}$ Un dernier axe de réflexion, en connexion étroite avec cette prétention de subordination nobiliaire aux intérêts généraux, fut ouvert: la première Hermandad introduisit un argument novateur qui devait être amplement développé par les Hermandades suivantes, celui de la défense de l'intégrité du patrimoine royal. ${ }^{10}$

Malgré l'intervention, au cours de sa genèse, de l'infant insurgé, la Hermandad fit irruption en tant que force politique prétendant à une stabilité et à une autonomie face à l'autorité royale. L'organisation prévoyait toute une série de réunions annuelles convoquées à la fois par région et de manière à réunir l'ensemble des composantes du mouvement. Dans le même temps les représentants de l'association entretenaient un rapport étroit avec les représentants des villes au sein de l'institution des Cortes du royaume. ${ }^{11}$

En 1284, après le décès du roi Alphonse $\mathrm{X}$ et la reconnaissance de Sancho IV comme roi légitime, ce dernier attendit en vain la dissolution de la Hermandad. Bien au contraire, le mouvement ratifia sa vocation à la permanence et l'institutionnalisation avec une nouvelle réunion de l'ensemble des concejos convoquée à Medina del Campo. La peur de la force politique que l'ensemble des villes avait montrée dans le contexte de la guerre civile poussa bientôt le nouveau roi à précipiter la dissolution d'une institution dont il avait lui-même encouragé la création. ${ }^{12}$

La deuxième irruption de la Hermandad sur la scène politique se produisit précisément après la mort de Sancho IV en 1295. La minorité du nouveau roi Ferdinand IV déclencha les appétences nobiliaires et condui-

${ }^{8}$ Voir le texte de constitution de la Hermandad publiée par C. Gonzalez Minguez, Aproximación al estudio del movimiento Hermandino, II, p. 54-58, particulièrement, p. 55.

${ }^{9}$ Ibidem, p. 56.

${ }^{10}$ Ibidem, p. 54. Voir aussi J. M. Minguez, Las Hermandades Generales de los concejos de Castilla cit., pp. 563-567.

${ }^{11}$ Ibídem, p. 555.

${ }^{12}$ C. Gonzalez Minguez, Aproximación al estudio del movimiento Hermandino cit., II, 35 . 
sit le royaume à une nouvelle guerre civile. ${ }^{13}$ Dans ce contexte, la Hermandad commença à se reconstituer de façon spontanée, cette fois à la propre initiative des concejos, et la mère et tutrice du roi fut contrainte de chercher l'appui de l'organisation afin de faire face aux aspirations du prétendant au trône, l'infant don Juan. Dans un bref délai, furent constituées la Hermandad Générale du Léon et de la Galice, celle de la Castille, celle de Tolède et celle du royaume de Murcie. ${ }^{14}$ À côté de ce mouvement, on assista à l'émergence de toute une série de confédérations plus petites associant quelques conseils municipaux, qui respectaient néanmoins les accords acquis dans le cadre des Hermandades plus générales. En outre, quelques associations assermentées furent formées sous le nom de Hermandad dans une seule ville, à Cuenca par exemple. ${ }^{15}$ Ceci démontre jusqu'à quel point l'appel à la Hermandad pouvait fonctionner comme un élément de cohésion à l'intérieur des conseils municipaux, bien que les intérêts sous-jacents fussent parfois contradictoires.

Par rapport aux Hermandades précédentes, les fédérations qui surgirent à cette période témoignèrent d'un plus grand degré de stabilité institutionnelle: ainsi, une capitale fut fixée pour chaque Hermandad générale; de même, l'Hermandad se dota d'un sceau et chaque Hermandad se concevait comme une forme institutionnelle supérieure aux organismes qui la composaient et dotée de la capacité de faire respecter les accords qu'elle pouvait conclure à l'ensemble des membres de l'association. ${ }^{16}$

Certes, les divers Hermandades Generales ne parvinrent pas à articuler une plate-forme unitaire, mais, grâce à leur position de force face à la régente, elles obtinrent des transferts importants de pouvoir politique en direction des villes, ou plutôt, de ses élites dirigeantes. ${ }^{17}$

Le programme politique de la Hermandad se présente comme la défense de l'Honneur du roi, de son patrimoine et de ses droits et plus concrètement de l'exercice de la justice. ${ }^{18}$ Au travers de cette invocation, il est facile de percevoir une continuité marquée avec les objectifs déclarés des Hermandades précédentes: ainsi, la défense du droit local et du statu quo fiscal, de telle sorte que toute nouvelle imposition devait être approuvée

${ }^{13}$ Sur ce sujet voir C. González Mínguez, Fernando IV de Castilla: (1295-1312): la guerra civil y el predominio de la nobleza. Valladolid 1976.

${ }^{14}$ C. Gonzalez Minguez, Contribución al estudio de las Hermandades durante el reinado de Fernando IV de Castilla. Vitoria 1974.

15 A. Benavides. Memorias de Fernando IV de Castilla. Madrid, 1860, vol. II, Colección diplomática, p. 75.

${ }^{16}$ Ibídem, pp. 6 et 12 . II, p. 39.

${ }^{17}$ C. Gonzalez Minguez, Aproximación al estudio del movimiento Hermandino cit.,

${ }^{18}$ A. Benavides. Memorias de Fernando IV de Castilla cit., II, p. 4. 
par l'ensemble des villes avant de devenir légitime ${ }^{19}$; de même, la sauvegarde de l'ordre et de la justice trouve une application concrète dans toute une série de dispositions qui obligent les associés à réagir contre une quelconque agression violente. Cependant, il est assez révélateur de voir que les chartes de Hermandad définissent prioritairement les actes violents comme violence aristocratique et qu'elles légitiment aussi la réponse armée face à ce genre d'agression. ${ }^{20}$

À cet égard, il est intéressant de noter que l'Hermandad était perçue par les agents seigneuriaux comme une menace envers leurs propres intérêts. Ainsi, l'évêque de Tolède exprima sa crainte que l'intégration dans la Hermandad de certains concejos appartenant à sa seigneurie ne débouche sur une révolte armée contre son autorité. ${ }^{21}$

Quoiqu'il en soit, l'appui fourni à la régente permit à la Hermandad de se consolider comme une force politique dans l'ensemble du royaume et d'obtenir toute une série de concessions. Les diverses Hermandades furent reconnues officiellement par la régente quelques jours après sa genèse, lors des Cortes de Valladolid en 1295, où les délégués des villes furent seuls représentés. ${ }^{22}$

Outre cette reconnaissance et l'assurance de respecter les chartes de franchise et le droit local, la régente entérina lors de la réunion des Cortes le principe d'inaliénabilité du patrimoine royal et octroya une série de concessions au profit des élites des villes: l'exercice des offices principaux de la justice royale, dont la noblesse fut écartée, ainsi que l'affermage de la perception des impôts et la lieutenance des forteresses royales. ${ }^{23}$

La Hermandad se présente alors comme une institution politique solide qui, grâce à l'appui prêté à la régente, est parvenue à élargir son espace de pouvoir.

Trois ans plus tard, lors des Cortes de Cuellar, la Hermandad imposa la formation d'une commission de douze représentants des conseils municipaux afin d'accompagner de façon permanente le roi et de contrôler l'action politique de la régente. ${ }^{24}$

En 1302, un an seulement après avoir atteint sa majorité, Ferdinand IV accorda aux villes une confirmation générale de leurs privilèges et institu-

${ }^{19}$ Ibídem, pp. 4 et 6.

${ }^{20}$ Ibídem, p. 4.

${ }^{21}$ A. Benavides. Memorias de Fernando IV de Castilla. Colección diplomática cit., II, p. 38.

${ }^{22}$ Cortes de los antiguos reinos de León y de Castilla, publicadas por la Real Academia de la Historia. Madrid 1861. Vol. I, p. 132.

${ }^{23}$ A. Benavides. Memorias de Fernando IV de Castilla cit., p. 37.

${ }^{24}$ Cortes de los antiguos reinos de León y de Castilla cit., p. 135. 
tionnalisa définitivement les Hermandades, en reconnaissant la capacité des conseils municipaux de convoquer la assemblée des villes. ${ }^{25}$ Par ce biais, la monarchie leur octroyait une légitimité et reconnaissait la capacité des municipalités de se fédérer à volonté.

Cependant, la reconnaissance fut accompagnée du déclin inespéré de l'institution, laquelle coïncide aussi avec la fin de la guerre civile. On doit chercher la raison de ce déclin ailleurs que dans l'interruption des hostilités et plus concrètement dans la ratification du droit et des chartes de franchise locales, ainsi que dans les privilèges octroyés à la plupart des villes, en particulier les exemptions fiscales accordées en matière commerciale dont bénéficièrent les élites locales. Ces aiguillons semblent avoir suffi à encourager la décadence momentanée des Hermandades. ${ }^{26}$

Nonobstant, la renaissance du mouvement se produisit au bout de quelques années, avec en toile de fond, une nouvelle crise de succession. Après la mort de Ferdinand IV, en 1212, deux factions nobiliaires commandées respectivement par l'infant don Juan et par l'infant don Pedro appuyé par la grand-mère du roi et la régente, Marie de Molina, se disputèrent la garde du roi Alphonse XI, âgé d'un an seulement à cette époque. La situation fut utilisée par la noblesse pour lancer l'assaut contre le pouvoir en espérant une augmentation de ses revenus.

La première Hermandad fut constituée dans le royaume de Léon. ${ }^{27}$ Quelques concejos se rassemblèrent au sein d'une Hermandad dont la justification résidait dans «la défense du roi» et afin de «punir les vols, les morts et malfetrías qui se produiraient». ${ }^{28}$ La charte de Hermandad pointait directement l'aristocratie du royaume comme la cause des violences commises. ${ }^{29}$ Quelques jours plus tard, réapparut la Hermandad de Castille, et dans un bref délai celles de Galice, des Asturies, d'Estrémadure et d'Andalousie se reconstituèrent.

La nouveauté réside cette fois dans la participation de l'Hermandad à l'affrontement des factions nobiliaires. En 1313, certains conseils municipaux de l'Hermandad de León conclurent un accord avec l'un des prétendants au rôle de tuteur du roi, l'infant Don Juan, accord ratifié par la suite II, p. 41.

${ }^{25}$ C. Gonzalez Minguez, Aproximación al estudio del movimiento Hermandino cit.,

${ }^{26}$ Ibídem.

${ }^{27}$ Voir notemment à ce sujet Ruiz De La Peña, J. I, La Hermandad leonesa de 1313, dans León Medieval, León 1978, pp. 141-164.

${ }^{28}$ A. Martín Expósito et J. M. Monsalvo Antón, Documentación medieval del archivo municipal de Ledesma. Salamanca 1986, p. 49.

${ }^{29}$ Ibídem. 
par l'Hermandad de Castille. La participation à ces conflits partisans et la présence nobiliaire au sein de la Hermandad, apparemment contradictoire avec les principes exprimés dans la charte de constitution de la Hermandad de Léon, ont donné naissance à quelques interprétations qui soulignent la dénaturalisation des Hermandades en 1313, par rapport aux mouvements précédents, ainsi que leur instrumentalisation par les factions nobiliaires.

Il me semble que ce n'était pas le cas. Dans les premiers accords signés par les conseils municipaux avec l'infant Don Juan, ainsi que dans la ratification postérieure, réalisée au cours d'une assemblée des Hermandades de Castille et de Léon, toutes les composantes centrales du programme Hermandino se trouvent représentés: défense des intérêts locaux, restauration de l'ordre public ... et même compromis de défense mutuelle face aux manifestations de violence nobiliaire. ${ }^{30}$

Conscients du pouvoir du mouvement populaire, les différents candidats qui prétendaient contrôler le roi essayèrent d'attirer la faveur de la Hermandad. Pour l'ensemble des villes, l'accord passé avec ces prétendants n'est jamais qu'une voie transactionnelle permettant de faire avancer le programme politique des villes, auprès de la réunion des Cortes en 1313. Les dispositions approuvées par les Cortes sont clairement dépendantes du programme de l'Hermandad. Le résultat fut la ratification des principes établis en 1295 et plus encore, la définition de la priorité d'intervention de la justice locale sur les officiers de la justice royale. ${ }^{31}$

L'acmé du mouvement des Hermandades se produisit entre 1315 et 1317. Pendant les Cortes de 1315 se constitua la plus grande Hermandad, formée de 96 conseils municipaux de l'ensemble de la Couronne de la Castille et intégrée aussi par un certain nombre de nobles, qui essayèrent de se joindre à l'énorme force que représentait alors la Hermandad afin de contrôler l'action des tuteurs du roi, même si la charte de l'Hermandad regroupait une majorité d'éléments à forte coloration antinobiliaire. L'assemblée des villes se montre cette fois consciente de sa force et prétend médiatiser l'action politique des tuteurs du roi. ${ }^{32}$

La formation de la Hermandad est explicitement justifiée en tant que réponse à la violence nobiliaire et par la nécessité de garantir l'intégrité du

${ }^{30}$ Voir le texte de l'accord dans J. I Ruiz De La Peña, La Hermandad leonesa de 1313 cit, pp. 157-153.

${ }^{31}$ Ibídem, p. 152.

${ }^{32}$ C. Gonzalez Minguez, Aproximación al estudio del movimiento Hermandino cit., II, pp. 46-47. 
domaine royal et d'apporter un correctif au défaut de justice. ${ }^{33} \mathrm{Si}$ la Hermandad prétendait défendre la figure du roi, dans la pratique cependant, elle supplantait une partie de ses compétences et préparait l'intervention des villes dans l'action du gouvernement. Le même mouvement était financé par l'usurpation des recettes de la fiscalité royale. ${ }^{34}$

La charte de constitution de la nouvelle Hermandad établissait quelques dispositions destinées au contrôle des tuteurs du roi, des officiers de la justice royale et de la violence déployée par l’aristocratie, y compris la restitution des terres usurpées depuis la mort du roi Fernando IV. En outre, une organisation institutionnelle bien plus développée qu'auparavant fut mise sur pied: les compétences des juges de l'Hermandad furent fixées de façon précise et toute une série de réunions de l'Hermandad étaient prévues, à la fois à l'échelon des royaumes, à l'échelle régionale et pour l'ensemble de la fédération des concejos. ${ }^{35}$

La Hermandad s'était constituée avec une vocation d'institutionnalisation et de permanence. Deux ans plus tard, lors des Cortes de 1317, dont le caractère presque révolutionnaire a été maintes fois souligné, l'Hermandad fit approuver point par point le programme établi en 1315. ${ }^{36}$ Le programme de la Hermandad acquit force de loi et la confédération des villes fut reconnue comme l'une des institutions du royaume. L'intégrité du droit local fut reconnue et les officiers de la justice de l'Hermandad furent assimilés à ceux de la justice royale, leur primauté étant même établie dans certains cas.

La Hermandad était alors parvenue au sommet de son pouvoir et tout semblait indiquer que sa permanence était assurée. Mais la Hermandad ne réussit pas à maintenir sa cohésion et ne put éviter une certaine décomposition, jusqu'à sa disparition en 1325. Cette année-là, Alphonse XI décréta la dissolution des Hermandades sans rencontrer de véritable opposition de leur part. ${ }^{37}$

${ }_{33}$ Cortes de Burgos de 1315, dans Cortes de los antiguos reinos de León y de Castilla, publicadas por la Real Academia de la Historia. Madrid 1861, vol. I, p. 248.

${ }^{34}$ Comme il le montre une disposition postérieure des Cortes de Carrión de 1317. Cortes de Carrión de 1317, dans Cortes de los antiguos reinos de León y de Castilla cit., vol. I, p. 307.

${ }^{35}$ Cortes de Burgos de 1315 cit., pp. 249-261.

${ }^{36}$ Cortes de Carrión de 1317 cit., pp. 301-303.

${ }^{37}$ C. Gonzalez Minguez, Aproximación al estudio del movimiento Hermandino cit., II, p. 48. 


\section{La controverse de l'historiographie}

Jusqu'à présent, le récit du mouvement Hermandado que nous venons d'effectuer reste très consensuel et pourrait être accepté par la plupart des historiens de ce phénomène. Il s'agissait pourtant d'une institution complexe, parfois contradictoire, qui a provoqué chez les historiens des interprétations divergentes, lorsque ces derniers essayèrent de rendre compréhensible l'évolution du mouvement et d'interpréter son subit déclin.

L'historiographie de la Hermandad est déjà ancienne. Au début du siècle dernier, Julio Puyol a formulé l'interprétation la plus élaborée dans une perspective libérale. ${ }^{38}$ L'institution était vue à la fois comme l'instrument de l'opposition des villes à la noblesse, et comme l'un des antécédents des institutions représentatives.

En 1951, L. Suárez publia son étude sur la Hermandad et contribua à fixer la position qui fut longtemps l'interprétation dominante au sein de médiévistes engagés dans la célébration de l'absence de féodalisme dans la couronne de Castille. ${ }^{39}$

Pour Suárez, la Hermandad peut difficilement être considérée comme un instrument de confrontation antinobiliaire, dans la mesure où il faut tenir compte du caractère débonnaire de la noblesse castillane, et par conséquent, d'un type de domination difficilement comparable à celle du reste de la noblesse européenne.

Dans cette perspective, les Hermandades sont vues plus spécifiquement comme un instrument au service de la cause royale, surgissant en vue de la restauration de l'ordre public dans les moments de crise politique et destinées à disparaître une fois l'ordre rétabli.

Il me semble difficile d'accepter ce monarchisme inconditionnel de la Hermandad, surtout si l'on considère que sa première manifestation apparaît afin d'appuyer une révolte contre le roi légitime. De même, il est très difficile de nier la composante antinobiliaire, partie intégrante des Hermandades, que l'auteur rejette pourtant d'une façon systématique et qu'il étend aux Hermandades du $\mathrm{XV}^{\mathrm{e}}$ siècle. A cet égard, l'impression que le chroniqueur Galíndez del Castillo portait sur ces dernières est tout à fait ré-

${ }^{38}$ J. Puyol y Alonso, Las Hermandades de Castilla y León. Estudio histórico seguido de las Ordenanzas de Castronuño hasta ahora inéditas. Madrid 1912.

${ }^{39}$ L. Suarez Fernandez, Evolución histórica de las Hermandades castellanas, "Cuadernos de Historia de España», XVI (1951), pp. 5-78 et dans la même ligne A. Alvarez de Morales, Las Hermandades, expresión del movimiento comunitario en España, Valladolid 1974. 
vélatrice, lorsqu'il mettait en exergue que «les populaires ... avaient pensé subjuguer complètement la noblesse du royaume avec l'Hermandad». ${ }^{40} \mathrm{Il}$ est vrai aussi que cette composante antinobiliaire s'insère dans un ensemble d'aspirations et d'intérêts très souvent contradictoires.

Depuis 1975, les historiens d'orientation marxiste ont repris et reformulé l'interprétation d'inspiration libérale. Marqué par les travaux de R. Hilton et E. Hobsbawn, Julio Valdeón, interprète les Hermandades comme des institutions créées pour la sauvegarde des intérêts des conseils municipaux, qui devaient bientôt servir à canaliser l'attitude populaire de résistance face à la violence et aux usurpations déployées par l'aristocratie du royaume, laquelle n'était jamais qu'une réponse au déclin de ses revenus, fruit d'une crise structurelle. ${ }^{41}$

Plus attaché à la conceptualisation marxiste, Salustiano Moreta interprète les Hermandades comme le résultat des alliances conjoncturelles et transitoires entre les villes et la fraction non hégémonique de la noblesse, ces deux groupes partageant l'objectif d'affronter la violence aristocratique et chacun d'eux essayant de matérialiser un ensemble d'intérêts plus exclusifs. ${ }^{42}$

L'un des apports les plus intéressants à ce débat provient de J. M. Mínguez, qui a démontré la forte relation existant entre la Hermandad et les intérêts des élites urbaines. La défense des ordonnances juridiques locales face au déploiement centralisateur monarchique est directement liée à la défense d'une structure qui aurait permis leur consolidation à la tête des villes, et donc, la sauvegarde de leur parcelle de pouvoir. ${ }^{43}$

La dernière analyse du phénomène est produite par César González Mínguez, qui partage l'idée de la primauté des élites urbaines dans le développement du mouvement. Il considère les Hermandades comme un mouvement essentiellement conservateur, qui envisage la défense des or-

${ }^{40}$ J. Torres Fontes, Estudio sobre la Crónica de Enrique IV del Dr. Galíndez de Carvajal. Murcia 1946, pp. 261-262.

${ }^{41}$ J. Valdeón Baruque, Los conflictos sociales en el reino de Castilla en los siglos XIV y XV, Madrid 1975, pp. 67-72 et plus récemment Id., Resistencia antiseñorial en la Castilla medieval, dans El chivo expiatorio. Judios, revueltas y vida cotidiana en la Edad Media, Valladolid 2000, pp. 133-160.

${ }^{42} \mathrm{~S}$. Moreta Velayos, Malhechores feudales. Violencia, antagonismos y alianzas de clases en Castilla. Siglos XIII- XIV, Madrid 1978.

${ }^{43}$ Minguez, J. M., Las Hermandades Generales de los concejos de Castilla, dans Concejos y ciudades en la Edad Media Hispánica. II Congreso de Estudios Medievales, Madrid 1990, pp. 537-567. 
donnances juridiques locales. Créées dans les moments d'instabilité politique, elles seraient une réaction au déploiement de violence aristocratique et à toute forme de violence, sans remettre en cause les structures sociales de domination. ${ }^{44}$

\section{Quelques réflexions pour la contextualisation des Hermandades}

Etablir le caractère conservateur du mouvement Hermanado est plutôt le résultat d'une pratique historiographique à la marge des propres préoccupations et des intérêts manifestés par les participants au mouvement. D'une part, l'Hermandad aspirait à se consolider comme une force politique. D'autre part, l'émergence des Hermandades se produisit dans un contexte de violence nobiliaire répandue, si bien que la possibilité d'un glissement vers une confrontation ouverte avec l'aristocratie était extrêmement forte.

Dans les années troublées où les Hermandades firent leur apparition, une série de révoltes antiseigneuriales se produisirent également, en particulier dans certaines villes de seigneurie épiscopale: Santiago, Orense, Lugo, Palencia... Ici, les affrontements plus ou moins habituels suscités par l'élection des officiers au sein des institutions locales, ont déclenché des soulèvements armés des villes contre la seigneurie, lesquels se sont aussi propagés aux campagnes proches. ${ }^{45}$

Cette attitude trouve un certain appui dans l'Hermandad, dont les représentants prirent parfois la parole pour les défendre lors des réunions des Cortes, face à la réponse apportée par la justice royale. ${ }^{46}$

De même, on peut constater que l'apparition d'une nouvelle Hermandad était perçue comme une menace par les agents seigneuriaux, qui témoignaient de leur méfiance face à l'incorporation à la fédération de concejos appartenant à leurs seigneuries respectives. Parfois, la formation de la Hermandad provoqua en réaction l'apparition de groupes nobiliaires constitués pour la défense de leurs intérêts, à l'instar de la Hermandad

${ }^{44}$ C. Gonzalez Minguez, Aproximación al estudio del movimiento Hermandino en Castilla y León, "Medievalismo», 1 et 2, 1991 et 1992 pp. 35-55 et 29-53; Id. Contribución al estudio de las Hermandades durante el reinado de Fernando IV de Castilla, Vitoria 1974 et plus récemment Id. Poder y conflictos sociales. Una visión desde la Historia del movimiento hermandino castellano, dans Conflicto, violencia y criminalidad en Europa y América, Bilbao 2004, pp. 36-37.

${ }^{45}$ Voir infra.

${ }^{46}$ Par exemple les émeutes à la ville de Lugo Cortes de Carrión de 1317, dans Cortes de los antiguos reinos de León y de Castilla, publicadas por la Real Academia de la Historia. Madrid 1861, vol. I, p. 310. 
d'évêques apparue en 1313, qui est une réponse directe aux Hermandades créées cette même année. ${ }^{47}$

Les alliances des conseils municipaux avec certains nobles avaient un caractère purement conjoncturel et étaient interprétées de façon différente par les secteurs distincts de la société municipale. ${ }^{48}$ Par exemple, l'accord établi entre quelques conseils municipaux de la Hermandad de Léon et l'infant don Juan, déclencha un soulèvement populaire dans la ville de Zamora à l'occasion de l'entrée en ville des membres de l'élite locale qui avaient signé le compromis. ${ }^{49}$

Loin de se comporter comme un ensemble homogène, les villes sont à leur tour la scène d'une série de tensions qui opposent aux élites le reste de la société urbaine. A cette époque, les élites ont déjà consolidé leur position de supériorité dans la société politique locale. Elles contrôlent de facto les institutions locales et profitent en même temps des exemptions fiscales. ${ }^{50}$ De ce fait, cette scission provoqua au cours de cette période et dans les années suivantes quelques révoltes populaires dans des villes comme Cordoue ou Ubeda.

Le déroulement de ces émeutes n'est pas très connu, parce que les références que nous offrent les chroniqueurs à ce sujet sont parfois assez laconiques. A Cordoue, le petit peuple se souleva contre l'oligarchie locale en 1307, et la révolte fut finalement étouffée grâce à l'intervention royale. Quelques années après, ces émeutes se reproduisirent à cause de l'élection des officiels locaux et le petit peuple profita des conflits partisans dans l'ensemble du royaume. Plus précisément il chercha le soutien du prétendent, l'Infant Don Juan Manuel, pour contrecarrer l'appui octroyé par le régent à l'élite locale. Dans la même ligne, une révolte populaire se produisit à Ubeda contre l'élite locale dans les premières années du règne de Alphonse XI. ${ }^{51}$

${ }^{47}$ J. I. Ruiz de la Peña, Las ciudades de señorío eclesiástico y los conflictos por el control del gobierno local (1252-1350), dans Conflictos sociales, políticos e intelectuales en la España de los siglos XIV y XV, Logroño 2004, p. 142.

${ }^{48}$ Sur le caractère conjoncturel des alliances entre Hermandades et aristocratie est très éclairant l'étude sur l'Hermandad leonesa de 1313 de J. I. Ruiz De La Peña, La Hermandad leonesa de 1313, dans León Medieval, León 1978, pp. 141-164.

${ }^{49} \mathrm{~J}$. Valdeón Baruque, Los conflictos sociales en el reino de Castilla en los siglos XIV y XV cit., p. 69.

${ }^{50}$ Sur ce sujet voir J. M. Minguez, La transformación social de las ciudades y las Cortes de Castilla y León, dans Las Cortes de Castilla y León en la Edad Media. León 1988, V. II, pp. 15-43 et M. González Jiménez, Las Cortes de Castilla y León y la organización municipal, Ibidem, pp. 351- 375.

${ }^{51}$ J. Valdeón Baruque, Los conflictos sociales en el reino cit., pp. 27-75. 
La défense du droit coutumier et des réglementations locales par les élites est par la suite liée à la sauvegarde d'un espace de pouvoir et à la reproduction d'une structure sociale qui les avait placé à la tête des villes.

Il est certain que les élites locales pouvaient percevoir la violence nobiliaire comme une menace, dans la mesure où elle était aussi projetée sur les municipes qui appartenaient au patrimoine royal, et ceci même si leur intérêt se rattachait fondamentalement au maintien de leur propre position privilégiée. Cela contribue fortement à expliquer, par exemple, la lente décadence des Hermandades après les privilèges octroyés par Fernando IV, aussi bien que l'absence d'opposition lorsque Alfonso XI décida de les dissoudre en 1325. A cette époque-là, on commençait déjà à entrevoir la politique développée par le roi dans les années suivantes et qui visait à consacrer la position de privilège des élites à la tête de la société urbaine, par le biais de l'institutionnalisation des offices locaux. ${ }^{52}$

Cependant, le caractère antinobiliaire des Hermandades constituait à la fois un fort facteur de cohésion à l'intérieur de la société urbaine et un vecteur de mobilisation dans les campagnes, que les membres des élites locales étaient prêts à ranimer à condition qu'il ne constitue pas un obstacle au maintien de leur position privilégiée. Il est significatif que, durant la période d'activité des Hermandades Generales, aient été constituées, à des fins strictement défensives, des confédérations plus petites associant quelques conseils municipaux à des situations très concrètes de brigandage et de violence nobiliaire. ${ }^{53}$

Il est vrai que les intérêts des élites contribuèrent au déclin rapide de l'Hermandad. Rien, pourtant, ne nous autorise à le définir comme un mouvement essentiellement conservateur. L'Hermandad fut capable de peser de tout son poids dans la sphère politique, d'articuler un appareil institutionnel et même d'organiser des réponses armées face aux agressions subies par ses membres.

Loin d'être un mouvement de restauration de l'ordre, l'Hermandad suppose l'irruption dans la société politique du programme des villes. Si les villes respectent la légitimité fondatrice de la royauté, elles n'en cherchaient pas moins à redéfinir ses compétences. Elles aspiraient à institutionnaliser

52 J. M. Minguéz, Las Hermandades Generales de los concejos de Castilla, dans Concejos y ciudades en la Edad Media Hispánica. II Congreso de Estudios Medievales Madrid 1990, p. 566.

${ }^{53}$ Par exemple entre les concejos de Oviedo et Grado, en 1309: I. Ruiz de la Peña, Las ciudades de señorío eclesiástico y los conflictos cit., p. 142. D’autres exemples sont donnés par S. Moreta Velayos, Malhechores feudales. Violencia, antagonismos y alianzas de clases en Castilla. Siglos XIII-XIV, Madrid 1978. 
l'assemblée des concejos comme force politique et à opérer une redistribution du pouvoir favorable aux villes.

Dans cette perspective, il me semble que l'Hermandad reste comparable à des émeutes plutôt contemporaines, comme le Tuchinat, bien que l'Hermandad n'ait pas débouché sur une révolte armée: on y trouve en effet des thèmes semblables tels que l'appel à la défense du roi et le dépouillement pratique de ses attributions.

Le programme politique des villes ne disparut pas avec le déclin des Hermandades. Bien au contraire, il devait s'exprimer par la suite à l'occasion de plusieurs réunions des Cortes en 1387 et 1442 et ressurgir une fois les Hermandades reconstituées en 1464. Il en demeura alors à la fois les objectifs politiques et les thèmes fédérateurs: la défense du roi et de son patrimoine et la restauration de la justice. ${ }^{54}$

\section{Les soulèvements dans les villes de seigneurie épiscopale}

Dans le même contexte d'insécurité et d'affrontements dans l'ensemble du royaume qui a facilité l'irruption des Hermandades dans la sphère politique, il faut placer les conflits qui éclatant dans les villes de seigneurie épiscopale déjà mentionnés. Les situations les plus violentes se produisirent dans les villes de Palencia, Saint Jacques de Compostelle, Lugo et Orense où les habitants avaient pris les armes contre la seigneurie. Mais les affrontements se reproduisirent à moindre échelle dans les autres villes de seigneurie ecclésiastique un peu partout, et les moyens employés furent la résistance passive, le refus au paiement des rentes et le rejet des officiels de la seigneurie. ${ }^{55}$

A Palencia, l'affrontement entre ville et seigneur se déroule entre 1280 et 1315. Il s'agit d'une longue séquence de conflits dont les enjeux furent l'élection des officiels du concejo et le contrôle de la fiscalité locale. Nonobstant, la prétention maximaliste des habitants de Palencia n'était que la suppression de la seigneurie et l'appartenance de la ville au patrimoine

${ }^{54}$ Sur le programme politique des villes, voir B. González Alonso, Rey y reino en los siglos Bajomedievales, dans Conflictos sociales, políticos e intelectuales en la España de los siglos XIV y XV. Logroño 2004, pp. 147-164. Sur la formation des Hermandades Generales au XV $\mathrm{XV}^{\mathrm{e}}$ siècle, voir J. L. Bermejo, Hermandades y Comunidades de Castilla, «Anuario de Historia del Derecho Español», LVIII (1988), pp. 277-412 ainsi que J. Valdeón Baruque, Los conflictos sociales cit., pp. 167-174.

${ }^{55}$ Une revision generale dans J. I. Ruiz de la Peña Solar, Las ciudades de señorío eclesiástico y los conflictos por el control del gobierno local (1252-1352), dans J. I. De la Iglesia Duarte (Ed.), Conflictos sociales, políticos e intelectuales en la España de los siglos XIV y $X V$, Logroño 2004, pp. 113-146. 
de la Couronne. ${ }^{56}$ Dans le contexte de guerre civile dans le royaume, le concejo essaya de s'approcher du régent pour contrecarrer le pouvoir épiscopal, mais le soutien qu'elle a octroyé aux aspirations de l'évêque déclencha par deux fois des émeutes dans la ville, en 1296 et en 1300, et une tentative de meurtre du seigneur. Si l'intervention d'une partie de l'élite locale, craintive quant à la radicalisation du conflit craintive quant à la a permis de désactiver la révolte à ce moment-là, quelques années plus tard, ce furent les mêmes élites locales qui dirigeaient la révolte générale de la ville, en 1315. Cette année-là, la pression exercée par l'évêque sur la municipalité provoqua la révolté armée encouragée par ceux qui avaient contenu les rages citoyennes auparavant. Finalement, la collaboration royale fait suffoquer la révolte.

Cette opposition entre les différentes couches de la population urbaine est plus difficile à percevoir dans le soulèvement de la ville de Saint Jacques de Compostelle. Après une_longue série de d'affrontements entre le concejo et la seigneurie épiscopale, le conflit se rouvrit en 1318, lorsque la ville se souleva contre la seigneurie en profitant des difficultés politiques dans l'ensemble du royaume et plus précisément le procès de succession dans le siège archiépiscopal. ${ }^{57}$

La révolte s'étendit aussi aux campagnes proches et ne fut étouffée que deux ans après, lors de la conquête par l'archevêque du château de Roche Bone, qui contrôlait l'accès à Santiago, en 1320. Ses dirigeants appartenaient à l'élite locale avec le concours de certains membres de l'aristocratie régionale galicienne, élément fédérateur du rejet de la seigneurie sur la ville et de la demande d'appartenance au domaine royal. Si la monarchie, par le biais du régent, commença par encourager les demandes citoyennes, elle finira par basculer et collaborer avec la restauration de la seigneurie de l'archevêque.

Finalement, les événements à Lugo ne semblent pas si différents, même si les évidences dont nous disposons sont plus limitées. Autour de l’année 1300, les habitants avaient occupé la forteresse épiscopale et usurpé les symboles de la seigneurie. Leur résistance à l'autorité de l'évêque se maintiendra pendant douze ans. ${ }^{58}$

${ }^{56}$ Conflit etudié en detail par A. Esteban Recio, Palencia a fines de la Edad Media. Una ciudad de señorío episcopal, Palencia 1989, pp. 154-166.

${ }^{57}$ E. Portela et M. C. Pallares, De 'Gelmírez' a los Irmadiños. Conflictos sociales en la ciudad de Santiago, dans C. Estepa Díez et C. Jular (Eds.), El camino de Santiago: Estudios sobre peregrinación y sociedad, Madrid 2000, pp. 117-23.

${ }^{58}$ E. Portela et J. García Oro, La iglesia y la ciudad de Lugo en la baja Edad Media. Los señoríos. Las instituciones Los hombres, Santiago de Compostela 1997, p. 276. 
Bref, toutes les révoltes urbaines dans les villes épiscopales révèlent une situation similaire: la guerre civile devient la scène appropriée pour l'émergence des aspirations des villes à se libérer de la dépendance seigneuriale, mais la restauration du pouvoir royal et de l'ordre rendirent sa défaite inévitable.

\section{La deuxième moitié $d u X V^{e}$ siècle}

On ne trouve pas de mouvements d'une semblable envergure dans la deuxième moitié du siècle. Le compromis d'aide mutuelle de l'ancienne Hermandad de Léon fut ponctuellement invoqué en 1350 par le concejo de Valencia de Don Juan pour faire face à la pression de l'évêque de León. ${ }^{59}$ Quelques années plus tard, certains conseils municipaux asturiens constituèrent une Hermandad pour s'opposer aux prétentions du comte de Noreña, dont le pouvoir était hégémonique dans cette zone, en particulier pour rejeter quelques formes de prélèvement considérées comme abusives. ${ }^{60}$

L'appel à la Hermandad restait potentiellement subversif. Nonobstant, il faudra attendre 1431, pour rencontrer un soulèvement au nom d'une Hermandad à une échelle régionale: il s'agit de la première guerre Irmandiña, au sud de la Galice. ${ }^{61}$

La caractéristique de la deuxième moitié du XIV ${ }^{\mathrm{e}}$ réside ailleurs, dans une succession de conflits qui ne débordent pas l'échelle locale et qui oscillent entre des formes de résistance indirecte, le recours aux tribunaux royaux et la révolte ouverte. La résistance à l'expansion des puissants semble être l'élément commun.

La guerre civile entre 1366 et 1369 suivie de l'arrivée au pouvoir et de l'arrivée au trône de la dynastie Trastámara introduisit quelques modifications. L'aristocratie profita si bien de cet affrontement pour consolider sa position privilégiée que ce changement dynastique a pu être défini comme l'événement qui avait permis à la noblesse de surpasser la crise de reproduction de l'ensemble des relations sociales. ${ }^{62}$

Par la suite, s'opéra une accélération du processus de transfert des rentes et du patrimoine royal à l'aristocratie qui devait engendrer toute une

${ }^{59}$ J. I. Ruiz de la Peña, La Hermandad leonesa de 1313, dans León Medieval, León 1978 , pp. $162-164$.

${ }^{60}$ E. Benito Ruano, Hermandades en Asturias durante la Edad Media, Oviedo 1972.

${ }^{61}$ En tout ce qui concerne les révoltés Irmandiñas au XV $\mathrm{XV}^{\mathrm{e}}$ siècle, voir C. Barros, Mentalidad justiciera de los Irmandiños, siglo XV, Madrid 1990.

62 J. Valdeón Varuque, Reflexiones sobre la crisis bajomedieval en Castilla La crisis del siglo XIV en Castilla, «En la España Medieval», 5, 1984, pp. 1047-1057. 
série de résistances surtout dans les villes et villages qui comptaient une longue tradition d'appartenance au domaine royal. Le refus d'accepter la nouvelle dépendance seigneuriale conduisit très souvent à des révoltes, et parfois même à l'assassinat du nouveau titulaire de la seigneurie.

Les exemples en sont variés: Molina, Agreda, Sepulveda, Baena, Feria, Zafra, la Parra, Paredes de Nava. Je n'ai pas le temps ici d'entrer dans tous les détails mais je voudrais souligner quelques aspects.

L'exemple le plus emblématique est celui de Paredes de Nava, un village de la Castille qui appartenait traditionnellement au domaine royal et donné par le roi Enrique II au noble aragonais Felipe de Castro en 1366. Ses demandes de rentes en 1371 déclanchent une révolte villageois, l'aboutissement fut le meurtre du seigneur et la répression postérieure du soulèvement. ${ }^{63}$

Dans la plupart des cas, la résistance des 'concejos' ne fut pas suffisamment effective et l'opposition des villes fut écrasée par les armes: c'est le cas, par exemple, de Feria, Zafra et La Parra ${ }^{64}$ Nonobstant, il est possible de trouver aussi des exemples contraires, par exemple à Agreda. Une fois donnée la ville par le roi Enrique III à Juan Hurtado de Mendoza en 1395, ses habitant prirent les armes pour empêcher le nouveau seigneur d'entrer dans la ville. Etant donnée la situation stratégique de cette ville frontalière, la résistance a finalement provoqué la révocation de la donation royale. ${ }^{65}$

Un dernier exemple intéressant est offert par quelques villages des Montagnes de León, au nord de l'Espagne. Trois ans après la constitution de la seigneurie par donation royale à l'aristocrate Pedro Suarez de Quiñones en 1396, les villages résistaient encore à l'autorité du nouveau seigneur. La confirmation de la validité de la donation obligea cependant les concejos à changer de stratégie et à exploiter la voie judiciaire. C'était le début d'une longue série de procès qui se prolonge pendant tout le XV siècle. ${ }^{66}$

En somme, les situations et les résultats sont variés mais, d'une manière générale, on peut trouver quelques éléments similaires: Tout d'abord, une fois la révolte écrasée, l'affrontement ne s'éteint pas mais, au contraire, se

${ }^{63} \mathrm{~J}$. Valdeón Baruque, Movientos antiseñoriales en Castilla en el siglo XIV, dans El chivo Expiatorio. Judios, revueltas y vida cotidiana en la Edad Media, Valladolid 2000, pp. 210-212.

${ }^{64}$ Ibídem, pp. 216-218.

${ }^{65}$ Ibídem, pp. 219-221.

${ }^{66}$ Voir l'analyse détaillée de P. Garcia Cañón, Concejos y señores. Historia de una lucha en la montaña occidental leonesa a fines de la Edad Media, León 2006. 
prolonge dans le temps d'une manière sourde et sous diverses formes qui cherchent à redéfinir le contenu concret des attributions seigneuriales.

Ensuite, ces épisodes sont fondateurs d'une mémoire sociale, nourrie pendant des générations, qui va stimuler longtemps après plusieurs tentatives de renversement de la situation, que ce soit par la voie judiciaire, pendant la période des Rois Catholiques ou par la voie armée, en profitant de la révolution des Comunidades de Castille, en 1520. ${ }^{67}$

J'espère que ces quelques exemples contribuent à ratifier l'impression que l'exceptionnalité de la Couronne de Castille par rapport au reste de l'Occident européen n'existe pas, la seule différence étant le degré et l'extension de ces révoltes.

${ }^{67}$ Je me permets de renvoyer à mes propres travaux, H. R. Oliva Herrer, Justicia contra señores. El mundo rural y la política en tiempos de los Reyes Católicos, Valladolid 2004. 



\section{GiovanNi CHERUBini}

\section{L'ITALIA}

Nel contesto della storia europea del XIV secolo l'Italia si distingue per alcune importanti, ben note (soprattutto quella che scoppiò a Firenze nel 1378) rivolte di lavoratori impegnati nella manifattura laniera, mentre, al contrario, il paese, anche per le sue divisioni politiche e le conseguenti diversità negli assetti di potere delle campagne rispetto ai paesi europei (il discorso vale soprattutto per l'Italia del centro e del nord), non conobbe grandi ed estese rivolte di contadini. Non si ebbero insomma grandi, sanguinose ed estese sommosse da paragonare alla jacquerie francese del 1356 e alla rivolta inglese del 1381. Di conseguenza non si possiedono, neppure ora, studi ampi e numerosi che si siano posti esplicitamente il problema, e quando tra la fine del 1990 e l'inizio del 1991 fui incaricato di organizzare una pubblicazione sull'argomento, alla quale, per motivi finanziari, non si affiancò, come era stato previsto, un apposito convegno, mi trovai in qualche imbarazzo nel mettere insieme un gruppo qualificato e appassionato di studiosi, per quanto la storiografia italiana sul mondo rurale del Medioevo fosse diventata ormai adulta. Diverso invece il caso delle sommosse dei lavoratori della lana, alle quali ho ora accennato, che nel 1378 trovarono il loro teatro nella grande ed avanzata Firenze, ed otto anni prima nelle meno grandi, ma pur rilevanti città di Siena e di Perugia. Si può anzi sin da ora anticipare, che per questo aspetto l'Italia centro-settentrionale mostra tutta la sua modernità nelle strutture sociali e nei rapporti di lavoro, o se si vuole tutti i nuovi problemi di un mondo urbano in cui si era nettamente affermato il lavoro salariato, e si manifestavano i primi conflitti tra datori di lavoro e operai, i segni palesi di una prima affermazione del capitalismo. Questa novità, diversamente che per il precedente caso dei rivoltosi o dei contestatori contadini, ha invece attirato da tempo l'interesse degli studiosi, e l'osservazione vale ovviamente, in primissimo luogo e quasi esclusivamente, per la rivolta fiorentina, per la quale si dispone anche di una serie di fonti, narrative o documentarie, abbastanza numerose, e di una serie di studi di studiosi appartenenti a paesi ed orientamenti ideologici molto diversi, fra i quali non sono mancati ovviamente, in periodo di «guerra 
fredda», né studiosi americani, né studiosi sovietici, entrambi tuttavia convinti, al di là delle diverse interpretazioni, che in quella Firenze del Trecento venissero vissute le prime manifestazioni di una società capitalistica o borghese.

Aggiungo tuttavia subito che né le rivolte o la sorda contestazione contadina, né le esplosioni dei lavoratori della lana possono essere ricondotte e spiegate, come pur si è fatto in passato, soltanto attraverso l'esame del conflitto sociale tra padroni e lavoratori, delle condizioni di lavoro o di altro argomento di questa natura, ma che esse debbano essere più o meno ampiamente collegate a tutto ciò che la grande tragedia demografica del XIV secolo significò anche per queste vicende. Fortunatamente la ricerca è andata, per questo aspetto, molto più avanti di quanto non fosse trenta, quaranta o cinquant'anni fa. Ho vissuto, anche personalmente, le vicende di questa storiografia, come studioso e come docente, e ne avverto ancora il fascino, per quanto da un certo tempo io mi sia allontanato da questi temi, pur tenendoli in conto sul piano della riflessione e dell' informazione bibliografica. Negli anni accademici 1969-70, 1970-71, 1971-72, secondo le nuove formule di insegnamento emerse come risposta alla contestazione studentesca della «lezione cattedratica», tenni tre seminari rispettivamente dedicati a La Peste Nera (1347-50) ${ }^{1}$, a La rivolta dei «ciompi» di Siena (1371), a La rivolta inglese del 1381, che sensibilizzarono, tra l'altro, il sottoscritto oltre che i suoi studenti a temi di ricerca insieme italiani ed europei e si concretizzarono, nei primi due casi, anche nella ciclostilatura, opportunamente organizzata e rivista, delle relazioni dei diversi gruppi di iscritti, che circolarono così, sia pure in un ambito ristretto, ma mi parve apprezzate, al di là del piccolo ambito del seminario. Da queste esperienze e correlate con queste esperienze, oltre che grazie alle indagini dirette dedicate soprattutto, ma non soltanto, alla società contadina e ai rapporti tra il mondo rurale e quello urbano, nacquero anche una serie di altre mie incursioni in questo campo di studi, basate insieme sia sulla riflessione che sulle conoscenze accumulate. La prima, che non produsse, per la verità, nessun mio pubblico intervento scientifico, divulgativo o informativo, salvo, se ben ricordo, una intervista televisiva, riguardò la preparazione di un Convegno fiorentino sulla rivolta dei ciompi del $1378^{2}$. L'idea venne all'amico Charles Marie de La Roncière, che pensò con me ad un possibile

${ }^{1} \mathrm{Mi}$ è stato poi chiesto, a distanza di molti anni, di riprendere il tema sul piano della storiografia, con il saggio La peste nera: l'accertamento storiografico, in AA. VV., La peste nera: dati di una realtà ed elementi di una interpretazione, Spoleto 1994, pp. 383-402.

${ }^{2}$ AA. VV., Il tumulto dei Ciompi. Un momento di storia fiorentina ed europea, Firenze 1981. 
comitato scientifico e mi pregò di illustrare l'idea al Comune di Firenze, come puntualmente feci ottenendo una risposta affermativa. Il Comitato fu costituito da Ernesto Sestan, Nicolai Rubinstein, Thony Molho, Hidetoshi Hoshino, Bruno Dini, ed il sottoscritto (La Roncière rifiutò recisamente, con uno scrupolo fuori del comune, di farne parte perché, da lontano, non avrebbe, a suo giudizio, potuto essere utile). Il Comitato lavorò, pensò ai titoli e ai relatori, ma poi scomparve stranamente nel volume degli Atti, apparsi nel 1981, che non furono, per la verità, editi dal Comune di Firenze.

Nel 1984 e 1985, quasi a coronamento di un ciclo di conoscenze e di interessi specifici, pubblicai due saggi generali, insieme di interpretazione e di informazione bibliografica, intitolati rispettivamente I lavoratori nell'Italia dei secoli XIII-XV: considerazioni storiografiche e prospettive di ricerca, e Artigiani e salariati nelle città italiane del tardo Medioevo, che mi sembrano ora, anche più di quanto già mi sembrassero in passato, appartenere allo stesso interesse per le rivolte sociali ${ }^{3}$. Nel 1991 parlai, a Bari, presso l'Accademia Pugliese delle Scienze, di Movimenti e sommosse popolari del XIV secolo, in realtà limitandomi a descrivere, dopo alcune considerazioni generali ed uno sforzo di contestualizzazione e di spiegazione, le tre più note rivolte di quel secolo, vale a dire la jacquerie del 1356, il tumulto dei ciompi del 1378 e la rivolta inglese del 1381. Nel 1992 tenni ad una delle Settimane di Estella, in Navarra, una relazione su I lavoratori fiorentini della lana fra solidarietà di mestiere e primo capitalismo ${ }^{4}$.

Ricordo infine più diffusamente, dopo averne soltanto accennato all' $i$ nizio, quello che fu l'ultimo mio impegno in questo settore di studi, ma non più in direzione delle rivolte sociali cittadine, anzi dei lavoratori cittadini della lana, ma piuttosto dei sommovimenti sociali in ambito rurale, per i quali avevo sempre provato un forte interesse, sotto la suggestione, oltre che di quello che ero venuto scoprendo o non scoprendo, attraverso i miei studi, sulle campagne italiane, anche sotto la suggestione delle grandi rivolte europee che già a grandi linee conoscevo. Ricostruisco i contorni dell' iniziativa, oltre che sul filo della memoria, sulla base di alcune lettere, un volantino, una serie di appunti ${ }^{5}$. Fui incaricato di valutare la possibilità

${ }^{3}$ I due saggi furono rispettivamente editi in AA. VV., Artigiani e salariati: il mondo del lavoro nell'Italia dei secoli XII-XV, Pistoia 1984, pp. 1-26, e in AA. VV., Aspetti della vita economica medievale, Atti del Convegno di studi nel X Anniversario della morte di Federigo Melis, Firenze 1985, pp. 707-727. Li ho entrambi ripubblicati nel mio Il lavoro, la taverna, la strada. Scorci di Medioevo, Napoli 1997, pp. 7-54.

${ }^{4}$ AA. VV., Cofradías, gremios, solidaridades en la Europa Medieval, XIX Semana de estudios medievales, Estella '92, Pamplona 1993, pp. 101-111. Ora riedito in G. Cherubini, Il lavoro, la taverna, la strada, cit., pp. 55-66.

${ }^{5}$ Grazie soprattutto non alla mia scarsa precisione ma ad una preziosa cartellina conservata da Gabriella Piccinni, che fece parte del gruppo di studiosi che partecipa- 
di mettere in piedi una pubblicazione ed eventualmente e prioritariamente un Convegno dall'Istituto Alcide Cervi di Roma sui Movimenti e rivolte contadine nell'Italia del Medioevo. Se il Convegno poi non si tenne, per insorte difficoltà finanziarie, l'insieme degli studi andò invece a costituire il n. 16 degli «Annali» dell'Istituto, datato 1994 (Protesta e rivolta nell'Italia medievale). Del febbraio del 1991 è una mia prima lettera ai potenziali collaboratori, del marzo successivo una riunione operativa presso l'Istituto, del novembre 1995 è l'uscita effettiva del volume, che fu presentato a Spoleto, a fianco della Settimana di studi del Centro di Studi sull'alto Medioevo nell'aprile dell'anno successivo. Il clima storiografico in cui l'iniziativa nacque non mi sembrava dei migliori. Avevo in effetti osservato al Convegno della Società degli storici italiani tenutosi ad Arezzo all'inizio di luglio del 1986, tracciando un profilo per molti altri aspetti positivo, e avevo poi ribadito, tre anni dopo, nel testo scritto, che nella storia agraria, o anche nella storia agraria italiana erano avvertibili una serie di rischi, come l'eccesso del descrittivismo, la difficoltà a gerarchizzare i fenomeni o ad identificare il gioco delle cause e degli effetti, il progressivo ed ingiustificato abbandono della conoscenza e della pratica dei fatti giuridici $^{6}$. Ma proprio quel clima storiografico che mi pareva poco favorevole mi spinse naturalmente ad accettare la responsabilità dell'impresa. Non me ne pentii e non ne sono pentito neppure ora. Intanto è possibile, ma non sta a me giudicare, che quella piccola avventura sulle Rivolte abbia rafforzato in più d'uno la convinzione di praticare un terreno d'indagine degno di studio e di attenzione. Proprio da costoro, o da un gruppo di costoro Cortonesi, Montanari, Piccinni, Andreolli, Licinio, Pinto - è nato il Centro di studi di Montalcino per la storia delle campagne e del lavoro contadino, che ogni anno tiene una sua stabile settimana di incontro, un suo «Laboratorio internazionale di storia agraria». Si tratta di un importante, operosissimo momento di riflessione e di discussione, aperto anche a studiosi non italiani. Nel 2003 questa riflessione e questa discussione sono state dedicate proprio a Conflitti sociali e rivolte contadine nell'Europa medievale, quasi a confermare, in una società ed anche in un mondo degli

rono all'iniziatiava rispondendo ad un mio questionario, o con una successiva relazione congressuale, o con l'uno e l'altro impegno. Riprendo da quella cartellina i nomi di Bruno Andreolli, Daniele Andreozzi, Sante Bortolami, Giorgio Chittolini, Raffaele Colapietra, Alfio Cortonesi, Rosa Maria Dentici Buccellato, Barbara Fois, Jean-Claude Maire Vigueur, Massimo Montanari, Roberta Mucciarelli, Maria Grazia Nico Ottaviani, Gabriella Piccinni, Claudio Regni, Giovanni Riganelli, Giovanni Vitolo.

${ }^{6} \mathrm{G}$. Cherubini, La storia dell'agricoltura fino al Cinquecento, in AA. VV., La storiografia italiana degli ultimi vent'anni, I, Antichità e Medioevo, Roma-Bari 1989, pp. 333-354. 
studi che pare aver dimenticato, qualche volta, che la storia umana, insieme a tesori di solidarietà, di amicizia, di giustizia e di fratellanza, esibisce anche la sua spietata durezza $\mathrm{o}$, se si preferisce, l'oggettivo conflitto tra chi più ha e chi meno ha, tra chi prevarica e chi deve subire, che lo studio del conflitto sociale è in definitiva una doverosa e giustificata conquista della conoscenza del mondo.

Ricordo infine che nel corso di quella esperienza collettiva promossa e sostenuta dall'Istituto Alcide Cervi furono discussi problemi di grande rilevanza e furono offerti contributi importanti, per noi sfortunatamente soltanto in parte utilizzabili in questa sede, perché non tutti centrati sul XIV secolo o anche sul XIV secolo, che qui in particolare ci interessa. Utili ci sono invece, oltre alla mia breve premessa al numero già ricordato degli «Annali», la perspicace conclusione di Jean-Claude Maire Vigueur, Per una periodizzazione delle lotte contadine nell'Italia medievale, ed i saggi di Massimo Montanari, Conflitto sociale e protesta contadina nell'Italia altomedievale; di Bruno Andreolli, Per una campionatura delle rivolte cittadine e rurali nel Trentino medievale; di Sante Bortolami, Lotta e protesta contadina nel Veneto dal Medioevo alla prima età moderna: un bilancio; di Daniele Andreozzi, La rivolta contadina del 1462 nell'episcopato di Piacenza; di Maria Grazia Nico Ottaviani, Sistemi cittadini e comunità rurali nell'Umbria del Due-Trecento; di Giovanni Riganelli, Rivolte contadine e borghi franchi in area perugina nel Duecento; di Claudio Regni, Fiscalità cittadina e comunità rurali: Perugia secoli XIV e XV; di Alfio Cortonesi, Rivendicazioni contadine e iniziativa antisignorile nel tardo Medioevo. Testimonianze dal Lazio meridionale; di Roberta Mucciarelli e Gabriella Piccinni, Un'Italia senza rivolte? Il conflitto sociale nelle aree mezzadrili; di Giovanni Vitolo, Rivolte contadine e brigantaggi nel Mezzogiorno angioino; di Raffaele Colapietra, La rivolta contadina del 1370 [nel territorio dell'Aquila]; di Barbara Fois, Protesta, processi, ribellioni e fughe di servi nelle campagne della Sardegna giudicale (secc. XII-XIV). Aggiungo doverosamente a questo elenco almeno il saggio di Rinaldo Comba, Rivolte e ribellioni fra Tre e Quattrocento ${ }^{7}$, uscito più o meno intorno allo stesso periodo ed opera di uno studioso accomunato ai precedenti per il suo interesse verso la storia rurale e più in generale verso la storia sociale.

Non è mia intenzione, né mi sembra indispensabile riassumere in questa sede le molte considerazioni ed i molti dati offerti in questo complesso di studi. Mi limito perciò soltanto a qualche considerazione molto generale. La prima conferma, quasi ce ne fosse stato bisogno, che l'Italia del centro-

${ }^{7}$ Edito in La Storia. Il Medioevo, 2, Popoli e strutture politiche, a cura di N. Tranfaglia e M. Firpo, Torino 1986, pp. 673-691. 
nord, anzi, più particolarmente, l'Italia dei comuni, l'Italia dominata dalle città sembra non conoscere $\mathrm{o}$ appena intravedere, nel corso del XIV secolo, il fenomeno della rivolta contadina. È possibile, come ho più indietro accennato, che a questo contribuisse la ristrettezza territoriale di quegli stati urbani (a questo e per questo settore non contrastava, in misura ancora decisiva, il potere ampiamente sovracittadino della sede papale), ma si può forse più generalmente osservare, sulla scia di questi studi, che, sia dove fosse già in via di consolidamento il fenomeno della conduzione mezzadrile della terra, sia dove si fosse almeno ridotto il potere dei signori nelle forme più tradizionali, le città, attraverso il reticolo del loro potere nelle campagne - giurisdizionale, militare, economico, civile, ecclesiastico - fossero ormai riuscite ad instaurare un forte controllo sugli uomini, sulle terre e sulle comunità. Ma è opportuno avanzare subito alcune considerazioni di contorno, vale a dire la novità rappresentata dalla metà del secolo in poi ed anche un po' prima dalla decongestione demografica conseguente all'esplosione, anzi alle ripetute esplosioni della peste nera dopo quella del ' 48. La non egualitaria falcidia di vite umane prodotta dall'epidemia, che colpiva, secondo fu detto da qualcuno, in modo classista, mise nelle mani dei contadini sopravvissuti un nuovo e potente strumento di contrattazione del proprio lavoro, o per attenuare i censi tradizionali ed accentuare la libertà delle terre e delle persone, oppure, quando il contadino fosse ormai diventato un mezzadro, per spostare a danno dei padroni della terra il compito di fornire gli animali e le sementi. Ma anche osservando poi, più in generale, che il conflitto tra padroni e contadini, per niente venuto meno né del tutto irretito da un rapporto paternalistico, si era ormai spostato o stava spostandosi, generalmente, sulla ripartizione dei prodotti e sulla appropriazione contadina, attraverso il furto dei prodotti, continuato e difficilmente controllabile dal proprietario o dai suoi agenti. Su questa appropriazione ci informa per prima, con parlanti espressioni e lontana dall'essere o dall'essere soltanto un gioco letterario, una certa e diffusa satira anticontadinesca o ciò che comunque ne scrivono più direttamente $\mathrm{i}$ padroni.

Di tono completamente diverso e se di vuole più tradizionale è quello che risulta per il regno meridionale in età angiona, cioè per il Mezzogiorno continentale. A prima vista - ed è possibile che del fatto si debba in qualche misura almeno tener conto - il regno sembrerebbe, per la sua estensione e l'unitarietà della sua documentazione, poca o molta che ne sia rimasta, il luogo adatto per far emergere un'altra Italia, un'Italia segnata dalle rivolte e dalla protesta. Ed in effetti questa pare essere stata la realtà, ma tuttavia con l'indispensabile correttivo che nel paese non si ebbero grandi rivolte, nessuna spontanea o coordinata insurrezione che coinvol- 
gesse, temporaneamente, interi complessi regionali o sub-regionali, paragonabile, per intendersi alla jacquerie francese del 1356 o alla rivolta inglese del 1381, ma si verificarono piuttosto, almeno sin verso la metà del Trecento, puntuali e fittissime esplosioni in questo o quel castello, contro questo o quel signore, più di una volta accompagnate dall'uccisione di qualche ufficiale $o$ anche del potente locale. In definitiva una manifestazione di quel ribellismo connesso con la società feudale, così come lo sciopero è connesso con la società capitalistica, di cui parlò Marc Bloch. Alla rivolta si accompagnava più di una volta, nel Mezzogiorno, l'abbandono non consentito delle terre da parte dei contadini, lo spostamento in altre aree più accoglienti per l'uno o per l'altro motivo, ma anche la presenza di un brigantaggio endemico, che traeva insieme alimento dalle condizioni sociali e dalle caratteristiche dell'ambiente e della difficile viabilità, oltre che dalla commistione tra partecipazione o sua utilizzazione da parte dei baroni. Tuttavia anche nel Mezzogiorno la grave crisi demografica di cui ho già detto qualcosa pare avere allentato, come sembrano dimostrare i primi decenni del XV secolo, le tensioni più fitte e più forti.

Diversamente che per le rivolte contadine l'Italia del XIV secolo, o meglio sarebbe dire l'Italia comunale del XIV secolo, si distingue, fra tutti i paesi europei, per un gruppetto di rivolte cittadine, più precisamente di rivolte, di tumulti, di insurrezioni dei lavoratori appartenenti al settore laniero. Non solo sul piano sociale, ma anche sul piano politico. Come ho già anticipato queste si verificarono, nel 1371, nelle due città di Perugia e di Siena e, nel 1378, nella ben più grande città di Firenze. Fra le tre rivolte quella che ha da tempo e di gran lunga attirato il maggior numero di studi e di approfondimenti è la rivolta fiorentina, meglio nota come tumulto dei «ciompi». Mentre delle altre due, oltre al noto volume, di taglio generale, di Victor Rutenburg, Popolo e movimenti popolari nell'Italia del '300 e del '400, edito a Mosca-Leningrado nel 1958 e tradotto in italiano nel $1971^{8}$, che ne parla per l'intero capitolo III, trattarono rispettivamente, nel 1910 e nel 1907, su una nota rivista tedesca, due saggi del Broglio D’Ajano', ed ha trattato di recente, per l'insurrezione senese, in un breve ma puntuale saggio, Franco Franceschi ${ }^{10}$. Per la rivolta fiorentina, della quale è stato in-

${ }^{8}$ Bologna 1971.

${ }^{9}$ R. Broglio d'Ajano, Lotte sociali a Perugia nel secolo XIV, e Tumulti e scioperi a Siena, «Vierteljahrschrift für Sozial und Wirtschaftsgeschichte», VIII (1910) e V (1907), poi rifusi nel volume Lotte sociali in Italia nel secolo XIV, Roma 1911.

${ }^{10} \mathrm{~F}$. Franceschi, La rivolta di Barbicone, in AA. VV., Storia di Siena, I, Dalle origini alla fine della Repubblica, a cura di R. Barzanti, G. Catoni, M. De Gregorio, Siena 1995, pp. 291-300. 
dagato anche il ricordo e le sue evoluzioni nel tempo ${ }^{11}$, sono stati invece molto numerosi gli studi, illuminati e sostenuti, fra l'altro, da cospicue ricerche sull'industria laniera della città, sull'organizzazione di quella produzione, sulle condizioni materiali e giuridiche dei lavoratori di quel settore e sull'intero contesto di quell'ampia porzione della società cittadina che le fonti indicano come "popolo minuto». Ricordo a questo proposito almeno sei opere, il volume di Alfred Doren, del 1901, sul lanificio della città ${ }^{12}$, il volumetto di Niccolò Rodolico, del 1899, sul «popolo minuto» ${ }^{13}$, una parte di un grosso volume di Federigo Melis (in realtà un libro nel libro), che ricostruisce con il corredo delle cifre il sistema della manifattura della lana ${ }^{14}$, il volume di Hidetoshi Hoshino sul commercio della lana e il mercato dei panni ${ }^{15}$, il volume di Sam Cohn sulle classi lavoratrici fiorentine ${ }^{16}$, infine lo splendido volume di Franco Franceschi sui lavoratori dell'arte dopo il tumulto del 1378, pubblicato nel 1993, che costituisce un autentico modello di storia sociale, caratterizzato da una non frequente convivenza, nelle sue pagine, tra la sicurezza dell'interpretazione sociale, la duttilità delle indagini, l'informazione sul continuo rinnovamento degli studi ${ }^{17}$.

Per la storia del tumulto fiorentino le ricerche -non tutte le richiamosono altrettanto numerose e significative, a cominciare almeno dal volume di Niccolò Rodolico, del $1945^{18}$, che nelle pagine di prefazione esamina quello che se n'era sino ad allora scritto. Seguono la maggior parte delle pagine del volume di Victor Rutenburg, e l'altro ricordato volume di Atti del Convegno fiorentino del 1981, che trattò del tumulto nel contesto della storia fiorentina, parlando di ciompi, salariati, produzione laniera, sistema corporativo, delle vicende della città, del regime politico dopo la rivolta, dei livelli di vita dei cittadini, del ricordo della rivolta nel corso dei secoli, infine dei movimenti popolari europei nella seconda metà del Trecento. L’ultimo importante contributo è stato quello di Alessandro Stella su La ré-

${ }^{11}$ E. Sestan, Echi e giudizi sul tumulto dei ciompi nella cronistica e nella storiografia, in AA. VV., Il tumulto dei ciompi, cit., pp. 125-160.

${ }^{12}$ A. Doren, Die Florentiner Wollentuchindustrie vom 14. bis zum 16. Jahrhundert. Ein Beitrag zur Geschichte des modernen Kapitalismus (vol. I degli Sudien aus der Florentiner W irstschaftgeschichte), Stuttgart 1901.

${ }^{13}$ N. Rodolico, Il popolo minuto. Note di storia fiorentina (1343-1378), Bologna 1899, $2^{\mathrm{a}}$ ediz. con presentazione di Ernesto Sestan, Firenze 1968.

${ }^{14}$ F. Melis, Aspetti della vita economica medievale (Sudi nell'Archivio Datini di Prato), Siena-Firenze 1962. parte V, L'industria laniera (pp. 453-729).

${ }^{15} \mathrm{H}$. Hoshino, L'arte della lana in Firenze nel basso Medioevo. Il commercio della lana e il mercato dei panni fiorentini nei secoli XIII-XV, Firenze 1980.

${ }^{16}$ S. K. Cohn Jr. Laboring Classes in Renaissance Florence, London 1980.

${ }^{17}$ F. Franceschi, Oltre il «Tumulto». I lavoratori fiorentini dell'Arte della Lana fra Tre e Quattrocento, Firenze 1993.

${ }^{18}$ N. Rodolico, I ciompi. Una pagina di storia del proletariato operaio, Firenze 1945. 
volte des ciompi. Les hommes, les lieux, le travail, edito a Parigi nel 1993, che combina insieme ampie valutazioni quantitative e, come spesso è avvenuto negli studi, una calda simpatia per i rivoltosi. Una simpatia che ritroviamo, su piano europeo, in un ampio e più recente volume collettivo edito a Parigi nel 2002 e frutto di un Congresso internazionale tenuto tre anni prima a Montréal, in Canada, nel quale, per la verità, l'oggetto dell' indagine è più ampio, perché costituito dal «menu peuple», dal «popolo minuto», o da realtà sociali indicate con espressioni simili ${ }^{19}$. Lo segnalo anche perché in quel volume è contenuto un breve intervento di Alessandro Stella dedicato ai ciompi, ed animato dallo stesso spirito di cui ho detto, ma nel quadro degli intenti generali del Congresso di definire e precisare le condizioni materiali e sociali del «menu peuple» ${ }^{20}$.

Della rivolta fiorentina mi pare sia opportuno ricordare più di un aspetto e più di una specificità. Intanto essa conobbe anche qualche precedente manifestazione da parte dei lavoratori, prima fra tutte quella che ebbe per teatro, nel 1345, affollatissime assemblee e per protagonista lo scardassiere Ciuto Brandini, finito sul patibolo per aver tentato, alla guida dei suoi compagni di lavoro, di dar vita ad una «fratellanza» capeggiata da consoli e «capitudini» e finanziata con una tassa di immatricolazione, così come facevano le altre arti della città, «affinché essi potessero più fortemente resistere a tutto». Il giudice che lo condannò non risparmiò le espressioni di esecrazione e di odio verso di lui e verso i suoi simili, ma le solidarietà di mestiere si erano ormai pienamente sviluppate fra i lavoratori nei luoghi di lavoro, come risulta anche dai sentimenti che si diffusero tra costoro al momento della cattura di Ciuto. Questa presa di coscienza appare ormai dispiegata nel tumulto del 1378 , sia sul piano della valutazione delle condizioni di lavoro da parte dei ciompi sia su quello dei diritti politici, da cui i lavoratori della lana erano esclusi perché membri passivi dell'arte relativa, che accoglieva invece i datori di lavoro, in un contesto istituzionale basato proprio sulle arti. I ciompi, ribellandosi, chiesero perciò congiuntamente di avere una propria arte - ne vennero concesse tre, due delle quali accolsero lavoratori di condizione un po' più elevata e non tutti impegnati nel lanificio -, di poter contare su una produzione minima di panni, di essere pagati non più in moneta continuamente sottoposta alla svalutazione (i lanaioli vendevano invece le stoffe prodotte contro i solidissimi fiorini d'oro, lucrando in tal modo a danno dei lavoranti), di non

${ }^{19} \mathrm{AA}$. VV., Le petit peuple dans l'Occident médiéval. Terminologies, perceptions, réalités, a cura di P. Boglioni, R. Delort, C. Gauvard, Paris 2002.

${ }^{20}$ Ivi, pp. 145-152, A. Stella, "Ciompi ... gens de la plus basse condition ... crasseux et dépenaillés”: désigner, inférioriser, exclure. 
dover più sottostare all'odiato ufficiale forestiero nominato dall'Arte, come a dire dai padroni, per i giudizi relativi alle questioni di lavoro.

Mi basta accennare soltanto a queste generalissime questioni, perché altri e con più competenza di me parlerà della rivolta in questo convegno. Aggiungo soltanto due altre considerazioni. La prima che riguarda l'illusione dei rivoltosi, di tipo ancora medievale e corporativo, ed almeno all'inizio, di poter conciliare, all'interno del governo, attraverso una sua composizione che tenesse conto delle diverse categorie sociali in campo, $\mathrm{i}$ differenti e contrapposti interessi sociali. La seconda riguarda invece la quantità dei lavoratori coinvolti. Su una popolazione cittadina, che era allora scesa a forse 55.000 abitanti, la prima nuova arte, che organizzava i ciompi, annoverava, secondo un cronista, 9.000 uomini, le altre due, quelle dei farsettai e dei tintori, complessivamente altri 4.000 uomini: una massa di lavoro imponente se si considera l'ipotetico totale dei fiorentini maschi in età da lavoro.

Resta da avanzare qualche ipotesi sulle cause del tumulto, se non ci si accontenta, come non ci si accontenta più, della sobillazione iniziale, e si può immaginare interessata, di Salvestro dei Medici. Sul piano strutturale si può osservare che la novità del lavoro all'interno dell'Arte della Lana, caratterizzato da consistenti fasce di salariato e dalla possibilità di emersione di una presa di coscienza della propria condizione di lavoro e di sfruttamento in mezzo ai lavoratori, e di una connessa solidarietà di mestiere, si accompagnò, come è stato ricostruito da qualche autore, una presa d'atto sempre più chiara da parte dei lavoratori -autore ed amplificatore ne fu, come è stato osservato, qualche predicatore- di una loro nuova condizione di «poveri», non i poveri tradizionali volontari delle scelte religiose e morali, ma i nuovi e differenti poveri prodotti dal lavoro, anzi dalle condizioni disumane del lavoro. Ma c'è ancora dell'altro. È difficile infatti non vedere, nella sommossa dei ciompi e nella chiarezza, per quanto in larga misura ingenua, dei loro obbiettivi, una combinazione, da un lato, tra la loro condizione di fondo, la loro, per quanto parziale, presa di coscienza, l'emergere della loro solidarietà, e dall'altro della congiuntura, del modificarsi del mercato, del gioco e degli effetti della crisi demografica, della condizione politica della città, in un insieme di spinte e di controspinte sulle quali sarebbe ancora opportuno indagare, ma che sembra difficile ignorare. Di tutto questo fornì un appassionato e complesso esame Charles-Marie de La Roncière nella sua grande thèse -grande per ampiezza e per tematiche e grande per risultati- nell'ormai lontano 1975, dalla quale, nel 1982, fu tratta la parte relativa a Prix et salaires à Florence au XIV e siècle (1280-1380). Essa terminava proprio con una impegnata Conclusion générale dedicata al «tumulto dei ciompi nella congiuntura economica», che ora mi sforzo di riassumere bre- 
vemente. La domanda centrale è se l'evoluzione dei prezzi e dei livelli di vita abbia giocato un ruolo nella maturazione e nell'esplosione della crisi. L'elemento centrale del malore dei ciompi, di cui ho già detto qualcosa, viene identificato nella loro subordinazione professionale e nella loro soggezione politica. Ma altre preoccupazioni emergono, come l'indebitamento o la svalutazione della moneta piccola, di cui ho detto, o l'iniquità della fiscalità cittadina, il livello della produzione, i salari. Si tratta di un malessere che non era limitato ai ciompi, ma che coinvolgeva anche le arti minori, allargando in tal modo il possibile fronte della protesta.

Dopo aver osservato che le lamentele e i timori dei lavoratori, ciompi ed altri, non avevano nulla di eccezionale per il mondo degli umili, lo studioso francese nota tuttavia che il settore del salariato si era ormai molto allargato nelle città europee e che aveva visto peggiorare la sua condizione nel corso del XIV secolo, attraverso un restringimento progressivo della condizione economica dei lavoratori (a Parigi, nelle Fiandre, a Perugia, a Siena, e altrove). Questo peggioramento si accompagnava a qualche contropartita, prima fra tutte quella dell'innalzamento dei salari, soprattutto dei salari reali. A Firenze, dopo il 1348, essi fanno un salto enorme, e questo fatto crea una evidente contraddizione con il peggioramento della posizione dei salariati di fronte ai datori di lavoro. Ma a peggiorare decisamente la situazione venne poi un deterioramento a breve termine, iniziato nel 1375 e legato alla guerra dei fiorentini contro il pontefice. La produzione delle stoffe subisce un calo sensibile, la crisi nell' impiego dei lavoratori, non ostante l'esplosione di peste del 1374, minaccia il loro lavoro. Il costo della vita cresce e soprattutto il grano raggiunge nel 1375 un prezzo di fame. Il valore del fiorino aumenta in relazione con la moneta piccola. La stessa guerra contro il pontefice, così strettamente legata alle cose della religione, pare fatta apposta per inquietare le coscienze, ed è comprensibile che i fedeli disorientati finiscano per rivolgersi a predicatori marginali e infiammati. Lo scontento è dunque palese, tra il 1375 e il 1378, ma non tutto pare accordarsi con l'esplosione della rivolta dei lavoratori della lana. È possibile che la nuova ripartizione dell' imposta abbia scontetato gli umili, mentre il giudizio appare più ipotetito su altri piani. In definitiva si può forse pensare piuttosto ad influenze puramente congiunturali e di natura diversa nell'esplosione del tumulto, in primissimo luogo riconducibili alla vita materiale dei salariati. In definitiva a creare il clima del tumulto, dopo un buon numero di anni di salari in aumento e di migliori condizioni di vita dei lavoratori, sarebbe stato il mutamento della congiuntura, che faceva avvertire più pesantemente l'allontanarsi delle cose a cui costoro si erano ormai abituati. E a questa osservazione molte altre Charles Marie de La Roncière ne aggiunge sulle idee che pare circolassero nelle loro teste, sul- 
l'influsso di qualche predicatore, su molto altro ancora, che non intendo qui diffusamente riassumere.

Vorrei piuttosto concludere, riprendendo alcune osservazioni già fatte, che il movimento dei ciompi non sarebbe stato affatto un movimento rivoluzionario. I programmi elaborati dai rivoltosi nel luglio e nell'agosto del 1378 restano limitati, perché chiedono, per gli operai della lana, soltanto una partecipazione al potere, senza pensare a toglierlo a chi ne disponeva. I rivoltosi mostrarono anzi un chiaro desiderio di collaborazione, e le loro condizioni economico-sociali di salariati e la nuova povertà di cui presero coscienza grazie alla predicazione del domenicano Taddeo Dini, se contribuirono a scatenare la sommossa, contribuirono forse anche a frenarla. Attraverso il predicatore essi compresero infatti di essere i veri poveri e di avere il diritto ad esigere giustizia sulla terra, tuttavia senza spingersi a soppiantare i ricchi. Tutto quello che ho sin qui detto, pur che non si pretenda di giudicare una rivolta del Trecento con gli occhi della rivoluzione d'Ottobre, mi pare che ponga bene in risalto la modernità di quegli avvenimenti e la necessità di continuamente affinarne la comprensione. 


\section{LES RÉVOLTES URBAINES EN ALLEMAGNE AU XIV ${ }^{e}$ SIÈCLE: UN ÉTAT DE LA QUESTION}

Longtemps l'historiographie allemande sur les révoltes, comme beaucoup d'autres, a été dominée par une approche phénoménologique et événementielle, pour ne pas dire impressionniste, des épisodes troublés. Cette méthode cherchait avant tout l'établissement d'une typologie fondée tantôt sur les lieux, tantôt sur la gravité, ou bien sur la nature des participants, les objectifs, les meneurs, la taille des villes, la durée, la nature des revendications ${ }^{1}$... Il est évident que ces approches ont donné naissance à autant d'interprétations différentes et, conséquemment, de terminologies différentes, pour qualifier la révolte. L'allemand dispose de ce point de vue de plusieurs termes tels que "Aufstand», "Aufruhr», "Auflauf», "Unruhe», assez proches des mots que l'on trouve dans les sources de l'époque rédigées en langue vernaculaire (des mots en vieil-allemand, notons-le, à la fois plus nombreux et plus neutres qu'en latin). Mais on rencontre également des notions modernes construites par les historiens telles que «Bürgerkampf», «Konflikt», "Auseinandersetzung» développées et employées essentiellement chez les spécialistes d'histoire urbaine ${ }^{2}$ tandis que la «Revolte» tendait à se réduire à la qualification des mouvements remettant en cause les autorités de l'Eglise et de la royauté comme ce fut le cas, pour les historiens, pendant la crise hussite en Bohême par exemple ${ }^{3}$.

${ }^{1}$ Pour un survol historiographique, consulter l'article "Aufruhr» par Wilfried Ehbrecht dans le Lexikon des Mittelalters, t. 1, 1977, col. 1206-1207 et l'article «Bürgerkämpfe, städtische» par Id., Lexikon des Mittelalters, t. 2, 1981, col. 1046-1047. Voir également: Alfred Haverkamp, Innerstädtische Auseinandersetzungen und überlokale Zusammenhänge in deutschen Städten während der ersten Hälfte des 14. Jahrhunderts, dans Reinhard Elze, Gina Fasoli (dir.), Stadtadel und Bürgertum in den italienischen und deutschen Städten des Spätmittelalters, Berlin 1991, pp. 89-126.

${ }^{2}$ Peter Blickle, Unruhen in der ständischen Gesellschaft 1300-1800, München 1988, p. 7 et suiv., Eberhard Isenmann, Die deutsche Stadt im Spätmittelalter 1250-1500, Stuttgart 1988, pp. 191-198.

${ }^{3}$ Sur ce point, voir l'article «Revolution» par Jörg Fisch et Neithard Bulst (pour la partie Mittelalter) dans les Geschichtliche Grundbegriffe. Historisches Lexikon zur politisch-sozialen Sprache in Deutschland, dir. par Otto Brunner, Werner Conze, Reinhart Koselleck, Stuttgart, rééd. 2001, vol. 5, pp. 670-689. 


\section{Classements}

Plusieurs typologies ont ainsi successivement vu le jour, et cela d'autant plus que deux historiographies se trouvaient entraînées dans un dialogue sur le sujet, celle de l'Allemagne de l'Ouest et celle de l'Allemagne de l'Est' Chez l'une comme chez l'autre, pour expliquer les révoltes qui secouent les villes de l'Empire au XIV ${ }^{\mathrm{e}}$ siècle comme au siècle suivant, se croisent et s'entremêlent, selon les modèles interprétatifs, les causes issues de mouvements messianiques et eschatologiques (liées ou non aux massacres des Juifs ou moment de l'irruption de la Peste Noire et aux processions des Flagellants; liées ou non aux déchirements de l'Église à la suite du schisme pontifical, particulièrement dans les cités épiscopales), ou bien les facteurs déclenchant issus de protestations sociales, fiscales et salariales, émanant de réactions aux crises conjoncturelles (disettes, pestes, guerres), ou encore nés des revendications politiques pour le partage du pouvoir en ville. À cette approche de nature causaliste ont pu se superposer des approches plus mécanistes d'un côté, plus descriptives d'un autre, plus institutionnelles enfin au sens d'une Verfassungsgeschichte allemande qui jouit, aujourd'hui encore, d'un large écho et d'une légitimité fondée sur de réels résultats que sont venues récemment renouveler la prise en compte et l'intégration des considérations de la culture politique, de l'idéologie et de l'identité urbaines, des rituels et des normes tant pour ce qui est du règlement des conflits que pour la production discursive par les textes écrits ${ }^{5}$. Ainsi a-ton pu tenter de faire le départ entre des révoltes planifiées et des révoltes spontanées, ou bien de séparer des révoltes à dominante externe, tantôt liées par exemple à la politique du $\mathrm{roi}^{6}$, principalement sous Louis IV le Bavarois et sous Charles IV de Bohême, en prenant soin de prendre en compte le temps de leur compétition dans les années $1340^{7}$; tantôt liées à

${ }^{4}$ Emblématique pour l'Allemagne de l'Est: Karl Czok, Zunftkämpfe, Zunftrevolutionen oder Bürgerkämpfe, Leipzig 1959. Sur les caractéristiques de l'historiographie est-allemande en la matière: Evamaria Engel, Bürgertum - Bürgerkampf Bürgerstadt. Probleme beim Versuch einer Synthese deutscher Stadtgeschichte des Mittelalters, dans Michael Borgolte (dir.), Mittelalterforschung nach der Wende 1989, München 1995, pp. 407-425. Sur le jeu réactif des deux historiographies est- et ouestallemandes en histoire sociale voir Michael Borgolte, Sozialgeschichte des Mittelalters, München 1996, pp. 249-277 («Klassen, Schichten, Bürgerkämpfe»).

${ }^{5}$ Voir en ce sens le recueil des articles rassemblés par Wilfried Ehbrecht dans Konsens und Konflikt. Skizzen und Überlegungen zur älteren Verfassungsgeschichte deutscher Städte, Köln/Weimar/Wien 2001, particulièrement «Stadtkonflikte um 1300. Versuch einer Typologie», pp. 181-197.

${ }^{6}$ Heinz Angermeier, Königtum und Landfriede im deutschen Spätmittelalter, München 1966. 
la pression des princes territoriaux, singulièrement après l'adoption de la Bulle d'Or de $1356^{8}$, et dans le cadre des ligues urbaines ${ }^{9}$ dont la formation s'accélère entre 1350 et 1380 jusqu'à leur défaite des années 1388-1389. On a pu également distinguer parmi les révoltes à dominante plutôt interne celles qui relèvent d'une division apparue au sein des couches dirigeantes, comme à Brunswick dans le dernier tiers du XIV ${ }^{\mathrm{e}}$ siècle par exemple, celles résultant d'une remise en cause des élites dirigeantes par les métiers (Constance entre 1370 et 1389) ${ }^{10}$ et/ou par le populaire, celles résultant d'une lutte au sein des métiers supérieurs (Lübeck en 1384), et celles enfin résultant d'une substitution d'une élite par une autre. On a pu encore parler de révoltes propres au Sud allemand (marquées par un partage du pouvoir urbain avec les métiers obtenu par ces derniers dès la première moitié $\mathrm{du} \mathrm{XIV}^{\mathrm{e}}$ siècle) par rapport à des révoltes du Nord ${ }^{11}$ où le phénomène ne se produit que dans la seconde moitié du XIV ${ }^{\mathrm{e}}$ siècle et est essentiellement le fait des villes de la Hanse. D’autres distinctions ont encore été introduites entre des révoltes urbaines détachées de leur environnement rural ou au contraire liées à des troubles survenus dans les campagnes; entre des révoltes d'un $\mathrm{XIV}^{\mathrm{e}}$ appartenant encore au mouvement communal précédent ou bien des révoltes d'un $\mathrm{XIV}^{\mathrm{e}}$ siècle traduisant déjà une émancipation de la société et de l'économie urbaines à l'égard du système féodal et annonçant peu ou prou les prodromes de la Réformation dans les villes du Nord de l'Empire, telles Brunswick, Rostock ou Lunebourg ${ }^{12}$. Des facteurs déformants ou aggravants ont pu être repérés pour affiner les schémas expli-

${ }^{7}$ Peter-Johannes Schuler, Die Rolle der schwäbischen und elsässischen Städtebünde in den Auseinandersetzungen zwischen Ludwig dem Bayern und Karl IV, «Blätter für deutsche Landesgeschichte», 114, 1978, pp. 659-674.

${ }^{8}$ Bernd-Ulrich Hergemöller, Fürsten, Herren und Städte zu Nürnberg 1355/56. Die Entstehung der Goldenen Bulle Karls IV., Köln/Wien 1983.

${ }^{9}$ Karl Czok, Städtebünde und Zunftkämpfe in ihren Beziehungen während des 14. und 15. Jahrhunderts, Leipzig 1956/57; Werner Mägdefrau, Der Thüringer Städtebund im Mittelalter, Weimar 1977; Peter Moraw, Die Funktion von Einungen und Bünden im spätmittelalterlichen Reich, dans Volker Press (dir.), Alternativen zur Reichsverfassung in der Frühen Neuzeit?, München 1995, pp. 1-20; Hanse, Städte, Bünde. Die sächsischen Städte zwischen Elbe und Weser um 1500, 2 vol., Magdeburg 1996; Bernhard Kirchgässner, Hans-Peter Becht (dir.), Vom Städtebund zum Zweckverband, Sigmaringen 1994; Eva-Marie Distler, Städtebünde im Spätmittelalter. Eine rechtshistorische Untersuchung zu Begriff, Verfassung und Funktion, Frankfurt am Main 2006.

${ }^{10}$ Edi Joos, Die Unruhen der Stadt Konstanz 1300-1450, "Zeitschrift für die Geschichte des Oberrheins», 116, 1968, pp. 31-58.

${ }^{11}$ Stadt im Wandel. Kunst und Kultur des Bürgertums in Norddeutschland 11501650, Stuttgart 1985, 4 vol.

${ }^{12}$ Bernd-Ulrich Hergemöller, 'Pfaffenkriege' im spätmittelalterlichen Hanseraum. Quelle und Studien zu Braunschweig, Osnabrück, Lüneburg und Rostock, Köln/Wien 1988. 
catifs. Tout d'abord l'effet d'enchaînement que l'on peut repérer d'une révolte à l'autre par le biais de la communication ou de l'imitation, par le biais aussi de pratiques administratives, juridiques et politiques développées en commun au sein d'un même cercle régional ${ }^{13}$ comme on le voit par exemple quand des troubles éclatent à Trèves une semaine après la fin du pouvoir des anciennes familles dirigeantes à Cologne en 1396. Ensuite, il faut compter également avec l'augmentation de l'enregistrement des révoltes par les sources, un phénomène lié d'une part à la croissance de l'écrit documentaire dans les villes allemandes comme dans le reste de l'Occident au $\mathrm{XIV}^{\mathrm{e}}$ siècle, mais un phénomène lié spécifiquement dans l'Empire au démarrage puis au net accroissement de la rédaction des chroniques urbaines particulièrement dans la seconde moitié du XIV siècle $^{14}$. C'est ainsi que le livre des serments de Cologne (Eidbuch), s'ouvre en 1321 par la mention d'une révolte («Concursus qui dicitur uployf dicitur», bel exemple au passage d'un bilinguisme en train de naître en même temps que l'inscription documentaire urbaine) tandis que parallèlement se met en place l'écriture d'une chronique de la ville ${ }^{15}$. À Erfurt, Brunswick et Brême, on peut également relever dans les années 1300-1310 une coïncidence entre la consignation de révoltes et les premières codifications du droit urbain. Enfin, quand les métiers d'Augsbourg se soulèvent en $1368^{16}$, l'événement marque le début de la rédaction de la chronique de la ville: «do kam ain gros folk gewappent uff den Pernlaich» ${ }^{17}$. Une dernière grille de lecture tend enfin à

${ }^{13}$ Rolf Kiessling, Städtebünde und Städtelandschaften im oberdeutschen Raum. Ostschwaben und Altbayern im Vergleich, dans Monika Escher, Alfred Haverkamp, Frank G. Hirschmann (dir.), Städtelandschaft, Städtenetz, zentralörtliches Gefüge, Mainz 2000, pp. 79-116.

${ }^{14}$ Heinrich Schmidt, Die deutschen Städtechroniken als Spiegel des bürgerlichen Selbstverständnisses im Spätmittelalter, Göttingen 1958; Rolf Sprandel, Chronisten als Zeitzeugen, Köln/Weimar/Wien 1994; Peter Johanek (dir.), Städtische Geschichtsschreibung im Spätmittelalter und in der Frühen Neuzeit, Köln/Weimar/Wien 2000.

${ }^{15}$ Georg Mölich (dir.), Spätmittelalterliche städtische Geschichtsschreibung in Köln und im Reich, Köln 2001.

${ }^{16}$ Friedrich Blendinger, Die Zunfterhebung von 1368 in der Reichsstadt Augsburg. Ihre Voraussetzungen, Durchführung und Auswirkung, dans Franz Quarthal, Wilfried Setzler (dir.), Stadtverfassung, Verfassungsstaat, Pressepolitik. Festschrift für Eberhard Naujoks zum 65. Geburtstag, Sigmaringen 1980, pp. 72-90; Jörg Rogge, 'Ir freye wal zu haben'. Möglichkeiten, Probleme und Grenzen der politischen Partizipation in Augsburg zur Zeit der Zunftverfassung (1368-1548), dans Klaus Schreiner, Ulrich Meier (dir.), Stadtherrschaft und Bürgerfreiheit. Handlungsspielräume in deutschen und italienischen Städten des Späten Mittelalters und der Frühen Neuzeit, Göttingen 1994, pp. 244-277.

${ }^{17}$ Dieter Weber, Geschichtsschreibung in Augsburg, Augsburg 1984; Jörg Rogge, Für den gemeinen Nutzen. Politisches Handeln und Politikverständnis von Rat und Bürgerschaft in Augsburg im Spätmittelalter, Tübingen 1996; Peter Johanek, Geschichts- 
présenter les révoltes selon un cycle idéaltypique plus ou moins complet (phase latente, réunion par serment, phase violente, règlement de comptes et du conflit, retour à la paix, serment et procession de réconciliation) pour mieux en dégager les éléments changeants et invariants, particulièrement en terme de rituels.

On peut signaler, à cet endroit du passage en revue des classifications possibles proposées par les médiévistes, que les médiévaux eux-mêmes ont parfois tenté d'introduire une typologie. Afin de caractériser les révoltes urbaines successives survenues à Brunswick ${ }^{18}$, mouvements qu'il baptise du terme générique de "Zwietracht», c'est-à-dire de «dissensio», le chroniqueur Herman Bote (vers 1450-1520) ${ }^{19}$ distingue onze catégories différentes entre 1292 et 1513 fondées sur une classification animalière héritée pour une grande part de l'encyclopédisme du XIII ${ }^{\mathrm{e}}$ siècle. Il nomme ainsi pour le seul XIV ${ }^{\mathrm{e}}$ siècle, la «rébellion des bœufs» (1292-1294) qu'il appelle aussi «querelle des métiers», le «soulèvement des truies» ou «dispute du Conseil» entre 1374 et 1386, la «guerre des curés» ou «dispute des loups» en 14131420. On peut noter à ce propos que les chroniques, comme en témoigne l'exemple de Herman Bote, proposent une palette variée d'explication aux troubles: riches contre pauvres, endettement, blocus économique, guerre, peste, trahison, mésentente entre les groupes de la ville. Au sein de cette typologie, un conflit urbain bien particulier se détache sous la plume du chroniqueur, celui qui secoua la ville entre 1374 et 1386 et au commence-

schreibung und Geschichtsüberlieferung in Augsburg am Ausgang des Mittelalters et Rolf Kiessling, Zum Augsburg-Bild in der Chronistik des 15. Jahrhunderts, dans Johannes Janota, Werner Williams-Krapp (dir.), Literarisches Leben in Augsburg während des 15. Jahrhunderts, Tübingen 1995, pp. 160-182 et 183-215; Jörg Rogge, Vom Schweigen der Chronisten. Überlegungen zu Darstellung und Interpretation von Ratspolitik sowie Verfassungswandel in den Chroniken von Hektor Mülich, Ulrich Schwarz und Burkhard Zink, dans Ibid., pp. 216-239.

${ }^{18}$ Jürgen Bohmbach, Die Sozialstruktur Braunschweigs um 1400, Braunschweig, 1973; Wilfried Ehbrecht, Hanse und mittelalterliche Bürgerkämpfe in Niedersachsen und Westfalen, «Niedersächsisches Jahrbuch», 48, 1976, pp. 77-105; Mathias Puhle, Die 'Große Schicht' in Braunschweig», dans Jörgen Bräcker, Volker Henn, Rainer Postel (dir.), Die Hanse. Lebenswirklichkeit und Mythos, Lübeck 1998, pp. 812-822.

${ }^{19}$ Joachim Ehlers, Hermen Bote und die städtische Verfassungskrise seiner Zeit, dans Detlev Schöttker, Werner Wunderlich (dir.), Hermen Bote. Braunschweiger Autor zwischen Mittelalter und Neuzeit, Wiesbaden 1987, pp. 119-131; Hartmut Boockmann, Eine Krise im Zusammenleben einer Bürgerschaft und ein 'politologisches' Modell aus dem 15. Jahrhundert. Der Braunschweiger Chronist Hermen Bote über den Aufstandsversuch von 1445/1446, dans Herbert Blume, Eberhard Rohse (dir.), Hermann Bote. Städtisch-hansischer Autor in Braunschweig 1488-1988, Tübingen 1991, pp. 133154. Hartmut Boockmann, Ein skeptischer Bürger beschreibt Umsturzversuche, dans Id., Fürsten, Bürger, Edelleute. Lebensbilder aus dem späten Mittelalter, München 1994, pp. 151-181. 
ment duquel huit conseillers furent décapités tandis que les autres furent tantôt bannis, tantôt emprisonnés, leurs biens confisqués et leurs demeures brûlées. Si cette révolte passe dans l'historiographie allemande pour un modèle du genre dans l'Allemagne septentrionale du XIV siècle $^{20}$, c'est sans doute parce que le récit qu'en donne le chroniqueur n'est pas seulement intéressant pour le travail historiographique à l’ouvre à près d'un siècle et demi de distance, mais également en raison du parti pris par l'auteur en faveur du Conseil renversé en 1374 et de l'avertissement qu'il lance de se garder de tout type de conflit: «Vous Conseils des villes, bourgmestres et conseillers, qui avez en charge le gouvernement des cités, prenez garde de ne point agiter les perles au nez des cochons. Car les cochons ne savent pas apprécier les perles à leur valeur et se vautrent dans la fange des ruelles... Ainsi arrive-t-il souvent que l'on se dispute jusqu'à ce que l'un tue l'autre et succombe avec ses ennemis. C'est ce qui s'est produit ici dans la ville de Brunswick avec moult mauvais propos attisés par le sourd aiguillon d'une haine ressassée, ce que je passerai sous silence car tenir sa langue est le meilleur service que l'on puisse rendre au bien commun... ${ }^{21}$. L'autre intérêt de ce passage, en dehors de la tentative de classification proposée, réside dans l'ambivalence finalement reconnue par l'auteur dans la recherche des causes. Ainsi Herman Bote ne méconnait-il pas que régnait à Brunswick en 1374 une situation critique due à l'endettement exagéré de la ville, mais il attribue la faute des désordres aux métiers envieux et jaloux du pouvoir qui formèrent un «vorbunt», une «conjuratio» qui de ce fait sapait les bases mêmes de l'édifice urbain conçu également comme une «conjuration» mais d'une nature supérieure. Pour dénoncer cette pratique, il baptise les mécontents de «partiebröder», employant le terme de parti, de faction, à l'origine des maux de la cité. On voit bien sous la plume du chroniqueur proche des milieux au pouvoir vers 1500 que perdurent depuis le temps des premiers troubles non seulement un certain légalisme (un Conseil est un Conseil) mais aussi une forme de «totalitarisme» de l'ordre juridique et institutionnel urbain. Cependant, à côté de cette présentation somme toute classique, le chroniqueur stigmatise aussi la position des puissants du Conseil qui ne surent pas prévoir la crise, et il laisse même entendre que la chronologie décalée des huit exécutions sommaires de 1374 reflète en vérité les mésententes qui séparaient les grandes familles diri-

${ }^{20}$ Pierre Monnet, Élites et conflits urbains dans les villes allemandes de la fin $d u$ Moyen Âge, contribution au numéro spécial des «Cahiers d'Histoire» (45/4) consacré aux Élites en conflits sous la direction de Claude-Isabelle Brelot et Françoise Bayard, Lyon 2001, pp. 533-561.

${ }^{21}$ Die Chroniken der deutschen Städte. Die Chroniken der niedersächsischen Städte (6: Braunschweig 1), Leipzig 1868, p. 311. 
geantes du Conseil déchu. Toute cohérente que paraisse la classification du chroniqueur, elle n'empêche pas moins que surgisse face à la singularité de l'événement une interprétation tenant compte de la complexité des faits.

Malgré les tentatives, toutes relatives, du chroniqueur de Brunswick pour mettre de l'ordre dans l'histoire troublée de sa cité, l'historien demeure souvent confronté à la difficulté de s'entendre sur les notions et se retrouve souvent perdu dans le maquis des mots restitués par les sources (discordia, dissensio, rumor, seditio, conspiratio, tumultus, concursus, murmuracio voire rebellio et, en vieil-allemand, upror, aufrure, uppstot, tohopelop, upzat, uplop, samenung, schicht, twidracht, unrat, unruh, unmut, misdaet, frevel, overval, gewalt, stöss, irrung, klag, bewegnuss, sache, beschwerung, spenn, unfriden, stoss, bruch, geschrei, krieg, empörung, c'est-à-dire tout sauf la révolte et la révolution). L'historien s'est ensuite trouvé confronté à la difficulté de proposer des approches comptables admises par tous tant les résultats chiffrés paraissent très fluctuants ${ }^{22}$. Pour les uns ${ }^{23}$, on dénombrerait 148 révoltes «souvent sanglantes» pour la période 13011500 avec un pic observable entre 1350 et 1400 et des épisodes particulièrement marquants (Lübeck, Dantzig, Brunswick) et coïncidemment inscrits dans la «vague» européenne de 1378-1382. D’autres s'accordent autour d'un chiffre de 210 entre 1301 et 1550 dans 100 villes ou bien 250 dans 140 villes pour la même époque, tandis qu'un troisième comptage donne 83 désordres urbains pour le XIV ${ }^{\mathrm{e}}$ siècle dont 38 avant 1350 et 45 après $^{24}$. Un quatrième en avance 170 pour le seul XIV ${ }^{\mathrm{e}}$ siècle, dont 89 avant 1350 et 81 après, un cinquième propose, d'après les méthodes d'enregistrement du troisième, 140 troubles graves au XIV ${ }^{\mathrm{e}}$ siècle avec une égale répartition avant et après $1350^{25}$. Enfin un sixième parle de 44 pour la seule décennie $1295-1305^{26} \ldots$ Ces fluctuations ne sont pas le privilège des historiens quatorzièmistes, les seizièmistes sont en effet tout aussi partagés entre une

${ }^{22}$ Evamaria Engel, Die deutsche Stadt des Mittelalters, München, 1993, fournit un décompte provisoire de quelque 170 commotions pour le seul $\mathrm{XIV}^{\mathrm{e}}$ siècle tandis que Bernd-Ulrich Hergemöller, Gesellschaftliche Veränderungen im engeren Reichsgebiet um 1400, dans Ferdinand Seibt, Winfried Eberhard (dir.), Europa 1400. Die Krise des Spätmittelalters, Stuttgart 1984, pp. 39-52 (ici p. 51-52) en recense 78 pour la période 1360-1432.

${ }^{23}$ Pour ces dénombrements de révoltes: Peter Blickle, Unruhen in der ständischen Gesellschaft 1300-1800, München 1988, p. 7 et suiv.; Eberhard Isenmann, Die deutsche Stadt im Spätmittelalter 1250-1500, pp. 191-198.

${ }^{24}$ Erich Maschke, Deutsche Städte am Ausgang des Mittelalters, dans Wilhelm Rausch (dir.), Die Stadt am Ausgang des Mittelalters, Linz 1974, p. 1-44.

${ }^{25}$ František Graus, Pest - Geissler - Judenmorde. Das 14. Jahrhundert als Krisenzeit, Göttingen 1987.

${ }^{26}$ Wilfried Ehbrecht, Stadtkonflikte um 1300. Versuch einer Typologie cit. 
école qui a dénombré 18 révoltes urbaines de 1511 à 1520 puis 45 de 1521 à 1530 , et une autre qui en compte 180 de 1518 à 1525 , une troisième qui en totalise 16 pour la seule année 1521, 52 en 1522, 44 en 1523, 40 en 1524 et 51 en 1525, donc un total de 203 de 1521 à $1525^{27}$.

Il est entendu que l'approche statistique présente des faiblesses de taille, qui renvoient en fait à des questions de terminologie, des problèmes de compréhension du fait urbain dans sa totalité, de catégorisations sociales, de déformations documentaires: en cela, ces chiffres expriment autant d'incertitudes que ceux communément fournis sur le nombre des habitants (souvent à l'unité près!) ou bien sur les «budgets» urbains... L'entrée dans le sujet par le biais comptable n'en révèle pas moins que les villes allemandes ne peuvent être détachées d'un contexte européen d'ensemble qui continue de se focaliser, pour le XIV ${ }^{\mathrm{e}}$ siècle, sur la décennie 1320-1330, ensuite sur le milieu du siècle avec la Peste et enfin sur les deux décennies 13601380. Par ailleurs, ces ordres de grandeur, sans cesse retravaillés par les historiens depuis le début du $\mathrm{XX}^{\mathrm{e}}$ siècle, établissent que le $\mathrm{XIV}^{\mathrm{e}}$ siècle ne serait pas davantage un siècle de révoltes urbaines que le $\mathrm{XV}^{\mathrm{e}}$ siècle ne serait un temps de révoltes rurales; et qu'au cours de la période 1300-1400, en dépit des pics précédemment mentionnés, leur nombre serait à peu près également réparti avant et après $1350^{28}$. Un dernier point de consensus apparent touchant le nombre et la répartition chronologique semble se dégager: le $\mathrm{XIV}^{\mathrm{e}}$ siècle «allemand» semble succéder à un XIII ${ }^{\mathrm{e}}$ siècle plus calme si on le compare au XIII ${ }^{\mathrm{e}}$ siècle urbain français d'un côté et italien de l'autre. La raison de ce décalage peut être cherchée du côté de la chronologie de l'Empire au XIII ${ }^{\mathrm{e}}$ siècle, qui voit le mouvement communal s'immiscer, essentiellement dans la seconde moitié du siècle, dans les interstices laissés vacants par un pouvoir royal en recomposition après la mort de Frédéric II en 1250 tandis que les pouvoirs territoriaux des grands princes n'avaient pas encore atteint leur maturité souveraine. Par comparaison, la poussée princière du $\mathrm{XIV}^{\mathrm{e}}$ siècle expliquerait à la fois la multiplication des tensions en ville et la multiplication des ligues urbaines (les deux étant liées), cela dans un ensemble politique et territorial qui ne connait pas la guerre de Cent Ans, qui est disputé par trois dynasties essentiellement basées au Sud et à l'Est, tandis que, parallèlement, le Nord et le Nord-Est voient finir de s'installer la Hanse d'un côté et l'ordre teutonique de l'autre ${ }^{29}$. Reste que le

${ }^{27}$ Peter Blickle, Unruhen in der ständischen Gesellschaft 1300-1800 cit.

${ }^{28}$ Rhiman A. Rotz, 'Social Struggles' or the Price of Power? German Urban Uprisings in the Late Middle Ages, dans «Archiv für Reformationsgeschichte», 76, 1985, pp. 64-95.

${ }^{29}$ Sur la conjoncture politique et territoriale d'ensemble de l'Empire tardo-médiéval: Peter Moraw, Von offener Verfassung zu gestalteter Verdichtung. Das Reich im spä- 
dénombrement des révoltes pose aussi la question des cycles et des réactions en chaîne d'une ville à l'autre: faut-il parler de contamination, de contagion? Même sur ce plan les avis restent partagés: ces chaînes de révoltes sont-elles réelles ou bien le fruit d'une invention de la tradition par l'écrit et la mémoire? Les avis divergent tout autant sur la chronologie d'ensemble: le XIV ${ }^{\mathrm{e}}$ siècle des révoltes s'arrête-t-il en Allemagne avec la crise hussite qui fait basculer dans un nouveau cycle ${ }^{30}$, ou bien faut-il prendre les $\mathrm{XIV}^{\mathrm{e}}$ et $\mathrm{XV}^{\mathrm{e}}$ siècles tout ensemble dans un mouvement qui débouche sur 1525 et la Réforme ${ }^{31}$ ? Partagés également sont les avis sur le caractère sanglant des révoltes urbaines allemandes: moins meurtrières ou tout aussi meurtrières qu'en France et en Italie? Enfin, on a pu remarquer à bon droit que ces épisodes ont concerné à hauteur de $80 \%$ les grandes villes et, parmi elles, plus spécialement les villes d'Empire. Il faut ici tenir évidemment compte des effets déformants de la documentation et réviser par conséquent l'hypothèse qui avait pendant longtemps consisté à mettre en relation la concentration des révoltes identifiées (parce que lisibles par écrit) sur les villes d'Empire avec le degré d'autonomie politique de ces dernières. Cette remise en cause oblige à trois remarques conséquentes: la mise en relation des révoltes avec le processus urbain de mise par écrit (les chroniqueurs sont pour beaucoup notaires et conseillers de ville...), la prise en compte des cas où la révolte a eu lieu mais n’a pas été enregistrée, l'introduction dans l'interprétation des cas où elle a été enregistrée mais n'a pas eu lieu ou du moins pas sous la forme rapportée (ici la consignation a moins pour fonction la mémoire que le rappel des normes).

Le bilan chronologique et comptable, aussi imparfait fût-il, invite à formuler deux remarques. Incontestablement, le contexte germanique n'est pas séparable d'un contexte européen plus large et, dans l'Empire comme dans le reste de l'Occident, il paraît possible, en prenant du champ, de distinguer au moins un soulèvement d'une révolte, cette dernière se caractérisant dans un contexte urbain par son aspect public, par l'effet de masse et la participation d'un grand nombre de couches sociales, par son retentissement extra-urbain et parfois suprarégional, par l'ampleur de la répression (souvent militaire et extérieure), par un début de revendication d'un autre ordre politique ou

ten Mittelalter 1250-1490, Berlin 1985; Hartmut Boockmann, Stauferzeit und spätes Mittelalter. Deutschland 1125-1517, Berlin, 1987; Ernst Schubert, Einführung in die deutsche Geschichte im Spätmittelalter, Darmstadt 1998.

${ }^{30}$ Voir sur ce plan les interprétations de František Graus, Pest - Geissler Judenmorde. Das 14. Jahrhundert als Krisenzeit cit.

${ }^{31}$ Voir ici les thèses développées par Peter Blickle, Unruhen in der ständischen Gesellschaft 1300-1800 cit. 
religieux ${ }^{32}$. Mais, dans ce contexte, se dessinent quelques spécificités propres à l'Empire qu'il convient de relever.

En premier lieu, il faut souligner le lien existant entre les troubles urbains et la compétition dynastique pour le trône, comme on l'a déjà mentionné, et cela pour la première moitié du XIV ${ }^{\mathrm{e}}$ siècle, principalement dans l'Allemagne moyenne et méridionale proche des possessions patrimoniales des dynasties concurrentes. Un certain nombre d'épisodes peuvent en effet clairement être mis en relation avec les doubles élections royales (Louis IV de Bavière et Frédéric le Beau de Habsbourg en 1314, Charles IV de Luxembourg et Louis IV de Wittelsbach en 1346, Charles IV et Günther de Schwarzbourg en 1349, Sigismond de Luxembourg et Jobst de Moravie en 1410). On peut repérer ce lien à la fin du XIII ${ }^{e}$ siècle, à l'image des événements de Spire où, en 1304, une nouvelle faction du Conseil composée de marchands neufs du Rhin chasse le groupe plus ancien des monétaires en s'alliant à quelques métiers. Mais, à ce schéma somme toute classique se superpose une autre dimension, celle d'un milieu de monétaires chassé également au titre de l'appui qu'il avait apporté à Adolphe de Nassau contre Albert de Habsbourg. Ce dernier avait alors désavantagé Spire en termes de privilèges douaniers accordés à la cité dont la marchandise, par voie de conséquence, s'était révoltée... À la mort d'Albert en 1308, les vieilles familles chassées du Conseil reviennent et expulsent à leur tour les marchands $^{33}$. Le contexte disputé des premières années du règne d'Albert de Habsbourg joue également un rôle important au cours des troubles survenus à Augsbourg en 1302-1303, à Worms en 1303 et à Trèves en 1304 d'autant que, dans ce dernier cas, le rôle de l'archevêque-électeur est considérable. Il existe donc un contexte des révoltes urbaines qui se trouve lié à la question de l'élection royale et aux effets des prises de parti royal, épiscopal, princier... par les élites du Conseil. Le même type de corrélation est patent pour la série des troubles de 1345-1350 nés de la lutte entre Charles de Luxembourg et Louis le Bavarois, série au sein de laquelle la Peste est évidemment un facteur aggravant mais non point déclenchant (ce qui du coup, au sein de l'épisode, confère aux pogroms perpétrés contre les Juifs de Bâle, Spire, Nuremberg, Francfort, Strasbourg, Augsbourg, Erfurt et Nördlingen un aspect politique et fiscal marqué puisque ces communautés sont instrumentalisées et maltraitées avec la bénédiction des équipes dirigeantes des

\footnotetext{
32 Sur cette critérisation: article «Revolte» par Neithard Bulst dans le Lexikon des Mittelalters, Stuttgart 1999, vol. 7, col. 773-776.

${ }^{33}$ Voir Ernst Voltmer, Reichsstadt und Herrschaft. Zur Geschichte der Stadt Speyer im hohen und späten Mittelalter, Trier 1981 et Alfred Haverkamp, Innerstädtische Auseinandersetzungen und überlokale Zusammenhänge in deutschen Städten während der ersten Hälfte des 14. Jahrhunderts cit.
} 
Conseils en fonction de leurs motivations politiques). L'influence de la position des cercles gouvernants à l'égard de la politique royale ne peut pas non plus être niée pour la vague de troubles des années 1327-1333 à Mayence, Strasbourg, Ratisbonne, Spire et Ulm au sein de laquelle se placent l'opposition entre Louis de Bavière et le pape d'un côté et sa descente en Italie de l'autre. Bien entendu, la corrélation entre les révoltes urbaines et le contexte de la politique royale et dynastique demeurera tant que les effets de la Bulle d'Or de 1356 n'auront pas produit les résultats que son concepteur, Charles IV de Bohême, en attendait, c'est-à-dire une stabilisation dynastisée de l'élection royale, acquis qu'il escomptait mettre au profit des Luxembourg mais que les Habsbourg détourneront continument en leur faveur au $\mathrm{XV}^{\mathrm{e}}$ siècle $^{34}$.

Ce développement induit une remarque corollaire. On remarquera en effet plus spécifiquement pour l'Allemagne, mais c'est un indicateur d'une configuration générale de la société politique de l'Empire à la fin du Moyen Âge, qu'il n'y a pas de sortie de la crise et de la révolte par le haut, c'est-àdire soit par l'inclusion de la ville-État dans une seigneurie, soit par l'institution d'une sorte de tyrannie d'un seul. Tous les essais de pouvoir solitaire après la révolte échouent en Allemagne, à l'exception notable du pouvoir autocratique du primus magister civium Rudolf Brun de Zurich entre 1336 et $1360^{35}$ : ni Siboto Stolzhirsch à Augsbourg en $1303^{36}$, ni le clan familial des Auer à Ratisbonne 1330-1334, ni Ulrich Kunzelmann à Ulm en 1328-1330, ni le patricien Rienoldt à Lindau en 1390 ne réussirent à s'imposer seuls à la tête du gouvernement urbain, c'est-à-dire à l'exclusion des autres cercles dirigeants. Cela se vérifie au $\mathrm{XV}^{\mathrm{e}}$ siècle. Les tentatives malheureuses d'exercice personnel et solitaire du pouvoir par Heinrich Toppler à Rothenbourg en 1408, par Peter Egen ou von Argun en 1450 à Augsbourg, par Heinrich Rubenow à Greifswald en 1462, par Ulrich Schwarz à Augsbourg en 1478 et par Hans Waldmann en 1489 à Zurich montrent que la pratique oligarchique du pouvoir urbain devait demeurer collective et que toute sortie de crise devait se faire par et avec le groupe ${ }^{37}$. Il semble surtout que l'échec de ces tentatives de pouvoir personnel tienne

${ }^{34}$ Evamaria Engel, '... und den alten rat wider in ire stule, huser, er und guten setzen'. Bürgerkämpfe in der Regierungszeit Sigmunds von Luxemburg, dans Helmut Bräuer, Elke Schlenkrich (dir.), Die Stadt als Kommunikationsraum. Beiträge zur Stadtgeschichte vom Mittelalter bis ins 20. Jahrhundert. Festschrift für Karl Czok zum 75. Geburtstag, Leipzig 2001, pp. 281-309.

${ }_{35}$ Anton Largiader, Bürgermeister Rudolf Brun und die Zürcher Revolution von 1336, Zürich 1936.

${ }^{36}$ Karl Bosl, Die wirtschaftliche und gesellschaftliche Entwicklung des Augsburger Bürgertums vom 10. bis zum 14. Jahrhundert, München, 1969; Wolfgang Zorn, Augsburg. Geschichte einer deutschen Stadt, Augsburg 1972. 
à l'incapacité dans laquelle furent ces hommes riches et puissants, arrivés au sommet de leurs cités respectives, à réunir une clientèle parmi les élites dirigeantes mêmes, soit faute d'un "programme» politique, soit davantage en raison de l'attachement de ces élites à un système de gouvernement dans lequel le bien commun était aux mains d'un petit groupe aux yeux duquel le privilège de gouverner appartenait à plusieurs et non à un seul. Le conflit au sein des élites n'est donc pas avant tout un problème de richesse ou même de prestige social, dans ce contexte, mais relève d'un problème de philosophie politique, de mode de gouvernement urbain dans lequel le puissant solitaire ne parvient pas à capter durablement à son profit le renversement de l'ordre politique provoqué par une révolte. Il n'est d'ailleurs pas toujours évident, face aux sources, de bien établir la différence entre ce qui relève de la tentative de pouvoir d'un seul consécutive à une phase de trouble et le jeu violent et vengeur des luttes de clans au sein des familles dirigeantes: ainsi l'interprétation de l'élimination de Ulrich Schwarz à Augsbourg en $1478^{38}$ et de l'exécution sommaire de Niklas Muffel en $1469^{39}$ à Nuremberg laisse-t-elle davantage croire à des règlements de compte au sommet qu'à la pacification postérieure à une vague de troubles. Quoi qu'il en soit, ces phénomènes, tant au XIV $\mathrm{Xu}^{\mathrm{e}}$ au $\mathrm{XV}^{\mathrm{e}}$ siècle ${ }^{40}$, sont sans doute à mettre en relation avec l'absence de partis de longue durée à la différence de ce que l'on trouve en Italie: pas de guelfes et de gibelins en Allemagne au $\mathrm{XIV}^{\mathrm{e}}$ siècle (et donc pas de phénomène massif d'exil) même si les doubles élections royales et les doubles élections épiscopales à Cologne ou à Brême par exemple constituent des facteurs favorables à l'éclosion de révoltes urbaines. Mais justement, les dynasties changent et avec elles les noyaux territoriaux de leur possession patrimoniale... De surcroît, le roi-empereur lui-même (on pense surtout au règne de Charles IV) n'a pas systématiquement appliqué la même politique vis-à-vis des villes troublées: il préserve

${ }^{37}$ Hartmut Boockmann, Spätmittelalterliche deutsche Stadt-Tyrannen, «Blätter für deutsche Landesgeschichte», 119, 1983, pp. 73-91.

${ }^{38}$ Jörg Rogge, Für den Gemeinen Nutzen. Politisches Handeln und Politikverständnis von Rat und Bürgerschaft in Augsburg im Spätmittelalter, Augsburg 1996.

${ }^{39}$ Gerhard Fouquet, Die Affäre Niklas Muffel. Die Hinrichtung eines Nürnberger Patriziers im Jahre 1469, «Vierteljahrschrift für Sozial- und Wirtschaftsgeschichte», 83, 1996, pp. 459-500; Gerhard Hirschmann, Die Familie Muffel im Mittelalter, «Mitteilungen des Vereins für die Geschichte Nürnbergs», 41, 1950, p. 257-392. Valentin Groebner, Ratsinteressen, Familieninteressen. Patrizische Konflikte in Nürnberg um 1500, dans Klaus Schreiner, Ulrich Meier (dir.), Stadtregiment und Bürgerfreiheit. Handlungsspielräume in deutschen und italienischen Städten des Späten Mittelalters und der Frühen Neuzeit, Göttingen 1994, pp. 278-309.

${ }^{40}$ Laurence Buchholzer, Une affaire municipale à Rothenbourg/Tauber (1396-1404), dans Patrick Boucheron, Jacques Chiffoleau (dir.), Religion et société urbaine au Moyen Âge. Études offertes à Jean-Louis Biget, Paris 2000, pp. 201-224. 
les intérêts des couches dirigeantes en place dans les villes d'Empire qui lui importent (Francfort, Nuremberg et Augsbourg), laisse par ailleurs plutôt l'équilibre s'établir entre anciens conseillers et nouveaux représentants des métiers en Souabe entre 1347 et 1350. À ce propos, si à Augsbourg (en faveur de la famille des Auer, mais pour un temps seulement) ${ }^{41}$, à Nuremberg (1349) et à Francfort $(1366)^{42}$, le souverain s'est engagé aux cotés du patriciat en place, il soutint ailleurs un équilibre entre métiers et cercles patriciens comme à Ulm en 1348, voire avalisa la domination des métiers comme dans les villes souabes de Nördlingen, Memmingen, Ravensbourg et Kaufbeuren entre 1347 et 1350 . Au XV siècle, l'intervention royale dans les conflits urbains fut également mesurée, soit que le pouvoir royal avait continué à perdre de son efficacité réglementaire dans l'Empire, soit que les autorités urbaines aient répugné à faire appel à un roi sans cesse en quête d'argent et enclin à tirer un profit financier de toute querelle susceptible de provoquer son entregent. Sigismond par exemple a bien tenté d'intervenir de manière active et en faveur des élites établies dans le conflit urbain qui déchirait l'ancien et le nouveau Conseil à Brême, ville d'ailleurs exclue de la Hanse pour cette raison depuis 1426. Mais il est intéressant de constater que le conflit s'est finalement résolu plus ou moins sans lui, entre 1433 et 1436 , alors que le souverain était tout absorbé par l'évolution du concile de Bâle ${ }^{43}$. Il est donc rare qu'une révolte urbaine laisse durablement s'installer un nouveau "seigneur» urbain en ville ou bien signale une intrusion massive du pouvoir royal: ici encore, des trois pouvoirs en jeu, c'est l'élément princier territorial qui prendra la main au $\mathrm{XV}^{\mathrm{e}}$ siècle.

En second lieu, pour ce qui touche aux spécificités propres à l'Empire, on notera qu'une relative autonomie des événements troublés peut être observée entre le Nord et le Sud de l'Allemagne (bien plus qu'entre l'Ouest et l'Est). Autrement dit, aucun phénomène d'ampleur général touchant tout l'Empire à la fois ne peut être détaché à la différence de ce que l'on pourra rencontrer au XVI ${ }^{e}$ siècle ${ }^{44}$. Dans le Nord, les grands troubles urbains datent plutôt de la seconde moitié du XIV ${ }^{\mathrm{e}}$ siècle et se trouvent clai-

${ }^{41}$ Johann Schmuck, Ludwig der Bayer und die Reichsstadt Regensburg, Regensburg, 1997; Peter Schmid (dir.), Geschichte der Stadt Regensburg, Regensburg 2000.

${ }^{42}$ Pierre Monnet, Les Rohrbach de Francfort. Pouvoirs, affaires et parenté à l'aube de la Renaissance allemande, Genève, 1997; Id., Le financement de l'indépendance urbaine par les élites argentées: l'exemple de Francfort au XIV ${ }^{e}$ siècle, dans L'argent au Moyen Âge (Congrès de la SHMES de Clermont-Ferrand, mai 1997), Paris 1998, pp. 187-207.

${ }^{43}$ Friedrich Bernward Fahlbusch, Städte und Königtum im frühen 15. Jahrhundert. Ein Beitrag zur Geschichte Sigmunds von Luxemburg, Köln/Wien 1983, pp. 211-212.

${ }^{44}$ Rhiman A. Rotz, 'Social Struggles' or the Price of Power? German Urban Uprisings in the Late Middle Ages cit. 
rement en relation avec la Hanse, tandis qu' ils se trouvent davantage en relation avec le contexte royal dans le Sud pour ce qui regarde la première moitié du XIV ${ }^{\mathrm{e}}$ siècle. Plus particulièrement, si l'on réfléchit en termes d'approche régionale, la connexion qui s'établit entre les ligues urbaines d'un côté et la propagation des révoltes ou le règlement des conflits de l'autre, mérite d'être soulignée (le $\mathrm{XIV}^{\mathrm{e}}$ siècle est le siècle des ligues en même temps qu'il est aussi un siècle de révoltes, le parallèle doit donc faire sens) ${ }^{45}$. Avant même la formation des premières ligues (si l'on excepte le cas de la ligue du Rhin de 1254), des mécanismes de solidarité interurbaine en cas de révolte dans l'une des cités peuvent être observés. À Worms en 1293, des troubles éclatent en ville, dont l'apaisement est dû pour beaucoup à l'intervention de députés des villes voisines de Mayence et de Spire: «les honorables gens des Conseils de Mayence et de Spire se sont entremis et ont fait que nous sommes redevenus d'accord» ainsi que le disent les sources de la ville ${ }^{46}$. Le même processus se reproduit, avec les mêmes acteurs, lors des troubles de Worms en 1360. Lorsque des désordres surviennent à Spire en 1327 puis à Mayence en 1332, on retrouve cette fois à fronts renversés les mêmes protagonistes pour jouer les pacificateurs, tous unis dans des pratiques que des habitudes de concertation interurbaine renforçaient depuis la formation de ligues régionales constituées sur la base de l'ancienne vaste ligue du Rhin de $1254^{47}$. Avec la formation des ligues à proprement parler (un phénomène inséparable de la transformation du Conseil de ville en autorité), la pratique a tendu à faire que toute ville en désordre était mise à l'écart des institutions liguées ${ }^{48}$. L'exemple de la ligue souabe le prouve avec une disposition adoptée dès le 22 octobre 1347 qui stipule que les villes liguées, lorsque l'une d'entre elles est confrontée à un soulèvement (ufflauff), doivent se réunir à Ulm et décider, à la majorité, de la conduite à adopter pour faire cesser les troubles

${ }^{45}$ Karl Czok, Städtebünde und Zunftkämpfe in ihren Beziehungen während des 14. und 15. Jahrhunderts cit.

${ }^{46}$ Heinrich Boos (éd.), Urkundenbuch der Stadt Worms, Berlin, 1890, vol. 2: 13011400, $\mathrm{n}^{\circ} 14:$ «des hant sich geerbeit die erber lude vomme rade ze Mainzen und ze Spire unde hant daz zubracht daz wir einmudig wordin sin»; Evamaria Engel, Städtebünde im Reich von 1226 bis 1314 - eine vergleichende Betrachtung, dans Konrad Fritze (dir.), Hansische Studien III. Bürgertum, Handelskapital, Städtebünde, Weimar 1975, pp. 177209.

${ }^{47}$ Konrad Ruser (éd.), Die Urkunden und Akten der oberdeutschen Städtebünde vom 13. Jahrhundert bis 1549, Göttingen 1979-2005, 3 vol. (le troisième volume en trois tomes est paru en 2005 et couvre la période 1380-1389); Catalogue de l'exposition Propter culturam pacis. Der rheinische Städtebund von 1254-1256, Koblenz 1986; Ernst Voltmer (dir.), Der Rheinische Städtebund von 1254/56, Worms, 1986.

${ }^{48}$ Mathias Puhle (dir.), Hanse, Städte, Bünde. Die sächsischen Städte zwischen Elbe und Weser um 1500, Magdeburg 1996, 2 vol. 
et rétablir le Conseil dans son autoritét ${ }^{9}$. Cet engagement, notons-le, reposait sur la valeur accordée au serment prêté pour entrer dans la ligue ${ }^{50}$, de sorte que la pacification d'une ville en proie à la révolte découlait des obligations de la conjuratio selon un modèle bien connu d'extension spatiale de la paix urbaine à un cercle interurbain. Il est de même remarquable que cet espace de la conjuration à but de paix ait donné naissance à un espace de communication au sein duquel le serment et le mécanisme de frein à la révolte circulent comme en témoigne la reprise, mot pour mot, de la disposition du 22 octobre 1347 dans la lettre d'union des villes d'Empire de Basse-Souabe de 1348 et dans le texte fondateur de la ligue souscrite entre Augsbourg, Ulm et Nördlingen le 29 juin 1348. On peut également citer le cas plus modeste de la ligue de Wetteravie autour de Francfort ${ }^{51}$ dont les quatre villes s'engagent à intervenir mutuellement en cas de "soulèvements et divisions/partitions»" ${ }^{52}$. Dans le même ordre d'idées s'inscrit l'exemple de la ligue de Poméranie dont les villes en 1352 se prêtent mutuelle assistance jusqu'à l'exclusion de l'une d'elles «si aliqui consules sive cives in aliqua dictarum civitatum inter se ligarent aut discordarent». On retrouve un mécanisme comparable au sein des villes de la ligue saxonne dans la seconde moitié du $\mathrm{XIV}^{\mathrm{e}}$ siècle, dès 1360 puis après la constitution de leur fédération ${ }^{53}$. On peut même avancer que, depuis l'éclatement de troubles urbains à Stendal en 1285, à Brunswick en 1292, à Magdebourg en 1293 et dans toutes ces villes (avec Helmstedt et

${ }^{49}$ Rolf Kiessling, Städtebünde und Städtelandschaften im oberdeutschen Raum. Ostschwaben und Altbayern im Vergleich cit.; Ernst Bock, Der schwäbische Bund und seine Verfassungen 1488-1534, Breslau 1927, Neudr., Aalen 1968; Harro Blezinger, Der schwäbische Städtebund in den Jahren 1438-1445. Mit einem Überblick über seine Entwicklung seit 1389, Stuttgart 1954; Horst Carl, Der Schwäbische Bund 1488-1534. Landfrieden und Genossenschaft im Übergang vom Spätmittelalter zur Reformation, Leinfelden 2000.

${ }^{50}$ Wilhelm Ebel, Der Bürgereid als Geltungsgrund und Gestaltungsprinzip des deutschen mittelalterlichen Stadtrechts, Göttingen 1958; Lothar Kollmer, Promissorische Eide im Mittelalter, Kallmünz, 1989. On signalera entre parenthèses que la lacune d'une traduction française du maître ouvrage de Paolo Prodi sur le serment n'est toujours pas comblée: Paolo Prodi, Il sacramento del potere. Il giuramento politico nella storia costituzionale dell'Occidente, Bologna 1992. Traduction allemande: Das Sakrament der Herrschaft. Der politische Eid in der Verfassungsgeschichte des Okzidents, Berlin 1997.

${ }^{51}$ Heinrich Werner, Zur Geschichte der Wetterauer Städtebünde im 13. und 14. Jahrhundert, «Mitteilungen des Oberhessischen Geschichtsvereins», 7, 1898, pp. 56-76.

52 «ufflufe unde zweyunge».

${ }^{53}$ Mathias Puhle, Der sächsische Städtebund und die Hanse im ausgehenden Mittelalter, «Hansische Geschichtsblätter», 104, 1986, pp. 21-34; Wilfried Ehbrecht, Eintracht, Zwietracht. Ursache, Anlass, Verlauf und Wirkung von Stadtkonflikten, dans Mathias Puhle (dir.), Hanse, Städte, Bünde. Die sächsischen Städte zwischen Elbe und Weser um 1500 cit., pp. 298-321. 
Göttingen) entre 1340 et 1355, la constitution d'une ligue et le retour régulier de révoltes suivent une évolution parallèle. L'un des articles de la fondation de la ligue saxonne de 1360 prévoit en effet que s'il advenait «que quelque commun se soulève contre le Conseil, toutes les villes viennent en aide à cette ville» ${ }^{54}$. Il s'agit peu ou prou de la reprise de dispositions déjà adoptées depuis le début du siècle entre plusieurs de ces villes, tel le texte d'entente souscrit entre Magdebourg et Halberstadt en 1315 qui prévoyait que «si survenait un soulèvement ou une discorde de la part de ou bien entre nos amis de cette ville, ce qu'à Dieu ne plaise, et si l'on nous en faisait la demande, ainsi voulons nous sans esprit mauvais et en toute fidélité nous y rendre et avec tout notre engagement travailler à réduire la dite discorde et voulons également la pareille de la part de nos amis si survenait une discorde entre nous dans notre ville, ce qu'à Dieu ne plaise ${ }^{55}$. Des formulations comparables sont ensuite répétées dans les textes d'union de 1370 entre Hanovre, Goslar, Minden, Hildesheim, Hameln et Einbeck puis de 1382 entre Göttingen, Goslar, Lunebourg, Hildesheim, Brunswick, Hanovre, Helmstedt et Ülzen (cette fois ce sont les termes de «upstunde» et de «samminghe» qui sont employés, soit de «soulèvement» et de «rassemblement»). En tout cas, pour Brunswick, et ce dès 1374, des représentants de Goslar, Hildesheim et Helmstedt furent envoyés dans la ville alors en proie à un soulèvement des métiers exclus du Conseil et dirigé contre les lignages du premier banc consulaire. Ce n'est qu'après l'échec des pourparlers menés au sein de la ligue que Brunswick fut mise au ban de la Hanse en 1375 pour cinq ans et les produits de son commerce boycottés ${ }^{56}$. Des mesures semblables de rétorsion furent prises à l'encontre de Stralsund en 1386, de Magdebourg en $1402^{57}$, de Minden en 1405, de Halberstadt en 1423-1425 ou de Brême en 1426 et de Halle en 1427, selon la même logique d'un lien établi entre révolte interne et affaires extérieures des ligues, et suivant un mécanisme qui voit d'abord la ligue saxonne

54 «... Were ok... jenich meynheyt sik erhove wedder den rad dar scolden desse stede alle der stad to helpen...».

${ }^{5}$ «....worde ouk oplope adir twidracht von adir twisschen unsen frunden vorgeschreven in orer stad, des got nicht wille, wenne uns dat to weten worde, so wolden wy ane vortoch darto komen unde getruwelik met allemn flyss arbeyden unde sulke twidracht underfangen unde breken, unde wolden ok des gelik unse frunde, off twidrachten in unser stad uner uns worden, dar got vor si...»

${ }^{56}$ Mathias Puhle, Die Politik der Stadt Braunschweig innerhalb des sächsischen Städtebundes und der Hanse im späten Mittelalter, Braunschweig 1985.

${ }^{57}$ Wilfried Ehbrecht, Magdeburg im Sächsischen Städtebund. Zur Erforschung städtischer Politik in Teilräumen der Hanse, dans Helmut Maurer (dir.), Festschrift für Berent Schwineköper, Sigmaringen 1982, pp. 391-414. 
tenter d'intervenir puis la Hanse porter l'affaire devant sa diète ${ }^{58}$. Dès 1418, Lübeck faisait adopter des statuts «anti-révolte» (tohopesate) par la diète de la Hanse, qui prévoyaient l'exclusion de la fédération d'une ville en proie aux troubles ou bien du Conseil renversé et faisaient interdiction aux villes membres de donner asile aux fauteurs de troubles. Il est savoureux de noter que la mesure a commencé par toucher Lübeck, au point que lorsque le retour au calme y est confirmé en 1418 par la restauration du pouvoir des anciennes familles dirigeantes, une nouvelle rédaction des statuts communs aux villes de la Hanse est entreprise. Ces dispositions se heurtèrent parfois au refus de certains Conseils, tels ceux de Stade et Stettin, choqués par cette intrusion dans leur autonomie ${ }^{59}$. La ligue tentait ainsi de se muer en instance concurrente de régulation des conflits internes et externes tout ensemble ${ }^{60}$, à côté des institutions princières et royales, et de constituer une expérience intéressante de réarticulation de la paix urbaine à la paix territoriale dans des espaces où le roi ne se montre plus vraiment au cours de la période. Il demeure remarquable que, confrontées à des désordres intérieurs parfois très violents et récurrents, des villes unies par ailleurs dans le cadre (pas si contraignant mais volontaire) des ligues n'aient pas cherché à faire plus souvent appel au roi, à l'évêque ou au seigneur territorial laïc pour sortir de leurs oppositions. Bien entendu, une partie des historiens a voulu y voir, en dehors du prolongement de l'esprit communal sur lequel l'historiographie ouest-allemande a davantage insisté, la poursuite et la préservation des intérêts bien compris de la classe dirigeante des Conseils urbains menacée par les révoltes des métiers. On le voit, les ligues comme les révoltes, surtout celles du $\mathrm{XIV}^{\mathrm{e}}$ siècle, ont donné lieu à des interprétations différenciées qui ont contribué à des redéfinitions terminologiques et à de réorientations problématiques qu'il convient maintenant d'examiner.

${ }^{58}$ Bernd Kannowski, Bürgerkämpfe und Friedebriefe. Rechtliche Streitbeilegung in spätmittelalterlichen Städten, Köln 2001.

${ }^{59}$ Wilfried Ehbrecht, Hanse und mittelalterliche Bürgerkämpfe in Niedersachsen und Westfalen, «Niedersächsisches Jahrbuch», 48, 1976, pp. 77-105; Volker Henn, Städtebünde und regionale Identitäten im hansischen Raum, dans Peter Moraw (dir.), Regionale Identitäten und soziale Gruppen im deutschen Mittelalter, Berlin 1992, pp. 41-64.

${ }^{60}$ Heinz Angermeier, Die Funktion der Einung im 14. Jahrhundert, «Zeitschrift für bayerische Landesgeschichte», 20, 1957, pp. 475-508; Peter Moraw, Die Funktion von Einungen und Bünden im spätmittelalterlichen Reich», dans Volker Press (dir.), Alternativen zur Reichsverfassung in der Frühen Neuzeit?, München 1995, pp. 1-20; EvaMarie Distler, Städtebünde im Spätmittelalter. Eine rechtshistorische Untersuchung zu Begriff, Verfassung und Funktion, Frankfurt am Main 2006. 


\section{Reclassements}

Face à la diversité des constructions typologiques, fort de quelques spé-

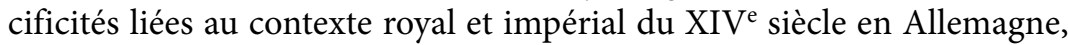
mais embarrassé par l'apparent «désordre» des mots, des formes et des chiffres (d'autant que rares sont les sources médiévales, dans l'espace germanique comme ailleurs, qui restituent une révolte dans son ensemble du début à la fin), l'historien s'est trouvé tenté par une remise en "ordre» conceptuelle. Celle-ci, surtout après 1945, s'est opérée par le biais de notions communes, héritées pour certaines de l'avant-guerre, telles que «Verfassungskämpfe», «Bürgerkämpfe», «Zunftrevolution» («combats constitutionnels», «combats civiques», «révolution des métiers», des trois c'est sans doute la plus idéologiquement connotée et celle qui fut abandonnée après 1945, y compris par les historiens est-allemands qui la remplacèrent parfois par celle de «Volksbewegung», de «mouvement populaire», en raison de la limitation trop restrictive des révoltes à la seule action prétendue des métiers), tandis que d'autres notions telles que «Stadtkonflikte» ou tout simplement «Auseinandersetzungen» («conflits urbains», «confrontations»), plus descriptives, s'imposaient dans les années 1980 à la faveur d’une désidéologisation de l'interprétation des troubles urbains. Ces concepts et notions eurent une longévité d'autant plus grande qu'ils se trouvaient à la fois partagés et disputés jusqu'en 1989 par deux historiographies, celle de l'Allemagne de l'Ouest et celle de l'Allemagne de l'Est (c'est la spécificité majeure de la question pour l'Allemagne) qui comptait justement parmi ses fleurons, on le comprendra sans mal, la recherche sur les révoltes urbaines ${ }^{61}$. Il faut noter que les recherches développées de part et d'autre ont moins porté sur la notion de révolte ou de lutte qu'elles n'ont davantage tourné autour de la question de la stratification sociale et de la distribution de la population urbaine en couches. On pourrait presque dire que la question des révoltes urbaines abordée par les médiévistes est-allemands emmenés par l'école de Karl $\mathrm{Czok}^{62}$ était moins portée à écrire une histoire idéologique de la révolution qu’à écrire une histoire sociale (médiévale) des classes: une histoire hautement politique (qui définit comme le fait Karl Czok la révolte comme un "Bürgerkampf», c'est-à-dire une "confrontation pour le contrôle du gouvernement de la ville entre les lignages possédants et dirigeants et l'opposition bourgeoise avec la participation de la pauvreté

${ }^{61}$ Pierre Monnet, L'histoire des villes médiévales en Allemagne: un état de la recherche, «Histoire urbaine», 11, 2004, pp. 131-172.

${ }^{62}$ Voir par exemple: Die Bürgerkämpfe in Süd- und Westdeutschland im 14. Jahrhundert, dans Carl Haase (dir.), Die Stadt des Mittelalters, vol. 3: Wirtschaft und Gesellschaft, Darmstadt 1976, pp. 303-327. 
urbaine» $)^{63}$, mais aussi une histoire appuyée sur un dépouillement systématique des registres fiscaux, tâche qui a en effet été accomplie dans les années 1960 à partir des fonds d'archives des villes côtières de la Hanse (Stralsund, Rostock...). C'est sans doute ce dialogue germano-allemand qui permit à l'école ouest-allemande, incarnée entre autres par Erich Maschke ${ }^{64}$, de desserrer l'étau des études constitutionnelles sur les villes en travaillant sur la notion de «Schicht», c'est-à-dire de «couche», dont la définition opératoire postule une société urbaine composée de strates essentiellement horizontales où les conflits se déclenchent aux frontières des couches et au moment où la verticalité devient trop forte et perturbante, ce qui revient à poser la question de l'ascension ${ }^{65}$. La participation et les motivations politiques et sociales des métiers face aux dirigeants (patriciens ou nobles) ont été au cœur des interprétations engendrées par cette approche, de même que l'attitude passive ou active des couches populaires. Cette focalisation des études ouest-allemandes sur les couches, et des études estallemandes sur les classes (cette dernière tendance posant la question des révoltes urbaines en termes de crise ou d'adaptation des villes à la féodalité tardo-médiévale), mettait en exergue, pour expliquer les révoltes, des mécanismes internes à la ville en soulevant plus précisément le problème de l'inadaptation des normes constitutionnelles («Verfassungsnormen») à la réalité constitutionnelle («Verfassungswirklichkeit»), charge aux révoltes de tenter à dates régulières de réduire le fossé entre les deux. Une telle approche ménageait une confrontation avec d'autres historiographies, notamment par le biais de la discussion du schéma tripartite pirennien qui voyait dans le XIII ${ }^{\mathrm{e}}$ siècle la lutte de la ville contre le seigneur pour la conquête des privilèges, dans le $\mathrm{XIV}^{\mathrm{e}}$ siècle la phase du patriciat opposé aux métiers ou sa variante du patriciat noble dressé contre le patriciat bourgeois pour le partage du pouvoir, et dans le $\mathrm{XV}^{\mathrm{e}}$ siècle la phase des métiers riches et occupés à la marchandise opposés aux métiers pauvres, déjà aliénés par le rapport au travail et de ce fait dominés, pour le partage des richesses ${ }^{66}$. On relèvera qu'un tel schéma avait d'ailleurs cours depuis les années 1950 dans l'historiographie soviétique. Sur un autre front, le dialogue des historio-

${ }^{63}$ Ibid., p. 303.

${ }^{64}$ Erich Maschke, Deutsche Städte am Ausgang des Mittelalters cit.; Id., Verfassung und soziale Kräfte in der deutschen Stadt des späten Mittelalters, vornehmlich in Oberdeutschland, «Vierteljahrschrift für Sozial- und Wirtschaftsgeschichte», 46, 1959, pp. 289-349 et 433-476; Id., Städte und Menschen, Wiesbaden, 1980, 2 vol.

${ }^{65}$ Ulf Dirlmeier, Merkmale des sozialen Aufstiegs und der Zuordnung zur Führungsschicht in süddeutschen Städten des Spätmittelalters, dans A. Guarducci (dir.), Gerarchie economiche e gerarchie sociali secoli XII-XVIII, Firenze 1990, pp. 171-214.

${ }^{66}$ Henri Pirenne, Les villes du Moyen Âge, rééd., PUF, Paris 1992. 
graphies allemandes avec l'historiographie italienne a pu se nouer notamment par le biais de l'institut germano-italien de Trente. Il s'est également noué, quoique dans une bien moindre mesure, avec l'historiographie française. Quelques exceptions peuvent être relevées dans cet échange modéré de part et d'autre du Rhin à propos des révoltes urbaines, d'une part la réception de l'historiographie est-allemande opérée par le biais polonais ${ }^{67}$, et de l'autre les travaux de Philippe Dollinger sur l'espace médian compris entre la France et l'Allemagne ${ }^{68}$ ainsi que le classique Ongles bleus, Jacques et Ciompi de Michel Mollat et Philippe Wolff qui constitue un bon témoignage de la réception en France de l'historiographie ouest-allemande tout en prenant acte de l'apport de l'historiographie est-allemande puisque Karl Czok y est abondamment cité tandis que le sous-titre de l'ouvrage se propose explicitement de discuter la notion de «révolution ${ }^{69}$. Il n'est pas inutile de rappeler les lignes de force de la démonstration de ce classique pour les pages qui concernent l'Empire. À suivre le fil de l'ouvrage, le XIV ${ }^{\mathrm{e}}$ siècle est caractérisé dans les villes de l'Empire par l'opposition entre patriciat et métiers, lesquels se frayent une place dans les Conseils sans que le système urbain en sorte fondamentalement bouleversé. La typologie des trois Allemagnes proposée par cette synthèse se situe dans le droit fil des recherches allemandes des années 1950-1970: d'un côté une Hanse patricienne et oligarchique, c'est-à-dire faiblement corporative; de l'autre un vaste Sud-Ouest et une Rhénanie supérieure rendus plus «démocratiques» par le jeu des métiers (on peut citer Strasbourg mais aussi Constance, que le livre ne mentionne pas mais qui convient encore mieux au schéma proposé avec les trois révoltes de 1342, 1370 et 1389 qui semblent signaler le triomphe des métiers); enfin le reste de l'Allemagne constituant un type mixte des deux premiers modèles. On retient de la lecture du livre que les révoltes du XIV ${ }^{e}$ siècle dans l'Empire ne changent pas la donne territoriale et économique et qu'il ne peut être question de «révolution». Il est intéressant de remarquer que, parmi les grands exemples traités, ce sont hormis Strasbourg et Nuremberg les cas de villes de l'Allemagne médiane et surtout

${ }^{67}$ On pense notamment aux travaux de Bronislaw Geremek Le salariat dans l'artisanat parisien aux XIII ${ }^{\mathrm{e}}-\mathrm{XV} \mathrm{e}^{\mathrm{e}}$ siècles, Paris 1968 et Les marginaux parisiens aux XIV $\mathrm{e}_{-}$ $X V^{\mathrm{e}}$ siècles, Paris 1976.

${ }^{68}$ Philippe Dollinger, Le patriciat des villes du Rhin supérieur et ses dissensions internes dans la première moitié $d u X I V^{e}$ siècle, «Schweizerische Zeitschrift für Geschichte», 3, 1952, pp. 248-258; Id., Patriciat noble et patriciat bourgeois au XIV siècle, "Revue d'Alsace», 90, 1950-1951, pp. 52-82; Id., Das Patriziat der oberrheinischen Städte und seine inneren Kämpfe in der ersten Hälfte des 14. Jahrhunderts, dans Heinz Stoob (dir.), Altständisches Bürgertum, Darmstadt 1978, pp. 194-209.

${ }^{69}$ Michel Mollat, Philippe Wolff, Ongles bleus, Jacques et Ciompi. Les révolutions populaires en Europe aux XIV et $X V^{\mathrm{e}}$ siècles. Paris 1970. 
septentrionale qui sont convoqués, c'est-à-dire le monde de la Hanse et de son arrière-pays. L'autre fait frappant, à relire Ongles bleus, réside dans le fait que le triptyque des trois Allemagnes est entièrement intra-muresque: rien sur les ligues, rien surtout sur l'intervention des princes et du roi. Or, on peut certes ranger la Franconie par exemple dans la première catégorie des villes demeurées oligarchiques, mais parce que le roi l'a voulu ainsi, spécialement Louis de Bavière puis Charles IV pour «leurs» villes d'Empire du $\mathrm{Sud}^{70}$, en y incluant aussi Francfort.

La double historiographie germano-allemande ouverte sur les autres historiographies européennes des années 1960-1980 peut dès lors se résumer à deux caractéristiques principales: une explication essentiellement interne à la ville et, ce point est lié au précédent, une motivation sociale des conflits, dont l'interprétation de fond oscille entre une crise du féodalisme d'un côté (est) ou une modernisation par le droit et le contrat de l'autre (ouest), l'une et l'autre grille permettant de ne pas exclure les campagnes de ce récit. On retrouve ce double tropisme dans l'historiographie classique rassemblée dans deux synthèses publiées à une vingtaine d'années d'intervalle: le livre d'Edith Ennen d'un côté ${ }^{71}$, celui d'Evamaria Engel de l'autre $^{72}$, ce dernier particulièrement intéressant en cela qu'il provient d'un tout autre horizon idéologique que le premier puisqu'il reflète l'école estallemande d'histoire urbaine, mais aussi parce qu'il fut conçu peu avant 1989 et a été publié, avec ses options clairement affichées et inchangées, après la réunification par un éditeur ouest-allemand. On rencontre donc des différences marquées d'approche d'un livre à l'autre, celui d'Edith Ennen s'inscrivant assez bien dans une historiographie typique de l'Allemagne fédérale du miracle économique et de la construction européenne (la ville allemande est confrontée à ses voisines italiennes et françaises et, pour la fin du Moyen Âge, se caractérise par son innovation économique qui fonde une typologie entrepreneuriale synonyme par ailleurs d'une perte du lien social et d'une dégradation de l'environnement) tandis que celui d'Evamaria Engel se fait l'écho d'une historiographie estallemande attentive aux conflits politiques dans la ville, au caractère révolutionnaire du mouvement communal, à la fonction de prélèvement de l'économie urbaine sur l'économie agraire, à la formation des ligues urbaines et à la naissance de la notion de marché encadré par une bourgeoisie

${ }^{70}$ Peter-Johannes Schuler, Die Rolle der schwäbischen und elsässischen Städtebünde in den Auseinandersetzungen zwischen Ludwig dem Bayern und Karl IV. cit.; BerndUlrich Hergemöller, Fürsten, Herren und Städte zu Nürnberg 1355/56. Die Entstehung der Goldenen Bulle Karls IV. cit.

${ }^{71}$ Die europäische Stadt des Mittelalters, Göttingen 1972.

72 Die deutsche Stadt des Mittelalters, München 1992. 
anti-féodale. Les chapitres consacrés de part et d'autre aux révoltes présentent cependant d'assez notables points communs. C'est ainsi que l'on retrouve chaque fois un parallèle assez classique établi entre la révolte des métiers de Cologne en 1396 ou même celle de 1384 à Lübeck (révolte menée par le marchand de chapelets d'ambre, le bien nommé Heinrich Paternostermacher) et celle de Florence de 1378. Il faut dire qu'avec une population évaluée dans les deux cas à 25.000/30.000 habitants, Cologne et Lübeck sont alors les deux plus grosses villes de l'Empire, c'est-à-dire présentent une taille qui permet une comparaison lointaine avec les métropoles italiennes, sans pourtant que l'on rencontre à Cologne et à Lübeck une revendication salariale semblable à ce que l'on peut observer en 1378 à Florence, faute sans doute de concentration ouvrière d'ampleur comparable. On remarquera qu'au sein d'une même page (facteur commun aux deux synthèses mentionnées), les deux événements reçoivent successivement les qualificatifs de "Aufstand», "Auseinandersetzung», «Gewaltstreich», «Umsturz», «Rebellion», «Tumult», «Aufruhr», «Unruhe», comme si en dépit des constructions historiographiques différenciées et affirmées, ni le marché d'un côté ni l'anti-féodalité de l'autre ne parvenaient à fournir un seul terme pour désigner des troubles complexes et multiformes. La description et l'issue des deux grandes révoltes de 1384 et de 1396 suivent ensuite le même schéma explicatif: aux dissensions apparues au sein du groupe dirigeant entre un patriciat ancien et une nouvelle marchandise succède une alliance stratégique conclue entre un clan au pouvoir et les métiers supérieurs écartés du gouvernement urbain (par exemple les tisserands, foulons et tailleurs à Cologne exclus de la constitution de 1378) ${ }^{73}$. S'ensuit une phase de débordements violents achevée par un compromis passé entre la couche marchande (qui se réserve dans le Verbundbrief de Cologne $65 \%$ des sièges du nouveau Conseil) et le patriciat précédemment écarté mais qui revient aux affaires pour museler les métiers trop remuants $^{74}$.

Par ailleurs, Cologne et Lübeck avaient ceci de commun qu'elles étaient au cœur de l'organisation hanséatique qui atteint son apogée au XIV ${ }^{\mathrm{e}}$ siè-

73 Wolfgang Herborn, Die politische Führungsschicht der Stadt Köln im Spätmittelalter, Bonn 1977; Klaus Militzer, Ursachen und Folgen der innerstädtischen Auseinandersetzungen in Köln in der zweiten Hälfte des 14. Jahrhunderts, Köln 1980.

${ }^{74}$ Reinhard Barth, Argumentation und Selbstverständnis der Bürgeropposition in städtischen Auseinandersetzungen des Spätmittelalters. Lübeck 1403-1408, Braunschweig 1374-1376, Mainz 1444-1446, Köln 1396-1400, Hamburg 1974; Gudrun Gleba, Die Gemeinde als alternatives Ordnungsmodell. Zur sozialen und politischen Differenzierung des Gemeindebegriffs in den innerstädtischen Auseinandersetzungen des 14. und 15. Jahrhunderts. Mainz, Magdeburg, München, Lübeck, Köln/Wien 1989. 
$\mathrm{cle}^{75}$. De fait, un point spécifique de focalisation de l'écriture allemande des révoltes a consisté depuis longtemps dans l'observation des conflits à l'intérieur des villes de la Hanse. La conclusion largement acceptée s'accorde à dire que, sur le long terme, les contestations des années 13601380 n'ont jamais vraiment réussi à remettre en cause la domination des élites marchandes liées au commerce de la Hanse dans ces villes, d'autant qu'une forme de solidarité entre les gouvernements urbains paraît s'être développée pour assurer aux couches dirigeantes respectives le prolongement de leur pouvoir. Le sort de Carsten Sarnow, marchand de Stralsund allié aux petits métiers pour s'emparer du Conseil puis exécuté au début des années 1390 semble emblématique de ce maintien des mêmes groupes au Conseil et du jeu de la solidarité intra-hanséatique. Cette dernière, on l'a vu, joua également un rôle important au cours des troubles qui agitèrent Brunswick en 1374: le bourgmestre et huit conseillers furent exécutés sommairement lors d'une révolte conduite par les artisans des quartiers périphériques de la ville contre les familles dirigeantes du vieux centre (Altstadt), ce quartier payant le plus lourd tribut avec quatre des huit conseillers tués et 37 des 52 conseillers chassés qui en étaient originaires. En dehors de la prise en compte nouvelle du facteur de la politique extérieure dans cet épisode (une politique aventureuse d'alliance et les revers subis face aux princes de Saxe ont conduit le Conseil de Brunswick à augmenter la pression fiscale pour financer la guerre), la dimension spatiale de la révolte constitue l'autre nouveauté relevée par l'historiographie sur le sujet. Quant à la solidarité intra-hanséatique, elle joua à plein puisque Brunswick fut exclue de la Hanse par la diète en 1375 sous la pression de Lübeck, Hambourg et Lunebourg où s'étaient réfugiés les conseillers bannis depuis 1374. Le nouveau Conseil, confronté à une crise économique aggravée par l'exclusion de la Hanse, proposa un compromis en 1380, marqué par le retour des bannis et par l'adoption en 1386 d'une nouvelle constitution qui rétablit plus ou moins la suprématie des lignages de l'Altstadt ${ }^{76}$.

${ }^{75}$ Jürgen Bracker, Volker Henn, Rainer Postel (dir.), Die Hanse. Lebenswirklichkeit und Mythos, Lübeck 1989; Philippe Dollinger, La Hanse (XII ${ }^{\mathrm{e}}-X V I I^{\mathrm{e}}$ siècles), rééd. Paris 1988. Klaus Friedland, Die Hanse, Berlin/Köln 1991;Angelo Pichierri, Die Hanse - Staat der Städte. Ein ökonomisches und politisches Modell der Städtevernetzung (Stadt - Raum - Gesellschaft), Opladen 2000; Horst Wernicke (dir.), Die Städtehanse 1280-1418, Weimar 1983.

${ }^{76}$ Hans-Leo Reimann, Unruhe und Aufruhr im mittelalterlichen Braunschweig, Braunschweig 1962; Jürgen Bohmbach, Die Sozialstruktur Braunschweigs um 1400, Braunschweig 1973; Wilfried Ehbrecht, Hanse und mittelalterliche Bürgerkämpfe in Niedersachsen und Westfalen, «Niedersächsisches Jahrbuch», 48, 1976, pp. 77-105; Matthias Puhle, Die Braunschweiger, Schichten' des späten Mittelalters und ihre verfassungsrechtlichen Folgen, dans Manfred R. W. Grazmann (dir.), Rat und Verfassung im 
Mais, au-delà des différences, un principe commun semble relier les trois épisodes de Lübeck, Cologne et Brunswick détachés par l'historiographie susmentionnée: l'agitation entretenue par les métiers les plus orientés vers le commerce. Une fois ceux-ci partiellement satisfaits ou matés, l'ordre politique ancien revient en force et, à la fin du XIV ${ }^{\mathrm{e}}$ siècle, le bilan des troubles équivaut à un statu quo.

Cette conclusion de l'historiographie ouest-allemande des années 19601980, rejointe par sa partenaire orientale en la matière, soulignant la pérennité du pouvoir des couches dirigeantes en dépit des révoltes et de la crise du XIV ${ }^{\mathrm{e}}$ siècle, s'inscrit dans un mouvement de fond qui la déborde en amont et en aval. Dès $1953^{77}$, Philippe Dollinger démontrait que les couches dirigeantes des villes du Rhin supérieur ne constituaient nullement une couche sociale homogène mais agrégeaient des éléments nobles, ministériaux et «bourgeois» ${ }^{78}$ qui se regroupaient en factions instrumentalisant tel ou tel corps de métier pour déstabiliser l'autre. À partir du cas strasbourgeois, il pouvait montrer que si les métiers puissants étaient parvenus dès 1308 à briser le monopole du Conseil patricien et noble, les troubles de 1338 (annoncés par les combats de rue qui avaient opposé dès 1332 les clans des Zorn et des Mülnheim $)^{79}$ reflétaient une image plus complexe aboutissant à la formation d'un Conseil de 50 membres composé pour moitié d'anciennes familles demeurées au pouvoir en jouant de l'alliance avec certains corps de profession en rupture avec le reste des métiers, attirés par l'élite dirigeante et, ce faisant, «politisés» et «légitimés». Des études postérieures $^{80}$ ont repris ce schéma d'une division des élites entre patriciat ancien et métiers supérieurs, division aboutissant à un partage du pouvoir urbain dont l'accès demeura finalement aussi étroit qu'au XIII ${ }^{\mathrm{e}}$ siècle. Presque au même moment, Erich Maschke montrait dans un article fondateur que les troubles suscités par les métiers les plus développés et évolués des villes de Haute-Allemagne ne revendiquaient en rien l'établissement d'un ordre social et politique nouveau mais souhaitaient un meilleur partage du pouvoir, revendication détournée à leur profit par les

mittelalterlichen Braunschweig, Braunschweig 1986, pp. 235-251; Mathias Puhle, Die 'Große Schicht' in Braunschweig, dans Jörgen Bräcker, Volker Henn, Rainer Postel (dir.), Die Hanse. Lebenswirklichkeit und Mythos cit., pp. 812-822.

${ }^{77}$ Philippe Dollinger, Le patriciat des villes du Rhin supérieur et ses dissensions internes dans la première moitié du XIV $V^{e}$ siècle cit.

${ }^{78}$ Philippe Dollinger, Patriciat noble et patriciat bourgeois au XIV siècle cit.

${ }^{79}$ Philippe Dollinger, Das Patriziat der oberrheinischen Städte und seine inneren Kämpfe in der ersten Hälfte des 14. Jahrhunderts cit.

${ }^{80}$ Martin Alioth, Gruppen an der Macht. Zünfte und Patriziat in Strassburg im 14. und 15. Jahrhundert. Untersuchungen zu Verfassung, Wirtschaftsgefüge und Sozialstruktur, Basel/Frankfurt am Main 1988. 
élites anciennes pour rester au pouvoir ${ }^{81}$. Plus récemment, d'autres analyses ont repris l'interprétation de certains conflits compris comme des luttes entre groupes et factions déjà au pouvoir économique et politique de la cité. C’est ainsi que les événements survenus à Lübeck entre 1408 et 1416, au terme desquels l'ancien Conseil renversé revient aux affaires après avoir entrouvert la porte à quelques nouveaux issus de métiers supérieurs, ont été observés à la lumière d'une entente au sommet ignorant le reste du Commun et des métiers ${ }^{82}$. Une analyse semblable a pu être menée dans le cas de la ville de Minden en $1405^{83}$. De la même façon, les conflits urbains survenus à Ratisbonne et à Ulm ont pu être interprétés à la lumière des oppositions entre les factions formées au sein des groupes dirigeants, à l'image de la lutte des Auer contre les Chratzer dans cas de Ratisbonne et du combat des Kunzelmann contre les Roth dans le cas d'Ulm ${ }^{84}$. À Hildesheim, l'étude du déroulement des troubles de 1343 (le «uplop» des sources) a montré qu'il convenait de chercher les origines et les étapes du conflit parmi les huit «vieilles» familles qui occupaient alors près des deux tiers des 36 sièges du Conseil, davantage que parmi les homines novi menant la lutte, lesquels finirent certes par entrer dans le nouveau gouvernement mais uniquement avec l'appui des représentants de l'ancien Conseil ${ }^{85}$. À Constance, l'étude des cinq grands troubles urbains survenus entre 1342 et $1430 \mathrm{a} \mathrm{mis}$ en exergue le rôle central tenu par l'épisode de 1370 au cours duquel un groupe de cinq familles patriciennes, jusqu'alors exclues du gouvernement, a manœuvré aux côtés des métiers pour forcer les portes du Conseil ${ }^{86}$. L'analyse de l'évolution politique et sociale de la ville de Spire au XIV ${ }^{\mathrm{e}}$ siè-

${ }^{81}$ Erich Maschke, Verfassung und soziale Kräfte in der deutschen Stadt des späten Mittelalters, vornehmlich in Oberdeutschland cit.

${ }^{82}$ Reinhard Barth, Argumentation und Selbstverständnis der Bürgeropposition in städtischen Auseinandersetzungen des Spätmittelalters. Lübeck 1403-1408, Braunschweig 1374-1376, Mainz 1444-1446, Köln 1396-1400 cit.; Rhiman A. Rotz, The Lubeck Uprising of 1408 and the Decline of the Hanseatic League, «Proceedings of the American Philosophical Society» cit.; Friedrich Bernward Fahlbusch, Städte und Königtum im frühen 15. Jahrhundert. Ein Beitrag zur Geschichte Sigmunds von Luxemburg, Köln/Wien 1983, pp. 82-95.

${ }^{83}$ Wilfried Ehbrecht, Form und Bedeutung innerstädtischer Kämpfe am Übergang vom Mittelalter zur Neuzeit: Minden 1405-1535, dans Wilfried Ehbrecht (dir.), Städtische Führungsgruppen und Gemeinde in der werdenden Neuzeit, Köln/Wien 1980, pp. 115-152.

${ }^{84}$ Alfred Haverkamp, Innerstädtische Auseinandersetzungen und überlokale Zusammenhänge in deutschen Städten während der ersten Hälfte des 14. Jahrhunderts cit.

${ }^{85}$ Brigitte Schwarz, Der uplop van den penninghen in Hildesheim 1343, dans Wilfried Ehbrecht (dir.), Städtische Führungsgruppen und Gemeinde in der werdenden Neuzeit cit., pp. 99-113.

${ }^{86}$ Edi Joos, Die Unruhen der Stadt Konstanz 1300-1450 cit. 
cle a conclu à la thèse d'une redistribution du pouvoir par le jeu des factions patriciennes et marchandes parvenant en 1304 à éliminer à la fois «par le haut» les anciennes élites des monétaires de la ville (Münzerhaus-genossenschaft) et «par le bas» les métiers les plus en pointe qui souhaitaient faire leur entrée dans les instances du Conseil ${ }^{87}$.

L'historiographie est-allemande a bien rejoint, à partir de postulats différents, l'interprétation globale d'une vague de troubles qui, pour s'accumuler dans le dernier tiers du XIV ${ }^{\mathrm{e}}$ siècle, n'en remettent pas pour autant en cause les structures politiques et sociales fondamentales de la société urbaine, une conclusion finalement assez en phase avec le développement des pays européens après la crise de 1968. Toutefois, au-delà de cette commune analyse socio-politique focalisée sur les métiers et sur les couches/classes (sans qu'un consensus se soit dégagé sur le degré de différenciation sociale, simple ou complexe, de la société urbaine tardo-médiévale), l'historiographie est-allemande avait davantage que sa consoeur proposé une interprétation plus globale des révoltes urbaines au sein d'une triple conjonction constitutionnelle, politique et sociale formée, en premier lieu, par le détournement de la force intégratrice de la conjuration communale au profit d'un petit groupe ${ }^{88}$, en second lieu par l'offensive princière et royale contre le monde urbain (spécialement sous Charles IV avec, pour réponse urbaine, la formation des ligues), en troisième lieu par la paupérisation de la société urbaine liée à l'augmentation du capital marchand dont la concentration débordait sur les campagnes par l'achat de terres d'un côté et par l'introduction des premières formes de travail à la commande dans les villages de l'autre ${ }^{89}$. Il faut donc retenir de ce schéma explicatif d'ensemble, lié à l'analyse de la crise du féodalisme, non pas tant les conséquences limitées de la vague des révoltes du second XIV ${ }^{\mathrm{e}}$ siècle (la révolution n’a pas eu lieu et il faut attendre la Réforme pour trouver une radicalité bien plus poussée...) mais davantage ce que cette vague révèle des structures politiques et sociales d'ensemble de la société. C'est cette approche qui justifie dès lors, dans ce courant, l'emploi du terme de «Bürgerkampf» (qui fait la «Bürgerstadt», au sens où c'est la lutte qui fait le citoyen-bourgeois) pour désigner les révoltes, ensuite seulement séparées en «Unruhe» (désordre, rébellion) de nature extra-constitutionnelle et en «Aufruhr» (soulèvement) empruntant des voies politiques canalisant la vio-

${ }^{87}$ Ernst Voltmer, Reichsstadt und Herrschaft. Zur Geschichte der Stadt Speyer im hohen und späten Mittelalter cit.

${ }^{88}$ Werner Mägdefrau, Revolutionäre kommunale Bewegungen und spätmittelalterliche Bürgerkämpfe in den Städten des Thüringer Dreistädtebundes, Jena 1971.

${ }^{89}$ Michael Borgolte (dir.), Mittelalterforschung nach der Wende 1989 cit.; Id., Sozialgeschichte des Mittelalters cit. 
lence dans un cadre constitutionnel inchangé. Parallèlement, se développait du côté ouest-allemand, et finalement s'imposait après 1989, un schéma d'une part plus sociologique et plus large délaissant la notion de couche pour celle de groupe social et d'autre part un schéma plus synthétique et descriptif s'intéressant à la pluralité des conflits («Stadtkonflikten»), c'està-dire à un phénomène qui pouvait inclure aussi bien les conflits sociaux que les conflits institutionnels, intra- et extra-urbains, avec les seigneurs, avec le clergé, avec les princes... Cette ouverture signalait deux avancées: la première consistait à tirer parti de la théorie des conflits d'un côté et la seconde à ne pas séparer les conflits internes à la ville de ceux qu'elle devait conduire et subir au dehors (ligues, faides, guerres), les derniers déclenchant souvent les premiers qui peuvent en retour relancer ceux-ci.

À partir de la notion de conflits s'est introduite à la fin des années 1980 une césure ${ }^{90}$ qu'est venue renforcer la disparition brutale de tout l'appareil académique est-allemand peu après 1989 et qu'est venue conforter une tendance historiographique lourde en faveur d'une histoire culturelle de la violence et du règlement des conflits d'un côté (gestes, rituels, discours $)^{91}$, et d'une histoire sociale renouvelée par les approches anthropologiques de l'autre (des élites vers les marginaux, des états vers les groupes, de l'immobilité vers la mobilité $)^{92}$. Ce tournant s'est signalé de deux manières. D'un côté par l'introduction des apports nouveaux d'une histoire rénovée du droit ${ }^{93}$. Plus particulièrement, ce travail des historiens du droit s'est concentré non seulement sur l'évolution de l'appareil judiciaire urbain à la faveur des révoltes, mais également sur la condamnation des meneurs (en évoquant la question de la justice politique) ${ }^{94}$. Il

${ }^{90}$ Sur ce changement des paradigmes: Steffen Patzold, Konflikte als Thema in der modernen Mediävistik, dans Hans-Werner Goetz, Moderne Mediävistik. Stand und Perspektiven der Mittelalterforschung, Darmstadt 1999, pp. 198-205.

${ }^{91}$ Sur le tournant correspondant en France, voir le volume des actes du congrès des Médiévistes (SHMESP) à Angers en 2000: Le règlement des conflits au Moyen Âge, Paris, 2001. Voir aussi, dans une perspective franco-allemande, le volume des Tendances actuelles de la recherche en histoire médiévale en France et en Allemagne sous la direction de Jean-Claude Schmitt et Otto Gerhard Oexle, Paris 2002.

${ }^{92}$ Sur ce dernier point et particulièrement sur le lien entre mobilité et conflit, ibid., pp. 225-235.

${ }^{93}$ Eberhard Isenmann, Die deutsche Stadt im Spätmittelalter cit.; Karl S. Bader, Gerhard Dilcher, Deutsche Rechtsgeschichte. Land und Stadt im alten Europa, Berlin 1999. Eberhard Isenmann, Gesetzgebung und Gesetzgebungsrecht spätmittelalterlicher deutscher Städte, «Zeitschrift für historische Forschung», 28, 2001, pp. 1-94 et 161-262; Pierre Monnet, Otto Gerhard Oexle (dir.), La ville et le droit au Moyen Âge. Stadt und Recht im Mittelalter, Göttingen 2003.

${ }^{94}$ Friedrich Battenberg, Herrschaft und Verfahren, Politische Prozesse im mittelalterlichen römisch-deutschen Reich, Darmstadt 1995; Ulrich Andermann, Politische Justiz 
reste sans doute encore à approfondir la question de savoir quand la justice urbaine leur appliquait le droit commun des criminels ou bien quand une juridiction d'exception était constituée, ainsi par exemple à Brunswick en 1374-1380, au titre de la lutte contre le tyran, ou bien en 1396 à Lindau. De même conviendrait-il d'en savoir davantage sur le lien entre révolte et procédure inquisitoriale, entre révolte et accusation d'hérésie, un problème central en Rhénanie d'un côté et aux confins des pays de Bohême de l'autre ${ }^{95}$. Dans un second temps, les historiens du droit ont porté leur attention sur les modes d'argumentation juridique qui permettent aux juristes du temps de distinguer entre la guerre juste qui met aux prises deux adversaires de même condition juridique et la sédition qui fait intervenir deux acteurs dans une relation déséquilibrée et donc condamnable de droit. D'autre part, des études ont mis au jour le rôle joué par l'accusation de mauvaise justice portée contre le Conseil dans la motivation des révoltes: Brunswick en 1293, Erfurt en 1309, Spire en 1330 ou Rottweil en 1378 en apportent de bons témoignages. La question du décalage entre les normes constitutionnelles et la pratique constitutionnelle a été également débattue sous l'angle des normes juridiques, la révolte devenant le révélateur et le moment d'ajustement de ce décalage. Enfin, l'observation du règlement juridique des conflits par la mise en place d'une procédure de paix négociée et signée par une lettre de paix a conduit à constater qu'au XIV ${ }^{\mathrm{e}}$ siècle, de ville en ville, suivant d'ailleurs une géographie intéressante des révoltes, le vocabulaire contenu dans la lettre de conciliation et de réconciliation (Erfurt en 1309, Magdebourg en 1330, Zurich en 1336, Francfort en 1358, Augsbourg en 1368, Brunswick en 1380, Nordhausen en 1375, Cologne en 1396) traduisait une forme d'uniformisation ${ }^{96}$. On retrouve presque partout les mêmes arguments aux mêmes endroits touchant la bonne coutume, le bien commun ${ }^{97}$,

im Spätmittelalter. Neue Fragen zu niederdeutschen Stadtkonflikten, dans Hans-Peter Becht, Jörg Schadt (dir.), Wirtschaft - Gesellschaft - Städte. Festschrift für Bernhard Kirchgässner zum 75. Geburtstag, Ubstadt-Weiher 1998, pp. 43-63.

${ }^{95}$ František Graus, Pest - Geissler - Judenmorde. Das 14. Jahrhundert als Krisenzeit cit., pp. 408-509.

${ }_{96}$ Bernd Kannowski, Bürgerkämpfe und Friedebriefe. Rechtliche Streitbeilegung in spätmittelalterlichen Städten cit.

${ }^{97}$ Peter Hibst, Utilitas publica. Gemeiner Nutz - Gemeinwohl, Frankfurt am Main 1991; Pierangelo Schiera, 'Bonum Commune' zwischen Mittelalter und Neuzeit. Überlegungen zur substantiellen Grundlage der modernen Politik, "Archiv für Kulturgeschichte», 1999, pp. 283-303; Winfried Eberhard, Der Legitimationsbegriff des 'gemeinen Nutzens' im Streit zwischen Herrschaft und Genossenschaft im Spätmittelalter, dans Jörg O. Fichte, Karl-Heinz Göller, Bernhard Schimmelpfennig (dir.), Zusammenhänge, Einflüsse und Wirkungen (Kongressakten zum ersten Symposium des Mediävistenverbandes in Tübingen, 1984), Berlin 1986, pp. 241-254; Peter Blickle, Der 
l'égalité et l'union entre riches et pauvres ${ }^{98}$, l'amitié, la réforme. L'analyse de la notion de crimen lesae majestatis appliquée à la révolte urbaine constitue sans doute une autre originalité de cet ensemble d'études juridiques, d'autant que l'on peut l'observer à trois niveaux d'application: par le Conseil de ville lui-même ou par les villes entre elles, par le prince (Wetzlar en 1372, Munich en 1397) et le roi (Wurtzbourg en 1400, Breslau en 1420), par l'Église aussi. Ce sont là trois niveaux de discours qui permettent à la fois de condamner mais aussi de gracier. La question de la grâce est cependant moins développée de ce côté du Rhin en raison de la plus faible représentation d'une histoire anthropologique du droit en Allemagne, sans doute due à une coupure plus nette encore qu'en France séparant le droit, l'histoire et l'histoire du droit. On signalera encore, parmi les champs d'enquête ouverts par une nouvelle histoire du droit et des institutions, que l'on ne dispose pas d'étude globale sur les forces de police et de sergents dont le Conseil disposait face aux révoltes: l'impression demeure d'effectifs faibles, comme ailleurs, mais la capacité de résistance policière et militaire du pouvoir en place à la révolte est quand même essentiel pour notre propos.

Parallèlement, il convient de souligner l'apport qu'a constitué depuis les années 1990 une histoire des rituels appliquée à la thématique ${ }^{99}$. C'est ainsi que les épisodes de la genèse du conflit, puis de son déroulement et de son règlement ont été revisités en fonction de phases nettement distinguées entre le rassemblement («sammenunge»), le défilé des bannières («bannerlauf»), l'occupation des portes de la ville, le retour vers l'Hôtel du Conseil et la prestation d'un nouveau serment (Rothenbourg en 1348, Spire en 1327, Ratisbonne en 1330). Emblématique de ce point de vue est le rituel d'amende honorable qui met fin, en 1380, à Lübeck, au conflit survenu au sein du Conseil de Brunswick ou bien la construction de chapelles d'expiation et de réconciliation, à des fins de réparation de l'honneur des individus et de la ville tout à la fois ${ }^{100}$, après des révoltes à Brunswick en

Gemeine Nutzen. Ein kommunaler Wert und seine politische Karriere, dans Herfried Münkler, Harald Bluhm (Hg.), Gemeinwohl und Gemeinsinn. Historische Semantiken politischer Leitbegriffe, Berlin 2002, pp. 85-107.

${ }_{98}$ Barbara Frenz, Gleichheitsdenken in deutschen Städten des 12. bis 15. Jahrhunderts. Geistesgeschichte, Quellensprache, Gesellschaftsfunktion, Köln 2000.

${ }^{99}$ Jean-Claude Schmitt, Otto Gerhard Oexle (dir.), Les tendances récentes de l'histoire du Moyen Âge en France et en Allemagne cit.; Hans-Werner Goetz (dir.), Die Aktualität des Mittelalters, Bochum 2000; Pierre Monnet, L'histoire des villes médiévales en Allemagne: un état de la recherche cit.; Jörg Jarnut, Bernd Schneidmüller (dir.), Mediävistik im 21. Jahrhundert. Stand und Perspektiven der internationalen und interdisziplinären Mittelalterforschung, München 2003.

${ }^{100}$ Jörg Rogge, Ehrverletzungen und Entehrungen in politischen Konflikten in spätmittelalterlichen Städten, dans Klaus Schreiner, Gerd Schwerhoff (dir.), Verletzte Ehre. 
l'honneur de saint Auctor en 1380 (mesure complétée par un pèlerinage à Rome pour huit conseillers rebelles) et à Magdebourg en l'honneur de saint Matthieu. En 1416, à Lübeck, un rituel de réconciliation accompagne le retour du Conseil déchu qui rentre dans la Marienkirche puis dans l'Hôtel de la ville. On citera également, selon le même point de vue, les recherches menées sur les processions, et plus particulièrement sur les défilés du Fastnacht dont certains ont tourné à l'émeute, ainsi à Bâle en 1376 (Böse Fastnacht) et à Magdebourg en $1397^{101}$. Le rôle de la rumeur n'a pas été occulté et il a été analysé de manière originale en relation avec les pogroms perpétrés contre les Juifs dans les années 1349-1350 102 et, d'autre part, du point de vue des lieux, en lien avec l'espace de la révolte et son extension, souvent depuis les réunions aux abords des couvents mendiants (Zurich, Francfort-sur-le-Main, Wetzlar) ou bien des auberges ${ }^{103}$. Dans ce prolongement, une attention renouvelée a été accordée aux cloches (Strasbourg en 1349, Zurich en 1370, Bâle en 1376), mais aussi aux bannières. À propos de ces dernières, Herman Bote le chroniqueur de Brunswick du XV $\mathrm{XV}^{\mathrm{e}}$ siècle (vers 1450-1520) rappelle leur rôle dans le déclenchement de la révolte de 1293 ( «Aufluf») menée par les métiers qui a commencé par un défilé des «bannières, écussons et boucliers» ${ }^{104}$. Ces bannières sont également déter-

Ehrkonflikte in Gesellschaften des Mittelalters und der Frühen Neuzeit, Köln/Weimar/ Wien 1995, pp. 110-143

${ }^{101}$ Leander Petzoldt, Narrenfeste. Fastnacht, Fasching, Karneval in der Bürgerkultur der frühen Neuzeit, dans Uwe Schultz (dir.), Das Fest. Eine Kulturgeschichte von der Antike bis zur Gegenwart, München 1988; Harry Kühnel, Die städtische Fastnacht im 15. Jahrhundert. Das disziplinierte und öffentlich finanzierte Volksfest, dans Peter Dinzelbacher, Hans Dieter Mück (dir.), Volkskultur des europäischen Mittelalters, Stuttgart 1987, pp. 109-127; Dietz-Rüdiger Moser, Fastnacht, Fasching, Karneval. Das Fest der "verkehrten Welt", Graz 1986 et sa contribution Fastnacht und Fronleichnam als Gegenfeste. Festgehaltung und Festgebrauch im liturgischen Kontext, dans Detlef Altenburg, Jörg Jarnut, Hans-Hugo Steinhoff (dir.), Feste und Feiern im Mittelalter, Sigmaringen 1991, pp. 359-376. Sur le lien avec les jeux de la Passion: Dorothea Freise, Geistliche Spiele in der Stadt des ausgehenden Mittelalters, Göttingen 2002.

${ }^{102}$ František Graus, Pest - Geissler - Judenmorde. Das 14. Jahrhundert als Krisenzeit cit., pp. 155-390.

${ }^{103}$ Hans-Conrad Peyer, Gastfreundschaft, Taverne und Gasthaus im Mittelalter, München/Wien 1976; Id., Von der Gastfreundschaft zum Gasthaus. Studien zur Gastlichkeit im Mittelalter, Hannover 1987.

${ }^{104}$ Joachim Ehlers, Hermen Bote und die städtische Verfassungskrise seiner Zeit cit.; Detlev Schöttker, Werner Wunderlich (dir.), Hermen Bote. Braunschweiger Autor zwischen Mittelalter und Neuzeit cit.; Hartmut Boockmann, Eine Krise im Zusammenleben einer Bürgerschaft und ein 'politologisches' Modell aus dem 15. Jahrhundert. Der Braunschweiger Chronist Hermen Bote über den Aufstandsversuch von 1445/1446 cit.; Herbert Blume, Eberhard Rohse (dir.), Hermann Bote. Städtisch-hansischer Autor in Braunschweig 1488-1988 cit.; Hartmut Boockmann, Ein skeptischer Bürger beschreibt Umsturzversuche cit. 
minantes dans le déroulement de la «Weberschlacht» de Cologne en novembre 1371 ou bien quand les métiers, qui obtiennent gain de cause à Strasbourg en 1332 en voyant le Conseil passer de 24 à 50 sièges, confisquent le sceau et la bannière de la ville. À Brême, à la fin du conflit de 1304, une procession réunit les deux partis opposés sous les deux bannières rassemblées et, dans cette même ville, en 1365, le défilé des bannières, «bannerelop», s'achève par l'incendie du quartier patricien, tandis qu'après le retour au calme, la réconciliation se fait sous la forme d'une refonte du sceau urbain et d'une réparation de la statue de Roland qui avait été renversée (statue qui, représentant les libertés urbaines, cristallise autour d'elle, à Halle comme à Magdebourg par exemple, le déroulement des conflits... $)^{105}$. De même, les couleurs ont été prises en compte: sans atteindre le niveau de perfectionnement et de symbolique des villes italiennes, le jeu des couleurs s'affrontant dans la révolte a pu être étudié dans le cas de Colmar où le Conseil, en 1331, interdit aux «zwo parten» de porter leur couleurs respectives, le rouge et le noir ${ }^{106}$. La spécificité des recherches allemandes récentes sur ces sujets tient à la mise en relation de ces thèmes avec la culture développée dans les «Trinkstuben» des villes allemandes, celles des élites comme celles des groupements professionnels ou confraternels ${ }^{107}$. Ces poêles («Stuben») ou lieux de réunion de l'élite locale, apparus dans le Sud-Ouest de l'Empire dès les années 1330-1340, ne servaient pas seulement de lieu de sociabilité, de politisation, de communication et de socialisation des cercles des groupes dirigeants ${ }^{108}$, mais contribuaient à renforcer l'identité du groupe replié sur lui-même, à consolider les liens de la memoria entre les membres, à exercer une attractivité spatiale et à occuper un espace politique que l'ensemble de la ville peut ressentir comme tel. À ce titre, c'est-à-dire comme lieu d'identification interne et externe des élites, la maison du cercle peut faire l'objet d'attaques au cours d'épisodes de troubles comme les sources de Memmingen, d'Augsbourg ou de Constance le montrent pour la fin du XIV $\mathrm{X}^{\mathrm{e}}$ siècle et la première moi-

${ }^{105}$ Bernd Ulrich Hucker, Der hansestädtische Roland, dans Hanse, Städte Bünde cit., pp. 474-494.

${ }^{106}$ Cité par František Graus, Pest - Geissler - Judenmorde. Das 14. Jahrhundert als Krisenzeit cit., p. 454, note 68.

${ }^{107}$ Gerhard Fouquet, Matthias Steinbrink, Gabriel Zeilinger (dir.), Geschlechtergesellschaften, Zunft-Trinkstuben und Bruderschaften in spätmittelalterlichen frühneuzeitlichen Städten, Ostfildern 2003, en particulier Jörg Rogge, Geschlechtergesellschaften, Trinkstuben und Ehre. Bemerkungen zur Gruppenbildung und den Lebensordnungen in den Führungsschichten mittelalterlicher Städte, pp. 97-127.

108 Pierre Monnet, Les élites urbaines et leur espace dans les villes d'Allemagne à la fin du Moyen Âge, dans Mercado immobiliario y paisajes urbanos en el Occidente. Siglos XI$X V$, Pamplona 2007, pp. 301-346. 
tié du XV $\mathrm{XV}^{\mathrm{e}}$ siècle. Quand le Conseil était pendant un temps dans une position et dans une composition peu favorables voire hostiles à la domination du groupe des élites appartenant clairement à un cercle, ce dernier pouvait se trouver la cible d'une pression ou d'une inimitié dont la maison pouvait devenir le symbole matériel. C'est ainsi qu’à Memmingen, par exemple, le Conseil dominé entre 1449 et 1453 par les métiers a tenté d'empêcher le cercle d'acquérir sa maison commune sur la place du marché et à proximité de l'Hôtel du Conseil ${ }^{109}$.

Dans ce vaste passage en revue des études récentes ayant focalisé l'attention des chercheurs sur les temps, les lieux, les symboles et les rituels de la révolte en ville, d'autres points peuvent encore être repris et faire l'objet d'approfondissements: l'incendie de l'écrit ou de l'hôtel des Conseils par exemple (on en trouve assez peu d'occurrences en Allemagne et les cas répertoriés ne présentent pas l'ampleur ni la violence de ce que l'on trouve pour Florence, Londres ou Paris entre 1378 et la fin du siècle); ou bien la chasse aux «étrangers» (émeutes «anti-allemandes» à Cracovie en 1311-1312, «anti-hongroises» dans la même ville en 1377, «anti-allemandes» encore à Stockholm en 1389), sans oublier naturellement les chasses aux Juifs. Par ailleurs, l'analyse des rituels tend à confirmer en partie le grand «légalisme» que l'on peut observer dans ces épisodes: commencé par un serment (Rothenbourg en 1348, Nuremberg et Erfurt en 1349, Lübeck en 1380, Munich en 1398...), le trouble s'achève aussi par le serment et le plus souvent par une refonte et une proclamation solennelle de la constitution, comme l'indiquent les exemples du Vieherrenbrief de Erfurt en 1310, du Schwörbrief de Strasbourg en 1334, du Zunftbrief de Augsbourg en 1368, du Verbundbrief de Cologne en 1396, des Bürgerbriefe de Rostock en 1408. Il existe bien un besoin puissant de légitimité politique dans de très nombreux conflits urbains de la fin du Moyen Âge ${ }^{110}$. Un exemple: le conflit qui a opposé en 1365-1366 le Commun des bourgeois au Conseil de la ville de Brême s'est achevé par la résolution de ne plus accepter de nouveaux bourgeois avant d'avoir prêté un nouveau serment. On voit ici que le conflit, une fois surmonté, a abouti à un nouveau départ politique, à une refondation du pacte civique, à la tenue de nouveaux registres de bourgeoisie et à un lien manifeste entre le serment et le souvenir, mais le tout contrôlé par le Conseil, certes réaménagé, mais issu de l'ancien qui avait été contesté. De surcroît, on connaît l'épisode grâce à

${ }^{109}$ Albrecht Rieber, Das Patriziat von Ulm, Augsburg, Ravensburg, Memmingen, Biberach, dans Hellmuth Rössler (Hg.), Deutsches Patriziat 1430-1740, Limburg 1968, pp. 299-351.

${ }^{110}$ Marie Theres Fögen (dir.), Ordnung und Aufruhr im Mittelalter. Historische und juristische Studien zur Rebellion, Frankfurt am Main 1995. 
une chronique intégrant son déroulement et son règlement dans la mémoire urbaine officielle ${ }^{111}$.

L'ensemble de ces approches à la fois plus juridiques et plus anthropologiques a permis de réexaminer le conflit sous un angle sociologique nouveau: le conflit dissout ou resserre les groupes sociaux et se révèle donc sociologiquement productif et performant. Il transporte d'anciens conflits, les actualise et les transmet. Sur cet arrière-plan, un autre fait historiographique marquant s'est produit à la charnière des années 1980-1990. Il est associé à la publication d'une synthèse consacrée par Peter Blickle aux troubles dans la société d'ordres entre 1300 et $1800^{112}$. En reprenant la notion de Unruhe, de désordre (réservée à la société d'ordres que jamais d'ailleurs les révoltes ne remettent en cause) qu'il substitue à celle de conflit (réservée selon lui à la société de classes), l'auteur réalise à la fois un vaste desserrement géographique mais aussi chronologique du conflit urbain. En insistant sur les effets pervers de la construction territoriale dans une société d'ordres, tant en ville qu'à la campagne, en faisant intervenir la dimension d'un conflit plus général entre le principe communal d'un côté et le principe d'autorité de l'autre (à la racine selon lui du double processus de judiciarisation et de criminalisation de la révolte à la fin du Moyen Âge), en faisant enfin du conflit urbain tardo-médiéval l'occasion d'une refonte de la culture contractuelle centro-médiévale sur la base des valeurs du bien Commun, de la nécessité et de la liberté comme principes annonciateurs de la modernité politique (mais point nécessairement sociale), Peter Blickle érige le désordre citadin en variante d'un mouvement de fond traversant la société entre 1300 et 1800 , donc unissant la ville et la campagne, et incluant la Réforme du XVI ${ }^{\mathrm{e}}$ siècle articulée autour de la révolte rurale-urbaine de 1525. La performance de cette synthèse a consisté avant tout à réintroduire la campagne dans une histoire des troubles urbains qui en était traditionnellement assez détachée compte tenu de l'absence de vastes contados autour des villes allemandes, à quelques exceptions près comme Nuremberg, Ulm ou Rothenbourg ${ }^{113}$ qui ne furent précisément pas les villes les plus agitées, et compte tenu aussi d'un maillage territorial tantôt pris en main par la principauté tantôt momentanément par les ligues

${ }^{111}$ Wilfried Ehbrecht, uppe dat sulck grot vorderffenisse jo nicht meer enscheghe. Konsens und Konflikt als eine Leitfrage städtischer Historiographie, nicht nur im Hanseraum, dans Peter Johanek (dir.), Städtische Geschichtsschreibung im Spätmittelalter und in der Frühen Neuzeit cit., pp. 51-109.

112 Peter Blickle, Unruhen in der ständischen Gesellschaft 1300-1800 cit.

${ }^{113}$ Hans K. Schulze (dir.), Städtisches Um- und Hinterland in vorindustrieller Zeit, Köln/Wien 1985. 
urbaines ${ }^{114}$. Cette moindre connexion entre villes et campagnes au sein des troubles urbains allemands du XIV ${ }^{\mathrm{e}}$ siècle a longtemps paru assez paradoxale jusqu'à prendre en considération le fait quau contraire on ne trouve ni capitales politiques ${ }^{115}$ ni monstres démographiques dans l'Empire, c'està-dire que l'on ne rencontre pas de villes comparables à Paris, Londres et Florence où se produisent les révoltes majeures du XIV ${ }^{e}$ siècle et qui peuvent assurer, pendant un temps, un effet d'entraînement à l'échelle de toute une principauté ou de tout un royaume. Là encore, seule Prague, à partir des troubles hussites, jouera ce rôle pour la Bohême et une partie de l'Empire mais sur un mode religieux qui occulte jusqu'à la rendre invisible la composante sociale et politique (pourtant présente, y compris dans ce cas) des troubles urbains. Quoi qu'il en soit, l'apport de l'élargissement géographique et conceptuel réalisé par Peter Blickle vaut d'être souligné, en particulier parce qu'il fait de la révolte urbaine comme rurale un élément des structures de l'Empire, critiqué pour son aspect féodal et non pour son aspect impérial, et parce qu'il place la révolte au sein d'une réflexion d'ensemble sur le mouvement proprement occidental d'un conflit entre liberté et représentation dans les sociétés politiques anciennes d'Europe (la révolte contribuant du XIII ${ }^{\mathrm{e}}$ au XVIII ${ }^{\mathrm{e}}$ siècle à faire émerger et à tenter de résoudre cette contradiction jusqu'à l'imposition de la notion de contrat). Il fait cependant bien moindrement intervenir dans le modèle explicatif deux dimensions, liées l'une à l'autre, qui méritent d'être prises en compte, celle des discours d'un côté (la révolte est le temps par excellence de la mise en place de couples notionnels tels que «Conseil/métiers», «Supérieurs/inférieurs», Honorables/ déshonorables» ou bien «Pauvres/riches») ${ }^{116}$, celle

114 Monika Escher, Alfred Haverkamp, Frank G. Hirschmann (dir.), Städtelandschaft - Städtenetz - zentralörtliches Gefüge cit.; Holger T. Gräf, Katrin Keller (dir.), Städtelandschaft, réseau urbain, urban network. Städte im regionalen Kontext in Spätmittelalter und früher Neuzeit, Köln/Weimar/Wien 2004.

${ }^{115}$ Wilhelm Berges, Das Reich ohne Hauptstadt, dans Das Hauptstadtproblem in der Geschichte. Festgabe zum 90. Geburtstag F. Meinecke, Tübingen 1952, pp. 1-29; PaulJoachim Heinig, Reichsstädte, freie Städte und Königtum 1389-1450. Ein Beitrag zur deutschen Verfassungsgeschichte, Wiesbaden 1983; Eberhard Isenmann, Reichsstadt und Reich an der Wende vom späten Mittelalter zur frühen Neuzeit, dans Josef Engel (dir.), Mittel und Wege früher Verfassungspolitik, pp. 9-224; Peter Moraw, Reichsstadt, Reich und Königtum im späten Mittelalter, «Zeitschrift für historische Forschung», 6, 1979, pp. 385-424; Theodor Schieder, Gerhard Brunn (dir.), Hauptstädte in europäischen Staaten, München/Wien 1983; Uwe Schultz (dir.), Die Hauptstädte der Deutschen. Von der Kaiserpfalz in Aachen bis zum Regierungssitz Berlin, München 1993; Alfred Wendehorst, Jürgen Schneider (dir.), Hauptstädte. Entstehung, Struktur und Funktion, Neustadt an der Aisch 1979.

116 Très souvent en effet les sources présentent les conflits comme le résultat d'une opposition entre les riches et puissants d'une part et le Commun des bourgeois de 
de la mémoire et de l'écriture de l'histoire de l'autre qu'il convient maintenant de détailler quelque peu.

À cette vaste strate historiographique qui voit l'approche juridique et anthropologique enrichir l'approche sociale des conflits urbains s'en est ajoutée une autre, majeure mais point surprenante car on la retrouvait au même moment dans d'autres historiographies. En effet, l'attention portée parallèlement à partir des années 1970 aux chroniques urbaines en tant que productions de la mémoire ${ }^{117}$ et de l'identité ${ }^{118}$ a naturellement contri-

l'autre. C'est ce que semblent rapporter par exemple la Schöppenchronik de Magdebourg pour l'année 1330 au sujet du «désaccord (twidracht) opposant le Commun (meinheit) et les riches (rikesten) ou supérieurs (obbersten)» (Die Chroniken der deutschen Städte (7). Die Chroniken der niedersächischen Städte (Magdeburg 1: Die Magdeburger Schöppenchronik), Leipzig 1869, p. 200. Voir Wilfried Ehbrecht, Bürgertum und Obrigkeit in den hansischen Städten des Mittelalters cit.) ou bien les chroniques d'Erfurt au sujet des troubles intra-urbains de 1309-1310, quand «il se produisit une désunion (zweitracht) entre le commun peuple et les riches hommes» (Rochus von Liliencron (éd.), Dueringische Chronik des Johann Rothe, Jena 1859, p. 524. Voir Eberhard Holtz, Zur politischen und rechtlichen Situation Erfurts im 15. Jahrhundert im Vergleich mit anderen mitteldeutschen Städten, dans Ulman Weiss (dir.), Erfurt. Geschichte und Gegenwart, Weimar 1995, pp. 95-105) ou bien lorsqu' «un grand désaccord (zweiunge) survint entre les riches et le Commun». Or, on sait bien que les «riches» et puissants ainsi désignés sont bien les maîtres et dirigeants de la cité et, à ce titre, placés au centre du Commun et non pas exclus du serment de bourgeoisie. Par conséquent, la formulation signifie que l'on a ici affaire à une pensée politique qui partage en quelque sorte le travail de la communauté et le bien être de la cité: aux riches et puissants de gouverner avec leur capital et leur savoir, au reste du Commun de contribuer par son travail, ses armes et ses ressources à la défense de la ville en danger (Wilfried Ehbrecht, $\mathrm{Zu}$ Ordnung und Selbstverständnis städtischer Gesellschaft im späten Mittelalter, «Blätter für deutsche Landesgeschichte», 110, 1974, pp. 83-103). Comme une étude l'a bien montré à propos de la situation sociale et politique de Wurtzbourg, c'est bien la capacité à agir politiquement au Conseil qui représente la ligne de démarcation décisive entre ce que les textes appellent ici la «ryeche partye» et le reste des «Buorgere zuo Wirczburg» (Winfried Schich, Würzburg im Mittelalter: Studien zum Verhältnis von Topographie und Bevölkerungsstruktur im Mittelalter, Köln 1977). Il semble que, pour les chroniqueurs, le désordre surgisse quand justement l'élite des riches et des puissants ne gouverne pas, ou bien gouverne seulement dans son intérêt, en dehors du Commun. Cela veut bien dire que dans toute commotion urbaine la responsabilité des élites est engagée, soit pour avoir failli aux tâches de son gouvernement, soit pour n'avoir pas su régler un conflit. On en veut pour preuve que la lettre des serments mettant fin au conflit reprend de nouveau la formulation «riches et Commun» dont la réunion constitue le pilier de la paix urbaine restaurée.

${ }^{117}$ Heinrich Schmidt, Die deutschen Städtechroniken als Spiegel des bürgerlichen Selbstverständnisses im Spätmittelalter cit.; Rolf Sprandel, Chronisten als Zeitzeugen cit.; Peter Johanek (dir.), Städtische Geschichtsschreibung im Spätmittelalter und in der Frühen Neuzeit cit.; Georg Mölich, Uwe Neddermeyer, Wolfgang Schmitz (dir.), Spätmittelalterliche städtische Geschichtsschreibung in Köln und im Reich, Köln 2001; Hanno Brand, Pierre Monnet, Martial Staub (dir.), Memoria, communitas, civitas. Mémoire et conscience urbaines en Occident à la fin du Moyen Âge, Stuttgart 2003. 
bué à enrichir l'approche. D'ailleurs, le terme de «schicht», si fréquent pour désigner les révoltes, ainsi de celles de Magdebourg ou de Brunswick, est lié à celui de «Geschichte»: c'est une «sale histoire», ou bien ce sont simplement «les événements» comme, par exemple, le vocabulaire officiel des quatrième et cinquième République en France désignait par ces termes la guerre d'Algérie. Pour s'en convaincre, il n'est que de rappeler, entre autres, le lien étroit qui unit ce que l'historiographie traditionnelle a appelé la révolte des métiers («Zunftrevolution») à Augsbourg en 1368, mettant fin au pouvoir des anciens «lignages», et le début d'une nouvelle historiographie augsbourgeoise ${ }^{119}$ qui accompagne la refonte non pas des institutions mais de l'organisation corporative (puisque l'ensemble des citoyens fut versé dans un seul corps, «rich und arm», soumis à un seul serment, le couple notionnel «riche/pauvre» signalant ici le rétablissement de l'unanimité de la communauté $)^{120}$. À Brême aussi, en 1365, la révolte qui aboutit au remplacement d'un groupe ancien de familles dirigeantes par un nouveau au terme d'un défilé des bannières («bannerenlop») s'accompagne d'une césure dans l'écriture de l'histoire urbaine ${ }^{121}$. De nombreuses études ${ }^{122}$ montrent aussi que la mention des révoltes/seditiones intervient au sein du texte de la chronique, ou plus encore au sein des descriptions et éloges de villes, au moment où l'on parle des institutions et du Conseil. Il est en tout cas frappant de voir que les changements politiques intervenus au sommet de la cité, surtout quand il s'agissait de changements de factions au pouvoir, ont trouvé un écho et en même temps une légitimation dans les chroniques

118 Ulrich Meier, Mensch und Bürger. Die Stadt im Denken spätmittelalterlicher Theologen, Philosophen und Juristen, München 1994; Giorgio Chittolini, Peter Johanek (dir.), Aspekte und Komponenten der städtischen Identität in Italien und Deutschland (14.-16. Jahrhundert), Berlin/Bologna 2003; Bernhard Kirchgässner, Hans-Peter Becht (dir.), Städtische Mythen, Stuttgart 2003.

${ }^{119}$ Wilfried Ehbrecht, uppe dat sulck grot vorderffenisse jo nicht meer enscheghe. Konsens und Konflikt als eine Leitfrage städtischer Historiographie, nicht nur im Hanseraum cit.

${ }^{120}$ Jörg Rogge, Ir freye wal zu haben. Möglichkeiten, Probleme und Grenzen der politischen Partizipation in Augsburg zur Zeit der Zunftverfassung (1368-1548), dans Klaus Schreiner, Ulrich Meier (dir.), Stadtherrschaft und Bürgerfreiheit. Handlungsspielräume in deutschen und italienischen Städten des späten Mittelalters und der Frühen Neuzeit, Göttingen 1994, pp. 244-277.

${ }^{121}$ Christoph Heiduk, Almut Höfert, Cord Ulrichs, Krieg und Verbrechen nach spätmittelalterlichen Chroniken, Köln/Weimar/Wien 1997.

${ }^{122}$ Karl Czok, Bürgerkämpfe und Chronistik im deutschen Spätmittelalter, «Zeitschrift für Geschichtswissenschaft», 10, 1962, pp. 637-645; Peter Moraw, Politische Sprache und Verfassungsdenken bei ausgewählten Geschichtsschreibern des deutschen 14. Jahrhunderts, dans Hans Patze (dir.), Geschichtsschreibung und Geschichtsbewusstsein im späten Mittelalter, Sigmaringen 1987, pp. 175-205. 
urbaines $^{123}$. Ainsi, en 1396, un nouveau Conseil entérine-t-il la fin de l'ancien régime patricien de Cologne. À cette occasion, une nouvelle "constitution» (Verbundbrief) est rédigée par le secrétaire de ville, auteur parallèlement d'un «Nouveau livre» («dat nuwe boich») qui explique le changement politique par l'incapacité des anciens lignages à gouverner, par leur corruption et par leurs conflits internes ${ }^{124}$. La révolte et la mise par écrit de l'histoire urbaine sont donc liées, ne serait-ce aussi que par les phénomènes de damnatio memoriae qui frappent ici ou là tel ou tel marchand, conseiller ou artisan rebelle. Le cas est patent si l'on relit le «Schichtbuch» ou «Livre des troubles», déjà mentionné et commenté, composé par Hermann Bote (vers 1450-1520) de Brunswick dans la deuxième décennie du XVI ${ }^{\mathrm{e}}$ siècle et relatant la succession des commotions qui agitèrent la ville de 1292 à 1513 . Que le livre de la mémoire publique et historique de la ville puisse également servir à prévenir l'arrivée d'un nouveau conflit, c'est bien ce que montre l'œuvre de la plume de Hermen von Vechelde, auteur au début du XV $\mathrm{XV}^{\mathrm{e}}$ siècle d'une «hemelik rekenscop» ou «rapport secret» commandé par le nouveau Conseil de Brunswick mis en place après les troubles de 1386, œuvre qui devait être lue tous les trois ans en réunion plénière du Conseil en souvenir des troubles de $1374^{125}$.

La mémoire urbaine, qui mêle souvent écriture privée et écriture collective ${ }^{126}$, peut se faire aussi occasion du règlement de comptes ou de la justification: c'est le cas des témoignages autobiographiques qui prennent valeur de justification à la suite des démêlés de leur auteur avec sa cité ou son Conseil. Jörg Kazmeier par exemple, maire de Munich pendant les troubles de 1397-1403, ne relate les événements survenus en ville que pour mieux légitimer sa fuite et sa conduite ${ }^{127}$. Banni en 1398, il rentre à Munich

${ }^{123}$ Jean-Marie Moeglin, Les élites urbaines et l'histoire de leur ville en Allemagne (XIV ${ }^{e}-X V^{e}$ siècles), dans Les élites urbaines au Moyen Âge (XXVII ${ }^{\mathrm{e}}$ Congrès de la SHMES, Rome 1996), Paris 1997, pp. 351-383.

${ }^{124}$ Georg Mölich, Uwe Neddermeyer, Wolfgang Schmitz (dir.), Spätmittelalterliche städtische Geschichtsschreibung in Köln und im Reich cit.

${ }^{125}$ Hans-Leo Reimann, Unruhe und Aufruhr im mittelalterlichen Braunschweig cit., Johannes Bernhard Menke, Geschichtsschreibung und Politik in deutschen Städten des Spätmittelalters, «Jahrbuch des Kölnischen Geschichtsvereins», 33, 1958, pp. 1-84 et 34, 1960, pp. 85-194, ici pp. 61-84.

126 Pierre Monnet, La mémoire des élites urbaines dans l'Empire à la fin du Moyen Âge entre écriture de soi et histoire de la cité, dans Hanno Brand, Pierre Monnet, Martial Staub (dir.), Memoria, communitas, civitas. Mémoire et conscience urbaines en Occident à la fin du Moyen Âge cit., pp. 49-70.

${ }^{127}$ Karl August von Muffat (éd.), Jörg Kazmair's Denkschrift über die Unruhen zu München in den Jahren 1397-1403, dans Die Chroniken der deutschen Städte (15). Die Chroniken der bayerischen Städte (Regensburg, Landshut, Mühldorf, München), Leipzig 1878, pp. 411-583. 
en 1403 et redevient bourgmestre et conseiller jusqu'à sa mort en 1417. De 1398 à 1403, du temps de son exil, il ne parle plus dans son récit que de «ceux de Munich» tandis que, signe de désolidarisation, le «je» du narrateur et la ville ne sont plus jamais mentionnés ensemble ${ }^{128}$. Ses notices s'arrêtent peu avant son retour, comme si la déception du combat politique perdu et la dérive d'une ville qui pour un temps ne le concernait plus, avaient laissé trop de traces pour reprendre le fil de la narration et le récit des meilleurs jours revenus. Il est en tout cas assuré que sa plume, utilisant une langue politique déconsidérant ouvertement l'adversaire politique qui l'a contraint à l'exil, emploie une rhétorique qui associe systématiquement le désordre à un groupe ambitieux de patriciens menés par un envieux, Ulrich Tichtl, lequel n’hésite pas selon lui à briser l'unanimité urbaine et à pervertir le fonctionnement du Conseil en créant des commissions à seul fin de procès politique.

L'essentiel des études menées à partir des sources narratives a consisté à décrypter le discours et l'interprétation qui se trouvait derrière le masque uniformisateur de la lutte «arm/reich» rapportée par certains chroniqueurs comme le principe premier des révoltes, couple peu à peu remplacé (mais selon quelle chronologie?) par une trilogie «Bürger/Handwerker/Pöbel» (qui tend donc à réserver le qualificatif de bourgeois/ citoyens aux bons bourgeois agressés par la révolte tandis que la trilogie traditionnelle des «oratores/bellatores/laboratores» parait remaniée pour associer la révolte à ces derniers)... La spécificité du XIV ${ }^{\mathrm{e}}$ siècle résiderait-elle dès lors dans le recouvrement terminologique du couple «arm/reich» par celui de puissants-dominants/dominés? On constate par exemple qu'à Wurtzbourg la «ryeche partei» du Conseil, qui doit affronter les contestations récurrentes du Commun, désigne en fait le clan des conseillers puissants ${ }^{129}$. En 1368, la réforme des institutions urbaines à Augsbourg, appuyée sur la fusion de l'ensemble du Commun dans une seule et même «corporation» qui inclut les conseillers déchus, regroupe «rich und $a r m »{ }^{130}$. On touche ici à une dif-

${ }^{128}$ Ibid., p. 485. Pierre Monnet, Élites et conflits urbains dans les villes allemandes de la fin du Moyen Âge cit., et Id., Ville réelle et ville idéale: une géographie au prisme des témoignages autobiographiques dans les cités du Sud de l'Empire à la fin du Moyen Âge, «Annales H.S.S.», 2001, pp. 591-621, version allemande: Reale und ideale Stadt: Die oberdeutschen Städte im Spiegel autobiographischer Zeugnisse des Spätmittelalters, dans Kaspar von Greyerz, Hans Medick, Patrice Veit (dir.), Von der dargestellten Person zum erinnerten Ich. Europäische Selbstzeugnisse als historische Quellen (1500-1850), Köln/ Weimar/Wien 2001, pp. 395-430.

129 Winfried Schich, Würzburg im Mittelalter: Studien zum Verhältnis von Topographie und Bevölkerungsstruktur im Mittelalter cit.

${ }_{130}$ R. H. Lutz, Wer war der gemeine Mann?: der dritte Stand in der Krise des Spätmittelalters, München 1979. 
férence d'interprétation importante concernant l'historiographie urbaine: s'agit-il d'une parole exprimant la conscience de ville d'Empire propagée par les milieux dirigeants des Conseils des grandes villes où s'écrivent les chroniques $^{131}$, ou bien celles-ci traduisent-elles une position défensive de la part de ces mêmes couches ${ }^{132}$, situation qui les inciterait à instrumentaliser à leur profit la légitimité conférée par l'histoire de la cité? On notera, en tout cas, que les chroniques urbaines en Allemagne n'ont ni voulu ni pu construire une figure de la stature d'un John Ball par exemple. Quant au discours des sources narratives, il donne aussi une image des révoltes plutôt menées par des jeunes et par des hommes: quelle est la place des femmes? C'est là, comme dans d'autres domaines, l'un des angles morts de la recherche, faute de sources suffisantes, en attendant les dépouillements de sources judiciaires ${ }^{133}$. Quoi qu'il en soit, le recours aux sources narratives de la mémoire urbaine permet de mieux établir un lien entre la révolte et l'identité, autrement dit entre la culture des groupes sociaux et leurs revendications politiques. C'est que la révolte est aussi une guerre des signes et des symboles. Guerre des signes et des symboles aussi dans la mesure où la ville en proie à une révolte devient une proie facile pour la noblesse, du moins dans le discours et l'argumentation des chroniqueurs favorables aux Conseils en place.

\section{Ouvertures}

L'introduction des rituels, liés à l'identité, le travail sur la mémoire des révoltes ainsi que les apports d'une histoire juridique ont sans doute préparé ce que l'on peut désigner comme le «retour» du politique dans les études des troubles urbains depuis une vingtaine d'années, non pas pour revenir à une interprétation fondée sur le simple examen des rapports de force mais par la prise en compte de la complexité territoriale, institutionnelle et seigneuriale dans laquelle les villes évoluaient. Un tel retour équivaut en quelque sorte à ramener à sa juste place la ville dans une société encore féodale et de plus en plus princière comme l'était l'Empire des XIV et $\mathrm{XV}^{\mathrm{e}}$ siècles, tout en ménageant à l'analyse une place résultant du statut et du nombre spécifiques des villes libres et des villes d'Empire dans l'Allemagne de ce temps. C'est ainsi que le rôle du roi et des grands prin-

${ }^{131}$ Heinrich Schmidt, Die deutschen Städtechroniken als Spiegel des bürgerlichen Selbstverständnisses im Spätmittelalter cit.

${ }^{132}$ Johannes Bernhard Menke, Geschichtsschreibung und Politik in deutschen Städten des Spätmittelalters cit.

${ }^{133}$ Par exemple, pour Constance: Peter Schuster, Eine Stadt vor Gericht. Recht und Alltag im spätmittelalterlichen Konstanz, Paderborn 2000. 
ces ecclésiastiques (les évêques!) et laïcs est revenu sur le devant de la scène, certes comme le pouvoir seigneurial à combattre par le Commun en révolte mais aussi comme l'instance de compromis et de règlement des conflits, rôle qui n'a d'ailleurs pas peu contribué à asseoir la domination du prince non plus seulement sur la ville mais sur un territoire plus vaste (l'exemple de l'archevêché de Cologne de ce point de vue est parlant), poussée dont l'une des conséquences, comme on l'a vu, a été la formation de ligues urbaines, singulièrement au $\mathrm{XIV}^{\mathrm{e}}$ siècle. L'autre conséquence de ce retour du politique dans l'étude des révoltes urbaines réside dans la connexion ainsi établie avec la très dynamique recherche menée depuis une quinzaine d'années à partir des comptabilités urbaines et des sources fiscales ${ }^{134}$ : le lien entre fiscalité, guerre et révolte s'en trouve de ce fait mieux étudié (même s'il reste beaucoup à faire sur la fiscalité et les finances en lien avec la vie politique troublée des cités) par le biais de l'endettement des cités, étant entendu que la guerre, la révolte et le rôle fiscal sont sans doute les trois occasions conjoncturelles et documentaires au cours desquelles s'expriment le mieux les catégorisations sociales au sein d'une opération qui met au jour la transformation du Conseil en autorité (Obrigkeit) et sert aussi à redéfinir le pouvoir, la Herrschaft conçue non comme une construction homogène et linéaire mais comme le produit d'un rapport de forces entre plusieurs sources de pouvoir. Le récit des troubles urbains du $\mathrm{XIV}^{\mathrm{e}}$ siècle à Ratisbonne par exemple n'est guère compréhensible si l'on se contente d'une définition figée du pouvoir urbain, mais devient plus intelligible si l'on s'accorde à définir le pouvoir urbain comme une mosaïque complexe faisant intervenir le Conseil, l'évêque, le roi, le duc de Bavière et les couvents, au premier rang desquels Saint-Emmeram. Cet argument renforce l'idée d'une ville qui est loin d'être constituée seulement de bourgeois de plein droit mais réunit de nombreux groupes vivant sur des immunités enchevêtrées. Une telle remarque invite à son tour à inscrire la révolte non point dans un schéma pyramidal mais dans un schéma d'échanges et donc de rapports de force, ce qui n'est pas incompatible avec la notion d'autorité (incidemment, par ce biais, c'est toute la place, sans doute sous-évaluée et mal connue pour les villes allemandes, de la noblesse dans les révoltes urbaines qui devrait être réexaminée à l'aune de l'hypothèse courante, et donc à revisiter, d'un reflux du pouvoir noble en ville dans la première moitié

${ }^{134}$ Wybbe Jappe Alberts, Mittelalterliche Stadtrechnungen als Geschichtsquellen, «Rheinische Vierteljahrsblätter», 23, 1958, pp. 75-96; Erich Maschke, Jürgen Sydow (dir.), Städtisches Haushalts- und Rechnungswesen, Sigmaringen 1977. Voir surtout le site internet des bases de données documentaires et bibliographiques sur les comptabilités médiévales et modernes: http://online-media.uni-marburg.de/ma_geschichte/ computatio/. 
du siècle $)^{135}$. Il ne s'agit pas pour autant d'oublier l'enquête terminologique, et cela d'autant moins que de nombreuses occurrences dans les sources laissent à penser que la multiplication des révoltes fiscales semble avoir poussé à réserver dans certains cas le terme de «discordia generalis» à ce type de troubles, spécialement dans les villes épiscopales. C’est de ce dynamisme des recherches consacrées à la fiscalité et à la comptabilité urbaines que peut naître, pour les villes allemandes, un renouveau d'une histoire économique un peu délaissée qui, pour le lien avec les révoltes, devrait reprendre la question de la pauvreté, du travail et de l'artisanat. C'est dans cette optique par exemple que l'on pourrait examiner à nouveaux frais une typologie des révoltes touchant Magdebourg entre une révolte pour cause de dettes de guerre en 1293, pour cause de blocus d'exportation en 1330, pour cause de dépréciation monétaire en 1402 et pour cause d'accroissement de la fiscalité indirecte en 1459.

Au terme de ces évolutions et inflexions historiographiques, on peut avoir d'un côté l'impression, si l'on est pessimiste, d'un éclatement des schémas interprétatifs au profit d'une pluralité de causes et d'effets qui finit par pousser certains historiens à dire que chaque ville est un cas particulier et, par conséquent, chaque révolte un cas spécifique (ce retour du particularisme et du localisme se trouvant parfois renforcé par la puissance traditionnelle et toujours actuelle des études d'histoire régionale en Allemagne, de la Landesgeschichte). Si l'on est optimiste, on peut en conclure au contraire à une approche aussi diverse et complexe que l'est la révolte elle-même. Les dénominations actuelles pour parler des troubles urbains du XIV ${ }^{\mathrm{e}}$ siècle dans les manuels et synthèses des quinze dernières années semblent prendre acte de cette indécision, de cette complexité, de cette prudence qui peut confiner au "politiquement correct»: les chapitres parlent ainsi de "städtische Auseinandersetzungen», de "confrontations», répudiant la notion même de «révoltes». Pour autant, cette position d'attente ne se révèle pas forcément favorable à un changement attendu et nécessaire de paradigmes qui consisterait avant tout à envisager les révoltes non pas comme un accident, une exception, une interruption introduits dans l'ordre urbain, mais comme les étapes de sa marche normale et de sa logique profonde: la révolte non point comme obstacle mais comme témoin et comme facteur de l'évolution de la société et de la modernité citadines, facteur sans lequel une compréhension globale de la ville insérée dans une logique globale de la société médiévale n'est guère pensable. On

${ }^{135}$ Joseph Morsel, La noblesse et les villes à la fin du Moyen Âge. Nouvelles perspectives de recherche, "Bulletin d'Information de la Mission Historique Française en Allemagne», 32, 1996, pp. 33-54 et Id., L'aristocratie médiévale, Paris 2005. 
ne voit décidément bien une structure que lorsqu'elle bouge. La spécificité médiévale du conflit urbain résiderait alors non pas tant dans son statut d'illustration de la théorie moderne des conflits, qui érige la révolte en état normal de la société, mais se signalerait davantage par le fait que la société médiévale, et donc la ville, se meut dans une tension entre le conflit et le consensus, entre la discordia et la concordia.

Une telle option suppose de réviser pour les uns, ou de confirmer pour les autres, une conception d'ensemble de l'organisme urbain non pas tant comme organe politique mais plus profondément comme société, comme groupe de groupes, comme communauté plurielle du serment et du souvenir. Autrement dit, la révolte urbaine est moins un problème politique ou économique de la ville des $\mathrm{XIV}^{\mathrm{e}}$ et $\mathrm{XV}^{\mathrm{e}}$ siècles qu'un problème de système de représentations et de revendications dans une société complexe, c'est-àdire de culture (temps, espace, classements, images). Cela revient à penser que la complexité terminologique dont la réflexion est initialement partie n'est pas un obstacle qu'il conviendrait de réduire mais serait plutôt comme une grammaire qu'il conviendrait d'interpréter (c'est ici qu'une sémantique historique s'avère indispensable), laquelle renverrait avec ses formes propres au vaste couple notionnel médiéval de la renovatio/reformatio. Qu'estce qui fait par exemple que Giovanni Villani puisse parler pour les troubles florentins de «tante novita e varie rivoluzioni» (couple terminologique que l'on retrouvera sous la plume de Domenico Buoninsegni au XV siècle pour qualifier la révolte des Ciompi de 1378: "grande novita et revoluzione quasi incredibilie») et que son frère Matteo emploie le terme de «rivolture» pour désigner les renversements et les agitations dans des villes italiennes et même de France, tandis que l'on ne rencontre jamais en Allemagne de telles occurrences pour qualifier les révoltes urbaines? On imagine qu'il existe à cela des raisons qui ne sont pas seulement terminologiques et philologiques mais agissent comme autant d'indicateurs d'une évolution globale de la société, c'est-à-dire aussi d'une évolution globale de la société urbaine, tant il est vrai que dans le sujet de la révolte urbaine, la qualification du conflit est inséparable de celle de la ville. Réfléchir aux révoltes en ville c'est bien le faire sur le fond d'une définition de la cité comme commune, comme communauté du serment, du droit, de la paix et du souvenir, comme un lieu de rencontre et d'accumulation (souvent contradictoire) entre le commerce et l'artisanat, comme un lieu de domination sur la campagne, comme un lieu politique de services et de fonctions.

À ce titre, quelques remarques conclusives et prospectives peuvent être avancées. Tout d'abord, l'analyse du discours de la révolte et sur la révolte indique une très forte charge sociale: cela ne veut pas dire que toute révolte soit un mouvement social mais que dans toute révolte se retrouve 
une pratique sociale ou, en d'autres termes, que l'histoire des révoltes est une histoire des structures sociales et de leur inhérente conflictualité. C'est sans doute dans cette direction que doit continuer à porter l'étude des mots de la révolte. De même on manque d'études sur l'acclimatation en ville aux $\mathrm{XIV}^{\mathrm{e}}$ et $\mathrm{XV}^{\mathrm{e}}$ siècles, par le biais justement des révoltes, de tous les concepts issus de la patristique et de la littérature juridique et scolastique des siècles précédents: seditio, conjuratio, rebellio, conspiratio ${ }^{136}$. Deux débats au moins en sortiraient éclairés: la paix urbaine (puisque, comme pour la guerre, la révolte ne peut se concevoir hors du couple pax/bellum, c'est-à-dire qu'elle est une demande et une vérification de la paix par la mise à l'épreuve de celle-ci) ${ }^{137}$ est-elle le produit et la performance de l'autorité, de cet État qu'est aussi la cité, ou bien le produit du consensus et du contrat négocié entre les groupes? Cette question centrale de l'horizontalité ou de la verticalité de la révolte et de son règlement se posait déjà pour les médiévaux et continue de se poser pour les médiévistes: insérer, grâce au discours des contemporains, la révolte dans une problématique de la paix par l'union ou par la force c'est traiter un problème qui dépasse de loin celui de la révolte même, c'est qualifier l'ensemble de la société médiévale. Un second débat, lié en vérité au premier, reste ouvert: celui de savoir si la transformation du pouvoir urbain en autorité, en Obrigkeit, s'accompagne comme pour la justice royale d'une tendance à la criminalisation/diabolisation de la révolte. Les occurrences du terme «Teufel» pour signaler une révolte urbaine ne sont pas rares en effet, on les trouve par exemple dans les annales d'Erfurt pour 1283 qui parlent d'un mouvement entraîné par un «spiritu diabolico», des termes qui reviennent aussi à Schweidnitz et à Kempten respectivement en 1311 et en 1343 et à Wurtzbourg en 1346. Sigismund Meisterlin, à propos de la révolte de Nuremberg en 1348, parle pour sa part de "Teufelswerk», et Detmar, le chroniqueur franciscain de Lübeck qui écrit en 1385, signale qu'à Brunswick en 1374 on voyait le diable à l'oeuvre «de duvel los». Il s'agirait aussi de savoir, en l'occurrence, si un lien peut être établi entre cette «diabolisation» topique et les accusations d'hérésie portées soit contre les meneurs des révoltes soit contre les conseillers contestés... À Erfurt en 1306, par exemple, le droit de la ville

${ }^{136}$ On ne fera ici que rappeler la typologie de Thomas d'Aquin: «Bellum proprie est contra extraneos et hostes, rixa est unius ad unum, vel paucorum ad paucos, seditio autem est inter partes unius multitudinis inter se dissidentes, puta cum pars civitatis exercitatur in tumultum contra aliam». Pour aller plus loin, Joseph Canning, Histoire de la pensée politique médiévale (300-1450), Fribourg (Suisse) 2003 (édition anglaise de 1996).

${ }^{137}$ Pierre Monnet, La ville et la guerre dans quelques cités de l'Empire aux XIV et XV siècles: de l'urgence immédiate à la mémoire identitaire, à paraître, Aix-en-Provence 2008. 
assimile la révolte et la discorde («zweyung», «dissensio»), à une désobéissance, tandis que les nouveaux statuts adoptés par la Hanse à Lübeck en 1418, qui justement mettent fin à une longue décennie de troubles dans cette ville avec le retour en force des anciennes familles du Conseil exilées, déclarent passibles du ban de la Hanse, c'est-à-dire d'un bannissement de toutes les villes hanséatiques, tout meneur séditieux de révolte. On se contentera sur le plan d'une sémantique historique rudimentaire, de remarquer que, vers la fin du XIV ${ }^{\mathrm{e}}$ siècle, dans le discours normatif et juridique des Conseils, un lien semble s'établir entre «ufrur» et «unfug», entre la révolte et la folie ou bêtise, ce qui du coup signalerait un renversement majeur du sens de la fonction du Conseil de ville (fondé sur une «discipline» moderne des mœurs): non plus organe représentatif mais organe répressif, un renversement de sens qui du coup renverse aussi le sens de la révolte et engage dès lors la légitimité de l'acte et pose la question, partant, d'un éventuel droit de résistance.

À ces deux problèmes de nature générale qui peuvent intéresser l'ensemble des villes d'Occident s'ajoutent des enjeux propres aux villes de l'Empire. En effet, comprendre les révoltes dans un ensemble régional politiquement individualisé, c'est sentir ce qu'elles présentent de commun et de différent par rapport à des événements comparables survenus dans le reste de l'Europe. Du côté des éléments communs, on ne peut pas nier que les occasions de déclenchement se retrouvent en Allemagne comme ailleurs, qu'il s'agisse de la guerre, de l'épidémie, de la cherté, des impôts, des conflits du travail ou de la tentative de remise en cause de certains privilèges urbains par les seigneurs, de quelque nature qu'ils soient. De même, les révoltes dont les sources font le plus état sont celles qui sont survenues dans des villes suffisamment grandes pour que le travail de mémoire y soit entrepris mais aussi pour que les différenciations sociales fassent sens politiquement. Du côté des participants et des victimes, on retrouvera sans peine des acteurs connus: métiers, élites du Conseil, populaire; mais aussi des victimes connues, à commencer par les Juifs... De même, en ce qui concerne le déroulement ou le règlement des conflits, ou bien pour ce qui touche aux rituels aussi, les éléments communs avec les situations française, italienne, flamande ou anglaise l'emportent. L'historien rencontre, semble-t-il, en Allemagne et ailleurs les mêmes difficultés à bien décrypter le discours uniformisateur des sources dominé par le couple riche/pauvre et à établir, à partir des sources encore, des seuils significatifs de pauvreté insupportable et donc «dangereuse». En revanche, au rang des spécificités révélatrices de l'Empire, on a pu compter la moindre connexion entre villes et campagnes, l'intervention régulatrice des ligues, la présence très différenciée du roi entre le Nord et le Sud de l'Empire, l'absence de ré- 
bellion de grande ampleur se répandant à partir d'un centre, l'intervention accrue des princes territoriaux dans le contexte d'un Empire régulé par la Bulle d'Or à partir de 1356 . On retiendra d'autres spécificités qui, davantage que les premières, ont pu donner naissance à des divergences notables d'interprétation entre deux historiographies allemandes particulièrement actives dans le champ des révoltes et attentives à se positionner l'une par rapport à l'autre jusqu'à la césure de 1989 qui marque un changement de génération, de régime et d'idéologie. Tout d'abord se pose la question de la nature des deux vagues de révoltes de 1330-1340 et de 1370-1380 et du lien qu'elles entretiennent avec deux moments, assez sensibles dans les villes de cet espace, d'une oligarchisation socio-culturelle des élites. Ensuite, se pose la question du contexte d'un Empire dont le XIV ${ }^{\mathrm{e}}$ siècle, s'il n'est pas marqué par la Guerre de Cent Ans, se situe d'une part dans une transition entre le reflux du pouvoir royal classique amorcé en 1250 et le début de l'offensive princière manifeste dans le dernier tiers du XIV ${ }^{\mathrm{e}}$ siècle (défaite des ligues urbaines à la fin des années 1380 d'une part, un phénomène qu'il conviendrait de mettre davantage en relation avec les révoltes urbaines, et apogée de la Hanse de l'autre, le tout sur fond de rivalité entre les trois dynasties des Luxembourg, des Wittelsbach et des Habsbourg) et se situe d'autre part au sein de l'imposition de la paix territoriale, depuis le milieu du XIII ${ }^{\mathrm{e}}$ siècle, par la condamnation de toute forme de conjuratio externe à la ville (condamnation qui toutefois ne s'effectue pas dans une institution centrale d'Empire en l'absence de l'équivalent d'un Parlement comparable à celui de Londres ou de Paris par exemple). Enfin se pose la question des sources sur les révoltes qui, en ville au $\mathrm{XIV}^{\mathrm{e}}$ siècle, sont de plus en plus majoritairement rédigées en allemand par des chroniqueurs dont beaucoup écrivent sous la surveillance plus ou moins avouée du Conseil, rédacteurs qui sont confrontés au problème de la dénomination des troubles et de la transposition de la terminologie latine. Il semble que, surtout après 1350 , une progressive distinction s'établisse entre «Auflauf», qui tend à désigner le trouble suscité par un seul ou par quelques uns contre l'ordre public (passible alors du bannissement comme on le constate à travers l'emploi du terme dans les Achtbücher, les livres de bannissement nurembergeois du XIV ${ }^{\mathrm{e}}$ siècle) et «Aufruhr» qui tend à désigner la révolte de plus grande ampleur tournée contre le Conseil et l'organisation, disons la «constitution» des institutions. Une gradation supplémentaire se fait jour concernant l'emploi du terme «Ufstand» réservé au soulèvement séditieux et illicite comme on en trouve l'expression à Cologne en 1348 pour qualifier le soulèvement des bouchers chargés d'une double péjoration professionnelle et politique puisque ces derniers sont appelés «ungevoige», un terme dérivé de «unvolk», la tourbe, c'est-à-dire ce qui ne fait justement pas un 
peuple organisé («upstant des ungevoige»). Mais ce ne sont là que signes épars car la plupart des autres termes appartenant à la palette des mots de la révolte sont d'un emploi soit interchangeable, soit plus encore local. Or, cette dernière remarque a son importance: à la différence en effet du latin d'un côté ou bien du français en tant que langue royale de la centralisation de l'autre ${ }^{138}$, l'allemand des $\mathrm{XIV}^{\mathrm{e}}$ et $\mathrm{XV}^{\mathrm{e}}$ siècles est bien plus proche des événements et bien plus localisé (là encore c'est la traduction de la Bible par Luther qui donnera une unité aux mots allemands de la révolte, ce qui n'est pas sans conséquence sur le discours et l'idéologie de la Réforme au XVI siècle). De la sorte, l'emploi très régional et urbain des mots allemands de la révolte est le signe de l'évolution particulière des territoires allemands dans le sens de l'éclatement et de la juxtaposition. À côté des mots, les images: on manque assurément d'une étude iconographique des images de la révolte, sachant que l'on ne voit guère de foule d'émeutiers. De ce point de vue, on ne dispose pas d'un équivalent pour l'Allemagne des fresques de Sienne, qui sont aussi une peinture de la révolte comme figure du désordre et de la discordia ${ }^{139}$. Au contraire, quand un anonyme peint vers 1530 le cycle des douze mois de l'année accroché sur les murs de l'Hôtel du Conseil d'Augsbourg, aucune allusion n'est volontairement faite dans cette peinture idyllique des travaux et des jours de l'élite locale aux troubles violents qui ont affecté la ville entre la Guerre des Paysans de 1525 et les rivalités confessionnelles ${ }^{140}$.

Finir sur cette remarque touchant au système de représentation, à la «culture» urbaine de la révolte, c'est replacer au centre de l'enquête le discours des contemporains et les mots de la révolte, autrement dit le filtre documentaire. C’est à ce prix sans doute que pourrait être comblée une la-

${ }^{138}$ Serge Lusignan sur la langue des rois au Moyen Age, Paris 2004.

139 Patrick Boucheron, 'Tournez les yeux pour admirer, vous qui exercez le pouvoir, celle qui est peinte ici. La fresque du Bon Gouvernement d'Ambrogio Lorenzetti, «Annales HSS», 2005, 60/6, pp. 1137-1199.

${ }^{140}$ On en trouvera la reproduction fidèle et détaillée dans Pia Maria Grüber (éd.), Kurzweil viel ohn Mass und Ziel. Alltag und Festtag auf den Augsburger Monatsbildern der Renaissance, München 1994. Un site internet complet est dédié à l'ensemble du cycle: http://www.dhm.de/ausstellungen/kurzweil/index.htm. Sur Augsbourg: Rolf Kiessling, Bürgerliche Gesellschaft und Kirche in Augsburg im Spätmittelalter: ein Beitrag zur Strukturanalyse der oberdeutschen Reichsstadt, Augsburg 1971; Dieter Weber, Geschichtsschreibung in Augsburg: Hektor Mülich und die reichsstädtische Chronistik des Spätmittelalters cit.; Johannes Janota, Werner Williams-Krapp (Hg.), Literarisches Leben in Augsburg während des 15. Jahrhunderts cit.; Jörg Rogge, Für den Gemeinen Nutzen. Politisches Handeln und Politikverständnis von Rat und Bürgerschaft in Augsburg im Spätmittelalter cit.; Christoph Böhm, Die Reichsstadt Augsburg und Kaiser Maximilian I. Untersuchungen zum Beziehungsgeflecht zwischen Reichsstadt und Herrscher an der Wende zur Neuzeit, Sigmaringen 1998. 
cune actuelle des recherches sur la dimension religieuse, cléricale, eschatologique, parfois aussi anti-pontificale des conflits, domaine un peu laissé en friche depuis l'œuvre monumentale et magistrale de František Graus ${ }^{141}$, qui n’a pas non plus oublié le lien entre révoltes et hérésies, une dimension un peu occultée pour le $\mathrm{XIV}^{\mathrm{e}}$ siècle allemand par l'ombre que projettent sur le siècle suivant les mouvements conciliaires et surtout la crise hussite. C'est justement parce que cet historien prend les révoltes du XIV $\mathrm{X}^{\mathrm{e}}$ siècle comme un tout, c'est-à-dire avec les pogroms anti-juifs consécutifs à l'arrivée de la Peste, qu'il est l'un de ceux à avoir posé le plus radicalement la question de la révolte comme fait de mentalité et d'autre part à avoir mis ce dernier point en relation avec le lien établi entre l'accroissement apparent du nombre de révoltes et l'invention documentaire. En outre, son livre pose la question de la césure chronologique du $\mathrm{XIV}^{\mathrm{e}}$ siècle en érigeant le hussisme et les révoltes pragoises en une coupure nette. Cette perspective lui permet de récuser la coupure traditionnelle de 1525 et, partant, de réexaminer la conception de la crise de la fin du Moyen Âge. Il faut comprendre cette analyse comme une invitation à saisir que le travail à mener consiste non pas à savoir si le moindre frémissement anti-fiscal survenu telle année dans tel lieu était bien ou non une révolte, mais pourquoi la documentation narrative, normative et juridique appelle cet événement du même nom qu'une très vaste et violente commotion ailleurs. Autrement dit, le véritable chantier scientifique consiste à déterminer, à partir de l'identification d'une forme donnée de révolte ou de protestation violente, le type de normes et de valeurs qui sont en jeu, la nature du groupement social qui permet et exprime la protestation, le type nouveau de regroupement social qui en résulte, la nature des discours et des productions de mémoire qui accompagnent et transmettent l'événement. Une telle méthode permettrait peut-être dès lors d'intégrer à l'analyse les silences réels ou supposés: la cartographie des prétendues absences de révoltes est en effet tout aussi instructive que la géographie des révoltes avérées. Ainsi, pourquoi 13 mentions de troubles à Colmar entre 1261 et 1424 ou bien 11 à Wurtzbourg de 1247 à 1400 alors que l'on ne possède pas grand-chose pour Ratisbonne, Nuremberg ou Francfort, villes de grand commerce, d'artisanat important, de fossé profond de fortune entre riches et pauvres?

${ }^{141}$ Pest - Geissler - Judenmorde. Das 14. Jahrhundert als Krisenzeit cit. Sa conclusion détache pour les $\mathrm{XIV}^{\mathrm{e}}$ et $\mathrm{XV}^{\mathrm{e}}$ siècles trois éléments, liés entre eux, qui caractérisent à ses yeux la «crise» de la fin du Moyen Âge: les révoltes, les pogroms de 1349-1350 et la crise hussite en Bohême. On n'omettra pas de signaler qu'il s'agit de l'œuvre d'un historien dont le destin personnel a été partagé entre les pays et les cultures tchèque et allemande, juif, décédé en 1989, c'est-à-dire en pleine révolte et révolution. 
Mais cette question n'est plus seulement «allemande», elle invite, dans la comparaison européenne, à replacer les révoltes au sein d'évolutions globales de la société médiévale considérées au regard des grands problèmes de la modernité: judiciarisation, scripturalité, naissance du capitalisme, criminalisation, consensus permis par la révolte entre le contrat et la contrainte, normalisation et modernisation ${ }^{142}$. Comme l'on voit, à la différence des gouvernants du Moyen Âge, mais sans doute aussi d'aujourd'hui, l'historien n'a pas peur des révoltes.

142 Peter Blickle (dir.), Theorien kommunaler Ordnung in Europa, München 1996; Id., Der Kommunalismus als Gestaltungsprinzip zwischen Mittelalter und Moderne, dans "Gesellschaft und Gesellschaften. Festschrift Ulrich Im Hof», Berne 1982, pp. 95-113. En français: Peter Blickle (dir.), Résistance, représentation et communauté, Paris 1998. 
UNA RIVOLTA ANTINOBILIARE NEL PIEMONTE TRECENTESCO: IL TUCHINAGGIO DEL CANAVESE

\section{Introduzione}

Fra il 1386 e il 1391 divampò in Piemonte un'estesa rivolta di comunità rurali, che i principi e i signori locali stentarono molto a placare, alternando misure repressive e concessioni negoziate. Fin dal primo momento le fonti ufficiali associarono la rivolta a un'area specifica, il Canavese, e dettero ai ribelli il nome di Tuchini: così, il tesoriere del principe d'Acaia rendicontò le spese sostenute fra settembre e ottobre 1386 "pro guerra Tuchinorum in auxilium nobilium Canapicii"; nei conti di un funzionario locale del conte di Savoia, il castellano di Bard, è registrato negli stessi mesi lo stipendio di due uomini messi di guardia in una torre sul confine con la canavesana valle di Brosso, "ne Tuchini de Valle Brocii ipsam caperent"; e anche negli ordinati consiliari di qualche città piemontese si registra in quell'autunno l'invio di armati "in guerra nobilium de Canapicio quam habebant cum Tuchinis"'.

Il nome dei Tuchini, insomma, è attestato contemporaneamente in fonti prodotte da amministrazioni diverse, tutte interne però ai domini della dinastia sabauda. Non c'è dubbio che esso si diffuse (e, sembra di capire, venne adottato dagli stessi ribelli) per analogia con le rivolte popolari così chiamate, endemiche ormai da anni nella Francia meridionale: una realtà con cui funzionari, vassalli e sudditi dei Savoia erano pienamente familiari, dal momento che il conte Amedeo VII era un principe francofono, residente per lo più Oltralpe, e largamente coinvolto nella politica del regno di Francia attraverso la madre Bona di Borbone e lo zio, il duca Luigi di

Nelle note si farà uso delle seguenti abbreviazioni: AST = Archivio di Stato di Torino; PD = AST, Sez. I, Protocolli dei notai ducali; PC = AST, Sez. I, Protocolli dei notai camerali; TG = AST, Sez. Riunite, Inv. 16, Conti dei Tesorieri Generali; BSSS = Biblioteca della Società Storica Subalpina.

${ }^{1}$ Cfr. S. Cordero di Pamparato, Il Tuchinaggio e le imprese di Facino Cane nel Canavese, in Eporediensia, Pinerolo 1900 (BSSS, IV), docc. 2 e 3; A. Caffaro, Pineroliensia, Pinerolo 1906, p. 183. 
Borbone. Il nome dei Tuchini attecchì nei domini sabaudi, dove restò in uso come sinonimo di agitazione antinobiliare, tanto che nel 1515 un editto del duca Carlo II proibì di menzionarlo, insieme ad altri nomi tradizionalmente forieri di disordini come quelli di guelfi e ghibellini ${ }^{2}$ - ma con scarso successo, giacché ancor oggi nelle località che furono teatro dell' insurrezione trecentesca il suo ricordo è ben vivo, ed è anzi fonte di un certo orgoglio comunitario.

Per quanto storici ed eruditi piemontesi si siano da sempre affaticati a proporre ipotesi sul significato del nome dei Tuchini, è insomma chiaro che la sua origine è da ricercarsi interamente sul versante francese. Al di là dell'identità onomastica, la più recente storiografia sulle insurrezioni in Linguadoca lascia comunque intravvedere una certa analogia con la ribellione canavesana. Le ricerche di Vincent Challet hanno smentito la lettura tradizionale, che riduceva il movimento dei Tuchins a un mero banditismo rurale, originato dalla miseria e capace di reclutare aderenti soltanto fra gli emarginati ${ }^{3}$; al contrario, hanno dimostrato il suo profondo radicamento nell'organizzazione comunitaria e le sue connotazioni di autodifesa contro la violenza degli uomini d'arme, anch'essa endemica nella Francia della guerra dei Cent'anni ${ }^{4}$. L'analogia è però solo parziale, perché nel caso piemontese l'identificazione fra i Tuchini e le comunità rurali risulta ancora più completa, e più chiaramente politici gli obiettivi della sommossa: che esprime sì una protesta contro la violenza nobiliare, ma quella degli stessi signori locali, non soltanto quella casualmente esercitata da mercenari di passaggio; e che, soprattutto, costituisce l'inasprimento momentaneo di un conflitto di più lunga durata fra i nobili canavesani e i loro sudditi, motivato dalla sopravvivenza, in quell'area, di forme di dipendenza insolitamente gravose.

${ }^{2}$ P. Venesia, Il Tuchinaggio in Canavese (1386-1391), Ivrea 1979, p. 19.

${ }^{3}$ Per questa lettura tradizionale cfr. M. Mollat - Ph. Wolff, Ongles bleus, Jacques et Ciompi. Les révolutions populaires en Europe aux XIV et XV siècles, Paris 1970, pp. 180 sg., 276; G. Fourquin, Le sommosse popolari nel Medioevo, Milano 1976 (ed. or. 1972), p. 146 sg.; A. Leguai, Les révoltes rurales dans le royaume de France, du milieu du XIV ${ }^{e}$ siècle à la fin $d u X V^{e}$, «Le Moyen Age», 88, 1982, pp. 49-75, alle pp. 59-67.

${ }^{4} \mathrm{~V}$. Challet, La révolte des Tuchins: banditisme social ou sociabilité villageoise?, «Médiévales», 34, 1998, pp. 101-112; Id., Au miroir du Tuchinat: relations sociales et réseaux de solidarité dans les communautés languedociennes à la fin du XIV siècle, "Cahiers de Recherches Médiévales», 10, 2003, pp. 71-87; Id., Compagnons contre gens d'armes en Languedoc: les Tuchins au secours des communautés, in Contrôler les agents du pouvoir, a cura di L. Feller, Limoges 2004, pp. 343-355; Id., Conflits et relations sociales en Languedoc à la fin du Moyen Âge: le Tuchinat dans la sénéchaussée de Carcassonne, «Bulletin de la Société d'Etudes Scientifiques de l'Aude», 105, 2005, pp. 85-93; Id., Au coeur de la révolte: les conflits paysans et leur résonance en milieu urbain en Languedoc à la fin du Moyen Âge, in Espaces d'échanges en Méditerranée. Antiquité et Moyen Âge, a cura di F. Clément, J. Tolan e J. Wilgaux, Rennes 2006, pp. 149-162. 
Fino ad oggi, queste connotazioni del Tuchinaggio nel Canavese non sono state sufficientemente poste in evidenza. L'interpretazione storiografica della vicenda è condizionata dalla lettura ottocentesca del Gabotto, che attribuiva alla rivolta una causa politica nel senso più ristretto del termine: e cioè le manovre del marchese di Monferrato, che avrebbe sobillato i rustici contro i nobili canavesani fedeli ai Savoia. Pesano su questa interpretazione il lealismo dinastico del Gabotto, che nei Savoia vedeva la potenza unificante del Piemonte e poi dell'Italia e non nascondeva la sua antipatia verso tutti quei poteri, come appunto i marchesi aleramici, che si erano opposti a quel gran disegno; la scarsa comprensione che al suo tempo si aveva delle dinamiche politiche e della gestione dei conflitti a livello locale e comunitario; ma anche la cecità ideologica così frequente nella storiografia borghese quando si occupa di rivolte contadine, regolarmente degradate a furori irrazionali, privi d'ogni logica o comunque cinicamente manovrati dall'esterno. Emblematica di questa incomprensione del Gabotto la sua denuncia degli "accorti sobillatori, che, naturalmente, non mancarono di dar a bere a' rozzi ed ingenui montanari le solite fole degli arruffapopoli, ricantando i nomi di usurpazione, prepotenza, libidine, da un lato, di giustizia, diritti, libertà, dall'altro" ${ }^{5}$. Nella storiografia successiva, la natura antisignorile dell'insurrezione ha ricevuto maggiore attenzione ${ }^{6}$; manca tuttavia, finora, una riconsiderazione generale della vicenda, tale da evidenziare che l'insurrezione canavesana, come non ebbe niente in comune con generiche fureurs paysannes, così non fu neppure frutto di pura sobillazione. Al contrario, essa si inserì con uno scopo e un tempismo piuttosto precisi in un conflitto politico molto complesso, di cui le comunità rurali conoscevano perfettamente la posta e in cui erano attori tutt'altro che passivi.

\section{Lo spazio geografico e politico della rivolta}

Al pari di altre regioni storiche prive di un moderno riscontro amministrativo, il Canavese presenta confini alquanto vaghi: molti comuni che hanno inglobato nella loro denominazione ufficiale l'aggettivo "Canavese" risultano esterni all'area così com'era concepita nel Trecento. Dal punto di vista morfologico, il Canavese comincia a settentrione di Torino, al di là

${ }^{5}$ F. Gabotto, Il Tuchinaggio in Canavese ed i prodromi dell'assedio di Verrua, «Bollettino Storico-Bibliografico Subalpino», I, 1896, pp. 81-95; integralmente ripreso in Id., Gli ultimi principi d'Acaia e la politica subalpina dal 1383 al 1407, Torino 1898, pp. 53-70 (la cit. a p. 55).

${ }^{6} \mathrm{Cfr}$. in particolare le poche pagine ad essa dedicate da C. Rotelli, Una campagna medievale. Storia agraria del Piemonte fra il 1250 e il 1450, Torino 1973, pp. 11-13. 
della Stura di Lanzo, con un'area pianeggiante, ancor oggi in parte boscosa e all'epoca per larghi tratti incolta ${ }^{7}$. La successiva area collinare e prealpina, che si estende a nord-ovest fino alle Alpi, dominate dal massiccio del Gran Paradiso, e ad est fino alla Dora Baltea, si presenta al contrario fin dal Medioevo straordinariamente popolata, con una griglia fittissima di insediamenti abbastanza forti da essere, ancor oggi, sedi comunali indipendenti, ma che distano l'uno dall'altro spesso non più di un paio di chilometri. C'è poi l'entroterra alpino, costituito dalle valli dell'Orco, Soana e Chiusella, che si spinge profondamente nelle montagne in direzione nordovest, fino al colle del Nivolet che consente di scendere in Valle d'Aosta.

Si tratta insomma di una zona tutt'altro che omogenea dal punto di vista geografico e insediativo, nonostante le dimensioni abbastanza ristrette: poco più di trenta chilometri da ovest a est, dalla Stura alla Dora, e altrettanti da sud a nord, dal Po fino alle pendici alpine. Ma a queste misure va poi aggiunta la profondità delle valli, la più lunga delle quali, la valle dell'Orco, si estende per una quarantina di chilometri fino all'ultima comunità abitata, a oltre 1600 metri di altezza. Ivrea, sulla Dora, è la sede diocesana da cui dipende oggi come allora la maggior parte del territorio canavesano ${ }^{8}$; ma nel Trecento, tecnicamente, la città era considerata esterna al Canavese vero e proprio, che a differenza di adesso si definiva abbastanza precisamente in termini politici. "Est autem Canepicium comitatum diversorum comitum scitus in australi plaga Lombardie carens civitatibus", spiega il cronista novarese Pietro Azario, che scrive un quarto di secolo prima della rivolta ed è una fonte preziosa per ricostruirne il contesto ambientale $^{9}$. Il Canavese insomma si definiva come il territorio rurale governato da un gruppo di famiglie, tutte imparentate fra loro in quanto discendenti dagli antichi conti di Pombia, che al più tardi dalla fine dell'XI secolo avevano cominciato a chiamarsi "comites de Caneves" (o, più latinamente, "de Canapixio") ${ }^{10}$. Nell'epoca che qui ci interessa, i conti del

${ }^{7}$ Gli attuali comuni di S. Carlo Canavese, S. Francesco al Campo, Bosconero e S. Giusto Canavese sono di fondazione moderna; l'area corrispondente era, nel Medioevo, sostanzialmente disabitata, come pure quella adiacente dove è presente il toponimo Vauda, che designava un'area forestale (attuale comune di Vauda Canavese e frazione di Vauda Inferiore, già Vauda di Front; anche l'attuale territorio del comune di S. Carlo Canavese era noto in precedenza come Vauda di Cirié). L'area è oggi in gran parte compresa nella Riserva Naturale della Vauda.

${ }^{8}$ Per il confine tra la diocesi di Ivrea e quella di Torino, che includeva una ridotta porzione del Canavese fino a Cuorgné, cfr. G. Casiraghi, La diocesi di Torino nel medioevo, Torino 1979 (BSSS, 196), p. 45.

${ }^{9}$ P. Azario, De statu Canapicii liber, in RIS ${ }^{2}$, XVI/4, p. 183.

${ }^{10}$ Le più antiche attestazioni sono citate nel commento del Cognasso all'Azario, op. cit., pp. 181-2 n. Sul comitato di Pombia e la sua dissoluzione cfr. G. Andenna, Alcune 
Canavese erano polverizzati in una molteplicità di lignaggi, raggruppati sulla base della discendenza in tre gruppi fortemente solidali al proprio interno: i conti di Valperga, i conti di S. Martino e i signori di S. Giorgio ${ }^{11}$.

I singoli lignaggi avevano spesso mezzi molto modesti, soprattutto per effetto d'una consuetudine ereditaria che ignorava la primogenitura e imponeva ad ogni generazione la spartizione delle quote: benché si definissero orgogliosamente conti di Valperga, quei tre fratelli che nel 1335 possedevano soltanto un ottavo dei luoghi di Rivarolo, Barbania e Ozegna rappresentavano certamente una nobiltà impoverita ${ }^{12}$. L'Azario, che pure scrive dopo due epidemie di peste e in un momento in cui il trend demografico era ormai in calo, osserva che i conti di S. Martino s'erano moltiplicati fino ad essere il quadruplo degli altri, e "tanti sunt... de personis quod sua ipsis non sufficiunt", soprattutto "volendo universi ducere vitam magnam"13. L'unica difesa contro un'eccessiva polverizzazione del possesso era la gestione consortile, una consuetudine ampiamente praticata in tutto il Piemonte, con l'indivisione tra fratelli o anche tra cugini, e la più generale solidarietà collettiva fra tutti coloro che portavano lo stesso cognome. Se i singoli erano in ristrettezze, collettivamente ciascuno dei tre raggruppamenti era una potenza, e disponeva di entrate paragonabili a quelle di una piccola città: nella perequazione fiscale piemontese del 1450, agli homines dei conti di S. Martino e loro alleati sarà attribuita una quota d'imposta di 1977 fiorini, e a quelli dei Valperga e loro aderenti una quota di 1671 cifre da confrontare ad esempio con la quota gravante sul vicino capoluogo diocesano, Ivrea, che ammontava appena a $1125^{14}$.

osservazioni a proposito delle fondazioni cluniacensi in Piemonte (sec. XI-XIII), in L'Italia nel quadro dell'espansione europea del monachesimo cluniacense, Cesena 1985, pp. 4557; Id., Grandi patrimoni, funzioni pubbliche e famiglie su di un territorio: il "comitatus plumbiensis" ed i suoi conti dal IX all'XI secolo, in Formazione e strutture dei ceti dominanti nel Medioevo: marchesi conti e visconti nel regno italico (secoli IX-XII), I, Roma 1988, pp. 201-228; G. Sergi, Dall'inquadramento pubblico alla signoria vescovile: il caso di Orta, in Id., I confini del potere. marche e signorie fra due regni medievali, Torino 1995, pp. 357-377.

${ }^{11}$ Questi ultimi erano cugini più lontani, giacchè erano un ramo dei conti di Biandrate, discendenti anch'essi dai conti di Pombia, ma originariamente distinti dai conti del Canavese.

12 A. Bertolotti, Passeggiate nel Canavese, Ivrea 1868, II, p. 16.

${ }^{13}$ Azario, De Statu cit., p. 186 sg.

${ }^{14}$ A. Tallone, Parlamento sabaudo, III, Bologna 1929, p. 311. A parte bisognerebbe poi calcolare i redditi dei conti di S. Giorgio, che nel 1385 controllavano circa un sesto del territorio complessivo del consortile, ma che nel Quattrocento dipendevano ormai interamente dal marchesato di Monferrato, e sfuggivano dunque alla fiscalità sabauda. 


\section{Odio di parte e violenza nobiliare}

La peculiare condizione politica del Canavese è una delle premesse per comprendere la rivolta dei Tuchini, soprattutto in quanto determinava un'estrema litigiosità e propensione alla violenza fra i signori locali. I Valperga e i S. Giorgio da un lato, i S. Martino dall'altra erano divisi da una feroce rivalità, "se non tamquam consortes pertractando, sed ac si una pars esset christiana et alia sarazena", come osserva ancora l'Azario. Il cronista novarese non ha dubbi sul fatto che la causa fosse proprio l'eccessiva proliferazione dei lignaggi signorili, e il conseguente impoverimento dei singoli, i quali si trovavano a disporre di mezzi insufficienti per mantenere un tenore di vita nobiliare, sicché "necessarium fuit ut alia raperent"15.

Gli attriti fra consorti e la tentazione della violenza erano aggravati da una situazione patrimoniale estremamente intricata. I possessi dei diversi gruppi di lignaggi tendevano, sì, a formare degli aggregati separati, ma penetravano comunque profondamente gli uni negli altri, in zone fittamente popolate dove per lo più fra un castello e l'altro c'era appena mezz'ora di cammino, e non erano rare le situazioni come quella del castello di Montalenghe, così vicino al rivale borgo di S. Giorgio che "nullus de ipso burgo pisare poterat quin a castro Montalengo videretur"16. Proprietà dei S. Martino incuneata nel bel mezzo dei possedimenti dei S. Giorgio, Montalenghe all'epoca del Tuchinaggio era occupata da questi ultimi ormai da tanto tempo che il loro diritto era riconosciuto perfino in sede giuridica, ma i S. Martino non avevano rinunciato a lagnarsi dell'usurpazione (ed è suggestivo che l'unica vittima chiaramente identificata dell'insurrezione sia proprio un signore di Montalenghe, spossessato dei suoi beni e impiegato dai parenti S. Martino come castellano nella valle di Brosso) ${ }^{17}$. A loro volta i conti di Masino, un ramo dei Valperga i cui possedimenti si estendevano, eccezionalmente, al di là della Dora ${ }^{18}$, possedevano sulla carta una quota di Strambino, luogo adiacente ai loro possessi, ma situato al di qua del fiume e in mano ai S. Martino, che non permisero mai ai rivali di riscuotere le rendite di loro spettanza ${ }^{19}$.

${ }^{15}$ Azario, De Statu cit., p. 187.

${ }^{16}$ Azario, De Statu cit., p. 189.

${ }^{17}$ Cfr. G. Frola, Corpus statutorum Canavisii, III, Torino 1918 (BSSS 94), pp. 328332 per le rivendicazioni dei S. Martino; AST, Città e Provincia d'Ivrea, Mazzo 12, S. Giorgio, 3, e PD 59 ff. 68-69, per le investiture sabaude ai S. Giorgio. Per il Montalenghe vittima dei Tuchini cfr. sotto, n. 54.

${ }^{18}$ Tanto che l'Azario li considera un comitato a sé, annesso al Canavese vero e proprio, "cui comitatus Maxini unitur" (Azario, De Statu cit., p. 183).

${ }^{19}$ Cfr. AST, Città e Provincia d'Ivrea, Mazzo 6, Masino, 2, 8, 13; Frola, op. cit., I, p. $\operatorname{lxxv}$ e III, p. 348. 
Fonte ancora più inesauribile di tensioni e conflitti era poi il fatto che in un'area cruciale i due schieramenti, nonostante l'odio che li divideva, non erano mai arrivati a spartirsi beni e giurisdizioni. Nel grosso borgo di Pont e nel suo mandamento, che comprendeva l'intera estensione delle valli alpine di Orco e Soana, il potere continuava ad essere amministrato indiviso da un podestà che almeno in teoria avrebbe dovuto essere nominato dall'intero consortile, con tutte le difficoltà che nascevano da questa coesistenza forzata. Non per nulla gli statuti di Pont sono i più antichi di tutto il Canavese, risalendo già al Duecento, e vennero ripetutamente aggiornati nel corso del Trecento, sempre alla ricerca di un impossibile modus vivendi fra i condomini: particolarmente significativa l'aggiunta del 1324 in cui, "ad generalem concorsiam pervenientes unanimiter domini consortes in simul tam de Sancto Martino quam de Valperga", si stabilisce che per dieci anni non si possa nominare giudice né notaio "de terra dominorum de Sancto Martino nec de terra dominorum de Valperga", e più in generale che "aliquis familiaris dictorum dominorum non possit esse potestas", nella speranza che i condomini fossero costretti a far convergere la scelta su qualcuno davvero al di sopra delle parti ${ }^{20}$. Ma nessun compromesso riuscì mai a reggere a lungo: l'Azario ci informa che appena si sentivano abbastanza forti per farlo i guelfi S. Martino si impadronivano delle "terras et castra comunia, in quibus non permittebant aliquem Gibellinum nominari”, mentre a loro volta quando ne avevano la possibilità "Gibellini ipsi custodire faciebant dicta castra comunia per eorum familiares"21.

Giacché, a completare il quadro e inasprire ulteriormente la rivalità, i due partiti si definivano guelfi e ghibellini e si muovevano di conseguenza nell'intrico complesso della politica trecentesca, cercando aderenze nelle fazioni guelfa e ghibellina d'Ivrea e nei principati confinanti; i quali a loro volta, pur nell'estrema libertà d'azione che si riservavano e nel frequente stravolgimento delle alleanze, avevano comunque una certa tradizionale coloritura di parte. Ghibellini, i Valperga e i S. Giorgio cercavano volentieri, finché fu loro possibile, la protezione del marchese di Monferrato e dei Visconti, mentre i guelfi S. Martino trovavano naturale chiedere aiuto contro i propri nemici al conte di Savoia e al principe d'Acaia. Si capisce allora che nel corso del Trecento le rivalità intestine fra i conti canavesani abbiano potuto tradursi in vere e proprie operazioni belliche su ampia scala. L'Azario racconta diffusamente come nel 1339 i Valperga assumessero a Milano una compagnia mercenaria di trecento barbute, "que gens pulcra fuit et tota teutonica", conducendola nel Canavese per fare la guerra ai

${ }^{20}$ Frola, Corpus cit., I, p. 47.

${ }^{21}$ Azario, De Statu cit., p. 187. 
S. Martino, le cui terre vennero minuziosamente devastate ed arse. L'anno seguente, i guelfi si vendicarono con la stessa moneta; assunte a loro volta trecento barbute, fra cui alcuni dei medesimi mercenari pagati fino a poco prima dai Valperga, le scatenarono contro i castelli e le villae dei rivali, con lo stesso, tragico strascico di devastazioni ${ }^{22}$.

Proprio nel descrivere questa vicenda l'Azario attesta che la necessità di difendersi dalla violenza dei signori rafforzava la coscienza di sé e la capacità d'azione autonoma delle comunità canavesane. Racconta il cronista che la grande scorreria dei mercenari tedeschi al soldo dei Valperga giunse fino a Pont, dove distrusse uno dei castelli dei S. Martino, che fino ad allora ne avevano posseduti sul posto ben due; contemporaneamente Giovanni di Valperga entrò nella Valle Soana e "sibi faventibus hominibus suis dicte vallis" s'impadronì del castello di Pertica che ne costituiva la chiave d'accesso. Subito dopo, però, ne cedette il controllo agli abitanti e sgombrò la valle; "et sic deinceps homines vasalli dictorum comitum, tam guelforum quam gibellinorum, ipsas valles ceperunt tam caute custodire quod nullus ipsorum dominorum durante guerra intravit". Gli abitanti, insomma, si fortificarono nella valle e di comune accordo impedirono ai signori di entrarvi e continuare anche lì le reciproche devastazioni; il cronista peraltro sottolinea che non si trattò affatto di ribellione, perché le comunità continuavano a osservare i propri obblighi verso i signori e pagare loro il dovuto: "set annuatim ipsis dominis ut consueverant respondebant et non ultra". L'episodio appare estremamente significativo d'una capacità di autogestione e autodifesa degli homines, che accomuna due intere valli nella dichiarata volontà di non lasciarsi coinvolgere nella faida tra i signori, pur adempiendo scrupolosamente ai propri doveri: "propter que dicte valles a presenti guerra deinceps estiterunt conservate et legales homines fuerunt alterutrorum dominorum"23.

Non è il caso di descrivere qui in dettaglio le successive esplosioni di violenza che a più riprese turbarono il Canavese, intervallate da periodi più o meno prolungati di sospettosa pace. È invece cruciale segnalare che proprio negli anni immediatamente precedenti la rivolta dei Tuchini la violenza aveva ripreso a montare, i nobili si trovavano visibilmente in una fase di crescente sovreccitazione, e aggressioni personali e cavalcate distruttive degli uni contro le terre degli altri erano ridiventate quotidiane. La documentazione processuale di cui disponiamo, così precisa da arrivare addirittura alla stima economica dei danni inferti, attesta un primo picco della

${ }^{22}$ Azario, De Statu cit., pp. 188-92. Cfr. F. Gabotto, Storia del Piemonte nella prima metà del secolo XIV (1292-1349), Torino 1894, pp. 183-185.

${ }^{23}$ Azario, De Statu cit., p. 190. 
violenza negli anni 1378-79, e un secondo a partire dal 1382 fino al 1384, all' immediata vigilia cioè della rivolta ${ }^{24}$. Ma se siamo informati così in dettaglio di questi incidenti, è perché le lotte intestine fra i nobili canavesani avevano smesso da un pezzo di riguardare soltanto loro e i disgraziati abitanti delle loro terre. Fin dal principio del secolo altri attori erano entrati sulla scena e si erano conquistati una parte progressivamente più rilevante, riducendo in proporzione l'autonomia e la libertà d'azione dei signori locali. Sono i principi territoriali confinanti, il cui ruolo è altrettanto importante di quello dei signori per comprendere le condizioni ambientali in cui maturò la rivolta dei Tuchini.

\section{Il ruolo dei principi territoriali}

Che nel corso del Trecento i principi abbiano sistematicamente allargato la propria autorità, limitando gli spazi d'azione dei signori locali e costringendoli a forme di coordinamento e sottomissione, espresse in area piemontese tramite l'omaggio vassallatico, è di per sé un'ovvietà. Peculiare del Canavese è però la presenza ingombrante ai suoi confini di ben tre dominazioni principesche in espansione, caratterizzate da un instabile intreccio di alleanze e rivalità. L'area canavesana si trovava al punto d'incontro fra la dominazione dei conti di Savoia, che premevano contemporaneamente da sud, dalle valli di Lanzo e di Susa, e da nord, dalla Valle d'Aosta; quella dei loro cugini i principi d'Acaia, padroni di Torino, e che, subordinati in teoria al ramo primogenito della dinastia, condussero in realtà in certi momenti del Trecento una politica autonoma fino all'insubordinazione; infine quella, già indebolita ma ancora aggressiva, dei marchesi di Monferrato, radicati a sud e ad est del Canavese, nell'area collinare al di là del Po.

La competizione fra i tre principati rappresentò nel Trecento un fattore di destabilizzazione in tutta la zona di Ivrea e del Canavese. Tutt'e tre tendevano ad allargare la propria egemonia nei modi consueti: costringendo, cioè, i signori locali a riconoscersi loro vassalli e a tenere in feudo da loro castelli e giurisdizioni; offrendo, o imponendo, il proprio arbitraggio nelle controversie locali; e naturalmente, confiscando e occupando i possedimenti di chi rifiutava di sottomettersi. Altra peculiarità del Canavese è però la marcata riluttanza dei nobili locali ad accettare queste forme di sottomissione. Dopo tutto, anch'essi portavano il titolo di conti e ancora alla fine del Trecento ricordavano benissimo che i loro antenati non erano subordinati a nessuno, ma tenevano i propri possedimenti direttamente dal-

${ }^{24}$ PD 59 f. 43; AST, Città e Provincia d'Ivrea, Mazzo 1, 17. 
l'imperatore. Non a caso l'Azario, che li conosceva bene, apre il suo opuscolo De statu Canapicii ricordando che in passato i "Canepicii comites et nobiles solebant liberi esse et tempore pacifico nulli preterquam imperio respondere", salvo constatare, in chiusura, che "nunc pauperes effecti sunt et submissi iugo perpetue servitutis"25.

La bellicosità dei nobili canavesani, abituati da generazioni a farsi la guerra e pieni di rancore nei confronti dei principi che esigevano da loro omaggio e sottomissione, si combinò col fatto che non uno solo, ma ben tre principi rivali erano in competizione per imporre il proprio dominio sul Canavese, e determinò una condizione di eccezionale instabilità. Il processo di assoggettamento dei poteri locali a quelli principeschi era di rado pacifico, ma qui presentò caratteri particolarmente disordinati e conflittuali. Tutti i poteri esistenti nell'area, compresi il comune di Ivrea e il suo vescovo, furono costretti nel corso del Trecento a subordinarsi ora al conte di Savoia, ora al principe d'Acaia, ora al marchese di Monferrato; ma queste soggezioni erano di rado definitive, e le improvvise rotture di fedeltà e gli spettacolari cambi di campo, coll'inevitabile strascico di vendette e spedizioni punitive, erano all'ordine del giorno.

La situazione divenne solo apparentemente più stabile allorché, avvicinandoci all'epoca in cui sarebbe esplosa la rivolta dei Tuchini, uno dei tre competitori, il conte di Savoia, emerse progressivamente come il più forte. Nel corso del suo lungo regno Amedeo VI, il Conte Verde, domò spietatamente l'insubordinazione del cugino principe d'Acaia e contenne con successo le ambizioni del marchese di Monferrato, fino ad affermarsi come la potenza egemone nell' intero Piemonte settentrionale. Nel 1372, alla morte del vecchio marchese Giovanni II, il suo successore Secondotto, minorenne e sotto tutela, firmò col temibile vicino un trattato alquanto sfavorevole, impegnandosi a versargli 200.000 fiorini per fare la guerra contro i Visconti e dandogli in pegno tutti i suoi possedimenti canavesani. Il 29 dicembre di quell'anno il marchese di Monferrato ordinò a tutti i conti canavesani che erano ancora suoi vassalli, appartenenti ai raggruppamenti ghibellini dei $S$. Giorgio e dei Valperga di Mazzé e di Rivara, di prestare omaggio al conte di Savoia, e ai sindaci delle loro terre di giurargli fedeltà ${ }^{26}$.

Nei mesi successivi Amedeo VI, il cui balivo di Val di Susa e capitano generale di qua dai monti Yblet de Challant aveva nel frattempo assunto per la prima volta il titolo di "baillivus valis Secuxie et Canapicii"27, cominciò a incassare effettivamente gli omaggi di quei nobili ${ }^{28}$. Nell'estate

\footnotetext{
${ }^{25}$ Azario, De Statu cit., pp. 181 e 197.

${ }^{26}$ AST, Ducato di Monferrato, mazzo 4, 21 e 22.

${ }^{27}$ Frola, Corpus cit., II, pp. 515 sgg.

${ }^{28}$ AST, Città e Provincia d'Ivrea, mazzo 12, S. Giorgio, 3.
} 
1373 l'imperatore Carlo IV accettò di cedergli la fedeltà dell'unica famiglia canavesana rimasta fino allora nella vassallità immediata dell'impero, $\mathrm{i}$ Valperga conti di Masino, che si videro perciò costretti anch'essi a prestare omaggio al conte ${ }^{29}$. Il conte di Savoia si ritrovava dunque, almeno sulla carta, unico signore di tutti i nobili canavesani; ma la situazione si era stabilizzata solo in apparenza. La documentazione non consente infatti di affermare con certezza che tutte le famiglie interessate abbiano davvero obbedito all'ordine del marchese di Monferrato e prestato l'omaggio come richiesto; quanto al marchese stesso, non deve essere stato troppo convinto di quel che gli era stato fatto firmare, tant'è che negli anni seguenti si ebbero a più riprese nuovi negoziati e richieste di modifica del trattato, culminate in un nuovo, provvisorio compromesso nel 1378. Raggiunto grazie alla mediazione di Gian Galeazzo Visconti, l'accordo riconosceva comunque al conte di Savoia il possesso di "totum territorium Canapicii de citra Padum" e il diritto ad esigere la fedeltà di tutti quei conti e signori canavesani che in passato erano stati vassalli dei Monferrato ${ }^{30}$.

5. Dalla pacificazione del 1379 a quella del 1385: violenze nobiliari e mobilitazione delle comunità

È in questo contesto di palpabile tensione che abbiamo notizia, per la prima volta dopo qualche anno, di una ripresa delle violenze nobiliari nel Canavese. Era l'occasione, evidentemente, per Amedeo VI di far pesare la sua autorità, e dimostrare ai signori canavesani che non erano più liberi di risolvere le proprie controversie a modo loro. Il suo plenipotenziario in Piemonte, Barthélemy de Chignin, ordinò seccamente ai Valperga di portare le loro querele contro i S. Martino davanti al conte di Savoia ${ }^{31}$; un ordine analogo per i S. Martino non è attestato, ma i S. Martino erano guelfi e da molto tempo avevano accettato la sottomissione alla dinastia sabauda come il male minore, mentre i Valperga erano ghibellini e diversi dei loro rami erano stati costretti solo da poco a prestare omaggio al conte, anche ammesso che tutti l'avessero davvero prestato. Il 27 settembre 1379, dopo parecchi mesi di negoziati, il conte Amedeo VI pronunciò la sua sentenza, che si proponeva ufficialmente di mettere fine alle violenze fra i nobili canavesani e confermare ciascuno nel pacifico godimento dei suoi diritti ${ }^{32}$.

Questa sentenza del 1379 riveste un'importanza centrale per comprendere il contesto in cui poco più di sei anni dopo si scatenerà il Tuchinaggio.

${ }^{29}$ AST, Città e Provincia d'Ivrea, Mazzo 6, Masino, 3 bis.

${ }^{30}$ AST, Ducato di Monferrato, mazzo 4, doc. 24; mazzo 5, docc. 1, 4 e 5.

${ }^{31}$ PD 69 f. 55.

${ }^{32}$ PD 59 f. 43. 
Le ulteriori pacificazioni che il figlio e successore del Conte Verde, Amedeo VII, imporrà nel Canavese, tanto quella del 1385 che precede di pochi mesi l'esplosione della rivolta, quanto quella del 1391 che a tutti gli effetti la chiude, faranno esplicito riferimento a questa "pacem dudum ultimo factam per dictum dominum et genitorem nostrum carissimum", deplorandone la violazione da parte dei nobili canavesani e proponendosi di rimetterla in vigore. Per qualche tempo, in verità, la pacificazione aveva tenuto, grazie all'enorme prestigio e autorità di Amedeo VI. Già nei giorni seguenti la lettura della sentenza, e poi nei mesi successivi, la maggior parte dei nobili che erano stati in passato vassalli del marchese di Monferrato rinnovarono con formula più piena o prestarono per la prima volta l'omaggio al conte di Savoia, in tardiva esecuzione del famoso trattato del $1372^{33}$.

A manifestare il loro scontento rimanevano solo i conti di Masino, poco soddisfatti del diploma imperiale che li aveva costretti a subordinarsi al Conte Verde: il 13 agosto 1380 in Borgomasino risulta insediato un podestà sabaudo, che aprì un'inchiesta contro i signori e gli abitanti del luogo, giacché correva voce d'una congiura per aprirne le porte al marchese di Monferrato ${ }^{34}$. L'inchiesta non ebbe tuttavia ulteriori sviluppi e c'è motivo di pensare che per evitare guai peggiori anche i conti di Masino si siano rassegnati a prestare omaggio ad Amedeo $\mathrm{VI}^{35}$. Alla vigilia del Tuchinaggio, tutti gli innumerevoli rami dei conti canavesani erano ufficialmente vassalli del conte di Savoia e tenevano in feudo da lui l'insieme dei loro possedimenti.

La violenza, tuttavia, non era sopita e tornò ad esplodere non appena Amedeo VI uscì di scena. Il 15 luglio 1382 il conte partiva per accompagnare Luigi d'Angiò nella progettata conquista del regno di Napoli, e già ad agosto abbiamo notizia delle prime cavalcate in Canavese, compiute da Antonio di Mazzé e dai signori di Rivara e di Favria, tutti dei Valperga e antichi vassalli del marchese di Monferrato, contro le terre dei S. Martino. A partire da questo momento e per più di un anno e mezzo, fino al febbraio 1384, l'elenco delle scorrerie, delle ville prese con la forza e bruciate, del bestiame portato via e dei contadini malmenati o costretti a riscattarsi è troppo lungo perché si possa riportarlo qui; basti citare ad esempio la scorreria dei signori di Rivara contro Aglié appunto nel febbraio 1384, il cui bilancio fu di parecchie case bruciate o distrutte, quattro morti, tre feriti fra

${ }^{33}$ PD 59 ff. 68-72, 78-79, 81; PD 63 f. 61v; AST, Città e Provincia d'Ivrea, mazzo 8, Mazzé, 5.2 e mazzo 12, Strambino, 1.

${ }^{34}$ AST, Città e Provincia d'Ivrea, mazzo 6, Masino, 4.

${ }^{35}$ Lo si deduce dal fatto che dopo la morte di Amedeo VI il suo successore Amedeo VII ebbe regolarmente, nel 1384, l'omaggio dei conti di Masino: AST, Città e Provincia d'Ivrea, Mazzo 6, Masino, 5-6. 
i signori locali e quarantaquattro fra i loro uomini, e il taglio di sessanta giornate di vigna, con un danno stimato in 4000 fiorini ${ }^{36}$.

Non placò certo la violenza la notizia della morte di Amedeo VI, all'inizio di marzo 1383. Il figlio, Amedeo VII, aveva già 23 anni, ma era lontano, impegnato a guerreggiare contro gli Inglesi in Fiandra; la madre, Bona di Borbone, e il consiglio governavano a suo nome e fecero quel che potevano per pacificare i nobili canavesani, ma con alterno successo. Una tregua fra i S. Martino e i Mazzé, imposta il 9 aprile 1383, per un po' parve rispettata: tanto che nell'autunno si trattò di estenderla anche agli altri Valperga, e il 18 ottobre 1383 il capitano di Piemonte Yblet de Challant partì da Ripaille per Ivrea, "pro facto tractando treugam illorum de Sancto Martino et de Valperga". Ma la missione non sembra abbia avuto alcun esito significativo, e già ad Ognissanti la tregua esistente venne infranta da Antonio di Mazzé, dopodiché le incursioni ripresero a susseguisi più fitte di prima ${ }^{37}$.

Dopo la scorreria forse più sanguinosa, quella già citata del febbraio 1384 contro Aglié, venne un nuovo ordine del conte che intimava alle parti di sospendere le ostilità. Di questo "preceptum factum per excelsam dominationem vestram quod nulla pars offenderet aliam" parlano le denunce presentate dai S. Martino, secondo i quali i loro avversari non se ne dettero per intesi: anzi, durante l'ultima e la più vasta delle loro scorrerie, intrapresa il 21 marzo 1384 con "totum effortum dominorum Valpergie, Ripparie, Sancti Georgii, Mazadii, Maxini consortumque suorum”, gli aggressori levarono fra l'altro il grido "vivat dominus Galeaz et marchio Montisferrati ad arma ad arma". Era certamente un segnale inquietante, e gli aggrediti, in quel caso i signori di Front, ne approfittarono ovviamente per sottolineare che essi "tanta damna passi fuerant et obedientes fuerant et sunt, et dicti eorum vicini inobedientes sunt".

Dopo i fatti del 21 marzo il conte, o i suoi luogotenenti sul posto, si devono essere allarmati sul serio, perché intervennero con maggior decisione; e non è certamente un caso se quella scorreria è anche l'ultima denunciata. Di lì a poco, anche se non sappiamo esattamente quando, gli uomini di Amedeo VII entrarono nelle valli di Pont, dove i Valperga avevano nel frattempo scacciato i S. Martino dalla loro parte, e l'intero mandamento venne sequestrato ("ad manum nostram posita") 38 . Nel maggio e giugno 1384 di-

${ }^{36}$ L'elenco, realmente impressionante, delle devastazioni reciproche è registrato nella sentenza di Amedeo VII del 13 dicembre 1385, in AST, Città e Provincia d'Ivrea, Mazzo 1, 17.

${ }^{37}$ Per lo Challant, Gabotto, Gli ultimi principi d'Acaia cit., p. 16; il resto in AST, Città e Provincia d'Ivrea, Mazzo 1, 17.

${ }^{38}$ Anche tutte queste informazioni in AST, Città e Provincia d'Ivrea, Mazzo 1, 17. 
versi nobili canavesani rinnovarono al nuovo conte l'omaggio che avevano prestato a suo tempo al padre; è forse significativo che ad essere conservati con più cura negli archivi sabaudi siano stati proprio gli omaggi dei rami più malfidati del consortile di Valperga, fra cui i conti di Masino ${ }^{39}$. Ed egualmente a giugno vennero avviati nuovi negoziati con il marchese di Monferrato, che era ora Teodoro II Paleologo, per l'ennesima revisione del controverso trattato del $1372^{40}$.

Le trattative proseguirono per un anno e mezzo, fino al dicembre 1385, e contemporaneamente si accumulava sui tavoli dei consiglieri del conte un foltissimo dossier di lagnanze provenienti dal Canavese. Si trattava innanzitutto della minuziosa enumerazione, da parte dei conti di S. Martino, di tutte le aggressioni che avevano subito a partire dal 1378, e in particolare negli anni di follia tra il 1382 e il 1384, con la precisa quantificazione economica dei danni provocati da ogni singola incursione. I Valperga e i S. Giorgio si limitarono a presentare una supplica per così dire forfettaria, lamentando di essere stati aggrediti dai S. Martino "cum vexillis et manu armata" con danno di addirittura 40.000 fiorini oltre all'uccisione di diversi loro uomini, ma seppero indicare un solo episodio specifico; ed è legittimo ritenere che in questa occasione le famiglie ghibelline, che più di tutte avevano motivo d'essere scontente d'essere state abbandonate dal marchese di Monferrato e costrette ad assoggettarsi al conte di Savoia, siano state davvero, al di là della retorica dei loro avversari, i maggiori responsabili dello scatenarsi della violenza.

Ma il dato per noi di gran lunga più significativo è che il conte aveva ricevuto anche ripetute "querele... contra dictos nobiles" da parte degli "homines et comunitates", sudditi tanto dell'una quanto dell'altra parte, con richiesta "a nobis fieri iusticia... contra dictos dominos comites". Le comunità, in altre parole, di fronte all'ennesimo scatenarsi della violenza nobiliare avevano reagito appellandosi all'autorità che adesso, per la prima volta, appariva in grado di imporsi egualmente a tutti i signori. E, ciò che risulta ancor più significativo, lo avevano fatto accordandosi fra loro $\mathrm{e}$ agendo tutte insieme, tanto che i signori, spaventati, si erano a loro volta querelati presso il conte "de suis hominibus et comunitatibus villarum suarum que et qui fecisse dicebantur contra dictos utriusque partis dominos comites unionem et monopolium sine causa". Pochi mesi prima dell'esplosione del Tuchinaggio è dunque attestato ufficialmente, dal conte Amedeo VII in persona, che le comunità soggette ai conti canavesani si erano mosse collettivamente, avevano formato una lega e si erano appellate

\footnotetext{
${ }^{39}$ AST, Città e Provincia d'Ivrea, mazzo 6, Masino, 5-6; mazzo 13, Valperga, 6-7.

${ }^{40}$ AST, Ducato di Monferrato, mazzo 5, docc. 15-17.
} 
a lui; e non solo per ottenere protezione contro la violenza dei propri signori, ma anche, come vedremo fra poco, per mettere sul tavolo tutti i motivi di controversia che ormai da molto tempo li opponevano a questi ultimi.

Non c'è da stupirsi che i conti canavesani si siano allarmati, e abbiano cercato di dimostrare al principe la pericolosità, anzi l'illegalità di questo passo. Ma non c'è neppure da stupirsi se Amedeo VII, da parte sua, non trovò così offensivo che i sudditi dei suoi vassalli vecchi e nuovi si rivolgessero a lui come arbitro delle controversie che li opponevano ai signori. Si misura qui in tutta la sua ampiezza lo spazio d'azione che il rafforzamento dei principati territoriali apriva alle comunità rurali, introducendo nel conflitto politico un nuovo, e più potente giocatore, che non aveva nessun motivo per schierarsi a priori con gli uni anziché con gli altri, e che anzi a ben vedere aveva tutto l'interesse a vedere ridimensionato il potere dei signori locali. Anziché accogliere la querela dei conti canavesani contro le comunità insubordinate, Amedeo VII scese in Piemonte nell'autunno 1385, col duplice intento di ratificare il compromesso faticosamente raggiunto col marchese di Monferrato, e di imporre la sua pacificazione a tutte le parti in causa. I signori e le comunità del Canavese si impegnarono nel mese di ottobre ad accettare l'arbitrato del conte; nel corso di novembre, $\mathrm{i}$ segretari comitali Guigues Marchand e Mermet Rouget ascoltarono i testimoni, e finalmente Amedeo convocò le parti a Torino il 13 dicembre per ascoltare la sua sentenza ${ }^{41}$.

\section{La pacificazione del 1385}

\section{a) La pacificazione fra $i$ Valperga e i S. Martino}

La sentenza del conte venne pronunciata in due giorni successivi, il 13 e il 14 dicembre, alla presenza dei rappresentanti di entrambi gli schieramenti nobiliari e di venti procuratori in rappresentanza delle comunità loro soggette. Il primo giorno Amedeo VII si pronunciò sulle discordie fra i "nobiles et dilectos fideles nostros" conti di S. Martino e i "nobiles et fideles nostros" conti di Valperga (una divergenza terminologica che non era casuale); il secondo giorno fu invece dedicato a "sopire factum dictorum dominorum comitum et popularium". I due momenti meritano di essere analizzati separatamente, ma va sottolineato che nell'insieme la formulazione della sentenza tradisce una certa debolezza: non si trattò di un intervento col pugno di ferro, ma piuttosto di un compromesso che il conte

${ }^{41}$ Ricordiamo che il documento è in AST, Città e Provincia d'Ivrea, Mazzo 1, 17. 
sembra essersi sforzato di far accettare, più che imporlo d'autorità, e di cui non è chiaro quanto le parti abbiano potuto ritenersi soddisfatte.

L'impressione d'un intervento non particolarmente energico affiora fin dalle prime frasi: la sentenza si apre assicurando tutti i nobili interessati che il loro onore non è stato messo in discussione dalle offese e accuse reciproche ("ambe ipse partes et quilibet earum suum honorem conservaverunt integraliter in predictis, et quod neutra dictarum partium incurrerit aliquod dedecus in dictis verbis prolatis"). Analoga impressione suscita la formulazione prudente con cui Amedeo, il secondo giorno, apre il suo arbitrato fra i nobili e le comunità, dichiarando d'aver pronunciato "tam ex plenitudine potestatis ordinarie quam ex potestate nobis data per dictas partes super dictis querellis et debatis": e dunque riferendosi espressamente al consenso delle parti anziché rivendicare semplicemente la propria superiore giurisdizione.

Venendo al merito della sentenza, la pacificazione imposta ai Valperga e ai S. Martino non appare neppur essa particolarmente energica, soprattutto in considerazione del foltissimo dossier di lamentele che era stato presentato. Il conte osservò che nessuna delle parti aveva prodotto testimoni ed era dunque impossibile arrivare a condanne, sicché si limitò a ordinare che a ciascuno fosse restituito ciò che gli era stato sottratto; in particolare, Pont e le valli vennero dissequestrate e restituite ai legittimi proprietari. In questo caso specifico, i S. Martino potevano ritenersi soddisfatti, giacché il sequestro da parte della gente del conte era avvenuto dopo che i Valperga li avevano espulsi, ed è dunque esplicitamente a favore dei S. Martino che venne attuato il dissequestro ("nostram manum inde tollimus ad utilitatem dominorum de sancto Martino comitum"). Ma non era poi molto rispetto alle lagnanze presentate, considerando che l'impianto della sentenza mantiene invece la più scrupolosa equidistanza fra le partes.

\section{b) La pacificazione fra signori e sudditi}

Se dunque la sentenza relativa alle discordie fra i nobili si rivela sostanzialmente interlocutoria, limitandosi a evocare la precedente sentenza del 1379, e ordinare a tutte le parti in causa di rispettarla, si tratta ora di valutare l'intervento del conte nella controversia fra i signori e i loro sudditi. Che i rapporti fra i conti canavesani e le comunità avessero già raggiunto, e anzi superato, lo stadio dell'insubordinazione, è difficile dubitarne; del resto pochi anni dopo Amedeo VII, rievocando per confermarla la sua sentenza del 1385, dichiarerà espressamente che essa era stata originata dalle discordie che avevano opposto i Valperga e i S. Martino ai loro sudditi "qui inhobedienciam et rebellionem adversus eos hostenderunt". Egualmente 
certo è che la ribellione si era già tradotta nella costituzione d'una lega giurata fra le comunità, un passo che i signori avevano denunciato come illegale e che anche Amedeo VII sconfessò: possiamo infatti anticipare qui che la sentenza del 1385 si concluse dichiarando "quod omnis iura liga unio monopoliumque facti et iurati inter ipsos homines subditos et populares utriusque partis... sint cassa, vana, inrita et nullius valoris", e cassando parimenti tutti gli scritti, "instrumenta, lictere seu franchisie" fatti in proposito (indicazione preziosa, per noi, che il movimento era stato pubblico e ufficialmente formalizzato, dando luogo alla stesura di impegni scritti di solidarietà).

Ma resta da vedere qual era il merito della controversia, e come si pronunciò il conte a questo riguardo. Contrariamente a quel che potremmo pensare, la sostanza delle proteste popolari non verteva sulla violenza dei signori e sui danni che essa provocava ai sudditi. Al contrario, le comunità avevano presentato un elenco di richieste che rivela una diffusa insofferenza per il prelievo signorile, nelle molteplici forme in cui era esercitato, e una chiara volontà di ridimensionarlo. Il conte era chiamato a risolvere le controversie fra signori e populares riguardo le successioni, il fodro, la taglia, la roida, le prestazioni obbligatorie per la manutenzione del canale del mulino signorile, la custodia e i lavori di fortificazione al castello, le tasse che il signore prelevava sui passaggi di proprietà, l'entità dei fitti perpetui in natura e in denaro, infine, e molto significativamente, il diritto delle comunità di suonare la campana a martello anche senza l'autorizzazione degli ufficiali signorili.

Il quadro così delineato è quello di un potere signorile estremamente capillare e gravoso, non limitato da nessuna carta di franchigia: una situazione che cominciava a non essere più consueta nel Piemonte del tardo Trecento. Particolarmente insolito, tanto da essere al primo posto fra le rivendicazioni dei sudditi in questa e (come vedremo) in ogni altra occasione, era il controllo esercitato dai signori sulle successioni, così stretto da avvicinarsi a quella che in altre realtà signorili era chiamata manomorta. Il signore non riconosceva il diritto di testare, e prelevava l'eredità dei defunti che non lasciavano eredi maschi diretti e legittimi; appellandosi al conte nel 1385 le comunità, senza mettere globalmente in discussione questo diritto, chiedevano almeno che fossero risolte con chiarezza determinate situazioni, evidentemente le più foriere di controversie. Al conte esse chiesero di stabilire la procedura da seguire nel caso di successione tra fratelli indivisi; di obbligare il signore che raccoglieva una successione a farsi carico dei debiti e degli obblighi dotali del defunto; e di autorizzare la figlia non ancora sposata a succedere al padre, e scegliere da sé il proprio sposo. 
Per comprendere quanto fosse cruciale questa questione delle successioni nel Canavese trecentesco, è utile fare un passo indietro e verificare quale fosse in proposito la situazione delle poche comunità che prima del 1385 erano già riuscite a ottenere carte di franchigia. Non a caso questa situazione privilegiata riguardava soltanto comunità che a un certo momento erano venute a trovarsi sotto il dominio diretto del conte di Savoia o del principe d'Acaia, comprensibilmente disposti ad alleggerire gli oneri signorili per acquistare in cambio la fedeltà dei nuovi sudditi. Nel 1342 Giacomo d'Acaia concesse franchigie agli abitanti della castellania di Balangero, costituita dalle tre comunità di Balangero, Mathi e Villanova, che in precedenza erano state infeudate ai S. Giorgio ed ora erano passate sotto il suo controllo diretto. Il principe dichiarò di possedere "servitutem et servitutes sucessionis et sucedendi personis morientibus secondum mores et usus in dictis locis et eorum mandamentis diucius observatis", oltre ai vari diritti riscossi in caso di alienazione. Essendovi l'intenzione di fortificare i tre luoghi per interesse comune, e desiderando gli abitanti "franchiri et liberari a servitutibus supradictis", i sindaci delle tre comunità si impegnarono a eseguire i lavori di fortificazione, e in cambio il principe le liberò "ab omni iure et servitute ac usu sucessionis et sucedendi", in modo tale che i beni di chi moriva "ab intestato" spettassero agli eredi legali, e solo in mancanza di eredi "ultimo loco sucedat dominus"; inoltre le affrancò da ogni prelievo sui passaggi di proprietà, in modo che gli abitanti possedessero le loro terre "liberas, franchas et alodiales", col diritto di libera vendita senza permesso né investitura ${ }^{42}$.

Come si vede, nel momento in cui un piccolo gruppo di comunità è in grado di negoziare col signore la concessione di franchigie, ciò che più preme acquistare è la libertà delle successioni, e secondariamente quella delle alienazioni: era questo evidentemente, e di gran lunga, l'aspetto più detestato del prelievo signorile. Sostanzialmente analogo il caso dell'unica altra comunità canavesana che riuscì ad ottenere franchigie prima dell'esplosione del Tuchinaggio, e cioè Rivarolo. Questo importante centro della pianura, a lungo conteso fra i Valperga e i S. Martino che vi possedevano ciascuno un castello, era passato dal 1351 nelle mani del conte Amedeo VI, che vi insediò un proprio castellano. Fin dal 1358 il conte riconobbe che il luogo non prosperava "ob libertatum franchisiarum privilegiorum capitulorum et statutorum deffectu", e concesse perciò "capitula et statuta"; si

42 Frola, Corpus cit., I, pp. 257-265. Nel 1356, le franchigie sono confermate da Filippo d'Acaia (ivi, pp. 266-269), allargando la libertà di testare anche a chi muoia lontano dalla castellata, e aggiungendo l'obbligo per il castellano di assegnare un tutore gratuitamente agli orfani. 
trattava però, appunto, di statuti e non franchigie, che non modificavano natura ed entità del prelivo signorile, pur con una forte impronta garantista a favore degli abitanti e contro abusi del castellano ${ }^{43}$.

Nel 1376, finalmente, il Conte Verde, al fine preciso di ripopolare Rivarolo, concesse altre "franchisie et privilegia". In parte si trattava di immunità fiscali straordinarie, tipiche di una località in cui si cercava di attirare immigrati: esenzione dai pedaggi per trent'anni, esenzione da ogni taglia e focatico per cinque anni. In parte si trattava di fissare oneri che in precedenza erano stati imposti a misericordia, ovvero le ammende ("banna") e la cavalcata. Su un solo punto Amedeo VI accettò di rinunciare unilateralmente a una componente del controllo e del prelievo signorile: riconoscendo per sempre agli abitanti completa libertà di testare e donare, e dunque abolendo a tutti gli effetti l'odiato diritto di successione del signore ${ }^{44}$.

Erano passati appena nove anni da quando Rivarolo godeva di queste libertà concesse da Amedeo VI e si deve presumere che l'esempio abbia pesato non poco sulle aspettative delle altre comunità canavesane, allorché nel 1385 si rivolsero a suo figlio Amedeo VII. A nessuno poteva sfuggire che i luoghi in cui si affermava il potere diretto del principe avevano ottenuto l'abolizione degli aspetti più detestati del potere signorile. Rimane, a questo punto, da valutare la risposta che il conte diede alle loro richieste. Tenendo conto che Amedeo VII sentenziava non solo "ex plenitudine potestatis ordinarie", ma anche per il consenso delle parti che l'avevano scelto come arbitro, e che in quel momento il suo interesse poliico era innanzitutto di pacificare il Canavese e rafforzare la fedeltà dei signori, molti dei quali erano suoi vassalli solo da poco e non di propria volontà, non stupisce che la sentenza sia stata interlocutoria.

La richieste delle comunità vennero integralmente accolte solo su alcuni punti: quando il signore raccoglieva la successione di un suo uomo, doveva farsi carico della dote e dei debiti, e le figlie non ancora sposate potevano ereditare; quando un uomo voleva dare i suoi beni in pagamento di un debito, il signore era tenuto ad accordare il suo consenso, riscuotendo un diritto simbolico ("capiendo duodecim denarios monete de qua fiet mentio in dictis contractibus et non ultra"). Sulla maggior parte dei punti fu invece proposto un minuzioso, e spesso tortuoso, compromesso. Chi era tenuto a pagare il fodro doveva continuare a pagarlo secondo la consuetudine; la taglia invece sarebbe stata dovuta solo nei casi eccezionali, come matrimonio delle figlie, addobbamento cavalleresco, riscatto del signore. I

${ }^{43}$ Frola, Corpus cit., III, pp. 127-135.

${ }^{44}$ Frola, Corpus cit., III, pp. 136-138. 
fitti in natura si dovevano pagare secondo la consuetudine, mentre venne fissato il tasso di quelli in denaro; agli abitanti però venne concesso di fare ricorso, se avessero potuto esibire "instrumenta consueta a quadraginta annis citra per que appareret ipsos debere ad minorem extimationem"; ma titoli più vecchi di quarant'anni non sarebbero stati accettati. Rimaneva il divieto di suonare le campane senza il permesso dei signori o del loro podestà, tranne nei casi urgenti di incendio o di attacco nemico; però nei luoghi dove non c'era un podestà i signori dovevano designare un facente funzioni a cui chiedere il permesso, e se non l'avessero fatto "eo casu dicti homines dictas campanas pulsare possint pro sua voluntate". Sulla roida venne proposta una mediazione complessa, che teneva conto dell'esistenza di accordi precedenti e di eccezioni individuali; ma chi era tenuto ai lavori per il canale del mulino doveva continuare a farlo quando era necessario. Quanto all'obbligo di custodire il castello, gli abitanti vi erano tenuti "in numero consueto" in tempo di guerra, in tempo di pace invece solo una persona per fuoco ogni venti giorni, "videlicet illi qui dictam custodiam sunt facere consueti"; anche i lavori di fortificazione potevano essere richiesti solo in tempo di guerra.

E sulla successione dei fratelli indivisi, che era al primo posto nell'elenco delle richieste, e come sappiamo andava a toccare il punto più dolente delle relazioni fra signori e sudditi? Qui, non a caso, la decisione del conte risultò ancora più interlocutoria. Egli stabilì che fosse nominata una commissione composta da due dei conti di S. Martino "quos minus tanget hoc negotium", quattro uomini della loro terra, più i due maggiori plenipotenziari del conte che operavano da anni in Piemonte, Yblet de Challant e Barthélemy de Chignin; e la commissione avrebbe deliberato "amicabiliter... pro bono pacis et concordie", fermo restando che per quanto riguarda le altre successioni, i signori avrebbero continuato a percepirle come da consuetudine. I Valperga e i loro uomini dovevano mettere in piedi un'analoga commissione.

Se fosse finita qui, la sentenza non apparirebbe particolarmente soddisfacente per le comunità, ma neppure tale da provocare una reazione estrema; dopo tutto, i deputati portavano a casa qualcosa e vista la composizione delle commissioni potevano sperare di ottenere in un prossimo futuro anche qualcosa di più. Ma Amedeo VII non si fermò qui. Le comunità erano pur sempre colpevoli di aver costituito illegalmente una lega, con tanto di accordi scritti e giurati. Ora si voltava pagina, la sentenza garantiva una pace perpetua fra $\mathrm{i}$ conti canavesani e i loro sudditi, ma per questo favore principesco, e per la remissione di tutte le pene in cui la loro ribellione li avrebbe fatti incorrere, gli uomini delle comunità dovevano pagare. "Pro omnibus que dicuntur et petuntur deliquisse ratione iure lige unionis et ma- 
nipolii predictorum", agli uomini dei S. Martino venne intimato di sborsare 14.000 fiorini "nobis dicto Sabaudie comiti qui eos ponimus in bona pace, et hoc de consensu dictorum dominorum", a quelli dei Valperga 15.000, a quelli dei Masino 5000. Solo così, "mediantibus predictis", si sarebbe avuta in futuro "bona pax et amicicia" fra signori e sudditi ${ }^{45}$.

\section{La guerra dei Tuchini (primavera 1386 - estate 1387)}

\section{a) I primi segnali di rivolta (primavera-estate 1386)}

Non possiamo dare per certo che la rabbia per l'enorme somma che bisognava pagare, e in cambio di concessioni così modeste, abbia scatenato la rivolta dei Tuchini, ma certo la tentazione di individuare un preciso rapporto di causa/effetto è forte. Anticipiamo qui che quando, dopo cinque anni di rivolta, il conte Amedeo VII imporrà nel 1391 una definitiva pacificazione nel Canavese, acconsentirà fra l'altro a rinunciare al pagamento richiesto nel 1385; alle comunità e ai singoli coinvolti nella ribellione saranno bensì imposte forti multe, ma il totale così incassato risulterà comunque inferiore ai 34.000 fiorini pretesi in origine. Che dopo una lunga e durissima ribellione le comunità canavesane se la siano cavata pagando meno di quello che era stato loro chiesto nel 1385, conferma che questa prima richiesta può davvero essere apparsa esorbitante, e aver scatenato una reazione violenta.

Ma non si può neppure escludere che la pacificazione imposta dal Conte Rosso abbia suscitato reazioni di altro tipo. I segnali di debolezza che a noi è parso di intravvedere nella formulazione della sentenza possono essere stati percepiti con ben altra chiarezza dalle parti: possono dunque aver incoraggiato i signori all' intransigenza, nella convinzione che il conte non sarebbe stato abbastanza forte da imporre davvero il compromesso, e possono aver suscitato fra le comunità la sensazione che nella mediazione comitale non c'era da sperare, inducendole a passare alla violenza. Infine, non si può neppure escludere che nell'atteggiamento del conte (e in tutto ciò che non si trova nei documenti scritti, ma può ben essere stato colto da chi era presente al negoziato) le comunità abbiano creduto di vedere un tacito incoraggiamento a radicalizzare le proprie rivendicazioni: come vedremo, il comportamento del conte e dei suoi fun-

${ }^{45}$ Si noti che la sentenza del 1385 è conservata solo in trascrizione all'interno di quella del 1391; e giacché si tratta di un documento assai complicato e di difficile lettura, il Gabotto credette che questa ammenda fosse stata imposta nel 1391, per i fatti del Tuchinaggio (Gabotto, Gli ultimi principi d'Acaia cit., p. 152); e questo errore, che qui si rettifica per la prima volta, è poi sempre stato ripreso in seguito. 
zionari durante la crisi sarà abbastanza ambiguo da autorizzare anche questo tipo di lettura.

Quale che sia l'ipotesi più solida - e allo stato attuale delle nostre conoscenze è impossibile escluderne alcuna - è indubbio che la sentenza pronunciata dal conte il 14 dicembre 1385 non garantì affatto l'auspicata "bona pax", anzi fu la causa scatenante della rivolta. I primi sintomi che qualcosa di preoccupante stesse accadendo nella zona si possono riconoscere pochi mesi dopo nelle disposizioni impartite dalle autorità sabaude per il rafforzamento delle piazzeforti confinanti col Canavese e l'allestimento di forze militari. Già il 21 marzo 1386 il castellano di Bard, ricevuto l'ordine di ispezionare il castello e tenervi uomini "ultra garnisionem solitam", ne rafforza la guarnigione con sette sergenti, e da aprile vi aggiunge, eccezionalmente, alcuni uomini d'arme nobili, mai meno di due ${ }^{46}$. Egualmente ai primi di marzo il castellano di Rivoli fa un acquisto di ferro "pro ingeniis et bombardis Domini rehactandis"; ad agosto, un magister bombardarum è a Rivoli e procede a sperimentare l'efficienza delle bombarde, e insegnarne l'uso a uno scudiero del conte mandato appositamente a impararlo ${ }^{47}$. A settembre Othon de Grandson, nominato da Amedeo VII capitano generale in Piemonte in momentanea sostituzione di Yblet de Challant, prende in prestito 500 fiorini per radunare uomini d'arme, e invia a Rivarolo e Cirié, sui confini del Canavese, quindici casse di verrettoni da balestra; a ottobre anche le famose bombarde, due in tutto, prenderanno la via da Rivoli a Cirié. Nel frattempo anche il principe d'Acaia aveva convocato l'esercito generale a Torino, prima per il 15 e poi per il 20 settembre $^{48}$.

Di per sé, queste misure potrebbero preludere a qualunque movimento bellico. La prima, esplicita indicazione che invece fossero determinate dal diffondersi di una sollevazione popolare risale al 15 luglio 1386, quando il tesoriere di Amedeo VII, Pierre Gerbaix, ricevette l'ordine di avanzare i fondi per pagare "brigandi" e balestrieri prestati ai signori di Valperga, Castellamonte, Front, Baldissero, Loranzé e S. Martino d'ordine del capitano di Piemonte, e per fabbricare a Ivrea delle bandiere "pour mettre sur les chasteaux desdits gentilshomes". Il conte, dunque, ostentava la sua protezione verso i nobili canavesani, facendo collocare sui loro castelli le proprie insegne; una misura che non avrebbe avuto alcun senso se il Canavese fosse stato minacciato d'invasione da parte di nemici esterni, e che infatti non aveva precedenti ${ }^{49}$.

\footnotetext{
${ }^{46}$ Cordero, Il Tuchinaggio cit., doc. 2.

${ }^{47}$ Cordero, Il Tuchinaggio cit., docc. 1 e 11.

${ }^{48}$ Gabotto, Gli ultimi principi cit., pp. 59-60; Cordero, op. cit., doc. 1.

${ }^{49}$ Cordero, Il Tuchinaggio cit., doc. 12.
} 
L'elenco delle famiglie minacciate è anch'esso significativo. Vi rientrano tanto esponenti della parte dei Valperga, quanto (e in larga maggioranza) dei S. Martino; non sono menzionati, però, i rami collaterali dei Valperga, come i Masino, i Mazzé e i Rivara, e neppure i loro alleati S. Giorgio, insomma tutti quei nobili che erano stati fino a poco tempo prima vassalli del marchese di Monferrato e solo da poco avevano prestato omaggio al conte di Savoia; e infatti, come vedremo, le terre di tutti costoro non saranno toccate dalla rivolta. Non è abbastanza per giustificare l'opinione del Gabotto che voleva l'insurrezione istigata dagli stessi Valperga contro i rivali ${ }^{50}$, giacché i possedimenti dei Valperga del ramo primogenito, a partire da Cuorgné, saranno al contrario un epicentro dell'insurrezione e i signori ne soffriranno come tutti gli altri. Il fatto rilevante è che alla pacificazione del dicembre 1385, mentre erano presenti indistintamente tutti i conti canavesani, non erano state convocate tutte le comunità, ma soltanto i sudditi dei Valperga, appunto, primogeniti e quelli dei S. Martino; solo loro, evidentemente, avevano fatto ricorso alla giustizia del conte per denunciare i danni che subivano a causa delle rivalità fra i loro signori, non i sudditi dei Masino, dei Mazzé, dei Rivara e dei S. Giorgio, abituati fino a pochissimo tempo prima a considerare come referente il marchese di Monferrato e non certo il conte di Savoia; e proprio le comunità convocate nel dicembre e condannate a pagare la pesante multa di cui sopra sono quelle stesse che nell'estate successiva minacciavano i loro signori, costringendo il conte di Savoia a mandare armati in loro soccorso.

Questa geografia della rivolta ha una sola logica possibile: benché dopo il trattato del 1372 e il privilegio imperiale del 1373, confermati dall'arbitrato di Gian Galeazzo Visconti del 1378, tutti i signori canavesani fossero tenuti a prestare omaggio al conte di Savoia, compresi quelli che in passato erano stati vassalli del marchese di Monferrato o direttamente dell'imperatore (e cioè appunto i S. Giorgio, i Rivara, i Mazzé e i Masino), tuttavia le comunità dipendenti da questi ultimi non presero parte alla lega giurata, al successivo appello rivolto al conte di Savoia, e, poco dopo, all'insurrezione contro i signori. Che questo diverso comportamento dipendesse da una minor fiducia nella mediazione di Amedeo VII, non ancora sentito dagli homines come signore legittimo, resta la spiegazione più verosimile.

\section{b) L'aggravarsi del conflitto}

Dalle misure puramente difensive le autorità sabaude passarono, alla fine dell'estate 1386, a quelle offensive, sperando evidentemente di soffocare

${ }^{50}$ Gabotto, Gli ultimi principi cit., p. 54. 
quella che le fonti chiamano ormai apertamente col nome di rivolta dei Tuchini. Il tesoriere dell'hôtel registra che fra il 26 settembre e il 17 ottobre 1386 il principe d'Acaia si trova nella zona di Cirié, Rivarolo e Castellamonte "pro guerra Tuchinorum in auxilium nobilium Canapicii"; il conte di Savoia invia genti d'arme "pro debato existente inter comites et nobiles Canapicii ex una parte et eorum subditos et rebelles ex alia"; e il comune di Pinerolo, su richiesta del principe, manda cinquanta uomini "in guerra nobilium de Canapicio quam habebant cum Tuchinis" ${ }^{1}$. La consonanza delle espressioni, in fonti prodotte da amministrazioni diverse e a poca distanza dai fatti, dimostra chiaramente che l'insurrezione era percepita come una ribellione dei sudditi contro i nobili canavesani. La definizione è esplicita e per quanto si possa desiderare di approfondire l'analisi e sfumare le posizioni, non è lecito dubitarne globalmente: la rivolta era indirizzata contro i signori, e non, ad esempio, contro la dominazione sabauda.

Le operazioni militari condotte nell'autunno non portarono ad alcun risultato. Tutto indica che nell'inverno successivo, una volta ritirate dal Canavese le genti d'arme del conte e del principe e cessato anche il mandato di Othon de Grandson, la rivolta dilagò. La cronologia, a dire il vero, è ipotetica, e gli eventi possono essersi scaglionati, con scarti da luogo a luogo, per tutto il corso del 1387, ma l'esito è indubbio e univoco: in gran parte dell'area interessata dalla rivolta, gli "homines et subditi dictorum nobilium locorum singularium popullares", violando la pacificazione imposta pochi mesi prima da Amedeo VII, insorsero di comune accordo contro i signori, "illicitas pactiones, iuras, conventiculas, monopolia et colligaciones invicem faciendo", ed espellendoli dai loro castelli ${ }^{52}$. Quasi quarant'anni dopo i conti di S. Martino motiveranno la concessione di franchigie ai loro uomini di Aglié con la fedeltà che essi avevano dimostrato "tempore tuzinagii, in quo tempore omnes homines Canapicii erant ipsorum dominis rebelles et dominos suos traderant oblivioni nec in serviciis eorum dominorum hambulabant sed pocius in destruccione personarum eorum dominorum et bonorum", che è una buona descrizione degli eventi dal punto di vista traumatizzato dei nobili che ne erano stati vittime ${ }^{53}$.

In realtà, gli atti di violenza connessi all'insurrezione appaiono piuttosto limitati, benché si siano ingigantiti nella memoria popolare e anche nella storiografia. L'unica fonte di cui disponiamo in proposito sono i conti

${ }^{51}$ Cordero, Il Tuchinaggio cit., doc. 3; Caffaro, Pineroliensia cit., p. 183.

52 Tanto risulta chiaramente dalla sentenza del 1391, in AST, Città e Provincia d'Ivrea, Mazzo 1, 17, parzialmente edita in Tallone, Parlamento cit., II, pp. 24-31.

${ }^{53}$ Frola, Corpus cit., I, p. 95. 
della tesoreria sabauda che a cose finite, e cioè dopo la pacificazione del 1391, registra il pagamento delle composizioni da parte delle comunità coinvolte nel Tuchinaggio. Le motivazioni delle ammende elencano aggressioni e saccheggi ai castelli o residenze nobiliari di Brosso, Chy, Arundello, Lessolo, Strambinello, Montestrutto, Loranzé e Castellamonte, l'uccisione di un solo nobile, Giovanni di Montalenghe dei conti di S. Martino, e di sua moglie e lo stupro di un'altra donna dei conti di Castellamonte ${ }^{54}$. Al di là di questi eccessi, poco significativi in confronto al livello di violenza che i conflitti fra i nobili avevano toccato negli anni precedenti, il fatto cruciale è quello politico: una dopo l'altra, le comunità espulsero i signori e presero nelle proprie mani il potere e la difesa del luogo. Ancora nel 1391 i signori delle località ribelli, come registra la pacificazione finale, erano in esilio e attendevano ansiosamente che il conte di Savoia, ripreso il controllo della zona, li rimettesse in possesso dei loro beni, "cum non habeant omnimode unde substinere valleant statum ipsorum".

\section{c) L'allargarsi del conflitto (inverno-estate 1387)}

Nel corso del 1387 l'insurrezione si estese sporadicamente ad aree esterne, benché adiacenti, al Canavese; assumendo, tuttavia, caratteri di saccheggio occasionale piuttosto che di stabile occupazione insurrezionale del territorio. La prima zona coinvolta fu la valle della Dora a settentrione di Ivrea, fino alla gola di Bard che immette nella valle d'Aosta. I signori di quest'area, riconducibili al numeroso consortile dei signori di Settimo, erano vassalli del vescovo di Ivrea, ma ormai da tempo si erano assoggettati al conte di Savoia, che controllava direttamente alcuni dei loro castelli, come Montalto. Nel gennaio 1387 il capitano di Piemonte, che era di nuovo Yblet de Challant, convocò ripetutamente a Ivrea i castellani comitali della Valle d'Aosta "pro facto Tuchinorum Canapicii", e fece proclamare la cavalcata "ad eundum Yporrigiam contra rebelles Canapicii" 55 . Il castellano di Bard ebbe ordine di inviare armati a difesa dei castelli di Settimo, "pro sucurrendo et auxilium dando dominis dicti loci”, e di Montestrutto; nonostante tale soccorso, quest'ultimo è elencato nella pacificazione del 1391 come uno dei castelli assaliti e saccheggiati dai Tuchini ${ }^{56}$.

In questo caso, dunque, non siamo di fronte ad aggressioni dei ribelli contro i loro signori, ma ad atti di violenza dalle connotazioni molto più difficili da cogliere, forse legati a rivalità locali. Ma è anche vero che qual-

\footnotetext{
${ }^{54}$ Cordero, Il Tuchinaggio cit., doc. 41.

${ }^{55}$ Cordero, Il Tuchinaggio cit., docc. 6 e 22.

${ }^{56}$ Cordero, Il Tuchinaggio cit., doc. 2.
} 
che tempo dopo un uomo di Settimo sarà processato e impiccato coll'accusa di essere "de comictiva et sequacibus rebellorum Tuchinorum Canapicii”, uno di Montalto sarà multato coll'accusa di aver voluto aprire il castello agli insorti, e parecchi di Montestrutto saranno accusati di aver aiutato i ribelli e partecipato al saccheggio del castello; ciò dimostra che gente del posto partecipò dappertutto alla sommossa, che quindi deve aver assunto anche in quest'area i connotati di una ribellione antisignorile ${ }^{57}$.

Nell'estate 1387, anche la Valle d'Aosta fu interessata da scorrerie di Tuchini, che scendevano in Valsavaranche dalla valle dell'Orco attraverso il colle del Nivolet. A più riprese si fa menzione di scontri armati fra gli abitanti della Valle, che difendono il loro territorio e il loro bestiame, e i ribelli; uno di costoro, che si era spinto fino ad Aosta "ad explorandum", venne arrestato e si suicidò in carcere prima d'essere impiccato. Il balivo di Aosta dovette prevedere servizi di guardia rafforzati nei castelli comitali di Aosta, Chatelargent, Bard e Champorcher, "ad tuciorem custodiam ibidem faciendam die noctuque propter guerram tuchinorum ibidem circumvicinancium", ed emanò disposizioni che vietavano di vendere vettovaglie ai ribelli o prestar loro assistenza. L'impressione è che nel generale clima d'illegalità provocato dall'estendersi della rivolta molti scontri siano da ricondurre alla tradizionale rivalità fra i pastori valdostani e quelli canavesani per lo sfruttamento dei pascoli d'altura, e del resto l'esito più frequente delle scorrerie dei Tuchini in Valle è proprio il furto di pecore, razziate nei pascoli e portate a Ceresole.

Ma più di un valdostano venne multato per aver avuto contatti con i Tuchini, aver fatto loro da guida e venduto loro da mangiare nonostante le ordinanze, e del resto in Valle c'erano anche simpatie esplicite per i ribelli: almeno un tale, a La Salle in Valdigne, dovette sborsare 6 fiorini di ammenda perché aveva esclamato "quod se volebat facere tuchinum contra nobiles vallis Digne et clericos", segno che le connotazioni di classe della rivolta erano evidenti a tutti e potevano suscitare consensi. Nell' insieme, comunque, le popolazioni valdostane sembrano essere state più che altro spaventate da quel che succedeva ai loro confini: un tale di La Thuile si fece multare dal balivo per aver fatto finta d'essere un Tuchino, "loquendo linguam lombardam" e divertendosi a spaventare il servo dell'osteria, e almeno altre due persone vennero colte a commettere la stessa prodezza, nell'intento di spaventare i bambini del posto; mentre uno dei signori di Vallaise venne mul-

${ }^{57}$ Gabotto, Gli ultimi principi cit., pp. 58-59, e cfr. sotto, n. 60.

${ }^{58}$ AST, Inv. 68, Conti della castellania di Aosta, 1384-1388, e Conti della Castellania di Bard, 1387-1388; in gran parte editi in Cordero, Il Tuchinaggio cit., docc. 2 e 37. 
tato perché, in un eccesso di nervosismo, aveva arrestato sulla strada maestra dei pacifici pellegrini vercellesi, scambiandoli per ribelli58 ${ }^{5}$.

\section{d) La spedizione punitiva dell'aprile 1387}

Di fronte al dilagare della rivolta e al rischio d'una sua estensione anche fuori dal Canavese, le autorità sabaude sembrano aver tentato un'unica spedizione punitiva: ne abbiamo un'attestazione isolata, ma più che sufficiente, in una lettera che il principe d'Acaia scrive al conte Amedeo VII, a Ripaille, alla fine di aprile 1387, per informarlo "de captione et homicidiis factis contra tuchinos die martis xxiii huius mensis aprilis... et xxv aprilis" ${ }^{\prime 2}$; e una conferma nella condanna appunto di quell'uomo di Settimo di cui s'è detto poco sopra, Simone Fornero, accusato di complicità coi Tuchini e impiccato a Bard il 4 luglio 1388 dopo 14 mesi di detenzione - il che permette di calcolare che fu arrestato appunto a fine aprile o inizio maggio del $1387^{60}$.

Queste operazioni militari furono le ultime condotte, per il momento, contro i Tuchini, e non ebbero un esito significativo: l'insieme del territorio ribelle rimase saldamente in mano ai rivoltosi. L'interruzione delle operazioni repressive nel Canavese dopo questa data è da ricondurre, come vedremo più avanti, all'inaspettato allargarsi della guerra, giacché il marchese di Monferrato decise di approfittare della crisi per affidare nuovamente alle armi la decisione del suo annoso contrasto con il conte di Savoia. Ma d'altro lato vi si riflette anche l'ambiguità della posizione di quest'ultimo: che se, ufficialmente, non poteva fare a meno di prendere le difese dei suoi vassalli contro i populares ribelli, aveva però ancor più da guadagnare mantenendosi in una posizione interlocutoria, che gli permettesse di mediare fra le parti ed eventualmente occupare quegli spazi da cui la ribellione avesse costretto i signori ad arretrare.

\section{Il conte tratta con i ribelli}

Uno degli aspetti più interessanti del Tuchinaggio, da cui traspare tutta la complessità della politica trecentesca, è il modo in cui la rivolta, $\mathrm{o}$ anche soltanto la sua minaccia, aprì spazi di contrattazione nuovi, che tutti gli attori seppero utilizzare con spregiudicatezza. Un primo esempio, assai istruttivo, risale già all'autunno del 1386, subito dopo che s'erano ritirate le genti

${ }^{59}$ F. Saraceno, Regesto dei principi d'Acaia 1295-1418 tratto dai conti di tesoreria, «Miscellanea Storica Italiana», 20, 1882, p. 167.

${ }^{60}$ Cordero, Il Tuchinaggio cit., doc. 38, dai Conti della Castellania di Bard; anche nei Conti della Castellania di Aosta, 1384-1388, è registrato un soggiorno del balivo a Bard per il processo "contra Symonem Fornerii de Septimo ibi carceratum". 
d'arme radunate dal principe d'Acaia sui confini del Canavese in un primo, vano tentativo di soffocare la ribellione con la forza. Il 24 ottobre 1386 i consignori di Valperga si incontrarono con i sindaci e altri rappresentanti della comunità di Valperga nel cimitero della chiesa parrocchiale, e lì, su esplicita sollecitazione del capitano generale Othon de Grandson, prendendo atto che fra loro e la comunità erano insorte "plures quaestiones et querelle, et maiores verti sperarentur", concessero agli abitanti amplissime franchigie, la prima delle quali riguardava - prevedibilmente - la libertà di testare ${ }^{61}$.

Se pensiamo al ruolo decisivo che la mediazione del capitano di Piemonte deve aver avuto nel convincere i signori a una concessione del tutto unilaterale e gratuita; e se badiamo all'implicita minaccia di quell' inciso apparentemente casuale, "et maiores verti sperarentur", ci accorgiamo subito delle opportunità che il diffondersi della ribellione poteva offrire a una comunità capace di mantenere il sangue freddo, manovrando nello spazio che si apriva fra gli interessi del conte di Savoia e quelli dei signori locali. Ottenuto ciò che voleva, la comunità di Valperga si mantenne estranea alla ribellione, tanto che quando si giunse alla pacificazione generale del 1391 non si preoccupò neppure, benché convocata, di mandare propri rappresentanti all'assemblea; e del resto non aveva alcun interesse da difendere in quella sede, giacché non fu condannata ad alcuna ammenda. Ma egualmente interessante è il fatto che il plenipotenziario comitale si sia proposto con tanta disinvoltura per aiutare la comunità a ottenere concessioni che di fatto si basavano esclusivamente sulla minaccia di ribellarsi.

Se Valperga offre l'esempio di una comunità che seppe ottenere il massimo negoziando la propria astensione dalla rivolta, spazi d'azione significativi si aprivano anche per le comunità compromesse nella sollevazione: a conferma che il ricorso alla violenza non era una scelta estrema e senza ritorno, ma uno dei linguaggi riconosciuti del confronto politico, anche se certamente il più pericoloso da maneggiare. Nello stesso momento in cui radunava genti d'arme per fronteggiare i ribelli, il capitano di Piemonte, che dall'inizio del 1387 era di nuovo Yblet de Challant, era disponibile per mediare fra i signori e gli insorti: così, ai primi di giugno intervenne per avviare un negoziato fra i signori e gli uomini di Strambino - altra comunità che infatti nel 1391 non fu oggetto di alcuna sanzione ${ }^{62}$.

Ma un'altra trattativa condotta a buon fine nel corso dell'estate, su scala enormemente più vasta, conferma che tanto le autorità sabaude quanto le comunità ribelli erano pronte ad accordarsi sopra la testa dei signori. Il balivo di Aosta, Nicola Marchisio, fu incaricato di scendere fino a Bard "causa

\footnotetext{
${ }^{61}$ Frola, Corpus cit., I, pp. cii-civ e III, pp. 492-494.

${ }^{62}$ Gabotto, Gli ultimi principi cit., p. 71.
} 
habendi colloquium et tractandi cum hominibus vallium et locorum Soane, Brosii et Caprine existencium de genere et iura Tuchinorum, quatenus se darent domino nostro Comiti". Ė dunque confermato che la ribellione coinvolgeva le comunità tutt'intere, con le loro autorità comunali alla testa. Il Marchisio ebbe un primo incontro coi loro ambasciatori nel giugno 1387; il suo mandato era di valutare non già se fossero disposti ad arrendersi, ma piuttosto se adesso che avevano abbandonato i loro signori avrebbero accettato di sottomettersi alla signoria diretta del conte.

Che questi colloqui (con le spese di soggiorno dei rappresentanti dei ribelli rimborsate sul bilancio del balivo di Aosta) abbiano avuto luogo potrebbe già apparire abbastanza sorprendente, ma ancor più lo è la conclusione. Il balivo infatti riferisce di aver più volte fatto da intermediario fra $\mathrm{i}$ ribelli e il conte, e di essere stato impegnato in quelle trattative per più di due mesi. I negoziati non coinvolsero soltanto le tre valli citate, ma un gran numero di altre comunità, senz'altro pari a più di metà del territorio ribelle. Tutti questi luoghi negoziarono col rappresentante del conte per verificare se fosse possibile mettersi sotto la sua protezione, abbandonando i signori contro cui si erano ribellati. Ed è proprio quello che accadde a una parte di loro; giacché il balivo conclude con legittima soddisfazione: "et tractavi quod homines Vallium Brozii, Caprine et Peagne, necnon homines comunitatum Scarmagni et Vialfredi, se submiserunt dominio prefati domini nostri Comitis"63.

Il più completo fra questi atti di sottomissione che sia giunto fino a noi riguarda le otto comunità della Val Caprina, o Valle di Chy. Il 9 luglio, a Ivrea, i consoli di cinque comunità e molti altri deputati, in tutto 26 uomini fra cui un notaio, in rappresentanza dei loro paesi "et aliorum de Valle Caprina", come risultava da una procura rogata fin dal 21 febbraio, si presentarono a Yblet de Challant, il quale a sua volta disponeva di pieni poteri concessi dal conte allo scopo di "rebelles... reppacificari". Il documento stipulato di comune accordo esordisce ricordando come fra i conti di S. Martino e di Castellamonte, da una parte, e dall'altra i loro uomini della Val Caprina, fossero insorte da tempo "lites, questiones et controversie", da poco tramutate in "bella, homicidia, depopulaciones, incendia et strages immense"; come alla pretesa di obbedienza avanzata dai conti, gli abitanti ribattessero di non essere più tenuti a obbedire, "cum ipsi nobiles eorum dominio sint abusi, naturalem dominacionis ussum in tirannidem permutantes", per cui i loro diritti dovevano intendersi naturalmente devoluti al conte di Savoia.

${ }^{63}$ Cordero, Il Tuchinaggio cit., doc. 23. 
Il capitano di Piemonte, ascoltate benevolmente le loro ragioni, li accolse seduta stante nella dipendenza e sudditanza del conte; garantì piena e totale immunità per qualunque colpa fino allora commessa; e concesse ampie e vantaggiosissime franchigie. La prima concessione, come si può immaginare, riguardava la piena facoltà di testare "sicut quicunque liberi homines et allodialia possidentes" e il diritto degli eredi dei defunti intestati di ereditare secondo il diritto comune fino al quarto grado; non è questa la sede per esaminare in dettaglio le altre franchigie, che sono comunque, ripetiamolo, eccezionalmente generose, e comprendono il diritto di presentare al conte una quaterna di nomi, fra cui sarebbe stato scelto il podestà ${ }^{64}$.

Lo stesso giorno della sottomissione della Val Caprina, anche i consoli della Val di Brosso, e più precisamente di Brosso, Traversella, Novareglia, Vico, Drusacco, Meugliano e Lessolo, si presentarono al capitano generale ed ottenero sostanzialmente le stesse concessioni, a condizioni pressoché identiche ${ }^{65}$. Quanto questa sottomissione si sia poi tradotta, in pratica, nell'effettiva consegna dei castelli in mano a funzionari sabaudi, è impossibile dire (ma si è portati a pensare che non si sia andati molto avanti, vista la disinvoltura con cui il conte, nel 1391, si rimangiò le promesse, e le multe che quelle comunità furono comunque costrette a pagare). Quello che è certo è che gli accordi raggiunti escludevano una reintegrazione dei signori, contro cui anzi le comunità richiesero, e ottennero, esplicite garanzie ("ita quod nunquam in aliam perpetuam successionem aliquam transferantur"): l'unico riconoscimento dei diritti sottratti ai signori stava nella clausola per cui le comunità si impegnavano a contribuire economicamente "si contingat ipsum dominum nostrum dare in scambium aliquod seu scontrum dominis de Canapicio pro hiis que habebant in ipsis locis".

In conclusione, appare ulteriormente confermato che la rivolta era indirizzata contro i signori, e non contro il conte di Savoia; che quest'ultimo era più che disposto a giocare su due tavoli, radunando armati per riportare l'ordine e ostensibilmente garantire la sicurezza dei nobili minacciati, e d'altra parte negoziando direttamente coi ribelli; infine che per i rivoltosi la sottomissione diretta al conte di Savoia poteva apparire come la via più diretta per ottenere quelle franchigie che erano il vero scopo della loro

${ }^{64}$ Frola, Corpus cit., II, pp. 71 sgg.

${ }^{65}$ Gabotto, Gli ultimi principi cit., p. 76 sg.; il 28 luglio il conte conferma alla comunità di Brosso i patti concordati con lo Challant pochi giorni prima (ivi, p. 81). Il comune di Ivrea, prendendo atto che "modo vero de anno domini millesimo CCCLXXXVI et LXXXVII vigente guerra inter populares Canapicii et eorum dominos plures ville et loca ipsorum de Canapicio se submisserunt dominio et iurisdicioni domini nostri comitis", suggerì che quei luoghi dovessero essere uniti al suo mandamento e sottoposti alla giurisdizione del podestà cittadino, anch'esso di nomina comitale: AST, Città e Provincia di Ivrea, mazzo 1, doc. 18. 
ribellione. Quando il castellano di Cirié, importante piazzaforte sabauda sui confini del Canavese ribelle, multò un tizio "quia clamavit viva Savoy et populus et moriantur nobiles", la modestia dell'ammenda, appena 9 grossi, la dice lunga sulle convergenze che si stavano disegnando sotto la facciata della repressione ufficiale ${ }^{66}$.

\section{L'intervento del marchese di Monferrato}

Fino a questo momento non c'è nessuna indicazione di un collegamento fra i ribelli e il marchese di Monferrato ${ }^{67}$. Appare dunque preconcetta e priva di qualunque pezza d'appoggio la tesi del Gabotto, che voleva l'intero movimento nato per sobillazione del marchese. Ė vero invece che nella primavera del 1387 il marchese Teodoro II decise di approfittare della situazione già incandescente nei domini sabaudi per ottenere, con la forza, quell'annullamento del trattato del 1372 che non era riuscito a raggiungere per via di negoziati: il 23 aprile, mentre gli armati del principe d'Acaia combattevano i Tuchini nel Canavese, venne segnalata una scorreria di genti d'arme del marchese di Monferrato presso Torino. Il giorno seguente il conte di Savoia convocava l'esercito generale a Cirié per il 20 maggio; è possibile, dato il luogo delladunata, chel intenzione fosse di muovere nuovamente contro i ribelli del Canavese, ma latteggiamento aggressivo del marchese di Monferrato costrinse a cambiare programma. Per tutta l'estate del 1387 la "guerra... contra marchionem Montisferrati" divampò lungol'intero confine tra i possessi sabaudi e quelli marchionali, giungendo in diverse occasioni a coinvolgere anche larea canavesana; non però, per quanto ci risulta, quella direttamente toccata dalla ribellione ${ }^{68}$.

Nella zona investita dall'insurrezione la situazione è più difficile da ricostruire, ma l'impressione è che i funzionari comitali abbiano cercato finché possibile di difendere quei nobili che erano decisi a tener duro nei loro castelli. Fra il luglio e l'agosto 1387 risultano ripetuti interventi del capitano di Piemonte, Yblet de Challant, che ora fa portare 180 staia di segale e 16 carrate di vino "pro muniendo garnisionem castri Valpergie", ora assume "brigandi" da collocare "ad custodiam Castrimontis", ora concede fondi ai signori di S. Martino per pagare altri "xxii brigandis pro stando in gar-

${ }^{66}$ AST, Conti della Castellania di Cirié, 1387-1389.

${ }^{67} \mathrm{Nel}$ novembre 1386 il castellano di Verrua, avamposto sabaudo a ridosso del marchesato, aveva denunciato una scorreria di ribelli nel territorio da lui governato, ma sembra da escludere che fossero Tuchini spintisi fin lì dal Canavese (Gabotto, Gli ultimi principi cit., pp. 61-62).

${ }^{68}$ Gabotto, Gli ultimi principi cit., pp. 66-84; la cit. in Cordero, Il Tuchinaggio cit., doc. 19; cfr. Tallone, Parlamento cit., II, p. 7.

${ }^{69}$ Cordero, Il Tuchinaggio cit., doc. 2, p. 429; AST, Inv. 68, Conti della Castellania di Aosta, 1384-88; Gabotto, Gli ultimi principi cit., p. 77 (e cfr. 78). 
nisone ville Sancti Martini contra dictos tuchinos et marchionem qui dictam villam insultaverant" ${ }^{\prime 6}$. È questo il primo riferimento a un collegamento fra i Tuchini e il marchese di Monferrato, che nelle fonti successive diverrà via via più insistente. Nella percezione delle autorità sabaude, la guerra contro il Paleologo era sentita come una continuazione di quella già avviata contro i ribelli, non essendovi stata soluzione di continuità nell'impiego delle risorse: così, il sussidio concesso nel 1387 dal balivato di Aosta fu motivato "pro guerra habita contra marchionem Montisferrati et rebelles popullares Canapicii”, e i conti del tesoriere di guerra, chiusi però diversi anni dopo, accomunano la guerra contro il marchese di Monferrato "et rebelles seu Tuchinos Canapicii, Vercelleysii et eciam Valleysii". Quest'ultimo caso dimostra peraltro che la percezione unitaria delle operazioni era soprattutto una convenienza amministrativa, e magari propagandistica, dal momento che accomunava ai Tuchini anche i ribelli del Vallese contro cui Amedeo VII condusse in quegli anni una campagna del tutto separata ${ }^{70}$.

A noi, tuttavia, importa seguire l'intervento del marchese di Monferrato solo nella misura in cui coinvolse davvero l'area ribelle. Altre vicende, che pure ebbero luogo in territorio canavesano e che da sempre si tende a confondere con il Tuchinaggio, non ebbero in realtà niente a che fare con quest'ultimo. Ė il caso, in particolare, della ribellione dei conti di Masino, che visibilmente parteggiavano per il Paleologo e rifiutarono di aprire i loro castelli al conte Amedeo VII, e furono per questo spossessati e arrestati, riottenendo poi i loro possedimenti solo dopo un processo durato diversi anni. La storiografia, a partire dal Gabotto, non ha mai fatto alcuna distinzione fra questo incidente e la sollevazione dei Tuchini; tutta l'analisi fin qui condotta, e la documentazione su cui si appoggia, incitano invece a concludere che la ribellione dei conti di Masino coincise solo cronologicamente, ma ebbe poco o niente in comune, sia come scopi sia come quadro geografico, con il Tuchinaggio vero e proprio ${ }^{71}$.

Assai più importante è verificare quali reazioni abbia provocato fra le comunità ribelli, e soprattutto quelle che non avevano ancora negoziato la propria sottomissione al conte di Savoia, l'ingresso sulla scena del marchese di Monferrato. Esistono indizi isolati, ma validi dell'apertura di contatti fra le comunità ribelli e il marchese Teodoro. Lo sappiamo innan-

${ }^{70}$ AST, Inv. 68, Conti della Castellania di Aosta, 1384-88; Cordero, Il Tuchinaggio cit., doc. 10; TG 38 f. 84r, 88v, 144r, 158r; cfr. anche PC 89 f. 19v.

${ }^{71}$ La vicenda è nota essenzialmente grazie agli atti del processo istituito nel 1391 contro i conti di Masino, per cui vedi AST, Città e provincia d'Ivrea, mazzo 6, Masino, docc. 7-11; cfr. anche, per l'assedio e la presa dei castelli, Gabotto, Gli ultimi principi cit., p. 81. 
zitutto dalla pacificazione del 1391, in cui si accusano le comunità ribelli di aver tradito il conte, "invocando et recipiendo illustrem Theodolum marchionem Montisferrati pro eorum deffensore, protectore et domino, et sibi fidelitates et homagia faciendo et recognoscendo". È vero che a margine di questo punto, sull'unica copia coeva della sentenza pervenuta fino a noi, una mano non molto più tarda ha annotato dubbiosa: "rustici ut asseritur receperunt pro domino Theodolum marchionem Montisferrati", il che lascerebbe pensare che questa asserita dedizione non sia stata così generalizzata né di dominio comune ${ }^{72}$.

Ma in realtà un altro documento cruciale, la sentenza di Gian Galeazzo Visconti del 17 marzo 1389 che avviò a conclusione il conflitto fra Amedeo VII e Teodoro II, contiene un lungo elenco di località canavesane che si erano sottomesse al marchese, e annulla tutti gli omaggi prestati al marchese per tali luoghi ${ }^{73}$. La mappa di queste località risulta esattamente complementare a quella delle località che si erano nel frattempo sottomesse al conte di Savoia: riuniti, i due gruppi corrispondono all'insieme delle comunità soggette ai conti di S. Martino e al ramo primogenito dei Valperga, quelle stesse che erano state convocate a Torino per ascoltare la pacificazione del 1385. Come dire che dopo l'insurrezione e la cacciata dei signori, tutte le comunità negoziarono con uno dei due principi e si posero sotto la sua protezione; fermo restando che con ogni probabilità i ribelli, pur giurando fedeltà chi al conte e chi al marchese, mantennero il controllo armato del proprio territorio.

Rimane un'area che non abbiamo fin qui considerato, perché come s'è detto non c'è alcuna prova che sia stata coinvolta dall'insurrezione; si tratta dei possedimenti di quelle famiglie, S. Giorgio, Mazzé e Rivara, che erano state vassalle dei Monferrato fino al 1372, e che il Paleologo in realtà non aveva mai rinunciato a recuperare. Con quelle famiglie il marchese riallacciò immediatamente i rapporti, tentando di riprendere possesso dei loro territori, anche se non sempre con successo - come dimostra il caso del castello di Balangero, allora infeudato dai Savoia a Bartolomeo di S. Giorgio. Alla fine di maggio 1387, costui cambiò fronte e consegnò il castello al Paleologo; il conte Amedeo VII venne ad assediarlo e dopo una settimana il S. Giorgio cambiò partito un'altra volta e accettò di cedere il castello al conte, in cambio di 1800 fiorini. La popolazione locale, peraltro, si era opposta fin dall'inizio al tradimento del signore, impedendo agli uo-

72 AST, Città e Provincia d'Ivrea, Mazzo 1, 17, parzialmente edita in Tallone, Parlamento cit., II, pp. 24-31.

${ }^{73}$ AST, Ducato di Monferrato, mazzo 6, doc. 9.

${ }^{74}$ Gabotto, Gli ultimi principi cit., pp. 70 sgg; Cordero, Il Tuchinaggio cit., doc. 21. 
mini d'arme del marchese insediati nel castello di impadronirsi della villa, e Amedeo VII ricompensò gli abitanti donando loro 25 moggi di segale, dopodiché sul luogo fu insediato un castellano sabaudo ${ }^{74}$.

In altri casi, però, tutto indica che i nobili ebbero successo nel tentativo di cambiare fedeltà e consegnare i loro castelli al marchese di Monferrato. Quest'ultimo si comportò in quelle zone come il conte di Savoia si era comportato altrove all'inizio della ribellione, presentandosi cioè come mediatore fra i signori e le comunità e aiutando queste ultime ad ottenere franchigie o statuti. Rientrano certamente in questo contesto gli statuti di Foglizzo, concessi nel 1387, e quelli di Corio, concessi nel 1388, in entrambi i casi dai S. Giorgio; anche se si tratta appunto di statuti e non di franchigie $^{75}$. Ma i casi più significativi sono un po più tardi. Il 7 marzo 1390 gli uomini della castellata di Rivara giunsero a un accordo coi Valperga loro signori, ottenendone ampie franchigie; ancora una volta, le concessioni più ampie ed elencate al primo posto riguardavano la facoltà di testare. Il contesto è molto simile a quello che due anni e mezzo prima, all'inizio della rivolta, aveva interessato i loro vicini, gli uomini del comune di Valperga; mentre però in quel caso a mediare fra gli uomini e i signori era stato il rappresentante del conte di Savoia, stavolta a offrire il suo arbitrato a Rivara e a pronunciare la sentenza fu il marchese di Monferrato ${ }^{76}$. Nello stesso anno, il marchese pronunciò un arbitrato fra i S. Giorgio e i loro uomini di S. Giorgio, Ciconio e Lusiglié, concernente anche in questo caso in primo luogo le successioni ${ }^{77}$. Anche sotto questo aspetto, dunque, si delinea un sostanziale parallelismo: tanto nelle zone che si erano sottomesse al conte di Savoia, quanto in quelle che erano tornate sotto il controllo del marchese di Monferrato, gran parte delle comunità, giostrando fra il principe e i signori, fra l'offerta di rinunciare alla ribellione o la minaccia di cominciarla, riuscirono a ottenere le concessioni a cui aspiravano.

\section{La pace armata e gli arbitrati (agosto 1387-dicembre 1390)}

Analizzando questi interventi del marchese di Monferrato ci siamo portati troppo avanti nel tempo; è necessario riprendere il filo delle operazioni militari che abbiamo interrotto nell'estate 1387, e che del resto di lì a poco si interruppero davvero. Prima della fine di agosto il Paleologo, esaurite le

${ }^{75}$ Foglizzo: Frola, Corpus cit., II, pp. 379-393. Sugli statuti di Corio del 1388 vedi G.C. Pola Falletti, La castellata di Rivara e il Canavese, Torino 1945-50, pp. 257-262.

${ }^{76}$ Frola, Corpus cit., I, p. 121.

${ }^{77}$ Bertolotti, Passeggiate cit., II, p. 67.

${ }^{78}$ AST, Ducato del Monferrato, mazzo 5, doc. 18; cfr. Gabotto, Gli ultimi principi cit., p. 83, e Cordero, Il Tuchinaggio cit., docc. 31-34. 
risorse, toglieva l'assedio di Verrua, e fra lui e il conte iniziavano i negoziati per una tregua, affidata inizialmente all'arbitrato del doge di Genova ${ }^{78}$. Amedeo VII e il principe d'Acaia considerarono allora, per un momento, l'ipotesi di un intervento su larga scala contro i Tuchini. Ad agosto venne inviata una spia, un prete, in Val Soana a valutare la situazione ${ }^{79}$, e negli ultimi giorni del mese il principe d'Acaia organizzò la convocazione dell'esercito generale a Lanzo, "causa eundi super Tuchinos", mentre il capitano di Piemonte Yblet de Challant, che si trovava allora a Montalto, riceveva istruzioni per marciare attraverso la Valle d'Aosta "supra tuchinos". La cavalcata si spinse effettivamente fino a Cuorgné, ma senza risultati significativi; dopodiché le operazioni vennero sospese ${ }^{80}$. Un motivo è certamente che l'attenzione del conte venne distratta dalla ben più estesa rivolta scoppiata nel Vallese; ma è altresì probabile che, poiché una parte delle comunità ribelli si erano assoggettate al marchese di Monferrato, si sia preferito far rientrare la questione canavesana in quella più generale, e attendere l'arbitrato, prima di prendere provvedimenti concreti.

Fino alla fine del 1390, dunque per quasi tre anni, non c'è più notizia di combattimenti nel Canavese; e nei conti delle amministrazioni sabaude redatti in quel periodo ci si riferisce alla "guerra Tuchinorum de Canapicio" come a una vicenda localizzata e conclusa nel 1387. Gli unici strascichi sono di tipo giudiziario: l'impiccagione, già citata, di Simone Fornero di Settimo, giustiziato a Bard il 4 luglio 1388 dopo 14 mesi di detenzione e un processo durato oltre un mese, e quella a Cirié d'un Giacomo Picco, salito al patibolo ai primi del 1389 dopo un anno e quattro mesi di prigionia; le multe comminate dal castellano di Cirié a una mezza dozzina di persone accusate di aver venduto sale e vettovaglie ai ribelli "contra cridas", e d'aver levato grida sediziose in luoghi fedeli al conte, in particolare S. Maurizio ${ }^{81}$.

In assenza di qualunque testimonianza di conflitto armato, potremmo anche credere che la ribellione si fosse ovunque sedata; ma le cose non sono così semplici. Nelle aree che avevano negoziato la propria sottomissione al conte, i funzionari comitali riottennero un certo controllo del territorio ${ }^{82}$; i nobili però erano ancora nella situazione che Amedeo VII rievocherà

${ }^{79}$ Gabotto, Gli ultimi principi cit., p. 84.

${ }^{80}$ Cordero, Il Tuchinaggio cit., docc. 7 e 27; AST, Inv. 68, Conti della Castellania di Bard, 1387-88; cfr. Caffaro, Pineroliensia cit., p. 183.

${ }^{81}$ Fornero: Cordero, Il Tuchinaggio cit., doc. 38, e cfr. AST, Inv. 68, Conti della Castellania di Aosta, 1384-1388 e 1388-1389. Picco: Gabotto, Gli ultimi principi cit., p. 57. AST, Conti della Castellania di Cirié, 1387-1389.

${ }^{82}$ Gabotto, Gli ultimi principi cit., p. 137, sul castellano sabaudo insediato in val di Chy nell'aprile 1390. 
nella sentenza del 1391, impossibilitati a risiedere sulle loro terre e privati delle loro entrate. C'erano poi quelle aree dove la ribellione era stata evitata attraverso concessioni di franchigie, $o$ che comunque per i motivi più diversi non si erano unite alla rivolta: era il caso di tutti i possedimenti dei nobili che parteggiavano per il marchese di Monferrato, ma anche di località appartenenti a vassalli sabaudi, come Aglié, dove il conte manteneva un presidio di balestrieri e dove la comunità ricevette un'esenzione fiscale in risarcimento dei danni subiti per colpa dei ribelli ${ }^{83}$. Finalmente c'erano quelle aree, comprendenti fra l'altro il ricco borgo di Cuorgné e le due maggiori valli alpine, che si erano bensì dichiarate per il marchese di Monferrato, e di cui il conte aveva rinunciato, per il momento, a riprendere possesso con la forza; ma dove non c’è dubbio che il controllo del territorio era in mano ai rivoltosi - come risulta ad esempio dalla multa inflitta a un tale di Cirié "quia ultra ordinaciones factas per dominum ivit et conversavit in Corniaco cum rebellibus et Tuchinis" $"$.

La soluzione definitiva dell'intricato nodo, a questo punto, era affidata all'arbitrato in corso fra il conte di Savoia e il marchese di Monferrato. A una prima tregua imposta dal doge di Genova fin dal 10 settembre 1387, in cui era stabilito il diritto del conte di Savoia di tornare in possesso dei luoghi e delle fedeltà di cui era stato spogliato, erano seguite trattative a Genova, durate almeno fino all'estate 1388; a quel punto, Gian Galeazzo Visconti s'era intromesso nella vicenda offrendo il suo arbitrato, e le parti avevano accettato di rimettersi a lui. I negoziati proseguirono a Milano nell'inverno 1388, e finalmente il Visconti pronunciò una prima sentenza, ancora provvisoria, il 17 marzo $1389^{85}$.

La sentenza del Visconti rispecchiava esattamente la varietà di situazioni che era venuta a delinearsi sul territorio conteso. Dei luoghi già tornati pacificamente in possesso del conte e per cui non era stato prestato né omaggio né fedeltà al marchese non si faceva parola. I luoghi che appartenevano a vassalli del conte, fossero Valperga o S. Martino, ma si erano ribellati contro i signori e avevano invocato la protezione del marchese di Monferrato (e si trattava essenzialmente di Cuorgné e delle due valli di Pont) dovevano essere rimessi al medesimo Gian Galeazzo, in attesa di ulteriori decisioni; il cui tenore era però già intuibile dalla disposizione per cui tutti gli omaggi prestati al marchese di Monferrato per quelle località s'intendevano annullati. Invece, i luoghi che non si erano ribellati contro i loro signori, ma appartenevano a nobili che si erano dichiarati essi stessi

${ }^{83}$ Gabotto, Gli ultimi principi cit., pp. 81 e 84.

${ }^{84}$ AST, Conti della Castellania di Cirié, 1387-1389.

${ }^{85}$ AST, Ducato del Monferrato, mazzo 5, 18 e mazzo 6, 1; cfr. sopra, n. 78. 
per il marchese e gli avevano prestato fedeltà dovevano rimanere sotto il controllo di Teodoro; l'impegno che il predecessore di quest'ultimo si era assunto col famoso trattato del 1372, di darli in pegno al conte di Savoia, era annullato, come erano annullati tutti gli omaggi prestati per quei luoghi al conte dal 1372 in qua. Ma poiché alcune di queste località, e in particolare la castellania di Balangero, erano state nel frattempo riprese con la forza da Amedeo VII, Gian Galeazzo dichiarò che anch'esse dovevano venir rimesse nelle sue mani, in attesa di più matura deliberazione.

Il momento per quell'ultima deliberazione giunse nell'estate del 1390, quando il conte Amedeo VII, concluse vittoriosamente le operazioni contro la ribellione del Vallese, si preparò a chiudere la partita anche nel Canavese. Giunto a Ivrea il 23 agosto, proseguì per Milano dove negoziò con Gian Galeazzo Visconti fino a ottenere, il 27 settembre, la definitiva sentenza arbitrale, in cui si stabiliva "quod loca Corgnate et vallium ac dicti homines inhobedientes et rebelles" dovevano essere rimessi in possesso del conte ${ }^{86}$. Nel dicembre, il Conte Rosso mosse in armi contro i ribelli, per mettere fine una volta per tutte al Tuchinaggio.

\section{Repressione e pacificazione (1390-91)}

Non sappiamo se la presa di Cuorgné sia stata quel fatto d'armi che i più tardi cronisti sabaudi esaltano, ma certamente la campagna fu breve e vittoriosa $^{87}$. Nella pacificazione emanata qualche mese dopo, il 2 maggio 1391, il conte si limita a riferire d'esser disceso in Piemonte per mettere in esecuzione la sentenza del Visconti ("nos idem comes principaliter ob hanc causam novissime transivimus") e di aver ripreso il possesso di tutti i luoghi e ricevuto le fedeltà degli abitanti; dopodiché i suoi commissari istruirono inchieste e processi "contra nonnullos ex dictis rebellibus et tuchinis", di alcuni dei quali "fuit administrata iusticia", mentre con altri si compose "ad certas pecunie quantitates". Di questa repressione giudiziaria sussistono ampie indicazioni nei conti dei castellani sabaudi, che riportano già l'11 dicembre il processo a Ivrea contro sei "tuchinos sive carceratos", di cui uno è impiccato; il castellano di Cly fra il 12 e il 18 dicembre 1390 è a Ivrea dove il conte gli affida la custodia di altri "sex tuchinorum seu prysuneriorum... qui tuchini erant de Corgniaco et vallibus Corgniaci”, poi riportati a Ivrea alla fine di gennaio e di cui non conosciamo il destino; sempre a Ivrea sono impiccati a gennaio altri sette tuchini "de Corgniaco et valli-

${ }^{86}$ AST, Ducato di Monferrato, mazzo 6, doc. 11; la citazione è tratta dalla sentenza del 1391, per cui cfr. sopra, n. 52.

${ }^{87}$ Gabotto, Gli ultimi principi cit., p. 144. 
bus", diversi dai precedenti; a fine febbraio 1391 un tale è arrestato per ordine del conte e impiccato a Bard, e ancora ad agosto il castellano di Gassino impicca un uomo originario "de terra dominorum de Sancto Martino in Canapicio", accusato di aver partecipato "in quadam corsa facta dudum apud Gaxinum per Tuchinos"88.

Ma l'impressione è che a finire impiccato sia stato qualche povero diavolo che si era esposto troppo, e che la repressione si sia tradotta soprattutto in una vasta, e lucrosa, concessione di grazie e remissioni. I tre fratelli Galliani, notabili di Cuorgné, detenuti a Ivrea ancora nell'estate 1391 e poi da lì tradotti ad Avigliana, non finirono sulla forca, ma negoziarono col conte il pagamento di una multa colossale, 3800 fiorini che uno di loro, Antonio, pagò poi alla tesoreria sabauda, "occaxione rebellionis et tuchinarie facte per ipsum cum aliis de Corgniaco contra prefatum dominum nostrum". Ancora più colossale la multa pagata da un altro pezzo grosso di Cuorgné, Matteo de Ambrosio, che dovette sborsare ben 6333 fiorini; e 583 ne pagarono uno dei nobili de Silvesco, sempre di Cuorgné, e i suoi figli. I conti di tesoreria riportano le multe pagate da una dozzina di altri pesci più piccoli, per lo più della stessa zona o dell'imbocco delle valli: somme di 30, 40, anche 100 fiorini, comunque tutt'altro che irrilevanti se inflitte a privati, e tali da indicare che non si trattava di poveracci. È impossibile sfuggire alla conclusione che le comunità ribelli si erano mosse in blocco, guidate dai loro notabili, e che la ribellione era popolare nel senso tecnico con cui l'espressione veniva usata all'epoca, diretta cioè contro il potere dei signori, ma non era affatto un furore contadino ${ }^{89}$.

Se il Tuchinaggio era stato un modo di fare politica, o di proseguirla con altri mezzi, è chiaro che c'erano dei rischi quando ci si spingeva troppo in là. Ma la vicenda non è ancora finita, e la sua conclusione dimostra esaurientemente che essa era stata politica dall'inizio alla fine, e come tale era percepita dai protagonisti. Entro il gennaio del 1391, la ribellione era interamente liquidata, e Amedeo VII si spinse fino a Chivasso per incontrarsi con Teodoro II e concordare la definitiva pacificazione ${ }^{90}$. La sentenza di Gian Galeazzo era in realtà più che soddisfacente per il marchese, finalmente liberato dagli obblighi contratti nel 1372, e per quei nobili canavesani, come i signori di S. Giorgio o i Valperga di Rivara, che avevano

${ }^{88}$ Gabotto, Gli ultimi principi cit., p. 57; Cordero, Il Tuchinaggio cit., doc. 39; A. Pession, Comptes de la chatellenie de Cly (1390-1399), Aoste 2006 (BAA, XXXII), p. 402 sg.

${ }^{89}$ Cordero, Il Tuchinaggio cit., pp. 447-448.

${ }^{90}$ Cordero, Il Tuchinaggio cit., docc. 36 e 60.

${ }^{91}$ Fecero eccezione i Valperga di Mazzé, i cui possedimenti erano in gran parte oggetto di controversia con i signori di Vische, aderenti dei S. Martino. Il settembre 1391 
dichiarato la loro preferenza per lui: da allora in poi i loro possedimenti, benché incuneati nel Canavese sabaudo, vennero ufficialmente riconosciuti da tutti come parte del marchesato ${ }^{91}$. Amedeo VII dovette adattarsi a fare un passo indietro, pur di avere mano libera altrove: nelle aree che si erano sottomesse spontaneamente aveva già insediato propri castellani e podestà, mentre nell'area conquistata a forza nominò un "gubernator Corgnati et Vallium"92.

Era ora di venire incontro alle richieste dei nobili del Canavese, che lo assediavano già da un pezzo supplicandolo di restituire loro i possedimenti che avevano perduto allo scoppio della ribellione. Le comunità, d'altra parte, aspettavano di vedere come Amedeo VII si sarebbe mosso. Le impiccagioni e le multe rappresentavano solo una parte della soluzione; era necessaria anche una risposta politica, e tutti i presupposti condivisi spingevano per una pacificazione in cui il principe, dopo aver dimostrato la sua forza, desse prova della sua clemenza. L'atto con cui il Tuchinaggio si chiude anche ufficialmente a tutti gli effetti è la sentenza di pacificazione che la contessa madre Bona di Borbone, a nome del figlio Amedeo VII ritornato nel frattempo al di là delle Alpi, pronunciò a Ivrea il 2 maggio 1391, in presenza di trentotto conti canavesani (sette dei Valperga e trentuno dei S. Martino) e dei rappresentanti di trentun comunità.

La sentenza si configura fin dall'inizio come un ricalco di quella già pronunciata da Amedeo VII nel dicembre 1385. Già allora, dichiara il conte per bocca della madre, avevamo pronunciato una sentenza per mettere fine sia alle rivalità tra i conti di Valperga e quelli di S. Martino, sia alle liti tra i signori "et eorum homines et subdictos de Corgnato et vallibus et generaliter alios omnes eorum homines et subdictos qui inhobedienciam et rebellionem adversus eos hostenderunt". In spregio a quella sentenza i sudditi si erano ribellati, "inconsulte et improvide", contro i loro signori, e avevano intrattenuto una colpevole complicità col marchese di Monferrato. Ora, prosegue il conte, dopo la sconfitta dei ribelli e i processi istruiti contro i principali colpevoli è venuto il momento di accedere alle richieste dei nobili, e restituire loro tutto ciò che teniamo in mano nostra. Ma il linguaggio che impiega qui Amedeo VII è estremamente significativo: noi desideriamo, dice, "inter ipsos et dictorum eorum hinc inde homines de perpetua concordia et pace tractare". Altro, dunque, è la punizione dei colpevoli, affidata alla giustizia del conte; altro è la chiusura politica dell'intera vicenda, che non si configura semplicemente come un reintegro dei

il duca di Borbone, zio di Amedeo VII, di passaggio in Piemonte, pronunciò col consenso delle parti un ulteriore arbitrato, assegnando Mazzé al conte e Castiglione, Candia e Rondissone al marchese: AST, Ducato di Monferrato, mazzo 6, doc. 12.

92 Tallone, Parlamento cit., II, p. 31. 
signori nei loro possessi, ma come una nuova, definitiva pacificazione, che richiede un accordo fra le parti.

La sentenza si configura dunque come una pacificazione che dichiaratamente riprende quelle già pronunciate prima della rivolta. Per arrivarvi, il consiglio del conte ha esaminato attentamente le petizioni e querele di tutte le parti in causa, e non c'è dubbio che dietro la sentenza pronunciata il 2 maggio vi sia stato in realtà un negoziato, cui parteciparono, verosimilmente, quegli stessi che vennero poi convocati a Ivrea per ascoltare la lettura. La contessa Bona ribadì dunque, a nome del figlio, che la pacificazione pronunciata da Amedeo VI nel 1379 doveva essere integralmente osservata e messa in esecuzione, tranne le eventuali modifiche introdotte da quella di Amedeo VII nel 1385; e che a sua volta quest'ultima doveva essere osservata "inviolabiliter", salve, anche in questo caso, le eventuali novità e deroghe introdotte "per nostram pronunciacionem presentem". La prima di queste deroghe venne immediatamente specificata ed è di per sé piuttosto significativa: sei anni prima gli "homines dictorum nobilium" erano stati condannati a pagare una certa somma al conte, ma ora questo pagamento, che costituì forse, come abbiamo visto, l'occasione scatenante della rivolta, viene interamente condonato.

Non meno significative sono le altre deliberazioni che il conte, o il suo consiglio, ritengono necessario aggiungere, e che fanno di questa sentenza assai più un arbitrato e una mediazione fra i signori e i loro sudditi ribelli, che non una punizione di questi ultimi. In primo luogo, infatti, si decreta che d'ora in poi i conti canavesani "non possint inter se et eorum homines et subditos facere guerram", ma che per qualunque discordia saranno tenuti a ricorrere agli "officiales" del conte, il quale a sua volta si impegna a concludere ogni causa entro il tempo massimo di un anno, "summarie, simpliciter et de plano". Viene così negato, per la prima volta e decisivamente, quel diritto di guerra privata che i conti canavesani rivendicavano come ovvio (e che, ad esempio, era stato tutelato da un intervento di Amedeo V e Filippo d'Acaia nel $1318^{93}$ ), e compie un passo decisivo la giurisdizione del conte e dei suoi funzionari. Nello stesso senso va la clausola per cui, una volta che il conte avrà restituito ai nobili canavesani tutto ciò che tiene

${ }^{93}$ Concordando con i conti canavesani norme comuni per la repressione del brigantaggio, il conte e il principe avevano accettato di inserire questa clausola: "Item derobatores non intelligantur nobiles de Canapicio unus capiendo de rebus alterius quem diffidasset elapsis $\mathrm{x}$ diebus post diffidacionem cum quo haberet guerram, dummodo ipsa captio non fieret in terra ipsorum dd. comitis et principis": A. Bertolotti, Convenzioni e statuti pell'estirpamento dei berrovieri e de' ladri dal Monferrato, Canavese, Vercellese e Pavese nei secoli XIII e XIV, "Miscellanea di Storia Italiana», 12, 1871, pp. 812-814. 
in sua mano, e costoro gli avranno tutti giurato la fedeltà ligia, i loro sudditi avranno diritto di appello al conte ogni volta che si riterranno danneggiati dai signori.

Seguono, non meno significative, le clausole sulla pacificazione dei colpevoli di tuchinaggio. Ci sono uomini dei signori di Castellamonte, Front, Barbania e Strambino ancora "non puniti nec concordati de rebellionibus et tuchinagiis commissis"; la punizione e le ammende concordate spetteranno integralmente al conte e non ai signori. Quanto a coloro che sono "iam puniti et concordati", i signori non potranno in alcun modo molestarli ulteriormente "occaxione delicti dicti tuchinagii", col pretesto di farsi risarcire i danni subiti. Il conte si riserva di deliberare entro due anni sull'eventuale risarcimento spettante ai nobili per i danni provocati loro dai ribelli, e fino ad allora nessuno avrà il diritto di rivalersi contro i sudditi. Gli homines dovranno bensì restituire ai signori tutti i fitti, censi, servizi, successioni, roide loro spettanti, con gli arretrati per gli anni in cui ai signori è stato impedito di riscuoterli; ma quelle aree, come le valli di Brosso e di Chy, che nel frattempo si erano date al conte potranno dedurne i focatici pagati al conte mentre si trovavano sotto la sua amministrazione.

Il conte si riserva, naturalmente, di multare le comunità ribelli o comunque di concordare con loro una composizione; i nobili dovranno collaborare con gli ufficiali del conte all'esecuzione di qualsiasi provvedimento e confisca, ma saranno anche responsabili sotto obbligo dei loro beni per il pagamento delle multe. I sudditi avranno diritto di alienare liberamente i loro possedimenti per mettere insieme la somma concordata, senza che i signori possano interferire con queste vendite. Tutti i beni confiscati ai ribelli rimarranno in possesso del conte, e chi li acquisterà o li riceverà in dono sarà esente a vita da ogni obbligo e servizio nei confronti dei signori; questi ultimi potranno soltanto, se vorranno, ricomprarli allo stesso prezzo.

È implicito, da quanto fin qui detto, che quelle aree che si erano date al conte dopo essersi ribellate saranno anch'esse rimesse in possesso dei loro signori; il conte ha intenzione di ristabilire lo status quo con un unico provvedimento e non esita per questo a violare gli impegni assunti a suo tempo con le comunità. Senza menzionare questo particolare imbarazzante, la sentenza precisa comunque che a loro volta tutti gli obblighi e i pagamenti che qualunque comunità si fosse assunta nei confronti del conte "a tempore rebellionis et tuchinagii" s'intendono annullati. Ma il conte non può evitare di far fronte alla più importante delle rivendicazioni dei sudditi, che s'era già impegnato a risolvere "amicabiliter... pro bono pacis et concordie" nel 1385, e cioè la questione delle successioni tra fratelli indivisi: allora aveva stabilito la convocazione di commissioni miste, che per quanto ne 
sappiamo non avevano avuto il tempo di riunirsi; ora il conte, più sbrigativamente, attribuisce a due suoi consiglieri, un cavaliere e un dottore, il compito di sentenziare in proposito con soddisfazione di tutti.

Pronunciata la sentenza, la contessa Bona ordina che i nobili canavesani siano rimessi in possesso delle loro terre e di tutti i diritti che spettavano loro "ante rebellionem et ortum tuchinagii supradicti"; e infatti, il 6 e 7 maggio 1391 i suoi inviati vanno a Cuorgné "pro ponendo Dominum et comites Sancti Martini et Valpergie in possessionem Corgnati et Vallium" ${ }^{\prime 4}$. I termini della pacificazione indicavano con la massima chiarezza che i signori, riprendendo possesso dei loro beni, non avevano il diritto di esercitare alcuna rappresaglia sui ribelli. Come, concretamente, si siano svolte le cose è illustrato dal protocollo d'un notaio episcopale di Ivrea, Enriotto Boca, di Torre Canavese, da cui risulta che il 18 giugno 1391, "cum rixe, dissentiones et discordie iam dudum et per plures annos fuissent, vertissent et stetissent inter nobiles dominos de Canapicio et homines ipsorum de Castronovo, de poderio vallis Pontis, Vallis Chivum, Vallis Brozii et eciam totius Pedagnie et plurium aliorum locorum de Canapicio", ed essendo poi tutti questi luoghi pervenuti "quasi omnes et pro maiori parte ad manus et gubernationem atque dominium" del conte, il quale "dictos homines de Canapicio omnes ad dominos suos ipsos naturales de Canapitio omnimodo penitus et omnino relaxavit et remisit", quindici uomini della valle di Castelnuovo comparvero a Loranzé davanti ai signori, supplicando di perdonare "omnia delicta omniaque maleficia, ligas, cohadunatas, iura, tuchinagium"; e i signori, come prevedeva la sentenza del conte, concessero il perdono e la reinvestitura di tutto ciò che gli abitanti tenevano da loro ${ }^{95}$.

Ovviamente, quel che le comunità non dovettero pagare ai signori fu preteso dal conte; e questa volta toccò rassegnarsi. Le comunità della Valle di Brosso, accusate dei peggiori eccessi, tra cui i due omicidi e lo stupro che sono le uniche violenze personali specificamente menzionate nei capi d'accusa, pagarono 1000 fiorini, e i perpetratori materiali di quei delitti non vennero inclusi nel perdono; le comunità della Val Soana ne pagarono 1275; quelle della Valle di Castelnuovo, 2750; la comunità di Locana, 1650; quella di Cuorgné, 1500; le altre comunità più o meno compromesse pagarono somme minori, a volte consistenti, nell'ordine di qualche centinaio di fiorini, a volte minime - fino alle cinque comunità dette della Pedagna, ovvero Loranzé, Colleretto, Parella, Quagliuzzo e Strambinello, che si erano

\footnotetext{
${ }^{94}$ Cordero, Il Tuchinaggio cit., doc. 71.

${ }^{95}$ Venesia, Il Tuchinaggio cit., p. 124 sgg.

${ }^{96}$ Cordero, Il Tuchinaggio cit., pp. 449-451.
} 
sottomesse al conte al momento giusto, e dovettero sborsare solo 10 fiorini per l'esecuzione materiale delle lettere di remissione ${ }^{96}$.

\section{Conclusione}

Sommando le multe pagate collettivamente dalle comunità alle ammende individuali già ricordate, si arriva a un totale di 26.991 fiorini: molto meno dei 34.000 che erano stati chiesti alle stesse comunità nel 1385. Dopo una ribellione durata cinque anni, che aveva permesso loro di governarsi a lungo da sole e di non pagare censi né imposte, tenendo in propria mano per tutto quel tempo castelli e possessi agricoli dei signori, e negoziando alla pari con il conte di Savoia e il marchese di Monferrato, le comunità canavesane si trovarono a pagare, in cambio della remissione dei loro delitti, meno di quello che era stato chiesto, prima dell'insurrezione, semplicemente per assolverle dall'accusa di aver costituito una lega contro i loro signori. Se si aggiunge che la pacificazione del 1391 risultò di gran lunga più vantaggiosa per i sudditi di quanto non fosse stata quella di sei anni prima, avviando concretamente il ridimensionamento dello sfruttamento signorile, è difficile non concludere che dal punto di vista delle comunità ricorrere alla violenza per sbloccare una situazione senza via d'uscita poteva anche risultare pagante.

Ma si trattava, appunto, di comunità, e non di gruppi isolati di rustici. Ora che abbiamo ripercorso in dettaglio gli sviluppi della rivolta dei Tuchini, è giocoforza ribadire che il movimento, benché inequivocabilmente identificato dai contemporanei come una violenza dei populares diretta contro i nobiles, fu molto diverso dalla spontanea insurrezione contadina ancor oggi celebrata nella memoria popolare canavesana. A muoversi furono le comunità, soggetti politici e giuridici riconosciuti, e che in qualche caso, soprattutto nei centri più cospicui come Cuorgné, erano guidate da notabili agiati, scontenti quanto e più dei rustici d'essere considerati tecnicamente come sudditi e assoggettati a gravose forme di prelievo signorile. Proprio l'organizzazione in comunità, e la compattezza con cui esse si mossero, spiega la lunga durata del movimento e il suo parziale successo, al di là della repressione violenta che i ribelli, in certi momenti e in certi luoghi, dovettero subire. La robustezza delle comunità che si manifesta in questa occasione non è propria solo di zone arretrate e mon-

${ }^{97} \mathrm{Ne}$ ho studiato un esempio di lungo periodo in A. Barbero, Politica e comunità contadina nel Piemonte medievale, "Studi Storici», 35, 1994, pp. 5-48 (anche in Villafalletto. Un castello, una comunità, una pieve, a cura di R. Comba, Cuneo 1994, pp. 113-157). Una situazione paragonabile fa da sfondo all'importante lavoro di 
tuose, ma caratterizza l'intero Canavese come del resto l'intero Piemonte, creando una dialettica politica vigorosa, di cui sono protagonisti principi, signori locali, comunità rurali e solo in certe zone anche comuni urbani ${ }^{97}$. Anche per quanto riguarda la vitalità delle rivendicazioni contadine, la tenuta di questo tessuto comunitario conferma la profonda diversità dell'area piemontese rispetto a quell'Italia della mezzadria dove declino delle comunità rurali e assenza di una conflittualità violenta fra padroni e contadini appaiono strettamente intrecciati ${ }^{98}$.

H. Oliva Herrer, Justicia contra señores. El mundo rural y la política en tiempos de los Reyes Católicos, Valladolid 2004, che ha contribuito a rinnovare lo studio delle insurrezioni contadine nel tardo Medioevo.

${ }^{98}$ R. Mucciarelli - G. Piccinni, Un'Italia senza rivolte? Il conflitto sociale nelle aree mezzadrili, «Annali dell'Istituto 'Alcide Cervi'», 16, 1994, pp. 173-205. 


\section{RIVOLTE ANTIVISCONTEE A MILANO E NELLE CAMPAGNE FRA XIII E XIV SECOLO}

Nello studio sulle origini della signoria dei Visconti su Milano e la Lombardia, sono spesso prevalse letture fortemente orientate a interpretare tutto il Trecento alla luce degli sviluppi più tardi, maturati negli ultimi anni del dominio di Bernabò e di Galeazzo e, soprattutto, sotto il primo duca, Gian Galeazzo, quasi che sin dai primi momenti l'agire politico dei diversi membri della dinastia fosse ispirato da una coerenza e da una progettualità necessariamente ordinate agli sviluppi istituzionali di fine secolo $\mathrm{o}$, talvolta, quattrocenteschi ${ }^{1}$. Alcuni studi più recenti hanno invece iniziato a restituire una ricostruzione più dettagliata delle difficili fasi di costruzione del potere visconteo, della dialettica sociale e politica che le caratterizzò e dei compromessi a cui dovettero assoggettarsi i primi domini milanesi pur di consolidare e legittimare il loro nuovo potere ${ }^{2}$. Fra i soggetti

${ }^{1}$ Come ha osservato ad esempio P. Mainoni, Le radici della discordia. Ricerche sulla fiscalità a Bergamo tra XIII e XIV secolo, Milano 1997 (Storia lombarda, 3), p. 9.

${ }^{2}$ Sempre utile F. Cognasso, Note e documenti sulla formazione dello stato visconteo, «Bollettino della Società pavese di storia patria», XXIII, 1923, pp. 23-160. Sono ancora pochi gli studi recenti sui Visconti nella prima metà del Trecento: si vedano comunque gli importanti C. Storti Storchi, Aspetti generali della legislazione statutaria lombarda in età viscontea, in Legislazione e società nell'Italia medievale. Per il VII centenario degli Statuti di Albenga (1288), Bordighera 1990, pp. 71-101; Ead., Giudici e giuristi nelle riforme viscontee del processo civile per Milano (1330-1386), in Ius Mediolani. Studi di storia del diritto milanese offerti dagli allievi a Giulio Vismara, Milano 1996, pp. 47-187; P. Boucheron, Tout est monument. Le mausolée d'Azzone Visconti à San Gottardo in Corte (Milan, 1342-1346), in Liber largitorius. Études d'histoire médiévale offertes a Pierre Toubert par ses elèves, a cura di D. Barthélémy, J.-M. Martin, Genève 2003, pp. 303-329. Si vedano anche gli studi di Patrizia Mainoni e di Andrea Gamberini citati oltre. Per la fine del Duecento e gli anni di Ottone Visconti, oltre alle intuizioni esposte da G. G. Merlo, Ottone Visconti arcivescovo (e "Signore"?) di Milano. Prime ricerche, in Vescovi medievali, a cura di G. G. Merlo, Milano 2003, pp. 25-71 (già pubblicato come Introduzione a Gli atti dell'arcivescovo e della curia arcivescovile di Milano nel sec. XIII, I, Ottone Visconti (1262-1295), a cura di M. F. Baroni, Milano 2000), si veda A. Padoa Schioppa, La giustizia milanese nella prima età viscontea (1277-1300), in Ius Mediolani. Studi di storia del diritto milanese offerti dagli allievi a Paolo Vismara, Milano 1996, 
che seppero autorevolmente interloquire con i primi Visconti, oltre alle città progressivamente assoggettate, vi furono anche le maggiori comunità delle campagne che non solo poterono utilizzare la sponda offerta dai signori per allargare i loro margini di autonomia nei confronti dei comuni urbani $^{3}$, ma, come si vedrà nelle prossime pagine, si contrapposero con successo agli stessi Visconti, obbligandoli a mutare e moderare la loro politica fiscale.

Oggetto di questa ricerca è la conflittualità a Milano e, soprattutto, nelle campagne milanesi negli anni della prima affermazione viscontea, ossia il periodo compreso fra la sconfitta dei della Torre a Desio, nel gennaio del 1277, e il definitivo consolidamento del potere della casata su Milano e su gran parte della Lombardia ad opera di Azzone, fra il 1335 e il 1338. Le tensioni di questo periodo culminarono nella grande rivolta della parte settentrionale del contado milanese, che ebbe il suo cuore nell'attuale Brianza, la quale, negli anni Venti del Trecento, si sottrasse al governo cittadino: Monza, pur fra ripetuti conati autonomisti, fu riportata con la forza sotto l'autorità viscontea dopo quasi due anni, Cantù e Lecco, con i loro dintorni, non tornarono sotto il domino di Azzone che nel 1336.

Anche a causa di un'oggettiva scarsità di fonti e di una più generale modesta propensione storiografica allo studio delle rivolte agrarie precedenti alla crisi del XIV secolo ${ }^{4}$, i sommovimenti del contado non hanno riscosso particolare attenzione da parte della storiografia milanese ed è merito recente di Andrea Gamberini aver affermato con decisione l'estensione e la portata di questa "disarticolazione territoriale" . La maggior parte degli

pp. 1-46 e mi si permetta di rimandare a P. Grillo, "Reperitur in libro". Scritture su registro e politica a Milano alla fine del Duecento, in Libri, e altro, nel passato e nel presente, a cura di G. G. Merlo, Milano 2006, pp. 33-53.

${ }^{3}$ Su quest'aspetto della signoria viscontea esiste una consolidata tradizione di studi, per la quale basti qui il rimando a G. Chittolini, La formazione dello stato regionale e le istituzioni del contado. Secoli XIV e XV, Torino 1979; G. M. Varanini, L'organizzazione del distretto cittadino nell'Italia padana nei secoli XIII-XIV (Marca Trevigiana, Lombardia, Emilia), in L'organizzazione del territorio in Italia e in Germania: secoli XIII$X I V$, a cura di G. Chittolini e D. Willoweit, Atti della 35.a Settimana di studio, Bologna 1994, pp. 133-209; F. Somaini, Processi costitutivi, dinamiche politiche e strutture istituzionali dello Stato visconteo-sforzesco, in Comuni e signorie nell'Italia settentrionale. La Lombardia, Torino 1998 (Storia d'Italia diretta da G. Galasso, vol. VI), pp. 681-786, pp. 750-752.

${ }^{4}$ Come rileva R. Comba, Rivolte e ribellioni fra Tre e Quattrocento, in La storia. I grandi problemi dal Medioevo all'età contemporanea, a cura di N. Tranfaglia e M. Firpo, vol. 2, Popoli e strutture politiche, Torino, 1986, pp. 669-688. Per l'Italia si vedano comunque i saggi raccolti in Protesta e rivolta contadina nell'Italia medievale, a cura di G. Cherubini, «Annali dell'istituto Alcide Cervi», 16, 1994. 
studiosi si è invece soffermata poco sull'episodio e, soprattutto, non ne ha indagato le motivazioni, offrendone due spiegazioni stereotipate: l'adesione alla parte guelfa ( $m a$ anche questa adesione, in zone che erano piuttosto di tradizione filoimperiale, andrebbe giustificata) e una pretesa continuità con tradizioni autonomistiche che avrebbero avuto le loro radici nell'esperienza di autogoverno del Seprio e della Martesana attuatasi oltre un secolo e mezzo prima, sotto Federico $\mathrm{I}^{6}$.

Ciò che vorrei qui dimostrare è invece che la rivolta del contado milanese ebbe motivazioni specifiche, identificabili in una ben precisa politica economica e fiscale perseguita da Matteo e da Galeazzo Visconti. Solo in reazione a questa politica, le ricche e produttive comunità della Brianza assunsero una posizione anticittadina, con una nettissima frattura rispetto a quanto era accaduto sotto il reggimento comunale tra la fine del XII e la fine del XIII secolo.

\section{Il primo Duecento e la conflittualità antisignorile}

Per comprendere tale frattura, sarà opportuno soffermarsi rapidamente sulle forme di conflittualità che si ritrovano nelle campagne milanesi durante la prima metà del Duecento.

Principalmente, gli episodi violenti testimoniati nel contado di Milano sono legati alla conflittualità "verticale", fra signori e comunità soggette. $\mathrm{Si}$ tratta di episodi di rilievo locale, che non trovavano riscontro nelle narrazioni cronachistiche e la cui memoria, in assenza di registri giudiziari comunali superstiti, è rimasta legata agli archivi degli enti ecclesiastici titolari di diritti pubblici contro i quali gli atti violenti erano stati rivolti. La nostra conoscenza di tali eventi è dunque episodica e limitata a quanto è avvenuto nei pur vasti dominatus loci dei monasteri di Sant'Ambrogio e di San Maurizio o della canonica di Monza ${ }^{7}$.

${ }^{5}$ A. Gamberini, Il contado di Milano nel Trecento. Aspetti politici e istituzionali, in Contado e città in dialogo. Comuni urbani e comunità rurali nella Lombardia medievale, a cura di L. Chiappa Mauri, Milano 2003, pp. 83-135, alle pp. 93-99, citazione a p. 95, ora anche in Id., Lo stato visconteo. Linguaggi politici e dinamiche costituzionali, Milano 2005.

${ }^{6}$ Così G. Biscaro, Le relazioni dei Visconti di Milano con la Chiesa. Giovanni XXII e Azzone, in "Archivio storico lombardo", XLVI, 1919, pp. 84-229, qui alle pp. 100-101.

${ }^{7}$ Si veda P. Grillo, Milano in età comunale (1183-1276). Istituzioni, società, economia, Spoleto 2001, pp. 619-628, nonché Id., Statuti signorili della canonica di Monza: Calpuno, Castelmarte, Colzago, Cremella, Monguzzo (1196-1246), R. Rao, Comunità, signore e città nell'emanazione degli statuti di Arosio, L. Chiappa Mauri, Nelle terre del monastero di Sant'Ambrogio di Milano: statuti signorili e di comunità, tutti in Statuti rurali lombardi del secolo XIII, a cura di L. Chiappa Mauri, Milano 2004, pp. 21-38, 3956, 57-89. 
Si trattava di una microconflittualità locale nella quale l'atto violento era di norma incruento e spesso rivolto verso il simbolo principale dell'autorità signorile: il castello. Danneggiamenti o parziali smantellamenti delle strutture fortificate, quali si ritrovano ad Arosio nel 1211, a Origgio nel 1231, a Inzago prima del 1241, costituivano il momento culminante di lunghe e articolate fasi di confronto nelle quali trovavano posto anche iniziative di diverso tipo, quali il rifiutarsi di prestare giuramento, le invasioni dimostrative dei beni dominicali, la mancata prestazione dei conditia e dei canoni o altre forme di incruenta insubordinazione. Molto più rare erano invece le azioni rivolte contro le persone: aggressioni o ferimenti di religiosi o di loro ufficiali sono menzionati saltuariamente nella documentazione superstite e, spesso, avvenivano ad opera non di contadini e rustici, ma di rappresentanti delle aristocrazie rurali ostili. Molto frequentemente l'esito finale di tali confronti era la conclusione di compromessi che salvaguardassero le ragioni di entrambe le parti, come l'acquisizione delle prerogative signorili da parte delle comunità in cambio del pagamento di un canone ${ }^{8}$.

In questi confronti, il comune urbano sembra aver avuto un ruolo di secondo piano. Certamente, le collettività rurali, quando cercavano di liberarsi del giogo dominicale, miravano a una diretta soggezione alla città; quest'ultima, però, intervenne direttamente a favore dei rustici solo in momenti eccezionali e più che altro al fine di colpire l'aristocrazia rurale. Così avvenne, ad esempio, durante l'aspro conflitto fra popolo e nobili degli anni 1221-1225, quando il governo cittadino a predominanza popolare impose la nomina di podestà urbani in tutti i centri del contado sottoposti al districtus ecclesiastico. In altri casi - ma bisogna sempre ricordare che le nostre conoscenze derivano dagli atti conservati negli archivi degli enti monastico o canonicali, i quali, ovviamente, tramandano quasi esclusivamente le sentenze a loro favorevoli - i magistrati cittadini, vincolati anche dai dettami del Liber Consuetudinum - si espressero a favore del mantenimento dello status quo, sia nei confronti delle richieste dei contadini, sia verso le eventuali nuove pretese dei domini ${ }^{9}$.

Il cenno alla contesa politica fra Popolo e aristocrazia induce a porre il problema del ruolo, non facilmente definibile, delle comunità rurali nel-

${ }^{8}$ Per tutto ciò, Grillo, Milano in età comunale cit., pp. 595-604.

${ }^{9}$ R. Romeo, Il comune rurale di Origgio nel secolo XIII, Milano $1992^{2}$, p. 32; la teoria dell'appoggio del comune ai domini è formulata da G. L. Barni, Cives e rustici alla fine del XII secolo e agli inizi del XIII secondo il Liber consuetudinum Mediolani, «Rivista storica italiana», LXIX, 1957, pp. 5-60, una sua discussione in Grillo, Milano in età comunale cit., pp. 612-615. 
l'ambito dei ripetuti conflitti aperti fra le due partes. Certamente, alcuni grossi centri seppero approfittare delle divisioni cittadine e, schierandosi a favore della nobiltà, ottennero fin dal 1225 una situazione di privilegio. Nella pacificazione stabilita nel luglio di quell'anno si sanciva infatti che Cantù e Lecco, schieratesi in appoggio dei fuoriusciti aristocratici, venissero fiscalmente parificate ai cittadini ${ }^{10}$.

Un capitolo della pace di Sant'Ambrogio conclusa nel 1258 fra nobili e popolari prevedeva per "che tutte le ville che erano fatte borgi e tutti li maleficii perpetrati ne li borghi per il populo de Milano si reducessino al pristino stato e che fusseno in quello essere ch'erano avante a la partita de capitanii e valvasori. Item che il commune de Canturio fusse libero da ogni prestatione de talie in perpetuo"11. I centri del contado, ignoriamo purtroppo quali e quanti, assunsero dunque posizioni politiche autonome nel corso degli scontri del 1256-58 fra Popolo e nobiltà, cercando di assicurarsi uno status privilegiato. Essi non si muovevano però in una prospettiva di distacco dal distretto cittadino, ma miravano soltanto a garantirsi una posizione di superiorità rispetto ad altre località. Probabilmente molti dei nuovi borghi erano stati in precedenza insediamenti soggetti al dominatus loci e il cambiamento di titolo fu favorito dai populares per penalizzare i signori del contado.

La pace di Sant'Ambrogio e la successiva affermazione del predominio torriano fra 1259 e 1276 sembrano aver portato una generale tranquillità nel contado milanese. Nell'ambito dei rapporti con le comunità rurali il nuovo regime, come aveva già evidenziato il Romeo, proseguì fondamentalmente la politica precedente ${ }^{12}$, pur tentando di rafforzare le posizioni della famiglia egemone con lo sviluppo di legami clientelari nel contado ${ }^{13}$. La creazione di una sorta di cuscinetto di comuni amici che circondavano quasi tutto il distretto di Milano (Crema, Lodi, Bergamo, Como, Novara, Vercelli) allontanò anche la minaccia militare dei fuoriusciti, i principali scontri con i quali vennero combattuti nel territorio degli alleati, $o$ in aree periferiche come l'alto Seprio e la zona del lago Maggiore.

${ }^{10}$ Gli atti del comune di Milano nel secolo XIII, vol. I, (1217-1250), a cura di M. F. Baroni, Milano 1974, pp. 213-221, doc. 148, a p. 215.

${ }^{11}$ Gli atti del comune di Milano nel secolo XIII, vol. II/1 (1251-1263), a cura di M. F. Baroni e R. Perelli Cippo, Alessandria 1984, pp. 241-244, doc. 209, a p. 243.

12 Romeo, Il comune rurale di Origgio cit., pp. 81-82.

${ }^{13}$ Grillo, Milano in età comunale cit., pp. 640-642. 


\section{Gli anni di Ottone e di Matteo Visconti}

La vittoria di Desio, nel gennaio del 1277, vide la sconfitta e la cattura di Napoleone, leader della stirpe dei della Torre e personalità politicamente predominante a Milano. Il resto della famiglia venne scacciato dalla città con i suoi seguaci. Il nuovo regime, di matrice aristocratica e ghibellina, almeno agli inizi egemonizzato dalla forte figura dell'arcivescovo Ottone Visconti, nacque all'insegna della pacificazione e, almeno a parole, della ricomposizione sociale dopo le lacerazioni dell'epoca popolare e torriana ${ }^{14}$. In realtà, al suo interno emerse rapidamente una componente radicale, intenzionata a imprimere una forte connotazione di parte al governo cittadino. Questo, nel contempo, si dimostrò traumaticamente incapace a contenere il fuoriuscitismo torriano: nonostante isolati successi delle forze intrinseche, i malesardi milanesi furono in grado di operare quasi liberamente in tutto il contado milanese ${ }^{15}$.

Le campagne precipitarono così in un periodo di grave insicurezza, ben restituito dalla documentazione privata, con il diffondersi dei contratti che prevedevano agevolazioni o esenzioni dai pagamenti in caso di guerra. $\mathrm{Si}$ può ricordare un patto stipulato nel 1294 fra il comune di Inzago e il monastero di Sant'Ambrogio, al fine di rinforzare il locale castello "propter timorem guerre presentis existentis inter homines et comune Mediolani pro parte una et homines et comune Laude ac illos de la Ture et sequaces eorum"16.

Sin dai primi anni del regime, inoltre, si svilupparono nuove tensioni fra alcune comunità, che si erano appoggiate ai della Torre nei loro progetti di emancipazione e i signori locali, i quali, sostenuti dal comune urbano, volevano un ritorno alla situazione precedente. Vale la pena di soffermarsi su quanto accadde a Brivio, un centro di particolare importanza, per la presenza di un castrum e di un ponte sull'Adda, soggetto al dominatus degli ordinari della cattedrale: qui i della Torre avevano costruito una forte rete di clientele locali, imponendo talvolta trasferimenti coatti di proprietà ai loro più stretti seguaci e sottraendo almeno di fatto il luogo al potere dei ca-

${ }^{14}$ Da ultimo: Grillo, "Reperitur in libro" cit.

${ }^{15}$ Oltre alle classiche Storie di Milano, per i conflitti politici nella Milano degli anni Ottanta del Duecento si veda A. Bozzola, Un capitano di guerra e signore subalpino. Guglielmo VII di Monferrato (1254-1292). Per la storia dei Comuni e delle Signorie, «Miscellanea di storia italiana», Serie III, tomo XIX, 1922, pp. 261-443, qui alle pp. $376-383$.

${ }^{16}$ Archivio di Stato di Milano, Pergamene per fonti (d'ora in poi citato: ASMi, PPF), cart. 340, 1294 dicembre 31, edito in Documenti diplomatici tratti dagli Archivj milanesi, a cura di L. Osio, Milano 1864, pp. 47-48, doc. 37, con data errata 1295. 
nonici ${ }^{17}$. Quando una delegazione di costoro si ripresentò per rivendicare i diritti ecclesiastici, vi fu un tumulto contro di loro, a cui parteciparono un centinaio di uomini e molte donne, che diedero la caccia ai religiosi minacciando di ucciderli. In realtà la dimostrazione di forza si concluse in modo incruento e i tre ordinari si limitarono a passare, come afferma l'editore del documento "un brutto quarto d'ora"18.

Nelle nuove circostanze politiche si ripresentava in tal modo la vecchia conflittualità fra signori e comunità che già aveva contraddistinto la prima metà del secolo. In realtà, la politica del nuovo regime urbano andava ponendo le basi per nuovi e ben diversi processi, destinati a minare più radicalmente le ragioni della convivenza fra città e contado.

Il fallimento dei progetti di pacificazione e dei tentativi di soluzione militare del problema del fuoriuscitismo precipitarono le campagne milanesi in una severa crisi. La persistente minaccia torriana, la necessità di condurre una politica filoghibellina su scala regionale e, a partire dal 1285, le ambizioni egemoniche di Matteo Visconti imposero al nuovo regime un crescente carico militare, con un vertiginoso impennarsi delle spese a questo connesse. Ne derivò un altrettanto vertiginoso aumento della pressione fiscale. Non è facile verificare l'incremento del prelievo diretto, anche se il sistematico rifacimento dei registri d'estimo a partire dal 1288 testimonia la perdurante importanza di tale introito ${ }^{19}$. Si accrebbe senza dubbio notevolmente il numero delle imposizioni indirette. Agli anni Ottanta del Duecento risale la messa a punto di un capillare sistema di appalto dei dazi in città e nel contado: per la prima volta compaiono nella documentazione i dazi del grano, del vino e delle taverne. Almeno a partire dal 1289 cominciò a venir riscossa la gabella del sale ${ }^{20}$.

Una prima conseguenza di tale politica fu il tentativo di alcune comunità minori di sottrarvisi, sottoponendosi al districtus di enti ecclesiastici esenti. Nella parte meridionale del territorio milanese, appare assai significativa l'azione del monastero di Chiaravalle che, abbandonando progressivamente la conduzione diretta dei propri beni, installò nelle grange consistenti gruppi di massari, assoggettati all'autorità di un potestas di nomina abbaziale. Sperimentato a Valera nel 1255-56, tale procedimento nel-

${ }^{17}$ Come attesta una carta in ASMi, PPF, cart. 38, doc. 159, 1276 marzo 17.

${ }_{18}$ G. P. Bognetti, Un brutto quarto d'ora per tre canonici della metropolitana, «Archivio storico lombardo», XLV, 1918, pp. 130-134.

${ }^{19} \mathrm{G}$. Biscaro, Gli estimi del Comune di Milano nel secolo XIII, «Archivio storico lombardo", LV, 1928, pp. 343-495, a p. 476 e Grillo, "Reperitur in libro" cit., pp. 46-47.

${ }^{20}$ P. Mainoni, La gabella del sale nell'Italia del Nord (secoli XIII-XIV), in Politiche finanziarie e fiscali nell'Italia settentrionale (secoli XIII-XV), a cura di P. Mainoni, Milano 2001, pp. 39-85, qui a p. 41; Grillo, "Reperitur in libro" cit., p. 48. 
l'ultimo quarto del secolo venne adottato anche nelle rimanenti proprietà di Vione, Villamaggiore e Grangetta. Nascevano così nuove comunità, le quali erano sì dipendenti dai monaci, ma potevano anche contare sul fatto che "l'abate, con tutto il suo prestigio e le aderenze politiche, poteva ottenere per loro esenzioni dalle consuete imposizioni o almeno patteggiarne l'importo e le modalità di esazione direttamente col potere politico"21. L'abate di Chiaravalle sviluppò legami peculiari con Matteo Visconti, tanto che dopo la caduta di questi, nel 1302, i privilegi dei massari di Chiaravalle vennero drasticamente ridotti: essi furono ricondotti sotto la giurisdizione degli ufficiali cittadini e nuovamente assoggettati alle imposizioni pubbli$\mathrm{che}^{22}$. Non dissimile era quanto avveniva più ad ovest ad opera dei cistercensi di Morimondo, i quali a loro volta difesero tenacemente esenzioni e prerogative delle loro grange e degli uomini in esse insediati ${ }^{23}$.

Oltre a tale processo di ritorno signorile, si verificarono anche i primi episodi di esplicita ribellione. La crisi del $1285-87$, con una prima drammatica frattura in seno all'aristocrazia e le spedizioni contro i nobili raccoltisi a Castelseprio e appoggiati da Como furono l'occasione per un primo tentativo di secessione dal dominio cittadino. Il trattato di pace fra Milano e Como, concluso il 3 aprile 1286 includeva fra gli amici della città lariana, oltre ai nobili ribelli, "illos de ripperia Leuci et etiam de Vallesaxina": negli accordi si prevedeva che la rocca di Lecco e l'area "a rocheta supra ultra Abduam", rimanessero in mani comasche ${ }^{24}$. La secessione del borgo durò alcuni anni, finché, nel luglio del 1295, l'esercito milanese si recò a Lecco, dove il podestà Zanasio Salimbene impose ai borghigiani di abbandonare il luogo recandosi a Valmadrera e poi procedette ad incendiarlo, abbattendone la torre difensiva. Fu addirittura proibita la riedificazione dell'abitato ${ }^{25}$.

Il caso di Lecco è però peculiare e giustifica un breve excursus. È possibile infatti che Lecco, la quale già nel 1239 , sotto la protezione delle armi imperiali si era sottratta all'autorità di Milano ${ }^{26}$, soffrisse la dipendenza da

${ }^{21}$ L. Chiappa Mauri, Progettualità insediativa e interventi cistercensi sul territorio milanese nel secolo XIII, «Studi storici», 29, 1988, pp. 645-669, citazione alle pp. 657-658 (ora anche in Ead., Paesaggi rurali di Lombardia. Secoli XII-XV, Roma-Bari 1990).

${ }^{22}$ Chiappa Mauri, Progettualità insediativa cit., p. 659; C. Sacchetti Stea, Il monastero di Chiaravalle Milanese nel Duecento: Vione da "castrum" a grangia, «Studi Storici», 29, 1988, pp. 671-706, alle pp. 692-704.

${ }^{23}$ Molti atti in lite in ASMi, PPF, cart. 691, passim.

${ }^{24}$ Gli atti del comune di Milano nel secolo XIII, vol. III, (1277-1300), a cura di M. F. Baroni, Alessandria 1992, pp. 375-381, doc. 376.

${ }^{25} \mathrm{G}$. Giulini, Memorie spettanti alla storia, al governo ed alla descrizione della città e campagna di Milano ne' secoli bassi, IV, Milano $1856^{2}$, pp. 777-778. 
una città lontana, mentre molto più saldi e facili erano i legami economici e commerciali con la più vicina Como. Pierre Toubert, un quarantennio or sono, aveva rilevato che gli statuti trecenteschi dei villaggi della sponda lecchese del Lario denunciavano esplicitamente il fatto che i commerci di questi centri con Como erano più importanti di quelli con Milano ${ }^{27}$. Non a caso, Lecco sembra aver sempre teso a un rapporto privilegiato con il capoluogo lariano, tanto che gli Annales Mediolanenses affermano che nel 1336 Lecco fu ricondotta sotto l'autorità di Milano e liberata "de longa servitute Cumanorum" 28 . Como, d'altronde, era entrata nell'anno precedente fra le città soggette ad Azzone Visconti: la ricomposizione fra i due rami del Lario avvenne così sotto l'egida della nascente signoria sovracittadina.

L'aumento delle imposte pare comunque aver colpito equamente città e contado. Un bel documento del 1292, collocato per errore in un fondo pergamenaceo bresciano, illustra esaurientemente il peso che gravava sugli organismi locali, all'esterno e all'interno delle mura civiche. In quell'occasione, infatti, gli anziani di diverse parrocchie urbane e quelli di molte pievi del contado protestarono perché in occasione di una taglia imposta nel 1291 dal comune per la colossale somma di 150.000 lire, non erano stati sottratti agli estimi delle singole zone i beni dei banditi - gestiti direttamente dalle autorità civiche - e quelli di coloro i quali erano entrati in religione. Le richieste furono accolte dai sei sapienti "qui presunt rationibus comunis Mediolani"29, ma l'atto è una testimonianza esplicita dell'entità impressionante delle richieste di denaro da parte del comune e delle difficoltà che esse causavano sia in Milano, sia nelle campagne.

\section{Rivolta e cambio di regime: Milano 1302-1310}

In questo contesto, meglio si comprendono le ragioni della rivolta che esplose in città nel giugno del 1302, spodestando e costringendo all'esilio Matteo Visconti e suo figlio Galeazzo. Si tratta di un evento mal conosciuto della storia milanese, soprattutto perché gli storici tre-quattrocenteschi ${ }^{30}-$

${ }^{26}$ J.L.A. Huillard - Breholles, Historia diplomatica Friderici Secundi, vol. 5, Paris 1875 , p. 470.

${ }^{27} \mathrm{P}$. Toubert, Les statuts communaux et l'histoire des campagnes lombardes au XIV siècle, «Bullettin d'archéologie et d'histoire publié per l'Ecole Française de Rome», 72, 1960, pp. 397-508, qui alle pp. 497-500, ora anche in Id., Etudes sur l'Italie médiévale (IX ${ }^{e}-X I V^{e}$ siècles), Variorum reprints, London 1976.

${ }^{28}$ Annales Mediolanenses ab anno MCCXXX usque ad annum MCCCCII, in Rerum Italicarum scriptores, XVII, Mediolani 1730, coll. 635-840, qui a col. 711.

${ }^{29}$ ASMi, PPF, cart. 86, 1292 marzo 13.

${ }^{30}$ Per tutti, i quattrocenteschi Annales Mediolanenses, per i quali vi fu solo una congiura nobiliare, prontamente sventata, e una nobile rinuncia di Matteo che, uscito ad af- 
così come molti dei loro successori del XIX e del XX secolo - sono stati estremamente restii a riconoscere la possibilità che il popolo di Milano potesse ribellarsi contro i Visconti. La cacciata di Matteo e Galeazzo Visconti dalla città è stata dunque variamente attribuita alla pressione militare esercitata dai guelfi o alle manovre e ai tradimenti di signori rivali quali Alberto Scotti - offeso per il mancato matrimonio di suo figlio con Beatrice d'Este, andata in sposa a Galeazzo - o Corrado Rusca, aizzato dalla nuora ${ }^{31}$. Secondaria, e fondamentalmente non spiegata, rimane la contemporanea insurrezione popolare la quale impedì a Matteo e Galeazzo di organizzare una resistenza in città: il Franceschini, nella Storia di Milano Treccani, riprende quasi letteralmente il Giulini e riferisce rapidamente lo scoppio di tumulti "che sbocciarono in aperta rivolta" 32 , altri autori neppure fanno cenno all'evento.

Solo Bernardino Corio, seguendo il testo, oggi perduto, del memorialista contemporaneo Antonio de Retenate, riferisce dettagliatamente dei tumulti, anche se con una cronologia non troppo precisa che rende difficile ricostruire le vicende ${ }^{33}$. Una narrazione sintetica, ma puntuale di quanto accadde è fornita invece dagli Annales Parmenses, il cui autore disponeva probabilmente di testimonianze di prima mano, fornite dai suoi concittadini coinvolti negli eventi. Secondo il cronista, infatti, mentre Matteo muoveva con parte dell'esercito contro lo Scotti "Galeazzo suo figlio con certi soldati e cento militi di Parma, che erano lì in suo soccorso, rimase in Milano per la custodia della città. Però, essendo un tradimento organizzato a Milano contro il detto Matteo, i Milanesi rimasti in città si opposero a Galeazzo e ai suoi uomini e combatterono con lui e lo cacciarono con tutto il suo seguito fuori da Milano". Matteo, a sua volta, constatando di non poter rientrare, depose le armi e il potere ${ }^{34}$.

Molti autori trecenteschi, dal Fiamma al Villanis ${ }^{35}$, attribuiscono la cac-

frontare l'esercito guelfo, pur essendo più forte "potius elegit dominium civitatis renunciare quam strages hominum facere": Annales Mediolanenses cit., col. 688 .

${ }^{31}$ Così G. Franceschini, La vita sociale e politica nel Duecento, in Storia di Milano della Fondazione Treccani degli Alfieri, IV, Milano 1954, pp. 115-392, qui alle pp. 362363.

${ }^{32}$ Franceschini, La vita sociale e politica cit., p. 363; cfr. Giulini, Memorie spettanti cit., IV, p. 812: "in Milano accrebbe il tumulto e a poco a poco si cangiò in aperta ribellione".

${ }^{33}$ B. Corio, Storia di Milano, a cura di A. Morisi Guerra, I, Torino 1978 (Classici della storiografia), pp. 568-572.

${ }^{34}$ Chronicon Parmense ab anno MXXXVIII usque ad annum MCCCXXXVIII, a cura di G. Bonazzi, in Rerum Italicarum scriptores ${ }^{2}$, IX/9, Città di Castello 1902, p. 82.

${ }^{35}$ Cronica di Giovanni Villani a miglior lezione ridotta, Firenze 1823, vol. III, libro VIII/61, pp. 102-104. 
ciata di Matteo alla frattura con la pars nobilium ${ }^{36}$. In realtà, a Milano si combinavano due motivi di tensioni particolarmente forti. In primo luogo, l'élite politica comunale non intendeva accettare il tentativo di Matteo di attuare una vera e propria dinastizzazione della carica di Capitano del Popolo, nella quale si era associato il figlio Galeazzo, facendo confermare il tutto dal consiglio generale nel dicembre del $1300^{37}$. Ancor di più, egli aveva colpito le prerogative del consiglio generale, trasferendo nelle magistrature popolari del Capitano del Popolo, del giudice della Credenza di Sant'Ambrogio e negli anziani, la "piena facoltà di regolare a loro arbitrio la repubblica" ${ }^{38}$. Si trattava di una decisa svolta politica, volta a basare sul Popolo la costruzione di un regime autocratico ${ }^{39}$. Non c'è da stupirsi se, nella primavera del 1301, un'ondata di bandi colpì diverse famiglie eminenti cittadine, accusate di cospirare contro il nuovo regime $e^{40}$.

Nonostante Matteo e Galeazzo tentassero di appoggiarsi sulle magistrature di Popolo, in città regnava un diffuso malcontento per l'intollerabile pressione fiscale imposta dalle continue campagne militari condotte dai Visconti. Una fallimentare spedizione guidata da Galeazzo contro Pavia e Novara, fra l'aprile e il maggio del 1302, alimentò l'insoddisfazione fino all'esplosione violenta. La partecipazione popolare alla rivolta del 1302 e la sua natura antifiscale sono facilmente testimoniate da un episodio del 27 giugno di quell'anno, in una situazione di incertezza, quando un gruppo di duecento donne armate di coltelli assalì il broletto e mise a sacco il deposito del sale, vendendolo poi al prezzo "politico" di 12 soldi allo staio ${ }^{41}$. Le stesse cifre dell'insurrezione, pur da prendere con le dovute cautele, testimoniano d'altronde una partecipazione massiccia della popolazione, visto che, secondo le parole del Corio, almeno 6.000 uomini si concentrarono presso le case dei della Torre e altri 4.000 si radunarono a presidio del broletto, mentre altro "assai numero de gente" cercava di scacciare le guarnigioni delle porte ${ }^{42}$.

Poco sappiamo degli eventi del periodo 1302-1310, che non sono stati ancora oggetto di studi approfonditi e per i quali bisogna affidarsi quasi totalmente alla tradizione cronachistica. Limitiamoci qui a osservare che il nuovo regime comunale fu nuovamente soggetto, almeno dal 1305, all'ege-

${ }^{36}$ Galvanei Flammae, Manipulus Florum, sive Historia Mediolanensium, a cura di L. A. Muratori, in Rerum Italicum Scriptores, XI, Mediolani 1727, coll. 531-740, qui alla col. 717.

${ }^{37}$ Corio, Storia di Milano cit., p. 563.

${ }^{38}$ Giulini, Memorie spettanti cit., p. 807.

${ }^{39}$ Come aveva intuito G. Tabacco, Egemonie sociali e strutture del potere nel Medioevo italiano, Torino 1979, p. 359.

${ }^{40}$ Corio, Storia di Milano cit., p. 565.

${ }^{41}$ Corio, Storia di Milano cit., p. 569.

${ }^{42}$ Corio, Storia di Milano cit., p. 570. 
monia dei della Torre. Questi paiono aver rinnovato il loro legame con il Popolo milanese, ottenendo l'appoggio dei paratici e svolgendo una politica ad esso favorevole. In attesa di ricerche più puntuali, possiamo almeno constatare che questi anni furono una vera pausa di relativa pace nei turbolenti decenni a cavallo fra Due e Trecento caratterizzati dalle ripetute guerre promosse dalle ambizioni viscontee. Guido della Torre riuscì invece a porsi a capo di una importante lega di città, senza dover ricorrere sistematicamente alle armi per imporre la propria autorità. I benefici di tale situazione, per quanto riguarda la pressione fiscale e i commerci, sono facilmente intuibili, anche se andranno ancora verificati con indagini sul campo ${ }^{43}$.

Dal punto di vista delle campagne, Guido della Torre pare aver seguito una politica più radicale rispetto ai suoi predecessori, promuovendo un dialogo diretto con le comunità. Egli stesso assunse la podesteria pluriennale di un gran numero di comuni, grandi e piccoli, mentre altri furono retti da suoi parenti: in tal modo, la famiglia rafforzava le proprie basi di potere nel contado, mentre i centri rurali costruivano un rapporto immediato con la stirpe dominante, che si assumeva il compito di tutelarli. Non a caso, oltre alle realtà più importanti quali Monza o Vigevano ${ }^{44}$, si assoggettarono direttamente ai della Torre molte località minori, intenzionate a trovare appoggio contro $\mathrm{i}$ propri signori. Così Origgio, i cui abitanti nominarono Franceschino, figlio di Guido, loro podestà nel 1305, ottenendo in tal modo l'agognata autonomia dal districtus santambrosiano ${ }^{45}$, o Seregno, impegnata ormai da un trentennio in una lite con il monastero di Meda, per il possesso di un vasto appezzamento fondiario, dove Martino della Torre fu scelto quale rettore nel 1302 e venne riconfermato nel 1305 , con carica vitalizia ${ }^{46}$.

\section{Vecchi Visconti, nuove rivolte}

Il ritorno al potere di Matteo Visconti, avvenuto nel 1311 non grazie a un ritrovato appoggio popolare, ma sulla punta delle lance imperiali di Enrico VII, dovette suscitare dunque vive preoccupazioni, soprattutto in quei centri che avevano stabilito legami particolari con i della Torre. Monza, la quale ormai da un secolo, forse anche a causa della sua forte vocazione

${ }^{43}$ Si rimanda ancora a Franceschini, La vita sociale e politica cit., pp. 365-367.

${ }^{44}$ G. L. Barni, Dall'età comunale all'età sforzesca, in Storia di Monza e della Brianza. Le vicende politiche, a cura di A. Bosisio, G. Vismara, Milano 1973, pp. 185-373, qui alle pp. 250-251.

${ }^{45}$ Romeo, Il comune rurale di Origgio cit., p. 65.

${ }^{46} \mathrm{M}$. Tagliabue, Origine e sviluppo del borgo medievale, in Seregno. Una comunità di Brianza nella storia (secoli XI-XX), a cura di G. Picasso e M. Tagliabue, Seregno 1994, pp. 3-64, alle pp. 34-35. 
mercantile, aveva avuto relazioni privilegiate con la parte di Popolo di Milano, si preoccupò nel vedere sempre più precaria la posizione della stirpe milanese: il 4 gennaio 1311 il consiglio del comune, presieduto dal vicario del podestà, Gianfredo della Torre, nominò due messi per sottomettere la terra all'imperatore, dichiarando la diretta soggezione all'Impero, senza alcun intermediario ${ }^{47}$. Nell'aprile del 1311 Enrico rilasciò un diploma in tal senso, attribuendo Monza alla camera regia ${ }^{48}$. Lo stesso ottenne Treviglio, il 31 marzo $^{49}$. Nel luglio del 1311 la nomina di Matteo Visconti a vicario imperiale di Milano prevedeva esplicitamente l'eccezione di Monza e Treviglio "ad cameram regiam immediate spectantes" ${ }^{50}$. Nel 1313, però, di fronte alle richieste del Visconti e del comune cittadino, i due borghi furono restituiti "à la juridiction dou vicaire et dou cumun de Melan"51.

Il tentativo compiuto da Monza e Treviglio, pur abortito, si rivelò in breve tempo lungimirante. Il nuovo governo di Matteo e Galeazzo Visconti, infatti, fu assai simile al precedente, caratterizzato da una situazione di guerra quasi permanente e da una rapida crescita della pressione fiscale. Se il 1312 e il 1313 furono segnati da aspri conflitti contro i della Torre, che, appoggiati da Roberto d'Angiò, premevano dai confini occidentali e riuscirono a portarsi in armi fino a Rho; particolarmente indicativo è quanto accadde nel 1314, quando, dopo una campagna nel Piacentino in appoggio a Galeazzo, Matteo organizzò una spedizione contro Pavia con la sola motivazione, a quanto si diceva in Milano, di dare una giustificazione al numero di stipendiarii che egli teneva al suo servizio e alle enormi somme spese per pagarli. Per tali campagne, si abbatté sul contado una pesantissima richiesta di uomini armati, tale da suscitare le veementi proteste delle comunità: la pieve di Locate, ad esempio, abituata alla fine del Duecento a fornire una dozzina o poco più di guastatori, si vide ordinare l'invio e l'equipaggiamento di ben 47 uomini, in gran parte armati di lance lunghe, a un costo tale da dissestare le non floride finanze locali. Eloquente il tenore della supplica inoltrata in tale occasione contro "fodra et honera et andate que sepe et sepissime imponuntur per comune Mediolani" 52 .

${ }^{47}$ Barni, Dall'età comunale all'età sforzesca cit., pp. 252-255.

${ }^{48}$ A. F. Frisi, Memorie storiche di Monza e sua corte, vol. II, Milano 1794, p. 150.

${ }^{49}$ Monumenta Germaniae Historica, Legum, sectio IV, Constitutiones et acta publica imperatorum et regum, IV/1, ed. I. Schwalm, Hannover-Leipzig 1906, pp. 563-564, doc. 601, 1311 marzo 31.

${ }^{50}$ Ibid., p. 628, doc. 660, 1311 luglio 13.

${ }^{51}$ Ibid., pp. 1001-02, doc. 960, 1313.

${ }^{52}$ P. Grillo, "12.000 uomini, di cui 6.000 con lance lunghe e 3.000 con pancere e mannaie”. L'esercito milanese agli inizi del Trecento, «Società e storia», 116, 2007, pp. 232-253, qui a p. 252 , doc. 2 . 
Nel contempo, i Visconti promossero una rapida "normalizzazione" della situazione nelle campagne. Esemplare fu il caso di Origgio, dove, con l'appoggio delle magistrature urbane e della nuova societas iustitie, nonostante un tentativo di opposizione armata da parte dei rustici, fra il 1314 e il 1317 l'abate di Sant'Ambrogio sradicò il comune autonomamente organizzatosi, imponendo nuovamente i propri ufficiali e colpendo con pesantissime multe e sequestri di beni le decine di abitanti del luogo i quali si rifiutarono di accettare il ritorno alla soggezione $e^{53}$.

La politica fiscale di Matteo e Galeazzo attende ancora uno studio specifico, ma le ricerche di Patrizia Mainoni aiutano a comporre un quadro che giustifica le tensioni. Le casse del comune e del Visconti erano state svuotate dal pagamento delle enormi somme promesse da Matteo a Enrico VII per ottenere il titolo di vicario imperiale. Per recuperare il denaro, Matteo non esitò ad aumentare indiscriminatamente la pressione fiscale. Un provvedimento particolarmente grave fu l'innalzamento dei dazi sulle merci veneziane, che portò a una devastante guerra commerciale con la Serenissima, prolungatasi dal 1314 al 1317 e culminata nel blocco dell'importazione in Venezia dei panni di Milano e del distretto. L'esito fu pesante per la città e disastroso per Monza, che tentò addirittura, senza successo, di intraprendere autonomamente un negoziato col governo dogale. La conclusione dello scontro, nel 1317, non fu favorevole al centro brianzolo, la cui produzione tessile fu colpita da un pesantissimo dazio, superiore di oltre il $25 \%$ a quello che gravava sui drappi milanesi ${ }^{54}$.

L'occasione per la reazione delle comunità del distretto venne fornita dalla proclamazione della crociata contro i Visconti da parte di papa Giovanni XXII. La prima spedizione, condotta da Filippo di Valois nel 1320 , fu un fallimento sul piano militare, ma fu utile a misurare la disaffezione di parte del contado verso la dinastia milanese ${ }^{55}$ : il 19 maggio di quell'anno, il pontefice poté infatti assolvere dalle eventuali condanne spettanti ai seguaci viscontei gli uomini della Valle San Martino, di Palazzago e di Pontida, sottrattisi all'obbedienza di Matteo, e quelli di Lecco e riviera e della pieve di Incino che intendevano farlo ${ }^{56}$.

${ }^{53}$ Romeo, Il comune rurale di Origgio cit., pp. 62-66; per il ruolo della societas iustitie: ASMi, PPF, cart. 329, doc. 25, 1317.

${ }^{54}$ P. Mainoni, Fra Milano e Venezia, un rapporto difficile, in Ead., Economia e politica nella Lombardia medievale. Da Bergamo a Milano fra XIII e XV secolo, Cavallermaggiore 1994, pp. 185-206, qui alle pp. 189-191.

${ }^{55}$ Biscaro, I rapporti dei Visconti cit., pp. 85-86.

${ }^{56}$ Jean XXII (1316-1334). Lettres communes, a cura di G. Mollat, III, Paris 1906, p. 157, doc. 12092, 1320 marzo 25. 
Nel 1321 Matteo veniva scomunicato e, essendo egli morto poco dopo, nel 1322 la stessa sorte toccava a Galeazzo, suo figlio ed erede. Il $1^{\circ}$ ottobre 1322 le ostilità riprendevano e il 31 del mese Monza si ribellava, dopo alcuni tumulti in cui fu ferito il filovisconteo Giovanni Morigia. La reazione milanese fu però rapida e Lodrisio Visconti, con un nerbo di mercenari tedeschi assunse nuovamente il controllo del borgo il 16 novembre successivo ${ }^{57}$.

Nell'anno successivo, l'armata crociata effettuò un'operazione più decisa, agli ordini del legato Raimondo di Cardona, che il 25 febbraio 1323 passò l'Adda. Due giorni dopo, Monza tornò a ribellarsi ai Visconti e aprì le porte alle forze guelfe. Dopo alterne vicende belliche, Galeazzo riuscì a sventare l'immediata minaccia su Milano e dall' 8 agosto al $1^{\circ}$ ottobre pose un vano assedio a Monza. Nell'inverno 1323-24 le sorti del conflitto si ribaltarono: i Viscontei presero il controllo dei ponti sull'Adda e inflissero una dura sconfitta al di Cardona a Trezzo, il 16 febbraio. Ciò nonostante, Monza rimase ostile e fu sottoposta a un lunghissimo assedio, conclusosi solo il $1^{\circ}$ dicembre 1324 , con la resa e il saccheggio del borgo ${ }^{58}$.

Durante l'assedio di Monza, benché ormai la minaccia dei crociati andasse perdendo consistenza militare, si ribellò anche Cantù. Secondo gli Annales Mediolanenses il 20 giugno 1324 Gaspare Grassi "terram de Canturio forti muro communivit, cuius ambitus fere unius miliarii, habens in circuitu turres XXXV et de dominio civitatis Mediolani se subtraxit"59.

Le scelte dei diversi comuni furono dunque differenti. Lecco si separò da Milano con i centri vicini e probabilmente agì in stretta coordinazione con Como. Non sappiamo se e chi abbia preso l'iniziativa: agli occhi degli osservatori contemporanei, la comunità appare aver agito compattamente a difesa dei propri interessi, legati anche a una proficua attività manifatturiera soprattutto nel campo dell'industria dei metalli e del lanificio ${ }^{60}$.

A Cantù, al contrario, si ebbe un'originale e ambiziosa esperienza signorile. Il borgo, come si è già accennato, aveva ottenuto uno status privilegiato sin dal 1225, poi migliorato nel 1258, grazie alla sua partecipazione diretta agli scontri politici cittadini. Nel 1290 vi è attestazione anche di una sua autonoma capacità fiscale, visto che in un atto sono menzionati gli "omnia fodra, onera et talee hinc retro imposita [...] per comune Mediolani et per comune de Canturio"61. Economicamente il centro era assai vivace e

${ }^{57}$ Barni, Dall'età comunale all'età sforzesca cit., p. 263.

${ }^{58}$ Ibid., pp. 263-269.

${ }^{59}$ Annales Mediolanenses cit., col. 702.

${ }^{60}$ P. Mainoni, Introduzione a Lecco Viscontea. Gli atti dei notai del territorio lecchese (1371-1418), a cura di C. Guri, P. Mainoni, F. Zelioli, in corso di stampa.

${ }^{61} \mathrm{Gli}$ atti del comune di Milano nel secolo XIII, IV, Appendice, a cura di M. F. Baroni, Alessandria 1998, p. 467, doc. 528. 
contraddistinto da un'importante produzione di manufatti metallici, che $\mathrm{i}$ mercanti canturini esportavano poi sulla piazza di Genova ${ }^{62}$.

La totale scarsità di documentazione non consente di identificare con precisione chi fossero i Grassi de Canturio i quali guidarono la secessione del borgo, fortificandolo. Forse, ma le prove mancano, erano un ramo della famiglia capitaneale dei Grassi di Milano. Sullo scorcio del Duecento essi erano ben radicati nel borgo, dove avevano influenza sugli enti ecclesiastici6i ${ }^{63}$. Apogeo e motivo del declino del dominio familiare fu il conflitto degli anni 133435 con i Rusca di Como, che portò anche i Grassi a tentare di impadronirsi della città lariana. Essi subirono però una pesante sconfitta militare, che aprì la strada alla sottomissione ad Azzone Visconti, nell'anno successivo. Si noti comunque che le forze radunate contro Como - 180 cavalieri e 1.500 fanti secondo il cronista monzese Bonincontro Moriggia - testimoniano efficacemente la forza e la potenza della dominazione così costruita ${ }^{64}$.

Monza, infine, era incomparabilmente più grossa e ricca degli altri centri e caratterizzata da una fiorente manifattura laniera, i cui imprenditori agivano in prima persona sulle piazze di Venezia e Genova ${ }^{65}$. La cronaca del monzese Bonincontro Moriggia ci informa con maggior dettaglio sugli eventi prodottisi, soffermandosi in particolare sulle lacerazioni della popolazione in seno alla quale esisteva anche un pur minoritario partito filovisconteo. Da una tumultuosa riunione del consiglio municipale del 1322 nella quale emerse palese la frattura del gruppo dirigente locale ai tumulti (rumores) seguiti nel borgo, le pagine del cronista permettono di seguire la definizione di due diversi partiti - uno dei nobiliores ghibellini, vicini alla famiglia dominante milanese, e uno guelfo, più legato al mondo delle produzioni artigianali - la cui completa identificazione richiederà però ancora ricerche puntuali ${ }^{66}$.

Insomma, gli atteggiamenti dei tre maggiori centri brianzoli, che probabilmente condizionarono anche le vicende di numerose località minori,

${ }^{62}$ Grillo, Milano in età comunale cit., pp. 226-228.

${ }^{63} \mathrm{Si}$ veda ad esempio il caso di Giovanni Grassus beneficiale della chiesa di S. Paolo di Cantù: Gli atti degli arcivescovi di Milano, III, Ruffino da Frisseto (1295-96), Sede vacante, Francesco da Parma (1296-1308), a cura di M. F. Baroni, Milano 2005, p. 122, doc. 138.

${ }^{64}$ Chronicon Modoetiense ab origine Modoetie usque ad annum mcccxlix auctore Bonincontro Morigia, a cura di L. A. Muratori, in Rerum Italicarum scriptores, XII, Mediolani 1728, coll. 1055-1184, a col. 1167; cfr. anche Galvanei de la Flamma Opusculum de rebus gestis ab Azone, Luchino et Iohanne Vicecomitibus ab anno MCCCXXVIII usque ad annum MCCCXLII, a cura di C. Castiglioni, in RIS ${ }^{2}$ XII/4, Bologna 1938, p. 14.

${ }^{65}$ Mainoni, Fra Milano e Venezia cit., pp. 190-192; Grillo, Milano in età comunale cit., pp. 224-228.

${ }^{66}$ Chronicon Modoetiense cit., coll. 1121-1127. 
appaiono estremamente variegati, ma caratterizzati da un comune denominatore: la volontà di liberarsi dal dominio visconteo, più che da quello cittadino.

\section{Ricomposizione: limiti e successi di una ribellione}

Il successo di Matteo e Galeazzo Visconti contro le armi crociate non portò a un ristabilimento della situazione. Monza, piegata con la forza, non era affatto rassegnata, tanto che nel 1329, alla discesa di Ludovico il Bavaro, tentò nuovamente di distaccarsi da Milano, approfittando dello scontro fra l'imperatore e Galeazzo ed ottenendo la diretta soggezione all'Impero ${ }^{67}$. La ricostituita signoria era al momento troppo debole anche per procedere contro Lecco e Cantù.

Fu come è noto il figlio di Galeazzo, Azzone Visconti, a impegnarsi in una paziente opera di ricucitura del distretto, nella quale le armi ebbero un ruolo trascurabile, a favore di un'intelligente politica di concessioni. Nel 1329 Monza venne ricondotta all'obbedienza, ottenendo però, come Treviglio, uno status particolare, che prevedeva una dipendenza diretta dal signore e non da Milano ${ }^{68}$. Poi, nel 1336, Azzone, per usare le parole del Fiamma "assoggettò direttamente alla città di Milano Lecco con tutta la riva, che era stata ribelle per quasi 40 anni alla comunità di Milano. E volendo avere libero passaggio sopra Lecco, basandosi su sette sassi, costruì sul lago un ponte di otto altissime arcate e su ogni lato del ponte edificò due fortissime torri $[\ldots]$ nel borgo di Lecco, inoltre, sulla sponda del lago, costruì un forte castello, che ordinò di custodire con cura. Sicché Azzone Visconti allargò considerevolmente il contado di Milano e magnificamente lo coronò. Inoltre, ottenne il borgo di Cantù, circondato da mura e torri, che a lungo era stato disobbediente alla comunità e lo fortificò" ${ }^{69}$.

Come si è accennato, non fu però con la forza che Azzone procedette alla ricomposizione del distretto. Certo, i Visconti avevano consolidato le loro posizioni in zona, con l'espansione del dominio su Como nel $1335^{70}$, che isolò Cantù e Lecco rendendone insostenibile l'autonomia, ma vi fu da parte del nuovo signore di Milano un'attenta politica di concessioni, la quale rese accettabile per le comunità il ritorno sotto il potere della città e della dinastia.

Monza, poté contrattare le condizioni della propria sottomissione, ottenendo un ulteriore privilegio da parte di Azzone nel 1335, ossia larghi

\footnotetext{
${ }^{67}$ Barni, Dall'età comunale all'età sforzesca cit., p. 273.

${ }^{68}$ Ibid.

${ }^{69}$ Galvanei de la Flamma Opusculum de rebus gestis cit., pp. 18-19.

${ }^{70}$ Cognasso, Note e documenti cit., p. 77.
} 
margini di autonomia nella giurisdizione civile e penale che, anche se nella pratica non ebbero sempre un effettivo riscontro, rappresentavano un riconoscimento formale di grandissimo rilievo ${ }^{71}$. Più concretamente, il nuovo signore concesse ampie esenzioni fiscali, per consentire una più rapida ripresa del borgo ${ }^{72}$. Egli inoltre approvò e sanzionò gli statuti dei mercanti e lo statuto comunale, tanto che Claudia Storti Storchi ha potuto definire l'età di Azzone "un momento aureo" per Monza ${ }^{73}$.

Solo Monza e forse Treviglio ebbero privilegi particolari, ma la politica di Azzone fu ricca di concessioni anche nei confronti delle altre comunità. Una delibera comunale del 1331, sulla quale ha attirato recentemente l'attenzione Patrizia Mainoni, mostra come si cercasse di attuare un atteggiamento più conciliante sul piano fiscale, frenando l'arbitrio dei gabellieri del sale, impedendo le perquisizioni immotivate delle case e cancellando tutti i processi pendenti per evasione a carico di uomini del distretto ${ }^{74}$. Probabilmente nello stesso torno di anni, diverse località del contado produttrici di pannilana (Vigevano, Canobbio, Lecco, Monza, Treviglio) ottennero negli ordinamenti daziari del dominio "un trattamento fiscale differenziato" il quale "di fatto le poneva sullo stesso piano delle città"75.

Ai provvedimenti volti al controllo delle comunità assoggettate - quale la sistematica costruzione di fortezze e cittadelle, diffuse in tutte le città lombarde e ricordate dal Fiamma anche nei casi di Lecco e Cantù ${ }^{76}$

${ }^{71}$ C. Storti Storchi, Statuti di Monza del XIV secolo: formazione e caratteri generali, in Gli statuti medievali di Monza. Saggi critici, Milano 1993, pp. 17-36. Nel 1349, d'altronde, Galeazzo II ampliò il provvedimento sancendo esplicitamente che né il "potestatem Mediolani nec alios iusdicentes Mediolani presentes et futuros in dicta civitate non habere nec exercere posse aliquam iurisdictionem in dictum nostrum commune, burgenses seu districtuales dicte nostre terre Modoetie" (1349, dicembre 10), a stampa in Privilegia communitatis Modoetiae, Mediolani, ex typographia Pontiana, 1606, conservato in ASMi, Comuni, cart. 58.

${ }^{72}$ Barni, Dall'età comunale all'età sforzesca cit., p. 287.

${ }^{73}$ Storti Storchi, Statuti di Monza cit., p. 21.

${ }^{74}$ Mainoni, La gabella del sale cit., p. 73.

${ }^{75}$ P. Mainoni, La fisionomia economica delle città lombarde dalla fine del Duecento alla prima metà del Trecento. Materiali per un confronto, in Le città del Mediterraneo all'Apogeo dello sviluppo medievale: aspetti economici e sociali, Atti del diciottesimo Convegno Internazionale di studi tenuto a Pistoia nei giorni 18-21 maggio 2001, Pistoia 2003, pp. 141-221, qui a p. 149.

${ }^{76}$ La costruzione di cittadelle, d'altronde, oltre che essere uno strumento di controllo sulle città, rappresentava probabilmente anche una forma di rassicurazione volta a garantire la protezione delle comunità, soprattutto dai conflitti civili: su tale questione veda ora N. Covini, Castellani e castellanie del ducato visconteo-sforzesco, in De part et d'autre des Alpes: les chatelains des princes à la fin du Moyen Âge, Actes de la table ronde de Chambéry, 11 et 12 octobre 2001, a cura di G. Castelnuovo, O. Matteoni, Paris 2006, pp. 113-152, qui a p. 117. 
Azzone Visconti seppe dunque anche affiancare una politica che allettasse i maggiori centri del contado a una nuova sottomissione tramite una serie di concessioni che ponevano rimedio agli aspetti più traumatici dei precedenti regimi di Matteo e di Galeazzo.

\section{Conclusioni}

Come si spera di aver messo in luce, non sembra che la ribellione dei grossi borghi del contado milanese degli anni 1320-1336 sia stata dettata da una secolare volontà di indipendenza nei confronti della città. Essa fu invece originata da ben precise politiche fiscali ed economiche messe in atto dai primi Visconti. Si trattava d'altronde di località dalla forte vocazione manifatturiera (produzione di panni lana per Monza, di ferro per le zone di Cantù e di Lecco), per le quali era necessario un rapporto organico con i mercati urbani: non a caso, Lecco e Cantù si volsero rapidamente verso Como, la prima con un rapporto di alleanza che ai contemporanei milanesi pareva una vera soggezione, la seconda con un velleitario tentativo egemonico il quale, pur fallito, dimostra le ambizioni della famiglia signorile dei Grassi, ma anche la coscienza che l'area da loro capeggiata non aveva le dimensioni e la prosperità per una sopravvivenza autonoma senza un contatto con la città.

In tal senso, l'esito delle ribellioni - le quali, è bene ricordarlo, solo nel caso di Monza ebbero aspetti cruenti, nella sollevazione e nella repressione - fu sostanzialmente un successo ${ }^{77}$. È vero, infatti, che i tentativi autonomistici delle località abortirono e che la superiorità delle magistrature urbane e signorili fu ovunque ribadita, soprattutto nelle materie criminali, ma d'altro canto una gran parte delle cause che avevano portato alla rivolta furono eliminate o ridimensionate: Azzone moderò infatti il carico fiscale e concesse ambiti di autonomia e esenzioni daziarie. Si ponevano così le basi per una convivenza nuovamente armonica fra la città e i grossi borghi del contado, che per il mercato urbano tornarono a produrre e sul mercato urbano ripresero a rifornirsi.

Non si trattò sempre di un rapporto irenico: proteste, appelli e conflitti non mancarono, visto che assai di frequente gli interessi dei signori, dei Milanesi e delle comunità del distretto andarono a confliggere, chiamando le magistrature vecchie e nuove a un'incessante opera di giudizio, media-

77 Samuel Cohn ha richiamato l'attenzione sui numerosi successi ottenuti dall'opposizione antifiscale delle comunità contadine in atti di rivolta che spesso hanno avuto poca attenzione dalle fonti, ma che comunque segnarono pesantemente gli equilibri di forza, condizionando le politiche cittadine e signorili: S. K. Cohn, Creating the Florentine State. Peasants and Rebellion, 1348-1434, Cambridge 1999. 
zione e composizione che favoriva ora una parte ora l'altra alla ricerca di un equilibrio impossibile da ottenere e che vide, ad esempio, la progressiva subordinazione del lanificio monzese agli interessi di quello di Milano $^{78}$. Era però una conflittualità destinata a svilupparsi per tutto il resto del secolo tramite una confronto limitato al piano politico e istituzionale, senza ulteriori scoppi di violenza: la rivolta del 1320-36 aveva reso evidenti ai Visconti i limiti oltre i quali le comunità del contado non erano disposte a tollerare le pressioni del centro. Soltanto le ripetute crisi della dinastia, alla morte di Gian Galeazzo prima, e a quella di Filippo Maria, poi, avrebbero riaperto drasticamente la questione di un più generale riequilibrio dei poteri fra Milano, le altre città e le campagne nel più ampio quadro dello stato regionale ${ }^{79}$.

${ }^{78}$ Mainoni, Economia e politica cit., p. 18.

${ }^{79} \mathrm{Su}$ tali crisi si veda in particolare G. Chittolini, I capitoli di dedizione delle comunità lombarde a Francesco Sforza: motivi di contrasto fra città e contado, in Felix olim Lombardia. Studi di storia padana dedicati dagli allievi a Giuseppe Martini, Milano 1978, pp. 673-698 e Id., Guerre, guerricciole e riassetti territoriali in una provincia lombarda di confine: Parma e il Parmense, agosto 1447-febbraio 1449, "Società e storia», 108, 2005, pp. 221-249, nonché F. Cengarle, Immagini di potere e prassi di governo. La politica feudale di Filippo Maria Visconti, Roma 2006, pp. 17-25. 


\section{BOSCHI E ALPEGGI FRA CERTOSINI E CONTADINI NELL'ITALIA CENTRO-SETTENTRIONALE: FINE XII SECOLO - INIZI XV}

Beni comunali e beni comuni sono da vent'anni al centro di un vivace dibattito storiografico interessato soprattutto alle dinamiche sociali e istituzionali cittadine sviluppatesi per il loro controllo ${ }^{1}$. Non meno articolato, ma forse più sfuggente da un punto di vista generale, è il panorama che emerge dallo studio del mondo rurale non direttamente sottosposto a un comune urbano. In montagna, soprattutto, alpeggi, boschi, pascoli, terre di uso comune o ritenute tali, riferiti a luoghi a tutti noti e intensamente vissuti ${ }^{2}$, celano i fondamenti della vita materiale delle collettività, che, per la loro importanza, sono spesso oggetto di rapporti conflittuali, prolungati nel tempo. A conflitti e tensioni, dalla fine del XII secolo, non sfuggono nemmeno le domus certosine sorte in Italia, ancora caratterizzate, come ai tempi di Bruno di Colonia, dalla natura "alpestre" della loro forma di eremitismo ${ }^{3}$.

Il tema della conflittualità fra tali domus e le comunità rurali insediate nelle adiacenze dei loro patrimoni costituisce, per la natura e le finalità stesse di questi ultimi, una specie di filo rosso della storia delle aree di più antico insediamento certosino, che, dal punto di vista economico-agrario, sociale e istituzionale, appare caratterizzata da tratti peculiari. La specificità consiste in una diversa percezione e interpretazione che dello spazio, o meglio degli alpeggi, dei luoghi, dei monti e delle loro funzioni, avevano i due tipi di comunità a cui si è accennato: quelle dei monaci-eremiti e quelle dei rustici. Le tensioni che nascevano dallo scontro fra i due modi,

${ }^{1}$ Per una prima, penetrante rassegna sui beni comuni: J. C. Maire Vigueur, Premessa, in I beni comuni nell'Italia comunale: fonti e studi, «Mélanges de l'École Française de Rome. Moyen Age - Temps Modernes», 99, 1987, II, pp. 41-46. Degni di attenzione, anche per gli ampi riferimenti bibliografici, due studi di R. Rao, I beni del comune di Vercelli. Dalla rivendicazione all'alienazione, Vercelli 2005; Id., "Comunia". Le risorse collettive nel Piemonte comunale, Milano 2008.

${ }^{2}$ Per le tematiche inerenti allo spazio vissuto: R. Comba, Il territorio come spazio vissuto. Ricerche geografiche e storiche nella genesi di un tema di storia sociale, "Società e storia», 11, 1981, pp. 1-27.

${ }^{3}$ B. Bligny, L'Église et les ordres religieux dans le royaume de Bourgogne aux XI et $X I I^{e}$ siècles, Paris 1960, p. 305. 
per lo più radicalmente antagonisti, di interpretare i ruoli dei luoghi, le distinguevano sia da quelle che, normalmente, nelle campagne potevano opporre le collettività degli homines e i loro domini ${ }^{4}$, sia da quelle che nascevano dai rapporti fra le altre realtà monastiche (talora patrimonialmente organizzate come vere e proprie signorie rurali) e le comunità contadine con cui erano in contatto ${ }^{5}$.

La storia di tali tensioni costituisce così un'occasione di approfondimento, nel lungo periodo e con riferimento a luoghi precisi e a specifici ambiti geografici e socio-istituzionali, del più ampio tema della conflittualità nel mondo rurale. Si tratta, in altre parole, di seguire un percorso di indagine che, lungi dal privilegiare i momenti più acuti del conflitto sociale nelle campagne come ancora spesso avveniva alcuni decenni or sono ${ }^{6}$, si dimostri in grado di seguire i tempi lunghi della storia ${ }^{7}$ e di riconnetterla al rapporto concreto con i luoghi in cui gli uomini vivevano. La proficuità di simili accertamenti è, fra gli altri, evidenziata, per gli aspetti socio-istituzionali, dagli studi ormai classici di Peter Blickle sulle rivolte contadine

${ }^{4} \mathrm{Cfr}$. R. Rao, Risorse collettive e tensioni giurisdizionali nella pianura vercellese e novarese (XII-XIII secolo), «Quaderni storici», 120, XL (2005), fasc. 3, pp. 753-776 (alle pp. 758-761).

${ }^{5}$ Qualche considerazione preliminare sui rapporti fra montanari e certosini nel primo secolo di vita delle certose italiane in R. Comba, La prima irradiazione certosina in Italia (fine XI - inizi XIV), «Annali di storia pavese», XXV (1997), pp. 17-36 (alle pp. 29-33 sgg.). Tensioni meno drammatiche sembrano invece caratterizzare, per esempio, le relazioni dei cistercensi con il mondo rurale circostante: Id., Contadini, signori e mercanti nel Piemonte medievale, Roma-Bari 1988, pp. 29 sgg.

${ }^{6} \mathrm{Cfr}$. R. Comba, Rivolte e ribellioni fra Tre e Quattrocento, in La storia. I grandi problemi dal Medioevo all'Età contemporanea, direzione di N. Tranfaglia e M. Firpo, II, Torino 1988, pp. 673-692, ora, col titolo Le rivolte e i tumulti urbani, con qualche variante e senza apparato bibliografico, in La storia, VI, Dalla crisi del Trecento all'espansione europea, Roma 2004, pp. 69-97.

${ }^{7}$ Suggestioni in questo senso vengono anche dalle conclusioni dall'opera, interessante per le riflessioni di carattere metodologico suggerite, di H. Neveux, Les révoltes paysanes en Europe: XIV $V^{e} X V I I^{e}$ siècle, Paris 1997, p. 290: "la notion de 'revolte paysanne' trouverait sa nouvelle acception dans celle d'un sentiment de continuité, et également souvent dans une continuité réelle, dans le recours aux armes par des hommes et des femmes qui s'estiment tous des descendants ou des parents des anciens paysans et qui pensent qu'il n'y a pas de rupture, de cassure décisive et irrémédiable, entre eux et leurs prédécesseurs ou leurs confrères". Lo sguardo molto generale adottato dall'autore e l'attenzione prevalente alle "représentations paysannes qui président aux prises d'armes" (a p. 113), cioè alle interpretazioni contadine del conflitto, lasciano tuttavia molto nell'ombra i contesti giuridici, sociali e spaziali concreti, spesso duraturi nel tempo, in cui maturano sia la conflittualità, sia il senso della continuità di un'appartenenza. Alla base di quest'ultimo c'è anche non di rado una continuità di relazioni, pur in un quadro di metamorfosi, fra una comunità contadina, il suo territorio e l'eredità dei rapporti socio-istituzionali locali lasciata dalle generazioni precedenti. 
verificatesi nel basso Medioevo in alcune aree dell'Impero tedesco ${ }^{8}$, da ricerche assai più recenti, fra le quali, per l'area subalpina, a cui necessariamente in questa sede si farà spesso riferimento, si segnala il penetrante lavoro di Alessandro Barbero sui rapporti, a Villafalletto nel Cuneese, fra comunità, domini loci e 'stato' sabaudo 9 e, per la difficile convivenza fra una certosa e una comunità di rustici, da un' indagine di Paola Guglielmotti su Santa Maria di Pesio e i suoi "vicini"10. Sulle problematiche inerenti, in modo specifico, alla conflittualità emergente nel concreto dallo sfruttamento di un'area forestale di pertinenza certosina spunti degni di attenzione si trovano in alcune ricerche pionieristiche di Alfio Cortonesi ${ }^{11}$.

\section{Spazi vissuti: la montagna degli eremiti e quella dei contadini}

La storiografia monastica ha chiarito da tempo che l'idea che dell'eremo (termine rievocativo dell'esperienza, in Egitto, degli antichi padri del deserto) avevano i certosini non coincideva né con quella di un qualunque luogo appartato in cui realizzare una forma superiore di vita monastica, né con quella che negli stessi anni ne avevano, per esempio, i cistercensi ${ }^{12}$. L'elemento fondamentale di valutazione di questi ultimi era soprattutto la distanza dalle città o dai nuclei insediativi più consistenti: "in civitatibus,

${ }^{8}$ P. Blickle, Die Revolution von 1525, München 1981, trad. it. col titolo La riforma luterana e la guerra dei contadini. La rivoluzione del 1525, Bologna 1983; Id., Bäuerliche Erhebungen im spätmittelalterlichen deutschen Reich, "Zeitschrift für Agrargeschichte und Agrarsoziologie», 27, 1979, pp. 208-231 (= Peasant Revolts in the German Empire in the Late Middle Ages, «Social History», IV, fasc. IV, 1979, pp. 223-239), ora in Id., Studien zur geschichtlichen Bedeutung des deutschen Bauernstandes, Stuttgart - New York 1989, pp. 109-132. Nel corso del presente lavoro le citazioni si riferiranno a quest'ultima silloge. L'autore è ritornato sulla guerra dei contadini con un volume ulteriore, frutto di un ventennio di studi sull'argomento: cfr. Id., Der Bauernkrieg: die Revolution des Gemeinen Mannes, München 1998; Id., From the Communal Reformation to the Revolution of the Common Man, Leiden - Boston - Köln 1998.

${ }^{9}$ A. Barbero, Politica e comunità contadina nel Piemonte medievale, "Studi storici», XXXV, 1994, pp. 5-48 (= Id., Politica e comunità contadina nel Piemonte medievale. Il caso di Villafalletto, in Villafalletto: un castello, una comunità, una pieve, a cura di R. Comba, Cuneo 1994, pp. 113-157).

${ }^{10} \mathrm{P}$. Guglielmotti, I vicini di S. Maria di Pesio: uomini e comunità di Chiusa fino alla metà del Trecento, in All'ombra dei signori di Morozzo: esperienze monastiche riformate ai piedi delle Marittime (XI-XV secolo), a cura di R. Comba e G. G. Merlo, Atti del convegno: San Biagio Mondovì - Rocca de' Baldi - Mondovì, 3-5 novembre 2000, Cuneo 2003, pp. 221-270.

${ }^{11}$ A. Cortonesi, La "silva" contesa. Uomini e boschi nel Lazio del Duecento, in Il bosco nel Medioevo, a cura di B. Andreolli e M. Montanari, Bologna 1988, pp. 303-319; Id., Rivendicazioni contadine e iniziativa antisignorile nel tardo Medioevo. Testimonianze dal Lazio meridionale, «Annali dell'Istituto Alcide Cervi», XVI, 1994, pp. 157-172.

12 Per una messa a punto: Comba, La prima irradiazione certosina in Italia cit., pp. 27 sgg. 
castellis, villis, nulla nostra construenda sunt coenobia, sed in locis a conversatione hominum semotis" recita la più antica collezione di Statuta, non sempre osservati, emanata dal capitolo generale di Cîteaux ${ }^{13}$. Come hanno dimostrato gli studi di Jacques Dubois ${ }^{14}$, il deserto certosino era invece un'area montana dai limiti specificati con grande precisione, come quella definita nel 1086 nel più antico documento concernente la domus che oggi è chiamata la Grande Chartreuse ${ }^{15}$. I confini di ogni singolo eremo erano tracciati "non autour du terrain qui appartenait déjà aux Chartreux, mais autour des terres qu'ils estimaient nécessaires pour se constituer un désert"16; soprattutto erano delimitati con molta precisione e dovevano comprendere tutte le terre possedute dalla domus certosina che vi era insediata. L'area che essi racchiudevano costituiva uno spazio privilegiato, abitato soltanto da membri dell'Ordine e assolutamente vietato alle donne, che, almeno per tutto il XIII secolo, non potevano nemmeno esservi sepolte ${ }^{17}$. Quando, nel 1259, attingendo a disposizioni anteriori emanate dalla metà del secolo precedente, furono compilati gli Statuta antiqua, si previde la possibilità di modificarne i confini previa l'autorizzazione del capitolo generale $^{18}$, cosa che talora avvenne con l'approvazione della Sede apostolica ${ }^{19}$.

${ }^{13}$ Narrative and Legislative Texts from Early Cîteaux, a cura di Ch. Waddell, Cîteaux 1999, p. 325, cap. 1; Statuta capitulorum generalium ordinis Cisterciensis ab anno 1116 ad annum 1796, a cura di J. M. Canivez, I, Louvain 1933, p. 13, cap. 1.

${ }^{14}$ J. Dubois, Les limites des chartreuses, «Bulletin de la Société nationale des antiquaires de France», 1965, pp. 186-197, ora in Id., Histoire monastique en France au XII siècle. Les institutions monastiques et leur évolution, London 1982.

${ }^{15}$ Recueil des plus anciens actes de la Grande Chartreuse (1086-1196), a cura di B. Bligny, Grenoble 1958, pp. 5-7, doc. 1.

${ }^{16}$ Dubois, Les limites des chartreuses cit., p. 189.

${ }^{17}$ Cfr. S. Beccaria, Scelte di perfezione: attrazione devozionale e sociale di Santa Maria di Pesio fino alla metà del secolo XIV, in All'ombra dei signori di Morozzo cit., pp. 153-198 (a p. 186).

${ }^{18}$ P. L., vol. CLIII, Statuta Antiqua, coll. 1135, cap. 16; Dubois, Les limites des chartreuses cit., p. 188; Id., L'institutions des convers au XII siècle. Forme de vie monastique propre aux laics, in I laici nella "societas christiana" dei secoli XI e XII, Atti della terza settimana internazionale di studio: Mendola 21-27 agosto 1965, Milano 1968, pp. 183261 (alle pp. 199 sgg.), ora in Id., Histoire monastique de France cit.

${ }^{19}$ Dubois, Les limites des chartreuses cit., p. 188. Cfr. Comba, La prima irradiazione certosina cit., p. 28. Interessante e abbastanza ben documentato è il caso della certosa di Trisulti, anche con riferimenti precisi all'ampliamento dei limiti del proprio desertum: A. A. Strnad, Zehn Urkunden Papst Innozenz III. für die Kartause San Bartolomeo zu Trisulti: 1208-1215, in "Römische historische Mitteilungen", 11 (1969), pp. 23-58, alle pp. 49-53, doc. 6 del 30 settembre 1211; A. A. Sechi, La certosa di Trisulti da Innocenzo III al concilio di Costanza (1204-1414). Note e documenti, Salzburg 1981 (Analecta cartusiana, 74/1), pp. 79, reg. 6 del 30 settembre 1211; p. 95, reg. 39 dell'8 aprile 1247; p. 141, reg. 136 del 24 settembre 1357. Breve sintesi di tali sviluppi in B. Castelli, La certosa di Trisulti. Cenni storici per un monaco benedittino, Tournai 1912, pp. 20-22. 
Tanta attenzione alla delimitazione degli eremi dimostra l'importanza fondamentale loro attribuita da questi monaci che vi erano "fuggiti" alla ricerca della solitudine, indispensabile compagna di una ricca vita interiore di raccoglimento, di contemplazione e di preghiera, "per la salute eterna delle loro anime" 20 . Il rilievo che, di conseguenza, assumevano in tale contesto le domus certosine tuttavia non suggerì per lo più ai monaci, né nelle Alpi occidentali né nel Lazio, di riqualificare in senso religioso i nomi preesistenti dei luoghi in cui esse sorgevano: come dimostrano le appellazioni con cui fra XII e XIII secolo furono chiamate le certose di Pesio, di Casotto, della Losa e di Trisulti ${ }^{21}$. Soltanto Montebenedetto, dove a fine XII secolo furono costretti a spostarsi i monaci della Losa, sembrerebbe già recare un nome "ideale per una comunità votata alla preghiera" 22 , ma è molto probabile che tale nome, attestato inizialmente con riferimento evidente ad altra località prediale, sia stato auguralmente attribuito assai presto al sito non lontano da Villar Focchiardo dove i monaci effettivamente si trasferirono ${ }^{23}$.

In questi silenziosi spazi montani i certosini aspiravano a rinnovare l'esperienza dei padri del deserto e, facendo convivere eremitismo e cenobitismo, vivevano da anacoreti nelle proprie celle riunendosi soltanto in alcune occasioni fisse $\mathrm{e}^{24}$. Inoltre, in piena sintonia con una delle principali aspirazioni del movimento eremitico, intendevano, seguendo da vicino le orme del Cristo povero, coniugare la loro specifica forma di ascetismo con un'esistenza modellata in ogni momento da un rigido ideale di povertà personale $^{25}$. La percezione che essi avevano del loro spazio vissuto quotidiano sui monti, letta alla luce delle esperienze di ascetismo eremitico che avevano fortemente connotato il monachesimo occidentale, si coniugava ovviamente sia con la memoria di tali esperienze e delle connesse aspirazioni a riviverle in compagnia dei confratelli religiosi in attesa del "ritorno del

${ }^{20}$ Guigues Irr prieur de Chartreuse, Coutumes de Chartreuse. Introduction, texte critique, traduction et notes, a cura di "un chartreux" [Maurice Laporte], Paris 1984 (Sources Chrétiennes, 313), p. 206, cap. 20: "pro nostrarum sempiterna salute animarum in huius heremi secessu aufugimus".

${ }^{21}$ Comba, La prima irradiazione certosina in Italia cit., pp. $23 \mathrm{sgg}$.

${ }^{22}$ P. Guglielmotti, Certosini in Piemonte: un'innovazione circoscritta, in Il monachesimo italiano nell'età comunale, Atti del IV Convegno di studi storici sull'Italia benedettina; Abbazia di S. Giacomo Maggiore, Pontida, 3-6 settembre 1995, a cura di G. B. Trolese, Cesena 1998 (Italia benedettina, 16), pp. 139-162, qui a p. 146

${ }^{23} \mathrm{Cfr}$. oltre, note $44-55$ e testo corrispondente.

${ }^{24}$ Cfr. D. Knowles, Il monachesimo cristiano, trad. it., Milano 1969, p. 66.

${ }^{25}$ B. Bligny, Les premiers Chartreux et la pauvreté, "Le Moyen Age», LVII, 1951, pp. 27-60 (alle pp. 32 sgg.), soprattutto con riferimento alle Consuetudines di Guigo. Questi "parle fort peu de la pauvreté", ma essa "est implicitement contenue dans les diverses partie du texte" (p. 39). 
Signore, per aprirgli appena avrà bussato"26, sia con momenti di sereno apprezzamento estetico per le bellezze del paesaggio, che si sarebbe tentati di dire frequenti nel mondo certosino. "Come posso parlarti dell'amenità di questo luogo - aveva scritto fra XI e XII secolo Bruno di Colonia all'amico lontano Rodolfo il Verde, prevosto del capitolo di Reims, per invitarlo a raggiungerlo nel suo eremo calabrese -, della mitezza e salubrità del clima e dell'ampia e bella pianura che si estende lontano tra i monti e racchiude praterie verdeggianti e pascoli smaltati di fiori?"27.

Per i conversi e i devoti, per lo più illetterati, almeno nei tempi più antichi $^{28}$, gli stessi spazi, pur vissuti in un quadro esistenziale di povertà, di silenzio e di ascetismo, più che momenti di contemplazione, dovevano richiamare invece alla mente concrete attività agricole o pastorali svolte in luoghi specifici spesso distanti dal monastero, dalla correria o dalle grange; luoghi resi familiari dalla consuetudine e spesso fissati nella memoria da un toponimo che ne rievocava certe caratteristiche botaniche, la presenza significativa di animali particolari, avvenimenti di cui nella memoria collettiva si era forse già persa la traccia. Toponimi come alpis Vacherii, alpis Serpenterii, pratum Brunum, Clotum ursi ${ }^{29}$, vallis Orseria, Bech de Rocha Male Noctis ${ }^{30}$, fons Malimacelli ${ }^{31}$, per non citare che il nome di qualche località prediale soltanto ubicata nei deserta delle certose di Pesio e di LosaMontebenedetto, ancora dovevano rievocare a quanti le frequentavano non soltanto ai conversi, ai devoti, ai monaci - precise caratteristiche dei luoghi. Non mancavano località, come l'alpe del Belvedere ${ }^{32}$, il cui toponimo, dal chiaro significato, rinvia alle emozioni estetiche suscitate dalla vista del paesaggio circostante.

${ }^{26}$ Come nota seguente.

${ }^{27}$ Lettres des premiers Chartreux, Paris 1962 (Sources Chrétiennes, 88), p. 68 (p. 31 per la datazione), cit. nella traduzione di P. De Leo (Certosini e cistercensi nel Regno di Sicilia, Soveria Mannelli 1993, p. 29).

${ }^{28}$ Guigues Ir prieur de Chartreuse, Coutumes de Chartreuse cit., p. 248 cap. 42.2. Cfr. Dubois, L'institution des convers cit., pp. 217, 239, 255; Beccaria, Scelte di perfezione cit., p. 164.

${ }_{29}$ B. Caranti, La certosa di Pesio. Storia illustrata e documentata, I, Torino 1900, p. 3, doc. 1dell'anno 1173: "alpes scilicet Vacherii et Serpenterii et pratum Brunum". In attestazioni successive tali toponimi subiscono una metamorfosi: p. 110, doc. 106 del 13 febbraio 1320 dove si citano le "alpes Serpenterie, Vacarilis et prati Bruni". Inoltre: p. 111-112, doc. 107 del 25 maggio 1327: "invenit ipsos cum una paria ovium et caprarum in alpe Cloti ursi"; "fecerunt dampnum cum magna quantitate ovium et caprarum in alpe dicti monasterii ubi dicitur in Belvero, ad Clotum ursi”.

${ }^{30}$ Cartario della certosa di Losa e Monte Benedetto dal 1189 al 1252, a cura di M. Bosco, Torino 1974 (BSS, 195), p. 38, doc. 11 del 29 maggio 1197; p. 43, doc. 17 del 2 giugno 1200;

${ }^{31}$ Cfr. oltre, nota 33.

${ }^{32}$ Caranti, La certosa di Pesio cit., I, p. 112, doc. 108 dell'8 novembre 1337: "alpes dicti monasterii, videlicet alpem Serpenterie et alpem Belvedere et Clotum ursi"; 
Dal punto di vista materiale, con riferimento soprattutto a boschi e alpeggi intensamente sfruttati dalle certose, lo spazio vissuto di monaci e conversi si confondeva, o tendeva a confondersi e a scontrarsi, con quello degli abitanti del luogo che, tuttavia, pur cresciuti a sperare nella salvezza eterna, non avevano potuto fare, per raggiungerla, drastiche scelte di ascesi in povertà volontaria, semplicemente perché poveri erano già. I luoghi a cui si è fatto riferimento, ai contadini che da generazioni sudavano su quegli stessi monti per ricavarne frutti non certo abbondanti, vissuti giorno dopo giorno nel corso di una faticosa vita di lavoro e, quasi sempre, di stenti, dicevano altre cose, come è facile inferire dalle numerosissime attestazioni indirette di cui sono ricche le fonti. Parlavano soprattutto, in tempi di carestia o di pressione demografica, di una fame insaziabile di terra da disboscare e da mettere a coltura ${ }^{33}$, e in tempi normali, dell'opportunità di farvi legna e di portarvi animali al pascolo, oppure di alpeggi inclusi nei deserta controllati dai monaci, su cui sarebbe stato tanto bello condurre d'estate le proprie greggi a pascolare ${ }^{34}$, esattamente come, nelle Alpi Marittime non lontano da Pesio, facevano per esempio i montanari di Ormea ${ }^{35}$. La loro percezione delle valli in cui vivevano, profondamente influenzata da una povertà non voluta finiva così per confliggere con le interpretazioni che di quelle stesse aree davano i pauperes monaci delle domus certosine, il cui eremitismo ascetico, ispirato da una scelta netta di "povertà volontaria" personale, era garantito da patrimoni immensi e dal lavoro gratuito di donati e conversi.

Archivio di Stato di Torino (d'ora in poi ASTo), Sezioni riunite, II archiviazione, capo 17, n. 200/V: sentenza arbitrale fra la certosa di Pesio e il comune di Chiusa del 13 settembre 1428: le località prediali di Pulcrum videre e di Clotum ursi vi sono considerate come pertinenze dell'alpe Serpentera. La sentenza è edita, da un originale non ben conservato, in P. Camilla, La vicenda de La Chiusa di Pesio sino allo stato moderno attraverso $i$ suoi documenti, Cuneo 1985 (Biblioteca della Società per gli Studi Storici, Archeologici e Artistici della Provincia di Cuneo, 22), pp. 265 sgg. doc. 3. Cfr. sopra, nota 29.

${ }^{33}$ Caranti, La certosa di Pesio cit., I, p. 107, del doc. 105 del 12 febbraio 1320: alcuni contadini furono accusati di essere entrati in "quoddam territorium Sancte Marie vallis Pisii ordinis Cartusiensis, ibi nemora combusissent et ligonizassent circa locum ubi dicitur fons Malimaceli, situm ultra rivum et pontem Alme". Cfr. A. Rapetti, "Homines", monaci e boschi nelle terre della certosa di Pesio, in All'ombra dei signori di Morozzo cit., pp. 271-285. Cfr. oltre, testo corrispondente a nota 128.

${ }^{34} \mathrm{Cfr}$. sopra, nota 29 , e oltre, testo corrispondente alla nota 128 .

${ }^{35} \mathrm{R}$. Comba, Sources et problèmes de l'histoire de l'élevage dans les alpes piémontaises (XII ${ }^{e}-X V^{e}$ siècles), in L'élevage et la vie pastorale dans les montagnes de l'Europe au moyen âge et à l'époque moderne, Clermont-Ferrand 1984 (Publications de l'Institut d'Études du Massif Central, XXVII), pp. 7-14 (a p. 9).; R. Comba, A. Dal Verme, Allevamento, transumanza e commercio del bestiame nel Piemonte occidentale: secoli $X I I-X V$, in Greggi, mandrie e pastori nelle Alpi occidentali: secoli XII-XX, a cura di R. Comba, A. Dal Verme, I. Naso, Cuneo - Rocca de' Baldi 1966 (Da Cuneo all'Europa, 6), pp. 13-31 (a p. 18). 
I deserta certosini appaiono, in sintesi, come luoghi privilegiati dello scontro di principi ideali e di interessi materiali. Lungi dall'essere un vuoto 'deserto', erano infatti percorsi in tutti i sensi da uomini - in primis dagli stessi eremiti e dai loro conversi - "ben attenti alla tutela di rivendicazioni economiche e di diritti sulla proprietà", oltre che, naturalmente, allo sfruttamento delle fondamentali risorse boschive ${ }^{36}$.

2. La specificità dei "deserta" certosini come generatrice di conflittualità con il mondo rurale alla fine del XII secolo

Come fu possibile tale cortocircuito? Seguiamo da vicino nascita e primi sviluppi delle più antiche certose italiane. Fu l'area che circondava la Chartreuse, di circa tre chilometri per cinque a un'altezza variabile fra $\mathrm{i}$ 720 e i 1400 metri, con la disposizione caratteristica degli insediamenti stabili destinati alla vita eremitica - la "casa alta" (superior) per i monaci e la "casa bassa" (inferior) o "correria" per i conversi - a costituire un modello per le certose fondate nel XII secolo ${ }^{37}$. Nelle zone alpine, come da noi avvenne per le certose di Ardua-Pesio, Casotto e Losa-Montebenedetto, tale bipartizione insediativa fu presa a modello nonostante che i singoli edifici si componessero a quanto pare secondo combinazioni diverse ${ }^{38}$. Entro certi limiti fu così possibile, da questo punto di vista, avere come altrove "d'exactes répliques de la Grande Chartreuse en choisissant pour désert une vallée en cul de sac"39.

A dire la verità, i vari deserta in cui i seguaci di Bruno di Colonia cercarono di vivere la loro esperienza anacoretica, sui monti delle Alpi, del Frusinate e della Calabria ${ }^{40}$, non sempre erano propriamente disabitati e incolti, come del resto è stato osservato da tempo anche a proposito della Grande Chartreuse ${ }^{41}$ e ciò poteva creare occasioni di conflitto con le comunità rurali. Fra i patrimoni delle certose piemontesi soltanto quello di Pesio nei primi anni del Duecento appariva plasmato in senzo propriamente certosino, mentre i beni fondiari di Casotto e di Montebenedetto, pur connotati dalla presenza di nuclei abbastanza compatti di beni e di grange nei dintorni dei rispettivi monasteria, risultavano più simili nella loro struttura a quelli dei monasteri cistercensi ${ }^{42}$.

${ }^{36}$ Rapetti, "Homines", monaci e boschi cit., p. 284.

${ }^{37}$ Cfr. Guigues Ir prieur de Chartreuse, Coutumes de Chartreuse cit., pp. 200 sgg., capp. 16, 17, p. 238, cap. 36,4 . Per la situazione anteriore: Comba, La prima irradiazione certosina in Italia cit., pp. 19-20.

${ }^{38}$ Cfr. Comba, La prima irradiazione certosina cit., p. 27, nota 92.

${ }^{39}$ Dubois, L'institutions des convers cit., p. 200.

${ }^{40}$ Comba, La prima irradiazione certosina cit., pp. 10-11, 27-29.

${ }^{41}$ Bligny, L'Église et les ordres religieux cit., p. 262. 
Alla fine del XII secolo l'espansione fondiaria delle certose si caratterizzò talora per una politica di acquisti effettuati sia in pianura, sia entro $i$ confini dei singoli deserta, come richiesto dalla proibizione di acquisire terreni all'esterno, anche per evitare che sugli incolti che vi si trovavano gravassero diritti d'uso o di pascolo. Tale espansione, tuttavia, per quanto effettuata talora con cautela, non impedì che, contrariamente a quanto ipotizzato da Bernard Bligny ${ }^{43}$, i certosini entrassero presto in conflitto con le comunità rurali.

Gli eremiti della Losa, nella alta valle della Dora Riparia, ebbero per esempio, da subito, un rapporto conflittuale con i contadini che da tempo abitavano, possedevano beni fondiari e sfruttavano le montagne che il conte Tommaso I di Savoia aveva loro donato nel 1189 e nel $1191^{44}$. Non a caso: la percezione che essi ebbero dell'area in cui avrebbero dovuto vivere la loro esperienza ascetica fu del tutto negativa perché la situazione che la caratterizzava era molto lontana dall'idea che i monaci avevano del desertum e della solitudo indispensabili a praticarvi il loro modello di vita monastica. Nel 1197, asserendo di essere disturbati da un insopportabile "tumultum secularium hominum", essi richiesero un nuovo eremo al conte, tramite l'influente converso Thierry della certosa di Sylve-Bénite nell'Isère (Terricius de Silva Benedicta), parente del Barbarossa ${ }^{45}$. Ne ottenennero la valle Orseria e una montagna chiamata Mons Benedictus dalla sommità dei monti fino ai campi di Menolzio, oltre a "omne dominium et iusticias" che a Tommaso spettavano, eccezion fatta per i diritti dei contadini "che vi avevano coltivato delle terre" 46 . È tuttavia evidente che l'area in cui questa

${ }^{42}$ Comba, La prima irradiazione certosina cit., pp. 27-29. Per Pesio v. ora la puntuale ricostruzione di G. Coccoluto, Il "desertum" della certosa di Santa Maria di Val di Pesio. Realtà o programma?, in All'ombra dei signori di Morozzo cit., pp. 137-152.

${ }^{43}$ Bligny, L'Église et les ordres religieux cit., p. 298.

${ }^{44}$ Cartario di Losa e Monte Benedetto cit., pp. 29 sgg., docc. 1 e 2. Buon esame delle cause e delle vicende del conflitto in L. Patria, I certosini a Orgevalle, in L. Patria, V. Coletto, P. Nesta, Storia della parrocchia di Chiomonte, I, Dal Medioevo al trattato di Utrecht (1713), Borgone di Susa 1998, pp. 15-20.

${ }^{45}$ Su di lui: K. Görich, Ein Kartäuser im Dienst Friedrich Barbarossas: Dietrich von Sylve-Bénite (c. 1145 - 1205), Salzburg 1987 (Analecta Cartusiana, 53), soprattutto alle pp. 24 sgg. e 111 sgg.; U. Gherner, La comunità certosina del XIII secolo, in Guida alla Certosa di Monte Benedetto e al parco dell'Orsiera-Rocciavré, Torino 1995, pp. 17-21 (a p. 21); A. Mounier, Un Hohenstaufen à la chartreuse de la Sylve Bénite, Grenoble 1923; L. Delisle, Notes sur quelques manuscrits du baron Dauphin de Verna, «Bibliothèque de l'École des Chartes», LVI, 1895, pp. 645-690 (alla p. 660). Ringrazio Luca Patria per la segnalazione. Sulla certosa di Sylve-Bénite cfr. A. Gruys, Cartusiana: un instrument heuristique, II, Maisons, Paris 1977, p. 366, con riferimento alla bibliografia ivi citata.

${ }^{46}$ Cartario di Losa e Monte Benedetto cit., pp. 38-40, docc. 11 e 12 del 29 maggio 1197. In particolare quest'ultimo documento ricorda che i monaci richiesero di avere la valle Orseria e Monte Benedetto: "desiderio arcioris solitudinis postulaverunt a me Vallem Orseriam et Montem Benedictum a summitate rupium, sicut dividitur comita- 
montagna si trovava, fra il colle dell'Orsiera a sud e i dintorni di Menolzio a nord, ha ben poco a che fare con il sito attuale della certosa omonima, sul rivo della Buggia a sud-ovest di Villar Focchiardo, presso la quale, fra l'altro, non si trova alcun Monte Benedetto ${ }^{47}$. Con ogni probabilità il nome della "domus de Monte Benedicto", che compare già nel febbraio 1198 in una donazione fatta "in manu fratris Terricii de Silva Benedicta" ${ }^{48}$, costituì la ripresa del toponimo preesistente in chiave programmatico-augurale per la "domus Montis Benedicti de Losa"49 nel quadro di una specifica semantica dello spazio monastico medievale ${ }^{50}$.

Il nuovo desertum concesso da Tommaso di Savoia, tuttavia, pur portando un nome ideale per una comunità di religiosi, ancora non soddisfaceva i desideri degli eremiti, che ne cercarono un terzo. Esso fu trovato, sempre attraverso il potente Thierry, grazie alla donazione all'Ordine certosino della montanea sopra Villar Focchiardo da parte dei visconti di Baratonia e altri consignori, avvenuta il 2 giugno 1200 alla presenza di un numero significativo di testimoni di rilievo provenienti da altre case certosine ${ }^{51}$. Nell'autunno dell'anno 1200 il trasferimento era in corso: il 15 ot-

tus meus a Gratianopolitano comitatu et sicut rivus dividit montem de Mathicis et de Menons usque ad campos de Menons usque ad rivum de Iacernis, deinde sicut descendit ipse rivus a summitate rupium predictarum, deinde sicut dividit comitatum meum a comitatu Gratianopolitano et per sectam ipsarum rupium".

${ }^{47} \mathrm{Si}$ noti che le attestazioni più antiche della presenza certosina in quell'area non fanno riferimento ai "monaci di Monte Benedetto", ma accennano più semplicemente agli "heremitibus de montanea supre Villarium Fulchardum" (Cartario ... di Losa e Monte Benedetto cit., pp. 46-47, docc. 21 e 22 del 15 ottobre e 26 novembre 1200). Ecco, l'attuale Montebenedetto è ancora semplicemente la "montanea Villarii Fulchardi". Cfr. L. Patria, "In curia domini comitis". Conflitti giurisdizionali fra laici e monaci nella val di Susa sabauda, relazione tuttora inedita al convegno Certose di montagna, certose di pianura. Contesti territoriali e sviluppo monastico, svoltosi a Villar Focchiardo - Susa Avigliana - Collegno dal 13 al 16 luglio 2000, i cui atti sono stati pubblicati a Susa nel 2002 per le cure di Silvio Chiaberto. Devo molte informazioni alla squisita cortesia di Luca Patria, che ha discusso con me tutta la questione qui sviluppata.

${ }^{48}$ Cartario di Losa e Monte Benedetto cit., p. 40, doc. 13 del febbraio 1198.

${ }^{49}$ Cartario di Losa e Monte Benedetto cit., p. 41, doc. 14 del luglio 1198.

${ }^{50}$ Di tale semantica "Terricius de Silva Benedicta" era egli stesso evidentemente portatore, ma cfr., con riferimento all'anno 1208, la menzione di una "domina Raimunda priorissa Vallis Benedicte" quasi certamente coincidente con la priora del non lontano monastero cistercense di Brione in Val della Torre: Cartario ... di Losa e Monte Benedetto cit., pp. 148 sgg., doc. 119 del 16 aprile 1226. Cfr. A. D’Haenens, Quotidienneté et contexte. Pour un modèle d'interprétation de la réalité monastique médiévale (XI ${ }^{e}-X I I^{e}$ siècles), in Istituzioni monastiche e istituzioni canonicali in Occidente, Milano 1980 (Atti della settima settimana internazionale di studio: Mendola, 28 agosto-3 settembre 1977), pp. 567-598, trad. it. in Monachesimo e ordini religiosi del medioevo subalpino. Bibliografia degli studi: 1945-1984, a cura del Centro ricerche e studi storici, Torino 1985, pp. 17-56.

${ }^{51}$ Cartario di Losa e Monte Benedetto cit., pp. 42 sgg., doc. 17 del 2 giugno 1200: Enrico visconte di Baratonia, Palmerio di Reano e Bosone Carbonello fanno dona- 
tobre una donazione di terre in Comboira, rogata nella chiesa della Losa alla presenza di cinque monaci e sei conversi ${ }^{52}$, fu infatti destinata a Dio, alla Chartreuse "et servientibus de montanea Villarii Fulcardi". La sua conferma, avvenuta il 26 novembre in quest'ultimo villaggio nelle mani del priore Guido, fu indirizzata all'Ordine, alla domus della Losa e agli eremiti che vi servivano ${ }^{53}$; poco dopo, una vendita nelle mani dello stesso priore, fu infine destinata "ordini de Cardusca et domui de Monte Benedicto et heremittibus super montaneam Villarii Fulchardi" ${ }^{54}$. Il 4 giugno dell'anno seguente una vendita di terre ebbe ormai come riferimento il priore "de Monte Benedicto supra Vilarium Fulchardum"55. Il trasferimento di monaci e conversi era quindi stato completato, come si legge anche in una conferma delle concessioni precedenti fatta di Tommaso I di Savoia che accenna pure ai nuovi termini della domus certosina ${ }^{56}$ : termini che per noi, oggi, appaiono di ardua identificazione.

Nella nuova sede di Montebenedetto, tuttavia, lo sforzo dei monaci di crearvi un eremo abitato e sfruttato soltanto dai certosini e non frequen-

zione, fra le altre cose, a Dio, alla Madonna e all'Ordine certosino "de montanea una que iacet supra Vilarium Foscardum, de fossato de Salbasino in sursum sicut aqua pendet intus usque al Bec de Rocha Male Noctis in sursum". L'importanza attribuita dai certosini all'atto risulta chiaramente dal numero, dalla qualità e dalla provenienza dei testimoni appartenenti all'Ordine, che si aggiungono a una dozzina di religiosi e personaggi locali: dalla domus di Pomiers nell'Alta Savoia il priore Ugo del Bosco e il converso Aimone, da quella di Reposoir nella stessa regione il priore Amblardo, da quella della valle Pesio Bernardo. Conferme della donazione da parte dell'abate di San Giusto di Susa e del conte Tommaso I di Savoia nello stesso Cartario, pp. 44 sgg., docc. 18 e 19, rispettivamente del 10 e 18 giugno 1200. Sulle domus certosine menzionate nel documento cfr. Gruys, Cartusiana cit., II, pp. 342-343 (Pomiers), p. 349 (Reposoir). La conferma del conte è indirizzata alla "domus de Losa". Sui visconti di Baratonia: A. Tarpino, Tradizione pubblica e radicamento signorile nello sviluppo familiare dei visconti di Baratonia (secoli XI-XIII), «Bollettino storico-bibliografico subalpino", LXXIX, 1981, pp. 5-65 (alle pp. 53-55) e, con riferimento specifico a Villar Focchiardo, G. Chiarle, I visconti di Baratonia e di Villar Focchiardo, «Segusium», 38, 1999, pp. 35-82; cfr. Id., La certosa e il villaggio: uomini, ambienti, luoghi nei primi anni di Monte Benedetto, in Certose di montagna, certose di pianura cit., pp. 27-37 (alle pp. 32 sgg.).

${ }^{52}$ Cfr. M. Bosco, La Certosa di Monte Benedetto dalle origini al declino, in Guida alla Certosa di Monte Benedetto cit., pp. 27-47 (a p. 38), ma si trattava soltanto di una parte della comunità certosina: il resto, difficile da quantificare, già si trovava presso Villar Focchiardo, in quella che divenne presto la domus di Montebenedetto.

${ }^{53}$ Cartario di Losa e Monte Benedetto cit., p. 47, doc. 22.

${ }^{54}$ Cartario di Losa e Monte Benedetto cit., p. 48, doc. 23 del 27 novembre 1200.

${ }^{55}$ Cartario di Losa e Monte Benedetto cit., p. 49, doc. 24 del 4 giugno 1201.

${ }^{56}$ Cartario di Losa e Monte Benedetto cit., p. 57, doc. 33 del 28 dicembre 1202: "firmavit quod dederat domui de Losa, videlicet quidquid habebat infra terminos loci, culta et inculta, nunc manentibus religiosis in loco qui dicitur Mons Benedictus, et quidquid infra terminos possent acquirere". 
tato dai montanari dei dintorni ${ }^{57}$ ebbe un successo soltanto parziale per la compresenza di non chiarissimi diritti d'uso sui comunia a cui accenna la già menzionata donazione dei Baratonia del 2 giugno 1200, che sappiamo confermata "pro iussu dominorum" da tutti i "boni homines de Vilario Fulchardo" 58 .

Rapporti conflittuali con gli abitanti del luogo ebbe pure sin dagli inizi la certosa di Pesio, sorta nel 1173 nelle Alpi Marittime ${ }^{59}$, la cui vita materiale fu garantita da una cospicua dotazione fondiaria pro alodio, effettuata "cum omni populo Cluse" nelle mani del priore Ulrico dell'ordine certosino, da un potente consortile di famiglie signorili, che si definivano complessivamente domini de Morocio $^{60}$. A redigerne l'atto per loro ordine fu Giordano, giudice e notaio del Sacro Palazzo. Ne erano oggetto vasti beni fondiari situati "in montanis ville que dicitur Clusa" nel tratto meridionale della valle del Pesio, al di qua e al di là del fiume, fra i rivi Alma (ora Paglietta) e Corverio e la sommità delle Alpi, con specifico riferimento a due alpeggi (le già menzionate alpes Vacherii et Serpenterii) e al già citato prato Bruno ${ }^{61}$.

Poiché tale donazione è alla base delle tensioni e degli scontri che, per più secoli, avrebbero caratterizzato i rapporti fra la certosa e gli homines della Chiusa ${ }^{62}$, è bene approfondirne per un attimo il significato, su cui peraltro è spesso ritornata la riflessione degli storici.

È importante innanzitutto accertare l'assenza dalla donazione stessa di riferimenti a beni fondiari situati nell'alta valle e non appartenenti ai domini de Morocio o alla certosa stessa. Stefano Crivolo, un monaco, poi diventato priore, che nel Quattrocento scrisse una Chronica bonorum immobilium della certosa, lo esclude categoricamente ${ }^{63}$, ma è smentito da certa docu-

${ }^{57}$ Cartario di Losa e Monte Benedetto cit., pp. 76 sgg., doc. 48 e 49 dell'agosto 1206. Cfr. Chiarle, La certosa e il villaggio cit., p. 29.

${ }^{58}$ Cartario di Losa e Monte Benedetto cit., p. 43, doc. 17: "de via Male Noctis usque ad Salbasinum est comunis sine facere exartum ac pratum et tota alia res vicine possunt facere et tota paschua vicine de castaneretus in sursum; et de rivo Male Noctis in illuc possunt facere folia, salvis beolis et salvis magnis arboribus incidere usque ad Claret". Cfr. L. Patria, Le grange, in Guida alla Certosa di Monte Benedetto cit., pp. 30-35 (alle pp. 34-35); Chiarle, La certosa e il villaggio cit., pp. 29-30.

${ }^{59}$ Caranti, La certosa di Pesio cit., I, p. 3, doc. 1.

${ }^{60} \mathrm{P}$. Guglielmotti, I signori di Morozzo nei secoli X-XIV: un percorso politico del Piemonte meridionale, Torino 1990.

${ }^{61}$ Cfr. sopra, testo corrisp. alla nota 29.

${ }^{62}$ Già nel 1181 un documento ne ipotizzò l'eventuale distruzione, evidentemente da parte della comunità rurale del luogo: Cartario della certosa di Casotto (1172-1326), a cura di G. Barelli, Torino 1957, p. 3, doc. 3. Cfr. Comba, La prima irradiazione certosina cit., p. 24.

${ }^{63}$ Chronica Stephani de Crivolo prioris Cartusie, anno MCCCCXXXC, in Caranti, La certosa di Pesio cit., II, p. 10, d'ora in poi citata semplicemente come Crivolo, Chronica. Su di essa: P. Guglielmotti, La costruzione della memoria di S. Maria di Pesio: 
mentazione di fine XII secolo ancor oggi conservata riguardante terreni che ai contadini del luogo spettavano all'interno dei limiti dell'eremo donato dai signori di Morozzo con la carta di fondazione del 1173 e che vennero ceduti alla certosa soltanto nel $1194^{64}$.

Con tale questione è connessa quella del significato da dare al termine allodio, usato dal giudice e notaio che stese l'atto per indicare beni, per lo più incolti o boscosi, situati "in montanis ville que dicitur Clusa", dizione che lascia agevolmente supporre una loro afferenza, almeno parziale, a beni comuni di quel villaggio. Contesti analoghi, con riferimento allo sfruttamento di aree forestali coeve nel Piemonte sud-occidentale, mostrano, senza ombra di dubbio, che un bosco signorile considerato allodiale poteva essere gravato da consuetudini d'uso riconosciute di fatto dai domini loci alle popolazioni locali, mentre invece, per usufruire delle risorse forestali, i forestieri pagavano un pignus. Lo dicono per esempio con grande chiarezza documenti relativi alla grande selva Bannale, situata nei dintorni dell'attuale Bene Vagienna, e alla forse non meno estesa sylva Stapharda, a nord di Saluzzo ${ }^{65}$. Il contesto cambia di poco anche qualora si voglia ritenere che con la dizione "donacionem fecerunt supradicti domini meram et liberam pro alodio" il notaio abbia inteso riferirsi alla cessione della iurisdictio sull'area offerta, cessione che dava indirettamente alla certosa anche il diritto eminente sui comunia ${ }^{66}$.

La questione più dibattuta in sede storiografica ${ }^{67}$, considerata la successiva talora fortissima conflittualità fra le parti, concerne tuttavia la qualità della partecipazione degli abitanti della Chiusa alla donazione. Alcuni elementi del documento di fondazione inducono innanzitutto a ritenere che, se davvero ci fu, il consenso degli abitanti del villaggio della Chiusa alla donazione - appena accennato nel documento ("cum omni populo Cluse") - non dovette essere entusiastico, come sembra confermare la mancanza vicende proprietarie e coscienza certosina nella Chronica quattrocentesca del priore Stefano Crivolo, in Certose di montagna, certose di pianura cit., pp. 311-327.

${ }^{64}$ Caranti, La certosa di Pesio cit., I, pp. 8-9, doc. 8.

${ }^{65}$ Il libro Verde della Chiesa d'Asti, a cura di G. Assandria, vol. II, Pinerolo 1907, p. 168, doc. 296; Documenti dell'Abbazia di Santa Maria di Staffarda. Integrazione al cartario, a cura di P. Merati, Cuneo 2007, p. 168, doc. 13. Sulla selva Bannale e sulla sylva Stapharda cfr. rispettivamente R. Comba, Metamorfosi di un paesaggio rurale. Uomini e luoghi del Piemonte sud-occidentale dal X al XVI secolo, Torino 1983, pp. 3436, 47-50; Id., "In silva Stapharda". Disboscamenti, grange e borghi nuovi in un grande complesso forestale (XI-XIV secolo), "Rivista di storia dell'agricoltura», in corso di stampa.

${ }^{66}$ Lucide considerazioni sul tema in Rao, Risorse collettive e tensioni giurisdizionali cit., pp. 753-755. Cfr. P. Grossi, Il dominio e le cose. Percezioni medievali e moderne dei diritti reali, Milano 1992, pp. 57-122.

${ }^{67}$ Caranti, La certosa di Pesio cit., I, pp. 51 sgg.; Camilla, La vicenda de La Chiusa di Pesio cit., pp. XXXI sgg.; Guglielmotti, I vicini di S. Maria di Pesio cit., pp. 227-229; Comba, La prima irradiazione certosina cit., p. 24. 
di qualsiasi riferimento all'eventuale pronunciamento in merito da parte di istituzioni di tipo comunale (che quasi certamente ancora non c'erano) o, almeno, fra i testimoni e i garanti dell'atto, a qualche personaggio influente del luogo. Comunque siano andate le cose, al di là della presunta continuità giuridica dei diritti d'uso ${ }^{68}$, è certo che per comprendere adeguatamente la conflittualità con la certosa, che rifletteva in chiave locale le forti tensioni sulle terre di uso pubblico documentariamente ben percepite quasi ovunque fra XII e XIII secolo, va fortemente sottolineata la nascita e l'affermazione della comunità rurale di Chiusa, la cui prima attestazione risale al $1209^{69}$.

Per altro verso l'acutezza delle crisi che da tale conflittualità sarebbero scaturite non può essere compresa senza mettere in conto sia la percezione netta che i certosini avevano della specificità ideale e tendenzialmente giurisdizionale del loro desertum - che tendeva a essere presentato come un territorium in sé compiuto, ma senza che i monaci vi esercitassero un proprio potere di natura pubblica ${ }^{70}$-, sia la loro sistematica messa in opera di azioni indirizzate a difendere i propri interessi materiali ${ }^{71} \mathrm{e}$ a corroborare le proprie pretese giurisdizionali, come l'acquisto sistematico dei terreni che ancora loro sfuggivano all' interno dell'eremo ${ }^{72}$, l'istituzione di un propro corpo di polizia campestre ${ }^{73}$, l'attenzione alla delimitazione dei confini, via via ampliati, del proprio eremo ${ }^{74}$.

\section{Una forte conflittualità: i certosini di Trisulti e gli homines di Collepardo nel Duecento}

Sicuramente superiore a quella che segnò la vita delle altre certose italiane fu la conflittualità con le comunità rurali dei dintorni e soprattutto con quella di Collepardo, sul cui territorio era insediata, che caratterizzò da subito e per tutto il XIII secolo la storia della certosa di Trisulti, situata a

${ }^{68}$ Rao, Risorse collettive e tensioni giurisdizionali cit. pp. 753 sgg.

${ }^{69}$ Caranti, La certosa di Pesio cit., I, p. 17, doc. 19 del 18 ottobre 1209; Camilla, La vicenda de La Chiusa di Pesio cit., pp. XXXI, LXIV e 221, doc. 2, p. 221.

${ }^{70}$ Chiarle, La certosa e il villaggio cit., p. 29.

${ }^{71}$ Rapetti, "Homines", monaci e boschi cit., p. 84.

${ }^{72}$ Caranti, La certosa di Pesio cit., I, pp. 8-9, doc. 8 del 1194. Cfr. sopra, testo corrisp. alla nota 62 .

${ }^{73}$ Chiarle, La certosa e il villaggio cit., p. 29; Biblioteca Reale di Torino, Cartulario della certosa di Pesio, ms. sec. XIV, St. p. 777, doc. 101, del 5 maggio 1314; Atti del Comune di Cuneo (1230-1382), a cura di T. Mangione, Cuneo 2006 (Fonti, 8), p. 59, doc. 46 del 17 luglio 1319: "Ardicio de Ponçonasco, familiaris et camparius monasterii valis Pexii”. Cfr. Guglielmotti, I vicini di S. Maria di Pesio cit., p. 265.

${ }^{74}$ Chiarle, La certosa e il villaggio cit., p. 29; Coccoluto, Il "desertum" della certosa cit., pp. 137 sgg.; Comba, La prima irradiazione certosina cit., p. 28. Cfr. sopra, note 19, 55,56 e testo corrispondente. 
circa 800 metri sul livello del mare non lontano da Alatri, ai piedi del Rotonaria, nei monti Ernici, in una zona da oltre due secoli connotata da frequentazioni e presenze eremitiche sfociate verso la fine del X secolo nell'avventura cenobitica dell'abbazia di San Bartolomeo ${ }^{75}$. La svolta in senso certosino, quanto mai drastica, avvenne nei primissimi anni del XIII secolo (probabilmente nel 1204) per volere di papa Innocenzo III, che dotò il nuovo insediamento dei vasti beni che avevano costituito il patrimonio del vecchio cenobio ${ }^{76}$, fra cui la selva d'Eici, attentamente studiata qualche anno fa da Alfio Cortonesi ${ }^{77}$, su cui gravavano evidentemente antiche consuetudini d'uso maturate nel corso dei secoli XI e XII: da quando cioè, nel 1004, alcuni nobiles viri di Collepardo, con il consenso degli habitatores del luogo, avevano donato a Domenico di Sora, abate di San Bartolomeo, la grande selva d'Eici "cum terris sementariciis et cum silvis, vallibus et collibus et cum aqua viva et cum aquiolis ac cum omnibus ad eam pertinentibus"78.

Fu evidentemente la messa in discussione di tali consuetudini non fissate per iscritto e concernenti il diritto di pascolo e di legnatico da parte dei nuovi venuti, affezionati al rispetto del loro eremo, entro cui si trovava il bosco, a scatenare la reazione immediata dei contadini delle comunità confinanti, che, si legge in una lettera papale del 30 giugno 1206, già avevano avuto modo di dimostrarsi non soltanto graves e molesti, ma anche violenti, con i certosini per quanto riguardava i diritti signorili e la gestione dei beni e delle selve ${ }^{79}$. Si avviò così un periodo semisecolare di accesa conflittualità tra le parti, che sfociò da subito in una lite giudiziaria, parzialmente svoltasi alla presenza di papa Innocenzo III, in cui i Collepardesi non furono in grado di dimostrare con prove scritte quelli che ritenevano essere i loro diritti acquisiti ${ }^{80}$. La sentenza, emanata da Onorio III soltanto nel 1220, ribadì ovviamente il diritto esclusivo dei Certosini sulla selva ${ }^{81}$.

${ }^{75}$ Castelli, La certosa di Trisulti cit., pp. 5-10; A. Taglienti, Il monastero di Trisulti e il castello di Collepardo. Storia e documenti, Roma 1984, pp. 19 sgg.

${ }^{76} \mathrm{R}$. Comba, Il difficile inserimento sociale di una fondazione certosina di papa Innocenzo III: note sulla certosa laziale di Trisulti nel XIII secolo, in Certosini e cistercensi in Italia (secoli XII-XIV), a cura di R. Comba e G. G. Merlo, Cuneo 2000 (Storia e storiografia, 26), pp. 185-189; Id., La prima irradiazione certosina cit., p. 32.

${ }_{77}$ Cfr. sopra, nota 11.

${ }^{78}$ Taglienti, Il monastero di Trisulti cit., pp. 88-91; Cortonesi, La "silva" contesa cit., p. 307.

${ }^{79}$ Strnad, Zehn Urkunden cit., pp. 23-58, alle pp. 45-46, doc. 1 del 30 giugno 1206: "in multis graves extitistis et molesti super possessionibus ac silvis ipsius et iustitiis aliis violentiam exercentes”. Sechi, La certosa di Trisulti cit., pp. 77 e 143, doc. 1.

${ }^{80}$ Strnad, Zehn Urkunden cit., pp. 46-47, doc. 2 del 5 novembre 1208. Cfr. Sechi, La certosa di Trisulti cit., pp. 143-144, doc. 2.

${ }^{81}$ P. Pressutti, Regesta Honorii papae III, I, Roma 1888, p. 446, reg. 2691 del 10 settembre 1220. Cfr. Sechi, La certosa di Trisulti cit., pp. 886 e 164, doc. 24. 
Il peggioramento dei rapporti è evidenziato da una serie ripetuta di molestationes, che si concretizzavano soprattutto in illeciti tagli di piante e in ripetute azioni di pascolo abusivo, intervallate da iniurie e violenze che accendevano ulteriormente gli animi ${ }^{82}$, tanto che nel marzo 1220 un documento accenna a pericolose murmuraciones dei Collepardesi che lamentavano di aver perso "omne solatium pascuorum et lignorum"83. In una informativa di papa Onorio III al cardinale diacono di Sant'Angelo, Romano Bonaventura, rettore di Campagna e Marittima, spedita da Civitavecchia il 10 settembre 1220, l'atteggiamento dei Collepardesi, che presumevano di contravvenire alla sentenza di Innocenzo III, era invece qualificato senza mezzi termini come insolente rebellio, che doveva essere assolutamente repressa ${ }^{84}$.

Il conflitto toccò il culmine alla metà del secolo. A riacutizzarlo ${ }^{85} \mathrm{fa}$ cendo scoppiare una nuova rivolta fu molto probabilmente la palese intenzione del vicario di Campagna e Marittima di mettere in pratica una disposizione, rimasta fino a quel momento inapplicata, del defunto rettore di quella circoscrizione amministrativa pontificia, che prevedeva di far pagare un pegno di 10 soldi a ciascuno degli abitanti che pascesse animali o tagliasse legna nella selva d'Eici ${ }^{86}$. Gli homines di Collepardo, si legge in una lettera di papa Innocenzo IV scritta il 25 marzo 1250, "monasterium ipsum hostiliter invadentes et quosdam monachos et conversos eiusdem turpiter pertractantes, cellam ipsius prioris frangere ac libros et alia bona ibidem inventa, cum quibusdam animalibus eorum in predam adducere

${ }^{82}$ Strnad, Zehn Urkunden cit., pp. 47-48, doc. 3 del 5 dicembre 1208; pp. 53-54, doc. 7 del 5 ottobre 1211;. Pressutti, Regesta Honorii papae III cit., I, p. 212, reg. 1286 del 5 maggio 1218; p. 329, reg. 1993 del 2 aprile 1219; p. 390, reg. 2350 del 6 marzo 1220. Cfr. Sechi, La certosa di Trisulti cit., pp. 78 e 144-145, doc. 3; pp. 80 e 150, doc. 7; pp. 86-87, docc. 20, 21, 13.

${ }^{83}$ Taglienti, Il monastero di Trisulti cit., p. 449, doc. 10 del 20 marzo 1220.

${ }^{84}$ Taglienti, Il monastero di Trisulti cit., pp. 463-464, doc. 20 del 10 settembre 1221: "procedas ... ad reprimendam eorum insolentiam, qui contra sententiam ipsam venire presumpserunt, spiritualiter et temporaliter, prout expedire videris et rebellio eorundem exegerit, appellatione postposita, processurus". Sul cardinale Romano Bonaventura: C. Eubel, Hierarchia catholica Medii aevi sive summorum pontificum, s. r. e. cardinalium ecclesiarum antistitum series ab anno 1198 usque ad annum 1431 perducta e documentis tabularii praesertim Vaticani collecta, I, Monasterii 1898, p. 47.

${ }^{85} \mathrm{Il}$ conflitto non si era in realtà mai sopito del tutto. Poco prima della metà del secolo i documenti accennano per esempio al taglio di una vigna della certosa effettuato da ignoti: Taglienti, Il monastero di Trisulti cit., p. 471, doc. 27 del 2 marzo 1247.

${ }^{86}$ Taglienti, Il monastero di Trisulti cit., p. 472, doc. 29 del 22 marzo 1250: lettera del vicario di Campania e Marittima Angelo Capoccia al balivo di Collepardo, per richiamarlo all'osservanza di un precedente ordine emanato dal fu cardinal Riccardo, rettore di Campania e Marittima, di esigere un pignus di dieci soldi da tutti gli abitanti del luogo "qui pascunt animalia vel ligna incidunt in silva Eiici". Il balivo è accusato di non aver fatto rispettare l'ordine: "ut intelleximus, facere non curasti". 
nequiter presumpserunt". Inoltre, non contenti di ciò, dopo aver ucciso le api dei monaci e devastato le case, ruppero una loro gualchiera (balcatorium) e "quamdam vineam ac nemus ipsorum loci eiusdem ausu temerario destruxerunt" ${ }^{\prime 7}$. Il risultato fu che, mentre le molestie e i danni alla certosa subivano un incremento, l'amministrazione pontificia, sollecitata dalle reiterate querimonie dei monaci che richiedevano aiuto, si mise al lavoro, provocò interventi in loro favore a tutti i livelli, spiritualiter e temporaliter, e investì della questione i vescovi di Alatri e di Anagni, il rettore e il vicario di Campagna e Marittima, il podestà e il comune di Alatri, le comunità rurali di Vico e Collepardo il balivo di quest'ultima. Infine, a richiesta dei certosini, papa Innocenzo IV vietò ai Collepardesi la facoltà di deporre come testimoni in giudizio nelle cause vertenti contro la certosa ${ }^{88}$. $\mathrm{Fu}$ la goccia che fece traboccare il vaso. Non potendo documentare "per instrumenta" 89 quelli che ritenevano i loro diritti basati sulla tradizione, privati della facoltà di testimoniare nelle cause contro la certosa, nei primi mesi del 1252 alcuni Collepardesi "iniquitatis filii qui gerunt in vacuum nomen Domini”, per dirla con il linguaggio della querela presentata al papa dal priore e dai monaci di Trisulti, si recarono presso certi possedimenti della certosa, ne devastarono frutti ed alberi, distrussero "macerias quibus eedem possessiones cingebantur" e fecero altri imprecisati danni ${ }^{90}$. Inoltre, come se ciò non bastasse, qualche mese dopo "quidam homines castri Collepardi", forse gli stessi, comunque non identificati nella documentazione sopravvissuta, avrebbero a detta dei monaci illecitamente giurato di distruggere la certosa ("se ad invicem colligantes de ipso monasterio destruendo iuramentum illicitum prestiterunt") ${ }^{91}$, ricevendone conseguentemente minaccia di scomunica ${ }^{92}$.

La sentenza su tali avvenimenti, emanata da Stefano de Normandis, cardinale prete di Santa Maria in Trastevere ${ }^{93}$, e confermata da papa Innocenzo IV il 16 marzo 1254, riprese i contenuti di quella precedente di Onorio III, imponendo "perpetuo silenzio" ai Collepardesi sulla selva

${ }^{87}$ Taglienti, Il monastero di Trisulti cit., p. 473, doc. 30 del 25 marzo 1250.

${ }^{88}$ Taglienti, Il monastero di Trisulti cit., pp. 485-486, doc. 45 del 12 dicembre 1251: "auctoritate presentium districtius inhibemus ne homines de Collepardo contra vos et monasterium vestrum super causis et controversiis, que hinc inde vertuntur, ad perhibendum testimonium admittantur". Cfr. Sechi, La certosa di Trisulti cit., p. 100, doc. 50 .

${ }^{89}$ Cfr. Taglienti, Il monastero di Trisulti cit., p. 475, doc. 44 del 17 luglio 1251, lettera di Innocenzo IV agli homines di Collepardo: "per instrumenta eadem non apparuit vos habere in silva eadem aliquam rationem".

${ }^{90}$ Taglienti, Il monastero di Trisulti cit., p. 487, doc. 47 del 23 maggio 1252.

${ }^{91}$ Taglienti, Il monastero di Trisulti cit., p. 488, doc. 48 del 19 luglio 1252.

92 Taglienti, Il monastero di Trisulti cit., pp. 488-489, doc. 49 del 10 agosto 1252.

${ }^{93}$ Cfr. Eubel, Hierarchia catholica Medii aevi cit., I, p. 43. 
d'Eici, ma al contempo mostrò palesemente di non voler infierire sui rivoltosi, sia glissando sulla colligatio giurata, che non fu possibile o non convenne dimostrare, sia assolvendoli dalle ingiurie e dal pagamento dei danni che, con ogni evidenza, i monaci non richiesero ${ }^{94}$. È chiaro che, per quanto i partecipanti alla rivolta non fossero stati identificati personalmente, il punto di riferimento di ogni reazione all'ingombrante presenza patrimoniale della certosa di Trisulti e ai diritti che essa rivendicava era la comunità rurale di Collepardo ${ }^{95}$.

Irritati per la conclusione negativa della causa, i rivoltosi avrebbero minacciato immediatamente di "monasterium ipsum offendere graviter et etiam personas existentes ibidem"96, ma la sorveglianza della burocrazia pontificia e le pressioni papali sul comune urbano di Alatri destinate a frenare la loro insolentia ${ }^{97}$, forse non disgiunte dalla moderazione mostrata nella sentenza citata, sembrano aver avuto ragione, infine, del loro scontento: sedici anni dopo, la sentenza proferita dal cardinale Stefano de Normandis fu infatti ratificata da un sindicus dell'universitas hominum di Collepardo il 14 agosto $1280^{98}$.

A urtarsi con i monaci non furono soltanto i Collepardesi. Nel $1255 \mathrm{gli}$ abitanti di Vico rivendicarono non soltanto diritti d'uso sulla foresta, ma anche vaste estensioni di arativo (giratae) coltivate ad vicendam, cioè a rotazione, che i certosini avevano conquistato con il disboscamento e il dissodamento ${ }^{99}$. La tensione doveva essere alta ancora una decina di anni dopo, se, ausu temerario, si legge in una lettera papale, gli homines castri Vici emanarono uno statuto che vietava agli abitanti del luogo di andare a macinare ai mulini dei monaci, di lavorare per loro gratis o a pagamento, di far legati testamentari a favore della certosa e delle chiese esterne al $\mathrm{ca}$ strum di Vico ${ }^{100}$.

${ }^{94}$ Taglienti, Il monastero di Trisulti cit., pp. 493-496, doc. 55 del 16 marzo 1254 (a p. 496): "quia de damnis et iniuriis priori et conventui predictis illatis nobis non constitit - scrisse il giudice - ipsos Collepardenses, et eorum procuratorem pro eis, a dictis damnis et iniuriis duximus absolvendos".

${ }^{95}$ Sul ruolo delle comunità rurali nelle rivolte contadine: Comba, Rivolte e ribellioni cit., pp. 681-685. Cfr. oltre, testo corrispondente alla nota 117.

96 Taglienti, Il monastero di Trisulti cit., pp. 497-498, docc. 56 e 57 del 27 marzo 1254

97 Taglienti, Il monastero di Trisulti cit., pp. 497 sgg., docc. 56 e 57 del 27 marzo 1254 e 58 del 4 gennaio 1255. Sugli interventi papali in favore della certosa cfr. Cortonesi, La "silva" contesa cit., pp. 308 sgg.

${ }_{98}$ Taglienti, Il monastero di Trisulti cit., pp. 501 sgg., doc. 61 del 14 agosto 1280.

${ }_{99} \mathrm{P}$. Toubert, Les structures du Latium médiéval. Le Latium méridional et la Sabine $d u I^{e}$ siècle à la fin du XII e siècle, Rome 1973, vol. I, pp. $250 \mathrm{sgg}$.

100 Taglienti, Il monastero di Trisulti cit., p. 499, doc. 59 del 31 marzo 1264. 
4. La certosa di Pesio e gli homines Cluse nel XIII secolo: dal contenimento delle tensioni alla rivolta

Diversamente da quanto avvenne per la certosa di Trisulti, nel primo terzo del XIII secolo i rapporti fra i monaci e gli abitanti di Chiusa Pesio, resi stabili dallo strapotere dei signori di Morozzo in loco, furono improntati a una grande cautela, che si tradusse in un'assenza pressoché totale di transazioni fondiarie ${ }^{101}$. Tale cautela, appalesando lo sforzo di non turbare l'equilibrio assai precario su cui dalla fine del XII secolo si reggeva la convivenza fra la comunità rurale e quella certosina, lascia trasparire una situazione di conflittualità latente, sia pure attutita dalle occasioni di lavoro offerte ai rustici e dall'emigrazione nel borgo nuovo di Cuneo di una parte dei Chiusani. Le tensioni non nascevano più prevalentemente dall'inglobamento nei limites dell'eremo di una parte dei possessi dei rustici del luogo, ma dal fatto che il desertum della certosa, ormai consolidato ed esteso sino ai confini con Briga e Tenda, era in gran parte costituito da boschi, alpeggi, pascoli, corsi d'acqua su cui gravavano antichi diritti d'uso, anteriori alla donazione del 1173, pur avvenuta in accordo "cum omni populo Cluse", che potevano essere rivendicati in qualsiasi momento ${ }^{102}$.

Negli anni Quaranta del XIII secolo, ridotti a un ruolo marginale i Morozzo e altri signori da una alleanza di comuni del Piemonte sud-occidentale $^{103}$, la conflittualità fra gli homines della Chiusa e i certosini riemerse, divenne esplicita, coinvolse inizialmente le due comunità di Briga e Tenda e costrinse i monaci - più volte danneggiati nei propri beni e ormai di fatto privi dell'importante sostegno dei signori di Morozzo, fondatori della certosa - a cercare appoggi di rilievo: nei marchesi di Ceva, nei vescovi di Ventimiglia, nella Sede apostolica, nell'Impero ${ }^{104}$. Assai più significative

${ }^{101}$ Comba, La prima irradiazione certosina cit., p. 31; P. Guglielmotti, Gli esordi della certosa di Pesio (1173-1250): un modello di attività monastica medievale, «Bollettino storico-bibliografico subalpino», LXXXIV, 1986, pp. 5-44 (alle pp. 14 sgg.).

${ }^{102}$ Comba, La prima irradiazione certosina cit., p. 31.

${ }^{103}$ P. Camilla, Cuneo 1198-1380, Cuneo 1970, p. 33. A partire dagli anni Quaranta del XIII secolo infatti, i Morozzo furono marginalizzati politicamente e militarmente dalla prepotente avanzata dei nuovi comuni di Cuneo e di Mondovì in quella che era stata la loro area di riferimento: Guglielmotti, I signori di Morozzo nei secoli X-XIV cit., pp. 199-202, 231.

${ }^{104}$ Caranti, La certosa di Pesio cit., I, pp. 66 sgg., doc. 67 dell'11 novembre 1243, salvaguardia dei marchesi di Ceva ("quod non facerent nec dimicterent predicte domui vallis Pisii facere nullum malum quod possent defendere"); doc. 70 degli anni 12451251, salvaguardia di Giacomo vescovo di Ventimiglia ("si ad res illorum aufferendas iniqui viri manus extenderint et dederint bona eorum in direptionem et predam..."); pp. 69-70, doc. 71 del 17 marzo 1246, facoltà accordata all'abate di Susa da parte di papa Innocenzo IV di scomunicare coloro che turbano la pace e violano i possessi dei certosini di Pesio; pp. 70-71, doc. 72 del giugno 1247 con cui l'imperatore Federico II ri- 
furono però le violazioni dei confini del desertum e gli scatti di rivolta, acutizzati dalla fame di terre derivante dalla pressione demografica ${ }^{105}$, che dal 1260 opposero in forma intermittente la certosa agli uomini della Chiusa interessati a far valere quelli che ritenevano i diritti collettivi di pascolo e di legnatico, oltre che, probabilmente, di pesca nelle acque del Pesio.

Particolarmente importante, "in un crescendo di tensioni non smorzate" dalla conferma (nel settembre 1260) da parte dei domini di Morozzo della donazione dell'alta valle Pesio risalente al $1173^{106}$, fu la rivolta degli homines di Chiusa contro i monaci avvenuta negli ultimi mesi del '60. "Come cani, con rabbia e furore", si legge nella cronaca quattrocentesca del priore Stefano Crivolo $^{107}$, essi assaltarono la certosa. Informazioni più precise sono fornite da un documento del 30 gennaio 1261 con cui l'universitas e gli homines della Chiusa si dichiararono responsabili di molte violenze e promisero di accettare in merito la sentenza arbitrale del priore della certosa, Aimone: "promiserunt stare in arbitrio et dicto et in misericordia et in voluntate dicti domini Aymonis, prioris predicte domus, de omnibus predictis damnis et iniuriis". In particolare, per quanto riguarda il tumulto, riconobbero "se male fecisse et offendisse in pluribus domum vallis Pesii in iniuriis plurimis, in furtis, in rapinis, in percussione fratrum eiusdem domus, in frangendo ostia et cellas predicte domus, in pascendo alpes et prata predicte [domus] et in incidendo nemora et in multis aliis dampnis et iniuriis..." ${ }^{108}$. Da parte sua, continua il documento, il priore Aimone rimise ai Chiusani "omne damnum et iniuriam que predicte domui universaliter et singulariter fecissent", li assolse "sicut potuit" e promise di far revocare la scomunica inflitta in seguito alla sommossa dal vescovo di Asti.

Il documento è stato analizzato da Paola Guglielmotti, la quale ha osservato opportunamente che, se "l'ammissione e la promessa di riparare i danni sono collettive, quelle azioni - che rivelano una vera e propria ribellione e uno sfruttamento non episodico dell'alta valle, quasi a ripristinare una consuetudine - sono però attribuite in particolare a otto uomini nominativamente citati, più imprecisati multi alii" e nessuno "degli appartenenti alla circoscritta frangia dei sostenitori del monastero compare in-

ceve la certosa sotto la sua protezione; P. Guglielmotti, Due bolle papali inedite (1246e 1253) dal cartario della Certosa di Pesio, «Bollettino storico-bibliografico subalpino», LXXXVI, 1988, pp. 636-648.

${ }^{105}$ Per un inquadramento generale delle dinamiche demografiche in area alpina cfr. R. Comba, Forme e dinamiche dell'insediamento montano: le vallate tra il Colla e il Casotto dall'XI al XIII secolo, in Montaldo di Mondovi. Un insediamento protostorico. Un castello, a cura di E. Micheletto, M. Venturino Gambari, Roma 1991, pp. 35-45. Cfr. oltre, nota 125 .

${ }^{106}$ Guglielmotti, I vicini di S. Maria di Pesio cit., p. 247.

${ }^{107}$ Crivolo, Chronica cit., II, p. 24; Guglielmotti, La costruzione della memoria di S. Maria di Pesio cit., p. 320.

${ }^{108}$ Caranti, La certosa di Pesio cit., I, pp. 83-84, doc. 67. 
vece tra i maggiori responsabili delle violenze". In altre parole: il conflitto finisce per "dirompere perché nel comune prevalgono gruppi opposti a quelli che in precedenza hanno sostenuto la certosa"109.

Meno condivisibile, dopo il richiamo alla novità rappresentata localmente dal governo angioino (presente a Cuneo dall'estate 1259), è la valutazione eccessivamente positiva della capacità di quest'ultimo di "imporsi quale potere forte, che pretende di intervenire a tutto campo riducendo probabilmente i margini di informalità delle relazioni locali" ${ }^{110}$. A ben guardare, infatti, come si è accennato, la composizione del conflitto non avviene, come nel caso di liti di minore importanza, attraverso una sentenza emanata da un giudice cuneese "pro domino comite Provincie"111, ma attraverso un accordo privato tra le parti presentato come arbitrato del priore della certosa su quanto accaduto. L'accordo è stipulato nella chiesa di Sant'Antonino di Chiusa da tutta l'universitas del luogo (in particolare dai suoi sindici e dal suo sacerdos, il "dominus Segnorinus"), ed è evidentemente promosso e garantito soprattutto da personaggi ecclesiasticamente e religiosamente significativi, a livello locale, presenti all'atto in qualità di testimoni: frate Manfredo e frate Pietro dell'ordine dei Minori, un cui convento è documentato a Cuneo proprio da quegli anni ${ }^{112}$, ma che potrebbero provenire anche da Mondovì ${ }^{113}$, il già menzionato sacerdos della chiesa in cui è rogato l'atto, "dominus Segnoretus", e, per parte della certosa, frate Pietro, converso. L'amministrazione regia è presente all'atto soltanto attraverso il suo rappresentante locale: "Caminus, vicarius dicte universitatis [Cluse]" 114. Il supposto potere forte di Carlo I d'Angiò, che di lì a poco emanerà un ordine di non turbare i monaci nell'esercizio del loro diritto di

${ }^{109}$ Guglielmotti, I vicini di S. Maria di Pesio cit., p. 247.

${ }^{110}$ Atti del Comune di Cuneo cit., pp. 24 sgg., docc. 12-16 degli anni 1260-1267; Guglielmotti, I vicini di S. Maria di Pesio cit., p. 246. Sulla dominazione angioina nell'Italia nord-occidentale: Gli Angiò nell'Italia nord-occidentale (1259-1382), a cura di R. Comba, Milano 2006.

${ }^{111}$ Cfr. Caranti, La certosa di Pesio cit., I, p. 80, doc. 80 del 4 marzo 1260; p. 85, doc. 84 del 22 settembre 1261 .

${ }^{112}$ Cfr. R. Comba, I francescani a Cuneo nel Tre e Quattrocento: fra momenti di crisi, processi di disciplinamento e aspirazioni di riforma, in Angelo Carletti tra storia e devozione, Mostra a Cuneo in S. Francesco nel V centenario della morte: 15 dicembre 1995 -31 gennaio 1996, Cuneo 1995, pp. 29-40 (a p. 29). Sulla prima diffusione dei Minori in Piemonte: G. G. Merlo, La prima diffusione dei frati Minori in Piemonte, in Forme di religiosità nell'Italia occidentale dei secoli XII e XIII, Cuneo - Vercelli 1997, pp. 177-194.

${ }_{113}$ Sulla presenza dei Minori a Mondovì: R. Comba, Francescani e società comunale a Mondovi: tracce di un rapporto, in Storia di Mondovì e del Monregalese, II, L'età angioina (1260-1347), a cura di R. Comba, G. Griseri, G.M. Lombardi, Cuneo-Mondovì 2002, pp. 177-192.

${ }^{114}$ Caranti, La certosa di Pesio cit., I, pp. 83-84, doc. 83 del 30 gennaio 1261.

${ }^{115}$ Caranti, La certosa di Pesio cit., I, pp. 88-89, doc. 87 del $1^{\circ}$ marzo 1267. 
legnatico e di pascolo ${ }^{115}$, è evidentemente ancora in via di consolidamento ed è significativo che, per risolvere i propri problemi con la comunità locale, la certosa abbia cercato la via di un accordo con la controparte, accordo appena velato nella forma dal riconoscimento del proprio priore come arbitro, ma con ogni evidenza raggiunto grazie alla mediazione influente di due frati Minori. Del resto, anche in anni di poco successivi (fra il 1267 e il 1268) di recrudescenza della conflittualità per le iniurie apportate dalle universitates di Chiusa e di Briga "super terris, possessionibus, nemoribus, pasquis et rebus aliis" i monaci sembrano preferire l'appoggio papale e della gerarchia ecclesiastica che giungono a scomunicare alcuni consiglieri della Chiusa ${ }^{116}$.

Alla base della rivolta, come si vede, c'è anche qui, in ultima analisi, la comunità rurale. Vengono così confermate alcune conclusioni della storiografia tedesca, ormai consolidate dalle ricerche sulle ribellioni contadine nei territori imperiali: "Ohne Gemeinde keine bäuerliche Rebellion", non c’è rivolta senza la partecipazione della comunità rurale ${ }^{117}$. Un'ultima constatazione. Il pascolo sulle alpi e i prati della certosa e il taglio di legname dei suoi boschi a cui i documenti degli anni Sessanta del secolo XIII si riferiscono è significativo. Essi illuminano l'obiettivo dei rivoltosi: il ripristino, di fatto, di quelli che ritengono essere i loro antichi diritti d'uso su alpeggi e aree forestali. Come spesso succedeva - e come per un periodo successivo è stato accertato per le insurrezioni verificatesi in certi domini dell'Impero - obiettivo della rivolta era la soppressione di un'innovazione: nel caso specifico la cancellazione dei rivendicati tradizionali diritti d'uso dei rustici sui beni comuni. In altre parole, per prendere a prestito un convincente e ormai consolidato schema interpretativo della storiografia tedesca più attenta agli aspetti istituzionali, quella attuata dagli homines della Chiusa nel 1260 sarebbe stata una rivolta "per il vecchio diritto"118, per ristabilire cioè nell'uso delle risorse silvo-pastorali ${ }^{119}$ il ruolo decisivo della consuetudine e della tradizione.

${ }^{116}$ Caranti, La certosa di Pesio cit., I, pp. 90 sgg., doc. 89 del 4 dicembre 1267, doc. 90 del 3 gennaio 1268, doc. 91 del 17 gennaio 1268; Guglielmotti, I vicini di S. Maria di Pesio cit., pp. 247-248.

${ }^{117}$ Blickle, Studien zur geschichtlichen Bedeutung cit., p. 123; cfr. Id., Peasant Revolts in the German Empire cit., p. 235.

${ }^{118}$ G. Franz, Der deutsche Bauernkrieg, Darmstadt 1975 (prima edizione München 1933), pp. 1 sgg. Cfr. Blickle, Studien zur geschichtlichen Bedeutung cit., p. 112: S. Lombardini, La guerra dei contadini in Germania: punti di arrivo e punti di partenza nel dibattito storiografico recente, "Archivio storico italiano", CXL, 1982, pp. 355-442 (a p. 357); Neveux, Les revoltes paysannes cit., pp. $112 \mathrm{sgg}$. 


\section{Le certose italiane dalla fine del XIII alla metà del XIV secolo: fra croni-} cizzazione e diversificazione dei rapporti conflittuali

Le informazioni disponibili per l'ultimo ventennio del Duecento e per la prima metà del Trecento sulla conflittualità fra certosini e comunità rurali non evocano, in genere, momenti di scontro acuto paragonabili a quelli delle sommosse che riguardarono le certose di Pesio e di Trisulti nel corso del XIII secolo.

Esplicita continua a essere la documentazione concernente Santa Maria di Pesio, che sembrerebbe evidenziare, come nel XV secolo già aveva osservato il Crivolo, un quarantennio di relativa calma nei suoi rapporti con la comunità della Chiusa ${ }^{120}$, che sappiamo passata nel 1276, dopo la fine della dominazione angioina, dal distretto di Cuneo alla signoria dei Bressano sotto il controllo del comune di Mondovì ${ }^{121}$. Forse, però, più che di calma, si trattò di una sorta di pace armata fra le parti: i Chiusani continuarono a guardare con cupidigia alle alpi dei monaci e, magari, a salirvi occasionalmente per l'alpeggio, 'per necessità' sostenevano, in pieno accordo con l'autorità signorile in loco e col tacito assenso dei monaci, evidentemente desiderosi di evitare uno scontro aperto con la comunità e con i suoi signori. Attorno al 1284, si legge infatti in una dichiarazione del castellano della Chiusa, il dominus Pietro Cavalerio, e di tutti gli uomini del consiglio resa davanti al notaio della certosa, i Chiusani erano entrati "in alpo Serpenterie" con i loro animali e senza, non per impadronirsi di tale alpeggio ("occaxione tenendi dictum alpum, nec occaxione accipiendi possessionem dicti alpi"), ma "per necessità", perché non osavano "alpare in alpis Clusie propter eorum inimicorum"122.

${ }^{119}$ Sull'importanza delle risorse silvo-pastorali nelle rivendicazioni degli homines della Chiusa: Rapetti, "Homines", monaci e boschi cit., pp. 271-285.

${ }^{120}$ Crivolo, Chronica cit., p. 29: "Post hec quieverunt patres annis quadraginta quia usque ad annum 1310 non apparet ab ipsis hominibus Clusie nec a fratribus contra eosdem aliquid fuisse innovatum".

${ }^{121}$ Il "Liber instrumentorum" del comune di Mondovì, a cura di G. Barelli, Pinerolo 1904, pp. 6 sgg., doc. 26 del 22 maggio 1276 e doc. 27 del 2 dicembre 1277; E. Morozzo della Rocca, Le storie dell'antica città del Monteregale ora Mondovi in Piemonte, II, Mondovì 1899, pp. 252, 258; Camilla, Cuneo 1198-1380 cit., p. 233.

122 Biblioteca Reale di Torino, Cartulario della certosa di Pesio, ms. sec. XIV, St. p. 777, doc. 147 del 20 maggio 1284: in Chiusa, alla presenza di Anselmo Galle e Giacomo Baudana, "dominus Petrus Cavalerius castellanus et omnes homines de cunsilio, scilicet Iacobus Alfardus, Bonifacius Paruçia, Astessanus de Marsilia, Ramundus de Vineis, Villelmus de Carle, Facius Canus, Michiellis (sic) Bossius, Guillelmus Carreta, Mateus Cavalerius, Ruffinus Coterius, eorum nomine et nomine comunis Cluse, confessi fuerunt et manifestaverunt coram me Vacantum (?) Lauretum notarium recipientem et vice fratrum vallis Pexium (sic) quod non intraverunt in alpo Serpenterie cum bestiis nec sine bestiis occaxione tenendi dictum alpum, nec occaxione accipiendi possessio- 
Come si vede, non diversamente da quanto era avvenuto nel 1261, la questione fu risolta in modo sostanzialmente informale e non ricorrendo all'autorità territoriale superiore, rappresentata dal comune di Mondovì, che, legato alla Chiusa da un patto di alleanza, aveva probabilmente difficoltà a intervenire con decisione nella confusa situazione politica e militare evocata con chiarezza dalla dichiarazione appena menzionata ${ }^{123}$.

La situazione di incertezza dovette in quegli anni complicare anche le normalmente più pacifiche relazioni fra la Certosa di Casotto - per la prima volta (che si sappia) oggetto di "danni e ingiurie" - e i suoi "vicini" sottoposti all'autorità spirituale e temporale del vescovo di Asti: vicini confinanti probabilmente, in pianura, con la grangia di Consovero, non lontana da certi beni di Pesio ${ }^{124}$. Il tutto quasi a sottolineare, certo, il vuoto di potere creatosi con il crollo della dominazione angioina, ma anche, come con maggiore chiarezza emerge dalla documentazione successiva, una perdurante situazione di carenza di risorse, acuita dall' incremento demografico, che, come è noto, toccò il suo culmine fra XIII e XIV secolo ${ }^{125}$.

Nella primavera del 1305, in un contesto politico-militare caratterizzato nel basso Piemonte dal ritorno e da una presenza amministrativa angioina più strutturate che non nei primi anni della dominazione di Carlo I, la documentazione, secondo Paola Guglielmotti, sembra restituire "visi-

nem dicti alpi nisi pro necesitatem (sic) hominum Clusie ocaxione quia non audent intrare nec alpare in alpis Clusie propter eorum inimicorum". Diversa lettura del documento e diversa interpretazione in Guglielmotti, I vicini di S. Maria di Pesio cit., pp. 252-253.

${ }^{123}$ Cfr. Morozzo della Rocca, Le storie dell'antica città del Monteregale cit., pp. 248 sgg.

${ }^{124}$ Cartario... di Casotto cit., pp. 397 sgg., doc. 670 del 16 settembre 1285: Oberto, vescovo di Asti, ordina ai fedeli, ai rettori, ai ministri delle chiese della sua diocesi, nonché ai podestà, castellani e officiali dipendenti dalla chiesa astese, di proteggere la domus e i fratres della certosa di Casotto da coloro che, "Dei timore posposito" e "diabolico instigati furore", non temono di infliggere "eisdem fratribus aut rebus dampna vel iniurias", facendo ricorso, i primi, alla censura ecclesiastica, i secondi al remedium iusticie, cioè alla giustizia secolare. La situazione giuridica dal punto di vista ecclesiastico della certosa di Casotto, è chiaramente evidenziata in un documento del settembre 1325, dove si afferma che, "licet dictum monasterium pro parte sit in diocessi Albensi fundatum", è anche "pro parte situatum in dicta diocesi Astensi", dove possiede "grangias, administrationes, domos, predia et possessiones" per le quali è solito contribuire per il pagamento delle tasse ecclesiastiche con il clero astese. Cfr. Comba, La prima irradiazione certosina cit., p. 33, nota 143. Sul potere temporale del vescovo di Asti nell'antico comitato di Bredulo: R. Bordone, Un tentativo di «principato ecclesiastico» fra Tanaro e Stura. Le trasformazioni medievali del comitato di Bredulo, in Le strutture del territorio fra Piemonte e Liguria dal X al XVIII secolo, a cura di A. Crosetti, Cuneo 1992, pp. 121140.

${ }^{125}$ R. Comba, La popolazione in Piemonte sul finire del Medioevo. Ricerche di demografia storica, Torino 1977, in particolare pp. 35-46. 
bilità alla microconflittualità locale"; nel contempo varia però, "probabilmente in relazione con il variare della composizione dei gruppi dominanti, il tipo di microconflittualità, che assume un regime stabile e tende a non superare irreversibili punti di rottura" ${ }^{126}$. A rimanere stabile è il diverso modo di vedere boschi, alpeggi e pascoli alpini da parte di monaci e contadini, cosicché, sotto la forte spinta dell'incremento demografico, essi diventano i luoghi in cui si affrontano percezioni dello spazio e interessi materiali diversi e concorrenti.

È interessante, in questo senso, un documento del 1311 che mostra i certosini, sostenuti dall'apparato regio di governo a Cuneo nel cui distretto Chiusa era tornata ${ }^{127}$, intenti a contrastare pratiche di disboscamento e al tempo stesso animati dal "desiderio di evitare lo scontro aperto contro i Chiusani, sempre pronti a sfruttare ogni occasione che permettesse loro di accampare diritti su boschi e pascoli" ${ }^{128}$. Due anni dopo i Chiusani arrecano ai monaci nuovi gravi danni tagliando numerosi abeti nell'alpeggio della Serpentera, rubano tutti gli utensili di certi tornitori e ne costringono altri, che lavorano in un'altra montagna, ad allontanarsi ${ }^{129}$. Qualche anno più tardi, nel 1318, la situazione si tende pericolosamente per l'incendio doloso appiccato alla grangia del Castellar, i cui danni, secondo una perizia degli extimatores del comune di Cuneo, ammontano a ben 200 lire. Il comune di Chiusa è chiamato in causa, ma, a differenza di quanto era successo nella ribellione duecentesca, non vi sono individuate persone responsabili ${ }^{130}$. Due anni dopo, nel 1320, un gruppo di undici Chiusani accusati di aver arroncato e seminato cereali su quei monti, è invece "costretto a cedere al priore di Pesio tutto il raccolto proveniente dai ronchi abusivamente aperti nei boschi dell'alta valle"131. La sentenza definitiva su tali arroncamenti, emanata nel 1320 dal vicario angioino di Cuneo ${ }^{132}$, ribadisce in merito la posizione, assai ferma, dell'amministrazione regia, che tuttavia si rivela incapace di mediare le esigenze delle parti. Paola Guglielmotti parla così di una "cronicizzazione dei rapporti, che è tuttavia

${ }^{126}$ Guglielmotti, I vicini di S. Maria di Pesio cit., p. 259

${ }^{127}$ Atti del Comune di Cuneo cit., pp. 39 sgg., doc. 28 del 12 dicembre 1306.

128 Rapetti, "Homines", monaci e boschi cit., p. 280.

${ }^{129}$ Caranti, La certosa di Pesio cit., II, p. 232. Sulla percezione da parte dei Chiusani delle autorizzazioni citate ai tornitori: Guglielmotti, I vicini di S. Maria di Pesio cit., p. 264: "le autorizzazioni ai tornitori sono percepite come vere e proprie provocazioni, che riflettono oltretutto una diversa e in parte alternativa nozione di sfruttamento dell'alta valle..." Per il lavoro dei tornitori: Rapetti, “Homines", monaci e boschi cit., pp. 283284.

${ }^{130}$ Atti del Comune di Cuneo cit., pp. 57-58, doc. 45 del 28 maggio 1318, ASTo, Carte Vayra, mazzo 3, Sentenza del 21 agosto 1319.

${ }^{131}$ Rapetti, "Homines", monaci e boschi cit., p. 280, con riferimento a Caranti, La certosa di Pesio cit., I, pp. 107 sgg., doc. 105 del 12 febbraio 1320.

${ }^{132}$ Cfr. nota precedente. 
sempre un regime di convivenza per quanto faticoso possa risultare" ${ }^{133}$, e che appare confermata da altre sentenze di condanna inflitte nel $1327^{134} \mathrm{e}$ nel $1337^{135}$ dal vicario di Roberto d'Angiò a Cuneo, mentre si moltiplicano i bandi pubblici che minacciano", inutilmente, "pene severe contro i trasgressori ${ }^{136}$. Che non si tratti, però, sempre e soltanto di semplici trasgressioni, ma che queste siano talvolta associate a veri e propri episodi di violenza appare chiaramente da un ordine indirizzato nel settembre 1343 da Nicolò da Eboli, siniscalco angioino e capitano generale in Piemonte, agli uomini della Chiusa di desistere dai furti, dalle violenze e dalle minacce ai monaci ${ }^{137}$.

Molto interessante e degna di approfondimenti ulteriori è, nelle Alpi Cozie, la situazione evidenziata dalla documentazione trecentesca relativa alla certosa di Montebenedetto e ai suoi rapporti con le comunità confinanti, soprattutto con Villarfocchiardo, dove la compresenza di incerti diritti d'uso su comunia e alpeggi ${ }^{138}$, unita all'incremento dei dissodamenti ${ }^{139}$ crea fra XIII e XIV secolo situazioni di forte tensione con le popolazioni locali che, se non sempre in sommosse vere e proprie, sfociano in violenze, ingiurie ed insulti ai monaci a cui partecipano, come a Villarfocchiardo e a San Giorio, domini e comunità contadina ${ }^{140}$. Nel 1337-38, in una sommossa spontanea presso San Giorio, dove i monaci trovano una ventina di uomini e donne del luogo al pascolo in un prato della certosa e non vogliono allontanarsene, vari confratelli subiscono ferite gravi e viene ucciso

${ }^{133}$ Cfr. Guglielmotti, I vicini di S. Maria di Pesio cit., p. 268.

${ }^{134}$ Caranti, La certosa di Pesio cit., I, p. 111, doc. 107 del 25 maggio 1327.

${ }^{135}$ Caranti, La certosa di Pesio cit., I, pp. 112-113, doc. 108 dell'8 novembre 1337.

${ }^{136}$ Camilla, La vicenda de La Chiusa di Pesio cit., p. XCIX.

${ }^{137}$ Caranti, La certosa di Pesio cit., I, pp. 115 sgg., doc. 111 del 3 settembre 1343.

${ }^{138}$ Cfr. sopra, testo corrispondente alle note 57-58.

${ }^{139}$ ASTo, Corte, Regolari Certosini, Mombracco, serie I, vol. 9, n. 18, perg. originale del 3 aprile 1307: i monaci di Montebenedetto informano il castellano di San Giorio "de insultis et iniuriis actis per quosdam dicti loci in boverium et duos religiosos monasterii irruentes cum lapidibus desuper rupem montanee Montis Benedicti ad operandum et laborandum in quodam essarto monasterii nostri".

${ }^{140}$ Per Villarfocchiardo: ASTo, Corte, Regolari Certosini, Mombracco, serie I, vol. 21, Sentenza arbitrale del 22 giugno 1291 di Guglielmo Beroardi in una lite fra Montebenedetto e la comunità di Villarfocchiardo: "circa dampna data, iniurias et violentias et expensas, considerantes eciam quod homines Vilarii et domini Vilarii non observent precepta eis super hoc facta, sed violentias et iniurias inferunt predictis fratribus in predictis montaneis contra Deum et iusticiam..."; cfr. R. Del Giudice, Un cartulario medievale della certosa di Montebenedetto, Dattiloscritto presso il Dipartimento di Storia, Sez. medievale, Università di Torino, Relatore G. Tabacco, Anno acc. 19691970, pp. 263 sgg. Un excerptum fu pubblicato da F. S. Provana di Collegno, Notizie e documenti d'alcune certose del Piemonte, I, «Miscellanea di storia italiana», XXXII, 1895, p. 247, doc. 91. Per San Giorio: Id., Notizie e documenti cit., II, «Miscellanea di storia italiana», XXXVI, 1901, p. 350, doc. 41 del 25 maggio 1294; cfr. M. Berarducci, Le carte 
un famulus di Monte Benedetto ${ }^{141}$. Il fatto mette in evidenza la carenza nell'area di pascoli e boschi di uso collettivo, peraltro già evidenziata nella seconda metà del XIII secolo da molti documenti ${ }^{142}$. Anche in questo caso, come a Pesio e a Trisulti, il diverso modo che certosini e montanari hanno di vedere boschi ${ }^{143}$, pascoli, alpeggi, celle ${ }^{144}$, risorse si complica con interessi materiali contrapposti e i deserta diventano luoghi in cui questi si confrontano con percezioni dello spazio diverse: per i certosini assai idealizzate ma al tempo stesso molto concrete.

A Trisulti tali dinamiche ridiventano leggibili, fra Due e Trecento, anche per lo sfruttamento silvo-pastorale della selva d'Eici, sempre protetta dall'amministrazione pontificia e per lo più insidiata da tagli di alberi e da danneggiamenti delle semine ad opera di singoli Collepardesi ${ }^{145}$, quando non interessata, come nei primi anni Quaranta del Trecento, da non me-

della certosa di Montebenedetto e gli usi notarili della valle di Susa tra il XIII e il XIV secolo, Dattiloscritto presso il Dipartimento di Storia, Sez. medievale, Università di Torino, Relatore G. Tabacco, Anno acc. 1969-1970, p. 40, doc. 16.

${ }^{141}$ Provana di Collegno, Notizie e documenti d'alcune certose cit., II, pp. 370-371, doc. 61 degli anni 1337-1338 (per la datazione confronta ivi, p. 449): “... irruentes cum armis videlicet lanceis, spletis, piolis et tavolaciis in dictos fratres et eorum familiares ipsos fugaverunt usque dictam aquam Graviam, lapides proiicientes contra ipsos. Mortifere vulneraverunt Vincentium, unum ex famulis dicti monasterii quinque vulneribus et ex inde fuit plene interfectus per Ioannem Gibarius (sic) cum quodam venabulo. Percussus fuit in crure cum quodam spleto monacus dominus Iohannes de Rupecula nec non in manu sinistra que pene fuit abscissa, Aymo frater dicti monasterii ictu lancee fuit percussus per filium Morini Thome. Dominus Petrus vicarius eiusdem monasterii fuit in pectore percussus ex quodam grosso lapide in eo iniecto. Similiter frater Ioannes clericus de lapidibus et baculis fuit graviter percussus. Item frater Ioannes de Allono vulnus accepit in pectore et ventre ex ictu magni lapidis ita quod viscera apparent et fuit totus crepatus. Insuper frater Petrus de Ponte cum piolla seu secure et duobus lapidibus fuit in capite et in costato graviter percussus et in terram proiectus quasi mortuo".

${ }^{142}$ La fame di terre ad uso collettivo emerge chiaramente nella fondazione della villanova di Borgone (odierna San Valeriano) da parte di Filippo conte di Savoia e Borgogna: affinché essa potesse "recipere incrementum", il conte concesse ai suoi abitanti "predia et silvas, pascua et nemora, venationes et piscationes et omnia que continentur a Petra Culeria usque ad Rivum Gravie et usque ad decursum aque que vocatur Duria" (L. Patria, Assetti territoriali e affermazioni signorili nel balivato valsusino nel Duecento: la castellania sabauda di Susa, di prossima pubblicazione in «Segusium», testo corrisp. alle note 52-62 e Appendice, doc. 17 del 9 marzo 1277).

${ }^{143}$ ASTo, Corte, Regolari Certosini, Mombracco, serie I, vol. 3, n. 17, denuncia del 16 ottobre 1332 al castellano di San Giorio di certi danni nei boschi: “... inciderunt, estrompaverunt maliciose et minus iuste quercores folatas et alias arbores...".

${ }_{144}$ Provana di Collegno, Notizie e documenti d'alcune certose cit., I, p. 249, doc. 93 del 13 ottobre 1291.

${ }^{145}$ Castelli, La certosa di Trisulti cit., pp. 132-134; Taglienti, Il monastero di Trisulti cit., pp. 247 sgg., con riferimenti a epidodi di danneggiamento riferibili ai primi anni Venti del XIV secolo e assoluzione dalle censure ecclesiastiche in data 17 giugno 1322. 
glio precisati 'disordini con carattere generale'146. Per quanto riguarda tale selva, a partire dagli ultimi decenni del Duecento, come ha osservato Pierre Toubert, fu tuttavia con ogni probabilità il controllo di piccoli giacimenti ferrosi (ferrarie, minerie ferri, avene ferri) ubicati al suo interno ad alimentare una nuova occasione di conflittualità che si estese al comune di Alatri ${ }^{147}$. Nel 1294 gli homines di questa città assalirono "armata manu cum balistis, ensibus et arcubus et aliis armis" monaci e conversi che si recavano "ad mineriam ferri, seu ferreriam positam in silva Ecii" per appropriarsene ${ }^{148}$. Le tensioni con il comune laziale per tali giacimenti, che furono poi sfruttati in modo intermittente sino alla fine del Cinquecento ${ }^{149}$, a quanto pare non durarono a lungo e si esaurirono probabilmente nel terzo decennio del Trecento. Va da sé che anche in questo caso Trisulti ebbe l'appoggio del papa e dell'amministrazione pontificia, che sostennero la certosa nei confronti degli Alatrini. Occorre tuttavia tenere presente che la lontananza della sede apostolica, stabilmente insediata ad Avignone dal 1305, avrebbe reso difficoltoso per gran parte del secolo XIV ai monaci di Trisulti il rivolgersi direttamente al papa e ad essa, come evidentemente era stato fatto nel corso del secolo precedente anche grazie a uno specifico privilegio pontificio rilasciato il 7 luglio 1268 da Clemente IV nonostante le disposizioni contrarie emanate da un recente Capitolo generale dell'Ordine certosino ${ }^{150}$.

${ }^{146}$ Castelli, La certosa di Trisulti cit., pp. 133-134: "Fra tante angustie, pure l'anno seguente [1323] i ricorsi dei Trisultani furono accolti, ed ho trovato una nuova sentenza, 30 aprile 1337, del Giudice Generale di Campagna e Marittima contro molti cittadini di Collepardo condannati per tali delitti [usurpazione di beni della certosa, danneggiamenti alle semine, taglio abusivo di alberi nel bosco]. Ma è bene osservare che la cosa non riguardava tutto il popolo e, con esso, le autorità municipali, ma furono delitti commessi isolatamente da un certo numero di sconsigliati. Invece cinque anni dopo, altri disordini si rinnovarono e con un carattere generale. Nuovo processo, nuova condanna ed un monitorio severissimo, con minaccia di pene corporali e pecuniarie, in data del 2 settembre 1342, spedito da Anagni dal Giudice e Vicario Generale".

147 Toubert, Les structures du Latium médiéval cit., pp. 250 sgg.

148 Taglienti, Il monastero di Trisulti cit., pp. 235 sgg., e 504 sgg., doc. 63 del 5 aprile 1294, doc. 64 del 21 agosto 1294. Cfr. A. Pratesi, Un piccolo dilemma diplomatico, in Studi sul Medio Evo cristiano offerti a Raffaello Morghen per il $90^{\circ}$ anniversario dell'Istituto storico italiano, II, Roma 1974, pp. 861-872, ora in Id., Tra carte e notai. Saggi di diplomatica dal 1951 al 1991, Roma 1992, pp. 565-577 (edizione di tre documenti del 21 agosto 1293).

${ }^{149}$ Cfr. G. Barbieri, Industria a politica mineraria nello Stato pontificio dal '400 al '600. Lineamenti, Roma 1940, pp. 73 sgg., 145 sgg.

${ }^{150}$ Les registres de Clément IV: 1265-1268, I, Paris 1893, a cura di M. E. Jordan, p. 275, reg. 713; Regesta pontificum Romanorum ab anno p. Ch. N. 1198 ad 1304, a cura di A. Potthast, II, Berolini 1875, p. 1642, reg. 20423. Cfr. Sechi, La certosa di Trisulti cit., p. 132, doc. 118; Castelli, La certosa di Trisulti cit., p. 123. 


\section{Fra depressione economica e crisi delle dominazioni regionali}

Per la seconda metà del secolo XIV mancano nelle opere a stampa su Trisulti attestazioni di conflitti con gli homines di Collepardo e di Vico, ma non occorre necessariamente dedurne l'esistenza di rapporti pacifici: le due comunità, unite a molte altre, appaiono infatti negli anni 1366-1372 sostanzialmente autonome e in aperta ribellione con la dominazione papale ${ }^{151}$ ed è difficile immaginare che tale situazione non abbia influito sui loro rapporti con la certosa modificandoli sensibilmente. Nuovi elementi di conflittualità sorsero comunque nei primi decenni del Quattrocento in seguito all'ampliamento del tenimentum di Tecchiena, situato fra le città di Alatri e di Ferentino, che i certosini avevano acquistato dalla Camera Apostolica nel 1395 ma che, caratterizzato com'era da incerti confini, trascinò la certosa in una serie di liti, relativamente ben documentate, con $\mathrm{i}$ comuni di Alatri e di Ferentino ${ }^{152}$. La possibilità di osservare con attenzione questa nuova occasione di un duro confronto nulla toglie alla necessità di approfondire meglio, in futuro, se lo sarà possibile, lo stato effettivo dei rapporti fra la certosa di San Bartolomeo e il comune di Collepardo per quanto riguarda la selva d'Eici.

Nonostante che gravi carenze documentarie caratterizzino anche la storia della domus certosina di Pesio, i suoi rapporti con gli homines di Chiusa fra Tre e Quattrocento diventano comprensibili grazie alla cronaca, scritta attorno al 1435, di Stefano Crivolo ${ }^{153}$.

Innanzitutto, riferisce il cronista, a causa delle guerre, delle carestie e di una "longa et desperata desolatio" ${ }^{154}$, la certosa fu "aliquotiens quasi derelicta" 155 , tanto che, a fine Trecento ${ }^{156}$, non avendo di che vivere, i monaci dovettero "cum tota familia inde recedere et domum ipsam relinquere, vix

151 Taglienti, Il monastero di Trisulti cit., pp. 337 sgg.; A. Sacchetti Sassetti, Storia di Alatri, Alatri 1967 (2a ediz.), pp. 123 sgg.

${ }^{152}$ Castelli, La certosa di Trisulti cit., pp. 149-151, 154 sgg.

${ }^{153}$ Crivolo, Chronica cit., per la datazione della quale cfr. Guglielmotti, La costruzione della memoria cit., p. 311.

${ }^{154}$ Crivolo, Chronica cit., p. 39: "religiosis dicte domus contigit gustare de flagello impiorum. Decurrentibus enim hinc et inda cottidie in patria ipsa Anglicorum et Armeniacorum similiterque potentium vicinorum gentibus ac armigeris, ipsarum formidine incole percussi, ad aliquam culturam peragendam exire non erat qui ausus esset, et facta fuit fames in tota patria et victualium penuria maxima, etsi non statuta, tamen longa et desperata desolatio".

${ }^{155}$ Crivolo, Chronica cit., p. 13.

${ }^{156}$ Un periodo di vero e proprio abbandono della certosa dovette verificarsi negli ultimi anni del Trecento, durante l'episcopato monregalese di Damiano Zoagli: Cfr. A. Lerda, Su Damiano Zoagli primo vescovo di Mondovì, in La diocesi di Mondovi: le ragioni di una storia. Miscellanea di studi storici nel VI centenario: 1388-1988, Mondovì 1989, pp. 57-79. 
uno solo aut duobus remanentibus pro murorum custodia" ${ }^{157}$. Questa situazione di abbandono facilitò così l' "usurpazione" di beni e diritti della domus di Santa Maria di Pesio, sia da parte dei signori del luogo, sia da parte della comunità di Chiusa.

Negli ultimi anni del XIV secolo Girardo dei marchesi di Ceva, "ipsius loci Cluse dominus", vedendo "dictum monasterium personis et bonis satis attenuatum et penitus devastatum", si appropriò di una sega idraulica (resica) in rovina situata "in Podio Nigro" e la ricostruì, avviando contemporaneamente un'attività sistematica di "estorsione" delle scarse vettovaglie che si trovavano nella certosa, come il Crivolo seppe da testimoni, monaci e conversi, bene informati: "et dictum monasterium graviter angebat, prout a personis domus qui viderunt et passi fuerunt propriis auribus ego frater Stephanus ipsis narrantibus accepi" ${ }^{\prime 58}$. In modo analogo rialzarono la testa i Chiusani: "insurrexeruntque et ipsi homines ipsius universitatis modoque simili, predictum monasterium sencientes esse collapsum, adversus ipsum in rebelionem versi sunt"159.

La ribellione dovette toccare momenti di acuta tensione nei primi decenni del Quattrocento, quando la certosa, ormai rivitalizzata ma pur sempre indebolita dal lungo periodo di crisi, ricominciò a rivendicare il pieno e incondizionato rispetto del proprio desertum, cercando inizialmente appoggio e protezione soprattutto nella Sede Apostolica e, negli anni 14081409, trascinando come un tempo in giudizio gli homines della Chiusa, questa volta davanti al tribunale romano della Sacra Rota ${ }^{160}$. Per il terzo decennio del secolo è indispensabile attingere al racconto del Crivolo, che, monaco professo attorno al $1430^{161}$, con riferimento evidente a un periodo del proprio noviziato anteriore a una sentenza arbitrale del 13 settembre 1428 ("quam nullus ignorat" perché, a parer suo, emanata "in magnum damnum" della certosa) ricorda di aver visto con i propri occhi episodi incresciosi: i famuli di quest'ultima espulsi "de finibus et territorio monasterii", percossi, presi prigionieri; legname da opera già lavorato devastato per tre volte; trecento tronchi tagliati e distrutti in presenza anche di un commissario del duca, presente "pro salvagoardia tuenda"; il documento contenente tale salvaguardia ducale gettato in segno di disprezzo nel fiume; il festoso ballo successivo dei contadini a due a due "in presentia ipsius commissarii". Poi, non sazi, i Chiusani "pluries venerunt a furore populi in manu armata in dicto territorio monasterii ad piscandum et alia exercenda"

${ }^{157}$ Crivolo, Chronica cit., p. 39.

${ }^{158}$ Crivolo, Chronica cit., p. 43.

${ }^{159}$ Crivolo, Chronica cit., p. 43.

${ }^{160}$ Crivolo, Chronica cit., p. 17.

${ }^{161}$ Chronica d(omini) Benedicti a Costaforti anno MDCLXXVII, in Caranti, La certosa di Pesio cit., pp. 97 sgg., qui a p. 288. 
contro la volontà del priore e della certosa, nonostante un divieto emanato nel 1408 dal sommo pontefice sotto pena di scomunica e di 500 ducati "pro qualibet persona et qualibet vice"162. Inoltre aggredirono e rapinarono dei bovari (bifolchi) che portavano grano e vino al monastero, ruppero le botti e ne versarono il vino, aggredirono con balestre, lance e spade i famuli che seguivano il carico, li dispersero e ne ferirono gravemente uno con un coltello. La stessa cosa accadde a un converso, frate Stefano, durante un violento confronto svoltosi "a furore populi" presso la porta della casa alta ${ }^{163}$, "iuxta portam monasterii", dove fu duramente percosso anche un diacono secolare appartenente alla famiglia dei Pagani di Mondovì. Infine, un venerabile e anziano monaco, il dominus Alberto, fu percosso con lancia e bastone e ne mori ${ }^{164}$.

In tutte queste azioni il Crivolo vedeva dipanarsi una specie di filo rosso che portava alla distruzione del patrimonio monastico da parte dei Chiusani, proprio come avevano fatto "antiquitus patres eorum". Il risultato era che i certosini non osavano più "stare, ire et redire neque in valli conversari, nisi bene provisi et fulti et cum armatis"165. La soluzione del problema non fu trovata dalla certosa, come nell'età angioina, nel continuo ricorrere alla protezione papale o degli ufficiali del potere centrale denunciando violazioni e ottenendone scomuniche o sentenze in proprio favore. In modo non troppo dissimile da quanto era avvenuto nel 1261, si tenne invece nel settembre 1428 un arbitrato, affidato a Luca, marchese di Ceva e consignore della Chiusa, e a frate Andrea Bianchi, priore della certosa di Casotto, che molto innovò nei rapporti fra la certosa e gli homines del luogo ${ }^{166}$ : gli arbitri ribadirono sì che l'alta valle Pesio continuasse a spettare "pleno iure" ai monaci "quo ad dominium perpetuum et posessionem", ma riconobbero agli abitanti del luogo la facoltà di pascolare e tagliare legna per loro uso personale, pur con limitazioni a vantaggio della correria e della grangia di San Michele. I Chiusani riuscirono così a far valere, almeno in parte, i diritti di pascolo e di boscheggio che ritenevano di avere sul loro territorio "nulla impetrata licencia", col solo obbligo di versare ogni anno ai monaci un canone ricognitivo di quattro libbre di cera nuova il giorno della Candelora ${ }^{167}$.

Il motivo di tale riconoscimento era semplice, secondo il Crivolo: da molto tempo (longe antea) essi erano riusciti a "usurpare" - cioè a ricreare

162 Crivolo, Chronica cit., pp. 16-17.

${ }^{163}$ La casa bassa, o correria, era già stata parzialmente distrutta alla fine del Trecento: ne sopravvivevano soltanto la chiesa e il granaio: Crivolo, Chronica cit., p. 40.

${ }^{164}$ Crivolo, Chronica cit., p. 17.

${ }^{165}$ Crivolo, Chronica cit., p. 17.

${ }^{166}$ La vicenda de La Chiusa di Pesio cit., pp. 265 sgg., doc. 3 del 13 settembre 1428. Cfr. sopra, nota 32 .

${ }^{167}$ Camilla, La vicenda de La Chiusa di Pesio cit., p. 266. 
una consuetudine d'uso - una parte delle Alpes dell'alta valle Pesio ${ }^{168}$. Va però tenuto presente che tale indubbio mutamento era avvenuto in un contesto politico-militare assolutamente favorevole: la monarchia pontificia messa in difficoltà dal conciliarismo; i marchesi di Ceva, domini loci della Chiusa vassalli dei Savoia dal 1373 e da poco battuti sul campo da Amedeo VIII che aveva tolto loro il controllo delle valli Gesso e Vermenagna ${ }^{169}$, alla ricerca di una conferma visibile del loro radicamento locale e della loro capacità di controllo del territorio in un quadro di maggiore autonomia; quest'ultimo, duca da poco più di un decennio, degno erede di una dinastia osannata dal Crivolo per aver riportato la pace nella regione mettendo in fuga predoni e maligni, ma soprattutto conquistando "nobilium et populorum corda"170, reso prudente, forse, dal ricordo del tuchinaggio ${ }^{171}$.

E le altre domus subalpine? Per quanto manchino pubblicazioni specifiche e soprattutto vada attentamente approfondita la storia della certosa di Montebenedetto, pur oggetto fra Otto e Novecento dei robusti studi eruditi di Francesco Saverio Provana di Collegno ${ }^{172}$, per il periodo che va dalla peste nera ai primi decenni del Quattrocento, allo stato attuale delle ricerche sembrerebbe di poter escludere che esse siano state interessate da eclatanti momenti di rivolta. Le tensioni più significative verificatesi nei rapporti con le comunità rurali, accertate per la giovane fondazione di Mombracco in valle Po (XIII-XIV secolo) e per la ben più antica certosa di Casotto, ebbero infatti per oggetto questioni di carattere fiscale. Soltanto per Casotto, però, sfociarono in uno scontro armato. Mombracco ebbe infatti nel 1384 con l'universitas di Envie, che pretendeva la corresponsione da parte dei monaci delle imposte fondiarie al pari di qualunque altro contribuente, una controversia che si risolse con un lodo arbitrale ${ }^{173}$. Casotto,

${ }^{168}$ Crivolo, Chronica cit., p. 13.

169 P. Grillo, L'età sabauda, in Storia di Cuneo e del suo territorio: 1198-1799, a cura di R. Comba, Savigliano 2002, pp. 123-179, alle pp. 144-145; cfr. F. Gabotto, Storia di Cuneo dalle origini ai giorni nostri, Cuneo 1898, pp. 96-97.

${ }^{170}$ Crivolo, Chronica cit., p. 43. Cfr. Guglielmotti, La costruzione della memoria cit., p. 322.

${ }^{171}$ Cfr., da ultimo, A. Barbero, Una rivolta antinobiliare nel Piemonte trecentesco: il Tuchinaggio del Canavese, in questo stesso volume e Id., La rivolta come strumento politico delle comunità rurali: il Tuchinaggio nel Canavese (1386-1391), in Linguaggi politici nell'Italia del Rinascimento, a cura di A. Gamberini e G. Petralia, Roma 2007, pp. 245-266.

${ }^{172}$ Cfr. sopra, nota 140.

${ }^{173}$ Provana di Collegno, Notizie e documenti cit., I, p. 288, doc. 128 del 26 marzo 1384. Cfr. L. Cuttin, Un'esperienza eremitica nelle Alpi occidentali: la certosa di Mombracco fra XIII e XIV secolo, tesi di laurea, Facoltà di Lettere e Filosofia, Università 
quasi certamente per motivi analoghi, conobbe invece nel luglio 1396 un attacco armato guidato dal castellano sabaudo di Sant'Albano Stura a una delle proprie grange di pianura più importanti, quella del Consovero, a cui partecipò gran parte della popolazione di quella castellania ${ }^{174}$. Il fatto non stupisce: alle soglie del XV secolo le comunità rurali cercavano di imporre la propria autorità anche sugli enti monastici ed ecclesiastici che avevano beni all'interno dei loro confini e che sino a quel momento avevano potuto godere dei privilegi dell'esenzione e dell'immunità ${ }^{175}$.

Le questioni connesse con l'esenzione fiscale appena ricordate indirizzano verso problematiche diverse rispetto a quelle che si sono volute affrontare nel presente lavoro, da cui innanzitutto è emersa in modo lampante la peculiarità dei deserta certosini come generatrice di conflittualità con il mondo rurale. Gli eremi dei monaci sono apparsi infatti come i luoghi privilegiati di scontri secolari con le collettività contadine, in contesti storici via via cangianti, di modalità differenti di interpretare il proprio spazio vissuto, influenzate a loro volta da principi ideali e da interessi materiali. Inoltre la conflittualità, osservata sul lungo periodo, appare in stretto rapporto, oltre che con la memoria dei diritti collettivi su boschi, pascoli e alpeggi, con il rafforzamento istituzionale delle comunità rurali e la loro crescente coscienza della propria forza e dei propri diritti: senza dimenticare ovviamente le specifiche congiunture politiche ed economiche che costituirono il quadro entro cui i fatti si svolsero.

Da un punto di vista storiografico più generale, al di là della specificità dei contesti socio-ambientali in cui le rivolte e i momenti di più o meno acuta tensione fra rustici e certosini si verificarono, come si vede, la ricerca ha infine confermato ancora una volta il ruolo decisivo svolto, in ogni occasione dai piccoli comuni di montagna a più stretto contatto con i certosini. In questo senso, se essa per un verso conferma ancora una volta l'icastica affermazione di Blickle "ohne Gemeinde keine bäuerliche Rebellion"176, per altro verso invita a studiare ulteriormente, in modo rav-

degli Studi di Milano, a.a. 1999-2000, app., doc. 15; A. Spelta, Una comunità eremitica nelle Alpi occidentali: la certosa di Mombracco alla fine del Medioevo, tesi di laurea, Facoltà di Lettere e Filosofia, Università degli Studi di Milano, a.a. 1999-2000, p. 89.

${ }^{174}$ Originale pergamenaceo conservato in ASTo, Corte, Certosa di Casotto, m. 5. fasc. 475. L'attacco fruttò alla castellania 138 "capalle messium" a dimostrazione del fatto che esso sarebbe avvenuto per ragioni fiscali: "per certi carrichi pretesi dal sudetto castellano", come si legge in un regesto del documento scritto sul verso dell'originale di mano del XVII-XVIII secolo.

${ }^{175} \mathrm{Cfr}$. G. Chittolini, La formazione dello stato regionale e le sue istituzioni del contado, Torino 1979, pp. 309 sgg.

${ }^{176}$ Cfr. sopra, nota 117. 
vicinato, gli spazi vissuti, le risorse, la composizione sociale, le metamorfosi istituzionali, le forme di inquadramento politico-istituzionale, la cultura prevalentemente orale delle comunità contadine, che, a quanto sin d'ora si percepisce, appare in netto contrasto con quella, scritta, di cui erano portatrici le comunità monastiche. Anche su questa contrapposizione andrà fatta chiarezza: basti, per il momento, l'aver suggerito da questo punto di vista nuovi elementi di riflessione. 


\section{LE RIVOLTE DEL PANE: BOLOGNA $1311^{1}$}

«Item dicto anno [= 1311] frumentum et omnia comestibilia cara fuerunt Bononie, preterquam olei et lupini, et valebat corbes frumenti xxx solidos et ultra; et quia non poterat haberi de frumento, rumor fuit in platea et in tribio porte Ravenatis. Qua de causa obtemptum fuit in conscilio populi quod omnes de Lambertatiis, qui erat de casalibus et quibus erat interdictum palatium, iret ad confinia extra civitatem; et sic factum fuit». ${ }^{2}$ Così recita la Cronaca A, compresa all'interno del Corpus chronicorum bononiensium edito da Sorbelli, ripresa quasi parola per parola da tutte le cronache cittadine coeve e successive edite. È questa l'unica rivolta cittadina, nel corso del Trecento, per la quale le fonti indichino espressamente la penuria di generi alimentari: l'impossibilità di trovare frumento nel mercato cittadino del trebbio di porta Ravennate, il cui prezzo era già proibitivo per larghi strati della popolazione cittadina, scatenò una rivolta in una città stremata da alcuni decenni di lotte interne e dal conflitto con la signoria estense. Si tratta di una delle poche rivolte scoppiate in Italia nella prima metà del Trecento a causa dell'aumento dei prezzi del pane e del grano, come hanno dimostrato recenti indagini storiografiche $e^{3}$.

${ }^{1}$ Desidero ringraziare la mia Maestra, Anna Laura Trombetti Budriesi, per avere seguito con la consueta generosità questa ricerca, in ogni sua fase. Ringrazio altresì Bruno Andreolli, Samuel Cohn, Tiziana Lazzari e Giuliano Pinto per i loro consigli e suggerimenti.

${ }^{2}$ Corpus chronicorum Bononiensium, a cura di A. Sorbelli, in RR.II.SS., II ed., XVIII/1, vol. II, Città di Castello 1938, p. 317.

${ }^{3}$ Samuel Cohn, nella sua recentissima monografia dedicata alle rivolte sociali nell'Europa medievale tra 1200 e 1425, ha confutato la rilevanza dei moti per il prezzo del pane e del grano per l'Italia, la Francia e le Fiandre in questo ambito cronologico. Egli ne ricorda solo 11, e cioè meno dell' $1 \%$ delle rivolte registrate nelle fonti cronachistiche e documentarie analizzate nel corso della sua ricerca, registrando per l'Italia le rivolte del: 1302 e 1303 a Siena, 1310 a Firenze, 1311 a Bologna e 1329 a Roma, Siena e Firenze. Cfr. S. K. Cohn Jr., Lust for liberty. The politics of social revolt in medieval Europe, 1200-1425, Harvard University Press, Cambridge, Massachusetts, and London 2006, pp. 70-75. Per l'Italia, si vedano inoltre: R. Comba, Rivolte e ribellioni fra Tre e Quattrocento, in La Storia. I grandi problemi dal Medioevo all'Italia Contemporanea, a 
Come è noto, «la fase di ridimensionamento demografico, economico e politico, in una parola di decadenza, che avrebbe finito col declassare la città da "metropoli europea" a città d'importanza solo a scala regionale» ${ }^{4}$ ebbe origine a Bologna negli ultimi decenni del Duecento. Le vicende dello scorcio del secolo avevano segnato duramente il comune bolognese: le lotte tra i guelfi Geremei e i ghibellini Lambertazzi avevano a lungo caratterizzato la vita cittadina, indebolendo la struttura stessa del comune; nel 1274 la cacciata dei Lambertazzi aveva segnato l'affermazione sulla scena politica di Rolandino Passaggeri, maestro d'arte notarile e principale ispiratore dell'alleanza tra i Geremei e il populus. ${ }^{5}$ Era stata la guerra malamente perduta contro Venezia nel $1273^{6}$ a indebolire definitivamente la vecchia aristocrazia cittadina e a permettere al populus, guidato da Rolandino, di scendere in campo a fianco dell'aristocrazia guelfa, per cacciare dalla città dapprima migliaia di ghibellini, e poi anche centinaia di magnati guelfi. ${ }^{7}$

Il trionfo popolare aveva dunque coinciso con la fine del "secolo d'oro" di Bologna, e aperto la strada a nuovi conflitti. Nel 1278 Rolandino venne nominato anziano perpetuo, carica che gli conferiva di fatto la preminenza assoluta; lo stesso anno l'accordo tra Rodolfo d'Asburgo e papa Nicolò III, in cui il re dei Romani riconosceva la soggezione di Bologna e della Romagna alla Santa Sede, mutò profondamente il quadro politico cittadino. L'anno successivo i bolognesi giurarono fedeltà al papa, ma cominciò ben presto

cura di N. Tranfaglia e M. Firpo, Utet, Torino 1988, vol. I, pp. 673-691; Protesta e rivolta contadina nell'Italia medievale, a cura di G. Cherubini, "Annali dell'Istituto Alcide Cervi», 16, 1994

${ }^{4}$ A. I. Pini, Bologna, re Enzo e il suo mito, in Bologna, Re Enzo e il suo mito, Atti della Giornata di studio, Bologna, 11 giugno 2000, a cura di A.I. Pini e A.L. Trombetti Budriesi, Deputazione di storia patria, Bologna 2001, pp. 49-64. Sulla storia di Bologna nel Duecento, si veda la recente sintesi di R. Greci, Bologna nel Duecento, in Bologna nel Medioevo, a cura di O. Capitani, Bononia University Press, Bologna 2007, pp. 499-589.

${ }^{5}$ Su Rolandino Passaggeri, cfr. A. Palmieri, Rolandino Passeggeri, Zanichelli, Bologna 1933; G. Cencetti, Rolandino Passaggeri dal mito alla storia, "Notariato medievale bolognese», I, 1950, pp. 199-215; A. I. Pini, Un principe dei notai in una "repubblica di notai": Rolandino Passaggeri nella Bologna del Duecento, «Nuova rivista storica», LXXXIV, 2000, pp. 51-72.

${ }^{6}$ Cfr. A.I. Pini, Ravenna, Venezia e Bologna da Marcamò al Primaro (1251-1271), "Atti e memorie della Deputazione di storia patria per le province di Romagna», XLIII, 1992, pp. 233-261.

${ }^{7}$ G. Milani, Il governo delle liste nel comune di Bologna. Premesse e genesi di un libro di proscrizione duecentesco, «Rivista storica italiana», 108, 1996, pp. 149-229; Id., Dalla ritorsione al controllo. Elaborazione e applicazione del programma antighibellino a Bologna alla fine del Duecento, "Quaderni storici», 94, 1997, pp. 43-74; Id., L'esclusione dal comune. Conflitti e bandi politici a Bologna e in altre città italiane tra XII e XIV secolo, Istituto Storico Italiano per il Medioevo, Roma 2003. 
un nuovo scontro, che vide contrapporsi, all' interno della fazione guelfa, il populus alla oligarchia geremea. Furono decenni di accesa lotta tra fazioni, simboleggiati fisicamente dal V libro degli statuti comunali del 1288: ${ }^{\circ} \mathrm{con}-$ tenente i celebri Ordinamenti sacrati e sacratissimi - leggi straordinarie emanate dal popolo contro i magnati - esso venne strappato dal codice originale nel marzo del 1292, in un momento di reazione alla politica antimagnatizia condotta dalle compagnie del popolo, e sostituito da altre norme di carattere più conciliativo. Una reazione popolare portò al ripristino degli antichi ordinamenti e alla revisione di una parte di quelli che li avevano sostituiti. Furono allora raccolti gli Ordinamenti composti tra il 1282 e il 1292, inseriti nel V libro, ma senza seguire alcun ordine cronologico.

In questi decenni le lotte interne avevano proceduto di pari passo ai conflitti esterni. Alla già citata guerra contro Venezia era seguito un sanguinoso contenzioso con la signoria estense, che impegnò Bologna per tre anni, dal 1296 al 1298, su diversi fronti. ${ }^{9}$ Alma Gorreta, che ha dedicato ai primi del Novecento una breve monografia a questa guerra, ha individuato nella politica di espansione intrapresa da Obizzo d'Este a partire dal 1265 l'inevitabilità dello scontro. ${ }^{10} \mathrm{I}$ rapporti tra il comune bolognese e la signoria estense si mantennero formalmente buoni fino al 1290: fu addirittura stipulato un accordo che prevedeva la determinazione dei reciproci confini verso Modena; si convenne inoltre che bisognava scavare il letto del fiume Panaro a vantaggio di entrambe le parti. Ma con la caduta di Reggio Emilia in mano estense nel 1289, a distanza di poco meno di un anno di Modena, la situazione precipitò, poiché il contado bolognese era ormai quasi circondato dai possedimenti di Obizzo. L'arbitrato di Firenze relativo a una disputa sul dazio del sale ritardò l'inevitabile, insieme forse alla salute cagionevole di Obizzo e alla sua contesa con i Bonaccolsi, che lo impegnavano sul fronte mantovano; ma alla sua morte, avvenuta il 13 febbraio 1293, la successione del figlio Azzo VIII, diretto e assai energico continuatore della politica di espansione del padre, fece precipitare la situazione.

${ }^{8}$ Statuti di Bologna dell'anno 1288, a cura di G. Fasoli e P. Sella, Città del Vaticano, Biblioteca Apostolica Vaticana, vol. I, 1937; vol. II, 1939.

${ }^{9}$ A. Gorreta, La lotta fra il comune bolognese e la signoria estense (1293-1303), Zanichelli, Bologna 1906 (rist. anast. ed. Forni 1975). Sulla storia del Comune bolognese tra Due e Trecento, si veda la recente sintesi di A. Vasina, Dal Comune verso la Signoria (1274-1334), in Bologna nel Medioevo cit. pp. 581-651.

${ }^{10} \mathrm{Nel} 1265$ egli ottenne per concessione molti feudi ad Adria, a Rovigo e nel contado; nel 1285 per donazione ricevette Lendinara, contigua ai possedimenti di casa d'Este nel Veneto; nel 1278 riuscì a strappare ai veronesi Cologna; fallito nel 1273 il tentativo di organizzare una sua fazione a Mantova, che contese inutilmente ai Bonaccolsi, nel 1288 riuscì a divenire signore di Modena, e l'anno seguente signore di Reggio Emilia. Cfr. Gorreta, La lotta cit., pp. 13-14. 
Cominciò allora uno scontro che mise a dura prova Bologna e danneggiò gravemente le terre del suo contado, impedendone la regolare coltura $\mathrm{e}$ manutenzione idrica. Fin da subito Azzo mirò a colpire il territorio bolognese e a tentare di inondarlo: prima ancora di dichiarare formalmente guerra, fece costruire sterpate oltre il fiume Panaro e il torrente Muzza, con grave danno delle terre bolognesi confinanti; alcuni uomini di Cento riferirono che egli faceva costruire argini e sterpate anche nel settore più settentrionale del territorio bolognese. Si mirava dunque a chiudere le acque del Panaro e a farle riversare sul contado bolognese, e il consiglio del popolo, in numerose provvigioni dell'ottobre 1295 , fu costretto a ordinare a più riprese agli uomini di Castelfranco, Sant'Agata, Crevalcore, San Giovanni in Persiceto, Argelato e Cento di distruggere ogni argine o manufatto di qualsiasi genere fatto dai modenesi o dai ferraresi. ${ }^{11}$ Larea confinaria tra i territori di Modena e Bologna fu certo il più aspro teatro di scontro, ma lo scenario della guerra si era fatto ben più ampio: nello stesso anno il marchese Azzo VIII si fece promotore di un largo fronte di alleanze con le città ghibelline romagnole, le cui forze militari si concentrarono sotto la guida di Maghinardo Pagani da Susinana, di Galasso di Montefeltro e quindi di Uguccione della Faggiola, il quale condusse le operazioni belliche della lega antibolognese a partire dal febbraio 1297. Questa lega - che comprendeva i comuni di Cesena, Forlì, Faenza, Imola, Bagnacavallo, gli estrinseci di Ravenna, Rimini e Bertinoro, nonché i fuoriusciti bolognesi di parte lambertazza, assieme alle città di Modena, Reggio e Ferrara -, veniva quindi organizzata sia per contrastare il governo papale, sia per minare l'egemonia bolognese verso la Romagna, sottraendole Imola e Dozza, e verso il confine occidentale con Modena. A Bologna si strinsero Parma, Piacenza, Brescia e Milano, con il suo capitano Matteo Visconti, nonché gli estrinseci di Reggio e Modena capeggiati dai Rangoni, che furono i principali artefici della spedizioni militari nel versante orientale montuoso del Frignano.

Le vicende della guerra, che si concluse grazie all'arbitrato di Firenze e di papa Bonifacio VIII con la cessione a Bologna degli importanti castra limitanei di Bazzano e Savignano sul Panaro, sono note. Meno noti e molto importanti sono i risvolti economici e sociali provocati dallo scontro, che vorrei qui ripercorrere con dovizia di particolari, perché ritengo che la sommossa per il pane del 1311 affondi le sue radici proprio in questi anni.

Già nel 1295 il reggimento bolognese annaspava alla continua ricerca di denaro. Bologna si era estenuata con le continue guerre di Romagna, con il pagamento degli stipendiari da tenere sempre pronti all'occorrenza in città, con il frequente invio di truppe e aiuti agli alleati, e la naturale con-

${ }^{11}$ Cfr. docc. n. I e n. III in appendice a Gorreta, La lotta cit., pp. 157-159. 
seguenza delle lunghe guerre - la devastazione e l'incuria dei terreni - si era già da tempo palesata. ${ }^{12}$ Le strategie adottate dal comune per reperire denaro si rincorrono stancamente e sempre simili nelle carte delle riformagioni del consiglio del popolo, conservate in grande quantità presso l'Archivio di Stato di Bologna, a informarci minutamente sulla vita cittadina e sui problemi che di settimana in settimana dovettero affrontare $i$ bolognesi: si toglievano dal bando i Lambertazzi e i magnati, che dovevano presentarsi ad mandata comunis dietro pagamento di una determinata somma; si allargava il consiglio dei duemila a quattromila, per renderlo cespite di maggiori entrate; il 31 gennaio 1295 si ricorreva a una prestanza forzosa di 1.000 lire di bolognini per tutti i prestatores forenses, cioè per coloro che, non abitando in città o nel contado, non erano iscritti nelle società delle armi e della mercanzia ${ }^{13}$; e soprattutto si effettuava la vendita del frumento in modo arbitrario per la quantità da assegnare a ciascuno e per il prezzo. L'anno seguente, alla vigilia del conflitto, oltre al denaro ricavato da una colletta straordinaria imposta ai cittadini, in ragione di 2 denari ogni lira d'estimo, occorrevano ancora 8.000 lire di bolognini per poter completare il pagamento degli stipendiari.

Dalle riformagioni affiora un malessere generale, ben documentato dai provvedimenti presi dal comune contro molti bolognesi che si facevano falsamente chierici e conversi per sfuggire alle collette. Il malcontento è particolarmente profondo nelle terre del contado, sottoposte al pagamento di tasse volte a finanziare la guerra, trattate come paesi di conquista e infestate dai banditi; drammatica è la situazione delle località di confine, che per la loro posizione erano ovviamente più soggette alle scorrerie e alle spoliazioni da parte dei nemici. Lo stato dei castra del contado è in progressivo peggioramento, e continue suppliche sono rivolte al comune cittadino e documentate tra le riformagioni del consiglio del popolo.

Spicca tra esse quella di Castelfranco, uno dei principali borghi franchi bolognesi, fondato nel 1226 lungo la via Emilia verso Modena: ${ }^{14}$ il 28 gen-

${ }^{12} \mathrm{~V}$. Vitale, Il dominio della parte guelfa a Bologna (1280-1327), Zanichelli, Bologna 1901, pp. 62-63; Gorreta, La lotta cit., p. 50 ss.

${ }^{13}$ Gorreta, La lotta cit., p. 51; ASBo, Comune Governo, Riformagioni e Provvigioni, Riformagioni del Consiglio del Popolo e della Massa (1272-1337), vol. III, 2, 31 gennaio 1295.

${ }^{14}$ Su Castelfranco, cfr. M. Librenti - M. Zanarini, Archeologia e storia di un borgo nuovo bolognese: Castelfranco Emilia (MO), in Archeologia medievale in Emilia occidentale. Ricerche e studi, a cura di S. Gelichi, Mantova 1998, pp. 79-113; E. Angiolini, Il "borgo franco" di Castelfranco dalle origini al XV secolo: storia e archeologia, in La nascita del borgo franco. L'evoluzione del territorio dal XIII secolo ad oggi (Quaderno della mostra, Castelfranco Emilia [MO], 15 novembre 2003-10 gennaio 2004), Edizioni Aspasia, Bologna-San Giovanni in Persiceto 2003, pp. 23-27. 
naio 1295 il capitano, il massaro e gli uomini di Castelfranco affermano che essi si trovano in malo et pessimo statu, perché non vi sono uomini sufficienti a provvedere alla difesa e manutenzione del castrum; sono state distrutte oltre 150 case, e quelle che rimangono non sono abitate, perciò cadono a pezzi; gli abitanti delle terre vicine, a causa delle guerre, delle collette a essi imposte, dei frequenti laborerii e degli oneri personali e reali pretesi da Bologna sunt facti pauperes et egeni, tanto che, per pagare i debiti contratti con gli usurai, hanno dovuto vendere i mulini e gli altri beni immobili comuni che possedevano. E per di più sono ancora ingiustamente costretti a pagare la gabella per il mulino che un tempo avevano sul lato ovest del castrum, che è stato distrutto, perché l'acqua che lo alimentava ora va, attraverso il torrente Muzza, verso Sant'Agata. ${ }^{15}$ Gli abitanti di Castelfranco hanno inoltre un debito usurario di 5.000 lire da saldare, e a causa di ciò quasi tutti sono stati banditi; chi è rimasto nel castrum non riesce più a sostenere il peso fiscale, perché sono tenuti a pagare in ragione di 45.000 lire di estimo, quando invece possiedono al massimo 20.000 lire; per questo una cinquantina di famiglie, estimate tra le 1.000 e le 800 lire, se ne sono andate dal castrum per non farvi più ritorno. Il problema è - $\mathrm{e}$ lo sottolinea con forza la supplica - che se ne sono andati i più ricchi, con tutta la famiglia, e si sono recati oltre il torrente Muzza, nel contado modenese, proprio per evitare le insostenibili tasse bolognesi, vendendo i loro beni immobili a persone da cui il comune di Castelfranco non può esigere nulla. Lo stesso massaro nuovo di Castelfranco se ne è andato nella vicinissima Panzano, in territorio modenese, perché temeva di essere incarcerato per debiti se si fosse recato a Bologna a presentare le lamentele dei suoi compaesani, e non si trova più nessuno disposto ad assumere il suo ufficio. Così il vecchio massaro ha consegnato le chiavi del castrum al podestà di Castelfranco e al capitano dei custodi, ai quali non obbedisce più nessuno. Gli abitanti di Castelfranco superstiti chiedono dunque al comune bolognese di provvedere alla riparazione del castrum e di fare in modo che essi possano effettivamente seguire i suoi ordini.

Questo quadro così fosco di uno dei settori strategici del contado bolognese dovette impensierire non poco il reggimento comunale, che decise quasi all'unanimità di far eleggere dal capitano del popolo e dagli anziani e consoli tre sapienti per quartiere, con l'incarico di individuare il modo migliore di soccorrere Castelfranco. Nei mesi successivi fu deciso di diminuire le collette in base a un estimo più razionale, si ordinò alle famiglie fuggite via di fare ritorno al castrum, si decise di ricostruirne le case, di fortificarlo e di renderlo ancora più sicuro. Ma le spese necessarie erano

${ }^{15}$ Gorreta, La lotta cit., doc. X in appendice, pp. 162-164. 
notevolissime, e quindi i lavori procedettero a rilento, tanto che alla fine del 1296 ancora non erano stati completati; e la dice lunga il fatto che, quando si affidò ad alcuni sapienti appositamente eletti, tra cui il banchiere bolognese Romeo Pepoli, il compito di riportare sul posto gli abitanti di Castelfranco che se ne erano andati in precedenza, si conferì loro il potere di costringerli con la forza. ${ }^{16}$ Né mancarono casi di rivolte di intere località al comune bolognese: sappiamo che due anni prima, nell'inverno del 1294, il castrum di Stagno si era ribellato a Bologna, a indizio del fatto che le condizioni delle località fortificate sul confine dovevano essere non troppo dissimili da quelle di Castelfranco. ${ }^{17}$

Aumentava nel frattempo la difficoltà, da parte del comune bolognese, di reperire custodi disposti a recarsi nei castra limitanei per presidiare il confine. Che beneficio avrebbero tratto da questo servizio i bolognesi, anche i più poveri, dall'abbandonare la città e la famiglia per recarsi nelle zone nevralgiche dello scontro, a presidiare fortificazioni spesso assalite e bruciate, poco o per nulla aiutati dall'impotente comune cittadino, che, stretto tra spese continue, stentava anche a versare loro la paga? ${ }^{18}$ Così il comune, per rinfoltire le fila sempre più sparute dei custodi, decideva di cancellare ogni debito ai malpaghi che accettavano di recarsi a presidiare $\mathrm{i}$ castra bolognes $\mathrm{i}^{19}$; ma il provvedimento fu accolto piuttosto freddamente, e al capitano del popolo fu lasciato l'arbitrio sulla pena da applicarsi ai disobbedienti. «Non è più questione di punizioni e di severità: occorre danaro: occorre danaro per tutti, custodi, soldati, stipendiari, per quelli che, assegnati i cavalli loro imposti dal comune, non ricevono alcuna ricompensa, per i nunzi e gli ambasciatori, che partono sì a loro spese, ma che poi vogliono esser rimborsati». ${ }^{20} \mathrm{Nel}$ maggio del 1296 si dovette poi ribadire l'obbligo, per tutti gli abitanti della città e del contado tra i 18 e i 70 anni, di seguire le bandiere del podestà, minacciando gravi pene pecuniarie agli inadempienti: si esentavano solo gli ammalati, dietro presentazione del certificato di un medico e della testimonianza di due uomini degni di fede;

${ }^{16}$ ASBo, Comune Governo, Riformagioni e Provvigioni, Riformagioni del Consiglio del Popolo e della Massa (1272-1337), vol. III, 3, 16 maggio 1295.

${ }^{17}$ Gorreta, La lotta cit., doc. X in appendice, p. 164.

${ }^{18}$ Gorreta, La lotta cit., p. 72. ASBo, Comune Governo, Riformagioni e Provvigioni, Riformagioni del Consiglio del Popolo e della Massa (1272-1337), vol. III, 5, continue richieste di pagamento della paga da parte dei custodi che hanno terminato i loro turni di guardia si ripetono il 26 aprile, 10 maggio, 23 maggio, 1 giugno, 1 luglio 1296 ecc.

${ }_{19}$ ASBo, Atti del podestà, maggio-luglio 1296, cit. in Gorreta, La lotta cit., p. 72. Sono frequenti i processi contro i bolognesi che promisero di recarsi a presidiare il $\mathrm{ca}$ strum di Monteveglio e altri luoghi, per essere alleviati dal peso dei debiti e che poi non mantennero la promessa.

${ }^{20}$ Gorreta, La lotta cit., p. 73. 
pochi giorni dopo si provvedeva a rifare le venticinquine, cui tutti dovevano iscriversi, senza escludere neppure i chierici e i conversi.

La profonda avversione dei cittadini alle armi, testimoniata dal continuo e insistente reiterarsi di questi provvedimenti, rese necessario assoldare sempre maggiori milizie mercenarie, le masnade dei cosiddetti stipendiari, che a volte si rifiutavano di prendere parte alle cavalcate indette dal comune bolognese, perché pagati in ritardo di molti mesi. ${ }^{21} \mathrm{Nel}$ corso del 1297 la dolorosa formula «si trovi ogni mezzo per raccogliere denaro» costella le riformagioni del consiglio del popolo bolognese, che reiterò i soliti provvedimenti a questo scopo, giungendo anche a imporre una vendita forzosa del grano ai cittadini sino al prezzo di 28 soldi la corba ${ }^{22}$ : solo 2 soldi in meno dal prezzo che, come abbiamo visto, scatenò la rivolta cittadina del 1311.

In questa triste congiuntura, numerosi fatti d'arme furono avversi a Bologna e condussero all'incendio e alla completa distruzione di alcuni castra del contado: il 6 aprile 1296 venne incendiato Bisano, il 22 aprile Manzolino; ai primi di giugno dello stesso anno vennero depredati dalle truppe estensi Baratino, Durazzo e Riolo, «con il consiglio e l'aiuto di alcuni uomini del paese» ${ }^{23}$; ai primi di luglio Sant'Agata venne bruciata, mentre nella montagna Liano, nel successivo mese di agosto, finì quasi per cadere in mano di Maghinardo Pagani da Susinana; e ancora nel settembre e dicembre 1296 Sant'Agata veniva nuovamente depredata, e così pure la vicina Crevalcore. Furono spesso alcuni abitanti dei castra stessi, a volte anche alcuni custodi, ad aprire le porte all'esercito estense, prostrati dai continui scontri armati e dalle gravezze imposte dal comune bolognese, che faceva incombere la maggior parte delle operazioni di guerra sulle località del contado: a esse era addossato gran parte dell'arruolamento dei soldati e la taglia pagata per i guastatori, oltre all'esecuzione dei lavori edilizi necessari per la fortificazione delle difese. Tanto che proseguiva l'esodo degli abitanti delle zone di confine del contado bolognese, gravati da multe e debiti usurari, come abbiamo visto nel caso di Castelfranco, verso le terre del marchese.

Nel frattempo a Bologna il consiglio del popolo attribuiva sempre più di frequente poteri via via più ampi a due balie in particolare: i domini de blado, che da semplici ufficiali preposti all'annona, come prevedevano gli

${ }^{21}$ ASBo, Comune Governo, Riformagioni e Provvigioni, Riformagioni del Consiglio del Popolo e della Massa (1272-1337), vol. IV, 2, 27 maggio 1297; Gorreta, La lotta cit., p. 85 .

22 ASBo, Comune Governo, Riformagioni e Provvigioni, Riformagioni del Consiglio del Popolo e della Massa (1272-1337), vol. IV, 4, 18 ottobre 1297.

${ }^{23}$ ASBo, Atti del podestà, 6 aprile 1296, 23 aprile 1296, 7 giugno 1296, cit. da Gorreta, La lotta cit., pp. 89-90. 
statuti comunali della prima metà del Duecento ${ }^{24}$, giunsero a far parte del vertice decisionale del comune bolognese, entrando in ogni consiglio particolare insieme con il podestà e gli anziani e consoli, per prendere provvedimenti relativi alla guerra stessa, alle masnade, ai castra; e i domini quinque super augendis introitibus et minuendis expensis, che troviamo invece nominati per la prima volta nel maggio 1298, con l'incarico di porre rimedio alle gravi difficoltà economiche in cui versava il comune. ${ }^{25}$ Essi non seppero fare altro che imporre prestanze e collette, richiedendone almeno sei dal 14 gennaio al 17 dicembre 1298, e costringendo gli estimati a pagare fino a 12 soldi per ogni lira d'estimo. ${ }^{26} \mathrm{Ed}$ è in entrambe questa balie che troviamo ripetuto spesso il nome di Romeo Pepoli, anche solo come semplice consigliere aggiunto agli altri; quasi ogni atto del comune in cui si affida un compito o una speciale autorizzazione a qualcuno termina con la formula «salvo semper omni officio et arbitrio dominorum de blado et domini Romei de Pepolis». ${ }^{27}$

Uno degli ultimi atti dei bolognesi nel corso della guerra fu un atto quasi disperato, che doveva poi tornare a danno dell' intero comune: gli uomini della podesteria di Galliera procedettero alla tagliata del Reno, cioè all'apertura di una grande fenditura nell'argine destro del fiume; le acque traboccarono e allagarono oltre 30.000 tornature di terreno, pari a 6240 ettari. ${ }^{28}$

Così lo scontro si concluse in sostanza senza vincitori né vinti: a Bologna furono sottratte Imola e Dozza, che essa custodiva per la Chiesa; le terre del contado erano state quasi completamente devastate e molte strade risultavano essere distrutte e completamente impraticabili ${ }^{29}$; i due castra conquistati a duro prezzo, Bazzano e Savignano sul Panaro, erano semidistrutti, tanto che il 30 dicembre 1299 il consiglio del popolo prese la

${ }^{24}$ Statuti del comune di Bologna dall'anno 1254 all'anno 1267, a cura di L. Frati , Bologna 1869-1884, voll. 3. (Deputazione di storia patria per le province di Romagna, Monumenti istorici, s. I, Statuti n. 1), vol. III, pp. 499-526, passim.

${ }_{25}$ ASBo, Comune Governo, Riformagioni e Provvigioni, Riformagioni del Consiglio del Popolo e della Massa (1272-1337), vol. IV, 5, 12 maggio 1298; Gorreta, La lotta cit., pp. 96-97. Essi avevano un potere assai più esteso dei quattro defensores averis, perché avevano diritto di sorvegliare tutti i consigli e le balie, di opporsi a ogni spesa da loro giudicata eccessiva o inutile, e di intraprendere qualunque azione giudicata utile al reperimento di nuovi fondi.

${ }^{26}$ ASBo, Comune Governo, Riformagioni e Provvigioni, Riformagioni del Consiglio del Popolo e della Massa (1272-1337), vol. IV, 5: 14 gennaio, 10 aprile, 12 maggio, 16 luglio; vol. IV, 6: 23 settembre, 17 dicembre 1298.

${ }^{27}$ Gorreta, La lotta cit., p. 98.

${ }^{28}$ ASBo, Comune Governo, Riformagioni e Provvigioni, Riformagioni del Consiglio del Popolo e della Massa (1272-1337), vol. V, 1, 26 luglio 1299.

${ }^{29}$ Ibidem, vol. V, 2, 21 agosto 1299. 
decisione di intraprendere i lavori più urgenti nel contado, intervenendo «precipue in muro de Bazano, qui in magna quantitate ad ruinam trait et iam ex eo in quantitate cecidit, et in bitifredis qui sunt excoperti et sine clausura, et in [ ] ${ }^{30}$ de Savignano, et in muro quod cecidit, et in turribus de Castro Franco, que sunt discoperte et disspallanchate, ita quod super hiis stare non potest ad custodiam dicti castri». ${ }^{31} \mathrm{E}$ ancora una volta, poiché le casse del comune bolognese erano vuote, si ordinava ai massari di Savignano e di Bazzano di provvedere alle spese, e se il denaro stanziato fosse risultato insufficiente per gli ufficiali preposti alla riparazione dei $\mathrm{ca}$ stra, essi avrebbero dovuto ricorrere ai domini et officiales qui nunc presunt officio mollendinorum comunis Bononie, gli ultimi evidentemente ai quali restava ancora una qualche liquidità.

$\mathrm{Al}$ termine del conflitto le riformagioni registrano ancora la povertà delle terre soggette: i massari di Castel San Pietro rifiutavano di recarsi a Bologna per non venire imprigionati a causa dei debiti contratti dalla comunità da loro amministrata; Crespellano, Sant'Agata, Piumazzo, Crevalcore, Serravalle e tutte le terre sul confine con il modenese supplicarono il consiglio del popolo bolognese di esentarli dalle tasse, a causa della grande miseria in cui la guerra le aveva ridotte; Tossignano, presso Imola, si trovava senza custodi, poiché tutti gli uomini erano fuggiti a causa della scarsezza dei viveri. ${ }^{32}$ La pace sembrò portare, nei primi mesi del 1299, l’agognato sollievo a questa difficile situazione, poiché vennero rilasciati tutti i prigionieri da ambo le parti, fu eliminata ogni rappresaglia e il marchese bandì ufficialmente che tutte le vie fossero aperte nelle sue terre per chiunque volesse passarvi, giungendo persino a vendere al comune bolognese ingenti quantità di grano a buon prezzo. ${ }^{33}$

Ma il sollievo fu di breve durata. Appena due mesi dopo, il 26 maggio 1299, il procuratore del comune di Bologna Uguccione Soldaderii comparve innanzi al priore e al gonfaloniere di giustizia di Firenze, al cui arbitrato le parti erano ricorse per suggellare la pace, lamentando le scorrettezze di Azzo d'Este. ${ }^{34}$ Egli avrebbe dovuto aprire le strade delle sue terre, sia per terra sia per mare, «ita quod mercatores et quilibet alii volen-

${ }^{30}$ In sospeso nel ms.

${ }^{31}$ ASBo, Comune Governo, Riformagioni e Provvigioni, Riformagioni del Consiglio del Popolo e della Massa (1272-1337), vol. V, 3, c. 174v e ss., pubblicato in appendice a Gorreta, La lotta cit., doc. XV, pp. 167-168.

32 ASBo, Comune Governo, Riformagioni e Provvigioni, Riformagioni del Consiglio del Popolo e della Massa (1272-1337), vol. IV, 5, 31 gennaio 1298; vol. V, 1, 20 febbraio e 14 luglio 1299.

${ }^{33}$ Ibidem, vol. V, 1, 2 febbraio 1299, 5 febbraio 1299, 13 marzo 1299.

${ }^{34}$ ASBo, Comune Governo, Atti e diritti del comune, fascicolo n. 55, pubblicato in appendice a Gorreta, La lotta cit., doc. XVII, pp. 169-172. 
tes inde ire et redire possent cum mercationibus et sine, liberi et securi». Ma non lo aveva fatto, le strade erano rimaste chiuse, e anzi il marchese aveva espressamente proibito «quod mercatores comunis Bononie et alii mercatores volentes conducere frumentum et bladum ad ipsam civitatem Bononie ne conducerentur per aquas et stratas terrarum que detinentur per ipsum dominum marchionem», aumentando inoltre il dazio richiesto ai mercanti in ragione di 4 denari per lira del valore stimato di ogni merce diretta a Bologna. Azzo d'Este continuò a insidiare il comune bolognese anche negli anni seguenti, contando sulla fazione marchesana che aveva da tempo allignato in città; nel gennaio del $1301 \mathrm{fu}$ riferito al consiglio del popolo che egli aveva stabilito di prendere la città per fame, tagliandole le vettovaglie e dando oro per corrompere i custodi dei castelli, favorito in ciò dal fatto che i suoi sostenitori sedevano nel consiglio del popolo stesso e lo tenevano informato sulle azioni intraprese dei bolognesi. ${ }^{35} \mathrm{E}$ nel frattempo Bologna, per rimpinguare le sue casse, continuava a mungere le terre del contado ridotte all'estrema miseria: nel triennio 1300-1302 le suppliche delle terre del contado, che non riuscivano più a pagare le collette, sono continue; molto spesso, per tutta risposta, esse vengono bruciate. La carestia infuriava, e Bologna fu costretta ad acquistare il grano all'esterno, rivolgendosi a Venezia nell'agosto del $1303 .^{36}$

La penuria di biade che provocò la rivolta cittadina del 1311 attanagliava dunque la città almeno dagli inizi del secolo, a causa della crisi agricola indotta da anni di guerra che avevano portato a profonde e ripetute devastazioni nel contado bolognese, e a una inevitabile incuria che aveva in particolare danneggiato la rete idrica del territorio. Non mi è stato possibile, data l'estrema copiosità del materiale documentario, analizzare tutte le riformagioni del consiglio del popolo bolognese tra il 1303 e il 1311; una ricognizione più limitata mi ha tuttavia permesso in primo luogo di datare con precisione al 29 aprile 1311 la rivolta per il frumento citata nelle cronache. Procedendo a ritroso e in seguito alla rivolta per oltre quattro mesi complessivi di sedute del consiglio del popolo - dall'8 marzo 1311 al 25 giugno dello stesso anno -, ho potuto delineare un quadro abbastanza significativo delle disastrose condizioni sociali ed economiche del contado, soprattutto nel settore rivolto verso la nemica Modena, con le sue ripercussioni sulla vita cittadina bolognese.

In questo breve lasso di tempo, vengono segnalati ben undici settori del territorio del contado per i quali urge un intervento immediato. Il 19

${ }^{35}$ ASBo, Comune Governo, Riformagioni e Provvigioni, Riformagioni del Consiglio del Popolo e della Massa (1272-1337), vol. V, 5, 22 gennaio 1301, 27 gennaio 1301.

${ }^{36}$ Ibidem, vol. VI, 4, agosto 1303; Gorreta, La lotta cit., p. 149. 
marzo viene riferito al consiglio del popolo che la chiusa del ramo di Reno è distrutta, e che bisogna trovare 1.500 lire per ripararla; ma come trovare il denaro per farlo? Come di consueto per queste questioni spinose e sostanzialmente irrisolte, con 301 voti a favore e 13 voti contrari si stabilì di affidare la questione al capitano del popolo e agli anziani e consoli.

Lo stesso giorno fu fatto presente che il fiume Ravone, dal ponte di strada $\mathrm{S}$. Felice in giù, era talmente pieno che quando pioveva le acque tracimavano e chi possedeva terreni nei dintorni aveva subito gravi danni. Si rendeva necessario intervenire scavando e ripulendo il letto del fiume, nonché allargando e riattando gli argini. Con 300 voti favorevoli e 14 contrari si decise allora di procedere all'elezione di due soprastanti, scelti tra coloro che possedevano terre nelle vicinanze, per decidere il da farsi. ${ }^{37} \mathrm{E}$ ancora lo stesso giorno fu ricordato che «multi et multi de populo et de societate arcium et armorum populi Bononie, qui vere sunt de parte ecclesie e ieremensium», erano stati grandemente danneggiati dal temporaneo divieto di andare ad abitare a Castelfranco, Crevalcore, Sant'Agata e Nonantola, cioè nei castra di confine con il contado modenese. Questi uomini non potevano fare la spola quotidianamente con queste zone, ed erano così impossibilitati a lavorare le loro proprietà ivi situate, «quia pro maiori parte sunt pauperes et non habent qui pro eis laborent et coligent ipsa bona». Con 260 voti favorevoli e 54 voti contrari fu loro concesso di prendersi cura personalmente delle loro proprietà. ${ }^{38}$

Pochi giorni dopo, il 23 marzo 1311, si sottolineava nuovamente la gravità dell'inondazione del fiume Savena, che l'anno prima aveva rotto gli argini in più punti e aveva inondato «magnas quantitates terrarum imblavatarum, bene duo millia tornaturarum et ultra»: 2.000 tornature, cioè oltre 416 ettari di terreno. Gli uomini del posto facevano presente ai cittadini che bisognava trovare una soluzione a questo problema per scongiurare il pericolo di distruzione per tutte le terre della contrada, che avrebbero potuto essere rese sterili dalle acque. A suo tempo il consiglio del popolo aveva stabilito che la questione dovesse essere risolta dagli anziani del mese di febbraio 1310, e questi ultimi avevano nominato un sovrastante alla riparazione degli argini nella persona di Romeo Pepoli, con la facoltà di associarsi nell'incarico persone competenti a lui gradite. Gli si era attribuita allora «plenam et liberam potestatem, iurisdictionem, abitrium et bayiam faciendi et fieri faciendi omne opus et laboreria», che gli

${ }^{37}$ ASBo, Comune Governo, Riformagioni e Provvigioni, Riformagioni del Consiglio del Popolo e della Massa (1272-1337), vol. X, 1, cc. 8-9.

${ }^{38}$ Ibidem, cc. 9-10. 
vengono riconfermate in questa occasione, con 285 voti favorevoli e 27 contrari. ${ }^{39}$

Il 15 aprile 1311 i procuratori del comune Alberto Baciacomari ed Egidio da Argelato affermarono in consiglio che la strada di San Vitale, che portava a Medicina, «est devastata et in totum ruinata per aquam Sapine», tanto che carri e cavalli non potevano più transitare per il ponte. Si chiedeva di procedere velocemente alla manutenzione della strada, e se ne assegnò il compito al capitano del popolo e agli anziani e consoli. ${ }^{40}$

Il 28 aprile 1311, alla vigilia della rivolta del pane, una supplica di tutti gli abitanti del contado bolognese, e in primo luogo degli abitanti di San Giovanni in Persiceto e delle sue pertinenze, informò il consiglio del popolo bolognese che il fiume Samoggia aveva nuovamente rotto gli argini in più punti, «ita quod bladum in maxima quantitate dispergitur annuatim, scilicet usque vel ultra sex milia corbium»: 6.000 corbe di frumento, pari a 471.868 litri $^{41}$, perse ogni anno. ${ }^{42} \mathrm{Si}$ chiedeva di procedere alla manutenzione del fiume, a spese degli abitanti di S. Giovanni in Persiceto e di tutti coloro che possedevano terreni in quella contrada, dalla via che portava a S. Govanni fino al fiume Reno. È descritto con grande minuzia l'intervento da farsi: bisognava allargare gli argini alla lunghezza di 25 piedi, alzarli fino a 5 piedi ed era necessario pulire il letto del fiume. ${ }^{43}$

Lo stesso 28 aprile gli eredi di un tale Giovanni di Salamone, abitante nella terra di Val di Sambro, porgono una supplica relativa al suo mulino. Egli possedeva un mulino nella zona, presso un rio che scorreva in modo utile alla macinatura solo grazie alle piogge. A causa della guerra questo mulino è stato distrutto, e ora i suoi eredi vorrebbero ricostruirlo, ma a causa delle frequenti inondazioni il rivo è ruinato; chiedono perciò al comune di Bologna il permesso di provvedere alla sistemazione del rio e alla ricostruzione del mulino, dicendosi poi disposti a pagare le tasse relative alla molitura. Il permesso viene concesso quasi all'unanimità. ${ }^{44}$

${ }^{39}$ Ibidem, c. 12.

${ }^{40}$ Ibidem, c. 21.

${ }^{41}$ La corba bolognese, come misura di capacità per gli aridi, era pari a 78,6448 litri, come riporta A. Martini, Manuale di metrologia, ossia misure, pesi e uomini in uso attualmente e anticamente presso tutti i popoli, ed. Loescher, Torino 1883 (rist. anast. Roma 1976), p. 92.

42 ASBo, Comune Governo, Riformagioni e Provvigioni, Riformagioni del Consiglio del Popolo e della Massa (1272-1337), vol. X, 1, cc. 26-27.

${ }^{43}$ Ibidem, cc. 26-27.

${ }^{44}$ Ibidem, cc. 27 e 29. Si fa riferimento, nella supplica, a un non meglio identificato liber comunis Bononie molendinorum comitatus Bononie, in cui il mulino distrutto sarebbe stato regolarmente iscritto. 
Alcuni giorni dopo, il 10 maggio 1311, venivano segnalati nuovi settori di intervento nel contado. I ponti e i passi presso il castrum dell'Uccellino (attuale Torre dell'Uccellino) e di Garghi de Capraria (= di Caprara dell'Uccellino) erano «totaliter devastati, ita quod sine periculo transiri non potest»; si stabilì allora di rifarli completamente, per potersi recare in direzione di Ferrara. Ma soprattutto, una volta ancora si doveva trovare denaro per provvedere «circha reparationem castrorum comunis et populi Bononie et ipsorum custodiam et etiam balistarum et aliarum rerum pro defenssione comitatus Bononie nec non circha fortificationem civitatis Bononie», e non vi era denaro disponibile. Si stabilì allora, con 361 voti favorevoli e 64 contrari, di imporre una colletta ai cittadini bolognesi e ai nobili del contado, provvisti di estimo, in ragione di 1 denaro ogni lira d'estimo; nessun cenno ai comitatini, che evidentemente, con grande realismo politico, non erano ritenuti essere in grado di versare alcun contributo. Si approvò inoltre all'unanimità che tutte le entrate rappresentate dai dazi e dalle gabelle del comune venissero usate per la fortificazione del contado. Ma ancora non bastavano i fondi, e si cominciò a rinunciare al mantenimento di alcune fortificazioni: alla richiesta di istruzioni sulla possibilità di continuare a tenere custodi presso il castrum di Belvedere - sul confine modenese, tra Rocca Corneta e Gaggio Montano - e di Maçincolli - località non meglio identificata - con 324 voti favorevoli e 76 contrari si decise di provvedere alla loro completa distruzione. ${ }^{45}$

Né la situazione era migliore nelle località più prossime a Bologna. Il 21 maggio 1311 il sindaco di Granarolo, Bonbologno di Bencivenne, informò il consiglio del popolo che le vie intorno alla località erano tutte distrutte, in modo che non vi si poteva transitare né a piedi né a cavallo. Chiedeva di poter costruire quattro ponticelli in muratura, in modo che sotto di essi potesse scorrere l'acqua in eccesso che aveva reso impraticabili le strade in alcuni punti. Con 297 voti favorevoli e 69 contrari fu stabilito che gli anziani e consoli del mese di giugno dovessero eleggere due soprastanti con il compito di «imponere per tres gradus» una colletta: i più ricchi della zona avrebbero dovuto versare non più di 15 soldi, i meno ricchi 6 soldi e il ceto intermedio 10 soldi.

Nella medesima seduta del consiglio del popolo seguiva a ruota la supplica di Basilio Mangiavacca, preconsole della società dei notai, che - così come molti altri cittadini bolognesi - possedeva alcune proprietà presso

${ }^{45}$ Per la localizzazione dei castra e dei toponimi in territorio bolognese, cfr. L. Casini, Il contado bolognese durante il periodo comunale (secoli XII-XV), Arnaldo Forni Editore, Bologna 1991; per Belvedere, cfr. p. 239, mentre non ho trovato alcun riferimento a una località denominata Maçincolli. 
Minerbio e Cazzano. Gli abitanti di quelle contrade avevano dovuto sopportare l'estremo rigore dell'inverno, e non erano riusciti a far macinare le biade necessarie ai loro famuli presso i mulini che si trovano a una certa distanza e che erano risultati irraggiungibili «propter malas vias et passus». Non era stato finora possibile costruire mulini nelle vicinanze sul fiume Savena; il preconsole chiedeva allora - e ne ottenne il permesso, con 267 voti favorevoli e 99 voti contrari - di edificare un mulino presso Minerbio, senza prelevare indebitamente acqua dal fiume Savena. ${ }^{46}$

E ancora il 28 maggio 1311 si ricordava al consiglio del popolo la triste situazione delle località vicine a San Giovanni in Persiceto. Nel mese di dicembre del 1310 si era deciso che la via che portava da San Giovanni nella curia di Borgo Panigale, denominata via di San Martino, per la quale si arrivava a Panigale Vecchio e alle località poste a ovest del fiume Reno, dovevano essere inghiaiate per circa due miglia - poco più di 3,8 chilometri - a spese degli abitanti di Borgo Panigale Vecchio, San Vitale, Pollicino a ovest del Reno, Canetolo e Volta a ovest del Reno, e Bagni. Ma la spesa era risultata intollerabile per le località citate «propter paupertatem et carastiam magnam quam habent», e a causa dei gravi oneri che dovevano sostenere per la manutenzione della strada di San Giovanni in Persiceto e di Crevalcore, portando inoltre delle tegole presso i vari castra del comune di Bologna della zona. Per inghiaiare la strada vero Borgo Panigale avrebbero dovuto versare ancora circa 3 lire di bolognini per pertica, e la spesa era veramente intollerabile. Così gli abitanti del luogo chiedevano di essere esentati dall'inghiaiatura, e ottennero questa esenzione con 241 voti favorevoli e 41 contrari. ${ }^{47}$

L'11 giugno successivo si evidenziava la necessità di un intervento nella curia di Argelato, nella quale esisteva una strada, in località detta la Via della Croce, talmente rovinata che non vi si poteva passare né a cavallo né a piedi. Si rendeva necessario sgombrare i fossati del comune e si chiedeva di costruire chiaviche in muratura a spese dei residenti, ognuno per la parte confinante con la sua proprietà. Il permesso venne concesso con 324 voti favorevoli e 14 contrari. ${ }^{48}$

Le località citate per le quali era necessario l'intervento dell'uomo - il corso del Reno, del Ravone, del Savena, del Samoggia; la strada di San Vitale verso Medicina; la Val di Sambro; Torre dell'Uccellino e le località verso Ferrara; Castelfranco, Crevalcore, San Giovanni in Persiceto, Sant'Agata e Nonantola, Granarolo, Minerbio e Cazzano, Borgo Panigale

\footnotetext{
${ }^{46}$ ASBo, Comune Governo, Riformagioni e Provvigioni, Riformagioni del Consiglio del Popolo e della Massa (1272-1337), vol. X, 1, cc. 38 e 41.

${ }^{47}$ Ibidem, vol. X, 1, cc. 47-49.

${ }^{48}$ Ibidem, vol. X, 1, cc. 50 e 53.
} 
Vecchio, San Vitale, Pollicino a ovest del Reno, Canetolo, Volta a ovest del Reno e Bagni, Argelato - sono disseminate un po' in tutto il contado bolognese, con una particolare concentrazione nel settore di pianura verso Modena. Ma le cose non andavano meglio in città, e pare che anche la manutenzione delle terre immediatamente a ridosso di Bologna lasciasse a desiderare: il 23 marzo 1311 si chiedeva al consiglio del popolo di provvedere a che le vigne, i possedimenti e le località comprese nella guardia di Bologna fossero ben custodite, poiché molti popolari bolognesi rovinavano le proprietà rubandone i frutti e l'uva in particolare, ma anche le pertiche e i giunchi utilizzati come sostegno per le viti, nonché il legno utilizzato per la costruzione del palancato, che girava attorno alle fosse della città. Si stabilì con 294 voti favorevoli e 28 contrari che gli anziani e consoli dovessero verificare se la custodia delle vigne, delle proprietà e delle località situate nella guardia della città, nonché del palancato, spettava al podestà e alla sua curia, senza alcuna spesa aggiuntiva da parte del comune. In caso affermativo, il podestà doveva nominare uno o due notai a espletare questo compito; in caso negativo, avrebbero dovuto provvedere a risolvere il problema gli anziani e consoli. ${ }^{49}$

Nel giugno del 1311 si decise nuovamente di provvedere alla fortificazione della città di Bologna, perché i fossati non risultavano essere stati scavati, e neppure le porte cittadine erano state completamente costruite. Contestualmente si chiedeva di provvedere ai castra del contado aumentandone i custodi, costruendo balestre e curando i rifornimenti dei castra stessi. ${ }^{50} \mathrm{La}$ questione fu deferita al podestà, al capitano, agli anziani e consoli ai quali toccava provvedere «de fortiliciis civitatis, custodia castrorum et ambaxatoribus, spiis et nunciis mitendis».

Tutti questi provvedimenti, relativi alla cura e alla manutenzione delle terre della città e del contado, approvati, come abbiamo visto, sempre a larga maggioranza, necessitavano però dello stanziamento di somme ingenti per potere essere realizzati. Ma il denaro non era certo copioso nelle casse del comune, e altri provvedimenti ne richiedevano continuamente. Ad esempio i domini et officiales municionis castrorum et fortiliciarum di Bologna, regolarmente eletti ad brevia per il primo semestre del 1311, furono costretti a chiedere umilmente al comune di essere pagati. ${ }^{51}$ Così pure i capitani della montagna Nicola da Monzuno e Trisio da Monzuno, che dovevano essere pagati grazie a una colletta imposta agli abitanti del luogo; la maggior parte del denaro era stato esatto, ma erano rimasti alcuni mal-

\footnotetext{
${ }^{49}$ Ibidem, vol. X, 1, cc. 12-16.

${ }^{50}$ Ibidem, vol. X, 1, cc. 55-56.

${ }^{51}$ Ibidem, vol. X, 1, cc. 5-6.
} 
paghi, elencati regolarmente presso il disco dell'Orso, i quali vennero costretti a saldare le ultime 62 lire e 10 soldi. $^{52}$

Lo stato di estrema indigenza in cui versano gli strati più deboli della popolazione e della massa di poveri che si è riversata a Bologna è efficacemente dipinto dalle suppliche - tredici in tre mesi - presentate da altrettanti ordini religiosi al consiglio del popolo bolognese.

Il 15 aprile 1311 frate Guido, insieme con i suoi confratelli dediti «ad substentationem omnium pauperorum et presertim pauperorum verecundorum», presenti «in maxima quantitate» a Bologna, «satis ultra solitum morem», non riescono più a sopperire alle loro necessità, anche perché le elemosine solite sulle quali potevano contare in passato sono venute meno. Chiedono dunque un aiuto finanziario al comune di Bologna, che stanzia per loro 25 lire di bolognini. ${ }^{53}$

Nello stesso giorno porgono una supplica le sorelle del monastero di Santa Maria di Valverde, situato lungo la via che porta a Santa Maria in Monte, le quali si trovano «in maxima egestate, ita quod non habent quid comedant»; così pure le sorelle del convento di San Salvatore extra circulam di strada Santo Stefano, "quia in maxima paupertate sunt et cotidie mendicant nec habent penitus unde se allere». Un muro della casa in cui vivono è crollato, e hanno già dovuto pignorare i loro calici e i loro ornamenti per la liturgia per ripararlo. Se il comune non le aiuta - recita la supplica - saranno costrette a lasciare il monastero.

Quasi con gli stessi termini chiedono aiuto finanziario al comune le sorelle del monastero de Convertitis e quelle del monastero di Santa Maria di Castel dei Britti, che non hanno di che nutrirsi; le religiose del beato Nicola del campo del Mercato non sanno come campare, e per di più un muro della loro chiesa sta per rovinare a terra; se cadesse del tutto la chiesa verrebbe completamente distrutta, ma le povere donne non hanno denaro per ripararlo, e perciò chiedono al comune di intervenire. Vi sono anche i frati di San Agostino di strada Maggiore a chiedere sostegno economico al comune.

Sempre il 15 aprile vi sono infine le due suppliche dei rettori dell'ospedale del beato San Procolo di Bologna, frate Benvenuto, che ha cominciato a costruire una chiesa dedicata al beato Dionigio sul terreno dell'ospedale, di fronte al monastero di San Procolo; e frate Gibertino dell'ospedale di san Giacomo del ponte di San Ruffillo. Il primo si trova in una situazione di grave indigenza, "propter multitudinem pauperum et infirmorum et gi-

${ }^{52}$ Ibidem, vol. X, 1, cc. 8-9. La costrizione al pagamento incontrò 242 voti favorevoli e 47 voti contrari.

${ }^{53}$ Ibidem, vol. X, 1, cc. 19 e 21. Il denaro viene concesso con 368 voti favorevoli e 3 contrari. 
tadellorum pervenencium cotidie ad ospitalle», che sono in grande quantità; egli non riesce più a preparare il cibo per tutti, né può finire la chiesa, perché l'ospedale non ha rendite sue con cui sostentarsi e vive delle elemosine fatte dai cittadini, ora ormai quasi nulle. Il secondo dichiara che a capo del ponte era stata costruita una cellula sopra il fiume Savena, su una piccola proprietà del comune di 30 piedi, a spese di domina Gerardina, che abitava nelle vicinanze e che aveva destinato questa proprietà ai poveri. Non l'ha però lasciato per iscritto, e si richiede pertanto che la cellula venga assegnata in comodato d'uso ai numerosi poveri dell'ospedale, concessione che viene effettuata con 356 voti favorevoli e 16 contrari.

In tutti i casi in cui è stato richiesto l'aiuto finanziario del comune, vengono elargite 10 lire, votate con provvedimento unico dal consiglio del popolo con 368 voti favorevoli e 3 contrari. ${ }^{54}$

Poco più di un mese dopo, il 28 aprile 1311, è la volta delle suppliche dei frati che dimorano all'esterno della circla di Bologna, nel borgo di San Mamolo; vi hanno costruito una chiesa in onore dello Spirito Santo, e sono tanto poveri che non hanno di che vivere. Quasi con le stesse parole le sorelle di San Matteo Apostolo, che dimorano all'esterno della circla lungo la via Saragozza, e quelle del convento di San Lorenzo di strada Castiglione, ribadiscono la loro impossibilità a sostentarsi da sole. Queste ultime, in particolare, ricordano che gli statuti cittadini prevedevano il versamento di 100 corbe di frumento l'anno da parte del comune; così pure i frati del beato Giacomo de Caxadeo chiedono il versamento di 10 corbe di frumento l'anno. ${ }^{55}$ Il consiglio del popolo vota quasi all'unanimità un intervento in questi casi; e si noti che non fornisce le quantità di frumento stabilite, ma una somma di 10 lire al convento di strada Castiglione e di 5 lire al fratelli del beato Giacomo de Caxadeo.

Mi pare evidente da tutti questi indizi, disseminati nelle riformagioni del consiglio del popolo, che la congiuntura economica fosse particolarmente dura e che i prezzi delle derrate alimentari fossero saliti alle stelle negli ultimi sei mesi. Per quanto riguarda le biade, possiamo trarre altre notizie dalle riformagioni stesse, che ci informano degli estremi tentativi messi in opera dal comune per migliorare la situazione. I rifornimenti erano difficili, come abbiamo visto, già da anni, e nelle settimane precedenti la rivolta questa difficoltà, acuita dalla cronica mancanza di fondi nelle case del comune, si accentuò.

Sappiamo che un certo Arduino da Dugliolo nel mese di ottobre del 1310 aveva portato a Bologna 65 corbe di sale, «pro ubertate facienda co-

${ }^{54}$ Ibidem, vol. X, 1, cc. 20- 22.

${ }^{55}$ Ibidem, vol. X, 1, cc. 26 e 29. 
muni et populo Bononie», contando sul fatto che una riformagione del capitano del popolo e degli anziani e consoli aveva eliminato i dazi per operazioni di questo tipo. Ma a distanza di cinque mesi $\mathrm{i}$ frati che sovrintendevano all'ufficio del sale chiedevano ad Arduino il pagamento del dazio, ed egli fu costretto a rivolgersi al consiglio del popolo, ottenendo con 290 voti favorevoli e 24 contrari l'esenzione richiesta. ${ }^{56}$

Nel gennaio del 1311 il dottore in legge Paolo Galluzzi e i giurisperiti Bonifacio Tederisi e Paolo Odofredi erano stati inviati come ambasciatori del comune presso il conte di Romagna per chiedere il permesso di portare biade a Bologna. Pare che esse venissero effettivamente acquistate, ma non vi sono indicazioni nelle fonti relative alla loro quantità e alla data in cui furono effettivamente portate in territorio bolognese; quello che è certo è che due mesi dopo gli ambasciatori, il 23 marzo 1311, chiedevano al consiglio del popolo di essere pagati 220 lire e 10 soldi per la loro ambasceria, per la quale non avevano ancora ricevuto alcun compenso. ${ }^{57}$

Sappiamo inoltre che, per trovare il denaro necessario all'acquisto di biade al di fuori del contado bolognese, i frati Zaccaria di Argelato e Guglielmo del fu Giacomo, preposti all'ufficio del sale, avevano pagato a Giovanni Saboto e a Francesco Botti, deputati all'ufficio delle biade, 638 lire, 13 soldi e 7 denari, tratti dal denaro da loro raccolto grazie al dazio del sale, per saldare il frumento comprato in Romagna. Avevano inoltre fornito loro 80 sacchi per trasportare le granaglie, gli stessi sacchi che loro utilizzavano per il sale; ne chiedevano la restituzione ai domini de blado, così come anche i conduttori del dazio del vino chiedevano loro la restituzione di 4.000 lire avute per l'acquisto delle biade. ${ }^{58}$

L'esame delle riformagioni successive al 29 aprile 1311, giorno della rivolta - che nelle riformagioni del consiglio del popolo viene definita come «rumor factus in platea comunis et porte Ravenatis die iovis .xxviiii. aprilis» -, permette di cogliere la soluzione politica che il comune bolognese tentò di dare al problema vitale del rifornimento alimentare della città. Nella prima riunione utile del consiglio del popolo, avvenuta il 31 aprile 1311, vennero prese delle misure d'urgenza: in primo luogo vennero espulse da Bologna e dal suo contado tutte le bocche ritenute di peso in una situazione di carestia, individuate nei forestieri, nei banditi bianchi ghibellini provenienti dal ferrarese e in tutti gli estrinseci lontani dalle loro città, ai quali si davano tre giorni di tempo per andarsene; nessun bolognese do-

${ }^{56}$ Ibidem, vol. X, 1, c. 8 .

${ }^{57}$ Ibidem, vol. X, 1, cc. 10 e 15 . Il pagamento fu autorizzato con 252 voti favorevoli e 60 contrari.

${ }^{58}$ Ibidem, vol. X, 1, c. 10. 
veva dare loro aiuto o ricetto, sotto pena della distruzione della casa e del pagamento di 100 lire di bolognini. Si stabilì inoltre che il frumento del comune fosse venduto a 20 soldi la corba, ma solo ai veri cittadini bolognesi: cioè agli iscritti nelle matricole delle società delle arti e delle armi di Bologna, appartenenti alla parte della chiesa e dei geremei, che avevano preso parte agli eserciti e alle cavalcate del comune. Si intimava a chiunque volesse vendere delle biade di farlo esclusivamente nella piazza del comune e nel trebbio di porta Ravennate, sotto pena della distruzione della casa e di una pena pecuniaria di 10 lire di bolognini per ogni corba di frumento venduta in altro luogo; si proibiva ai cittadini e ai comitatini di segare le biade ancora in erbis, sotto pena di 10 lire di bolognini; si vietava ai beccai di dare biade da mangiare agli animali, con l'esclusione dei cavalli, dei maiali, degli asini e dei muli, sotto la stessa pena. ${ }^{59}$

Dieci giorni dopo si stabiliva di procedere a una nuova elezione dei $d o-$ mini et notarii bladi, in modo che fosse assicurata abbondanza di granaglie al popolo bolognese. In seguito a una discussione all'interno del consiglio del popolo, si giunse alla conclusione che però, prima di procedere a una nuova elezione, si doveva provvedere a precisare meglio «de eorum officio, arbitrio et balia» ${ }^{60}$; questo compito venne assegnato agli anziani e consoli e ai sapienti da loro scelti, e nel giro di una settimana ciò che essi avevano deciso venne nuovamente sottoposto al consiglio. Vennero definiti con grande precisione l'arbitrium e le competenze dei nuovi domini de blado, che avrebbero dovuto mettere in atto ogni strategia possibile per rifornire in modo adeguato la popolazione cittadina e scongiurare ulteriori rivolte per il pane: avrebbero potuto acquistare e condurre il frumento e ogni altro tipo di granaglia dai distretti di altre città in territorio bolognese; avrebbero potuto venderlo in città al prezzo da loro stabilito, con il permesso degli anziani e consoli; avrebbero dovuto adottare qualunque misura necessaria per impedire l'esportazione di granaglie o farine dal territorio bolognese, e vigilare affinché le granaglie provenienti dai mulini del contado bolognese giungessero nelle mani dei frati che dovevano poi assegnarle ai vari fornai cittadini, secondo le direttive da essi ricevute; avrebbero anche potuto stabilire i prezzi di vendita del frumento e delle altre granaglie ai fornai stessi. Questi capitoli furono approvati dal consiglio del popolo con 412 voti favorevoli e 32 contrari - si noti la grande partecipazione a questo consiglio del popolo, che solitamente si attestava in questi anni intorno ai 310/330 membri - con alcune importanti precisazioni: l'elezione dei nuovi domini bladi sarebbe passata tra il consiglio dei quattromila, che

${ }^{59}$ Ibidem, vol. X, 1, c. 30.

${ }^{60}$ Ibidem, vol. X, 1, cc. 33-34, 10 maggio 1311. 
avrebbe dovuto eleggere ad brevia quattro domini e quattro notai per ogni quartiere, e il consiglio del popolo, che avrebbe scelto con un nuovo scrutinio un dominus e un notaio per ogni quartiere. Essi avrebbero dovuto prestare una garanzia di 1.000 lire di bolognini per il corretto esercizio della loro carica; si stabiliva inoltre un periodo di vacanza piuttosto elevato per questa carica, 5 anni, e l'impossibilità di esercitare qualunque altro ufficio nel semestre successivo. ${ }^{61}$ Per ottimizzare al massimo l'incarico dei nuovi domini de blado, si decideva ancora, il 14 giugno 1311, di effettuare la loro elezione qualche tempo prima della loro effettiva entrata in carica, affinché potessero provvedere «de novo blado habendo pro anno venturo». ${ }^{62}$

Il meccanismo istituzionale pareva insomma essere stato ben congegnato, ma la situazione era ben lungi dall'essere risolta. Permaneva il maggior ostacolo a un politica annonaria di ampio respiro: non vi era denaro nelle casse di questi ufficiali, e di nuovo si chiedeva al consiglio del popolo, così come durante la guerra contro l'esercito estense, di "generaliter providere et confirmare unde, quomodo et qualiter habeatur pecunia pro blado emendo et merchacione facienda». E ancora una volta si stabiliva quasi all'unanimità, con votazione palese, che il difficile compito spettava al capitano del popolo e agli anziani e consoli, coadiuvati dai sapienti da loro scelti. ${ }^{63}$ I loro provvedimenti dovettero avere un'efficacia ben limitata, se una settimana dopo l'ufficiale ai mulini del comune Leonardo Tettacapra porgeva una supplica, a nome suo e del suo notaio Giacomo di Geri, poiché non avevano il denaro per comprare tutte le cose necessarie alla redazione delle scritture inerenti al loro ufficio; essi chiedevano di poter utilizzare il denaro raccolto dai dazi dei mulini anche per procedere alle spese necessarie al loro lavoro. ${ }^{64}$

Ancora lo stesso giorno si chiedeva al consiglio del popolo di deliberare cosa fare delle biade coltivate nell'anno in corso nel territorio bolognese, e specialmente nelle vicinanze del fiume Panaro; poiché ci si prefiggeva di avere disponibilità di granaglie sia in città, sia nel contado, si chiedeva al consiglio se il raccolto doveva essere lasciato al contado o condotto a Bologna. Con 331 voti favorevoli e 34 contrari fu deciso che ogni provvedimento intorno alle biade doveva rimanere per il momento competenza del capitano del popolo e degli anziani e consoli, cioè delle massime autorità espressione del governo popolare della città. E quattro giorni dopo gli stessi domini bladi, che avevano rimesso all'autorità del podestà, del capi-

${ }^{61}$ Ibidem, vol. X, 1, c. 36, 10 maggio 1311.

${ }^{62}$ Ibidem, vol. X, 1, c. 54, 14 giugno 1311.

${ }^{63}$ Ibidem, vol. X, 1, cc. 54 e 56, 14 giugno 1311.

${ }^{64}$ Ibidem, vol. X, 1, c. 58, 21 giugno 1311. Fu permesso loro di acquistare libros, inclaustrum, ceram, vernicem con 311 voti favorevoli e 54 contrari. 
tano del popolo, degli anziani e consoli e dei sapienti da loro prescelti il compito di decidere su come trovare denaro per acquistare le granaglie per l'anno seguente, concordarono con questi ultimi che le loro proposte dovevano ritornare nuovamente ad essere esaminate dal consiglio del popolo. ${ }^{65}$ La questione rimaneva in ultima analisi ancora molto scottante e delicata, e si riconosceva l'estrema importanza dell'approvvigionamento alimentare della città, soprattutto in anni di carestia e povertà diffusa, indicando nell' intero vertice di governo il responsabile della politica annonaria, nonché aumentando le competenze della magistratura dei domini bladi, che avrebbero potuto operare con grande autonomia.

Le riformagioni cittadine e le continue suppliche rivolte da intere comunità e singoli cittadini alle autorità comunali documentano il profondo malessere dei abitanti del contado e le loro condizioni di indigenza in modo generico. Per meglio valutare le loro condizioni di vita a cavallo tra Due e Trecento e poter disporre di qualche dato oggettivo, è possibile ricorrere alle fonti di natura fiscale. Per la zona di confine tra Bologna e Modena, è stato recentemente studiato da Marinella Zanarini l'estimo di Calcara, attualmente frazione del comune di Crespellano, situato a pochi chilometri da Castelfranco ${ }^{66}$. Il suo estimo del 1304 costituisce una felice anomalia rispetto agli altri estimi del contado bolognese: anziché procedere di fumante in fumante con le denuncia dei beni posseduti, come fanno in genere gli estimi del contado bolognese a noi pervenuti, la rilevazione di Calcara segue essenzialmente un criterio topografico incentrato sulle contrade, al cui interno ogni proprietà elencata risulta confinante con quella registrata precedentemente. Può quindi accadere che all'interno della stessa contrada il medesimo proprietario sia segnato più volte, in relazione al numero degli immobili denunciati. Non è perciò immediata la definizione del patrimonio dei singoli dichiaranti; ma proprio questo impianto catastale consente una ricostruzione sostanzialmente attendibile dell'assetto insediativo e delle caratteristiche ambientali; e, soprattutto, a essere censiti non sono solo i fumanti, ma anche i cittadini, gli enti ecclesiastici e i nobili che possedevano beni nel territorio di Calcara. ${ }^{67}$ Certo i dati desumibili da questo

${ }^{65}$ Ibidem, vol. X, 1, c. 61, 25 giugno 1311.

${ }^{66} \mathrm{Cfr}$. M. Zanarini, L'assetto insediativo e la distribuzione della proprietà a Calcara agli inizi del Trecento, in Archeologia medievale in valle del Samoggia. Studi e ricerche, Atti della giornata di studi (Bazzano, 16 ottobre 2004), a cura di R. Burgio, S. Campagnari e D. Cerami, Bologna 2005, pp. 25-70.

${ }^{67} \mathrm{Si}$ tratta di uno dei tre casi finora conosciuti di estimo a carattere topografico: gli altri due sono Galisano, nell'attuale comune di Medicina, nella pianura a est di Bologna, e San Lorenzo in Funo, nella pianura a nord di Bologna. Cfr. M. Zanarini - M. Librenti, Fonti storiche e ricerche di superficie: strutture e dinamica insediativi nel territorio di Galisano, "Civiltà padana. Archeologia e storia del territorio», I, 1988, pp. 103-143, alle 
estimo non possono essere generalizzati ed estesi all'intero contado bolognese, ma si ritiene che l'analisi del documento possa costituire un'efficace lente di ingrandimento sulla condizione dei comitatini residenti nella media pianura tra Bologna e Modena agli inizi del Trecento. Allo stato attuale degli studi, è comunque l'unica lente disponibile.

Calcara, allora come adesso, è una piccola comunità, che nel 1256 contava 15 fumanti, aumentati a 53 nel $1303 .{ }^{68} \mathrm{~A}$ essere censite sono oltre 2400 tornature di terra, cioè circa $5 \mathrm{kmq}$, comprese 150 tornature contese con le comunità vicine e altre sconfinanti nella curia di Piumazzo, attualmente frazione di Castelfranco. ${ }^{69}$ Per quanto riguarda la ripartizione delle colture, dall'estimo si evince la netta prevalenza dei terreni arativi, seguiti dai terreni prativi e infine da quelli arativi-vitati. L'immagine è quella di un territorio di media pianura segnato dal forte prevalere dell'arativo nudo, contro una presenza ancora esigua della coltura promiscua, la base del futuro paesaggio della piantata, e un'apprezzabile incidenza (oltre il $15 \%$ ) del prativo.

La proprietà risultava molto frazionata - fenomeno riscontrabile in gran parte dell'Italia centro-settentrionale -, con la metà degli appezzamenti censiti inferiori a un ettaro di superficie. Le proprietà registrate risultano così distribuite: il $41 \%$ apparteneva a enti ecclesiastici (in primo luogo la pieve di Monteveglio, le chiese locali di S. Nicolò e di S. Chierico di Calcara e, in misura minore, le chiese delle località limitrofe e anche qualche chiesa cittadina, S. Croce di Bologna e il monastero di S. Pietro di Modena), il $35 \%$ a cittadini bolognesi, il $12 \%$ ai fumanti - compresi alcuni delle località limitrofe, proprietari di terre a Calcara -, il $5 \%$ a nobili del contado, con un rimanente $7 \%$ comprensivo di forestieri e di casi di incerta attribuzione. Appare evidente che i fumanti costituiscono una presenza secondaria, con il controllo di appena il $12 \%$ delle risorse del territorio; una conferma di un fenomeno di più ampia portata, diffuso nelle campagne emiliane già dalla fine del Duecento: il progressivo declino economico del ceto dei fumanti, contro l'avanzare degli investimenti fondiari della borghesia cittadina. ${ }^{70}$

pp. 114-116; M. Zanarini - M. Librenti, Strutture materiali e forme insediative nel territorio bolognese in età medievale, in Archeologia e insediamento rurale in Emilia Romagna nel Medioevo. Contributi per una ricerca, a cura di S. Gelichi, Bologna 1991 (Insediamenti, territorio e società nell'Italia medievale - Ricerche e studi, Quaderni 34), pp. 23-106, alle pp. 58-60.

${ }_{68}$ ASBo, Comune, Estimi, s. III, 4, Registro dei fumanti, 1249, c. 88r; 9, c. 5r (1303).

${ }^{69}$ Cfr. Zanarini, L'assetto insediativo cit., p. 37 ss.

${ }^{70}$ Cfr. R. Dondarini, Popolazione ed economia del territorio di Granarolo durante il Medioevo, in Un granaio per la città. Uomini e vicende di Granarolo, a cura di F. Bocchi e R, Dondarini, Casalecchio di Reno (Bo), pp. 43-59; Zanarini, L'assetto insediativo cit., p. 41. 
Un'ulteriore conferma di questo declino ci è fornita, nel nostro caso specifico, dall'estimo dei fumanti di Calcara del 1315-16: vengono censiti in esso solo 20 fumanti, che controllavano in totale circa 300 tornature di terreno, di cui solo 170 localizzate a Calcara. Il patrimonio fondiario dei singoli fumanti, inoltre, risultava fortemente parcellizzato, con l'eccezione di un certo Guglielmo di Ribaldo - massaro della comunità nel 1304-5, evidentemente l'abitante di Calcara più benestante -, che raggiungeva complessivamente le 60 tornature. $^{71}$

Chi trasse vantaggio dalla difficile situazione degli abitanti del contado? Nel caso di Calcara alcuni cittadini bolognesi, che nel 1304 controllavano, come abbiamo visto, il $35 \%$ del territorio censito. Le loro proprietà risultavano ancora di superficie medio-piccola, ma gli investimenti di alcune famiglie, documentati per i decenni successivi, diedero origine a una sempre più incisiva opera di ricomposizione fondiaria. Per Calcara e i territori limitrofi, sono i bolognesi Bonromei, Beccadelli e Tebaldi - in particolare modo questi ultimi - ad accentrare lentamente nelle loro mani i terreni migliori. $^{72}$

Non disponiamo di studi analitici di ampio respiro per il bolognese a questo proposito, ma alcuni recenti studi molto circostanziati, relativi a singoli personaggi o a famiglie di spicco nell'economia e nella politica cittadina, possono aiutarci a indicare almeno una linea di tendenza. Romeo Pepoli, il ricco banchiere, il primo "criptosignore" che il comune bolognese ha avuto nel corso del Trecento ${ }^{73}$ Giacomo Casella, il figlio di un drappiere, che si trasformò con successo in beccaio e venditore di bestiame; ${ }^{74}$

${ }^{71}$ ASBo, Comune, Estimi, s. III, 16 (1315-16), cc. 147r-154v.

72 Zanarini, L'assetto insediativo cit., pp. 45-61, analizza con la consueta cura l'incremento dei beni della famiglia di Dino Tebaldi e dei suoi nipoti, famiglia molto nota e ben radicata a Bologna, di parte geremea. La studiosa rileva che Dino, attivo nei primi decenni del Trecento, continuò a gestire efficacemente la rete di relazioni economiche intessuta dal padre Nicolò, prestatore a usura, con i comuni di San Giovanni in Persicelo, Crevalcore e Piumazzo, e allacciandone di nuovi. L'ampliamento degli investimenti fondiari dei Tebaldi nella zona costituisce per la studiosa "un'ulteriore testimonianza delle difficoltà incontrate dalle comunità del contado, soprattutto da quelle di confine, vessate dalle pesanti tassazioni fiscali cittadine e al contempo gravate dalle spese militari per sostenere le difese di un territorio più esposto alle violenze degli eserciti nemici, cui si aggiungevano inevitabilmente le ingerenze e le pressioni dei vari creditori che, prestando ad usura, finivano per incidere sulla vita e l'autonomia delle comunità stesse".

${ }^{73}$ M. Giansante, Patrimonio familiare e potere nel periodo tardo-comunale. Il progetto signorile di Romeo Pepoli banchiere bolognese (1250 c.-1322), La Fotocromo Emiliana, Bologna 1991.

${ }^{74}$ A.I. Pini, Gli estimi cittadini di Bologna dal 1296 al 1329. Un esempio di utilizzazione: il patrimonio fondiario del beccaio Giacomo Casella, «Studi Medievali», XVIII, 
Filippo Boccadiferro, intraprendente rampollo di una famiglia di nobili del contado bolognese, prestatore a usura $;^{75}$ i Guastavillani, che fino al 1235 circa avevano accumulato un ricco patrimonio fondiario nel territorio di Gesso di Zola Predosa, grazie ai proventi del commercio di cereali e bestiame, per poi inurbarsi a Bologna e assurgere gradatamente al rango di famiglia senatoria; ${ }^{76}$ e, non ultimi, i Bentivoglio, che tra Due e Trecento cominciarono la loro lenta scalata verso il potere, a partire da Ivano Bentivoglio, uno dei quattordici membri della famiglia elencati nella matricola dei beccai del 1294, il primo a intraprendere la carriera notarile e a esercitare effettivamente la professione, nonché a indirizzare sulla sua stessa strada il figlio Francesco, dal quale discendono in linea retta i Bentivoglio che nel Quattrocento sarebbero diventati signori di Bologna: ${ }^{77}$ personaggi e famiglie certo molto differenti tra loro, ma che hanno in comune il rapido accrescimento del proprio patrimonio tra le fine del Duecento e i primi decenni del Trecento, documentato puntualmente dagli estimi redatti tra il 1297 e il 1329.

Il caso più eclatante è senza alcun dubbio quello del più volte citato Romeo Pepoli, il banchiere e usuraio bolognese ricordato dal cronista Giovanni Villani come «quasi signore» di Bologna, forse il più ricco cittadino di Italia, che dalla contingenza bellica con gli Estensi trasse nuovo slancio per la sua vertiginosa ascesa politica. Lo abbiamo già incontrato in tutte le commissioni ristrette destinate a esautorare progressivamente gli organi istituzionali di governo, le cosiddette balie. L'urgenza delle questioni da affrontare e la crescente influenza della fazione filoestense nella società bolognese le avevano rese necessarie, e Romeo, soprattutto a partire dai primi anni del Trecento, vi aveva sempre più spesso preso parte; il

1977, pp. 111-159, ora in Id., Campagne bolognesi. Le radici agrarie di una metropoli medievale, Le Lettere, Firenze 1993, pp. 39-92.

75 V. Braidi, Il patrimonio fondiario di una famiglia di nobili del contado: $i$ Boccadiferro di Piumazzo (1296-1329), in V. Braidi - G. Lorenzoni, Consorterie nobiliari sul confine tra Modena e Bologna: i Boccadiferro e i Grassoni (secoli XI-XIV), Deputazione di Storia Patria per le antiche Provincie Modenesi (Biblioteca, n.s. 169), Modena - Aedes Muratoriana 2003, pp. 19-171; V. Braidi, Consorterie nobiliari e controllo del territorio: il castello di Serravalle dagli Oddoni ai Boccadiferro, in Rocche e castelli lungo il confine tra Bologna e Modena, a cura di P. Bonacini - D. Cerami (Atti della giornata di studi di Vignola 25 ottobre 2003), Bologna 2005, pp. 129-174.

${ }^{76}$ Libro di conti della famiglia Guastavillani (1289-1304), a cura di E. Coser e M. Giansante, CLUEB, Bologna 2003.

77 Sui Bentivoglio cfr. C. Ady, I Bentivoglio, Varese, 1965 (ed. or. London 1937); F. Bocchi, I Bentivoglio da cittadini e signori, «Atti e Memorie della Deputazione di Storia Patria per le Province di Romagna», XXII, 1971, pp. 43-64; Ead., Il patrimonio bentivolesco alla metà del '400, Bologna 1971; Ead., Il potere economico dei Bentivoglio alla fine della loro signoria, «Il Carrobbio», 2, 1976, pp. 77-89. 
ruolo del banchiere, che a più riprese aveva anticipato somme ingentissime per l'onore e la libertà del comune di Bologna, era divenuto sempre più centrale. Un ruolo del tutto particolare, basato su di uno straordinario prestigio personale e sul potere di fatto che gli conferivano le sue immense ricchezze, una volta messe a disposizione delle finanze comunali.

Partecipando a tutte le balie che fra il 1310 e il 1312 governarono di fatto il comune, Romeo Pepoli divenne il perno della politica bolognese, in quanto la sua presenza e il suo consenso erano ormai condizione essenziale per la realizzazione di qualunque programma da parte delle istituzioni comunali: il ricorso alle sue casse si fece sistematico; grazie a lui, ad esempio, si restaurarono i castelli di Nonantola, Crevalcore e Castelfranco, a salvaguardia del confine con il modenese. E proprio nel 1312 la sua attività immobiliare privata conobbe una brusca impennata: intere comunità del contado, come abbiamo visto incapaci di far fronte alle collette imposte dalla città, furono costrette a cedergli i loro beni comuni per saldare i debiti contratti negli anni precedenti. Le grandi acquisizioni in solutum riguardarono soprattutto le località di Sant'Agata e Castelfranco verso Modena, Castel San Pietro verso la Romagna: dall'estimo di Romeo del 1315 , confrontato con quello precedente del 1296-97, risulta che egli acquisì in questo modo circa 270 ettari di terra a Sant'Agata, 27 edifici abitativi e due mulini; 330 ettari di terreno a Castelfranco, 41 edifici abitativi e un mulino; quasi 400 ettari di terra a Castel San Pietro, un centinaio fra edifici e lotti edificabili e altri tre mulini, che si aggiungevano a quelli che già possedeva nella zona.

La terra acquisita con la speculazione creditizia a danno di contadini e intere comunità, in tutta la più fertile pianura bolognese, continuò ad aumentare in modo omogeneo anche negli anni successivi, ed è stato calcolato che, in un ventennio, non solo fu più che decuplicata, ma anche più uniformemente distribuita. ${ }^{78}$ Per lo più i beni acquisiti venivano poi affittati ai precedenti proprietari, i quali, liberatisi con le cessioni del vincolo creditizio, si trovarono legati a Romeo Pepoli dalla nuova condizione di locatari. L'espansione sistematica nel contado, in cui l'acquisto patrimoniale si intrecciò indissolubilmente con la pressione sulle comunità, per sfociare infine in controllo capillare del territorio, costituì così un importante tassello al potere personale del ricco e influente banchiere bolognese, il primo "criptosignore" che il comune bolognese ha avuto nel corso del Trecento.

${ }^{78}$ Giansante, Patrimonio familiare cit., p. 145. 


\section{Franco FranCESCHI}

\section{I ‘CIOMPI’ A FIRENZE, SIENA E PERUGIA}

Nell'estate del 1371, sette anni prima che il Tumulto dei Ciompi incendiasse Firenze, le città di Perugia e Siena, a distanza di pochi mesi, furono teatro di rivolte alle quali parteciparono, come nel maggiore centro toscano, i lavoratori dell'industria dei panni di lana. Questa coincidenza dei protagonisti indusse lo storico sovietico Victor Rutenburg, alla fine degli anni Cinquanta del Novecento, a collegare organicamente i tre episodi e a interpretarli come manifestazioni, pur diversamente profonde, del conflitto fra «proletariato primitivo» e «borghesia in via di formazione» in una società urbana caratterizzata da «nascenti relazioni capitalistiche» ${ }^{1}$. È trascorso mezzo secolo ed è passata più di una stagione storiografica, ma mi sembra che il tema abbia mantenuto una sua rilevanza, ed è per questo che ho accettato volentieri l'invito a riprenderlo in esame, pur consapevole delle difficoltà e dei pericoli che l'approccio comparativo presenta.

A differenza dell'episodio fiorentino, divenuto precocemente una sorta di archetipo dell'insurrezione operaia («una pagina di storia del proletariato operaio» la definì Niccolò Rodolico) ${ }^{2}$, illuminato da una serie non ancora esaurita di studi ${ }^{3}$, le altre due sollevazioni hanno interessato poco gli storici. C’è stato bisogno del Rutenburg - come ho detto - perché un'indagine di un certo respiro sulle rivolte di Siena e di Perugia, anche se discutibile nelle conclusioni, venisse avviata ${ }^{4}$. Non è questa la sede per

${ }^{1}$ V. Rutenburg, Popolo e movimenti popolari nell'Italia del '300 e '400, trad. it., Il Mulino, Bologna 1971 [1958], p. 5.

${ }^{2}$ N. Rodolico, I Ciompi: una pagina di storia del proletariato operaio, Sansoni, Firenze $1980^{3}$ [1945].

${ }^{3}$ Per un primo approccio bibliografico al tema rimando ai due volumi più recenti: A. Stella, La révolte des Ciompi. Les hommes, les lieux, le travail, Préface de Ch. KlapischZuber, Editions de l'Ecole des Hautes Etudes en Sciences Sociales, Paris 1993 (che alle pp. 17-29 ripercorre i principali sviluppi del dibattito storiografico); E. Screpanti, L'angelo della liberazione nel tumulto dei Ciompi. Firenze, giugno-agosto 1378, Il Ponte, Firenze 2008.

${ }^{4}$ Rutenburg, Popolo e movimenti popolari cit. Sull'episodio senese cfr. anche Id., $\mathrm{La}$ vie et la lutte des 'Ciompi' de Sienne, "Annales. E.S.C.», XX, 1965, pp. 95-109; 
interrogarsi sulle radici della divergente 'fortuna' storiografica delle sommosse fiorentina da una lato, perugina e senese dall'altro, per la quale potrebbero essere indicate alcune logiche argomentazioni generali, relative cioè alla diversa rilevanza degli eventi, alla differente importanza dei centri coinvolti, alla sensibilissima disparità nel volume e nella qualità della documentazione sopravvissuta; noterò soltanto che, mentre a Firenze il Tumulto diventò - grazie alla storiografia umanistica - immediato oggetto di narrazione, di riflessione e di utile ammaestramento per le classi dirigenti, messe in guardia contro gli eccessi della libertà accordata alla 'plebe'5, nelle altre due città è sembrata prevalere presso i ceti colti la tendenza a minimizzare gli eventi del 1371, se non ad espungerli dal grande alveo della storia urbana; così sia la rivolta perugina che quella senese risultano documentate da un'unica narrazione coeva, la Cronaca senese di Donato di $\mathrm{Neri}^{6}$, e solo occasionalmente la storiografia del Quattro e del Cinquecento - come vedremo - ne ha ripreso la memoria.

N. Rodolico, La democrazia fiorentina nel suo tramonto (1378-1382), Zanichelli, Bologna 1905, pp. 101-111; R. Broglio D’Ajano, Tumulti e scioperi a Siena nel secolo $X I V^{\circ}$, «Vierteljahrschrift für Social- und Wirtschaftsgeschichte», V, 1907, pp. 458-466; La rivolta dei "ciompi" di Siena (1371), Seminario di Storia Medievale coordinato da G. Cherubini, Relazioni ciclostilate degli studenti, Università degli Studi di Firenze, Facoltà di Lettere e Filosofia, anno accademico 1970-71; V. Wainwright, The Testing of a Popular Sienese Regime. The Riformatori and the Insurrections of 1371, «I Tatti Studies. Essays in the Renaissance », 2, 1987, pp. 107-170; F. Franceschi, La rivolta di «Barbicone», in Storia di Siena, I, Dalle origini alla fine della Repubblica, a cura di R. Barzanti, G. Catoni, M. De Gregorio, Edizioni ALSABA, Siena 1995, pp. 291-300. Sulla rivolta perugina all'indagine comparativa del Rutenburg si può aggiungere ancora meno: si vedano comunque R. Broglio D’Ajano, Lotte sociali a Perugia nel secolo XIV, «Vierteljahrschrift für Social- und Wirtschaftsgeschichte», VIII, 1910, pp. 337-345, e le rapide note di J.C. Maire Vigueur, Comuni e signorie in Umbria, Marche e Lazio, in Storia d'Italia, diretta da G. Galasso, VII, t. 2, Comuni e signorie nell'Italia nordorientale e centrale: Lazio, Umbria e Marche, Lucca, UTET, Torino 1987, pp. 321-606: pp. 543-544.

${ }^{5}$ Cfr. su questo punto le considerazioni di E. Garin, Echi del Tumulto dei Ciompi nella cultura del Rinascimento, in Il Tumulto dei Ciompi. Un momento di storia fiorentina ed europea, Atti del Convegno internazionale di studi (Firenze, 16-19.IX.1979), Firenze, Olschki, 1981, pp. V-XXII; E. Sestan, Echi e giudizi sul Tumulto dei Ciompi nella cronistica e nella storiografia, in Il Tumulto dei Ciompi cit., pp. 125-160, in particolare pp. 125-135. Ed inoltre J. M. Najemy, A History of Florence 1200-1574, Blackwell, Oxford 2006, pp. 176-181. Alessandro Stella ha efficacemente scritto che «l'historiographie du 'Tumulte des Ciompi' commence [...] en même temps que les événements» (Stella, La révolte des Ciompi cit., p. 17).

${ }^{6}$ Cronaca senese di Donato di Neri e di suo figlio Neri, in Cronache senesi, a cura di A. Lisini e F. Iacometti, in «Rerum Italicarum Scriptores», sec. ed., t. XV, parte VI, Zanichelli, Bologna 1931-1939, pp. 566-685: pp. 639 (fatti di Perugia) e 639-642 (rivolta di Siena). 


\section{Gli avvenimenti}

Prima di proporre qualsiasi riflessione sugli obiettivi, i risultati e il significato delle rivolte oggetto di quest'analisi ritengo indispensabile procedere ad una disamina, per quanto sintetica, degli avvenimenti: disamina che purtroppo risulterà condizionata dal diverso grado di completezza delle informazioni relative alle vicende di Perugia e di Siena rispetto a quelle disponibili per gli eventi fiorentini.

\section{Perugia}

La rivolta del 1371 si inquadra nella «lunga catena di violenze che caratterizza la storia perugina del secondo Trecento» ${ }^{7}$ e trova i suoi immediati antecedenti nella ripresa del contrasto fra i nobili, incoraggiati dal Papato, e il regime popolare che - sotto l'etichetta dei Raspanti - guidava allora la città. Dopo il fallito complotto del 1368 , che aveva portato a numerose condanne e bandi di esponenti dei gruppi nobiliari, nonché allo scoppio di una guerra fra i Perugini e l'esercito pontificio, nel 1370 il Comune, isolato e sotto la pressione dei ceti più colpiti dagli effetti del conflitto, dovette concludere con la Santa Sede un trattato di pace assai oneroso: esso prevedeva infatti il rientro di tutti gli esiliati e il riconoscimento del pieno dominio della Chiesa sulla città ${ }^{8}$. A complicare le cose si aggiunse l'atteggiamento del nuovo papa Gregorio XI, che si rifiutava di affidare il vicariato ai Priori perugini designando in tale carica un suo legato, il cardinale di Bourges, al cui arrivo si opponevano però i Raspanti. In questa situazione, il 16 maggio 1371, ebbe luogo una manifestazione di piazza che, dopo avere tentato di imporre al Consiglio Generale l'entrata in carica del rappresentante pontificio, si trasformò in una vera e propria rivolta ${ }^{9}$. Come scrive il cronista senese Donato di Neri, «si levò uno romore apenatamente: cominciò in piaza per gente lavorante di lana, forestieri masnaderotti, e gridaro 'Viva la Chiesa e 'l Popolo. E fuvi morti 14 di nome, e robate e arse case, e cacciati tutti li Raspanti, e fuvi gran male di morti e di robati, e arse

${ }^{7}$ A. Grohmann, Economia e società a Perugia nella seconda metà del Trecento, in Società e istituzioni dell'Italia comunale: l'esempio di Perugia (secoli XII-XIV), Atti del Congresso storico internazionale (Perugia, 6-9.XI.1985), 2 voll., Deputazione di Storia patria per l'Umbria, Perugia 1988, pp. 57-87: p. 58.

${ }^{8}$ F. Mezzanotte, La pace di Bologna tra Perugia e Urbano V (23 novembre 1370), «Bollettino della Deputazione di Storia patria per l'Umbria», LXXIV, 1977, pp. 117174: pp. 122-125.

${ }^{9}$ Maire Vigueur, Comuni e signorie in Umbria cit., p. 543. 
case, e poi vi si fe' sacco» ${ }^{10}$. Nella sua essenzialità, Donato colloca all'origine del tumulto, la cui gravità sottolinea reiterando la notizia delle ruberie, degli incendi e degli omicidi, due diverse categorie di attori: i lavoratori della manifattura laniera cittadina e un gruppo di forestieri che, considerata l'ambiguità semantica del termine masnadiere, sarebbero potuti essere sia uomini d'arme che ladri di strada ${ }^{11}$.

In parte diverso è il racconto dei testimoni non coevi. Nel cosiddetto Diario del Graziani, del tardo Quattrocento, è un non meglio identificato «popolo» a «uscire [...] con l'arme in mano» dando inizio alla sommossa al grido di «viva il Populo!» ${ }^{12}$. Qui lo sviluppo dell'azione è descritto con maggiore ampiezza e l'autore della cronaca elenca puntualmente gli effetti della furia dei rivoltosi sulle proprietà dei «ricchi popolari» - cambiatoribanchieri, mercanti, imprenditori lanieri, giudici e notai - che rappresentavano il cuore del regime dei Raspanti ${ }^{13}$ :

et in un subito andar in casa di messer Guglielmo dottore e giudice, il quale stava in capo della piazza, et gli spezzarono la porta; et egli campò la vita fuggendo per un uscetto di dietro; e questo fecero, perché essendo egli un de i tre sopra la guerra, sempre s'era opposto al Papa e alla Chiesa. Ma i Raspanti in questo mezzo, tenendosi poco sicuri in Perugia, la notte pigliarono altro viaggio: le case loro furono robbate di porta in porta, e prima la casa d'Agnelino del Pian di Carpene: vi morì ser Agnolo da gli Statuti, e la sua casa fu abrugiata; et la casa di Berardello e di Dannelo, et di Vagni ditto il Priore; et quella di P. della Camilla, quella di Pecciolo, quelle di Grazino di Girolamo di messer Grazia; e quelle de i Michelotti non si finirono di abrugiare, perché i vicini le soccursero; e quelle di Bartolomeo di Ceccarello per porta S. Pietro: per porta Sole ci furono abbrugiate quelle di Ruggieri, che aveva la sua imagine in S. Lorenzo, la quale fu da loro cancellata; e quella di Variolo di Monuccio speziale; e quelle di Belardino d'Andrucciolo e di Longaruccio di S. Agnelo, che stava nel borgo di S. Antonio: in porta S. Pietro le case di Giovanni d'Andrucciolo di Pellolo et delli suoi fratelli s'abrugiarono tutte, perché i vicini gli aiutarono. Fu scaricato

${ }^{10}$ Cronaca senese di Donato di Neri, cit., p. 639.

${ }^{11}$ Per questa seconda interpretazione propende Samuel Cohn: Popular Protest in Late Medieval Europe. Italy, France and Flanders, Selected Sources Translated and Annotated by S. K. Cohn Jr., Manchester University Press, Manchester and New York 2004, p. 132; Id., Lust for Liberty. The Politics of Social Revolt in Medieval Europe, 12001425, Harvard University Press, Cambridge Mass.2006, p. 64.

12 Cronaca della città di Perugia dal 1309 al 1491 nota col nome di Diario del Graziani, a cura di A. Fabretti, «Archivio Storico Italiano», XVI, 1850, pp. 69-750: supplemento terzo, p. 215.

${ }^{13}$ Sull'attacco alle persone e ai beni degli uomini di legge si sofferma brevemente Victor Rutenburg (Rutenburg, Popolo e movimenti popolari cit., p. 120); sul significato più generale di queste azioni cfr. le considerazioni di Andrea Zorzi in questo stesso volume (A. Zorzi, La questione della giustizia e dell'ordine pubblico). 
il tetto a ser Paolo di Berarduccio, et a Guiduccio gli fu robbata la casa, et molt'altre case di quelli che avevano nome di Raspanti. Per questo si partì molti de i traditori il giorno dopo ${ }^{14}$.

Mentre la dinamica dei fatti appare chiara, nessun particolare conferma l'affermazione di Donato di Neri sulla composizione sociale degli insorti.

Qualcosa in più, invece, emerge dalla cinquecentesca Historia di Perugia di Pompeo Pellini, che rappresentò la base della ricostruzione dell'episodio compiuta dal Broglio d'Ajano nel $1910^{15}$, a sua volta generalmente seguita da chi ne ha scritto successivamente. Il suo autore, infatti, descrive il clima di sospetto e di paura che serpeggiava in città, racconta come nei giorni che precedettero la rivolta «si gridò verso un'hora di notte nella contrada di porta Santo Angelo 'viva il Popolo, et muoiano i Raspanti'» ${ }^{16}$, aggiunge che «alcuni giovani del Borgo di sopradetta contrada erano più de gli altri inobedienti» e avevano il fermo proposito, qualora la polizia cittadina si fosse avventurata nella zona «a far la cerca dell'armi», di «tagliarla tutta a pezzi» ${ }^{17}$. Più in generale il Pellini identifica senza incertezze il motore della sommossa nel «popolo minuto» della «contrada di porta Santo Angelo», la cui strategia d'azione fu decisa in una serie di incontri tenutisi nella Chiesa di Sant'Agostino sotto la guida di Colino degli Arcipreti ${ }^{18}$, membro di una importante famiglia nobiliare perugina.

Anche se forse si tratta solo di una coincidenza, le fonti sui fatti di Perugia sembrano dunque integrarsi per delineare i caratteri di un tumulto scatenato dalla parte più numerosa e meno abbiente del Popolo perugino, principalmente radicata in un'area della città ad alta concentrazione di attività artigianali, comprese quelle laniere ${ }^{19}$, ma in cui alla componente sociale e professionale se ne sarebbe aggiunta una generazionale: quella costituita dalla "gioventù di Porta Sant'Angelo», la stessa che, stando al Diario del Graziani, avrebbe animato anche la sollevazione contro i Raspanti del $1383^{20}$. Gli effetti immediati della rivolta, che vari indizi mo-

${ }^{14}$ Cronaca della città di Perugia cit., supplemento terzo, pp. 215-216.

${ }^{15}$ Broglio D’Ajano, Lotte sociali a Perugia cit.

${ }^{16}$ P. Pellini, Dell'historia di Perugia, 3 voll., rist. anast., Forni, Bologna 1968 [1664], I, lib. VIII, p. 1093.

${ }^{17}$ Ibid., I, lib. VIII, p. 1094.

${ }^{18}$ Ibid., I, lib. VIII, p. 1096.

${ }^{19}$ A. Grohmann, Perugia, Laterza, Roma-Bari $1985^{2}$ [1981], p. 48. Un'indagine relativa al periodo successivo conferma questi caratteri dell'area di Porta Sant'Angelo: P. Monacchia, Arti e artigiani in un rione perugino del XV secolo, in L'artigianato in Umbria dalle Corporazioni all'associazione di impresa, C.N.A.-Gramma, Perugia 1997, pp. 49-69.

${ }^{20}$ Cronaca della città di Perugia cit., supplemento III, p. 288; cfr. Cohn, Lust for Liberty cit., pp. 94-95. 
strano essere stata preceduta da una certa azione organizzativa, furono la morte di una quindicina di persone e la distruzione di una ventina di case, ma le sue conseguenze politiche furono ben più rilevanti. Il 19 il cardinale di Bourges poté fare ingresso in Perugia e proclamò che «reggeva la città per la Chiesa e senza alcuna condizione a favore dell'autonomia cittadina ${ }^{21}$. La fine del regime popolare ad opera delle forze congiunte del Papato, della nobiltà e del Popolo minuto, che significò anche il tramonto dell'indipendenza politica della città ${ }^{22}$, colpì molto negativamente il cronista senese testimone degli eventi: «E così ebe la Chiesa Perugia», commentò lapidariamente; e aggiunse: «E li Sanesi e li Fiorentini ne dimostrarono malcontenti, e dolenti di tal cosa tutti li buoni cittadini. E li Salimbeni e li Dodici di Siena ne mostraro allegreza, e loro brigate, che molto a la scoperta ne parlavano e dimostravano ${ }^{23}$. La notizia dei fatti perugini, dunque, circolava e provocava commenti discordanti a seconda delle diverse appartenenze ideologiche e delle differenti fedi politiche.

\section{Siena}

Anche a Siena la fine degli anni Sessanta portò significativi cambiamenti politici ${ }^{24}$. Infatti il regime detto dei Dodici dal numero dei componenti la suprema magistratura di governo, fondato sull'alleanza tra il ceto medio facente capo alle Arti e alcuni elementi magnatizi (che le fonti indicano generalmente come "gentiluomini», «nobili», «grandi») era in crisi: alle tensioni sociali ed ai motivi di instabilità politica, coagulatisi in più di un tentativo di congiura, si aggiungeva il deficit del bilancio comunale, appesantito dalle spese sostenute per assoldare, ma spesso anche per allontanare dal territorio della Repubblica le compagnie di ventura, mentre ripetuti furono gli assalti di epidemie e carestie. Negli ultimi mesi del 1368 si susseguirono una serie di episodi tumultuosi che finirono per determi-

${ }^{21}$ E. Dupré Theseider, La rivolta di Perugia nel 1375 contro l'abate di Monmaggiore ed $i$ suoi precedenti politici, «Bollettino della deputazione di storia patria per l'Umbria», XXXV, 1938, pp. 69-166: p. 87.

${ }^{22}$ Maire Vigueur, Comuni e signorie in Umbria cit., p. 544.

${ }^{23}$ Cronaca senese di Donato di Neri cit., p. 639.

${ }^{24}$ Per questo sintetico profilo, oltre ai contributi già segnalati nella nota 4 , ho utilizzato i lavori di V. Wainwright, Conflict and Popular Government in Fourteenth Century Siena: il Monte dei Dodici, 1355-1368, in I ceti dirigenti nella Toscana tardo comunale, Atti del III Convegno (Firenze, 5-7.XII.1980), Papafava, Firenze 1983, pp. 57-80; G. Cherubini, I mercanti e il potere a Siena [1987], ora in Id., Città comunali di Toscana, Clueb, Bologna 2003, pp. 297-348, in particolare pp. 333-334; A. Moscadelli, Oligarchie e Monti, in Storia di Siena, I, Dalle origini alla fine della Repubblica cit., pp. 267-278. 
nare «un ulteriore slittamento del potere verso gli strati più bassi della popolazione politicamente attiva ${ }^{25}$ ed un altrettanto deciso allontanamento da quel modello di governo a forte connotazione 'mercantile' che, materializzatosi nell'esperienza del regime dei Nove, aveva contraddistinto la prima metà del Trecento. Nello stesso tempo gli appartenenti alle famiglie che avevano in precedenza ricoperto ruoli istituzionali, e ne erano stati estromessi, si venivano costituendo in fazioni (i 'Monti'), che avrebbero ottenuto comunque nuove opportunità di partecipazione. In sostanza Siena sperimentò, a partire dal 1368, una lunga serie di governi 'di coalizione'.

Il 2 settembre di quell'anno il governo dei Dodici, praticamente isolato, fu rovesciato da un colpo di mano incruento ordito dai Gentiluomini con l'appoggio dei Noveschi e del Popolo minuto: il risultato, al di là dell'apporto delle diverse componenti, fu «una effimera restaurazione del vetusto predominio della nobiltà ${ }^{26}$, impersonata soprattutto dai grandi casati dei Tolomei, Salimbeni, Piccolomini, Saracini e Malavolti. Il nuovo equilibrio raggiunto, però non si mantenne che per qualche settimana. Il 23 settembre, per iniziativa dei Salimbeni, che perseguivano progetti di affermazione egemonica, scoppiò una nuova rivolta: furono aperte le porte al Vicario imperiale accampato nei pressi di Siena, deposti i governanti, cacciati in massa dalla città i nobili. Con l'approvazione del rappresentante dell'Imperatore vennero costituiti un Consiglio permanente con il compito di riformare lo Stato (detto appunto dei Riformatori), in cui figuravano 28 membri del partito dei Nove, 35 di quello dei Dodici, 61 del Popolo minuto, e un governo nel quale le proporzioni erano rispettivamente di 3 , 4 e 5 esponenti. Attraverso nuove convulsioni interne si giunse poi a metà dicembre ad una redistribuzione delle principali cariche ancora più favorevole ai ceti popolari: il Consiglio dei Riformatori fu infatti riservato ai soli membri del Popolo minuto (e significativamente da allora si assistette all'identificazione fra i due insiemi, al punto che lo stesso regime uscito da questa tormentata fase è passato alla storia come quello dei Riformatori); mentre dei 15 nuovi Signori che allora vennero creati 8 furono assegnati, secondo il linguaggio di un documento ufficiale, al «Popolo del maggior numero», 4 spettarono al partito dei Dodici («il Popolo del numero medio»), e 3 ai seguaci dei Nove («il Popolo del minor numero»). Le etichette non devono però trarre in inganno. Il Popolo minuto $\mathrm{o}$ «del maggior numero», che deteneva la maggioranza, non si identificava unicamente con i lavoratori dipendenti, ma si presentava come un più largo insieme nel

${ }^{25}$ Cherubini, I mercanti e il potere cit., p. 334.

${ }^{26}$ D. Marrara, I Magnati e il Governo del Comune di Siena dallo Statuto del 1274 alla fine del XIV secolo, in Studi per Enrico Fiumi, Pacini, Pisa 1979, pp. 239-276: p. 267. 
quale figuravano massicciamente i membri delle Arti minori. Quello dei Riformatori, comunque, restava un governo la cui ampia base sociale conosceva «ben pochi paralleli nella stessa Toscana ${ }^{27}$.

Questo era, in estrema sintesi, il quadro politico quando, all'inizio del luglio 1371, «li lavorenti e scardazieri dell'Arte di lana di Siena» - per usare ancora una volta le parole di Donato di $\mathrm{Neri}^{28}$ - entrarono in aperto conflitto con i propri datori di lavoro sulla questione dell'ammontare dei salari. Per dare vigore alle proprie richieste, respinte dagli imprenditori tessili, i lavoratori si radunarono sotto il palazzo dei Signori, ma, probabilmente con loro sorpresa ${ }^{29}$, non vennero ricevuti. A questo punto la dimostrazione assunse i contorni della sommossa: mentre un gruppo di rivoltosi si dirigeva verso un deposito di grano, infatti, gli altri minacciarono di uccidere i proprietari delle botteghe di lana. Il governo, all'interno del quale prevalsero sul momento i timori della minoranza formata dai Nove e dai Dodici, rispose facendo catturare quelli che riteneva probabilmente i capi della sedizione, tutti scardassieri appartenenti alla Compagnia del Bruco: Cecco dalle Fornaci, Giovanni di monna Tessa e Francesco d'Agnolo detto Burbicone o Barbicone, che in quel momento era anche uno dei Riformatori. Come risposta il 14 luglio «tutti quelli de la compagnia del Bruco con altri giurati furono insieme $»^{30} \mathrm{e}$, in armi, attaccarono il palazzo del Senatore per ottenere la liberazione dei prigionieri.

Il rilascio degli incarcerati non placò tuttavia i rivoltosi, che, anzi, impressero alla loro iniziativa un'accelerazione decisiva: al grido di «Muoia li Dodici e viva el popolo» - una parola d'ordine di natura eminentemente politica $^{31}$, ma forse spiegabile anche con il fatto che fra i primi si concentravano i maggiori imprenditori lanieri di Siena ${ }^{32}$ - essi attraversarono la città accendendo una serie di scontri che coinvolsero anche i Salimbeni, ormai smascherati nel loro disegno di appoggiarsi alternativamente ai Dodici e al Popolo del maggior numero con il fine di creare una signoria cittadina. Uno dei Salimbeni fu ferito e «la bandiera del popolo, la quale tenevano $[. .$.$] come consorti del popolo», fu loro strappata; sul terreno ri-$ mase anche il cadavere di Carlo di messer Francesco Malavolti. Nel frattempo venivano eseguiti arresti tra i Nove e i Dodici, che videro anche estromessi i loro sette membri dalla coalizione governativa, dove furono

${ }^{27}$ M. Luzzati, Firenze e la Toscana nel Medioevo. Seicento anni per la costruzione di uno Stato, Utet, Torino 1986, p. 137.

${ }^{28}$ Cronaca senese di Donato di Neri cit., p. 639.

${ }^{29}$ Wainwright, The Testing of a Popular Sienese Regime cit., p. 152.

${ }^{30}$ Cronaca senese di Donato di Neri cit., p. 639.

${ }^{31}$ Cohn, Lust for Liberty cit., p. 59.

32 È la tesi di Wainwright, The Testing of a Popular Sienese Regime cit., p. 153. 
sostituiti con altrettanti esponenti del Popolo minuto ${ }^{33}$. La rivolta aveva dunque conseguito un primo successo: ciò era potuto avvenire anche perché la risposta del governo alla violenza della Compagnia del Bruco era stata tutt'altro che inflessibile, un dato che può essere interpretato come il segno del progressivo cementarsi di un'alleanza sempre più stretta fra gli uomini della Compagnia e importanti esponenti del Popolo del maggior numero ${ }^{34}$. I più alti vertici del potere politico, però, non furono in grado di mantenere, nei giorni successivi, un contegno coerente, stretti com'erano tra la pressione della piazza e le paure, tutt'altro che infondate, di colpi di mano da parte dei sostenitori delle fazioni allontanate dal governo ${ }^{35}$.

Contro i Riformatori, in effetti, i Dodici e i Salimbeni ordirono un complotto, valendosi anche della connivenza del Capitano del Popolo, Francino di Naddo, che «se bene era del medesimo ordine Populare del maggior numero [...], non poteva sopportare che con tanta indignità lo stato si fusse ridotto nel suo tempo in mano d'huomini di così bassa conditione» ${ }^{36}$. La mattina del 30 luglio fedeli dei Salimbeni provenienti dal contado puntarono contemporaneamente verso il Palazzo pubblico e le abitazioni dei membri della Compagnia del Bruco, che, secondo un piano preordinato, dovevano essere - insieme ai Tolomei, ai Nove, al vescovo e a "certi altri»i principali obiettivi della spedizione. Mentre nella residenza assediata i Signori e la loro guardia resistevano, nel borgo d'Ovile, colti di sorpresa, molti lavoranti della lana furono massacrati senza pietà. Quelli che non riuscirono a fuggire o non ebbero il coraggio di gettarsi dalle mura caddero sotto i colpi implacabili delle balestre, delle lance, delle spade; senza arrestarsi neppure di fronte alla disperazione delle donne che cercavano una via di scampo "co' le culle in capo, co' fanciulli in braccio e per mano", esponenti di primo piano dei Dodici entrarono in quelle povere case, rubarono e tagliarono le tele sui telai, appiccarono il fuoco... Quando il destino della battaglia sembrava segnato il fronte delle vittime predestinate si ricompose: seguaci dei Nove e drappelli bene armati di rampolli degli Ugurgieri, dei Tolomei, dei Malavolti si posero infatti alla testa della Compagnia del Bruco. Combattendo vigorosamente, essi sbaragliarono i nemici in ogni punto della città in cui si erano attestati. Come scrive Donato di Neri, questi «non tenero colpo in niuno luogo e spariro come nebia». Subito dopo cominciarono i primi arresti, cui seguirono, per ordine dei Signori, le esecuzioni di cinque

${ }^{33}$ Cronaca senese di Donato di Neri cit., pp. 639-640.

${ }^{34}$ Wainwright, The Testing of a Popular Sienese Regime cit., p. 153.

${ }^{35}$ La rivolta dei "ciompi" di Siena cit., p. 81.

${ }^{36}$ O. Malavolti, Dell'Historia di Siena, rist. anast., Forni, Bologna 1982 [1599], parte II, lib. VIII, f. 139v. Più realisticamente il testimone contemporaneo adombra l'ipotesi che Francino si sia prestato "per denari»: Cronaca senese di Donato di Neri cit., p. 641. 
congiurati. Ad esse si aggiunse, dietro pressante richiesta della Compagnia del Bruco, quella del Capitano del Popolo: vestito di scarlatto, la testa adagiata su un panno dello stesso colore, Francino di Naddo fu decapitato il primo agosto al centro del Campo ${ }^{37}$. Nelle settimane successive seguirono altre condanne a morte, confische e distruzioni di beni, bandi, pene pecuniarie. Complessivamente 131 appartenenti ai Dodici, 85 popolani grassi seguaci dei Dodici e dei Salimbeni, 12 dei Nove (che il cronista definisce «rinegati») subirono sanzioni. Il 12 agosto il governo cambiò nuovamente composizione riaccogliendo una rappresentanza dei Nove, personaggi di grande peso economico e in prima linea contro il recente colpo di mano dei Dodici ${ }^{38}$. Questo assetto - una Signoria composta da 12 Riformatori e da 3 dei Nove, espressione del compromesso realizzato tra la maggioranza della coalizione, formata dai popolani minuti, e la minoranza, portatrice degli interessi degli strati più alti del ceto mercantile e imprenditoriale - era destinato a mantenersi fino alla caduta del regime, nel 1385.

\section{Firenze}

Non meno complessa risulta la trama degli avvenimenti fiorentini, per i quali si parla di tre o più correttamente di quattro distinte fasi, in un arco cronologico compreso fra il giugno 1378 e il gennaio $1382^{39}$. La prima si aprì il 18 giugno 1378, quando Salvestro dei Medici, appena divenuto Gonfaloniere di Giustizia, presentò alla Signoria una petizione con la quale proponeva di reintrodurre in tutto il loro rigore gli Ordinamenti di Giustizia del 1293. L'iniziativa deve essere inquadrata nel riaccendersi del lungo conflitto tra il 'partito oligarchico' e filo-papale - nel quale si riconoscevano membri di antiche famiglie magnatizie quali gli Adimari, i Bardi o i Pazzi, nonché importanti esponenti della fazione albizzesca, e che aveva trovato un punto di convergenza nella Parte Guelfa - e lo schieramento

\section{${ }^{37}$ Ibid.}

${ }^{38}$ Ibid., p. 642.

${ }^{39} \mathrm{Gli}$ eventi, come è facile comprendere, sono stati raccontati innumerevoli volte e questa brevissima descrizione ha unicamente la funzione di servire da traccia evenemenziale nella prospettiva comparativa di queste pagine. Le ricostruzioni più ampie, largamente fondate sull'utilizzazione del ricco materiale cronistico e documentario disponibile, restano quelle di Rodolico, I Ciompi cit., capp. IV-VI e Rutenburg, Popolo e movimenti popolari cit., capp. IV-VI; a queste si possono aggiungere le pagine di G. A. Brucker, Dal Comune alla Signoria. La vita pubblica a Firenze nel primo Rinascimento, trad. it., Il Mulino, Bologna 1981 [1977], pp. 48-82; Stella, La révolte des Ciompi cit., pp. 43-73; Screpanti, L'angelo della liberazione cit., cap. III. Un'ottima sintesi, pur nella sua stringatezza, è quella di Najemy, A History of Florence cit., pp. 161-171. 
che faceva capo alle Arti, composto da mercanti, banchieri, imprenditori tessili, artigiani e bottegai ma anche da membri di vecchie e importanti casate quali lo stesso Salvestro dei Medici, Andrea Rondinelli e Filippo Bastari. Uno scontro divenuto più acuto a partire dal 1375, con lo scoppio della guerra fra Firenze e il Papa, quando il governo conferì poteri straordinari alla magistratura degli Otto della Guerra e confiscò una parte sostanziosa dei beni ecclesiastici nel territorio fiorentino.

Salvestro compì una mossa abile, perché agli occhi di molti quella che era di fatto una lotta all'interno del ceto dirigente cittadino apparve davvero come una ripresa dell'antico confronto fra Magnati e Popolani. Sensibili al richiamo della lotta contro i Grandi, rafforzate dal «revival of corporate ideas $[\ldots]$ and of a decade of growing [...] involvment in political life ${ }^{40}$, le Arti mobilitarono le loro milizie e il 21 giugno manifestarono contro la Parte. Il giorno successivo una folla di artifices, ma nella quale si erano confusi operai tessili, varie altre categorie di salariati e immigrati (un libro di memorie ricorda «una brigata di forestieri fiamminghi» $)^{41}$, si riversò in piazza dei Priori chiedendo l'approvazione di norme tendenti a rafforzare la legislazione antimagnatizia; poi invase le strade della città assalendo, incendiando e saccheggiando le case dei membri più in vista della Parte Guelfa. Gruppi di 'incontrollabili' penetrarono nelle Stinche, il carcere cittadino, e liberarono tutti i detenuti, poi attaccarono la Camera del Comune, dov'era il deposito delle armi, ma vennero respinti da milizie corporative. Questi avvenimenti determinarono «the humiliation of the leaders of the Parte Guelfa and [...] a drastic reduction of the Parte's role in government ${ }^{42}$ rafforzando viceversa la posizione della comunità delle Arti, ma delusero le Corporazioni minori, che non raggiunsero lo scopo di aumentare la loro rappresentanza politica negli uffici, e lasciarono a bocca asciutta la massa dei lavoratori senza diritti, che nelle giornate degli scontri aveva preso coscienza della propria forza e cominciava ad organizzarsi. Per questo la situazione continuò a evolversi.

Una nuova fase del Tumulto si aprì in luglio, all'insegna dell'alleanza fra i lavoratori delle manifatture tessili - il cui cuore era costituito dai salariati del settore laniero, i Ciompi appunto - e i membri delle Arti minori, ormai persuasi che le élites mercantili e imprenditoriali non avrebbero mai acconsentito a concessioni sostanziali nei loro confronti. La rivolta, sta-

${ }^{40}$ Id., "Audiant omnes Artes": Corporate Origins of the Ciompi Revolution, in Il Tumulto dei Ciompi cit., pp. 59-93: p. 92.

${ }^{41} \mathrm{Da}$ un libro di memorie e ricordi di Pagolo di Ser Guido cimatore, in Stella, La révolte des Ciompi cit., pp. 272-275: p. 272.

${ }^{42} \mathrm{R}$. Trexler, Follow the Flag. The Ciompi Revolt Seen from the Streets, «Bibliothéque d'Umanisme et Renaissance», XLVI, 1984, pp. 357-392: p. 361. 
volta molto più organizzata, scoppiò il 20, e a fermarla non valsero le misure che i Priori presero in extremis, dopo l'arresto di alcuni dei capi del movimento. La grande impressione che gli eventi di quei giorni destarono nei fiorentini, e soprattutto negli appartenenti agli strati più elevati della società, il cui stato d'animo era sospeso fra l'incredulità e il terrore, è testimoniata dai numerosi resoconti che ci sono pervenuti ${ }^{43}$. Queste narrazioni ci mostrano una folla di diverse migliaia di lavoratori tessili e membri di tutte le Arti, esclusa quella della Lana, sotto il palazzo dei Priori, mentre reclama il rilascio degli arrestati ( rendeteci gli uomini, che avete costassù ritenuti!»); l'assalto alla casa del Gonfaloniere di Giustizia, Luigi Guicciardini, e successivamente alla sede dell'Esecutore, dove i rivoltosi si impadronirono del Gonfalone di Giustizia, lo stendardo che era insegna del capo del governo e simbolo della sua autorità; l'attacco al palazzo dell'Arte della Lana, dal quale a stento riuscì a fuggire l'odiato Ufficiale Forestiero, il magistrato chiamato dai lanifices ad amministrare la giustizia penale corporativa. E ancora: la conquista del palazzo del Podestà con la brutale uccisione del 'bargello' Ser Nuto («fu tutto tagliato per pezzi; il minore pezzo non fu oncie sei $\left.{ }^{44}\right)$ e il rogo dei documenti che - si diceva contenevano gli atti di processi istruiti contro i lavoratori. Fino all'atto politicamente più rilevante, la presa del palazzo della Signoria. La mattina del 22 luglio, infatti, i Priori eletti un mese prima, asserragliati da due giorni nella loro sede e ormai isolati («mai si vide signori abandonati, come furono questi priori, che non era nessuno che li confortasse e che si proferisse $»^{45}$ ), cedettero e gli insorti fecero irruzione nell'edificio-simbolo del potere cittadino:

E uno Michele di Lando, pettinatore overo che fusse sopra i pettinatori e sopra li scardassieri, fattore di bottega di lana, avea il gonfalone del popolo minuto in mano, cioè quello si cavò di casa lo executore, ed era in iscarpette sanza calze; con questo gonfalone in mano entrò in palazzo con tutto il popolo che 'l volle seguitare, e su per le scale n'andò infino nella udienza de' priori, e quivi si fermò ritto. $\mathrm{E}$ a voce di popolo gli dierono la signoria, e vollono che fusse gonfaloniere di iustizia e signore ${ }^{46}$.

${ }^{43} \mathrm{Il}$ grosso delle testimonianze cronistiche è stato pubblicato - come è ben noto nella raccolta Il Tumulto dei Ciompi. Cronache e memorie, a cura di G. Scaramella, «Rerum Italicarum Scriptores», seconda ed., XVIII, parte III, Zanichelli, Bologna 19171934.

${ }^{44}$ Cronaca Prima d'Anonimo, in Il Tumulto dei Ciompi. Cronache e memorie cit., pp. 73-102: p. 76.

${ }^{45}$ A. Acciaioli, Cronaca, in Il Tumulto dei Ciompi. Cronache e memorie cit., pp. 1141: p. 32.

${ }^{46} \mathrm{Ibid} .$, pp. $32-33$. 
Costretto il governo alle dimissioni e annullati i risultati del vecchio scrutinio elettorale, in attesa del nuovo da completarsi entro fine agosto, gli insorti formarono un Priorato provvisorio capeggiato dallo stesso Michele e rinnovarono i membri dei due Collegi che nel sistema fiorentino coadiuvavano la suprema magistratura: dei 37 individui complessivamente scelti solo 5 appartenevano a famiglie precedentemente rappresentate in quegli uffici ${ }^{47}$. Il nuovo esecutivo si sarebbe dovuto impegnare nella realizzazione del programma elaborato in una serie di riunioni segrete e la cui corretta attuazione era garantita dalla presenza dei rappresentanti dei rivoluzionari, i «Sindaci del Popolo minuto» e i «Sindaci delle Arti». Nei giorni immediatamente successivi, infatti, furono condannati all'esilio una trentina di membri della Parte Guelfa, venne creato un corpo di balestrieri del Popolo minuto (nel quale si arruolarono subito numerosi lavoratori) e furono costituite ben tre nuove Corporazioni, a testimonianza del fatto che l'insieme dei senza-diritti che ora ottenevano cittadinanza effettiva era più vasto del pur ampio gruppo dei lavoratori lanieri, ma anche di una notevole articolazione interna del fronte dei rivoltosi: si trattava dell'Arte dei Tintori, che comprendeva anche lavatori di lana, cardatori e saponai, tiratori e rammendatori, fabbricanti di strumenti per il lavoro tessile e tessitori di drappi di seta; di quella dei Farsettai, aperta anche a cimatori, sarti, barbieri e cappellai; di quella dei Ciompi, detta anche «del Popolo di Dio», formata da tutte le categorie di salariati della lana - scardassieri e pettinatori in testa - con l'aggiunta dei tessitori. Riplasmata la comunità delle Arti, vennero dettati nuovi criteri per le procedure elettorali, con una ripartizione paritaria delle cariche fra i 3 gruppi che ora formavano l'insieme delle Corporazioni fiorentine: le 7 maggiori, le 14 minori e le 3 neocostituite.

Gli entusiasmi della prima ora, tuttavia, erano destinati a spegnersi rapidamente. Nel giro di qualche settimana apparve infatti chiaro che l'azione della coalizione di governo era contraddittoria e insufficiente, mentre altrettanto evidente era il boicottaggio istituzionale esercitato contro i rappresentanti del Popolo minuto. A ciò si aggiungevano le conseguenze del blocco della produzione laniera attuato dai proprietari delle botteghe, che espose migliaia di lavoratori alla disoccupazione e alla fame, spettri contro i quali furono scarsamente efficaci misure quali l'ingiunzione a tutti i lanaioli della città di riprendere immediatamente il lavoro e produrre almeno 2000 panni al mese, la distribuzione in prestito di uno staio di grano a chiunque ne facesse richiesta, la sospensione della gabella sul grano e la

${ }^{47}$ G. A. Brucker, The Ciompi Revolution, in Florentine Studies. Politics and Society in Renaissance Florence, ed. by N. Rubinstein, Faber \& Faber, London 1968, pp. 314-356: p. 330 , nota 1 . 
farina per 6 mesi, la riduzione del prezzo del sale e della farina. Anche l'alleanza fra i diversi settori del mondo del lavoro che aveva animato la rivolta vacillava: l'insoddisfazione spingeva la componente operaia a radicalizzare il proprio programma, allontanandola inesorabilmente dalle posizioni più moderate dei bottegai e degli artigiani, compresi quelli operanti nella produzione dei panni di lana, e di tutti gli altri artifices. Verso la fine di agosto un gruppo di circa 200 lavoranti dell'Oltrarno, riuniti in un campo nella contrada di Camaldoli, decise di riprendere autonomamente l'iniziativa. Nel corso di un'affollatissima assemblea tenutasi in piazza San Marco il 27 venne costituita una commissione di 8 membri - cui fu attribuito il suggestivo nome di Otto Santi della balìa del Popolo di Dio - concepita come un vero e proprio "governo-ombra» o un contro-potere ${ }^{48}$, la cui legalità i Ciompi opposero a quella dell'esecutivo in carica. Il braccio di ferro che allora si aprì condusse, direttamente in piazza della Signoria, all'approvazione di una serie di richieste sostenute dalla folla e all'elezione di nuovi Priori. La piega presa dagli avvenimenti convinse però il governo $\mathrm{e}$ la comunità delle Arti, che poterono contare sul sostegno di Michele di Lando, a organizzare rapidamente la reazione: come scrisse il cosiddetto Squittinatore, l'unico cronista favorevole ai ribelli, «fo ordinato per tutte l'arti, e per tutti i cittadini di popolo grasso, di volere disfare e di volere torre l'onore e lo stato al popolo minuto, cioè di quell'arte che si chiamavano ciompi» ${ }^{49}$. Lo scontro finale si verificò il 31 agosto in piazza della Signoria. Attaccati dai soldati del Comune con pietre e frecce, aggrediti dalle mannaie e dalle lance dalle milizie delle Corporazioni, tra cui si distinguevano i beccai e gli artigiani delle due nuove Arti dei Tintori e dei Farsettai, gli operai della lana furono dispersi con gravi perdite. Il primo settembre un parlamento generale appositamente convocato abolì l'Arte dei Ciompi e tutte le prerogative e i diritti legati alla sua esistenza.

Il sanguinoso epilogo della rivolta radicale, tuttavia, non determinò il puro e semplice ritorno alla situazione vigente prima del Tumulto, ma segnò l'inizio di una nuova e peculiare fase politica. Estromessi dal Priorato e dalle borse elettorali i rappresentanti dell'Arte dei Ciompi, la comunità delle Arti recuperò la tradizionale divisione fra Maggiori (7) e Minori (16) e su questa base furono suddivisi tutti gli uffici di governo. Fra il settembre 1378 e il gennaio 1382 nei 189 posti del Priorato si alternarono 95 artefici minori e 94 maggiori, questi ultimi in larga misura non appartenenti alle famiglie che rappresentavano l'élite corporativa ${ }^{50}$. Quello che è passato

\footnotetext{
${ }^{48}$ Trexler, Follow the Flag cit., p. 362.

${ }^{49}$ Cronaca Prima d'Anonimo cit., p. 81.

${ }^{50}$ Najemy, A History of Florence 1200-1574 cit., p. 167.
} 
alla storia come il 'governo delle Arti' o 'delle Arti minori' «si avvicinò all'ideale artigiano più di ogni altro che Firenze abbia sperimentato: le sue magistrature si consultavano regolarmente con le Arti, attraverso le loro capitudini, e raccomandavano ai loro rappresentanti di incontrarsi spesso con la loro base» ${ }^{51}$, ciò che spiega perché «most contemporaries did not see the defeat of the Eight as the end of worker's power in Florence» ${ }^{52}$.

Resta il fatto che il nuovo governo si trovò gradualmente nell'impossibilità di condurre una mediazione tra spinte contrastanti: la pressione dei membri dell'oligarchia cittadina esclusi dal potere; le richieste di privilegi e riforme avanzate dai rappresentanti dei ceti più spiccatamente artigianali, compresi quelli raccolti nelle due nuove Corporazioni ancora in vita; l'insoddisfazione della massa dei salariati della lana ricacciati nella nonesistenza giuridica e politica; l'insofferenza dei proprietari delle aziende laniere decisi ad eliminare il potere di negoziazione acquisito dai tintori attraverso l'attività della loro Arte. In un clima che rimaneva teso anche per le continue trame insurrezionali ordite dai leaders dei Ciompi in esilio con l'aiuto di aristocratici sbanditi altrettanto avversi al regime, si giunse nel gennaio del 1382 all'ultimo atto. Una commissione appositamente creata per riformare il governo decretò la soppressione delle Arti dei Tintori e dei Farsettai, una redistribuzione delle cariche che limitava lo spazio politico delle Corporazioni minori, la cancellazione dei bandi emessi dal governo dei Ciompi e da quello delle Arti e l'indennizzo per coloro che avevano subito confische o distruzioni di proprietà. Era l'inizio, sebbene in forme non esasperate, di un processo che gradualmente avrebbe portato alla concentrazione del potere nelle mani di un'oligarchia sempre più svincolata dalle idee e dalla prassi proprie del mondo corporativo.

\section{Gli obiettivi e i risultati}

Perugia

La sola narrazione coeva della rivolta perugina del 1371 non fornisce informazioni utili per comprendere gli obiettivi degli insorti. Poco di più ci dice il Diario del Graziani, che lascia intuire, come unica ragione dello scoppio delle violenze, la resistenza dei Raspanti all'ingresso del legato pontificio in città ${ }^{53}$. Pompeo Pellini, che scrive nel Cinquecento, è invece assai più loquace. Anche per questo autore la cornice è lo scontro fra i Raspanti

\footnotetext{
${ }^{51}$ Brucker, Dal Comune alla Signoria cit., p. 55.

${ }^{52}$ Cohn, Lust for Liberty cit., p. 60.

${ }^{53}$ Cronaca della città di Perugia cit., supplemento III, p. 215.
} 
e le diverse forze che ne volevano abbattere il governo, a partire dai popolani minuti e dai nobili:

il Popolo era per prender l'armi in favor loro, et tutto adirato correre alle case de' Raspanti; cosa nel vero in tutto contraria alle passate attioni di questo popolo, perché mentre i nobili erano stati fuori della Città, non sarebbe stato alcuno di essi, che non havesse fatto ogni cosa a danni loro, ma hora la fame gli avea fatti volgere ad altri pensieri, et quelli, che odiavano, li facea amare, et quelli ch'amavano odiare».

La carestia, generata dalla guerra e dalla politica del governo, modificava dunque le alleanze e in Perugia era ormai convinzione diffusa che «il popolo minuto desiderava grandemente di havere occasione di romoreggiare, et travagliare la Città, così per potere in un tempo vendicarsi contra i Raspanti, come per poter anco rubbare le case di questo, e di quello Cittadino, non havendo la maggior parte di loro cosa alcuna da mangiare, né da sostentarsi $»^{54}$. Con questi presupposti non stupisce che - sempre secondo il Pellini - i rivoltosi chiedessero l'abolizione della gabella sul macinato e un radicale cambiamento nella politica degli Ufficiali dell'Abbondanza, così da ottenere che il «grano, che era stato da luoghi circostanti, et fuori del territorio perugino condotto, per supplire a' bisogni della povertà, si vendesse alle persone povere, et bisognose, et non a Raspanti, et ad altri Cittadini, che poco ne havevano di bisogno, et erano più de gli altri di danari abbondanti ${ }^{55}$. Tali richieste vennero sostanzialmente accolte se è vero che l'odiata imposta venne abolita ${ }^{56}$ e che il cardinale di Bourges, ancora prima di entrare in città, fece annunciare di avere già dato disposizioni per rifornire la popolazione di cereali ${ }^{57}$. Infine, quasi incidentalmente, l'Historia di Perugia afferma che il Popolo minuto perugino si sarebbe rivoltato per «rinovare modo di vivere nella Città ${ }^{58}$, ovvero per ottenere quel cambiamento di governo che avrebbe poi effettivamente avuto luogo con il ristabilimento del dominio della Chiesa su Perugia.

Siena

«La compagnia del Bruco si scuperse in Siena a dì 26 d'agosto, ed era nella contrada d'Uvile, ed erano congiurati circa 300 o più, ed erane capo Domenico di Lano ligrittiere, e dicevano che volevano pace e divizia, e an-

${ }^{54}$ Pellini, Dell'historia di Perugia cit., I, lib. VIII, p. 1094.

${ }^{55}$ Ibid., I, lib. VIII, p. 1095.

${ }^{56}$ Ibid., I, lib. VIII, p. 1101.

${ }^{57}$ Dupré Theseider, La rivolta di Perugia cit., p. 86.

${ }^{58}$ Pellini, Dell'historia di Perugia cit., I, lib. VIII, p. 1094. 
daranno per lo grano a chi n'arà, e chi n'arà ne lo darà ${ }^{59}$. Così il solito Donato di Neri introduce, sotto l'anno 1370, i protagonisti del tumulto che di lì a poco avrebbe sconvolto la città. Si tratta, a ben vedere, di una presentazione piuttosto contraddittoria: da un lato infatti, forse influenzato dal successivo corso degli avvenimenti, l'estensore della Cronaca senese sottolinea gli elementi di minaccia dell'ordine costituito insiti nella creazione della compagnia, dall'altro la dipinge come una tranquilla associazione di mutuo soccorso. Alcuni tratti sono tuttavia ben leggibili. Quella che cominciò ad operare nell'estate del 1370, con l'intento dichiarato di raccogliere cereali in un momento di penuria ed alti prezzi, era un'organizzazione con un preciso radicamento territoriale, una ragguardevole consistenza numerica, un 'capo' - in quel momento il rigattiere Domenico di Lano - di una certa levatura, se è vero che fino a poco prima era stato Capitano del Popolo nel governo dei Riformatori ${ }^{60}$. Piuttosto resta non del tutto precisata la composizione sociale della compagnia: le fonti cronistiche parlano di «lavorenti e scardazieri» o di «minori operai» dell'Arte della Lana $^{61}$, e dunque fanno pensare in primo luogo ai salariati operanti nelle botteghe dei lanaioli e a tutte le figure di apprendisti e garzoni dei vari mestieri lanieri, senza peraltro escludere del tutto categorie quali i tessitori e forse i rifinitori del panno. D'altra parte, trattandosi di un organismo a base territoriale, doveva necessariamente accogliere in una qualche misura anche gli esercenti mestieri non tessili e comunque non soggetti alla giurisdizione dell'Arte della Lana, come è evidenziato dalla presenza, al vertice dell'organizzazione, di un rigattiere. La contraddizione, tuttavia, è più apparente che reale: la contrada delle coste d'Ovile, infatti, si rivela come «one of the few uniformly poor, exclusively 'working class', districts of the city»; un'area urbana in cui i gli addetti al settore laniero convivevano con altri lavoratori e piccoli artigiani ${ }^{62}$.

Indipendentemente dai fini per i quali era nata, l'associazione entrò come parte attiva nei conflitti cittadini con obiettivi diversi, almeno uno dei quali è individuato dalla cronistica e alcuni altri sono desumibili dai provvedimenti che la sua iniziativa produsse (visto che sembra difficile credere a concessioni più ampie delle richieste). Vediamo il primo: «Li la-

${ }^{59}$ Cronaca senese di Donato di Neri cit., p. 634.

${ }^{60}$ La rivolta dei "ciompi" di Siena cit., pp. 78-79; Wainwright, The Testing of a Popular Sienese Regime cit., pp. 149-150.

${ }^{61}$ La prima espressione è utilizzata nella Cronaca senese di Donato di Neri cit., p. 639, la seconda è impiegata da Orazio Malavolti, Dell'Historia di Siena cit., parte II, lib. VIII, f. $138 \mathrm{v}$.

${ }^{62}$ Wainwright, The Testing of a Popular Sienese Regime cit., pp. 148-149, citazione a p. 148 . 
vorenti e scardazieri dell'Arte della lana di Siena ebbero parole e quistione co' li loro maestri [per] pagare sicondo l'ordine del comuno di Siena e non per quello dell'Arte» ${ }^{63}$; ovvero, in termini più espliciti, i lavoratori lanieri chiedevano un diverso trattamento retributivo e, nello scontro che li opponeva ai lanaioli, invocavano la superiore protezione del Comune, cui volevano fosse riservata la facoltà di decidere la materia salariale. Gli altri punti: nel novembre 1371 il governo dei Riformatori approvò una serie di misure in virtù delle quali il monopolio dei proprietari degli opifici nella direzione dell'Arte della Lana e la stessa autonomia decisionale dell'organismo corporativo risultavano attenuati. Fu infatti stabilito il principio della gestione collegiale, realizzato attraverso l'assegnazione, in parti uguali, dei seggi di Console e di Consigliere a lanaioli e rappresentanti dei mestieri sottoposti, sebbene con la precisazione che ad essere eletti fossero $\mathrm{i}$ "principali maestri» di ambedue i gruppi; in più venne imposto ai Consoli dell'Arte che qualsiasi loro statuto, ordine, provvisione o riforma non potesse avere validità senza il preventivo assenso del Consiglio generale del Comune. Anche sul fronte della 'libertà di lavoro' si registrarono interessanti novità: eliminando il diritto di regolamentazione fino ad allora detenuto dalla Corporazione, le nuove norme permettevano a chiunque volesse diventare produttore di panni di farlo pagando una tassa d'iscrizione (leggermente superiore per i forestieri); analogamente gli operai che non avevano contratto debiti o impegni con i propri datori di lavoro, o li avevano comunque onorati, sarebbero stati liberi di impiegarsi presso qualsiasi maestro ${ }^{64}$.

Sebbene nella dinamica dei fatti e nell'azione delle forze in campo rimangano a tutt'oggi zone d'ombra, sembra evidente che i lavoranti senesi non miravano a costituire una loro Arte. Questo atteggiamento, in cui si è voluta riconoscere una ingenuità di fondo, attribuita all'insufficiente grado di sviluppo della loro 'coscienza politica' rispetto a quella dei Ciompi fiorentini ${ }^{65}$, non mancava al contrario di logica e di realismo. In una città in cui l'influenza delle Corporazioni - con l'eccezione rappresentata proprio dagli anni dell'ormai tramontato regime dei Dodici aveva sempre trovato limiti sostanziali nella sovranità delle istituzioni comunali e nelle funzioni di controllo esercitate dalla Mercanzia ${ }^{66}$, la crea-

${ }^{63}$ Cronaca senese di Donato di Neri cit., p. 639.

${ }^{64}$ Il documento è stato pubblicato da Broglio D'Ajano, Tumulti e scioperi a Siena cit., Appendice, pp. 464-466.

${ }^{65}$ Rodolico, La democrazia fiorentina cit., p. 108.

${ }^{66}$ Cfr. G. Prunai, Appunti sulla giurisdizione artigiana senese, sec. XIII e XIV, «Bullettino senese di storia patria», IV, 1933, pp. 347-410; W. Bowsky, Un Comune italiano nel Medioevo. Siena sotto il regime dei Nove, 1287-1355, trad. it., Il Mulino, 
zione di una propria organizzazione di mestiere da contrapporre all'Arte della Lana poteva non bastare a rassicurare i sottoposti; in più essi intendevano, almeno inizialmente, sfruttare per la difesa dei loro interessi, anche attraverso il condizionamento di un'azione di forza, la presenza di un governo la cui ala maggioritaria era costituita da rappresentanti del Popolo minuto. Era un disegno sicuramente pericoloso, in quanto suscettibile di innescare, come puntualmente avvenne, la reazione delle altre componenti sociali e politiche. Di fronte alle diverse pressioni convergenti, infatti, la Signoria, anche nel breve periodo in cui fu completamente nelle mani del Popolo del maggior numero, mantenne un atteggiamento oscillante e non fu in grado, per esempio, di impedire la carneficina degli aderenti alla Compagnia del Bruco.

Nonostante l'alto costo in vite umane pagato, comunque, i sottoposti delle coste d'Ovile ottennero, sempre che la legislazione che modificava la gestione dell'Arte della Lana trovasse effettiva applicazione, risultati di una certa importanza e probabilmente non troppo difformi da quelli che erano gli obiettivi di partenza. Da sottolineare, in particolare, il significato della riforma degli uffici corporativi, che garantiva ai maestri dei mestieri sottoposti una rappresentanza paritaria: una conquista che assume maggior risalto se si considera che a Firenze la partecipazione di questi lavoratori al Consolato e al Consiglio della Corporazione laniera non superò mai la quinta parte ${ }^{67}$. Il regime dei Riformatori, che quelle misure aveva varato, restava, pur nelle sue insufficienze, un interlocutore non pregiudizialmente sordo alle aspirazioni dei lavoratori lanieri e la sua caduta, nel 1385, significò la fine di un'esperienza che non poté più essere ripetuta ${ }^{68}$.

Bologna 1986 [1981], pp. 293 sgg. ; M. Ascheri, Arti, mercanti e mercanzie. Il caso di Siena, in Id., Siena nel Rinascimento. Istituzioni e sistema politico, Il Leccio, Siena 1985, pp. 109-137.

${ }^{67}$ Prima del Tumulto solo ai tintori, fra tutti i lavoratori sottoposti alla giurisdizione dell'Arte della Lana fiorentina, era concesso di ricoprire le cariche corporative, ma con la rivolta del 1378 la situazione cambiò radicalmente in virtù della creazione delle Corporazioni autonome dei Ciompi e dei Tintori. Dopo la caduta del governo delle Arti (1382) e il rientro di tutti gli addetti al settore laniero nei ranghi dell'Arte della Lana le categorie più spiccatamente artigianali si videro riconosciuto il diritto di eleggere 2 dei 10 Consoli della Corporazione e 10 dei 50 membri del Consiglio; ma nel 1393, con la stretta oligarchica imposta dalla balia dominata dagli amici degli Albizzi, anche questa prerogativa venne cancellata (F. Franceschi, Oltre il 'Tumulto'. I lavoratori fiorentini dell'Arte della Lana fra Tre e Quattrocento, Olschki, Firenze 1993, pp. 85-86).

${ }^{68} \mathrm{Cfr}$. a questo proposito le considerazioni di Cherubini, I mercanti e il potere cit., pp. 336-338. 


\section{Firenze}

Il Tumulto dei Ciompi è uno degli eventi della storia fiorentina sul quale si sono registrate il maggior numero di ricerche. Tuttavia - come ha ricordato anche recentemente Samuel Cohn - questa storiografia, vasta e internazionale, si presenta profondamente divisa: pur nella diversità delle interpretazioni individuali è possibile tracciare una rozza linea di discrimine fra chi - come Gene Brucker, Sergio Bertelli, Mollat e Wolff, Raymond De Roover - ha spiegato essenzialmente la rivolta come un episodio della lotte di fazione, negando agli insorti coesione sociale e coscienza politica, giudicandoli manipolati dalle oligarchie e portatori di un'ideologia conservatrice se non reazionaria; e chi - come Niccolò Rodolico, Victor Rutenburg, Charles Marie de La Roncière, John Najemy, Richard Trexler, Alessandro Stella e lo stesso Cohn - ha invece sottolineato la capacità di autonoma iniziativa dei rivoltosi, l'originalità delle proposte elaborate e la rilevanza delle conquiste pur brevemente prodotte dal Tumulto ${ }^{69}$. Il confronto tuttavia, talvolta assai aspro, è apparso troppo spesso viziato dall'utilizzazione di paradigmi interpretativi modernizzanti, tratti dall'esperienza dei movimenti rivoluzionari e socialisti dell'Otto e Novecento ${ }^{70}$.

Ma che cosa chiedevano davvero gli insorti? Dalle tre petizioni identificate dai ricercatori relative al periodo di luglio (due presentate a nome del Popolo minuto e una delle Arti minori), frutto di una serie di riunioni clandestine accompagnate dalla creazione di un comitato direttivo e di un'organizzazione armata, emergono oltre venticinque distinte richieste ${ }^{71}$, peraltro anticipate nelle linee essenziali - secondo il racconto della cosiddetta Cronaca di Alamanno Acciaioli - dalla confessione di Simoncino detto Bugigatto, uno degli operai arrestati il 19 luglio $^{72}$. Al primo posto della lista più importante, quella che Victor Rutenburg ha definito il «programma di S. Lorenzo» perché messo a punto in un incontro tenutosi nell'omonima chiesa la notte del 21 luglio $^{73}$ e che rappresenta in maniera più

${ }^{69}$ Cohn, Popular Protest cit., pp. 201-202.

${ }^{70}$ Come ha sottolineato Stella, La révolte des Ciompi cit., pp. 62-65.

${ }^{71}$ Tutta la materia è stata recentemente riesaminata in uno specifico contributo da E. Screpanti, La politica dei Ciompi: petizioni, riforme e progetti dei rivoluzionari fiorentini del 1378, "Archivio storico italiano», CLXV, 2007, pp. 3-56; qui (Appendici, A, pp. 42-54) l'autore fornisce anche la trascrizione integrale della seconda delle petizioni presentate dal Popolo minuto, conosciuta ma mai edita, che giudica «espressione del partito degli Otto [...] guidato da Salvestro de’ Medici» (ibid., p. 10), ossia del «blocco di potere dell'alta borghesia mercantile-finanziaria» (ibid., p. 5, nota 5). L'articolo è poi rifluito nel capitolo 4 del volume L'angelo della liberazione cit.

${ }^{72}$ A. Acciaioli, Cronaca cit., p. 21.

${ }^{73}$ Rutenburg, Popolo e movimenti popolari cit., p. 205. 
diretta il punto di vista dei lavoratori tessili, figura la soppressione dell'Ufficiale Forestiero dell'Arte della Lana; al secondo l'abolizione della pena del taglio della mano per i debitori insolventi e, per due anni, dell'arresto per i medesimi; al terzo e al quarto la definizione della rappresentanza istituzionale del Popolo minuto, ovvero la facoltà di eleggere propri Consoli e notai con prerogative uguali a quelle riservate ai funzionari delle Arti già esistenti, la possibilità di ottenere una sede per riunirsi, nonché il diritto di occupare un quarto dei seggi nella Signoria e nei Collegi e, a rotazione con le Arti maggiori e quelle minori, la carica di Gonfaloniere di Giustizia; con il quinto punto si reclama l'impunità per i responsabili degli incendi e dei saccheggi perpetrati durante l'insurrezione di giugno. L'elenco continua con una serie di richieste tese a modificare radicalmente il sistema di tassazione e la gestione del debito pubblico, come l'abrogazione dei prestiti forzosi (le prestanze) e l'introduzione dell'estimo, l'imposta di ripartizione calcolata sugli effettivi patrimoni detenuti già vigente nel contado fiorentino; l'abolizione del pagamento degli interessi sui titoli del debito pubblico; la restituzione integrale ai creditori, da effettuarsi nell'arco di dodici anni e secondo l'effettivo valore nominale dei prestiti, delle somme prestate al Comune. Nella petizione non figura invece una richiesta cui gli studiosi hanno prestato una certa attenzione: quella di porre un limite alla continua svalutazione della moneta 'piccola' rispetto al fiorino, fissando il tasso di cambio, allora attestato sui 75 soldi per fiorino, a $68^{74}$.

Se l'ordine delle domande presentate rifletteva la loro urgenza è evidente che, per i Ciompi, la priorità assoluta era quella di liberarsi dal giogo della sottomissione all'Arte della Lana, una sottomissione che implicava innanzitutto l'impotenza dinanzi all'arbitrio del magistrato espressione della giustizia partigiana dei lanaioli. Scavando nella ricca documentazione superstite del tribunale della Corporazione laniera non è difficile rendersi conto di quanto l'incubo delle condanne pecuniarie, delle pene corporali e infamanti, della stessa tortura dovesse pesare sulla vita quotidiana di artigiani e salariati ${ }^{75}$. Ma essere 'sottoposti' significava, subito dopo, restare esclusi dalle decisioni dell'Arte in tutti gli altri campi, a partire da quello, delicatissimo, dei rapporti di lavoro e delle retribuzioni. Ricordiamoci le parole di Simoncino:

${ }^{74}$ La richiesta compare fra le ultime contenute nell'altra petizione del Popolo minuto, quella attribuibile al 'partito degli Otto' (cfr. nota 71), e questa circostanza fa sorgere qualche dubbio sul fatto che si trattasse di una rivendicazione funzionale soltanto agli interessi dei lavoratori salariati, così come è stata sempre intesa.

${ }^{75}$ Cfr. F. Franceschi, Criminalità e mondo del lavoro. Il tribunale dell'Arte della lana a Firenze nei secoli XIV e XV, «Ricerche storiche», XVIII, 1988, pp. 551-590; Id., Oltre il 'Tumulto' cit., soprattutto pp. 282-285. 
Disse che li scardassieri, pettinatori, vergheggiatori, tintori, conciatori, cardaiuoli, pettinagnoli, lavatori e altri che sono sottoposti all'Arte della Lana, non vi vogliono più essere sottoposti; e vogliono in tutto, che l'ufficiale non sia più, né avere a fare più nulla con lui; imperocché sono molto male trattati, sì dallo uffiziale, che per ogni piccola cosa ci martoria, e sì da maestri lanaioli, che gli pagano molto male, e, del lavorio che si viene dodici, ne danno otto. Il perché questi cotali dicono, che vogliono consoli per loro, e non vogliono avere a fare, né con lanaiuoli, né co' loro uffiziale. E anche dicono, che vogliono avere parte nel reggimento della città. E vogliono, che ogni ruberia e arsione fatta, non se ne possa conoscere per nessun tempo ${ }^{76}$.

La richiesta di una propria organizzazione corporativa (questo significa, naturalmente, «vogliono consoli per loro»), prima ancora che requisito indispensabile per ottenere una rappresentanza politica, era la strada obbligata per trattare ad armi pari con la controparte, per ottenere un miglioramento delle condizioni di lavoro e di vita. Condizioni di cui, oltre alla durezza, i sottoposti percepivano nettamente l'iniquità: quel lavorare per 12 e ricevere 8 non significava necessariamente che i salari fossero da fame, ma che certamente non erano il giusto corrispettivo dell'attività svolta. In questo senso credo che sia del tutto lecito ritenere, come è stato recentemente fatto in modo persuasivo, che i Ciompi avessero chiara coscienza dello sfruttamento cui erano sottoposti ${ }^{77}$, così come è lecito ipotizzare, considerando il loro programma in materia fiscale e finanziaria, che comprendessero perfettamente i complessi meccanismi attraverso i quali il regime dei prestiti forzosi ed il funzionamento del Monte determinavano «un passaggio continuo di surplus monetario dalla parte meno abbiente della popolazione a quella più ricca». In effetti, anche se non si può fare a meno di notare l'assenza, nella documentazione relativa al Tumulto, di espliciti riferimenti al livello troppo elevato della tassazione o alla necessità di ridurlo, è certo che l'insieme dei provvedimenti concepiti su questo terreno avrebbe condotto alla creazione di un sistema impositivo improntato a maggiore equità ${ }^{78}$. Alla coscienza dell'iniquità del trattamento

${ }^{76}$ Acciaioli, Cronaca cit., p. 21.

${ }^{77}$ Screpanti, La politica dei Ciompi cit., pp. 25-26.

${ }^{78} \mathrm{Cfr}$. la lucida analisi di R. Barducci, Le riforme finanziarie nel Tumulto dei Ciompi, in Il Tumulto dei Ciompi cit., pp. 95-102; la citazione è a p. 99. Resta però da comprendere fino a che punto riforme così profonde fossero realmente condivise da quanti, tra $i$ sottoposti dell'Arte della Lana, possedevano uno status professionale ed economico che li distingueva dalla massa dei salariati: penso a certe figure di artigiani tessili (tintori, conciatori, cimatori, tiratori, fabbricanti di strumenti) dei quali già Gene Brucker aveva mostrato la condizione di «petty entrepreneurs» e la capacità di investire somme talvolta consistenti nei titoli del debito pubblico (Brucker, The Ciompi Revolution cit., pp. 319-320, citazione a p. 319). Resta il fatto che si trattava di una parte minoritaria dell'artigianato 
retributivo e di quello fiscale si aggiungeva poi un'altra dolorosa consapevolezza, quella della fragilità della posizione dei lavoratori sul mercato delle braccia, aggravata certo dalla serrata dei lanaioli dopo i fatti di luglio, ma originata dalla declinante tendenza del settore delineatasi già da qualche anno $^{79}$ : una situazione che spinse i Ciompi a cercare di difendere i livelli di occupazione (e quindi i loro salari) imponendo ai proprietari delle botteghe l'obbligo di assicurare un volume minimo mensile di prodotto.

Il punto più alto del programma di luglio - non c'è bisogno di sottolinearlo - era rappresentato dalla rivendicazione della partecipazione al potere politico insieme alle componenti tradizionali, le Arti maggiori e quelle minori. A questo proposito si è talvolta parlato del «naive character of Ciompi aspirations» ${ }^{80}$, e tale può in effetti apparirci un disegno che presupponeva l'effettiva e paritaria accettazione dei rappresentanti dei lavoratori salariati da parte della comunità degli artifices. Più che di ingenuità, tuttavia, si è forse trattato di eccessiva fiducia nella forza del movimento e nella solidità dell'alleanza fra questo e le Arti minori, un'alleanza che, dopo la riforma costituzionale effettuata dal governo di Michele di Lando, garantiva almeno teoricamente la maggioranza nelle supreme magistrature cittadine $^{81}$. In realtà, se si torna a guardare ai pur intricati avvenimenti dell'estate del 1378 con l'ottica degli uomini del tempo (ed è operazione molto più complicata di quel che possa sembrare), è difficile non concludere con Rodolico, Stella, Cohn ${ }^{82}$ - che le richieste allora formulate erano destinate a modificare profondamente il regime di vita di un larghissimo strato di lavoratori e a incidere sull'ordine politico e sociale, se non su quello economico. Come ha sintetizzato Giovanni Tabacco, «le nuove Arti erano strumento validissimo per una radicale trasformazione delle condizioni del lavoro e del potere nella città di Firenze: anche più di quanto fossero validi, come mezzi di lotta ad alto livello sociale, la Parte Guelfa e gli Ordinamenti [di Giustizia] $»^{83}$.

laniero e assai esigua in rapporto all'insieme dei lavoratori dell'Arte della Lana. E nei giorni del Tumulto il numero doveva avere un peso decisivo! Per qualche dato di matrice non cronistica sulla consistenza degli addetti al settore laniero all'epoca della rivolta cfr. Franceschi, Oltre il 'Tumulto' cit., pp. 94-112, in particolare Tab. 11, p. 108.

${ }^{79}$ Per una presentazione dei diversi dati disponibili cfr. ibid., pp. 6-13.

${ }^{80}$ Brucker, The Ciompi Revolution cit., p. 345.

${ }^{81}$ Come scrissero in una lettera del 25 luglio due informatori senesi al governo della loro città, «in tutti gli ofici le due parti electe sono del popolo minuto»: il documento è stato pubblicato da Screpanti, La politica dei Ciompi cit., Appendici, 4, pp. 55-56; e successivamente in Id., L'angelo della liberazione cit., Appendici, 4, p. 233.

${ }^{82}$ Rodolico, I Ciompi, cit., pp. 121-122; Stella, La révolte des Ciompi cit., pp. 62-65; Cohn, Lust for Liberty cit., p. 60.

${ }^{83} \mathrm{G}$. Tabacco, Egemonie sociali e strutture del potere nel Medioevo italiano, Torino, Einaudi, Torino 1979, p. 349. 
Più radicale ancora era il programma di agosto, anche questo condensato in una petizione, che però non ci è pervenuta. Quello che in esso colpisce - nella formulazione datane dalla Cronaca dello Squittinatore, peraltro non sospetta di distorsioni imputabili alla simpatia dell'autore per i popolani grassi, e dalla Cronaca Seconda d'Anonimo - è la netta prevalenza della pars destruens sulla construens. Il punto centrale della petizione, che venne pubblicamente letta il 27 agosto in Piazza San Marco, era infatti la proposta di allontanare dagli uffici della Repubblica, per un periodo che poteva arrivare a dieci anni, tutti i rettori delle Arti, i Priori in carica e i componenti dei due Collegi che li affiancavano, ossia i Dodici Buonuomini e i Sedici Gonfalonieri. Se si considera che questa proposta era completata dalla richiesta di privare dei diritti politici i cavalieri, nonché di rinnovare completamente perfino il personale amministrativo e gli stipendiari del Comune, si può ragionevolmente ipotizzare che la finalità precipua fosse quella di disarticolare il vecchio ceto di governo ed i suoi nuovi amici con lo scopo di sostituirvisi. Un'analoga volontà punitiva rispetto ai ricchi patrizi e al vasto gruppo dei rentiers esprimeva, sul piano economico, la richiesta di non restituire ai loro titolari, per dieci anni, le somme raccolte dal Monte attraverso il sistema delle prestanze: dopo il taglio degli interessi sui titoli del debito pubblico lanciato in luglio i Ciompi avevano concepito in agosto «una correzione in senso radicale di questa riforma» ${ }^{84}$, giungendo a teorizzare, sebbene temporaneamente, «l'esproprio integrale» dei capitali prestati ${ }^{85}$.

\section{Qualche spunto comparativo}

La presenza, nelle rivolte che abbiamo analizzato, dei lavoratori della manifattura laniera non può essere considerata, in sé, un elemento sufficiente per costruire un'interpretazione unitaria. Certo, tutti e tre gli episodi appaiono come il prodotto di una nuova fase del conflitto che percorreva la società urbana, fase caratterizzata dallo sviluppo delle rivendicazioni del Popolo minuto, all' interno del quale si era accresciuto il ruolo dei salariati, in larghissima misura esclusi dalla rappresentanza corporativa e dal governo cittadino. Tali istanze e aspirazioni poterono prendere più facilmente corpo anche perché in alcune città dell'Italia centro-settentrionale la diffusione di attività produttive su larga scala, e in particolare di quelle tessili, aveva impresso ai rapporti sociali un carattere fortemente antagonistico, determinando all'interno dello schieramento popolare nuove

${ }^{84}$ Barducci, Le riforme finanziarie cit., p. 95.

${ }^{85}$ Screpanti, La politica dei Ciompi cit., p. 30. 
fratture. Etichettare questi conflitti come scontri fra "pre-proletariato» e «borghesia in formazione» non mi sembra però corretto né, soprattutto, euristicamente utile: in nessuno dei singoli casi esaminati, infatti, la complessa dinamica degli avvenimenti autorizza un'interpretazione così schematica, che perde ancora più forza se utilizzata come concetto-chiave in una prospettiva comparativa.

Il caso perugino in particolare - sul quale sarebbero comunque necessarie ricerche ben più approfondite di quelle disponibili - sembra distaccarsi dagli altri due per una minore specificità del ruolo dei lavoratori tessili, per la mancanza di rivendicazioni chiare sul terreno dei rapporti di lavoro e della loro traduzione corporativa, per l'assenza di un progetto politico nel quale i salariati o almeno i popolani minuti venisse a costituire la forza trainante: le richieste più concrete dei tumultuanti - come abbiamo visto - erano infatti una diversa politica annonaria e l'abolizione della gabella del macinato, la fine della guerra fra il Comune e la Chiesa, il ripristino dell'autorità papale e dell'egemonia nobiliare in città. Sarà un caso, ma Perugia era, dei tre centri urbani, quello in cui il peso della manifattura laniera era minore, nonché l'unico (e uno dei pochi in Italia ${ }^{86}$ ) dove il settore non era organizzato attraverso il modello dell'Arte unica, ma prevedeva Corporazioni separate, sebbene gerarchicamente sottoposte al controllo dell'associazione dei lanaioli, per le principali categorie di produttori di panni: Battilana, comprendente i salariati meno specializzati ed i tessitori; Cimatori, cui afferivano anche i purgatori; Tintori ${ }^{87}$.

Affinità maggiori esistono fra le sommosse senese e fiorentina, nate in ambienti che, pur con differenze di scala, erano più decisamente segnati dallo sviluppo di nuove forme di rapporti economici e sociali. In effetti vari studiosi, sebbene con diversità di accenti, hanno sottolineato le conseguenze della massiccia diffusione della 'manifattura disseminata' sulla manodopera impegnata nella produzione dei panni: da un lato la formazione di un vasto insieme di salariati non specializzati addetti alla preparazione della lana, privi di strumenti di produzione, normalmente retribuiti a giornata, soggetti alla dura disciplina del lavoro imposta dai lanifices nelle

${ }^{86}$ Una rapida panoramica in F. Franceschi, L'organizzazione corporativa delle grandi manifatture tessili nell'Europa occidentale: spunti comparativi, in Tra economia e politica: le Corporazioni nell'Europa medievale, Atti del Ventesimo Convegno Internazionale di Studi (Pistoia, 13-16.V.2005), Centro Italiano di Studi di Storia e d’Arte, Pistoia 2007, pp. 333-357: pp. 344-347.

${ }^{87}$ Cfr. Broglio D’Ajano, Lotte sociali a Perugia cit., pp. 339-341; Rutenburg, Popolo e movimenti popolari cit., pp. 26-27; G. Mira, Aspetti dell'organizzazione corporativa in Perugia nel XIV secolo [1959], ora in Id., Scritti scelti di storia economica umbra, a cura di A. Grohmann, Deputazione di storia patria per l'Umbria, Perugia 1990, pp. 133-165: Tab. I, p. 137 e pp. 151-153. 
loro botteghe; dall'altro la trasformazione dei tessitori e dei rifinitori del tessuto in lavoratori 'a fase', ovvero, a dispetto del sapere tecnico e del contesto 'artigianale' che contraddistingueva la loro attività, in salariati a cottimo. Processi cui aveva fatto seguito la trasformazione delle istituzioni corporative, con la formazione di un'unica Arte della Lana comprendente tutti coloro che operavano nel settore, dal mercante-imprenditore più facoltoso all'ultimo degli apprendisti, ma dominata dal gruppo dei lanaioli: solo questi ultimi erano gli artifices pleno iure, tra i quali si reclutava l'élite che, attraverso gli organi interni, governava la Corporazione monopolizzando la pienezza dei poteri deliberativi, esecutivi e giudiziari ${ }^{88}$.

$\mathrm{Al}$ di là delle similarità identificabili nelle strutture produttive e nei rapporti sociali in cui maturarono, al di là di una 'grammatica' comune - la presenza di leaders organici al movimento, di strumenti organizzativi efficaci, di simboli capaci, come le bandiere, di generare coesione e indirizzare la protesta ${ }^{89}$ - le rivolte di Siena e di Firenze condividevano alcuni obiettivi di grande significato: ridiscutere l'ammontare e lo stesso meccanismo di determinazione delle retribuzioni dei lavoratori, ottenere modalità di rappresentanza corporativa in grado di affrancare artigiani e salariati dalla condizione di 'sottopposti' che li caratterizzava, «avere parte nel reggimento della città».

Le vie scelte nei due centri toscani, però, non furono esattamente le stesse. A Siena la tutela degli interessi economici dei laboratores venne ricercata nella gestione collegiale dell'Arte della Lana e nel ruolo di garanzia svolto dal Comune, a Firenze nella nascita di tre nuove Corporazioni, una delle quali specificamente riservata agli operai lanieri e ai tessitori. Anche sul piano più squisitamente politico si registra una differenza di strategia, o almeno di risultati immediati: nella Città del Palio, dove esisteva un governo in cui il peso dei rappresentanti del Popolo minuto era decisivo, la rivolta portò al temporaneo rafforzamento di questa componente; nella Città del Giglio il successo della rivoluzione del luglio 1378 significò l'ingresso nell'esecutivo e nelle principali magistrature cittadine di coloro che fino ad allora erano stati - come ha scritto Alessandro Stella - dei «sans-droits»,

${ }^{88}$ Per Firenze si vedano almeno Rutenburg, Popolo e movimenti popolari cit., pp. 3476 ; A. Stella, «La bottega e i lavoranti»: approche des conditions de travail des Ciompi, "Annales. E.S.C.», XLIV, 1989, pp. 529-551; Ch. M. de La Roncière, La condition des salariés à Florence au XIV ${ }^{e}$ siècle, in Il Tumulto dei Ciompi, cit., pp. 13-40; Franceschi, Oltre il 'Tumulto' cit., in particolare pp. 81-86. Per Siena Rutenburg, Popolo e movimenti popolari cit., pp. 30-34; Id., La vie et la lutte cit.; La rivolta dei "ciompi" di Siena cit., pp. 33-44; Franceschi, La rivolta di «Barbicone» cit., pp. 294-296.

${ }^{89}$ Tutti aspetti sui quali si sofferma efficacemente la sintesi di Cohn, Lust for Liberty cit., in particolare pp. 125-128, 177-180, 183, 187. 
«sans-parole», «sans-plume» ${ }^{90}$. Una parte dei ribelli fiorentini poi, dinanzi alle difficoltà di dare attuazione al proprio programma, si spinse oltre costituendo un comitato ristretto destinato a funzionare come «organo di controllo permanente nel Palazzo della Signoria, fornito di potere di veto su ogni iniziativa legislativa da parte del governo ${ }^{91}$, e concependo una serie di riforme radicali che, se attuate, avrebbero probabilmente portato i loro promotori a impadronirsi dei centri nevralgici del potere politico, economico e militare. Questa minaccia contribuì in misura determinante a ricompattare il fronte degli artifices maggiori e minori (compresi gli stessi artigiani tessili) contro i Ciompi, che, isolati, vennero battuti in piazza, sconfitti politicamente e ricacciati nella condizione di non-esistenza sociale in cui versavano prima della sommossa. Ciò nonostante gli effetti della redistribuzione del potere originata dai fatti di luglio perdurarono oltre la liquidazione dell'Arte del Popolo di Dio, fino alla svolta politica del 1382.

Le rivolte di Siena e di Firenze, infine, sembrano presentare un'altra intrigante analogia: si situano entrambe al culmine di un processo di 'democratizzazione' della vita politica cittadina che offrì alla parte più numerosa della popolazione nuove opportunità di partecipazione e ne acuì le aspettative di cambiamento. In ambedue le città tale processo passò per un'accresciuta influenza della comunità delle Arti e dei ceti che queste rappresentavano sulle istanze di governo, con un'accentuazione peraltro più decisa, a Firenze, del ruolo del 'corporativismo' come cornice ideologica della lotta fra "valori artigiani ed ethos aristocratico»" ${ }^{92}$. Questa dimensione decisamente 'politica' delle due insurrezioni consiglia di valutare con prudenza interpretazioni troppo strettamente dipendenti dall'andamento della congiuntura demografica o economica ${ }^{93}$ : i rivoluzionari di Siena e di Firenze, in realtà, mostrarono una sorprendente consapevolezza dell'impossibilità di ottenere la tutela effettiva dei propri interessi senza modificare a loro favore i rapporti di potere vigenti.

${ }^{90}$ A. Stella, La révolte des Ciompi cit., p. 64.

${ }^{91}$ N. Rubinstein, Il regime politico di Firenze dopo il Tumulto dei Ciompi, in Il Tumulto dei Ciompi cit., pp. 105-124: p. 107.

${ }^{92}$ La definizione è di Brucker, Dal Comune alla Signoria cit., p. 28. Per Firenze il processo cui si fa riferimento è stato illustrato da Najemy, "Audiant omnes Artes" cit.; per Siena cfr. Wainwright, The Testing of a Popular Sienese Regime cit.

${ }^{93} \mathrm{O}$ quanto meno di distinguere le tendenze di lungo periodo dai movimenti a breve termine, il cui impatto sui comportamenti dei diversi ceti poteva essere assai più marcato, come osserva opportunamente Giuliano Pinto nel suo intervento in questo stesso volume (G. Pinto, Congiuntura economica, conflitti sociali, rivolte). 



\section{Francesco PANERo}

\section{SIGNORI E SERVI: UNA CONFLITTUALITÀ PERMANENTE}

Nell'affrontare il tema delle franchigie rurali nell'Europa occidentale durante il basso Medioevo, Robert Fossier ha distinto i rustici liberi - che beneficiano delle franchigie signorili o comunali - dai "non liberi", dai serfs, che non possono usufruirne perché non siedono in tribunale, non concorrono all'esercito, non sono partecipi delle consuetudines comunitarie, non sono soggetti ai carichi fiscali della comunità ${ }^{1}$. Per Fossier, fra XII e XIII secolo i non liberi rappresentano nell'Europa occidentale, a seconda delle località considerate, da un dieci a un trenta per cento della popolazione, ma questa percentuale vale soprattutto per la Francia, dove in quegli stessi secoli è molto alto il numero dei servi di proprietà regia, i quali continuano a essere "manumessi" dalla corona ancora nel tardo Medioevo, come già rilevava Marc Bloch nel suo primo lavoro di grande impegno, Rois et serfs, scritto all'inizio del Novecento ${ }^{2}$.

Guardando all'Italia bassomedievale, una stima prudenziale della popolazione servile impone un'oscillazione fra l'uno e il dieci per cento dei contadini, con molte comunità che non conoscono la presenza di servi e alcune aree in cui questa è invece considerevole: ad esempio nella città e nel contado bolognese alla metà del Duecento circa il sette per cento della popolazione è di condizione servile ${ }^{3}$. Anche nel territorio trevigiano la pre-

${ }^{1}$ R. Fossier, Les franchises rurales en Europe occidentale au Moyen Âge: fondements et problèmes, in Liberté et libertés. VIII centenaire de la charte des franchises d'Aoste, Aosta 1993, pp. 39-54.

${ }^{2} \mathrm{M}$. Bloch, Rois et serfs et autres écrits sur le servage, avec Postface par D. Barthélemy, Paris 1996 (I ediz. 1920). Cfr. anche M. Bloch, La servitù nella società medievale, nuova ediz. it. a cura di G. Cherubini, Firenze 1993.

${ }^{3}$ A.I. Pini, Città medievali e demografia storica, Bologna 1996, p. 115 sgg. I dati sono desunti dal Liber Paradisus della metà del secolo XIII ("Liber Paradisus" con le riformagioni e gli statuti connessi a cura di F.S. Gatta e G. Plessi, Bologna 1956; cfr. ora la nuova ediz. a cura di A Antonelli, Venezia 2007). Ma i contingenti servili bolognesi della metà del Duecento sono notevolmente superiori alla realtà dell'inizio del secolo, che registrava la presenza di appena il due per cento di servi fra città e contado: cfr. F. Panero, Persistenze della servitù altomedievale e forme di nuovo "servaggio" nell'Italia centro-settentrionale (secoli XII-XIV), in La servitude dans les Pays 
senza di servi, ancillae e masnade servili è ben documentata per tutto il Duecento e nella prima metà del Trecento (quando cominciano a essere attestati anche alcuni schiavi di tratta): nel 1317 il comune di Treviso acquista dai da Carrara beni, diritti sui vassalli e servi in diverse località del contado, procedendo subito a liberare quei servi che entro un termine stabilito si fossero autodenunciati al comune $e^{4}$. La soglia massima di queste percentuali viene pure toccata in alcuni anni particolari dagli schiavi presenti in alcune città portuali italiane nei secoli XIV e XV ${ }^{5}$.

Pertanto il problema della conflittualità fra signori e servi - a parte la rivolta dei contadini inglesi del 1381 e le ribellioni dei remenças catalani dagli anni ottanta del XIV secolo fino alla sentenza di Guadalupe di Ferdinando il Cattolico, o poche altre sommosse isolate, sulle quali ci soffermeremo in seguito - negli ultimi tre secoli del Medioevo non assume il rilievo che hanno i contrasti fra comunità rurali libere e signori nella seconda metà del Trecento.

Ciò nonostante, è utile affrontare il problema della conflittualità latente o palese fra servi propriamente detti e signori sia per rilevarne le cause, sia

de la Méditerranée occidentale chrétienne, Rome 2000 ("Mélanges de l'École française de Rome - Moyen Âge", 112/2), pp. 761-773, a p. 763 sg., tenendo conto delle osservazioni di G. Ortalli, La famiglia tra la realtà dei gruppi inferiori e la mentalità dei gruppi dominanti a Bologna nel XIII secolo, in Famiglia e parentela nell'Italia medievale, a cura di G. Duby e J. Le Goff, trad. it., Bologna 1981, pp. 125-143, alle pp. 130 sg., 142.

${ }^{4}$ G.B. Verci, Storia della Marca Trivigiana e Veronese, VIII, Venezia 1788, pp. 6973, docc. 843-844, a. 1317. Cfr. G. Cagnin, I patti agrari in territorio trevigiano dalla metà del secolo XII agli inizi del secolo XIV: tradizione e innovazione, in Storia di Treviso, II, Il Medioevo, Padova 1991, pp. 334, 350, nota 25. Ringrazio Giampaolo Cagnin per numerose notizie inedite su servi e schiavi trevigiani dei secoli XIII-XIV che gentilmente mi ha fornito.

${ }^{5} \mathrm{M}$. Balard, Remarques sur les esclaves à Gênes dans la deuxième moitié du XIII siècle, «Mélanges d'archéologie et d'histoire», 80, 1968, pp. 627-680; R. Delort, Quelques précisions sur le commerce des esclaves à Gênes vers la fin du XIV siècle, «Mélanges d'archéologie et d'histoire», 78, 1966, pp. 215-250; D. Gioffrè, Il mercato degli schiavi a Genova nel secolo XV, Genova 1971. Per Venezia si può continuare a far riferimento a Ch. Verlinden, L'esclavage dans l'Europe médiévale, II, Gent 1977, p. 550 sgg. Molto più basso che a Genova e a Venezia è invece il numero di schiavi presenti ad esempio a Firenze o a Pisa tra la seconda metà del Trecento e i primi decenni del Quattrocento: M. Boni e R. Delort, Des esclaves toscans, du milieu du XIVe au milieu $d u X V^{e}$ siècle, «Mélanges de l'École française de Rome - Moyen Âge», 112/2, 2000, pp. 1057-1077 (nonostante i dubbi sollevati dai due autori a p. 1063, è molto probabile che i "servi" di cui parla Leon Battista Alberti siano prevalentemente "servitori" liberi, anche se talvolta indubbiamente confusi con schiavi e schiave, questi ultimi numericamente in declino già nella prima metà del Quattrocento). Per un quadro generale cfr. F. Panero, Schiavi, servi e villani nell'talia medievale, Torino 1999, pp. 341-369. 
per chiarire come siano fluide e articolate le forme di dipendenza servile ma allo stesso tempo sia sempre netta la distinzione sul piano giuridico fra subordinazione libera e soggezione servile - nel quadro complessivo delle comunità rurali dell'Europa occidentale negli ultimi tre secoli del Medioevo.

Il conflitto permanente fra signori e servi - fatto di violenze, fughe, sotterfugi e sabotaggi ${ }^{6}$ - viene dunque composto via via attraverso concessioni di natura economica e atti di manumissione (gratuiti o previo pagamento di un riscatto della libertà), che in ogni caso non si possono confondere con le carte di franchigia signorile o con le affrancazioni comunali ${ }^{7}$, se non si vuole falsare il rapporto quantitativo esistente fra rustici-homines-massari liberi da un lato e servi-villani-adscripticii-homines alterius-homines de corpore (o homines proprii) dall'altro, e se si vuole avere la possibilità di distinguere la "violenza istituzionalizzata" nei confronti dei servi propriamente detti rispetto agli atti di violenza che suscitano la legittima reazione delle comunità di uomini liberi.

\section{Tipi di conflitto}

I conflitti fra servi e signori - che fra tarda antichità e alto medioevo talvolta erano sfociati in vere e proprie rivolte servili ${ }^{8}$ - negli ultimi tre secoli del medioevo consistono essenzialmente nel rifiuto di prestare corvées a merci (oppure nello svolgerle in modo inadeguato a danno del signore), nel trasgredire la normativa signorile nell'ambito della grande proprietà o della casa padronale (in modo da attuare una "resistenza sotterranea", una violenza per certi aspetti latente ai danni del padrone $)^{9}$, nel rifiutare la giustizia arbitraria dei domini e nel rivolgersi a un tribunale pubblico per negare l'esistenza della condizione servile o ascrittizia, che costituiscono il presupposto dei servizi richiesti: questi ultimi magari sono quantitativamente simili a quelli prestati dai rustici liberi, ma derivano dalla dipendenza ere-

${ }^{6} \mathrm{P}$. Bonnassie, Survie et extinction du régime esclavagiste dans l'Occident du haut moyen âge (IV ${ }^{e}-X I^{e}$ siècles), "Cahiers de civilisation médiévale», XXVIII, 1985, pp. 307-343.

${ }^{7}$ F. Menant, Le chartes de franchise de l'Italie communale. Un tour d'horizon et quelques études de cas, in Pour une anthropologie du prélèvement seigneurial dans les campagnes médiévales (XI ${ }^{e}-X I V^{e}$ siècles). Réalités et représentations paysannes, a cura di $\mathrm{M}$. Bourin e P. Martínez Sopena, Paris 2004, pp. 239-267; M. Mousnier, Ville et servage en Languedoc toulousain: l'air de la ville rend-il libre?, in La servitude dans les Pays de la Méditerranée cit., pp. 919-939.

${ }^{8}$ Bonnassie, Survie et extinction cit., p. $335 \mathrm{sg}$.

${ }^{9}$ P. Dockès, La libération médiévale, Paris 1979, p. 260. 
ditaria, che si vuole invece avere la possibilità di interrompere attraverso un'eventuale emigrazione legittima ${ }^{10}$.

C’è poi la fuga, che costituisce un ulteriore livello di resistenza al dominus. Essa rappresenta talvolta l'alternativa a ciò che potrebbe sancire il giudizio di un tribunale; oppure è l'unica via d'uscita in una reale e documentata condizione di servitù tradizionale o villanale e quindi consente di tentare la ricerca di condizioni di dipendenza più favorevoli in una situazione disperata di subordinazione perpetua; o è ancora il modo per sottrarsi alla giustizia del padrone, ammessa dalle leggi insieme con le punizioni corporali nei confronti di chi è giuridicamente servus ${ }^{11}$.

Si tratta quindi di conflitti continuativi, che si attenuano solo quando i signori fanno concessioni dirette o indirette, magari assecondando i matrimoni misti o accettando le conseguenze della solidarité des miséreux come ha scritto Pierre Bonnassie ${ }^{12}$ - ossia le "coperture" delle famiglie di contadini liberi nei confronti di quelle servili che vivono nella stessa comunità di villaggio e che si imparentano con i rustici liberi.

Il conflitto a volte si supera con la concessione di carte di manumissione, previo pagamento di un riscatto, come spesso capita in Francia fra XIII e XIV secolo nei confronti dei servi regi: Marc Bloch ha chiarito che però talvolta si trattava di affrancazioni di liberi, cioè di semplici "abbonamenti della taglia" signorile ${ }^{13}$, per cui si è in presenza di due situazioni molto diverse fra loro, che vanno sempre tenute ben distinte per evitare confusioni ed errate prospettive d'interpretazione. La confusione d'altronde era fatta talvolta anche dagli interessati, come quei discendenti di liberti abitanti nella Liguria di Ponente nella prima metà del Duecento, a Ceriana nei pressi di Sanremo, i quali essendo provvisti di una carta di manumissione, ritenevano di potersi sottrarre per questo al pagamento dei tributi pubblici a favore dell'arcivescovo di Genova. In tribunale, nel 1255 , la loro richiesta fu ritenuta ridicola dal giudice poiché per non pagare i tributi, cui erano soggette tutte le persone libere, bisognava ovviamente disporre di una carta di franchigia (o di "abbonamento della taglia", come avrebbe detto Bloch) e non di una carta di manumissione, che ren-

${ }^{10}$ I. Alfonso, La contestation paysanne face aux exigences de travail seigneuriales en Castille et Léon. Les formes et leur signification symbolique, in Pour une anthropologie du prélèvement seigneurial cit., pp. 300-309.

${ }^{11}$ Panero, Schiavi, servi e villani cit., p. 127 sgg.

${ }^{12}$ Bonnassie, Survie et extinction cit., p. 325.

${ }^{13}$ Bloch, Bianca di Castiglia e i servi del capitolo di Parigi, in Id., La servitù nella società medievale cit., p. 313 sgg.; Id., Libertà e servitù personali nel medioevo, in particolare in Francia. Contributo a uno studio delle classi, Ibid., p. $124 \mathrm{sgg}$. 
deva giuridicamente liberi, ma non esonerati dal pagare le imposte pubbliche e signorili ${ }^{14}$.

Per qualche aspetto la tipologia dei conflitti che coinvolgono servi e signori è simile ai contrasti esistenti fra mezzadri e padroni, anch'essi continui nel tempo, come hanno rimarcato Roberta Mucciarelli e Gabriella Piccinni ${ }^{15}$. Per i mezzadri liberi il conflitto è innescato da ciò che le clausole contrattuali non esplicitano, dalle richieste dei padroni di lavori aggiuntivi a totale carico della famiglia mezzadrile e quindi si manifesta con rifiuti e con atteggiamenti giudicati ingrati e dannosi verso la proprietà, nonché con la frode da parte del mezzadro stesso nella ripartizione dei prodotti ${ }^{16}$; ma il conflitto non sfocia quasi mai in rivolta perché i contatti fra proprietari e mezzadri sono costanti e la famiglia mezzadrile vive abbastanza lontana dalla comunità di villaggio e dalle altre famiglie mezzadrili, senza contare che in questo caso esiste però una comunanza di interessi da difendere (ad esempio la divisione degli oneri in caso di calamità e la ripartizione degli utili in caso di aumento della rendita), che non c'è nel rapporto fra servi e signori ${ }^{17}$.

Soltanto in parte, quindi, queste motivazioni spiegano le poche rivolte nel rapporto altrettanto perennemente conflittuale fra servi propriamente detti e signori. D'altronde va rilevato che la signoria territoriale di banno è favorevole a un allineamento fiscale dei servi casati ai residenti liberi del villaggio. Solo quando la grande proprietà non riesce a imporsi localmente come signoria bannale, pur assecondando i matrimoni misti cerca di conservare la memoria della condizione servile/ereditaria dei dipendenti e quindi della prole nata da queste unioni. Tra i tanti esempi possibili, è significativo il comportamento dei canonici della cattedrale di Novara nei confronti dei servi di Cannero e Oggiogno (Verbania), ai quali nel XIII secolo è permesso unirsi in matrimonio con i liberi della zona, è permesso possedere terre in concessione. In questo caso il conflitto signori/servi viene superato, ma si trasferisce a un livello superiore fra signore fondiario e signore di banno (l'abate del monastero di Arona): quest'ultimo infatti tende a considerare alla stregua di districtabiles liberi anche i servi sotto-

${ }^{14}$ Liber Iurium Reipublicae Genuensis, a cura di E. Ricotti, Torino 1854 (Historiae Patriae Monumenta, VII), I, col. 1226 sg., 25 ott. 1255. Cfr. F. Panero, Manumissioni di 'servi' e affrancazioni di 'rustici' nell'Italia settentrionale (secoli X-XIII), in La signoria rurale in Italia nel medioevo, Pisa 2006, pp. 385-404, a p. 397.

${ }^{15} \mathrm{R}$. Mucciarelli e G. Piccinni, Un'Italia senza rivolte? Il conflitto sociale nelle aree mezzadrili, in Protesta e rivolta contadina nell'Italia medievale, a cura di G. Cherubini, «Annali dell'Istituto Alcide Cervi», 16, 1994, pp. 173-205.

${ }^{16}$ Ibid., p. $187 \mathrm{sg}$.

${ }^{17}$ Ibid., p. 195 sgg. 
posti al grande proprietario antagonista, residenti nel territorio in cui la signoria bannale sta estendendo il suo dominio. Solo la manumissione con riscatto delle terre, trasformando de iure i servi in liberi districtabiles, pone fine ai contrasti giurisdizionali fra signore fondiario - che cede la proprietà e scompare dalla scena - e signore territoriale, che una volta compiuta la manumissione può finalmente imporre in modo incontrastato la propria autorità su tutti i residenti ${ }^{18}$.

\section{La geografia del conflitto in Italia}

\section{a) "Servi foranei" e "colliberti" in Sardegna}

In alcune regioni - come la Sardegna, dove la giurisdizione territoriale nei giudicati spetta appunto ai "giudici" - i grandi proprietari difendono più tenacemente i loro diritti sui servi e sui colliberti (i servi manumessi a condizione che continuino a prestare in forma ereditaria alcuni servizi ai patroni). Qui pertanto le motivazioni del conflitto si moltiplicano, come ha rilevato Barbara Fois, dal momento che a una relativa libertà di movimento acquisita dai servi foranei e alla loro abbastanza insolita capacità di stare in giudizio, di vendere e di comprare beni - diritti comunque documentati sistematicamente soltanto a partire dal secolo XII - si accompagna una maggior attenzione per i servizi dovuti, fermamente rivendicati dai signori/proprietari ${ }^{19}$.

Si tratta di prestazioni d'opera particolarmente gravose: quattro giorni alla settimana per il servo integru, vale a dire di totale proprietà del dominus, oppure di due giornate per il servus latus o lateratu (il cui servizio è diviso fra due padroni) o di un giorno per il servo la cui opera è ripartita in quattro parti. Ma il totale delle giornate lavorative gratuite non cambia: infatti sono sempre sedici al mese ${ }^{20}$. Gli uomini prestano le loro corvées nei lavori agricoli e nel settore dell'allevamento; le ancillae invece sono impegnate a macinare il grano, a cuocere il pane, a pulire, lavare, filare e tessere $^{21}$. Il dettaglio con cui vengono ripartiti i servizi di natura servile fra più padroni molto spesso determina contrasti, che talvolta possono sfociare in forme di ribellione aperta, di violenza o possono portare alla falsificazione di atti di manumissione collettiva grazie all'appoggio della comunità in cui i servi e i colliberti risiedono ${ }^{22}$.

${ }^{18}$ F. Panero, Servi e rustici. Ricerche per una storia della servitù, del servaggio e della libera dipendenza rurale nell'Italia medievale, Vercelli 1990, pp. 147-157.

${ }^{19} \mathrm{~B}$. Fois, Proteste, processi, ribellioni e fughe di servi nelle campagne della Sardegna giudicale (secc. XII-XIV), in Protesta e rivolta cit., p. $248 \mathrm{sg}$.

${ }^{20}$ Panero, Schiavi, servi e villani cit., p. 64 sgg.

${ }^{21}$ Ibid., p. 78, nota 108.

${ }^{22}$ Fois, Proteste, processi cit., p. 253 sg. 


\section{b) "Homines alterius" e ascrittizi in Umbria, Marche e Toscana}

Anche nell'Italia centrale fra le tante comunità rurali in lite con i signori è possibile ritrovare comunità di servi o comunque dichiarate tali dai signori. Molto noto è il caso degli uomini di Casalina, in Umbria, dove l'abate del monastero di S. Pietro di Perugia intorno alla metà del Duecento asseriva che gli abitanti di quel villaggio erano homines de corpore, ossia servi secondo la terminologia in uso in alcune regioni dell'Europa occidentale nei secoli XII e XIII ${ }^{23}$, mentre questi homines dichiaravano di essere liberi. Probabilmente l'abate cercava estendere a tutta la comunità lo status di alcuni uomini, che pur non essendo de iure servi, avevano accettato di sottoporsi all hominitium, una condizione ereditaria di dipendenza, abbastanza diffusa in area umbro-marchigiana e molto simile a quella degli ascripticii, che a livello contrattuale era tornata a diffondersi fin dall'inizio del secolo XII nel clima di grande rinnovamento giuridico che si ricollegava alla scuola dei glossatori ${ }^{24}$. Non è un caso, infatti, che per porre fine ai contrasti con la comunità di Casalina, l'atto di affrancazione del 1270 facesse riferimento non soltanto all'esonero da servizi e oneri, secondo il modello di tante carte di franchigia, bensì anche alla liberazione "ab omni conditione collonaria, censita, abscriptitia et qualibet alia conditione servili”25, ossia alle formule di liberazione dalla condizione ereditaria di servaggio ascrittizio e villanale.

Molti altri casi di liberazione di coloni e manenti, individuali o collettive, tanto in Umbria quanto in Toscana, pongono fine a contrasti dovuti non solo al pagamento di censi o alla prestazione di servizi ${ }^{26}$, ma innanzi-

${ }^{23}$ A.I. Galletti, Evoluzione dei rapporti di dipendenza nel XIII secolo: il caso dell'affrancazione di Casalina, «Benedictina», 19, 1972, pp. 289-317; O. Marinelli, L'affrancamento degli 'homines' di Casalina nel territorio perugino (1270), «Bollettino della Deputazione di Storia Patria per l'Umbria», LI, 1954, p. 8 sgg.; M.R. Palazzoli, Trasformazione delle classi rurali nell'Umbria medioevale, "Nova Historia», XII/2, 1960, p. 67 sgg., XIII/2-3, 1961, p. 55 sgg. Per la Francia cfr. Bloch, Bianca di Castiglia cit., p. 313 sgg.

${ }^{24}$ Martinus Fanensis, Tractatus de hominiciis, in C.E. Tavilla, 'Homo alterius'. I rapporti di dipendenza personale nella dottrina del Duecento. Il trattato 'De hominiciis' di Martino da Fano, Napoli 1993, p. 253 sgg. (ma cfr. anche p. 88 sgg.). Cfr. inoltre Das 'Formularium' des Martinus de Fano, a cura di L. Wahrmund, Aalen 1962. Nel corso del Duecento sono attestati anche in altre regioni europee atti di liberazione ab hominisco, che pur essendo un legame ereditario personale, molto spesso poggia su vincoli al manso concesso a tempo indeterminato a condizioni particolarmente onerose per i contadini: M. Bourin, Les "homines de mansata" en bas-Languedoc (milieu du XII ${ }^{e}$ siècle-milieu du XIV siècle): théorie, pratiques et résistances, in La servitude dans les Pays de la Méditerranée cit., pp. 883-917, a p. 903 sgg.

${ }^{25}$ Panero, Schiavi, servi e villani cit., p. 223 sgg.

${ }^{26}$ G. Nicolaj Petronio, "Libertas Ecclesiae" e "homagium" in una controversia tra il comune di Foligno e il monastero di Sassovivo nei secoli XIII e XIV, in Studi sul medioevo 
tutto pongono fine alla dipendenza ereditaria (già oggetto di forti contrasti ad Assisi all'inizio del Duecento) ${ }^{27}$; dipendenza ereditaria accesa da un contratto o determinata dalla permanenza sul fondo per più di trent'anni da parte dei figli di ascrittizi, dopo la morte dei genitori, come sta scritto nel Costituto dell'uso di Pisa ${ }^{28}$.

È dunque opportuno tenere distinte dalla dipendenza tradizionale dei rustici liberi le realtà giuridiche del villano senese, dell'ascripticius pisano, del colono fiorentino, del manente lucchese o, ancora, dell'homo alterius umbro-marchigiano; condizioni personali che si allineano tutte alla nuova contrattualistica postirneriana, che si uniforma al diritto romano e vincola personalmente ed ereditariamente i coltivatori che accettano la scrittura contenente un'esplicita promissio di dipendenza ereditaria e in secondo luogo dichiarano attraverso una confessio di essere coloni-ascrittizi, come prevedeva il diritto giustinianeo. Occorre distinguerle dalla condizione tradizionale dei rustici, degli homines, dei libellarii, dei massarii liberi, la cui dipendenza viene definita da un rapporto consuetudinario o contrattuale per la terra avuta in concessione o in ragione della residenza su un sedime signorile (o in un quartiere di un villaggio i cui sedimi abitativi sono di proprietà del signore di banno), patti che però - trattandosi di uomini personalmente liberi, che non si sono impegnati per una dipendenza ereditaria - prevedono la possibilità di allontanarsi dalla terra o dal sedime, anche a rischio di dover rinunciare a ogni diritto sulla terra in concessione ${ }^{29}$.

cristiano offerti a R. Morghen, Roma 1974, I, pp. 701-762; G. Riganelli, Rivolte contadine e borghi franchi in area perugina nel Duecento, in Protesta e rivolta cit., pp. 115-138; S. Tiberini, Le signorie rurali nell'Umbria settentrionale. Perugia e Gubbio (secc. XI-XIII), Roma 1999, p. 274 sgg.; Id., "Dominatus loci" e signoria fondiaria in territorio perugino tra XII e XIII secolo: a proposito di un documento del 1218 nel Cartario di S. Maria di Valdiponte, «Bollettino della Deputazione di Storia Patria per l'Umbria», XC, 1993, pp. 29-78, a p. 47 sgg.; Id., I 'borghi nuovi' di iniziativa comunale nei territori di Perugia e di Gubbio (sec. XIII), in Borghi nuovi e borghi franchi nel processo di costruzione dei distretti comunali nell'Italia centro-settentrionale (secoli XII-XIV), a cura di R. Comba, F. Panero, G. Pinto, Cherasco-Cuneo 2002, p. 206 sgg.

${ }^{27}$ A. Bartoli Langeli, La realtà sociale assisana e il patto del 1210, in Assisi al tempo di San Francesco, Assisi 1978, p. 306 sgg.; J.-C. Maire Vigueur, Nobiltà feudale, emancipazione contadina e struttura degli insediamenti nel contado di Spoleto (XIII secolo, prima metà del XIV secolo), in Atti del IX Congresso Internazionale di Studi sull'Alto Medioevo, Spoleto 1983, I, p. 487 sgg.

${ }^{28}$ I Costituti della legge e dell'uso di Pisa (sec. XII), a cura di P. Vignoli, Roma 2003, p. 284, rubr. XLI (XLII).

${ }^{29}$ F. Panero, Terre in concessione e mobilità contadina. Le campagne fra Po, Sesia e Dora Baltea (secoli XII e XIII), Bologna 1984, p. 154 sgg. e l'Appendice al saggio, La cosiddetta 'servitù della gleba': un problema aperto, pp. 207-276. 
A costo di essere schematici e ripetitivi, va ribadito con chiarezza che questa duplice situazione, sebbene con percentuali diverse dell'una e dell'altra categoria, è una caratteristica di tutti i Paesi dell'Europa occidentale; per questo di volta in volta è indispensabile chiarire la condizione giuridica dei dipendenti, in quanto nel mare magnum delle varie realtà locali le forme di dipendenza sono in definitiva soltanto due, ossia quella libera e quella ereditaria.

Proseguiamo allora con altri esempi italiani, che possono essere utili per un raffronto e per ampliare la discussione. Si tratta di casi piuttosto noti.

\section{c) Servi e villani nell'Italia centro-settentrionale (secoli XII-XIII)}

Nel Bolognese la manumissione dei servi elencati nel Liber Paradisus alla metà del Duecento non è la conseguenza di un conflitto fra dipendenti e signori, ma - come ha chiarito definitivamente Antonio Ivan Pini - serve a sanare un lungo contrasto fra signori e comune per l'imposizione della giurisdizione cittadina nel contado ${ }^{30}$. In seguito invece gli atti collettivi di liberazione riguardano la condizione ascrittizia dei manenti del contado bolognese: in questo caso si può osservare che, nonostante le disposizioni del comune tra il 1282 e il 1304, furono stipulati nuovi patti di adscriptio terrae, che se dai contadini non erano considerati (almeno nella fase incoativa) come contratti che potessero sminuirne la libertà personale, per il comune ledevano invece la capacità impositiva e giurisdizionale della città e pertanto furono dichiarati illegittimi dal comune di Bologna nel $1304^{31}$. Con ciò non si vuol negare che esistessero conflitti fra manenti e signori, come abbiamo già avuto modo di chiarire, anche perché, lo ripetiamo, spesso i proprietari tendevano a considerare coloni/ascrittizi i rustici liberi che avevano terre in concessione a tempo indeterminato ${ }^{32}$.

Le disposizioni del comune di Bologna del 1304 sostanzialmente si pongono nel solco della normativa emanata dal comune di Firenze nel 1289-90: anche in questo caso non dobbiamo vedervi una finalità diretta a smussare contrasti fra contadini e signori (che pur esistevano, viste le petizioni rivolte da alcune comunità del Mugello al comune di Firenze), bensì un atto di vera e propria liberazione di ascrittizi dei canonici della catte-

${ }^{30}$ Cfr. nota 3.

${ }^{31}$ P. Vaccari, L'affrancazione dei servi della gleba nell'Emilia e nella Toscana, Bologna 1926, p. 102 sgg.

32 Cfr. nota 22. Cfr. ancora i riferimenti agli atti processuali relativi allo status di villani/ascrittizi in E. Conte, Servi medievali. Dinamiche del diritto comune, Roma 1996, pp. 5-35 e a p. 306 per un richiamo esplicito da parte di Rolando da Lucca al pericolo per superficiari ed enfiteuti liberi della Tuscia di essere ritenuti sottoposti alla subordinazione perpetua tipica della "colonaria condictione". 
drale fiorentina, previo pagamento di un riscatto, per sottoporli come contribuenti liberi alla giurisdizione del comune ${ }^{33}$.

Altri interventi legislativi comunali toccano invece direttamente il tema del conflitto fra villani/manenti e signori.

Il Costituto di Siena del 1309-1310 identifica sostanzialmente la fuga dei villani con un atto di ribellione al signore, ma ammette altresì che il villano che rinuncia ai diritti "perpetui" sulla terra avuta in concessione possa inurbarsi, in linea con la normativa posta in essere dal comune dalla metà del XIII secolo in avanti ${ }^{34}$.

Gli statuti di Lucca del 1308 stabiliscono che se un manente ha abbandonato il fondo, questo dovrà essere coltivato dai rustici della comunità $\mathrm{e}$ i contadini sospettati di essere manenti fuggitivi devono dare al proprietario un fideiussore a garanzia del loro status di libertà ${ }^{35}$.

Nella Lombardia e nel Veneto invece, non si diffonde il nuovo servaggio di tipo ascrittizio, ma nel Tre e Quattrocento persistono qua e là sacche di servitù di masnada, in cui il conflitto è però spesso superato attraverso nuove concessioni signorili, come ad esempio quella di possedere terre o quella di poter procreare una parte dei figli in stato di libertà nel caso di matrimoni misti ${ }^{36}$.

Nemmeno le vertenze del 1157 e del 1162 fra la badessa del monastero di San Zaccaria di Venezia e i contadini dipendenti di Monselice sembrano equiparabili a quelle dei manenti toscani poiché se è vero - come scrive Sante Bortolami - che appare chiaro l'intento dei coltivatori "di forzare tradizionali vincoli di soggezione connessi col loro status di villani, e naturalmente il pesante carico di censi e opere connesso"37, i patti ad vilanaticum

${ }^{33}$ Panero, Schiavi, servi e villani cit., p. 292 sgg.

${ }^{34} \mathrm{P}$. Cammarosano, Le campagne senesi dalla fine del secolo XII agli inizi del Trecento: dinamica interna e forme del dominio cittadino, in Contadini e proprietari nella Toscana moderna, Firenze 1979, p. 162 sgg.; O. Redon, "Villanus" au XIII siècle dans la documentation siennoise, in La servitude dans les Pays de la Méditerranée cit., pp. 803825; Vaccari, L'affrancazione cit., p. 81.

${ }^{35}$ Cfr. Vaccari, L'affrancazione cit., p. 84 (con riferimento agli Statuti di Lucca del 1308, IV, rubr. 76).

${ }^{36}$ A. Battistella, La servitù di masnada in Friuli, «Nuovo Archivio Veneto», 62-64, 1906, pp. 45 sgg., 177 sgg., confrontato con P. Brancoli Busdraghi, "Masnada" e "boni homines" come strumento di dominio delle signorie rurali in Toscana (secoli XI-XIII), in Strutture e trasformazioni della signoria rurale nei secoli X-XIII, a cura di G. Dilcher e C. Violante, Bologna 1996, p. 292 sgg. e P. Cammarosano, L'alto medioevo: verso la formazione regionale, in Storia della società friulana. Il medioevo, a cura di $\mathrm{P}$. Cammarosano, Tavagnacco 1988, p. 134 sgg. Cfr. inoltre Panero, Persistenze della servitù altomedievale cit., p. $761 \mathrm{sgg}$.

${ }^{37}$ S. Bortolami, Lotta e protesta contadina nel Veneto dal Medioevo alla prima età moderna: un bilancio, in Protesta e rivolta cit., p. 49. 
cui essi si rifiutano di sottostare non si configurano come contratti di adscriptio terrae, ma come patti consuetudinari che non ammettevano la vendita dei diritti d'uso sulla terra in concessione ${ }^{38}$.

\section{d) Contadini fuggitivi nell'Italia del Sud}

Vediamo ancora qualche esempio del Sud-Italia. Tra gli ultimi trent'anni del Duecento e il primo Trecento nell'Italia meridionale sono documentate numerose fughe di contadini - essenzialmente per ragioni economico-fiscali - dalle terre regie e dalle terre dei baroni. Nonostante le promesse di una riduzione dei tributi per coloro che avessero fatto ritorno al luogo d'origine, era impossibile recuperare i fuggitivi e fermare il processo di abbandono di alcuni villaggi ${ }^{39}$, a causa delle fughe verso terre più fertili o verso proprietà che praticavano condizioni economiche migliori. La difficoltà maggiore per far ritornare indietro gli emigrati stava essenzialmente nel fatto che si trattava in prevalenza di rustici liberi. Spesso vi erano anche "popolani" che si contrapponevano alle aristocrazie locali ${ }^{40}$, ma nelle fughe erano talora coinvolti pure degli ascriptitii, i quali de iure si sarebbero potuti catturare e ricondurre dai loro signori, proprio perché la loro condizione giuridica, da questo punto di vista, era equiparabile a quella dei servi, come precisano diverse disposizioni legislative normanne e sveve ${ }^{41}$. Quindi è evidente che nelle regioni del Sud anche fra i contadini in rivolta contro la nobiltà durante le guerre fra Svevi e Angioini e nei primi anni del XIV secolo, vi fossero villani/ascrittizi fuggitivi, quantunque questo gruppo di dipendenti fosse ormai a quell'epoca una categoria giuridica in declino ${ }^{42}$.

${ }^{38}$ A. Castagnetti, Le comunità rurali dalla soggezione signorile alla giurisdizione del comune cittadino, Verona 1983, pp. 53, 74, 126 sg. È possibile invece che talvolta una contaminatio fra adscriptio e patti di villanatico si registri nel territorio piacentino durante i secoli XII-XIII: Ercole, Il "villanatico" e la servitù della gleba in alcuni documenti piacentini dei secoli XII e XIII, «Bollettino Storico Piacentino», 4, 1909 e 5, 1910, I, p. 271 sgg. Cfr. Panero, Terre in concessione e mobilità contadina cit., p. 272.

${ }^{39}$ G. Vitolo, Rivolte contadine e brigantaggi nel Mezzogiorno angioino, in Protesta e rivolta cit., p. 210 sgg.

${ }^{40}$ R. Caggese, Roberto d'Angiò e i suoi tempi, Firenze 1922, pp. 311-338.

${ }^{41}$ I. Peri, Villani e cavalieri nella Sicilia medievale, Roma-Bari 1993, pp. 30 sgg., 51 sgg.

${ }^{42} \mathrm{P}$. Corrao, Il servo, in Condizione umana e ruoli sociali nel Mezzogiorno normanno-svevo, a cura di G. Musca, Bari 1991, p. 61 sgg.; V. D’Alessandro, Servi e liberi, in Uomo e ambiente nel Mezzogiorno normanno-svevo, a cura di G. Musca, Bari 1989, p. 294 sgg.; S. Tramontana, Michele da Piazza e il potere baronale in Sicilia, MessinaFirenze 1963, p. 235 sgg. 


\section{I Paesi d'Oltralpe}

Se cerchiamo qualche raffronto con altri Paesi europei, vediamo che in Francia il conflitto fra signori e servi fino alla metà del Trecento si supera attraverso la manumissione di questi ultimi, i quali fra XIII e XIV secolo sono ancora numerosi sulle terre regie e su quelle appartenenti ad alcuni enti ecclesiastici. Si tratta di manumissioni previo pagamento di riscatti, che consentono alla corona di incamerare forti somme in denaro, di cui i servi dispongono grazie all'allineamento di fatto alle condizioni economiche dei liberi, attuatosi durante i secoli del trend positivo dell'economia e della crescita demografica ${ }^{43}$. Talvolta questo spontaneo avvicinamento alla condizione dei contadini dipendenti liberi può determinare conflitti, soprattutto dove il numero dei servi è ancora notevole: il desiderio di sfuggire al vincolo ereditario per ottenere l'equiparazione piena con i rustici liberi del luogo - per coloro che non possono permettersi di pagare un riscatto per la manumissione della propria famiglia - nel corso del Trecento può essere causa di sommosse, come accade ad es. a Laon nel $1338^{44}$.

In alcune regioni francesi - come la Champagne - la fine della servitù si realizza solo nel corso del secolo $\mathrm{XV}^{45}$; in altre, pur essendosi trasformata la condizione servile, la taglia arbitraria e la manomorta - che spesso ne sono un segno, anche se non dovunque una prova incontrovertibile permangono fino al secolo XVI, come avviene per alcune comunità del Delfinato e della Savoia o, per quanto concerne la manomorta, addirittura fino al Settecento ${ }^{46}$.

${ }^{43}$ Bloch, Rois et serfs cit., p. 66 sgg. ; L. Carolus Barré, L’affranchissement des serfs de la châtellenie de Pierrefonds par Blanche de Castille (v. 1252) et sa confirmation par Saint Louis (septembre 1255), in Violence et contestation au Moyen Âge, Paris 1990, pp. 59-111. Per l'emancipazione di homines de mansata nel XIV secolo cfr. Bourin, Les "homines de mansata" en bas-Languedoc cit., p. 905 sgg.

${ }^{44} \mathrm{G}$. Brunel, Les hommes de corps du chapitre cathédral de Laon (1200-1460): continuité et crises de la servitude dans une seigneurie ecclésiastique, in Forms of Servitude in Northern and Central Europe, a cura di M. Bourin, P. Freedman, Turnhout 2005, pp. 131-178. Cfr. il saggio di M. Bourin in questo stesso volume.

${ }^{45}$ A.-M. Patault, Hommes et femmes de corps en Champagne méridionale à la fin du Moyen-Âge, Nancy 1978, pp. 21 sgg., 83 sgg.

${ }^{46}$ Raccolta per ordine di materie delle leggi della real casa di Savoia, a cura di F.A. Duboin, VII, Torino 1831, p. 11 sgg.; P. Vaccari, Le affrancazioni collettive dei servi della gleba, Milano 1939, p. 89 sgg. (per i riferimenti a comunità del Delfinato e della Savoia soggette alla monarchia francese e ai duchi sabaudi); A. Soboul, La rivoluzione francese, trad. it., Bari 1966, pp. 48, 53, 134 sgg. (per la Franca Contea e il Nivernais, dove la manomorta viene abolita solo nel Settecento). Anche in alcune località della Sardegna la manomorta viene cancellata soltanto nel corso del Settecento. 
Per l'Inghilterra il cronista Jean Froissart individua le cause della rivolta del 1381 essenzialmente nel fatto che per consuetudine i nobili potevano esigere pesanti corvées dai loro contadini "et les tiennent en servage", egli aggiunge, particolarmente nelle contee di Kent, Essex, Sussex e Bedfordshire ${ }^{47}$. "Nous sommes appelé serf et batu, se nous ne faisons présentement leur service", egli fa dire a John Ball ${ }^{48}$. Un'altra componente della rivolta è però quella religiosa, che poggia sulla contestazione dei diritti signorili degli enti ecclesiastici: i rivoltosi sono infatti chiamati Lollardi. L'ala più radicale dei rivoltosi vorrebbe poi la soppressione dei privilegi feudali, come si evince dal fatto che la rivolta continua nonostante la concessione di carte di franchigia e dell'abolizione del servaggio da parte del re Riccardo $\mathrm{II}^{49}$. Quindi la componente servile dei rivoltosi in Inghilterra è evidente accanto ad altre componenti.

Del resto lo stesso Froissart distingue la rivolta inglese del 1381 dalle Jacqueries del 1358. In questo caso egli non parla infatti di servi in rivolta, ma di "méchans gens assamblés sans chief et sans armures", che uccidono i gentiluomini e violentano le loro donne ${ }^{50}$.

Non aveva avuto le caratteristiche della sommossa inglese nemmeno la sollevazione delle Fiandre degli anni 1323-1328, dovuta al rifiuto di pagare decime e imposte da parte di "contadini più o meno ricchi, folloni e tessitori”, come ha scritto Henri Pirenne ${ }^{51}$. E neppure quella piemontese dei Tuchini della fine del Trecento ${ }^{52}$.

Sul villeinage inglese dei secoli XIII-XIV è però opportuno spendere ancora qualche parola, innanzitutto per chiarire che nel gruppo dei "villani" inglesi solitamente vengono annoverati servi casati, contadini dipendenti

${ }^{47}$ J. Froissart, Oeuvres, a cura di K. de Lettenhove, Chroniques, ristampa anastatica dell'ediz. del 1867-1877, Osnabrück 1967, IX, p. 387.

${ }^{48}$ Ibid., IX, p. 388.

${ }^{49}$ Ibid., IX, pp. 392, 405 sgg.

${ }^{50}$ Ibid., VI, p. 45.

${ }^{51}$ H. Pirenne, Le soulèvement de la Flandre maritime de 1323-1328, Bruxelles 1900. Da ultimo cfr. S.K. Cohn, Lust for Liberty. The Politics of Social Revolt in Medieval Europe, Cambridge 2006. Cfr. poi il contributo di M. Boone in questo volume.

${ }^{52}$ F. Gabotto, Il "tuchinaggio" nel Canavese ed i prodromi dell'assedio di Verrua (13861387), «Bollettino Storico-Bibliografico Subalpino», I, 1896, pp. 81-95; P. Venesia, Il Tuchinaggio in Canavese (1386-1391), Ivrea 1979. Per un inquadramento del Tuchinaggio nell'ambito delle lotte politiche collegate con le rivolte trecentesche cfr. R. Comba, Rivolte e ribellioni fra Tre e Quattrocento, in La Storia, diretta da N. Tranfaglia e M. Firpo, II, Torino 1986, pp. 673-691, a p. 684 sg. Ma cfr. ora il saggio di A. Barbero in questi stessi atti. Le "servitutes" relative alle successioni (castellania di Balangero Canavese) vanno intese come "oneri gravosi" di cui si chiede l'affrancazione, ma non riguardano la condizione personale degli abitanti: Corpus statutorum Canavisii, a cura di G. Frola, Torino 1918, I, pp. 257 sgg. 
che regolavano il loro rapporto con il manor sulla base della consuetudine locale e contadini che avevano un contratto scritto. Quando, verso la metà del Duecento, fu redatto il trattato De legibus et consuetudinibus Angliae, attribuito al giudice della corona Henry of Bracton ${ }^{53}$, vennero classificate le varie categorie di dipendenti che si erano consolidate nel regno inglese dopo il 1086, anno della redazione del Domesday Book.

Semplificando il quadro complessivo, si può osservare che rispetto alla situazione registrata nel 1086 - quando a fronte di una maggioranza di contadini liberi, variamente denominati a seconda delle regioni, vi era un gruppo considerevole di servi, ma mediamente non superiore all'otto/dieci per cento della popolazione contadina ${ }^{54}$ - alla metà del Duecento questi servi erano collocati all'interno del manor e soggetti alla giurisdizione baronale accanto a villani giuridicamente liberi, ma vincolati in diversi modi al signore del manor e tutti soggetti a pesanti corvées, tra le quali si evidenzia l'obbligo del weekwork di tre giorni alla settimana sulle terre dominicali. Bracton registra infatti la presenza di contadini liberi caduti dopo la conquista in villenagio e soggetti a "opera servilia, sed certa et nominata, qui quidem dicuntur glebae ascripticii": essi tuttavia sono considerati dei privilegiati in quanto non prestano le opere a causa della loro condizione di servitù bensì "ratione tenementorum" e non possono essere privati della terra avuta in concessione a tempo indeterminato fino a quando mantengono fede agli impegni assunti nei confronti del dominus; vi sono poi altri villani "privilegiati", soggetti alla condizione di socagium villanum, i quali non possono cedere a terzi la tenure, ma se vogliono trasferirsi altrove debbono restituirla al dominus ${ }^{55}$; e poi, ancora, vi sono gli adventitii che hanno avuto le terre a contratto ${ }^{56}$; e infine c'è il villenagium purum (sul piano storiografico anche noto come villenage absolute), che è il più oneroso per i contadini che vi sono soggetti, i quali infatti sono equiparati ai servi, non

${ }^{53}$ P.R. Hyams, King, Lords and Peasants in Medieval England: the Common Law of Villeinage in Twelfth and Thirteenth Centuries, Oxford 1980, p. 83; J. Hatcher, English Serfdom and Villeinage: towards a Reassessment, "Past and Present», 90, 1981, pp. 3-39.

${ }^{54}$ R. Fossier, L'infanzia dell'Europa. Economia et società dal X al XII secolo, trad. it., Bologna 1987, p. 577 sg. Alcuni recenti considerazioni di G. Pasquali, Rapporti e patti di lavoro nelle campagne inglesi nei secoli X-XII, in Contratti agrari e rapporti di lavoro nell'Europa medievale, a cura di A. Cortonesi, M. Montanari, A. Nelli, Bologna 2006, pp. 65-86, a p. 80, indurrebbero a far oscillare la popolazione servile fra il 3 e il $10 \%$.

${ }^{55}$ Henrici de Bracton, De legibus et consuetudinibus Angliae, a cura di T. Twiss, Wiesbaden 1964, ristampa dell'edizione di Londra del 1878-1881 (Rerum Britannicarum Medii Aevi Scriptores, 70), I, I, XI, 1, p. 52; III, IV, XXVIII, 5, p. 378 sgg.

${ }^{56}$ Bracton, De legibus cit., III, IV, XXVIII, 5, p. 380. 
potendo abbandonare il manor ${ }^{57}$ : per questi vale in particolare la definizione di "servi della gleba". Ciò che accomuna tutte queste forme di dipendenza è la soggezione dei contadini del manor alla giustizia del dominus e l'esclusione, in via normale, dal tribunale pubblico, al quale si può comunque accedere per rivendicare la propria libertà, come accade quando un allodiero con alcune terre ottenute in base a un contratto avventizio di villanaggio venga considerato ingiustamente un "villano puro" 58 .

In definitiva, nel 1381 le rivendicazioni comuni prevalgono rispetto alle singole condizioni giuridiche, che sul piano storiografico vengono solitamente annullate, ma che i giuristi e i giudici della corona inglese dei secoli XIII e XIV conoscevano molto bene. Quindi se i villani di condizione servile partecipano alla rivolta è perché vivono fianco a fianco di altri contadini, che talvolta sono considerati ingiustamente "servi" dai domini del manor al momento di esigere prestazioni d'opera particolarmente onerose: in ogni caso rivendicano tutti una maggiore autonomia, una maggior equità fiscale, la possibilità di abbandonare il fondo cedendo a terzi i diritti d'uso sulle terre in concessione, il diritto di essere giudicati dal tribunale regio.

In alcune regioni della Catalogna, in particolare nelle diocesi di Gerona, Vic, Barcelona ed Elne, i contadini de remença - in base a patti agrari che recepivano le imposizioni ereditarie dell' adscriptio terrae postirneriana, oppure in seguito al giuramento di un "omaggio servile" (che comportava l'ereditarietà della dipendenza tipica degli homines proprii) $\mathrm{o}$, talvolta, in base al principio giustinianeo della prescrizione trentennale per i discendenti degli ascrittizi - erano stati legati fra XII e XIII secolo alla terra che avevano ottenuto in concessione perpetua: per andarsene dovevano pagare ai signori un riscatto pro redimentia ${ }^{59}$. Rispetto ai vantaggi immediati della disponibilità della terra a tempo indeterminato, gradualmente erano emersi i lati onerosi di quel tipo di subordinazione, che si rivelava essere senza dubbio ereditaria per un numero considerevole di contadini (per Jaume

${ }^{57}$ Bracton, De legibus cit., I, II, VIII, 2, pp. 198 sgg. , 208; III, IV, XXVIII, 5, p. 376 sgg.

${ }^{58}$ Bracton, De legibus cit., III, IV, XXIII, 5, p. 300; III, IV, XXVIII, 5, pp. 376-378.

${ }^{59} \mathrm{P}$. Bonnassie, Le servage: une sous-féodalité? Le témoignage des documents catalans (fin XI ${ }^{e}-X I I^{e}$ siècle), in La servitude dans les Pays de la Méditerranée cit., p. 643 sgg.; P. Freedman, The Origins of Peasant Servitude in Medieval Catalonia, Cambridge 1991, p. 103 sgg.; L. Lluch Bramon, Els remences. La senyoria de l'Almoina de Girona als segles XIV i XV, Girona 2005, pp. 52 sgg., 72 sgg., 88 sgg.; L. To Figueras, Servitude et mobilité paysanne: les origines de la "remença" catalane (XII ${ }^{e}$-XIII ${ }^{e}$ siècle), in La servitude dans les Pays de la Méditerranée cit., p. 827 sgg; P. Benito i Monclús, Senyoria de la terra i tinença pagesa al comtat de Barcelona (segles XI-XIII), Barcelona 2003, pp. 429-548. 
Vicens Vives tali patti avrebbero coinvolto nel XIV secolo circa un quarto della popolazione catalana $)^{60}$.

A partire dagli anni ottanta del Trecento i contrasti fra remenças e signori si erano moltiplicati in seguito alle crisi agrarie, per esplodere intorno alla metà del Quattrocento, quando il conflitto assunse l'aspetto di una vera e propria ribellione contro la richiesta signorile di oneri che erano definiti significativamente mals usos. Nel 1462, in particolare, la rivolta campesina si innestò sulle vicende della guerra civile catalana; una soluzione per la questione contadina venne solo nel 1486 quando con la sentenza arbitrale di Guadalupe, da parte di re Ferdinando il Cattolico, furono soppressi i mals usos, che di fatto avevano determinato la condizione di servaggio ereditario dei remenças. La rivolta di contadini in condizione di servaggio, anche in questo caso, era stata possibile perché $\mathrm{i}$ remenças erano pienamente integrati nelle comunità di villaggio, a carico delle quali i signori tendevano, talvolta con l'abuso, a imporre e a generalizzare i mals usos.

\section{Osservazioni conclusive}

Per chiudere la nostra panoramica, si può osservare che anche in Germania Gunther Franz, in un saggio dedicato al quadro europeo delle rivolte contadine tardomedievali, non rilevava una presenza significativa di persone in condizione servile, ma - guardando in particolare agli esiti delle lotte contadine della prima età moderna - metteva in luce quello che sarebbe il motivo principale del conflitto, che andrebbe ricercato nella piena consapevolezza dei contadini dei diritti che scaturiscono da una condizione di libertà di fronte all'esosità dello stato territoriale ${ }^{61}$.

Lo stesso Werner Rösener - il quale per lo più indulge a vedere un mondo contadino germanico costituito per la maggior parte da servi ancora nel pieno medioevo ${ }^{62}$ - osserva che era diffusa la convinzione secondo la quale il servizio dovuto ai signori dai contadini avrebbe potuto legittimamente cessare "nel momento in cui veniva a mancare loro la protezione

${ }^{60} \mathrm{~J}$. Vicens Vives, Historia de los remensas (en el siglo XV), Barcelona 1945. Cfr. P. Bonnassie, Les sociétés de l'an mil. Un monde entre deux âges, Bruxelles 2001, p. $262 \mathrm{sgg}$.

${ }^{61}$ G. Franz, Der Deutsche Bauernkrieg, Darmstadt 1975 (I ediz. 1933); Id., Persönlichkeit und Geschichte. Aufsätze und Vorträge, Göttingen 1977. Per le rivolte urbane cfr. il saggio di P. Monnet in questo volume.

${ }^{62} \mathrm{Ma}$ questo quadro è contraddetto dall'analisi puntuale sulla Baviera dei secoli XII e XIII da parte di Ph. Dollinger, L'évolution des classes rurales en Bavière depuis la fin de l'époque carolingienne jusqu'au milieu du XIII siècle, Paris 1949, che conserva tutto il suo valore nonostante sia abbastanza datata. 
dei signori"63, secondo un'ottica contrattualistica (che però, proprio per questo, aveva una ragione d'essere soltanto fra uomini che fossero personalmente liberi). Di conseguenza sono molte "le forme che assumeva la resistenza dei contadini quando venivano attaccati dai loro signori o quando questi disattendevano chiaramente i propri doveri. Dal rifiuto di prestare i servizi e di versare i tributi, all'emigrazione, alla fuga, sino a sollevazioni armate di vario tipo" 64 .

Come si può notare, si tratta di reazioni riscontrabili solo in parte fra $\mathrm{i}$ servi, perché quasi mai nel tardo medioevo si giunge a ribellioni collettive e cruente di servi propriamente detti verso i propri signori (a parte l'insurrezione inglese, le rivolte dei remenças e qualche altro caso sporadico, dove i dipendenti di condizione servile/villanale sono integrati nelle collettività contadine). Queste infatti presuppongono l'esistenza di una comunità di famiglie sufficientemente omogenee e solidali fra loro, mentre sul Continente i servi del contado, non ancora manumessi, nel Trecento sono per lo più ripartiti nelle case dominicali o inquadrati nelle masnade signorili, e in città - trattandosi di "schiavi di tratta" - sono sottoposti a un controllo assiduo da parte dei proprietari.

${ }^{63}$ W. Rösener, I contadini nel medioevo, Roma-Bari 1987, p. 280.

${ }^{64}$ Ibid., p. 281. Cfr. anche S. Lombardini, La guerra dei contadini in Germania: punti di arrivo e punti di partenza nel dibattito storiografico recente, "Archivio Storico Italiano», CXL, 1982, pp. 355-442. 

Giulia BARONE

\section{LE COMPONENTI RELIGIOSE DELLE RIVOLTE}

Il tema che mi accingo a trattare rinvia, sin dal titolo, ad un dibattito storiografico che ha assunto un'importanza centrale soprattutto tra la fine degli anni Sessanta e gli anni Settanta del XX secolo.

In quella fase, si fecero sentire, un po' in tutta Europa, gli influssi di una storiografia marxista, coltivata, in modo più o meno ortodosso, di qua e di là del muro che divideva in quegli anni il nostro continente. Non per nulla, ancor oggi, la "bibliografia di riferimento", per chi affronti questa problematica, risale a quegli anni.

Gli storici marxisti, partendo da considerazioni di Friedrich Engels nella sua "Guerra dei contadini", associavano strettamente le eresie, in una prima fase urbane, ma diffuse- in un secondo momento- anche nelle campagne, al diffondersi delle lotte contro il potere vescovile (in città) e a quello contro la borghesia cittadina che sfruttava le campagne tardo-medievali (nel mondo rurale).

Queste tesi trovarono una prima, concreta applicazione alla realtà italiana nella relazione che lo storico russo Skaskin ${ }^{1}$ presentò al X Congresso internazionale di scienze storiche, che si tenne a Roma nel 1955, e che segnò l'inizio della ripresa del dialogo scientifico tra gli storici che vivevano nell'Europa occidentale e quelli dei paesi controllati dall'Unione sovietica, divisi fino a quella data non tanto da ragioni metodologiche quanto da imperativi politici².

Alla fine degli anni Cinquanta fu soprattutto la scuola storica di Lipsia a produrre una serie di interessanti contributi sul nesso tra eterodossia, $\mathrm{o}$

${ }^{1}$ S. D. Skaskin, Le condizioni storiche della rivolta di Dolcino, in Rapports de la délégation soviétique au $X^{e ̀}$ Congrès international des Sciences Historiques, Roma 1955, cit. in C. Violante, Eresie urbane e eresie rurali in Italia dell'XI al XIII secolo, in L'eresia medievale, a cura di O. Capitani, Bologna 1971, p.158.

${ }^{2}$ Al Convegno del 1955, data la sua enorme importanza e non solo dal punto di vista storiografico, è stato dedicato un Convegno nel settembre 2005, cfr. La storiografia tra passato e futuro. Il X Congresso internazionale di Scienze Storiche. (Roma 1955) cinquant'anni dopo. a cura di H. Cools, M. Espadas Burgos, M. Gras, M. Matheus, M. Miglio, Roma 2008. 
più in generale nuovi atteggiamenti religiosi, e le società in cui questi si producevano. Gli interessi di questi storici spaziarono, in quegli anni, dal tema dei grandi movimenti di pace fra X e XI secolo (Töpfer) ${ }^{3}$, alla Riforma della Chiesa (Werner $)^{4}$, fino allo studio delle eresie. Tutti questi studi, pur nelle innegabili differenze, condividono la convinzione che le diverse manifestazioni della religiosità, pur diversissime tra loro, abbiano comunque caratteristiche "sovrastrutturali" e che le loro motivazioni vadano ricercate, sempre e comunque, nei fattori "strutturali".

Come hanno scritto, in un loro celebre saggio, Ernst Werner e Martin Erbstösser: “... si potrebbe dire che nei secoli XIII e XIV i desideri e le speranze di buona parte della popolazione appartenente a tutte le classi potevano, o meglio dovevano esprimersi mediante pretesti religiosi, poiché non esisteva ancora un'ideologia secolare e laica..."

Val forse la pena di segnalare che, negli ultimi anni, e senza che si rinvii più alla metodologia marxista, forse la più diffusa fra le interpretazioni proposte per spiegare il fenomeno dell'integralismo islamico sostiene che il linguaggio della religione, spesso tradotto in formule schematiche e poco rispettose del testo coranico, incontri tanto successo nel mondo musulmano proprio a causa di unarretratezza delle istituzioni politiche e dello sviluppo sociale che non consente lo sviluppo di "linguaggi alternativi" di impronta laica e secolare.

L'interpretazione marxista delle eresie non poteva lasciare indifferenti gli storici della Chiesa e dell'eterodossia di matrice cattolica. In ambito italiano, è nota la risposta che agli storici marxisti diede Cinzio Violante, in un altro celebre saggio "Eresie urbane e eresie rurali in Italia dall'XI al XIII secolo", in cui lo studioso riaffermava, ispirandosi all'interpretazione già proposta dal Morghen nel suo Medioevo cristiano ${ }^{6}$, la centralità del fattore religioso nel nascere delle eresie:

... le eresie comprese fra il secolo XI e il XIII nel Centro e nel Nord dell'Italia sono un fenomeno essenzialmente religioso; esse sono una delle manifesta-

${ }^{3}$ B. Töpfer, Volk und Kirche zur Zeit der beginnenden Gottesfriedensbewegung in Frankreich, Berlin 1957.

${ }^{4}$ E. Werner, 'Pauperes Christi'. Studien zu sozialreligiösen Bewegungen im Zeitalter des Reformpapsttums, Leipzig 1956. In tempi assai più recenti il Werner ha riproposto, in termini meno ortodossi, il problema del rapporto tra società e religiosità, cfr. E. Werner, Ketzer und Heilige: dal religiöse Leben im Hochmittelalter, Köln 1986.

${ }^{5}$ E. Werner - M. Erbstösser, Movimenti socio-religiosi nel Medioevo, in L'eresia medievale, cit., pp. 193-194. Il saggio è apparso in versione originale col titolo, Sozialreligiöse Bewegungen im Mittelalter, "Wissenschaftliche Zeitschrift der Karl-MarxUniversität Leipzig», VII, 1957-58, pp. 257-282.

${ }^{6}$ R. Morghen, Medioevo cristano, Bari 1951. A questa prima edizione hanno fatto seguito un'altra decina, sempre per i tipi di Laterza, che hanno integrato in più punti il testo originale. 
zioni di quell'anelito di riforma morale e di rinnovamento religioso che, con un'accentuazione spiritualista e un'adesione più rigida ai testi del Vangelo, s'impone negli ambienti laici, clericali e monastici. Le condizioni sociali hanno una loro importanza essenzialmente per quel che riguarda le possibilità di propaganda e diffusione delle eresie. In effetti sono sempre meno persuaso che i movimenti eretici siano semplicemente la trasposizione di rivendicazione economiche, sociali e politiche sul piano della lotta religiosa. Le ragioni profonde del progresso e del successo dei moti eretici devono sempre esser cercate in una considerazione generale della storia religiosa dell'epoca. ${ }^{7}$

Il vivace dibattito di quegli anni fu reso accessibile ad una più larga cerchia di pubblico per merito di Ovidio Capitani che curò la pubblicazione, nel 1971, di alcuni dei contributi più significativi di quella fase storica tra cui quelli precedentemente citati di Cinzio Violante e di Werner ed Erbstösser - in un fortunato volume antologico dedicato all'"Eresia medievale"8.

Ma ben presto il problema dell'esistenza o meno di un nesso tra fenomeni sociali, quali le rivolte - urbane o contadine- e il fatto religioso fu affrontato anche da chi, originariamente, non nutriva particolari interessi per il fenomeno religioso in quanto tale.

Personaggio emblematico di questa stagione culturale fu il francese Guy Fourquin, già autore - nel 1964, di una Storia economica del Medio Evo occidentale $^{9}$. Nel 1972 egli pubblicò un libro Les soulèvements populaires au Moyen Age ${ }^{10}$, tradotto in italiano già nel $1976^{11}$, in cui - nella parte consacrata alla tipologia delle sommosse- uno spazio rilevante veniva consacrato a quelle che l'autore definiva "i movimenti messianici”, tra cui, per la fine del Medio Evo, venivano analizzati la rivolta dei contadini inglesi del 1381 e la sommossa ussita, soprattutto nella sua frangia estrema, quella "taborita" (1420-1434) ${ }^{12}$. L'autore, nella schematizzazione sociologizzante del suo lavoro, dimostra di conoscere bene le situazioni sociali in cui hanno origine le rivolte, con una particolare attenzione alla dinamica élite/masse

${ }^{7}$ Violante, Eresie urbane e eresie rurali in Italia dell'XI al XIII secolo cit., pp. 211-212. Il saggio era apparso originariamente col titolo Hérésies urbaines et hérésies rurales en Italie du $11^{\text {ème }}$ au $13^{\text {ème }}$ siècle, in Hérésies et sociétés dans l'Europe préindustrielle, 11$18^{\text {ème }}$ siècle, Paris-La Haye 1968, pp.171-198.

${ }^{8}$ L'eresia medievale, cit. Pochi anni più tardi il Capitani ha affrontato, da un diverso punto di vista, il fenomeno "eresia", ponendo l'accento sugli eretici più che sulle loro dottrine, cfr. Medioevo ereticale, a cura di O. Capitani, Bologna 1983.

${ }_{9}^{9}$ G. Forquin, Histoire économique de l'Occident médiéval, Paris 1964, 2a ed. 1971.

${ }^{10} \mathrm{G}$. Fourquin, Les soulèvements populaires au Moyen Age, Paris 1972.

${ }^{11} \mathrm{G}$. Fourquin, Le sommosse popolari nel Medioevo, Milano 1976.

12 Ibidem, pp. 90-114. 
e all'estrazione sociale dei rivoltosi, mentre assai meno accurata è l'analisi degli elementi religiosi che entrano in gioco.

L'evidente difficoltà di dominare una problematica così complessa, con i suoi due versanti di storia economico-sociale e storia religiosa è, probabilmente, alla base della cooperazione fra due eminenti storici francesi, specialista l'uno di storia economica (Philippe Wolff), l'altro - oltre che di storia marittima- di storia della Chiesa e della religiosità (Michel Mollat). Il loro libro, del 1970, "Ongles bleus, Jacques et Ciompi. Les révolutions populaires en Europe aux XIV et XV siècles", ebbe immediato successo, tanto da essere tradotto in inglese solo tre anni più tardi. ${ }^{13}$

Per quanto riguarda i Ciompi, però, la storia religiosa del movimento è stata ricostruita, con estesissima conoscenza delle fonti e finissima analisi interpretativa da Charles de La Roncière, in un saggio pubblicato- nel 1974"Pauvres et pauvreté à Florence au XIV siècle", all' interno di un'opera curata da Michel Mollat e frutto di un decennale seminario di ricerca della Sorbona, "Etudes sur l'histoire de la pauvreté" 14.

Ma sono questi anche gli anni in cui, in Inghilterra, l'Hilton consacra le sue ricerche alle rivolte contadine del $1381^{15}$, mentre Christopher Hill concentra la sua attenzione sul XVII secolo, il tempo della rivoluzione puritana e di Cronwell ${ }^{16}$; si tratta, come è noto, delle due fasi della storia inglese, in cui il problema dell'intreccio tra rivolta (o addirittura rivoluzione) e fatto religioso è assolutamente ineludibile.

${ }^{13}$ M. Mollat / P. Wolff, Ongles bleus, Jacques et Ciompi. Les révolutions populaires en Europe aux XIV et $X V^{e}$ siècles, Paris 1970, p. 8: Les rapports entre les grandes hérésies et les agitations populaires posent un problème ardu. L'Eglise officielle n'était-elle pas un élement essentiel de l'ordre établi? Ebranler celui-ci, n'était-ce pas en meme temps attaquer celle-là? Tout révolutionnaire n'était-il plus ou moins un hérétique? Tout hérétique n'était-il pas un révolutionnaire? Quel est le lien entre les grandes hérésies, celle de Wycliff et des Lollards, celle de Huss, et les troubles contemporains? Plus d'une fois, nous serons amenés à franchir la limite qu'eut imposée une conception trop stricte des troubles «populaires». Il testo è comparso in una collana «les grandes vagues révolutionnaires».

Per l'edizione inglese si veda M. Mollat- P. Wolff, The Popular Revolutions of the Late Middle Ages, London 1973.

${ }^{14}$ Ch.-M. de La Roncière, Pauvres et pauvreté à Florence au XIV ${ }^{e}$ siècle, in Etudes sur l'histoire de la pauvreté (Moyen Age- XVI siècle), a cura di M. Mollat, II, Paris 1974, pp. 661-745. Una traduzione italiana del testo è reperibile in Ch.-M. de La Roncière, Tra preghiera e rivolta, con una postfazione di G. Cherubini, Roma 1993, pp. 197-281.

${ }^{15}$ R. Hilton, Bond Men made free. Medieval Peasant movements and the English Rising of 1381, con una nuova introduzione di C. Dyer, London- New York 2003 (la prima edizione dell'opera del 1973).

${ }^{16}$ Ch. Hill, Society and Puritanism in Pre-Revolutionary England, London 1964; Idem, Antichrist in $17^{\text {th }}$ Century England, 1971, trad. it. L'anticristo nel Seicento inglese, a cura di P. Adamo, Milano 1990 e Id., God's Englishman: Oliver Cromwell and the English revolution, London 1970. 
Da allora, la tematica si è praticamente esaurita: i risultati acquisiti in un paio di decenni non si prestavano, apparentemente, ad ulteriori approfondimenti. Negli Anni Ottanta, mentre Stati Uniti ed Unione Sovietica uscivano lentamente dalla "guerra fredda" e si aprivano a cauti tentativi di dialogo, paradossalmente diminuiva l'interesse per il confronto tra storici di opposte scuole di pensiero. La caduta del muro di Berlino (1989) e la fine dell'Unione Sovietica (1991) hanno del resto significato per molti, per una strana e paradossale associazione tra teoria interpretativa e realizzazioni politiche, anche la fine del marxismo, la conferma del fallimento non del sistema politico ed economico dell'Unione Sovietica, ma del pensiero di Marx ed Engels. La momentanea sospensione di un dibattito esplicitamente segnato dall'ideologia ha praticamente annullato l'interesse dei ricercatori per un tema in precedenza "di successo".

Esaurita questa forse troppo lunga introduzione storiografica, ritengo che, prima di entrare nel cuore della mia trattazione, siano ancora necessarie due premesse. La prima riguarda l'arco cronologico entro cui si articoleranno le mie considerazioni; mi concentrerò sul Trecento, o meglio sulla sua seconda metà, partendo dagli avvenimenti romani che portarono al potere Cola di Rienzo (1347), e privilegiando, nell'analisi, le rivolte che hanno avuto la penisola italiana come quadro.

La seconda premessa, metodologica, riguarda invece le fonti di cui ci si serviamo per le nostre ricostruzioni delle rivolte.

Se l'autore di una cronaca è sensibile al fatto religioso, il quadro dei moti popolari acquisterà il colore che Fourquin definisce "messianico"; ma se chi ci ha lasciato il racconto degli avvenimenti non vuole - o non è capacedi cogliere il senso di una simbologia o di un linguaggio ispirato alla Bibbia, i moti ci parranno ispirati a motivazioni puramente economiche o "laiche". Di qui la necessità di usare grande cautela, in assenza di un ampio ventaglio di fonti, prima di affermare recisamente l'importanza o meno del fatto religioso nel fenomeno rivolte

\section{Cola di Rienzo}

I moti popolari che, sapientemente guidati e coordinati dall'alto - in questo caso dall'assente pontefice Clemente VI, che teneva la sua sfarzosa

${ }^{17} \mathrm{G}$. Billanovich, Come nacque un capolavoro: la 'Cronica' del non più Anonimo romano. Il vescovo Ildebrandino Conti, Francesco Petrarca e Bartolomeo di Iacovo da Valmontone, "Atti dell'Accademia Nazionale dei Lincei. Rendiconti della classe di scienze morali, storiche e filologiche», VI,1995, pp. 195-211. 
corte ad Avignone- portarono nel 1347 al potere Cola di Rienzo ci sono noti, nelle linee principali, grazie alla Cronaca in volgare di un autore che, anche dopo le proposte di identificazione di Giuseppe Billanovich ${ }^{17}$, continuamo a chiamare l"Anonimo romano"18.

Certo, l'azione di Cola è stata analizzata anche a partire dal suo ricco Epistolario, dalle lettere papali e da quelle che al tribuno indirizzò Francesco Petrarca, all'inizio suo entusiasta ammiratore ${ }^{19}$, ma le reazioni popolari al suo agire e, soprattutto, alle sue eccezionali capacità oratorie, sono essenzialmente ricostruibili solo a partire da questo celebre testo.

Come è noto, il personaggio di Cola di Rienzo è stato oggetto, negli ultimi decenni, di diverse valutazioni: uomo dei nuovi ceti imprenditoriali secondo Maire Vigueur ${ }^{20}$, fine umanista e "antiquario" per Massimo Miglio $^{21}$, per non parlare delle sfumature introdotte in questi quadri dal Seibt $^{22}$ e dal di Carpegna. ${ }^{23}$

Ora, nel racconto dell'Anonimo, il linguaggio, la simbologia, i contenuti religiosi sono, per quel che riguarda Cola, abbondantemente e precisamente delineati. Colpisce, soprattutto, il ruolo che egli ha attribuito allo Spirito Santo, tendenza che gli è valsa la fama di essere vicino a movimenti eterodossi come il Libero Spirito ${ }^{24}$.

${ }^{18}$ Anonimo Romano, Cronica, a cura di G. Porta, Milano 1981.

${ }^{19}$ A Cola vennero indirizzate due delle Sine nomine del Petrarca (nr. 2 e 3 dell'edizione Dotti), mentre la n.4 era rivolta al popolo romano perché intervenisse a favore di Cola prigioniero, cfr. F. Petrarca, Sine nomine. Lettere polemiche e politiche, a cura di U. Dotti, Roma-Bari 1974. Per il rapporto con Cola si veda anche la bella introduzione del curatore.

${ }^{20} \mathrm{~J}$.-Cl. Maire Vigueur, Cola di Rienzo, in Dizionario biografico degli Italiani, XXVI, 1982, pp. 662-675. In un suo più recente contributo, così sintetizza il Maire Vigueur il suo pensiero sui provvedimenti presi da Cola: "Non contengono innovazioni strepitose se li confrontiamo alla politica dei precedenti regimi popolari. La novità sta piuttosto nel fatto che esprimono... una visione perfettamente coerente e globale della società comunale e dei suoi mali, oltre che delle misure atte a porvi rimedio. Furono tutti rigorosamente applicati, ivi compresi quelli che miravano a distruggere le basi sociali e militari del potere dei baroni...", cfr. J-Cl. Maire Viguer, Il comune romano, in Roma medievale, a cura di A. Vauchez, Roma-Bari 2001, p. 150.

${ }^{21}$ M. Miglio, Scritture, scrittori e storia. I. Per la storia del Trecento a Roma, Manziana 1991, passim.

${ }^{22}$ G. Seibt, Anonimo romano. Scrivere la storia alle soglie del Rinascimento, ed. italiana a cura di R. Delle Donne, Roma 2000 (ed. or. Stuttgart 1992).

${ }^{23}$ T. di Carpegna Falconieri, Cola di Rienzo, Roma 2002.

${ }^{24}$ Il cosiddetto movimento del "Libero Spirito" continua a suscitare dibattiti che non arrivano però a ricostruirne una chiara fisionomia storica, cfr. comunque R. Guarnieri, Il movimento del libero spirito. Testi e documenti, «Archivio italiano per la storia della pietà», IV, 1964, pp. 351-708. 
Anche se non vogliamo accettare un' interpretazione di questo tipo, che ci pare riposi su basi troppo fragili, è certo che Cola sceglie con cura meticolosa, per la grande manifestazione popolare che lo porterà al potere, la vigilia del 20 maggio, in quell'anno festa di Pentecoste, che liturgicamente celebra la discesa sugli Apostoli dello Spirito Santo. Più tardi, il l ${ }^{\circ}$ agosto, Cola vorrà essere armato "cavaliere dello Spirito santo"; infine, il 15 agosto, in occasione della più grande festa romana, quella dell'Assunzione della Vergine, si farà incoronare con ben sei corone, (di lillà, mirto, alloro, olivo); l'ultima, l'unica che possiamo definire veramente corona, in argento dorato, gli è posta sul capo dal commendatore dell'Ospedale romano di S. Spirito in Sassia ${ }^{25}$. Non va certamente mai dimenticato che lo Spirito santo ha sempre svolto, nella storia della Chiesa, un ruolo centrale nel momento della scelta dei superiori: non per nulla ogni elezione, e ancor oggi quella papale, è preceduta dalla celebrazione della messa dello Spirito Santo. Ma, in Cola, quella che è, ai nostri occhi, qualcosa di marginale, di puramente rituale, diventa centrale, il segno di un'elezione divina.

La Cronica abbonda di molti altri episodi in cui Cola utilizza sapientemente il fatto religioso: le immagini propagandistiche, che vengono presentate alle folle romane, da lui immaginate come veri e propri "manifesti", hanno spesso una coloritura religiosa e sono affissi sulle facciate delle chiese (a partire da Sant'Angelo in Pescheria) ${ }^{26}$; la grande processione con cui manifesta, in qualche modo, il suo programma politico è aperta da grandi vessilli su cui campeggiano figure di santi a personificare i valori cui vuole informare la sua azione politica (S. Paolo con la spada sguainata a simboleggiare la giustizia, S. Pietro con le chiavi, a personificare la concordia e la misericordia, ecc. $)^{27}$.

Ma, se passiamo alle motivazioni dei Romani, nel seguirlo, prima; più tardi, in dicembre, per cacciarlo violentemente dal potere, secondo la testimonianza dell'Anonimo, esse sono del tutto prive di connotazioni religiose. I cittadini romani che hanno formato, per alcuni mesi, la base di consenso che gli ha permesso, insieme all'evidente favore papale, di sviluppare la sua azione politica, sembrano mossi, in primo luogo, dal desiderio di ordine e di pace. In questo senso va interpretato il loro consenso all'azione antibaronale del Tribuno, visto che l'alta aristocrazia romana è accusata di fomentare una violenza endemica in città e fuori e di condizionare pesantemente la po-

${ }^{25} \mathrm{Su}$ questo episodio si veda di Carpegna Falconieri, Cola di Rienzo cit., pp. 100 ss.

${ }^{26}$ Anonimo Romano, Cronica, cit., pp. 109-110.

${ }^{27}$ Ibidem, p.112: "Lo secunno (confallone) era bianco, nello quale staieva santo Pavolo colla spada in mano, colla corona della iustizia. Questo portava Stefanello, ditto Magnacuccia, notaro. Nelo terzo staieva santo Pietro colli chiavi della concordia e della pace". 
litica annonaria cittadina. Di qui anche la sua vigorosa politica anti-clientelare. Ma gli uomini di affari, i giudici e i notai che lo seguono desiderano anche tasse meno elevate ma meglio distribuite e una giustizia rapida (il termine per la cause civili viene fissato in quindici giorni $)^{28}$.

La mentalità "laica" dell'autore ci impedisce di capire quanto il vero e proprio culto dello Spirito Santo avesse un'eco popolare, mentre è evidente il successo della sua propaganda per immagini, spesso religiose. Per concludere, il quadro che ci possiamo fare dei fatti romani del 1347 ci suggerisce una sorta di divaricazione tra un Cola che usa il simbolo e il linguaggio della religione, non solo a scopi propagandistici, ma con aperta e convinta adesione (come dimostrerà anche il seguito della sua vita tormentata) ${ }^{29}$; mentre il popolo romano, da sempre difficilmente coinvolto da predicatori profetico- messianici, sembra averlo seguito soltanto per ottenere il soddisfacimento di quelli che gli apparivano allora i suoi bisogni primari.

\section{I Ciompi}

I Ciompi, cui tanto spazio è consacrato all'interno di questo volume, possono contare su una ricchissima bibliografia, ma la componente religiosa delle rivolte è stata proposta in modo articolato solo dal già citato saggio del de La Roncière. Secondo lo studioso francese, la predicazione dei frati Predicatori fiorentini, nel corso del XIV secolo, contrariamente a quanto avveniva negli stessi anni in ambito francescano, avrebbe contribuito a trasformare il senso stesso del termine "povero" Non più identificato col biblico Lazzaro, in vana attesa dell'elemosina del ricco Epulone, non più parte di un meccanismo provvidenziale secondo cui il povero è necessario affinché il ricco possa salvarsi con l'elemosina, il povero si identifica ormai col salariato. Nelle omelie del domenicano Taddeo Dini il concetto di povertà si amplia infatti fino a comprendere quei lavoratori il cui salario è troppo ridotto per consentire loro di mantenere una famiglia, o coloro che si sono indebitati e non sono in grado di restituire quanto preso

${ }^{28}$ Ibidem, pp.113-114, ove si legge il "programma” politico di Cola.

${ }^{29}$ Pochissime sono le informazioni in nostro possesso sulla vita di Cola negli anni 1247-53. Sappiamo che trascorse un certo periodo di tempo sulla Maiella presso degli eremiti (da alcuni identificati con gruppi di dissidenti francescani legati al Clareno) e che nel 1350 si recò in Boemia dove ebbe, prima di essere incarcerato da Carlo IV su istanza di papa Clemente VI, uno scambio epistolare con l'imperatore e alcuni degli uomini a lui più vicini. A questo proposito si veda di Carpegna Falconieri, Cola di Rienzo, cit., pp.139-184. Sul carattere gioachimitico-profetico di alcuni temi delle lettere e sul mutamento delle idee politiche di Cola che ne consegue, si veda F. Pichiorri, Cola di Rienzo e la politica del suo tempo: il papato avignonese e Carlo IV, tesi di laurea, Facoltà di Lettere e Filosofia, Università degli Studi di Roma "La Sapienza", a.a. 2002-2003, passim. 
in prestito e infine chi - impotens et insufficiens- non è in grado di sostenere il carico fiscale ${ }^{30}$.

Per la prima volta, inoltre, a questi "nuovi poveri" non viene promessa la salvezza eterna se sopporteranno con pazienza la loro miserevole condizione e pregheranno con fervore per i loro benefattori, ma un posto accanto al Signore al momento del Giudizio finale o, ancor prima, un miglioramento della loro situazione socio-economica, in quanto Dio non può abbandonarli ${ }^{31}$. Sono questi gli elementi che darebbero ai Ciompi secondo il de La Roncière - almeno da quanto si può dedurre da un anonimo cronista che simpatizza per la loro causa, una coesione e un'autocoscienza "di classe". I Ciompi, nell' interpretazione dello storico francese, si sentono poveri, si definiscono poveri e ritengono di avere il diritto di sottrarsi a questa loro condizione ${ }^{32}$.

Questa suggestiva tesi del de La Roncière, che è tutta nutrita di fonti contemporanee, non ha trovato echi favorevoli nella storiografia sui Ciompi. Lo Stella, nel suo volume dedicato alla sommossa, che rappresenta forse la più avanzata ricerca sul tema ${ }^{33}$ dal punto di vista della "so-

${ }^{30}$ De La Roncière, Pauvres et pauvreté cit., p. 690: «L'introduction des salariés et des salariés brimés, dans la catégorie des pauvres, l'allusion, à propos des pauvres, à l'oppression concrète des usuriers, autant d'attitudes nouvelles, sauf erreur, dans la prédication florentine, attitudes qui montrent chez fra Taddeo, à cette date, une sensibilité particulière à cette forme d'indigence décrite plus haut, et si répandue en période de crise, qui est celle des salariés dans la gêne et endettés».

${ }^{31}$ Ibidem, p. 733: "Il ne prêche plus aux pauvres la résignation, une résignation que leur impose la valeur, pour d'autres, de leur situation, mais l'espoir. «Dieu entend- ditil- la clameur des pauvres injustement brimés», il les exauce... et il les exauce dès cette vie: «Le Seigneur les a exaucés et les bénit dans le temps de la tribulation qui est celui de la vie présente»...Ce sont les pauvres, en définitive, qui auront à juger avec le Christ au jugement dernier $»$.

32 Ibidem, p.737(qui lo storico francese utilizza la Cronica prima d'anonimo): “...pour ce défenseur des humbles, la notion de pauvreté est absolument centrale, et par cela meme, très "riche". $1^{\circ}$ La pauvreté, c'est d'abord una situation collective. Il est à chaque fois parlé des pauvres, que le mot soit au pluriel ou au singulier collectif; $2^{\circ}$ Cette situation collective concerne un très grand nombre d'individus. Le mot «Pauvre» est presque toujours opposé au mot «Riche»...(p. 738): «... Dans l’optique de leur chroniquer, leur groupe est animé d'un profond dynamisme, lequel les caractérise encore plus précisement comme pauvres... les pauvres sont présentés comme formant, en face des riches, un tout compact uni par la conscience de sa pauvreté».

${ }^{33}$ A. Stella, La révolte des Ciompi. Les hommes, les lieux, le travail, Paris 1993, pp.23 ss.: «Que les Ciompi aient cherché une légitimation théorique ou religieuse à leur action dans les repères culturels du temps paraît une démarche tout à fait plausible; qu'ils aient détourné le message évangélique sur la pauvreté reste une hypotése vraisemblable. Mais rien, sauf quelques phrases pretées aux émeutiers par les chroniqueurs nous a été transmis sur la pensée des Ciompi... la thèse de La Roncière reste encore à démontrer». Si può comunque notare che i Ciompi radicali scelgono, il 27-28 agosto, come 
ciologia del movimento", prende chiaramente posizione contro questa lettura degli avvenimenti. Neanche un accenno al rapporto religione/rivolta si può rinvenire nel bel libro di Franco Franceschi sull'età successiva al "tumulto" 34.

Il problema della nascita di una "coscienza di classe" e dell'apporto del Vangelo alla sua formazione è - come avevamo premesso- circoscritta ad una ben determinata fase storico-politica ${ }^{35}$.

\section{I moti in Francia ed Inghilterra}

Se, dall'Italia, ci spostiamo in Francia, il quadro sembra cambiare completamente. Come è stato notato da Monique Bourin in un altro saggio di questo volume, non si individuano motivi, linguaggi, simbolismo religioso in nessuno dei moti del Trecento francese: né nella Jacquerie, ispirata ai contadini di alcune regioni francesi dalla paura e dal rifiuto di un'élite militare che ha fallito il suo compito di "protezione" degli inermi, né nella rivolta parigina, tutta politica, guidata da Etienne Marcel, e neppure nelle "rivolte fiscali" del 1380-82 ${ }^{36}$.

Anche nei tanti moti che segnano il lungo e sventurato regno di Carlo VI, il re folle, non pare che la religione abbia mai svolto un qualche ruolo.

Può apparire sorprendente che, scorrendo le tante pagine che Bernard Guenée ha dedicato al monaco di S. Denis, autore della più completa ed interessante cronaca del regno, non sia possibile reperire il minimo accenno ad un'interpretazione dei moti del tempo ispirata a motivazioni anche latamente religiose. Le sommosse, le rivolte, gli "incendi" che turbano la società sembrano motivati da odio (odium) o scontento (displicentia) ${ }^{37}$. Nell'opera, che pare comunque contrassegnata da un certo "conservativismo", di vocabolario come di chiavi interpretative, nella lettura del presente, è totalmente assente anche il vocabolario delle divisioni sociali:

loro quartier generale, la chiesa domenicana di S. Maria Novella, scelta che lo Stella non giustifica in alcun modo.

${ }^{34}$ F. Franceschi, Oltre il “Tumulto". I lavoratori fiorentini dell'Arte della Lana fra Tre e Quattrocento, Firenze 1993

35 Una sintetica rappresentazione dell'atmosfera politico-culturale degli anni Sessanta si può leggere nell'Introduzione a Hilton, Bond Men made free cit., pp. XI-XII.

${ }^{36}$ Sulle rivolte dei primi anni del regno di Carlo VI si vedano H. Miskimin, The Last Act of Charles V: the Background of the Revolts of 1382, "Speculum», XXXVIII, 1963, pp.433-462 e Ch. M. Redding, The Estates of Normandy and the Revolts in the Towns at the beginning of the Reign of Charles VI, «Speculum», XLVII, 1972, pp. 79-90.

${ }^{37}$ B. Guénée, L'opinion publique à la fin du Moyen Age d'après la "Chronique de Charles VI" du Religieux de Saint-Denis, Paris 2002, soprattutto alle pp. 49-78 per i termini communis plebs, humilis plebs minor populus e il cap. IV, structures sociales et groupes d'opinion, présence du commun, pp. 93-110. 
nessun confronto/conflitto tra ricchi e poveri. Quest'ultimo termine sembra in parte coincidere con quello di "popolo", per designare in ogni caso solo gli individui privi di potere, che non si contrappongono però a chi possiede ${ }^{38}$.

E non si può certo dire che la Francia di fine Trecento ed inizi Quattocento non sappia esprimere nuove forme di religiosità: mistici e profeti - o meglio profetesse, la più celebre delle quali è Giovanna d'Arco- si moltiplicano in conseguenza della crisi della monarchia francese e della lacerazione della Cristianità causata dal Grande Scisma.

$\mathrm{Ma}$, nella maggioranza dei casi, queste variegate voci profetiche non animano le rivolte ma si schierano a favore del potere, sia questo pontificio o reale ${ }^{39}$.

Per finire, non si può passare certo sotto silenzio la grande rivolta delle campagne inglesi del 1381. Accanto alle motivazioni più propriamente economico-sociali (poll-tax, appesantimento dei diritti feudali, rivendicazioni di libertà e di concessioni con effetti immediati e stabili) ${ }^{40}$, è innegabile, in quanto attestato da diverse e convergenti fonti, la presenza nel movimento di membri del clero e di parole d'ordine ispirate dalla conoscenza dei testi sacri.

Da una parte, infatti, sono attivi fra gli insorti un buon numero di appartenenti al basso clero; dall'altra, sono conservate tracce della predicazione del più celebre di loro - John Ball- che avrebbe arringato le folle a

${ }^{38}$ La coincidenza fra pauper e impotens è stato proprio di tutto il pensiero dell'Alto Medioevo e di buona parte del Medioevo centrale, cfr. K. Bosl, "potens et pauper". Studio di storia del concetto, a proposito della differenziazione sociale nel primo Medio Evo e del pauperismo dell'alto Medio Evo, in La concezione della povertà nel Medioevo, a cura di O. Capitani, Bologna 1974, pp. 95-151. A p. 100 si può leggere "definizione negativa di pauper: chi non è potens"; ibidem, p.107: "indica prima di tutto la necessità di avere una protezione".

${ }^{39}$ Se nel caso di Giovanna d'Arco è universalmente nota la sua azione a difesa della monarchia, il Vauchez ha sottolineato il carattere "fondamentalement conservateur" anche dell'azione di Brigida di Svezia, che vuole migliorare il funzionamento della Chiesa, ma certo non contestarne il ruolo nella società (cfr. A Vauchez, Saints, prophètes et visionnaires. Le puvoir surnaturel au Moyen Age, Paris 1999, p. 128). Ma lo stesso si può dire di altre figure di profetesse attive durante il Grande Scisma (cfr. A. Vauchez, Influences franciscaines et réseaux aristocratiques dans le Val de Loire. Autour de la Bienheureuse Jeanne-Marie de Maillé (1331-1414), in Idem, Mouvements franciscains et société française, XII ${ }^{\grave{e}}-X X^{\grave{e}}$ siècles, Paris 1984, pp. 95-105). Tutte legate al potere principesco sono poi le sante donne studiate da Gabriella Zarri nell'Italia del Rinascimento, cfr. G. Zarri, Le sante vive. Cultura e religiosità femminile nella prima età moderna, Torino 1991.

${ }^{40} \mathrm{Su}$ origini, motivazioni e svolgimento della rivolta inglese si vedano MollatWolff, Ongles Bleus, Jacques et Ciompi cit., pp.186-210 e Hilton, Bond men made free cit., pp.144-165 per quanto riguarda il contesto in cui maturò la ribellione e pp. 165-175 sulla diffusione geografica della rivolta. 
partire dal tema, evocato più volte nei contributi di questo volume, dell'uguaglianza di condizione degli uomini nel Paradiso terrestre e della necessità di ripristinare questo stato originario ${ }^{41}$. Alcune delle richieste dei ribelli si sarebbero indirizzate esplicitamente contro la Chiesa possidente: si domandava la confisca dei beni ecclesiastici per distribuirli tra i parrocchiani, e la riduzione drastica del numero degli alti prelati (in Inghilterra, ad esempio, si chiedeva che fosse mantenuta una sola, grande diocesi).

Altre iniziative dei ribelli, anche se dirette contro i religiosi, hanno un significato puramente politico: è questo il caso, ad esempio, dell'assalto ad Highbury, proprietà del Gran Maestro degli Ospedalieri di S. Giovanni sir Robert Hales- che era però, per gli insorti, soprattutto l'odiato Tesoriere del Regno, e che fu per questo decapitato ${ }^{42}$.

Si è a lungo discusso delle possibili influenze delle contemporanee dottrine teologiche di Wycliffe e dei suoi "poveri preti" sul movimento. Mollat e Wolff negano che si possa parlare di influenza diretta, evidenziando il carattere puramente teologico dell'insegnamento del professore di Oxford $^{43}$, personalmente un conservatore dal punto di vista sociale, anche se non escludono una qualche forma di influenza indiretta. Assai più sfumato è il giudizio dell'Hilton ${ }^{44}$, che colloca nascita e sviluppo dei Lollardi nel contesto di una storia religiosa, come quella inglese, che non aveva conosciuto fino a quel momento alcun movimento ereticale.

Che si tratti di influenza diretta, o di manifestazioni concomitanti di atteggiamenti simili, è comunque certo che l'Inghilterra di quegli anni era percorsa da vene di anticlericalismo, basate sulla Bibbia, cui si aggiungevano - in alcuni casi - espliciti atteggiamenti di "comunismo evangelico".

È decisamente molto difficile formulare delle conclusioni. Vi sono indubbiamente, nella tradizione cristiano-evangelica, passi che paiono condannare in modo esplicito la ricchezza ("facilius est Camelum per

${ }^{41}$ L'Hilton nota a questo proposito che il sermone attribuito a John Ball "Whan Adam dalf and Eve span, wo was thanne a gentilman..." riprendeva in realtà temi in circolazione già all'inizio del XIV secolo, ibidem, p. 211.

42 Ibidem, pp.138-139. Non va poi dimenticato che le grandi abbazie del Regno erano anche proprietarie di estesissimi territori, su cui esercitavano un pesante dominio.

${ }^{43}$ M. Mollat- P. Wolff, Ongles Bleus, Jacques et Ciompi cit., pp. 208-209.

${ }^{44}$ Hilton, Bond Men made free cit., p.213: "Perhaps the very absence of a heretical movement brought the critical elements among the clergy to express themselves in the social and political movements of 1381. Perhaps the now discarded idea of a close link between Lollardy and the rising of 1381 was not after all so mistaken, provided that we regard Lollardy as something wider simply than the following of Wycliffe. After all, Ball was first imprisoned for illicit preaching in the 1360s." 
foramen acus transire quam divitem intrare in regnum coelorum" 45 ; " $\mathrm{Si}$ vis perfectus esse vade, vende quae habes et da pauperibus et habebis thesaurum in coelo et veni sequere $\mathrm{me}^{\mathrm{N}} 46$, ecc.) che hanno ispirato nei secoli movimenti popolari e singoli individui, il cui più celebre esempio è certamente Francesco d'Assisi.

Già ai tempi della Riforma ecclesiastica dell'XI secolo, si era riproposta con forza l'immagine della Comunità di Gerusalemme, come descritta nel IV capitolo degli Atti degli Apostoli ("la moltitudine dei credenti aveva un cuor solo e un'anima sola;né vi era chi dicesse suo quello che possedeva, ma tutto era tra loro comune") ${ }^{47}$.

La povertà volontaria come valore e la comunità dei beni dei tempi apostolici era diventata la base ideologica del monachesimo prima, dei canonici riformati poi ${ }^{48}$. Di "rinuncia" della Chiesa ai beni che deteneva in base a concessioni "feudali" si era parlato ai tempi di Pasquale II, all' $i$ nizio del XII secolo. Più tardi, all'inizio del Duecento, i Mendicanti, col loro rifiuto della proprietà e dei redditi avevano riproposto con forza il tema dell'imitazione di Cristo attraverso la rinuncia al possesso ${ }^{49}$. Il pensiero teologico aveva del resto sempre sottolineato che le differenze di fortuna dovevano essere considerate conseguenza del peccato di Adamo, così come la necessità del potere. E, nel corso del XII secolo, nella Parigi di Pietro Cantore, si era arrivati a sostenere che il furto in caso di assoluta necessità e di fronte al rifiuto dell'elemosina, non doveva essere ritenuto peccato ${ }^{50}$.

${ }^{45}$ Mt 19, 24.

${ }^{46}$ Mt 19, 21.

${ }^{47}$ At $4,32$.

${ }^{48} \mathrm{Su}$ questa interpretazione di Atti, IV, si veda ancor oggi il bel saggio di Giovanni Miccoli, "Ecclesiae primitivae forma", in Idem, Chiesa gregoriana. Ricerche sulla riforma del secolo XI, nuova edizione a cura di A. Tilatti, Roma 1999, pp. 258-383.

${ }^{49} \mathrm{Sul}$ valore da attribuire alla povertà francescana si sono scritte migliaia di pagine. Basti qui citare La povertà del XII secolo e Francesco d'Assisi, Atti del II Convegno internazionale della Società internazionale di Studi Francescani, (Assisi, 17-19 ottobre 1974), Assisi 1975. La centralità della povertà nell'esperienza di Francesco in G. Miccoli, Francesco d'Assisi. Realtà e memoria di un'esperienza cristiana, Torino 1991. Per le diverse intepretazioni che, storicamente, alla povertà hanno attribuito le diverse famiglie religiose che si rifanno al Poverello di Assisi cfr. G. G. Merlo, Nel segno di S. Francesco, Padova 2003. Più lineare è il concetto di povertà mendicante sviluppato dall'Ordine dei Predicatori, per cui si veda, M.-H. Vicaire, Les origines de la pauvreté mendiante des Prêcheurs, in Idem, Dominique et ses Prêcheurs, Fribourg-Paris 1977, pp. 222-265.

${ }^{50}$ Per una sintesi sull'evoluzione del concetto di povertà volontaria si veda G. Barone, Evoluzione della mentalità e fine della povertà volontaria, in Dizionario degli Istituti di Perfezione, VII, Roma 1983, coll. 332-337. 
Nei secoli del Basso Medioevo, queste idee, anche grazie alla sempre più capillare diffusione della predicazione, affidata a veri "professionisti della parola", diventano patrimonio comune di masse sempre più ampie. Diventa allora possibile - anche se non necessario - che temi biblico-evangelici, nei momenti di scontro sociale, vengano e ripresi e sviluppati in chiave politico-rivendicativa. 


\section{GiUliano Pinto}

\section{CONGIUNTURA ECONOMICA, CONFLITTI SOCIALI, RIVOLTE}

L'interpretazione 'congiunturale' delle rivolte bassomedievali, al cui interno quelle trecentesche ebbero uno spazio rilevante, data da molti decenni. Già lo metteva in rilievo Rinaldo Comba nella sintesi, ben fatta e ancora utile, del $1986^{1}$. Circa dieci anni dopo Hugues Neveux nel suo volume sulle rivolte contadine in Europa ha dedicato un capitolo al rapporto tra vicende economiche e ribellioni che una parte ben precisa della storiografia del secondo dopoguerra aveva collegato con stretti nessi di causa ed effetto ${ }^{2}$. Le rivolte (uso questo termine in modo molto generale e generico, e sono consapevole quanto sia difficile etichettare le diverse forme di contestazione violenta) sarebbero state conseguenza - semplifico assai - di una congiuntura negativa, ovvero di un abbassamento progressivo e sempre meno tollerabile delle condizioni di vita degli strati inferiori della società che sarebbero stati indotti a ribellarsi.

Prendiamo alcuni esempi tratti dagli studi comparsi nella seconda metà del secolo scorso.

Michel Mollat e Philippe Wolff intitolarono un capitolo del loro celebre volume del 1970 Ongles bleus, Jacques et Ciompi «Les révoltes contre la misère», e interpretarono il XIV secolo come un crescendo di ribellioni urbane e rurali, preparatorie per così dire ai grandi tumulti degli anni Ottanta ${ }^{3}$. Descrivendo episodi di conflittualità rurale nell'Inghilterra dei primi de-

${ }^{1}$ R. Comba, Rivolte e ribellioni fra Tre e Quattrocento, in La Storia. I grandi problemi dal Medioevo all'Età Contemporanea, diretta da N. Tranfaglia e M. Firpo, II, Il Medioevo, 2, Popoli e strutture politiche, UTET, Torino 1986, pp. 673-691: 674-675.

${ }^{2} \mathrm{H}$. Neveux, Les révoltes paysannes en Europe XIV ${ }^{e}-X V I I^{e}$ siècle, Albin Michel, Paris 1997, pp. 71-100. In realtà l'autore, un modernista, dedica gran parte della sua analisi (con largo spazio alla discussione delle diverse posizioni storiografiche) alle rivolte contadine dei secoli XVI e XVII: solo la Jacquerie è ricordata spesso in chiave comparativa.

${ }^{3} \mathrm{M}$. Mollat - Ph. Wolff, Ongles bleus, Jacques et Ciompi. Les révolutions populaires en Europe aux XIV et $X V^{e}$ siècle, Calmann-Lévy, Paris 1970, il cap. in questione è il III, pp. 91-137. I due autori distinguono tre periodi con caratteristiche diverse: un'epoca di conflitti di natura sociale interni alle città e ai mestieri a cavallo fra XIII e XIV secolo; le rivolte della miseria, che compaiono già all'inizio del XIV secolo ma che si accentuano dopo la Peste Nera; infine «Les annèes révolutionnaires (1378-1382)». 
cenni del Trecento, Mollat e Wolff scrivevano con una efficace similitudine: «ainsi les nuages s'accumulaient dans le ciel, annonçant de loin l'orage de $1381 »^{4}$. Guy Fourquin, che nel 1964 aveva pubblicato la sua ricerca sulle campagne della regione parigina alla fine del Medioevo, dedicò nella sua sintesi del 1972 un capitolo ai «Soulèvements liés à la conjuncture ${ }^{5}$. Su questa linea, di sottolineatura del peso determinante della congiuntura negativa, si erano posti già prima molti altri storici all'interno di ampi lavori di carattere generale ${ }^{6}$. In seguito anche Werner Rösener nella sua sintesi sui contadini nel Medioevo, uscita nel 1985, attribuisce alle ripercussioni della 'crisi' agraria del XIV il peggioramento delle condizioni di vita dei contadini e quindi vede in tale peggioramento una, se non la principale causa delle sollevazioni della seconda metà del secolo ${ }^{7}$.

Erano quelli i decenni (gli anni '60 e '70) in cui le contrapposizioni ideologiche e le vicende del '68 orientavano l'attenzione della storiografia internazionale verso le rivolte popolari del basso Medioevo e della prima età moderna ${ }^{8}$, così come era accaduto più volte nel corso del XIX e dei primi decenni del XX secolo9. Poi in questi ultimi vent'anni l'interesse verso queste tematiche si è nel complesso affievolito o ha assunto tagli interpretativi diversi ${ }^{10}$.

${ }^{4}$ Ibidem, p. 85.

${ }^{5} \mathrm{G}$. Fourquin, Les campagnes de la région parisienne à la fin du Moyen Age: Du milieu du XIII $I^{e}$ au début du XVI siècle, PUF, Paris 1964; Id., Les soulèvements populaires au Moyen Age, Paris, PUF, 1972 (trad. it., Mursia, Milano 1976).

${ }^{6}$ Comba, Rivolte e ribellioni cit., p. 675, che ricorda i lavori di E. Power, D. Waley e E. Perroy; anche se il giudizio di quest'ultimo appare abbastanza sfumato: E. Perroy, Il Medioevo. L'espansione dell'Oriente e la nascita della civiltà occidentale, trad. it., Sansoni Firenze 1958 (ed. francese Paris 1955), pp. 435-438.

${ }^{7}$ W. Rösener, I contadini nel Medioevo, trad. it., Laterza, Roma-Bari1987 (ed. orig. München 1985), pp. 291-293, 301-320.

${ }^{8}$ Neveux, Les révoltes paysannes cit., p. 20 e sgg. Non è un caso che nel 1971 si ristampasse il volumetto di M. Dommanget, La Jacquerie, Maspero, Paris 1971, uscito 13 anni prima (per il $600^{\circ}$ della rivolta), opera di uno studioso militante del movimento operaio e socialista, che già nella bandella definiva la Jacquerie come l'anello di congiunzione tra la rivoluzione comunale del XII secolo e la grande Rivoluzione nazionale del 1789. Ma anche la storiografia americana non fu insensibile alle sollecitazioni del '68. Nel maggio del 1969 si tenne all'università della California un convegno dal titolo significativo, i cui atti uscirono tre anni dopo: Violence and Civil Disorder in Italian Cities, 1200-1500, L. Martines ed., University of California Press, Berkeley 1972.

${ }_{9}^{9}$ Basti ricordare la storiografia sul Tumulto dei Ciompi ripercorsa da E. Sestan, Echi e giudizi sul Tumulto dei Ciompi nella cronistica e nella storiografia, in Il Tumulto dei Ciompi. Un momento di storia fiorentina ed europea, Olschki, Firenze 1981, pp. 125 160 , alle pp. 150-160.

${ }^{10}$ In Italia fa eccezione il volume Protesta e rivolta contadina nell'Italia medievale, a cura di G. Cherubini, «Annali» dell'Istituto 'Alcide Cervi', 16, 1994: si tratta di un numero monografico di oltre 250 pagine. A livello europeo, all' interno del progetto «Les origines de l'Etat moderne en Europe, XII ${ }^{\mathrm{e}}$ XVIII ${ }^{\mathrm{e}}$ siècles" diretto da W. Blockmans e 
All'interpretazione 'congiunturale' delle rivolte trecentesche si contrapponeva, pur con varie sfumature a seconda degli autori, una linea interpretativa - diciamo così - 'strutturale', d'impronta marxista. L'attenzione fu rivolta soprattutto alle rivolte contadine. Interpretazioni più ortodosse e schematiche nei lavori di Cistovzonov, di Rutenburg, degli storici della Germania Orientale ricordati nella relazione di Pierre Monnet ${ }^{11}$, che parlano tout court di lotta di classe dei contadini e dei lavoratori sottoposti delle città, all'interno delle «acute contraddizioni che oggettivamente si originavano dal processo di disgregazione in atto dell'edificio feudale» ${ }^{12}$. Ma si deve subito aggiungere che anche storici non marxisti come Bloch e Duby avevano visto nella conflittualità permanente tra signori e contadini un elemento per così dire strutturale della signoria. Bloch nella sintesi su Les caractères originaux de l'histoire rurale française affermava che «la rivolta agraria appare inscindibile dal sistema signorile, così come, per fare un esempio, lo sciopero dalla grande impresa capitalistica», ma aggiungeva che «ben più efficaci di quei fuochi di paglia [le insurrezioni armate] dovevan risultare le lotte sorde e pazienti condotte con tanta tenacia dalle comunità rurali» ${ }^{13}$. Insomma il conflitto tra contadini (spesso organizzati in comunità) e signori, dove alla contrattazione si alternavano episodi di vero e proprio scontro, anche violento, fu fenomeno di lunga durata non certo circoscrivibile agli ultimi due secoli del Medioevo ${ }^{14}$.

Altre interpretazioni delle rivolte tardomedievali, riconducibili anch'esse all'interpretazione marxista, appaiono assai più articolate. Rodney Hilton, ad esempio, attribuì un'importanza relativa al peso della congiuntura economica nelle agitazioni sociali del tardo Medioevo, vedendola piuttosto come elemento di esasperazione di conflitti sociali propri delle comunità contadine del tempo ${ }^{15}$. Guy Bois nel suo studio del 1976 sulla Normandia fra XIV e XVI secolo usava già nel titolo l'espressione 'Crise du féodali-

J.F. Genet, P. Blicke si è occupato di coordinare gli studi sulle forme di resistenza alla costruzione dello Stato, ovviamente inserite nel più ampio contesto politico: cfr. Résistance, représentation et communauté, P. Blicke ed., PUF, Paris 1998.

${ }^{11}$ Cfr. più indietro in questo stesso volume il saggio di P. Monnet, a p. 130.

${ }^{12}$ Comba, Rivolte e ribellioni cit., p. 674. Eloquenti le pagine dedicate alle rivolte bassomedievali nel manuale universitario di storia dell'Europa centro-occidentale scritto da storici sovietici stampato in URSS nel 1964 e poi nel 1976 in traduzione francese: Historie du Moyen Age, a cura di M. Abramson, A. Gourévitch, N. Kolesnitski, Éditions du Progrès, Mosca 1976, pp. 9, 195-202, 247-254, 290-301, 356-358.

${ }^{13}$ Cito dalla trad. it. M. Bloch, I caratteri originali della storia rurale francese, Torino, Einaudi, 1973, p. 199 (il volume uscì per la prima volta nel 1931). Quanto a George Duby, si veda la sua sintesi L'economia rurale nell'Europa medievale. Francia, Inghilterra, Impero (secoli IX-XV), trad. it., Laterza, Bari 1966 (prima ed. francese 1962), p. 513.

${ }^{14} \mathrm{Cfr}$. pure in questo volume il saggio di F. Panero.

${ }^{15}$ Cfr. le osservazioni di Comba, Rivolte e ribellioni cit., p. 675, alle tesi di Hilton. 
$\mathrm{sme}^{16}$. Il crescente squilibrio tra popolazione e risorse, lo sfruttamento obbligato di terre marginali, la stagnazione e poi la riduzione della rendita signorile (e accanto a questi fattori più strutturali, la guerra, la svalutazione monetaria, il maggior peso della fiscalità regia) avrebbero contribuito a rendere più tesi i rapporti tra signori e contadini; i primi si dedicarono a imprese militari per arrotondare le entrate e vennero meno ai loro compiti di difesa delle comunità contadine. La crisi della nobiltà si estese gradualmente a tutta la società. Quindi - si potrebbe dire schematizzando - un conflitto tra due classi su cui ebbe un peso notevole il fattore demografico, in genere trascurato dalla storiografia marxista più tradizionale.

Era sul fronte della lettura delle rivolte urbane che l'interpretazione che si rifaceva a un marxismo troppo schematico si scontrava in misura maggiore con la realtà dei fenomeni, come emerge da un'analisi attenta della documentazione. Mi limito a ricordare l'interpretazione di Victor Rutenburg delle rivolte dei lavoratori della lana di alcune città italiane (Firenze, Perugia, Siena) degli anni Settanta del XIV secolo, in particolare quella dei Ciompi, dove si attribuiva un peso rilevante alla proletarizzazione dell'artigiano cittadino, che avrebbe perso la proprietà dei mezzi di produzione (in particolare i telai) ora controllati dai mercanti-imprenditori ${ }^{17}$ : fenomeno che non trova riscontri significativi nelle fonti del tempo, anzi ${ }^{18}$. Il tutto si inseriva nello scontro tra un «proletariato primitivo (pre-proletariato)» e una nascente borghesia che stava creando nelle città relazioni di tipo capitalistico ${ }^{19}$.

Vediamo a questo punto, per tornare al tema del mio intervento, alcune delle caratteristiche della congiuntura economica del XIV secolo, per poi collegare - o non collegare - $\mathrm{i}$ fenomeni di rivolta a tale situazione, $\mathrm{o}$ quanto meno per cercare di coglierne alcuni nessi.

Il grosso delle rivolte, in particolare quelle a carattere più generale $\mathrm{e}$ quelle più note (Jacquerie, Ciompi, rivolta inglese del 1381) si collocano

${ }^{16}$ G. Bois, Crise du féodalisme. Economie rurale et démographie en Normandie orientale du début du $14^{e}$ siècle au milieu du $16^{e}$ siècle, Presses de la Fondation nationale des sciences politiques, Paris 1976, passim.

17 V. Rutenburg, Popolo e movimenti popolari nell'Italia del '300 e '400, trad. it., Bologna, il Mulino1971 (ed. originale, Mosca-Leningrado 1958), pp. 29, 33, 45.

${ }^{18} \mathrm{Cfr}$. Ch. M. de La Roncière, La condition des salariés à Florence au XIV es siècle, in Il Tumulto dei Ciompi cit., pp. 13-40, a p. 16; F. Franceschi, Oltre il «Tumulto». I lavoratori fiorentini dell'Arte della Lana fra Tre e Quattrocento, Olschki, Firenze 1993, pp. 179-180, 198-199. Ma si veda qui, più indietro, la relazione dello stesso Franceschi.

${ }^{19}$ Rutenburg, Popolo e movimenti popolari cit., p. 5. Lo storico russo riprendeva più o meno gli stessi concetti nel successivo lavoro di sintesi, su un arco cronologico più ampio, comparso in Italia nel 1982: V. Rutenburg, La crisi dell'ordinamento comunale e i moti cittadini, in Storia della società italiana, 7, La crisi del sistema comunale, Teti, Milano 1982, pp. 361-391, a p. 368 e sgg. 
nella seconda metà del secolo, un periodo che secondo l'interpretazione 'congiunturalista' di lungo periodo, sarebbe caratterizzato da tutta una serie di fenomeni negativi tali da determinare un peggioramento delle condizioni di vita del proletariato urbano e dei contadini dipendenti.

In realtà se noi prendiamo come punto di riferimento i livelli di vita degli strati sociali più bassi, pur consapevoli delle distinzioni tra città $\mathrm{e}$ campagna e tra le diverse aree geografiche, il periodo contrassegnato da una congiuntura negativa risulta essere soprattutto quello che precede la Peste del 1348, ovvero i 5-6 decenni compresi tra lo scorcio del XIII e la metà del XIV secolo.

I numerosi dati riportati nella grande sintesi di Wilhelm Abel su prezzi e salari relativi al periodo che qui ci interessa ${ }^{20}$, integrati dalle ricerche effettuate in tempi più recenti per l'Italia (in particolare per Firenze ${ }^{21}$ ), e per alcune aree iberiche ${ }^{22}$ (che sono le grandi assenti nel lavoro dello storico tedesco, ma non per colpa sua ${ }^{23}$ ), o ancora il trend relativo alla Normandia ricostruito da G. Bois ${ }^{24}$, appaiono inequivocabili, pur all'interno di scansioni temporali non del tutto coincidenti per le varie parti d'Europa. Fino

${ }^{20}$ W. Abel, Crises agraires en Europe (XIII $-X X^{e}$ siècle), trad. franc. revue et augmentée, Flammarion, Paris 1973, pp. 44-61. Ma si veda anche il quadro sintetico dell'economia europea tra 1300 e 1500 tracciato da C. M. Cipolla, Storia economica dell'Europa pre-industriale, terza ediz. riveduta, il Mulino, Bologna 1980, pp. 221-225.

${ }^{21} \mathrm{Cfr}$. i lavori di Ch. de La Roncière, Prix et salaires à Florence au XIV ${ }^{e}$ siècle, 12801380, École française de Rome, Roma 1982, pp. 269-357; R. A. Goldthwaite, I prezzi del grano a Firenze dal XIV al XVI secolo, "Quaderni storici», 10, 1975, pp. 5-36; G. Pinto, Il Libro del Biadaiolo. Carestie e annona a Firenze dalla metà del '200 al 1348, Olschki, Firenze 1978, pp. 47 e sgg., 131 e sgg; S. Tognetti, Prezzi e salari nella Firenze tardomedievale: un profilo, «Archivio storico italiano», CLIII, 1995, pp. 263-333.

${ }^{22}$ F. Zulaica Palacios, Fluctuaciones económicas en un periodo de crisis. Aragón en la Baja Edad Media (1300-1430), Zaragoza, Institución «Fernando el Católico, 1994, pp. 255 e sgg., 269-275. Lo studio ha il merito di confrontare in apposite tabelle l'andamento dei prezzi del grano e dei salari in Aragona con quelli ricostruiti per la Francia e l'Inghilterra. In Catalogna gli anni di carestia, ossia di forte rincaro del prezzo del grano, furono 29 nella prima metà del XIV secolo e solo 8 nella seconda metà: A. Riera Melis, Crisis frumentarias y políticas municipales de abastecimiento en las ciudades catalanas durante la Baja Edad Media, in Crisis de subsistencia y crisis agrarias en la Edad Media, R. Oliva Herrer, P. Benito i Monclus eds., Universidad de Sevilla, Sevilla 2007, pp. 125-159, a p. 147.

${ }^{23}$ Gli unici dati su prezzi e salari relativi all'Italia del XIV secolo riguardano il prezzo del grano a Genova (Abel, Crises agraires cit., p. 31), mentre la penisola iberica è del tutto assente; il che rispecchia lo stato degli studi, considerando che la prima edizione del libro è del 1935 e la seconda del 1966. Quest'ultima, del resto, portava nel titolo l'indicazione Europe centrale e non semplicemente Europe. Sullo studio di prezzi e salari a partire dal Medioevo si veda anche I prezzi in Europa dal XIII secolo a oggi. Saggi di storia dei prezzi raccolti e presentati da Ruggiero Romano, Einaudi, Torino 1967, in particolare l'Introduzione dello stesso Romano, pp. IX-XLIV.

${ }^{24}$ Bois, Crise du feodalisme cit., pp. 94-98. 
alla Peste Nera, grosso modo, il mercato del lavoro in città e in campagna fu contrassegnato da abbondanza di braccia e quindi da una forte concorrenza tra la manodopera; da qui salari nominali stabili se non in qualche caso in discesa ${ }^{25}$, contratti agrari progressivamente più gravosi per i lavoratori, almeno nelle aree esterne alla signoria rurale, come ad esempio nelle campagne dell'Italia centro-settentrionale dove i contratti di mezzadria e di colonia parziaria mutarono, soprattutto nel secondo quarto del XIV secolo, a vantaggio dei proprietari ${ }^{26}$. Ad aggravare il tutto, stava l'ascesa dei prezzi dei generi di prima necessità (dei cereali soprattutto), provocata sia da un aumento progressivo della domanda sia dall'infittirsi delle carestie, dovute soprattutto ai cattivi raccolti e talvolta aggravate dalle speculazioni degli intermediari ${ }^{27}$. Il rincaro progressivo dei prezzi delle derrate agricole abbassava sensibilmente i salari reali dei lavoratori cittadini; ne rendeva poi drammatiche le condizioni di vita in occasione delle impennate dei prezzi nei mesi in cui la carestia si faceva più grave ${ }^{28}$.

In cambio l'alto prezzo dei cereali poteva essere un elemento positivo per i produttori in grado di immetterli sul libero mercato. Ma chi si avvantaggiava realmente per questo rincaro? Difficilmente, o comunque in scarsa misura la gran massa dei contadini dipendenti o i piccoli proprietari contadini, tra i quali prevaleva nettamente l'autoconsumo ${ }^{29}$. Se ne

${ }^{25}$ I dati si riferiscono quasi esclusivamente a lavoratori dell'edilizia (specializzati e non) e a salariati agricoli, a quanti cioè lavoravano sulla base di un salario a tempo; tali dati possono essere estesi ragionevolmente a tutto il mondo del lavoro subordinato. Per le indicazioni cfr. i riferimenti alle note 18-21.

${ }^{26}$ G. Pinto, La Toscana nel tardo Medioevo. Ambiente, economia rurale, società, Firenze, Sansoni, 1982, pp. 317-318; Id., Le prestazioni d'opera nei contratti mezzadrili del Senese (secolo XIII-1348), in Le prestazioni d'opera nelle campagne italiane del Medioevo, Clueb, Bologna 1987, pp. 199-208.

${ }^{27}$ All'interno di una ricchissima bibliografia si veda in generale il saggio classico di É. Carpentier, Autour de la peste noire: famines et épidémies dans l'histoire du XIV siècle, "Annales, E.S.C.», XVII, 1962, pp. 1062-1092, e quello recentissimo di F. Menant, Crisis de subsistencias y crisis agrarias en la Edad Media: algunas reflexiones previas, in Crisis de subsistencias cit., pp. 17-60, con una ricca appendice bibliografica. Innumerevoli, naturalmente, i contributi relativi a singole regioni o a singole città. Tuttavia non dappertutto i prezzi dei cereali crebbero nel secondo quarto del XIV secolo; in aree fertili a prevalente economia rurale - è il caso della Normandia - si mantennero mediamente costanti o scesero leggermente (Bois, Crise du feodalisme cit., p. 96).

${ }^{28}$ Per qualche esempio di forti rincari del grano nell'arco di una stessa annata agricola cfr. Duby, L'economia rurale cit., p. 465; Mollat - Wolff, Ongles bleus cit., p. 92; de La Roncière, Prix et salaires à Florence cit., pp. 69-125; Pinto, Il Libro del Biadaiolo cit., pp. 102-103.

${ }^{29} \mathrm{Ne}$ sono una riprova, per l'Italia centro-settentrionale, i numerosi prestiti in grano a contadini di cui restano ampie testimonianze nelle imbreviature notarili: Pinto, $\mathrm{La}$ Toscana nel tardo Medioevo cit., pp. 207-223; J.-L. Gaulin, F. Menant, Crédit rural et endettement paysan dans l'Italie communale, in Endettement paysan \& crédit rural dans l'Europe médiévale et moderne, M. Berthe ed., Toulouse, Presses universitaires du Mirail, 
avvantaggiavano la grande proprietà fondiaria e una fascia ristretta di contadini agiati, in grado di disporre di surplus anche in anni di cattivi raccolti.

Nel contempo la signoria stava attraversando, più o meno in tutta Europa, un processo di limitazione dei propri poteri (e quindi anche della rendita fondiaria) da parte di comunità di villaggio che erano state in grado di organizzarsi e di portare avanti le proprie rivendicazioni ${ }^{30}$.

Naturalmente, va da sé che la congiuntura negativa non incideva nello stesso modo e con uguale peso su città e campagna, o meglio sugli strati inferiori della società urbana e su lavoratori agricoli dipendenti e piccoli proprietari contadini.

Nei decenni compresi tra l'ultimo quarto del XIII secolo e la metà del $\mathrm{XIV}$, sono attestate sì numerose rivolte, ma più che rivolte (con la sola eccezione di quelle che coinvolsero le città e parte delle campagne fiamminghe $^{31}$ ) si trattò di tumulti, di sommosse: episodi circoscritti, cioè, che si esaurirono di norma nell'arco di qualche giorno, in genere senza programmi e prospettive precise; spesso si trattò di tumulti legati alla scarsità di cereali ${ }^{32}$.

Prendiamo ad esempio l'Italia dove l'abbassamento dei livelli di vita degli strati inferiori della società fu più forte sia perché i prezzi dei cereali erano più alti, visti gli squilibri tra produzione locale e domanda ${ }^{33}$, sia per l'abbondanza di manodopera in città come in campagna dovuta alla forte crescita demografica. In Italia non incontriamo rivolte nel senso pieno del termine ma una serie di sommosse e di tumulti di breve durata, quasi tutti d'ambito urbano. Ricordiamo ad esempio, senza alcuna pretesa di completezza, i tumulti urbani legati alla scarsità o alla mancanza di grano che

1998 (Actes des XVII ${ }^{\text {es }}$ Journées internationales d'histoire de l 'abbaye de Flaran), pp. 35-67; ma cfr. anche nello stesso volume i contributi di Ph. R. Schofield, H.-J. Gilomen, A. Furió dedicati all'indebitamento contadino rispettivamente in Inghilterra, nei territori dell'Impero e nella penisola iberica del Medioevo; e inoltre Duby, L'economia rurale cit., pp. 391-392.

${ }^{30}$ Cfr. Duby, L'economia rurale cit. pp. 479-509; Rösener, I contadini nel Medioevo cit., pp. 303-306; e le considerazioni molto puntuali di Maire Vigueur per l'Italia (assente o scarsamente presente in genere nelle sintesi dedicate all'Europa medievale pubblicate al di là delle Alpi) nella Post-fazione che chiude il volume su Protesta e rivolta contadina nell'Italia medievale. Sui rapporti tra signori e contadini si veda anche in questo volume il saggio di F. Panero.

${ }^{31}$ Cfr. qui più indietro il saggio di M. Boone.

${ }^{32}$ Oltre ai numerosi riferimenti all'Italia nella pagina che segue, si vedano gli esempi riportati da Mollat - Wolff, Ongles bleus cit., pp. 92-93, 96-98, e inoltre gli episodi ricordati nella relazione di M. Bourin, qui indietro a p. 17.

${ }^{33}$ G. Pinto, Città e spazi economici nell'Italia comunale, Bologna, Clueb, 1996, pp. 77-96. Ricordiamo anche che in Italia vi era un forte addensamento urbano e un rapporto tra popolazione cittadina e lavoratori della terra fortemente squilibrato rispetto al resto d'Europa. 
si ebbero a Bologna nel $1311^{34}$, a Firenze nel 1329, e poi nel 1335, nel '43 e nel '47; sempre nel 1329 a Napoli e a Barletta, ancora Barletta nel 1340; e poi Siena nel 1303, nel '29 e nel '47; a Roma nel 1329 e nel ' $47^{35}$.

Un caso a parte fu quello di Ciuto Brandini, ma se ne sa poco perché le uniche fonti a disposizione sono un passo di una cronaca anonima e i verbali del processo intentato contro di lui. Si trattò in sostanza di un tentativo di organizzare in una confraternita i lavoratori più umili dell'Arte della Lana ${ }^{36}$; un episodio isolato in Italia, che trova un riscontro forse nelle lotte dei 'mestieri' delle città fiamminghe e del nord della Francia.

Si tratta comunque di episodi sporadici, in mancanza di un censimento sistematico, e quindi di una cronologia, che non può prescindere dallo spoglio della gran massa dei registri giudiziari conservata negli archivi delle città comunali ${ }^{37}$.

Nelle campagne italiane del Trecento siamo di fronte a episodi più di protesta e di contestazione che di rivolta; ma anche là dove la protesta dà vita a conflitti cruenti, si tratta per lo più di fiammate circoscritte o che non hanno il tempo di propagarsi ${ }^{38}$.

Nelle campagne fiorentine a fine 1347 (al termine di una fortissima carestia) e nei primissimi mesi del ' 48 (prima dell'arrivo della peste) è attestata una situazione che presenta qualche tratto di 'jacquerie', in un contesto dove la signoria rurale era scomparsa da tempo. Come scrive Giovanni Villani, «le più delle famiglie di contadini abandonarono i poderi, e rubavano per la fame l'uno all'altro ciò che trovavano» ${ }^{39}$. Furti e saccheggi di case e di mulini, aggressioni contro chi trasportava grano e, fatto ancor più significativo, devastazione di campi, ritornano con una certa frequenza negli atti giudiziari del tempo. Su richiesta dei proprietari cittadini, il Comune instaurò un sistema di sorveglianza nei vari popoli del contado, ma l'elemento forse più significativo, che fa pensare a qualcosa di coordinato - come risulta da una petizione del gennaio del 1348 indirizzata da un gruppo di proprietari fondiari al Consiglio maggiore - è il fatto che i ret-

${ }^{34}$ Vedi in questo volume il contributo di V. Braidi.

${ }^{35}$ Pinto, Il Libro del Biadaiolo cit., p. 128;

${ }^{36} \mathrm{~N}$. Rodolico, Il popolo minuto. Note di storia fiorentina, nuova ed., Olschki, Firenze 1968 (prima ed., Bologna 1899), pp. 37-40.

${ }^{37} \mathrm{Ma}$ si veda in questo volume la relazione di S. K. Cohn Jr., che fa riferimento a una ricognizione dettagliata di oltre 1.100 casi di proteste popolari tra il 1200 circa e il 1425; lo stesso Cohn ha pubblicato successivamente un importante lavoro di sintesi Lust for Liberty. The Politics of Social Revolt in Medieval Europe, 1200-1425, Italy, France, and Flanders, Harvard University Press, Cambridge Mass 2006. Per un'indagine condotta tempo addietro, sempre dallo stesso autore, utilizzando anche gli atti criminali fiorentini dei secoli XIV e XV si veda S. K. Cohn Jr., The Laboring Classes in Renaissance Florence, Academic Press, New York 1980.

${ }^{38} \mathrm{Si}$ rimanda ai contributi raccolti nel volume Protesta e rivolta contadina cit. 
tori di alcune comunità rurali istigavano $i$ contadini a non lavorare i poderi dei cittadini, a non macinare nei loro mulini, a saccheggiare i loro campi ${ }^{40}$. Poi l'arrivo della peste mise tutto a tacere.

Nell'Italia meridionale e in Sicilia fiammate di rivolte, dovute talvolta ad un aggravarsi delle condizioni economiche o a periodi di carestia, si inseriscono quasi sempre all'interno della dialettica tra comunità rurali e feudalità, tra contadini e signori, secondo uno schema valido per buona parte dell'Europa. Si trattò comunque di episodi circoscritti, di breve durata ${ }^{41}$.

Anche per i paesi d'Oltralpe il quadro non è molto diverso, con la già ricordata eccezione delle Fiandre. Semmai sia in Francia che in Inghilterra che nella penisola iberica sono meno frequenti i casi di tumulti legati alla mancanza di grano, proprio per quel diverso rapporto tra domanda e offerta locale, a cui abbiamo fatto riferimento, che dipendeva anche dalla presenza di una maglia urbana assai meno densa rispetto all'Italia e alle Fiandre ${ }^{42}$; in quei paesi poi, come in Italia, gli episodi di rivolta si fanno più frequenti e di più larga portata nella seconda metà del XIV secolo.

Perché dunque tra il 1250 e il 1350 troviamo povertà diffusa tra gli strati sociali inferiori ed episodi di rivolta non particolarmente fitti e di breve durata, in un rovesciamento sostanziale di quanto sostenuto da chi lega strettamente condizioni di miseria e scoppio di tumulti?

È difficile dare risposte precise, all'interno per altro di contesti economici, sociali e politici fortemente differenziati. Forse era ancora assente o non sufficientemente matura una presa di coscienza. Nelle città il malumore dei ceti meno abbienti si stemperava nei conflitti più generali, in quella che è stata definita come la "rivolta dei mestieri" o dei "medi" contro i "grandi"43. Forse si continuava a ragionare entro i binari di strutture politiche, sociali ed economiche che non si intendeva contestare a fondo, che non si mirava a rovesciare, ma solo a modificare.

${ }^{39}$ Giovanni Villani, Nuova cronica, a cura di G. Porta, Guanda, Parma 1991, XIII, 73, vol. terzo, p. 467.

${ }^{40}$ G. Pinto, Firenze e la carestia del 1346-47, ripubblicato in Id., La Toscana nel tardo Medioevo cit., pp. 357-359, 395-398; il provvedimento del gennaio 1348 è stato analizzato e pubblicato in Rodolico, Il popolo minuto cit., pp. 61-62, 114-115

${ }^{41}$ Cfr. G. Vitolo, Rivolte contadine e brigantaggi nel Mezzogiorno angioino in Protesta e rivolta contadina cit., pp. 207-225; ancora utile il lavoro di R. Caggese, Roberto d'Angiò e i suoi tempi, 2 voll., Bemporad, Firenze 1922 e 1930, pp. 311-337; per la Sicilia S. Tramontana, Michele da Piazza e il potere baronale in Sicilia, D’Anna, MessinaFirenze1963, p. 247.

${ }^{42}$ Cfr. Mollat - Wolff, Ongles bleus cit., pp. 91 e sgg., e inoltre in questo volume le relazioni di M. Bourin, P. Monnet, R. Oliva.

${ }^{43}$ Mollat - Wolff, Ongles bleus cit., pp. 53-90; e inoltre in questo volume la relazione di M. Boone. 
Nelle campagne, dominate dalla signoria rurale, la conflittualità tra signori e contadini era - lo ripeto - fenomeno permanente, anzi si manifestava con maggiore forza quando le comunità erano meglio organizzate. Nel corso del XIII secolo e all'inizio del XIV i conflitti di maggiore entità, relativi alla regione alpina e alle coste del mare del Nord, misero di fronte comunità contadine che avevano ottenuto ampi spazi di autonomia e che gestivano estesi beni comunali e alcuni principi territoriali che cercavano di estendere i loro poteri anche su comunità contadine libere e ben organizzate; la rivolta della Fiandra Marittima (1323-1328) vide in prima fila contadini della costa che avevano acquisito ampie libertà, avendo sottratto la terra alle acque $e^{44}$.

Naturalmente non sempre disagio dei ceti popolari urbani e disagio contadino andavano di pari passo. Basti pensare che per i consumi di prima necessità i cittadini si rivolgevano al mercato, i contadini in genere usufruivano dell'autoconsumo; ovvero i salariati e gli artigiani urbani erano più esposti alle oscillazioni dei prezzi. Ma per alcuni proprietari-contadini agiati la fiammata dei prezzi poteva portare vantaggi; al contrario potevano essere danneggiati da un ribasso eccessivo. La congiuntura quindi poteva avere effetti diversi non solo per le fasce sociali più basse della città e della campagna, ma anche all'interno dello stesso mondo contadino ${ }^{45}$.

Dopo la Peste Nera, inizierebbe la cosiddetta età dell'oro dell'artigianato ${ }^{46}$ grazie a salari nominali e a salari reali più alti, sensibilmente più alti, anche se non tali da trasformare radicalmente i livelli di vita dei ceti meno abbienti ${ }^{47}$. I contadini dipendenti e i salariati agricoli ottennero i primi clausole contrattuali più favorevoli, i secondi salari più alti ${ }^{48}$; comunque nelle campagne il quadro appare assai più articolato rispetto ai centri urbani dai forti connotati manifatturieri. Quanti - grandi proprietari e contadini agiati con molta terra a disposizione - traevano maggiori profitti dagli alti prezzi dei cereali della prima metà del XIV secolo, furono allora sicuramente svantaggiati; non così le famiglie contadine che si basavano esclusivamente o quasi sul lavoro familiare e sull'autoconsumo; ma nel

${ }^{44}$ Rösener, I contadini nel Medioevo cit., pp. 287-288, 292.

${ }^{45} \mathrm{Si}$ vedano le considerazioni di Neveux, Les révoltes paysannes cit., pp. 72-83.

${ }^{46}$ Così la definisce Abel, Crises agraires cit., p. 77; cfr. anche Cipolla, Storia economica cit., pp. 221-225.

${ }^{47}$ Cfr. sopra i rimandi alle note 20-24. Per l'entità di tali miglioramenti, in relazione a una realtà specifica, cfr. de La Roncière, Prix et salaires à Florence cit., pp. 443-450; Id., La condition des salariés cit., p. 24.

${ }^{48}$ Cfr. L. Feller, Paysans et seigneurs au Moyen Âge, VIII $-X V^{e}$ siècles, Armand Colin, Paris 2007, pp. 248-252; e in particolare per l'Italia, G. Pinto, Le campagne e la «crisi», in Storia della società italiana, 7, La crisi del sistema comunale, Teti, Milano 1982, pp. 121-156, alle pp. 149-150. 
complesso il livello di vita della popolazione rurale migliorò dopo la metà del Trecento. Un po' dappertutto invece entrò in crisi la piccola e media aristocrazia rurale, che vide diminuire le proprie entrate per l'abbandono delle terre seguito al calo demografico, per le condizioni migliori offerte ai contadini dipendenti per attirarli sulle terre rimaste libere, per la caduta dei prezzi dei cereali, per l'aumento dei salari dei lavoratori impiegati nelle riserve signorili. Spesso i signori cercarono di rivalersi sui contadini imponendo nuovi oneri personali o attraverso l'esercizio della giustizia, creando così ulteriori ragioni di conflitto ${ }^{49}$. Alla pressione signorile si aggiungeva la fiscalità regia e quella cittadina in forte aumento per le esigenze della guerra ${ }^{50}$.

Se il trend economico di lungo periodo non sembra giustificare fenomeni generali di ribellione, diverso è il discorso della congiuntura a breve, ovvero situazioni di malessere, di disagio economico che maturarono in un breve lasso di tempo e che costituirono talvolta il detonatore, questo sì, talvolta concause non trascurabili di alcuni dei tumulti e delle rivolte che contraddistinsero la seconda metà del XIV secolo e i primi decenni del XV.

Nell'episodio del Tumulto dei Ciompi il fattore congiunturale - che non è certo il più importante quando se ne cerchino le ragioni - fu rappresentato dal relativo peggioramento delle condizioni dei lavoratori della lana nei 3-4 anni che precedono il 1378: si sparse il timore di un ritorno a quelle durissime condizioni di vita che avevano connotato gli anni Quaranta e di cui i lavoratori più anziani mantenevano la memoria ${ }^{51}$. Ma naturalmente il Tumulto dei Ciompi, e quelli più o meno coevi che scoppiarono a Siena e a Perugia avevano motivazioni assai complesse ${ }^{52}$; né, in altri casi, situazioni di crisi di breve durata determinarono lo scoppio di rivolte o tumulti ${ }^{53}$.

Nel caso della rivolta inglese del 1381 i tentativi di controllare i salari, riportandoli verso il basso (sono le norme del 1349 riprese e ampliate nel 1351, nel cosiddetto Statuto dei lavoratori), e poi la poll-tax generalizzata, accentuarono il malcontento delle popolazioni rurali sino al punto di rottura $^{54}$; ma il programma dei rivoltosi prevedeva alla fine obiettivi di carattere assai più generale, di carattere radicale, si direbbe strutturale, quali l'affrancamento dei contadini, l'abolizione dello Statuto dei lavoratori, e poi

${ }^{49} \mathrm{Si}$ vedano le considerazioni di carattere generale di Duby, L'economia rurale cit., pp. 479-509; Rösener, I contadini nel Medioevo cit., pp. 301-313.

${ }^{50}$ Mollat - Wolff, Ongles bleus cit., pp. 107-108; Feller, Paysans et seigneurs cit., pp. 264-267.

${ }^{51}$ De La Roncière, La condition des salariés cit., pp. 33-35.

${ }^{52}$ Cfr. qui il saggio di F. Franceschi.

${ }^{53}$ Vedi le considerazioni di Neveux, Les révoltes paysannes cit., pp. 72-77.

${ }^{54}$ Mollat - Wolff, Ongles bleus cit., pp. 113-114; Feller, Paysans et seigneurs cit., pp. $252-253$. 
soprattutto l'esercizio dei diritti politici e la ripartizione tra $\mathrm{i}$ «comuni» dei diritti d'uso sui boschi e sui beni della Chiesa ${ }^{55}$.

Nel caso della Jacquerie si tende a sottolineare il peso delle devastazioni belliche e della fiscalità crescente, o percepita come tale, che avevano impoverito campagne che pure erano tra le più fertili della Francia, e accentuato il disagio delle popolazioni rurali. A ciò si aggiungeva il risentimento e l'esasperazione contro i signori che venivano meno ai loro compiti di difesa $^{56}$.

Infine altri due aspetti sono, a mio parere, da prendere in seria considerazione.

Non c'è dubbio che quanto si verifica negli anni immediatamente successivi alla Peste Nera e poi, con diversa incidenza, nei decenni seguenti, acuì i contrasti di classe - non ho problemi a usare questo termine, anche perché non ne trovo di più appropriati - tra datori di lavoro e lavoratori dipendenti, tra proprietari e contadini insediati sulla terra e salariati agricoli, creando una situazione di contrapposizione continua. Neppure per gli ultimi decenni del XIII secolo e per i primi del XIV mancano notizie di scontri su problemi di natura salariale, sulla durata della giornata di lavoro ecc. ${ }^{57}$, ma la conflittualità si accentua notevolmente dopo la metà del Trecento. Le testimonianze sono numerosissime: fonti narrative ${ }^{58}$ e soprattutto statuti e deliberazioni (il già ricordato Statuto dei lavoratori emanato in Inghilterra nel $1351^{59}$, le norme promulgate alle Cortes dal re Pietro I di Castiglia che fissavano minuziosamente i salari, categoria per categoria, prevedendo pene pecuniarie e corporali per gli inadempienti ${ }^{60}$,

${ }^{55}$ Mollat - Wollf, Ongles bleus cit., pp. 194-197; G. Cherubini, Movimenti e sommosse popolari del XIV secolo, in Accademia pugliese delle scienze, Atti e relazioni, XLVIII, 1991, pp. 41-59, alle pp. 51-53; ma si vedano soprattutto i classici lavori R. H. Hilton, Bond Men Made Free. Medieval Peasant Movements and the English Rising of 1381, Temple Smith, London 1973; The English Rising of 1381, R. H. Hilton and T. H. Aston ed., Cambridge University Press, Cambridge 1984; e inoltre qui il saggio di S. Cohn.

${ }^{56}$ Mollat - Wolff, Ongles bleus cit., pp. 116-131; e inoltre qui il saggio di M. Bourin.

${ }^{57}$ Come al solito le città fiamminghe sembrano anticipare tutte le altre (cfr., oltre alla relazione in questo volume di M. Boone, W. Prevenier, Conscience et perception de la condition sociale chez les gens du commun dans les anciens Pays-Bas des XIII et XIV ${ }^{e}$ siècles, in Le petit peuple dans l'Occident médiéval. Terminologies, perceptions, réalités, $\mathrm{P}$. Boglioni, R. Delort et C. Gauvard ed., Publications de la Sorbonne, Paris 2002, pp.175189), ma non mancano testimonianze anche per le città francesi (Mollat - Wolff, Ongles bleus cit., pp. 95-96) e per l'Italia centro-settentrionale: Rodolico, Il popolo minuto cit., pp. 28-45; G. Pinto, Il lavoro, la povertà, l'assistenza. Ricerche sulla società medievale, Viella, Roma 2008, pp. 48-51.

${ }^{58}$ Matteo Villani, Cronica, a cura di G. Porta, vol. I, Guanda, Parma 1995, I, 59, pp. 112-113; Marchionne di Coppo Stefani, Cronaca fiorentina, a cura di N. Rodolico. RIS ${ }^{2}$, t. XXX, parte I, p. 232.

${ }^{59}$ Mollat - Wolff, Ongles bleus cit., pp. 113-114. 
l'articolata normativa statutaria emanata dalle città italiane dopo la metà del XIV secolo ${ }^{61}$, ecc.). E poco importa se le autorità fossero in grado o meno di far rispettare tali norme. In quanto approvate, esse non potevano non essere un incentivo alla conflittualità e nel contempo spia di una conflittualità che stava aumentando.

Un altro aspetto, d'ordine psicologico, mi pare tutt'altro che secondario. Per spiegare la forte conflittualità della seconda metà del XIV secolo si deve tenere conto anche della 'inquietudine' dei tempi, delle grandi trasformazioni in corso che producevano appunto paura, insofferenza, irrequietezza, che trovavano spazio nella mentalità collettiva; insomma una particolare eccitabilità che rendeva immaginabile e possibile ciò che prima non lo era stato all'interno di canoni di comportamento legati alla tradizione $^{62}$.

Quindi se il contesto economico è uno, se non il primo, dei fattori di cui occorre tenere conto studiando rivolte e tumulti del XIV secolo, non si deve pretendere che esso da solo riesca a spiegare gli avvenimenti; soprattutto nelle rivolte urbane la complessità delle motivazioni risulta evidente $e^{63}$, e spesso esse attengono alla sfera delle relazioni sociali e della esclusione/partecipazione politica; è impossibile collocarle entro la camicia di forza di una chiave esplicativa unica. Allo stesso modo risulta chiaro come molte delle singole rivolte (urbane o rurali che siano) abbiano una loro specificità da inquadrare in un contesto ben preciso; solo un'analisi di tale contesto può aiutare a dare spiegazioni. Infine non c'è dubbio che le maggiori rivolte trecentesche non interessino città $o$ aree periferiche o arretrate; bensì le fertili campagne francesi e inglesi, e le grandi città della manifattura tessile fiamminghe e italiane. Anche questo è un elemento su cui riflettere.

${ }^{60}$ Ibidem, p. 115.

${ }^{61}$ La regolamentazione del lavoro salariato, presente anche nei testi precedenti, si infittisce nei corpi normativi successivi alla metà del XIV secolo; il caso più clamoroso - assai noto - è quello dello Statuto di Faenza dell'inizio del '400 (cfr. Pinto, Le campagne e la crisi cit., p.151).

${ }^{62}$ Rösener, I contadini nel Medioevo cit., p. 319, che cita i lavori di Frantisek Graus.

${ }^{63}$ Cfr. Comba, Rivolte e ribellioni cit., pp. 685-689. 

Jean-Claude Maire Vigueur

\section{LE RIVOLTE CITTADINE CONTRO I “TIRANNI”}

Basta riferirsi al titolo generale del nostro convegno e ricordarsi di quali sono i miei campi di ricerca per intuire che la mia relazione verterà esclusivamente sull'Italia del Trecento. Rivolte e tiranni, soprattutto quando sono messi in relazione l'uno con l'altro, sono invece due termini che richiedono qualche delucidazione.

Cosa si intendeva per tiranno nel Trecento italiano? La riposta è tutt'altro che univoca, per il semplice motivo che la nozione è stata oggetto di molteplici riflessioni da parte dei contemporanei, fossero intellettuali come i teologi, i giuristi, i letterati, i cronisti, o uomini d'azione come alcuni governanti delle città esposte alle mire espansionistiche o alle sopraffazioni di Signori e baroni: dalle loro elaborazioni viene fuori una grande diversità nei modi di concepire e definire la tirannia o tirannide, essendo del resto i due termini interscambiabili e non collegabili ad una determinata concezione della realtà tirannica. Anche due giuristi per tanti versi così vicini l'uno all'altro come potevano essere Bartolo da Sassoferrato e Baldo degli Ubaldi sviluppano due concezioni della tirannide piuttosto distanti tra loro: più politica quella di Bartolo, che stigmatizza la forma del governo e denuncia la sua illegittimità, più morale quella di Baldo che vede nella tirannide «un regime essenzialmente avverso al bene comune» ${ }^{1}$. Sta di fatto, però, che i due giuristi sono anche coloro che ci mettono sulle tracce del migliore criterio da adoperare per ridurre a due la molteplicità delle concezioni della tirannide in auge presso osservatori e attori della vita politica nel Trecento italiano. Il criterio, del tutto empirico, è quello che distingue tra la forma ed il contenuto o, se si preferisce, tra una concezione larga e una concezione stretta della tirannide. Rientrano nella prima categoria tutti coloro che hanno un comportamento tirannico, che ledono i diritti degli altri, e non solamente quindi coloro che si impadroniscono del potere in modo

${ }^{1}$ D. Quaglioni, Situazione e dottrine. Le elaborazioni dei giuristi, in Signorie in Umbria tra Medioevo e Rinascimento: l'esperienza dei Trinci, Perugia 1989, vol. 1, pp. 3853: p. 52. 
violento e arbitrario. La seconda include un numero più ristretto di persone, ovvero tutti quei Signori che esercitano un potere personale al di fuori o al di sopra delle istituzioni comunali, o che perlomeno hanno la capacità di influenzare, orientare, controllare in modo determinante il funzionamento delle istituzioni comunali. Dico subito che limiterò il mio intervento a questo secondo modo di intendere la tirannia e quindi alle sole Signorie cittadine, escludendo dal mio campo di visione comportamenti tirannici come quelli dei baroni romani, per due motivi molto semplici: da una parte per attenermi alle indicazioni degli organizzatori del convegno, dall'altra per non allargare a dismisura il campo della mia ricerca.

Anche se non sono il primo ad interrogarmi sul senso dell'altro termine, quello che figura nel titolo stesso del nostro convegno, credo sia utile dare qualche indicazione preliminare su cosa si può considerare o non considerare come rivolta nel caso specifico di un'azione indirizzata contro un tiranno. Tengo a ribadire, pur sapendo che altri l'hanno detto prima di me, che non possiamo accontentarci della definizione che ne danno i vocabolari più correnti, a cominciare da quello che ho sotto mano, il $D I S C^{2}$ che parla di «ribellione collettiva, anche violenta, contro il potere costituito». Si tratta infatti di una definizione troppo vaga o troppo stretta per applicarsi correttamente a tutte le realtà odierne (a partire da quanti partecipanti un'azione può essere definita come "collettiva»? Dove comincia e dove finisce la violenza? È violenza impedire alle forze dell'ordine di fare il proprio lavoro, entrare in una piazza, dentro una fabbrica, in un'università? E come la mettiamo con le rivolte non violente?) e che comporta margini di indeterminatezza molto più grandi ancora se la confrontiamo con le situazioni riscontrabili nel Medioevo. A ciò va aggiunto il fatto che il termine stesso non fa parte del linguaggio medievale. In italiano fa la sua prima apparizione con Guicciardini ai primi del XVI secolo ${ }^{3}$, mentre il Robert storico ${ }^{4}$ data dal 1500 circa le sue prime occorrenze in area francofona. Lo stesso vale per la maggior parte dei suoi odierni e molto approssimativi sinonimi, quali sedizione e insurrezione, con la sola eccezione di sommossa, termine usato insieme a sommozione da Villani ma con un altro senso. Troviamo invece nelle fonti italiane dell'epoca una copiosa serie di termini che hanno indubbiamente qualcosa a che vedere con la rivolta ma il cui significato è davvero troppo estensivo per servirci da guida in una riflessione sulle rivolte cittadine: $s i$ tratta di tumulto, di rumore (nell'espressione «correre a rumore»), di novità

${ }^{2}$ Dizionario Italiano Sabatini Coletti, Firenze 1997, p. 2286.

${ }^{3}$ S. Battaglia, Grande Dizionario della lingua italiana, vol. 16, Torino 1992, pp. 1077 1079.

${ }^{4}$ Dictionnaire historique de la langue française, sous la direction de Alain Rey, Paris 1998, vol. 3, p. 3237. 
(novitates in latino), di congiura, di cospirazione e di tutti i termini consimili quali leghe, sette, trattati, pratiche, ragionamenti, intelligenze, macchinazioni $^{5}$. Al pari di rivolta, tutti questi termini si riferiscono a forme di azione più o meno violente ma nelle quali mancano o rimangono comunque troppo indeterminate o le motivazioni politiche o la dimensione palesemente collettiva dell'atto di ribellione o di contestazione dell'autorità costituita.

Se lasciamo poi il registro dei problemi inerenti al lessico in vigore nelle fonti dell'epoca e ci spostiamo sul terreno delle idee e delle rappresentazioni nel tentativo di sapere come i contemporanei vedevano e concepivano le rivolte, non arriviamo a migliori risultati. Anzi ci si accorge ben presto della totale mancanza di una riflessione sistematica sulla rivolta: sia nella cronachistica che nella trattatistica la rivolta non è mai oggetto di discussione o teorizzazione, contrariamente a ciò che succede con altre forme di contestazione del potere costituito quali il tirannicidio o la congiura.

In definitiva né il lessico delle fonti né la riflessione dei contemporanei sulle forme della lotta politica in vigore nelle città o negli stati del loro tempo sono di grande aiuto per individuare le pratiche suscettibili di rientrare nella nozione di rivolta cittadina. Ė una nozione da costruire, da elaborare partendo dal significato attuale del termine e selezionando poi, tra le varie esperienze politiche delle città medievali, quelle che presentano maggiori analogie con le rivolte di oggi.

Comincerò tuttavia con un breve accenno a due pratiche politiche che solo marginalmente offrono qualche somiglianza con le rivolte cittadine. Si tratta in entrambi i casi di complotti o di congiure, nel senso proprio della parola - e quindi non di rivolte -, orditi contro il Signore o da persone a lui molto vicine come parenti e/o collaboratori più stretti, o da membri della fazione avversa. Complotti e congiure capaci però di rivestire almeno in parte l'aspetto di una rivolta cittadina in quanto i congiurati cercano e riescono a trascinare al loro seguito una parte della popolazione. Ed è un'evenienza che si verifica non di rado, forse, tuttavia, con maggiore frequenza nel secondo che nel primo caso.

Di complotti orditi nelle sfere più alte del potere signorile, nella ristrettissima cerchia dei personaggi che hanno direttamente accesso al principe, è piena la storia delle grandi e delle piccole Signorie cittadine del XIV e più

${ }^{5}$ Per l'utilizzazione di questi termini da parte di Machiavelli, cfr. E. Fasano Guarini, Congiure «contro alla patria» e congiure «contro al principe» nell'opera di Niccolò Machiavelli, in Complots et conjurations dans l'Europe moderne, Actes du colloque international organisé par l'Ecole française de Rome, l'Institut de recherches sur les civilisations de l'Occident moderne de l'Université de Paris-Sorbonne et le Dipartimento di storia moderna e contemporanea dell'Università degli studi di Pisa, Rome 30 septembre- 2 octobre 1993, sous la direction de Y.-M. Bercé et E. Fasano Guarini, Rome 1996, pp. 9-53: p. 28. 
ancora del XV secolo, a giusto titolo definito da Fubini come «l'età delle

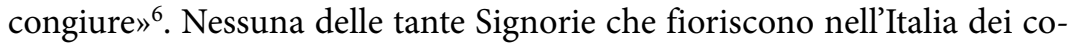
muni a partire dalla fine del XIII secolo appare al riparo da questo tipo di azione politica: né quelle che riescono ad estendere la loro autorità su una o più regioni, come dimostrano la storia dei Visconti e degli Sforza a Milano e quella dei Medici a Firenze, né quelle che a malapena e solo per brevi periodi riescono a superare le dimensioni dello stato cittadino, come la Signoria degli Scaligeri a Verona, dei Gonzaga a Mantova, degli Este a Ferrara, dei Carraresi a Padova, e neppure le ancora più piccole Signorie che pullulano nell'area romagnola e umbro-marchigiana. Anche se manca tuttora un censimento sistematico di questo tipo di complotti, non si corrono grossi rischi ad affermare che la maggior parte di essi nascono nella parentela stessa del Signore e sono il frutto del totale accaparramento del potere da parte del titolare della Signoria, del suo rifiuto di condividerne l'esercizio con fratelli o nipoti nonché, talvolta, delle condizioni nelle quali è avvenuta la successione «al trono» dopo la morte del precedente Signore. Gli autori di tali complotti mirano principalmente, se non esclusivamente, ad eliminare il titolare della Signoria per sostituirlo con uno di loro ma ciò non vuol dire che non abbiano talora bisogno di un sostegno popolare per raggiungere il loro fine. Anzi, ed è un punto che costituisce "per Machiavelli un nodo politico centrale ... ampiamente sottolineato dalla critica, tanto a proposito del Principe che dei Discorsi ${ }^{7}$, l'intervento del popolo appare spesso come un elemento determinante per l'esito del complotto, sia che ne assicuri il successo quando i promotori dell'impresa riescono a trascinarlo nelle strade della città, sia che ne provochi il fallimento quando preferisce schierarsi dalla parte del Signore e partecipa alla cattura se non addirittura al massacro degli autori del complotto. Detto questo, risulta il più delle volte molto difficile per lo storico, in presenza di situazioni concrete, valutare con un minimo di precisione il reale livello di partecipazione del popolo al complotto o alla difesa del Signore. Prendiamo come esempio la congiura di Fregnano Della Scala, figlio illegittimo di Mastino II ( $† 1351)$, contro il fratello Cangrande II nel febbraio 1354. Siamo di fronte ad una situazione di estrema banalità: quella di un figlio del precedente Signore che non accetta di essere relegato, dopo la morte del padre che lo preferiva a tutti gli altri figli (sette legittimi, cinque naturali), in una

${ }^{6}$ A dire il vero, l'articolo di Fubini dal cui titolo prendo in prestito l'espressione riguarda più precisamente l'età di Piero e di Lorenzo de' Medici: cfr. R. Fubini, L'età delle congiure: i rapporti tra Firenze e Milano dal tempo di Piero a quello di Lorenzo de' Medici, in Id., Italia quattrocentesca. Politica e diplomazia nell'età di Lorenzo il Magnifico, Milano 1994, pp. 220-252.

${ }^{7}$ Fasano Guarini, Congiure «contro alla patria» cit., p. 26. 
posizione di secondo ordine, e di un personaggio, per di più convinto di possedere doti intellettuali e militari superiori a quelle del fratello, scelto per succedere al padre solamente perché di nascita legittima. Dopo essersi assicurato la complicità dei Gonzaga, Fregnano approfittò di un momento delicato - la preparazione di una lega antiviscontea di cui faceva parte Verona - e dell'assenza di Cangrande, partito per Bolzano allo scopo di sollecitare l'aiuto militare del marchese di Brandeburgo suo cognato, per passare all'azione: con il falso pretesto della morte del Signore in un agguato tesogli dai signori di Castelbarco, convocò il popolo in assemblea, gli annunciò, oltre alla morte di Cangrande, l'imminenza di un attacco di Bernabò Visconti e ottenne di farsi nominare Signore della città insieme con i due fratelli legittimi di Cangrande, che non erano tuttavia in età di governare. Prese poi una serie di iniziative chiaramente volte a guadagnargli l'appoggio dei ceti popolari: scorrazzò per le vie della città gridando "'muoiano le gabelle" e fece ardere i registri delle condanne e li atti della corte» ${ }^{8}$, «aprì le porte delle carceri e promise al popolo un'elargizione» ${ }^{9}$. Con quale riscontro? Non disponiamo di testimonianze precise in proposito ma, a giudicare dalla resistenza incontrata da Cangrande quando, qualche giorno dopo, intraprese l'assedio della città con l'aiuto di truppe vicentine e padovane, Fregnano fu capace di trascinare al suo seguito almeno una parte della popolazione ${ }^{10}$. Non gli bastò, tuttavia, per respingere gli attacchi di Cangrande, capace anch'egli - e ritroviamo il problema cui accennavo prima - di mobilitare a suo favore una parte della popolazione di cui non siamo assolutamente in grado di precisare l'entità.

Lo stesso alone di incertezza avvolge le congiure ordite contro il Signore da membri della fazione avversa, almeno per quanto riguarda la partecipazione dei cittadini agli eventi che portano alla caduta della Signoria. Non riesco a capire, per esempio, perlomeno sulla base della bibliografia a mia disposizione, se la rivolta che nel giugno 1302 costrinse Matteo Visconti ad abbandonare il potere a profitto dei Torriani coinvolse i soli membri della fazione ostile ai Visconti o se i Torriani godettero in questa occasione del sostegno di frazioni della popolazione cittadina alle quali, sia detto en passant, non mancavano buoni motivi di preferire il ritorno al potere di una famiglia che aveva sempre cercato appoggi nel popolo piuttosto che

\footnotetext{
${ }^{8}$ M. Villani, Cronica, a cura di Giuseppe Porta, vol. I (Libri I-VI), Parma 1995, p. 450 .

${ }^{9}$ Della Scala, Fregnano, a cura di A. Menniti Ippolito, in Dizionario Biografico degli Italiani, vol. 37, Roma 1989, pp. 420-423: p. 421.

${ }^{10}$ Approfondita analisi degli aderenti alla congiura in G. M. Varanini, La classe dirigente veronese e la congiura di Fregnano Della Scala (1354), "Studi storici Luigi Simeoni», XXXIV, 1984, pp. 9-66.
} 
scendere in piazza a soccorso di un lignaggio che da più di un secolo si era messo alla testa di tutte le lotte per la difesa dei privilegi della nobiltà. È senza dubbio meglio accertata la partecipazione di ampi strati della popolazione, anzi del popolo, ai combattimenti che portarono, il 26 marzo 1308, alla cacciata di Giberto da Correggio, dal 1303 Signore di Parma ${ }^{11}$, ma ciò non toglie che il giorno precedente altri strati (o gli stessi?) della popolazione, e in particolar modo i beccai, il cui protagonismo in questo frangente non sfugge all'autore del Chronicon Parmense, si erano adoperati per fermare i disordini e riportare la pace tra le fazioni e che il 26 stesso, i molti de populo che all'ultimo momento si erano uniti ai Rossi e ai Lupi per dare la caccia a Giberto lo fecero urlando uno slogan, pax, pax, populus, populus, esattamente identico a quello gridato il giorno prima dai popolari che si interponevano tra le fazioni: il che ci fa pensare che perseguivano più il ristabilimento del regime di popolo che la sostituzione di una fazione con un'altra. In questo modo i popolari di Parma o perlomeno quelle frazioni della popolazione che il 26 marzo scelsero di dare mano ai Rossi e ai Lupi per cacciare Giberto da Correggio, non fecero altro che adottare una soluzione per certi versi analoga a quella usata dal popolo di Bologna quando, nel 1274, fu costretto a rinunciare alla sua neutralità ed a schierarsi, per motivi di natura sia interna che esterna, con i guelfi, costringendo un gran numero di Lambertazzi, ossia di ghibellini, ad abbandonare la città ${ }^{12}$. Con la differenza, di non poco conto, che il popolo di Bologna, lungi dal concedere qualche briciola di potere ai suoi nuovi alleati, accentuò ancor di più la sua egemonia all'interno del comune negli anni successivi alla cacciata dei Lambertazzi, mentre, il più delle volte, il sostegno fornito da forze popolari a congiure ordite dai membri di una fazione allo scopo di rovesciare una Signoria sostenuta dai membri dell'altra fazione si concluse per il popolo con un nulla di fatto, dal momento che il successo della congiura si traduceva nella semplice sostituzione del Signore e non nel ristabilimento di un regime fondato sulla supremazia del popolo. A Parma il successo dei Lupi e dei Rossi, di nuovo costretti ad abbandonare la città poco più di quattro mesi dopo il loro rientro, durò troppo poco per lasciare ai vincitori il tempo di ridefinire l'assetto istituzionale del loro potere ${ }^{13}$ ma tutto lascia

${ }^{11}$ Chronicon Parmense, in RIS ${ }^{2}$, IX, 9, a cura di G. Bonazzi, Città di Castello 1902, p. 105: «... et multi de populo civitatis adeserunt predictis dominis de Lupis et de Rubeis, et cum armis post ipsos veniebant una cum eis clamantes "pax, pax; populus, populus"».

${ }^{12} \mathrm{G}$. Milani, L'esclusione dal Comune. Conflitti e bandi politici a Bologna e in altre città italiane tra XII e XIV secolo, Roma 2003, pp. 206-207.

${ }^{13}$ Correggio, Giberto da, a cura di G. Montecchi, in Dizionario Biografico degli Italiani, vol. 29, Roma 1983, pp. 439-444: p. 441. 
pensare che avrebbe comunque assunto la forma di una Signoria, probabilmente di una Signoria collettiva. E poiché la maggior parte delle Signorie cittadine del XIII e XIV secolo affonda le proprie radici nelle lotte di fazione ed è la conseguenza quasi inevitabile del processo di bipolarizzazione dei sistemi di alleanza all'interno della nobiltà cittadina in quelle realtà comunali in cui il movimento di popolo non riesce ad imporre la propria egemonia nelle istituzioni, non c'è da stupirsi se la storia delle Signorie trecentesche è costellata da congiure ordite da membri della fazione rivale di quella del Signore volte non tanto a cambiare la natura del regime quanto ad assicurare la vittoria dei ghibellini sui guelfi o viceversa. Mi limiterò a due esempi che riguardano due città molto vicine l'una all'altra, Fabriano e Foligno.

A Foligno la dominazione dei Trinci sulla città risale all'inizio del XIV secolo ed è di indubbia matrice «faziosa»: è nel 1305 infatti che Nallo Trinci, capo della fazione guelfa, riesce ad impadronirsi del potere con l'aiuto militare delle due grandi città guelfe della regione, Spoleto e Perugia, e a cacciare dalla città il precedente Signore, un Anastasi, capo di una famiglia che dalla prima metà del XIII secolo disputava ai Trinci la leadership politica all'interno del comune e che dal 1264 deteneva il potere grazie all'appoggio dei ghibellini e dei popolari. Grazie a una serie di circostanze fortunate che eliminarono ogni motivo di dissapori tra gli eredi del Signore ogni qualvolta si poneva il problema della successione del Signore defunto, la Signoria dei Trinci non ebbe a patire congiure ordite da fratelli, nipoti o cugini esclusi dal potere. Ma più di settant'anni dopo il suo avvento, il 28 agosto 1377, fu rovesciata da una sommossa organizzata da membri della fazione ghibellina di Foligno, capeggiata ora dalla famiglia dei Brancaleone, subentrata nel la guida dei ghibellini agli Anastasi. Gli autori del colpo di stato avevano scelto il momento giusto per passare all'azione: il territorio intorno alla città era stato devastato dalle truppe della Lega della libertà, una coalizione di città ostili all'autorità pontificia alla quale Foligno era invece rimasta fedele, e la popolazione, stremata dalle privazioni, mugugnava contro il potere dei Trinci. Per questo motivo, oltre che per la più che probabile persistenza di forme di solidarietà verticale tra grandi lignaggi ghibellini e famiglie del popolo, i Brancaleone poterono contare sull'appoggio di una parte della popolazione di cui, tuttavia, non possiamo valutare la reale entità. E lo stesso vale per la sommossa che, meno di tre mesi dopo, il 6 dicembre 1377, riportò i Trinci al potere nella persona di Corrado Trinci, fratello del Signore che era stato trucidato dai rivoltosi del 28 agosto $^{14}$.

${ }^{14}$ G. Lazzaroni, I Trinci di Foligno dalla Signoria al vicariato apostolico, Bologna 1969, pp. 60-61. 
Molto più travagliata la dominazione dei Chiavelli a Fabriano. Non per problemi di successione, svoltasi ogni volta a favore del figlio maggiore $o$ di un nipote prescelto dal Signore senza subire contestazioni da parte degli altri eredi, ma per la fluidità del rapporto di forza tra le due fazioni che si contendevano il potere all'interno della città a partire dall'ultimo quarto del XIII secolo. Non solo le famiglie della nobiltà si dividevano in modo più o meno paritetico tra guelfi e ghibellini, con frequenti passaggi da una fazione all'altra, ma ognuna delle due fazioni poteva contare sull'appoggio di una robusta rete di alleanze tra i signori e i comuni della zona e per di più sembrava essere riuscita, a partire dagli anni 1320, a trascinare al suo seguito un consistente numero di popolari, anche se la maggioranza di essi pare scegliesse di preferenza il campo guelfo a quello ghibellino. Nell'aprile 1337, i Chiavelli tentarono di porre fine a questa situazione di instabilità organizzando, con cospicui aiuti esterni e complicità interne, un colpo di forza che portò all'uccisione di diciannove dei loro avversari e all'incarcerazione di un numero imprecisato di altre persone. Qualche mese dopo però i Chiavelli furono di nuovo cacciati dalla città e la Signoria di Alberghetto [II] venne sostituita da un regime di stampo popolare sostenuto dal partito filopontificio. Un nuovo colpo di forza riportò lo stesso Alberghetto al potere nel 1344, questa volta per un periodo di circa quindici anni. Segue poi una fase di estrema fluidità durante la quale i Chiavelli, ritirati il più delle volte nei loro castelli del territorio, riescono solo per brevi tratti a riprendere il controllo della città. Toccherà al successore di Alberghetto [II], morto nel 1376, ristabilire il dominio della famiglia sulla città: nel 1378, approfittando della ribellione di numerose città dell'Italia centrale contro l'autorità pontificia, suo figlio Guido si impadronì della città con truppe di varie origini e si fece poi attribuire dal comune il titolo di defensor communis et populi per vedere infine il suo potere legittimato dal papato al tempo di Bonifacio IX che, nel 1393, gli attribuì il titolo di vicario apostolico. Gli succedettero nel 1404 il figlio Chiavello e nel 1412 il nipote di costui, Tomasso. Tutti e due governarono la città in modo pacifico, cioè senza attuare misure repressive contro eventuali oppositori, e gli storici sono soliti mettere al loro attivo una serie di iniziative, in campo economico, religioso, artistico, che valsero loro un certo consenso da parte della popolazione. Nondimeno il 26 maggio 1435, giorno dell'Ascensione, la quasi totalità della famiglia fu sterminata nella chiesa di San Venanzio, dove assisteva alla messa solenne, da un gruppo di congiurati di probabile obbedienza guelfa ma di cui è impossibile dire se discendevano dai vecchi lignaggi rivali dei Chiavelli o se provenivano da altre frazioni della popolazione esasperate dai comportamenti del figlio del Signore, Battista, accusato dai contemporanei delle peggiori nefan- 
dezze $^{15}$. Una cosa tuttavia pare sicura: il numero dei congiurati non superava qualche decina di persone che miravano all'eliminazione fisica del Signore e dei suoi familiari, non a suscitare manifestazioni di piazza contro il regime signorile, anche se di fatto la strage portò a un ripristino delle vecchie istituzioni comunali. Questo è un tratto comune alla quasi totalità delle congiure quattrocentesche che, a differenza di quelle del Trecento, si caratterizzano anche per un profilo spiccatamente elitario dei loro promotori ed esecutori: non coinvolgono che un pugno di persone ma tutte di altissimo livello sociale, anche se, lo ripeto, nel caso di Fabriano non lo possiamo affermare con sicurezza. Possono dunque sussistere delle differenze nelle motivazioni dei congiurati, a seconda che siano animati dall'odio della parte avversa o da quello del parente che li ha esclusi dal potere, ma non nelle modalità di attuazione della congiura che si svolge ormai senza partecipazione della popolazione, contrariamente a ciò che succedeva molto spesso nel corso del Trecento. Alla congiura «di molti», così frequente nel Trecento, succede, come è stato giustamente osservato da E. Fasano Guarini, la congiura «di pochi» che si imporrà fino a tutto il Cinquecento come l'unico modello di congiura in grado di sconfiggere il potere arbitrario e assoluto del principe moderno ${ }^{16}$.

Ho finora ragionato partendo dall'idea che motivazioni e obiettivi delle congiure si distinguessero abbastanza radicalmente da quelli delle rivolte. Vedremo se l'esame delle rivolte al quale intendo ora dedicarmi confermerà o meno la bontà di questo postulato. Ciò che precede ci permette tuttavia di capire che tra congiure e rivolte esiste un elemento comune che rende talvolta difficile tracciare una netta linea di demarcazione tra queste due pratiche politiche. Non poche congiure infatti, soprattutto quando i loro promotori provengono dalle fila della fazione ostile a quella del Signore, cercano e spesso riescono ad ottenere la partecipazione ai loro piani di una frazione più o meno vasta della popolazione, se non addirittura del popolo nel senso sociopolitico della parola. Ė tuttavia fuor di dubbio che, a differenza di quanto succede nelle rivolte, il ruolo del popolo o di frazioni della popolazione rimane sempre secondario nello svolgimento delle congiure e ciò nel doppio senso della parola: gli elementi popolari non sono mai coinvolti dai promotori della congiura nella fase di ideazione

${ }^{15}$ Per gli eventi fino al 1344, cfr. V. Villani, Il protagonismo ghibellino e il ruolo dei Chiavelli a Fabriano e a Roccacontrada fra XIII e XIV secolo, in Il Trecento a Fabriano. Ambiente società istituzioni. Atti della giornata di studio - 16 giugno 2001, a cura di Giancarlo Castagnari, Fabriano 2002, pp. 167-231; per il periodo successivo, cfr. le voci Chiavelli, Alberghetto, Chiavelli, Chiavello, Chiavelli, Guido, Chiavelli, Tomassso, a cura di P. L. Falaschi, in Dizionario Biografico degli Italiani, vol. 24, Roma 1980, pp. 633-645.

${ }^{16}$ Fasano Guarini, Congiure «contro alla patria» cit., p. 41. 
e di preparazione della loro azione ed è piuttosto raro che il loro ruolo abbia un peso determinante sull'esito della congiura.

Procederò ora all'esame di una serie di rivolte che riguardano due città dell'Italia padana, Ferrara e Padova, e quattro dell'Italia centrale, Firenze, Pisa, Perugia e Viterbo. La scelta di Ferrara e di Padova non ha niente di casuale: tra tutte le Signorie medie/grandi dell'Italia padana, quelle degli Este a Ferrara e quella dei da Carrara a Padova sono le uniche ad aver dovuto affrontare movimenti rivoltosi di una certa gravità. Del tutto contingenti sono invece i motivi che mi hanno indotto ad introdurre le altre quattro città nel mio campionario. Sapendo che non avrei mai avuto il tempo necessario per procedere ad una ricognizione sistematica di tutte le rivolte riscontrabili nella storia delle grandi Signorie dell'Italia centrale nonché in quella delle numerose piccole Signorie dell'Italia centro-settentrionale, $\mathrm{mi}$ sono limitato a scegliere alcuni episodi da me già incontrati in occasione di precedenti ricerche oppure sui quali sapevo di poter disporre di lavori di qualità. Il mio campionario non ha quindi nessuna pretesa di sistematicità ed è perciò privo dei requisiti indispensabili per ogni tentativo serio di quantificazione e periodizzazione del fenomeno «rivolte». Credo, tuttavia, che sia possibile ricavarne conclusioni di portata più generale e suscettibili dunque di essere applicate anche ad episodi rimasti fuori dalla presente indagine, se si prende la precauzione di sottoporre ciascuno allo stesso protocollo investigativo. Il che vuol dire nella fattispecie creare le condizioni di un confronto sistematico tra gli episodi prescelti sulla base di quattro punti: 1) le modalità di preparazione e i promotori della rivolta; 2) le modalità di esecuzione della rivolta, con particolare attenzione al livello di partecipazione della popolazione; 3) le motivazioni, gli obiettivi e le rivendicazioni dei partecipanti alla rivolta; 4 ) le forme della violenza, in particolare di quella esercitata sulle persone sia nel corso stesso della rivolta che nella fase di repressione o di ritorsione/rappresaglie che segue la rivolta.

Comincio con la rivolta che negli ultimi giorni del luglio del 1343 portò alla cacciata di Gualtieri di Brienne, dal settembre dell'anno precedente titolare della Signoria a vita di Firenze e di tutte le città e territori sottoposti all'autorità del comune fiorentino. È uno degli episodi più famosi della storia di Firenze, oggetto nella cronaca di Giovanni Villani di un lunghissimo racconto che ne ha fortemente condizionato l'interpretazione da parte degli storici successivi, a cominciare dal Machiavelli che propone dell'episodio un racconto fin troppo coerente, privo di quelle piccole incertezze o approssimazioni che nella cronaca del Villani possono lasciar intendere ad un lettore attento che le cose, forse, non erano 
andate esattamente come l'autore vorrebbe far credere. Cosa dice il Villani di questa rivolta riguardo ai quattro quesiti che ci siamo appena posti?

La rivolta 0 , meglio, la ribellione ${ }^{17}$ contro il duca d'Atene scoppiò il sabato 26 luglio a mezzogiorno, dopo che il lavoro nelle botteghe era concluso. Iniziò sotto forma di una zuffa tra ribaldi del Mercato Vecchio, che furono incitati da membri delle famiglie Adimari, Medici e Donati a provocare scompiglio e a gridare "All'arme, all'arme». Era, pare di capire tra le righe, il segnale al quale tutti i cittadini «armati a cavallo e a piè» ${ }^{18}$ dovevano scendere in strada e occupare gli spazi pubblici. Villani accenna a più riprese $\mathrm{e}$ in vari modi all'ampiezza della partecipazione popolare alla rivolta, ampiezza da intendere sia in senso quantitativo ${ }^{19}$ che qualitativo $^{20}$. Non cerca tuttavia di nascondere lo stretto nesso che unisce la rivolta del sabato 26 a tre congiure che furono ordite nei giorni o nelle settimane precedenti da piccoli gruppi di individui chiamati per nome e cognome e nei quali non è difficile riconoscere, dopo Sestan ${ }^{21}$, personaggi che fanno tutti parte della ristrettissima élite dei magnati e della ricca borghesia d'affari, anche se i due ceti sono variabilmente rappresentati all'interno delle tre «sette» che complottarono contro il duca. Ciascuna delle tre congiure agisce per conto suo e non sa niente dell'esistenza delle altre ma tutte e tre sono così mal congegnate da scoraggiare i propri autori a passare all'azione. Quando una di esse viene scoperta e alcuni dei suoi autori sono arrestati, tutti gli altri congiurati prendono paura, scoprono l'esistenza delle altre congiure e decidono di unire le loro forze per organizzare la ribellione contro il duca. Tutto lascia dunque pensare, anche se Villani diversamente da Machiavelli ${ }^{22}$ non lo dice esplicitamente, che gli organizzatori della zuffa tra ribaldi, i cui nomi figurano tra i membri di due delle tre congiure da lui menzionate, avessero agito di comune accordo con l'insieme dei congiurati i quali vanno perciò considerati come i soli veri ispiratori e promotori della rivolta del 26 luglio 1343.

${ }^{17}$ G. Villani, Nuova Cronica, a cura di Giuseppe Porta, Parma 1991, XIII, 16, p. 330: «quasi tutti i cittadini di grande accordo insieme ... s'armarono per rubellarsi da llui».

${ }^{18}$ Ibidem, XIII, 17, p. 331.

${ }^{19}$ Ibidem, XIII, 17, pp. 330 e 333: «quasi tutti i cittadini», pp. 331-332: «tutti i cittadini».

${ }^{20}$ Ibidem, XIII, 17, p. 332: «grandi e popolani», p. 335: «il quale popolo fu molto amirabile a vedere, e possente, e unito».

${ }^{21}$ Brienne, Gualtieri di, a cura di E. Sestan, in Dizionario Biografico degli Italiani, vol. 14, Roma 1972, pp. 237-248: p. 245.

${ }^{22}$ N. Machiavelli, Istorie fiorentine, in Id., Opere, a cura di C. Vivanti, Torino 2005, vol. 3, p. 413. 
Anche se Villani insiste pesantemente, come ho già detto, sull'ampiezza della partecipazione popolare alla rivolta, il suo racconto contiene elementi che male combaciano con l'immagine di una popolazione unanimemente unita dall'odio contro il tiranno. D'altro canto, non può non colpire il fatto che le azioni più spettacolari o decisive per l'esito della rivolta siano da lui stesso messe all'attivo non di quella immensa folla che, a dir suo, avrebbe partecipato alla rivolta, bensì delle sole famiglie e gruppi che furono all'origine della sollevazione. Il duca infatti conservava dei partigiani che accorsero in suo soccorso in piazza della Signoria. Villani ne minimizza chiaramente il numero, citando solo alcuni dei magnati e dei ricchi uomini d'affari che per vari motivi si erano adoperati nel settembre del 1342 affinché la Signoria venisse conferita a vita, e non per un solo anno, a Gualtieri di Brienne. Le parole di cui fa uso subito dopo per designare i due unici mestieri («certi scardassieri e alcuno beccaio» ${ }^{23}$ ) che, secondo lui, sarebbero scesi in piazza per difendere il duca, rivelano in modo ancora più palese la sua volontà non solo di sminuire la popolarità del duca ma anche di gettare l'obbrobrio sulle basi sociali di un regime che, come testimoniano vari indizi sui quali tornerò tra poco, traeva la sua maggiore forza dall'appoggio del popolo minuto. C'è poi da interrogarsi sul ruolo realmente svolto dall'immensa folla di cittadini, costituita da più di $1000 \mathrm{ca}-$ valieri e 10000 piedoni, che, secondo Villani, avrebbe manifestato la sua ostilità al duca gridando "Viva il popolo e Comune in sua libertà, e muoia il duca e' suoi ${ }^{24}$. Non c'è dubbio che una presenza così massiccia di cittadini in armi in piazza della Signoria abbia soffocato nel duca ogni velleità di tentare un'uscita e di riprendersi il controllo della città. Resta il fatto che le azioni più violente della giornata del 26 , vere operazioni di commando che richiedevano un minimo di preparazione e di organizzazione, come l'assalto alle Stinche e al palazzo del podestà, furono compiute non dalla massa dei cittadini ma da pochi membri di quelle grandi famiglie - Donati, Cavicciuli, Pazzi ec. - che figurano tra i principali fautori delle congiure di cui si è detto prima ${ }^{25}$. Lo stesso si può dire per la decisione di chiudere piazza della Signoria e per le operazioni necessarie all'attuazione di un simile disegno che - sia detto en passant - non si capisce bene come abbia potuto consentire l'arrivo e la presenza sulla piazza di una grande folla di cittadini. Anche in quel caso, furono i membri di alcune grandi famiglie, $\mathrm{e}$ in particolare i Medici, i Rucellai e gli Altoviti, i cui nomi figurano tra i fautori di due delle tre congiure ordite contro il duca, a prendere questa

\footnotetext{
${ }^{23}$ Villani, Nuova Cronica cit., pp. 332-333.

${ }^{24}$ Ibidem, p. 335.

${ }^{25}$ Ibidem, pp. 333-334.
} 
decisione e a darsi da fare per «abarrare» le dodici strade che portano a piazza della Signoria ${ }^{26}$. È uno dei punti sui quali Machiavelli si distacca da Villani, offrendo dell'accaduto una versione meno contorta e più limpida e che consolida i miei sospetti sulle forzature operate dal Villani. Machiavelli non attribuisce infatti alle grandi famiglie, tra le quali i Cavicciuli hanno preso il posto degli Altoviti, la decisione di chiudere piazza della Signoria, bensì quella di invaderla in ordine di battaglia e di attaccare i partigiani del duca che vi erano raggruppati ${ }^{27}$. Tutto ciò m'induce a formulare tre considerazioni riguardo allo svolgimento delle operazioni che provocarono la caduta del duca di Atene: 1) la partecipazione alla rivolta dei «cittadini», come dice Villani - ed è più che probabile che il termine rimandi nella sua mente ai ceti medi della popolazione - è stata meno importante di quanto vuol far credere e non ha avuto comunque un peso determinante nell'esito dell'evento; 2) il popolo minuto è rimasto fuori della rivolta e se alcuni mestieri vi hanno preso parte è stato a difesa del duca; 3) decisivo invece è stato nelle diverse fasi della vicenda il ruolo di un certo numero di grandi famiglie, provenienti dalle fila dei magnati e da quelle dei grandi di popolo, le quali avranno senz'altro cercato di procacciarsi sostegni presso il resto della popolazione ma solo dopo il fallimento poco glorioso dei loro vari progetti di congiura.

A sentire Villani e Machiavelli, lo scontento suscitato dalla politica del duca di Atene e lo sdegno provocato dal suo comportamento e da quello del suo entourage erano così diffusi nell'insieme della popolazione che non c'era Fiorentino che non avesse buoni motivi per volersi liberare della sua dittatura. Senza procedere qui ad un esame dettagliato delle tante critiche mosse dai due autori contro la persona del Signore e il suo operato, cosa che richiederebbe troppo spazio, mi pare tuttavia utile osservare, ai fini del terzo quesito che mi sono posto, che Villani e Machiavelli non offrono esattamente la stessa visione della dittatura del duca di Atene o, meglio, che gli rivolgono critiche di natura diversa, ponendo ciascuno l'accento su certi aspetti piuttosto che su altri. Non ci possono essere dubbi sul fatto che per Machiavelli la grande colpa del duca di Atene sia stata di aver cambiato la natura del regime politico e di aver soffocato quelle libertà che facevano parte del patrimonio genetico dei Fiorentini, mentre Villani se la prende essenzialmente con la politica stessa del duca che, secondo lui, si svolgeva a tutto vantaggio di due categorie della popolazione, i magnati e il popolo minuto, per le quali sappiamo benissimo che nutriva una forte ostilità. Detto questo, anche Machiavelli sottolinea il carattere demagogico della

${ }^{26}$ Ibidem, p. 333.

${ }^{27}$ Machiavelli, Istorie fiorentine cit., pp. 413-414. 
politica di un tiranno che favorisce il popolo minuto allo scopo di ottenere il suo consenso e non mancano in Villani passi che accennano al desiderio dei «cittadini» (ecco di nuovo i ceti medi!) di «ricoverare la loro libertà e quella della republica del Comune» ${ }^{28}$. Chi dei due è più vicino alla realtà? È appena il caso di dire che non esistono testimonianze «obiettive» alle quali lo storico si possa appigliare per dare ragione all'uno piuttosto che all'altro, anche perché non tutti i partecipanti alla rivolta avevano le stesse ragioni di ribellarsi contro il duca. Molto significativo mi pare invece il fatto che il racconto del Villani lasci così poco spazio al desiderio di rovesciare un regime tirannico e dia tanto risalto a tutti i provvedimenti e comportamenti del duca suscettibili di provocare il rancore e l'ostilità nei suoi confronti se non di tutti i cittadini, visto che non può disconoscere le misure in favore del popolo minuto, perlomeno della stragrande maggioranza di loro. Sappiamo che all'epoca del Villani non esisteva ancora quella forte contrapposizione ideologica tra il regime della repubblica comunale e quello della Signoria cittadina che raggiungerà il suo culmine al momento del conflitto contro Giangaleazzo Visconti, anche se è vero che la caduta del duca di Atene fornirà ai Fiorentini una delle prime occasioni di prendere chiaramente coscienza dell'incompatibilità radicale dei due tipi di regime. Erede di una lunga tradizione di esaltazione delle libertà repubblicane, Machiavelli in prima persona capovolge il punto di vista di Villani e sceglie di mettere al primo posto della rivolta contro la dittatura del duca di Atene motivazioni di natura squisitamente politica, attribuendo ai contemporanei di Villani una percezione dell'antagonismo tra i due regimi che sicuramente non era allora così forte e nitida come Machiavelli immaginava più di un secolo e mezzo dopo. La sua versione dell'accaduto pecca insomma per anacronismo mentre quella del Villani è inficiata dalla sua palese, irrefrenabile repulsione nei confronti di una politica che lede gli interessi della sua classe e favorisce quelli delle parti più umili della popolazione. Occorre dunque dare ragione a Villani per quanto riguarda le motivazioni e gli obiettivi dei rivoltosi, che intendevano prima di tutto porre fine ad una politica lesiva dei loro interessi e solo in modo del tutto secondario ridare fiato al vecchio ordinamento repubblicano, ma senza prendere per buona la sua visione della politica attuata dal duca di Atene la quale, come è stato ampiamente dimostrato da studiosi come Becker e Brucker ${ }^{29}$, ub-

${ }^{28}$ Villani, Nuova Cronica cit., p. 334.

${ }^{29}$ M. B. Becker, Gualtieri di Brienne e l'uso delle dispense giudiziarie, "Archivio storico italiano», 113, 1955, pp. 245-250; Id., Gualtieri di Brienne e la regolamentazione dell'usura a Firenze, "Archivio storico italiano», 114, 1956, pp. 734-740; Id., La esecuzione della legislazione contro le pratiche monopolistiche delle arti fiorentine alla metà del quattordicesimo secolo, "Archivio storico italiano», 117, 1959, pp. 8-28; Id., Florence 
bidiva ad un disegno molto coerente, volto a restaurare l'autorità dello stato, a far prevalere gli interessi della collettività su quelli dei singoli e ad allargare le basi sociali del regime associando il popolo minuto allesercizio delle funzioni pubbliche.

Dopo più di una settimana passata senza poter uscire dal palazzo della Signoria, il duca ottenne dalle nuove autorità un salvacondotto che gli permise di lasciare la città insieme con tutta la sua gente. Parecchi dei suoi uomini d'armi erano stati ammazzati o feriti nei combattimenti di strada del 26 luglio, senza che ci fosse, a giudicare dal racconto di Villani, particolare accanimento nei loro confronti da parte dei Fiorentini in rivolta. Più crudele fu la sorte dei suoi collaboratori che ebbero la sfortuna di cadere nelle mani degli assedianti nei giorni che seguirono la caduta del duca: non sappiamo se vivi o morti furono comunque tagliati a pezzi, i loro cadaveri sottoposti a riti d'oltraggio e ci fu anche chi si cibò della loro carne $\mathrm{e}^{30}$. Tornerò più avanti sul significato di queste manifestazioni di violenza ritualizzata. Mi limito per il momento ad osservare che, oltre ai «fanciulli» ai quali vengono assegnati specifici compiti di oltraggio sui cadaveri, i principali autori di queste violenze sono i parenti delle persone che hanno subito condanne o torti da parte degli ufficiali giustiziati.

Dal 1288 al 1340, la storia di Pisa è costellata da episodi di governo signorile che si alternano con fasi di governo popolare, nel senso lato della parola, ma durante i quali gli organi collegiali del comune conservano l'essenziale delle loro prerogative e il personale politico non subisce profondi mutamenti. Le due prime Signorie, quella di Ugolino di Donoratico e di Nino Visconti nel 1288 e quella di Uguccione della Faggiola nel 1316, furono abbattute da rivolte che portarono nel primo caso a un ritorno al regime comunale e nel secondo all'arrivo al potere di un altro Signore, Gherardo di Donoratico. Anche la sollevazione del 1329 contro la Signoria di Ludovico di Baviera portò all'instaurarsi di una nuova Signoria, quella del figlio di Gherardo, Fazio Novello, che governò la città fino alla sua morte nel 1340. Dovette tuttavia affrontare nel 1335 una congiura che assunse le dimensioni di una vera rivolta anche se fallì. Una situazione più $o$ meno analoga si era già verificata a Pisa tredici anni prima, nel 1322, durante la Signoria di Ranieri di Donoratico (1320-1325), quando l'uccisione di alcuni membri di eminenti famiglie popolari provocò la violenta reazione di gran parte della popolazione che costrinse il signore ad allonta-

in transition. Volume one: the decline of the Commune, Baltimore 1967, pp. 123-143, M. B. Becker-G. A. Brucker, The Arti minori in Florentine Politics 1342-1378, «Medieval Studies», XVIII, 1956, pp. 93-104.

${ }^{30}$ Villani, Nuova Cronica cit., pp. 338-339; Machiavelli, Istorie fiorentine cit., p. 415. 
narsi dagli aristocratici e a riavvicinarsi ai ceti popolari sui quali si era fino ad allora appoggiato per governare.

La Signoria di Ranieri del resto non è stata l'unica ad avvalersi di un certo sostegno da parte del popolo o di una frazione di esso. Lo stesso infatti si può dire della Signoria precedente alla sua, quella del nipote Gherardo (1316-1320), e di quella, venuta dopo, di Fazio Novello (13291340). In questi due casi però, se non interpreto male le analisi del personale dirigente pisano contenute nel libro di Alma Poloni ${ }^{31}$, sono le famiglie mercantili del popolo grasso a costituire il principale appoggio di Gherardo e di Fazio Novello, mentre si può ipotizzare che sia stata proprio l'accentuazione in un senso sempre più signorile ed autoritario del suo governo ad aver spinto Ranieri a cercare «a destra», ossia presso i lignaggi della vecchia aristocrazia, un sostegno che il popolo, e prima di tutto il popolo grasso, era sempre più riluttante a dargli. Anche l'insurrezione che scoppiò, nel novembre del 1335, contro il governo di Fazio Novello, ebbe certamente a che vedere con il rafforzamento delle prerogative politiche del Signore. Ma, anche se è vero che i promotori della rivolta riuscirono a trascinare al loro seguito molti popolari nonché esponenti della nobiltà, non si trattava in realtà che di un piccolo gruppo di ricchi popolari esasperati dalla difficoltà di trovare maggiore spazio in un sistema politico monopolizzato dal Signore e dall'élite popolare che da una ventina di anni si dividevano pacificamente l'esercizio del potere. In un caso come nell'altro, i rivoltosi non ce l'avevano dunque con il regime della Signoria ma con le sue condizioni di funzionamento che tendevano a togliere o a rifiutare a frange della popolazione, che lo avevano sempre sostenuto, lo spazio al quale pensavano di aver diritto.

Non direi la stessa cosa dei motivi che portarono alla caduta della prime due Signorie pisane. Nel 1288 come nel 1316, questioni che, per semplificare, qualificherò di politica estera ebbero senz'altro un peso determinante nell'ostilità della popolazione nei confronti delle posizioni filoguelfe, così estranee alla tradizione cittadina, assunte dai primi due co-signori, Ugolino della Gherardesca e Nino Visconti, poi del ghibellinismo intransigente di Uguccione della Faggiola. Ma non c'è dubbio che, dietro al malcontento di certe parti della popolazione, ci furono anche motivi d'ordine interno legati alla natura del regime. $\mathrm{E}$ in particolar modo di quelle facoltose famiglie di mercanti che giocarono un ruolo non secondario nella rivolta del 1288 e furono tra gli organizzatori della rivolta del 1316 contro Uguccione. Nel suo libro, dal quale prendo in prestito la quasi totalità delle mie rifles-

${ }^{31}$ A. Poloni, Trasformazioni della società e mutamenti delle forme politiche in un Comune italiano: il Popolo a Pisa (1220-1330), Pisa 2004, pp. 275-338. 
sioni sulle Signorie pisane, A. Poloni traccia un ritratto molto suggestivo di uno di questi leaders popolari, Coscetto da Colle, che svolgerà un ruolo di primo piano nel governo della città accanto a Gherardo della Gherardesca negli anni successivi alla caduta di Uguccione ${ }^{32}$. Insiste in particolare sull'abilità politica di questo personaggio che funge da mediatore tra la frangia medio-alta della borghesia e le altre frazioni del popolo e riesce in questo modo a convogliare all'interno della coalizione antiuguccioniana ceti popolari piuttosto favorevoli al ghibellinismo di Uguccione. Non mi pare azzardato pensare che la borghesia che prese parte alla rivolta del 1288 abbia contato nei suoi ranghi personaggi della stessa stoffa o abbia perlomeno cercato di trascinare al suo seguito parte dei ceti inferiori. È comunque fuor di dubbio che in entrambi i casi la borghesia fu mossa dalla volontà di porre fine ad una forma di governo che non gli riconosceva il giusto spazio politico.

Ho finora concentrato l'attenzione sulle due principali componenti del popolo, la borghesia e i ceti inferiori, ed ho cercato di capire i motivi che li convinsero a partecipare o meno alle rivolte del 1288, 1316, 1322 e 1335, in modo da risponder al quesito $\mathrm{n}^{\circ} 3$. Per quanto riguarda le modalità concrete di svolgimento di queste insurrezioni, i dati forniti dalle cronache attestano la presenza attiva, tra i rivoltosi del 1288, 1316 e 1335, di elementi appartenenti a tre diverse categorie sociali, ossia la vecchia nobiltà cittadina, la borghesia d'affari o popolo grasso (termine non attestato nelle fonti pisane) e i gli strati medio-bassi del popolo, ma sono dati troppo esili o vaghi per permettere di valutare con una certa precisione il ruolo effettivamente svolto da ciascuna componente della popolazione nelle varie fasi dell' insurrezione e quindi di rispondere in modo soddisfacente al quesito $\mathrm{n}^{\circ} 2$, con la sola eccezione della sollevazione del 1322, che fu di matrice esclusivamente popolare, mentre non c'è dubbio, riguardo al quesito $\mathrm{n}^{\circ} 1$, che gli istigatori delle rivolte vadano individuati prevalentemente nella nobiltà (1286 e 1316) e in varie famiglie del popolo grasso $(1316,1329,1335)$, essendo la rivolta del 1322 di nuovo l'unica a scaturire da una reazione spontanea della popolazione contro la violenza dei nobili e il governo che la tollerava.

È troppo nota la fine inflitta ai vinti del 1288 dall'arcivescovo Ruggieri degli Ubaldini per aver bisogno di esser ricordata qui; vale tuttavia la pena osservare che se è altamente improbabile che Ugolino della Gherardesca si sia cibato dei figli, non è affatto escluso che le suggestioni cannibaliche del canto XXXII dell'Inferno (vv. 1-90) siano state ispirate a Dante dal racconto di atti di antropofagia a carattere più o meno rituale praticati nel corso di

${ }^{32}$ Ibidem, pp. 304-308. 
guerre tra fazioni. Non ho rilevato per le rivolte successive che un solo episodio di violenza fortemente connotato in senso rituale: il supplizio inflitto a Coscetto da Colle da Ranieri che lo fece «tranare, e tranando tagliato a pezzi, e gittato nell'Arno» ${ }^{33}$.

Le rivolte di cui parlerò ora, vale a dire le due rivolte ferraresi del 1385, quella padovana del 1388, quella perugina del 1375 e quella viterbese del 1387, hanno in comune il fatto di esplodere in momenti di grave disagio economico per le popolazioni sottoposte, nelle quattro città, alla dominazione di un governo tipicamente signorile. Il periodo è infatti segnato, in ognuno di questi centri, da una successione di guerre e di operazioni militari che provocano la rovina delle campagne e costringono i Signori ad aumentare la pressione fiscale su popolazioni cittadine già provate da difficoltà economiche di vario genere, ivi compresa, nel caso di Ferrara, una serie di catastrofi quali un incendio, un terremoto, inondazioni, carestie e pesti ${ }^{34}$. A ciò va aggiunto un fattore di natura politica, l'odio nei confronti di una dominazione sentita come straniera, che fu determinante nel caso della rivolta perugina del 1375 ma di cui troviamo traccia già all'inizio del secolo in tre rivolte che sconvolsero la città di Ferrara in meno di dieci anni. Mi soffermerò per cominciare su questi tre brevi episodi della storia di Ferrara degli anni 1308-1317 prima di passare all'esame dei più noti moti rivoluzionari dell'ultimo quarto del secolo.

Tutte le informazioni a nostra disposizione provengono dalla stessa fonte, il Chronicon Estense, il quale utilizza per designare coloro che parteciparono a queste rivolte espressioni che suggeriscono una forte partecipazione popolare: nell'agosto 1308 il cronista parla di multi cives et forenses e poi menziona la presenza massiccia tra gli insorti di situlares (fabbricanti di secchi) $)^{35}$; nell'ottobre dello stesso anno è l'intero populus che sembra insorgere contro il Signore pronto ad accettare una pesante tutela di Venezia sulla città pur di mantenersi al potere ${ }^{36}$, mentre attribuisce ad un generico Ferarienses la responsabilità dell' insurrezione che scoppiò il 4 agosto del 1317 contro i mercenari guasconi del vicario angioino incaricato di governare la città per conto della Santa Sede ${ }^{37}$. Detto questo, il cronista si affretta a precisare che tali Ferarienses erano in realtà tutti amici di Obizzo e di

${ }^{33}$ Ibidem, p. 315, n. 66.

${ }^{34}$ J. E. Law, Popular Unrest in Ferrara in 1385, in The Renaissance in Ferrara and its European Horizons, a cura di J. Salmons-W Moretti, Cardiff 1984, pp. 41-60.

${ }^{35}$ Chronicon Estense, in RIS $^{2}, \mathrm{XV}, 3$ (1-2), a cura di G. Bertoni e E. P. Vicini, Città di Castello-Bologna 1908 e 1937, vol. 1, p. 71.

${ }^{36}$ Ibidem, p. 72.

${ }^{37}$ Ibidem, p. 88. 
Rinaldo d'Este, i due membri della famiglia che aspiravano, nove anni dopo il passaggio di Ferrara sotto la dominazione pontificia, a ripristinare il potere degli Este sulla città: è dunque chiaramente la fazione filoestense a prendere quel giorno l'iniziativa di provocare l'insurrezione sapendo anche di poter contare sul sostegno più o meno attivo di buona parte della popolazione. I primi due ad essere citati dal cronista tra i capi della fazione filoestense sono del resto due Bocchimpani, membri di una famiglia alla quale apparteneva già il leader della rivolta dell'agosto 1308, quel Giovanni Bocchimpani che verrà decapitato dopo la sua cattura dagli uomini del Signore. La cronaca non contiene nessuna indicazione sugli eventuali istigatori o promotori delle due sollevazioni che condussero, nell'ottobre del 1308, all'abbandono della città da parte di Fresco d'Este e all'entrata delle truppe pontificie, ma sarebbe davvero strano che i sostenitori dei due Estensi rivali di Fresco non avessero approfittato di circostanze così favorevoli per tentare di portarli al potere. Ad ogni buon conto tale passaggio di testimone non si verificò, non solo perché uno dei due pretendenti, Francesco, rinunciò ai suoi diritti in favore del papato ma anche perché $i$ rivoltosi, o perlomeno parte di essi, avevano rivendicazioni e motivi di recriminazione che non combaciavano in toto con le mire dei sostenitori di Francesco e di Aldovrandino d'Este. Cerchiamo di capire quali potevano essere.

Il 1 febbraio 1308, Fresco d'Este, figlio illegittimo di Azzo [VIII] era subentrato al padre come signore di Ferrara contro la volontà dei due fratelli di Azzo, Francesco e Aldovrandino, che già in precedenza avevano contestato il diritto del loro fratello ad esercitare da solo i poteri di Signore di Ferrara ${ }^{38}$. Ora non c'è dubbio, se dobbiamo dare retta all'autore del Chronicon Estense ${ }^{39}$, che i promotori della rivolta dell'agosto 1308 fossero animati da una forte ostilità contro la persona del nuovo Signore, non solo del resto in quanto usurpatore di un potere che competeva ad altri membri della famiglia, come dice il cronista, ma anche a causa dei pericoli che la sua politica filoveneziana faceva incorrere all'autonomia della città. A ciò si aggiungevano nella mente degli insorti altri motivi che si riflettono nelle loro principali parole d'ordine (Moriantur traditores set vivat populus) e che lo stesso cronista esprime senza ambiguità: voluerunt disponere et privare dominum Frescum ... sue dominationis et civitatem reducere ad populum ${ }^{40}$. Comunque sia, gli insorti del mese di agosto furono sconfitti e non

${ }^{38}$ Este, Fresco (Francesco), a cura di P. Bertolini, in Dizionario Biografico degli Italiani, vol. 43, Roma 1993, pp. 349-359: p. 350.

${ }^{39}$ Chronicon Estense cit., p. 71.

${ }^{40}$ Ibidem, p. 71. 
raggiunsero dunque nessuno dei loro obiettivi. $\mathrm{Al}$ contrario la rivolta di ottobre portò alla cacciata di Fresco e al ristabilimento delle istituzioni comunali, il che corrispondeva sicuramente alle aspirazioni di una parte degli insorti, ma il cambio avvenne sotto la tutela di una dominazione «straniera», quella della Santa Sede, che dopo poco tempo sarebbe risultata alla popolazione non meno odiosa di quella dei Veneziani che si era cercato di evitare con la cacciata di Fresco. E di fatto, quando nove anni dopo scoppiò l'insurrezione che ristabilirà la Signoria degli Estensi sulla città, sembra che il popolo, e quindi non la sola nobiltà né la sola fazione filoestense, abbia partecipato «en masse» all'attacco della guarnigione guascone di cui non poteva non conoscere l'esito politico.

Almeno tre tipi di motivazioni diverse agirono dunque nella mente dei Ferraresi che per tre volte nei primi due decenni del XIV secolo si ribellarono contro il potere che reggeva la città: il desiderio di ritornare ad un ordinamento politico fondato sulla supremazia dei consigli e di magistrati scelti dal popolo, il cui ricordo non era stato cancellato da più di mezzo secolo di regime signorile sulla città, l'ostilità nei confronti di un Signore considerato come un usurpatore e più ancora la volontà di salvaguardare l'autonomia della città da ogni ingerenza straniera, fosse quella dei Veneziani o del potere pontificio. Ė appena il caso di dire che non c'era nessuna incompatibilità tra la prima e la terza di queste motivazioni, che potevano benissimo sommare i loro effetti nella mente degli insorti, ma non è neppure escluso che $\mathrm{i}$ «legittimisti», che contestarono il diritto di Fresco a succedere al padre deceduto all'inizio del 1308, abbiano visto nel ritorno agli ordinamenti comunali una soluzione del tutto accettabile e comunque preferibile al mantenimento di Fresco al potere. Viceversa, a giudicare dalla popolarità crescente degli Este nel corso degli anni 1310-1317, pare di capire che la popolazione si sia progressivamente resa conto che la migliore soluzione per liberarsi dalla tutela di un potere straniero come quello del papato fosse di riconsegnare alla famiglia il governo della città. Il che ci suggerisce, una volta di più, che a quell'altezza cronologica i cittadini vedevano in quei due regimi due forme di governo certamente diverse ma tra le quali si poteva scegliere in funzione di circostanze varie e senza che la scelta avesse qualcosa di definitivo o traumatizzante.

Non c'è molto da dire sulle violenze alle quali diedero luogo i moti rivoluzionari del 1308 e del 1317. Colpisce tuttavia il carattere contenuto delle violenze esercitate dagli insorti della prima rivolta se è vero, come dice il cronista, che rimisero in sella e lasciarono andare uno dei nobili venuti in soccorso di Fresco, caduto da cavallo, dicendogli che non avevano

${ }^{41}$ Ibidem, p. 71. 
motivi di offenderlo dal momento che egli non li aveva mai offesi ${ }^{41}$. Il Signore, dopo che i suoi sbirri ebbero domato la rivolta, non ebbe invece ritegno ed ordinò una serie di esecuzioni che si svolsero però secondo i riti abituali, quindi senza accanimento particolare contro i corpi o i cadaveri dei condannati: il leader, l'ho già detto, venne decapitato, gli altri furono impiccati dopo essere stati trascinati nelle vie della città ${ }^{42}$. Più crudele fu probabilmente la fine dei Gasconi che caddero nelle mani degli insorti del 1317 visto che, ci dice la solita cronaca, incontinenti dicti Gascones morti fuerunt omnes ad clamorem populi ${ }^{43}$.

Comincerò l'esame dei moti rivoluzionari di fine secolo con l'insurrezione che scoppiò il 3 maggio 1385 a Ferrara. Possediamo sull'accaduto due testimonianze molto particolareggiate, quella del Chronicon e quella di un documento veneziano, che concordano sull'essenziale e non lasciano molti dubbi sull'interpretazione da dare all'episodio. La popolazione, come già sappiamo, era stremata da una successione di catastrofi alle quali si aggiungeva il peso di una fiscalità che da una decina di anni non faceva che crescere. Ispiratore della politica fiscale, vicario e uomo forte della Signoria, allora tra le mani dei fratelli Niccolò [II] e Alberto [IV], era il giurisperito Tommaso da Tortona che nella primavera del 1385 diede fuoco alle polveri promulgando un estimo che prevedeva la tassazione dei beni mobili e colpiva fortemente gli interessi dei commercianti. Il 3 maggio una folla di circa 1000 persone, dice la cronaca, sine armis cum furore tamen, fa irruzione sulla piazza del duomo, sulla quale si affaccia il vecchio palazzo comunale, gridando Vivat dominus Marchio et moriatur proditor qui fuit et est causa tantarum importabilium gravitatum ${ }^{44}$. Il proditor, non c'è bisogno di dirlo, non è altro che Tommaso da Tortona il quale, per sfuggire al furore della popolazione, si precipita nella cancelleria degli Este situata al piano terra della Corte Vecchia, sempre su piazza del duomo, per trovarvi rifugio. Gli insorti non gli danno pace: irrompono nella cancelleria dopo aver sfasciato le porte, appiccano il fuoco ai registri ma non trovano Tommaso che nel frattempo era salito al piano superiore per mettersi sotto la protezione dei Signori. Secondo la fonte veneziana ${ }^{45}$, Niccolò avrebbe a questo punto tentato di calmare gli insorti rivolgendosi loro da una finestra del suo palazzo mentre, secondo il Chronicon Estense, sarebbe stato suo fratello Alberto a fare un simile tentativo, non senza far mostra di un certo coraggio visto che sarebbe sceso

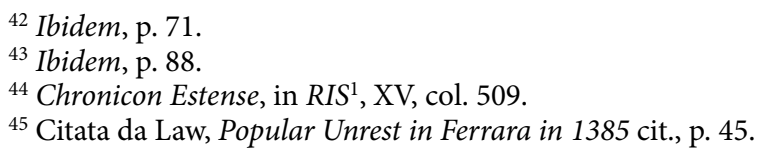


inermis sulla piazza e si sarebbe rivolto alla folla degli insorti ...multis ... blandis verbis ... ut eorum impetum et furorem mitigaret... ${ }^{46}$. Sempre secondo il Chronicon, Alberto avrebbe inoltre fatto consegnare alla folla i registri delle gabelle e degli estimi perché vi appiccasse il fuoco, il che fu subito fatto ma senza che ciò fosse sufficiente a placare il suo furore. Subito dopo infatti la folla prese di mira la casa del vicario dei Signori, situata a poca distanza dalla piazza, la mise a soqquadro e fece poi subire la stessa sorte alle case di altri ufficiali della Signoria, specialmente di quelli incaricati della percezione delle tasse. Verso sera, sempre in preda allo stesso furore contro i responsabili della politica fiscale, la folla tornò di nuovo sulla piazza del duomo e lì esigette da Niccolò che le fosse consegnato il proditor. Il Signore probabilmente esitò, poi, celebrato consilio, pro salubriori suo statu praedictum Dominum Thomasinum istius cladis autore praedictis popularibus in eorum manibus libere dari mandavit ${ }^{47}$. Avvenne allora ciò che era più che prevedibile: appena varcata la porta del palazzo, il vicario venne aggredito dai manifestanti che lo colpirono con ogni sorta di armi, spade, pugnali, bastoni, scure, sassi. Morto o semimorto fu attaccato a dei ganci e trascinato fino al grande rogo acceso sulla piazza, dove il suo cadavere fu messo a bruciare insieme con i registri delle tasse. Meno prevedibile fu forse il gesto di alcuni dei presenti i quali, prima che il cadavere fosse gettato sul rogo, ne estrassero il cuore e il fegato e se ne cibarono, poi canibus et avibus de ipsis interioribus ad manducandum proiecerunt; altri pezzi del cadavere finirono in punta ad aste portate in giro per le strade, altri furono esposti sulla banchina di uno dei porti della città $^{48}$. A notte fonda, appagato il furore della folla, ognuno tornò a casa sua e il silenzio, ci dice il cronista, si riversò sulla città.

Il Chronicon Estense prosegue datando a partire dal giorno successivo alla rivolta, il 4 maggio, l'avvio di colloqui tra cittadini e Signori che, secondo la fonte veneziana, sarebbero invece avvenuti subito dopo l'uccisione di Tommaso ${ }^{49}$. La divergenza sulla cronologia non modifica comunque in alcun modo il significato delle parole pronunciate dalle due parti. Le due testimonianze insistono infatti, e il Chronicon lo fa in un modo particolarmente pesante, sul desiderio del populus di dar garanzia al marchese Niccolò della propria assoluta fedeltà, pur ribadendo la necessità di procedere ad una profonda riforma del sistema delle tassazioni. Stando alle due fonti finora utilizzate, insomma, gli insorti del 3 maggio

\footnotetext{
${ }^{46}$ Chronicon Estense cit., col. 509.

${ }^{47}$ Ibidem, col. 510.

${ }^{48}$ Ibidem, col. 510.

${ }^{49}$ Law, Popular Unrest in Ferrara in 1385 cit., pp. 46-47.
} 
non intendevano assolutamente attentare al potere della Signoria e quanto era successo quel giorno era la reazione spontanea di una folla esasperata dall'ennesimo inasprimento della pressione fiscale. In realtà, e sono queste riflessioni che prendo in prestito dall'ottimo articolo di John $\mathrm{Law}^{50}$, abbiamo qualche motivo di pensare che la questione sia stata molto più seria di quanto ci voglia far credere il Chronicon Estense e che la Signoria degli Este sia stata, quel giorno, a due passi dall'essere travolta dall'insurrezione. Ce lo suggerisce prima di tutto la testimonianza di un cronista vicentino, Conforto da Costoza, la cui cronaca degli anni 1371-1387, di tipo annalistico, non brilla certo per la finezza o la profondità delle sue analisi politiche ma riproduce, senza troppo travisarle, notizie pervenute alle orecchie dell'autore. Innanzitutto Conforto fornisce indicazioni più precise delle altre fonti sul profilo sociale dei cittadini che inveiscono contro i responsabili dell'oppressione fiscale che li colpisce: sono persone del populus seu plebs minor, trascinate da un muratore e da un macellaio ${ }^{51}$. Quindi membri delle classi popolari la cui situazione doveva essere più disperata di quella dei ceti medio-alti e che, per questa ragione, sono forse disposti a commettere l'irrimediabile pur di ottenere soddisfazione. Di fatto il cronista riporta un grido degli assalitori rivolto ai due signori che la dice lunga sulla loro determinazione: Dates nobis $d$... huius civitatis destructorem, aliter furor hic super vos descenderet. I due signori furono risparmiati, lo sappiamo, ma secondo Conforto dopo aver dovuto accettare tutte le rivendicazioni della folla in materia di fiscalità, e per due mesi furono privati di ogni potere reale sulla città che rimase in balia degli insorti ${ }^{52}$.

Del resto, che una parte dei cittadini potesse rimettere in causa il potere stesso degli Este e anche la natura del regime in vigore a Ferrara è ampiamente dimostrato da una coniuratio civium $^{53}$ che fu scoperta pochi mesi dopo l'insurrezione del 3 maggio 1387. Nel settembre dello stesso anno, infatti, un notaio di Ferrara, Franceschinus de Montilino, rivela ai due marchesi l'esistenza di quemdam magnum tractatum ... ordinatum per ipsum Franceschinum et quosdam alios infrascriptos in civitate Ferrariae contra praedictos Dominos marchiones. Il piano prevedeva di far confluire a Ferrara di notte maximam multitudinem comitatinorum de districtu

${ }^{50}$ Ibidem, pp. 54-55.

${ }^{51}$ Conforto da Costoza, Frammenti di storia vicentina, in RIS ${ }^{2}$, XIII, 1, a cura di C. Steiner, Città di Castello 1915, p. 32.

52 Ibidem, p. 32.

${ }^{53}$ Coniuratio civium e populi tumultuatio sono le espressioni utilizzate da Giovanni da Ferrara, Ex Annalium Libris Marchionum Estensiorum Excerpta, in RIS ${ }^{2}$, XX, 2, a cura di L. Simeoni, Bologna 1936, p. 16, per designare il complotto del settembre 1385 e la rivolta popolare del 3 maggio dello stesso anno. 
Ferrariae poi, con la partecipazione di 700 cavalieri e di 600 pedoni, di correre civitatem proclamantes: Povelo, Povelo; e muora Dacii e Gabelle e li marchesi; et dictam civitatem ad regimen populare reducere intendebant, parte aliqua tamen ipsius civitatis derobata ${ }^{54}$. Il notaio traditore rivela $\mathrm{i}$ nomi di tredici dei congiurati, tra i quali figurano tre notai, un medico, un sarto e tre rigattieri; saranno poi decapitati su ordine dei marchesi due membri di uno dei più grandi lignaggi della nobiltà cittadina, quello dei Giocoli, i quali avevano promesso ai congiurati di far venire dal contado un certo numero di uomini armati. La congiura reclutava dunque i suoi aderenti in una gamma abbastanza larga di categorie sociali e, a differenza della populi tumultuatio del 3 maggio, mirava, senza nessuna ambiguità, ad un cambiamento radicale della forma di governo in vigore a Ferrara: i suoi autori non intendevano solamente porre fine all'oppressione fiscale ma abbattere il regime della Signoria e restaurare le istituzioni comunali di una volta. Furono puniti tutti con estrema severità dai Signori che, forse, dettero sfogo in questo modo al rancore accumulato dal mese di maggio contro coloro che avevano osato contestare la loro politica e il loro potere: la morte, per decapitazione e impiccagione, fu il castigo riservato alla maggior parte dei congiurati, alcuni dei quali furono inoltre trascinati fino al luogo del supplizio in groppa ad un asino.

Secondo una fonte veneziana ${ }^{55}$, l'insurrezione ferrarese del 3 maggio avrebbe fatto prendere coscienza al Signore di Padova, Francesco da Carrara il Vecchio, dei rischi che gli faceva correre la sua disastrosa politica di espansione territoriale, principale causa del malcontento della popolazione che, oltre a subire l'incremento costante della pressione fiscale, non ne poteva più delle esazioni e devastazioni commesse dalle truppe, fossero assoldate dal principe o dai suoi nemici. Apparentemente, l'avvertimento non sortì alcun effetto e Francesco il Giovane, in favore del quale il padre aveva abdicato il 28 giugno 1388, ereditò una situazione catastrofica. Per tre volte nel corso del mese di novembre dello stesso anno, i Padovani e la gente della campagna affluirono, «armata manu»e «con animo comoto di furore», sulla piazza davanti al palazzo del signore dove diedero sfogo alla loro esasperazione. Non solo «gridarono contra lo stato» ma proferirono anche minacce molto chiare all'indirizzo del Signore, dicendo per esempio che «colui ch'era colpevole e caxone di questi danni si vorebe lui e la sua progenie brusare» ${ }^{56}$. L'aspetto più strano tuttavia è che

${ }^{54}$ Chronicon Estense, in RIS ${ }^{1}, \mathrm{XV}$, col. 511.

${ }^{55}$ Citata da R. Cessi, Venezia e la preparazione della guerra friulana, «Memorie storiche foragiuliesi», X, 1914, pp. 414-473: p. 455.

${ }^{56}$ G. B. Gatari, Cronaca Carrarese, in RIS ${ }^{2}$, XVII, , a cura di A. Medin e G. Tolomei, Città di Castello 1909, p. 326. 
questa folla, così inferocita contro il Signore e la sua rovinosa politica, non solo non andò oltre lo stadio della violenza verbale ma, per di più, accettò, senza mugugnare, di ascoltare le parole rivoltele dal principe, una prima volta per bocca di un vecchio consigliere mandato a parlare con i manifestanti, la seconda e terza volta per bocca di Francesco stesso il quale, non senza un certo coraggio, scese in piazza per parlare direttamente con i suoi sudditi. Con un esito del tutto positivo se è vero che ogni volta i manifestanti si accontentarono delle parole del principe o del suo inviato e rientrarono nelle loro case senza commettere nessuna violenza. Detto questo, se la mossa del principe riuscì lì per lì a placare gli animi e ad evitare gesti irreparabili da parte della folla, non risolse nessuno dei problemi che rendevano la situazione insostenibile per il principe e i suoi sudditi e Francesco si trovò costretto nel giro di pochissimi giorni a cedere il potere a Giangaleazzo Visconti. Chi sa se l'avrà consolato l'idea che era comunque preferibile abbandonare il potere nelle mani di un nemico esterno piuttosto che esser cacciato o, peggio ancora, morire ammazzato dai propri sudditi!

Il fatto è che non mancano esempi di principi uccisi in condizioni che hanno ben poco da invidiare a quelle nelle quali - come abbiamo visto persero la vita personaggi come Simone da Norcia o Tommaso da Tortona. Mi limiterò qui a un solo esempio, quello del Prefetto Francesco di Vico, Signore di Viterbo da una dozzina di anni quando fu vittima, l'8 maggio 1387, di una rivolta scoppiata due giorni prima. I motivi della collera dei Viterbesi contro il loro Signore non si discostano da quelli che sono all'origine dei moti ferraresi o padovani degli anni 1385-1388: guerra e fiscalità sono le principali cause di un malcontento generale alle quali si aggiunge, in alcuni settori della popolazione, l'odio nei confronti di un Signore che personifica il trionfo della fazione nemica. La rivolta si svolse in due fasi. Il 6 maggio 1387 un primo assalto contro il palazzo del Signore fu respinto dai suoi fanti e dai suoi mercenari brettoni a cavallo. Il giorno successivo passò senza nessun segno di irrequietezza sicché il Signore, convinto di aver schiacciato la ribellione, mandò il giorno dopo i suoi Brettoni a perlustrare il territorio intorno alla città. Era il momento che i cittadini aspettavano per riprendere le armi. Con il rinforzo dei fuoriusciti rientrati in città, si precipitarono sulla piazza del comune dove da giorni erano accampati i fanti del Signore. Incoraggiati dal Prefetto, questi opposero una dura resistenza ma alla fine furono vinti e si diedero alla fuga. Come il Prefetto, del resto, che si rifugiò in una casa privata dove uno dei suoi nemici personali, Angelo di Palino Tignosi, lo raggiunse e lo trafisse con la spada. Il cadavere verrà poi trascinato sulla piazza del comune dove rimarrà a lungo esposto, con la bocca appoggiata alle natiche del proprio ca- 
vallo ucciso nella mischia. Era stato sufficiente meno di un giorno per far crollare la Signoria di Francesco di Vico ${ }^{57}$.

Fu molto più faticoso per i Perugini sconfiggere le truppe dell'abate di Monmaggiore, ossia del vicario pontificio che dal 1371 governava Perugia con mano di ferro. La prima preoccupazione dell'abate era stata di attuare un vasto programma di costruzioni militari volto a reprimere ogni tentativo di ribellione da parte della popolazione. I Perugini tuttavia non si lasciarono intimidire dall'impressionante fortezza di porta Sole, edificata nel punto più alto della città, né dall'ingegnoso sistema di passaggi coperti che permetteva all'abate e ai suoi uomini d'armi di circolare dal palazzo dei Priori alla fortezza senza correre il rischio di essere aggrediti. Esasperati dalla politica sempre più dura del vicario e dagli abusi commessi dai suoi familiari, incoraggiati dai successi ottenuti dagli avversari del papato nella guerra degli Otto Santi, i cittadini si riversarono in massa nelle strade della città per esigere la partenza dell'abate e la fine dell'odiata Signoria. La sollevazione ebbe luogo il 7 maggio 1375 e vide, se dobbiamo prestar fede alla cronaca cittadina detta del Graziani, la partecipazione unanime di una popolazione per una volta determinata a dimenticare le sue divisioni interne pur di arrivare ai suoi fini: «Del detto anno [1375] adi 7 del vittorioso mese di dicembre, per operazione e virtù divina, il santo populo di Perugia, un venerdì mattina, tutto in comune, piccoli e grandi, gentiluomini e popolari, avendo dimenticato ogni ingiuria e discordia, e ridotti tutti ad un volere, pace e concordia, baciando l'uno inimico l'altro, andarono in piazza, tutti concordemente gridando: Viva il populo e muoia l'abbate e li pastori della Chiesa! $»^{58}$. La folla invade la piazza del comune costringendo il capo della guarnigione, un nipote del cardinale Albornoz, a rinchiudersi con le sue guardie all'interno del palazzo dei Priori. In mancanza di viveri, gli assediati dopo un po' abbandonano il palazzo per rifugiarsi, seguendo la via dei passaggi coperti, nella ben più munita cittadella di porta Sole dove si sono raccolti tutti i mercenari al soldo dell'abate, all'incirca 1500 uomini. Inizia allora un assedio che durerà fino al 1 gennaio, e durante il quale i Perugini prenderanno tutte le disposizioni necessarie per isolare totalmente la fortezza dal resto della città e impedire ogni tipo di rifornimento e di aiuto agli assediati, oltre a sottoporli ad una pioggia continua di proiettili. Per ragioni diverse ma convergenti, nessuno dei due contendenti aveva interesse ad ottenere una vittoria totale sull'avversario e la moderazione finì per prevalere

${ }^{57}$ C. Pinzi, Storia della città di Viterbo, vol. 3, Viterbo 1899, pp. 420-428.

${ }^{58}$ E. Dupré-Theseider, La rivolta di Perugia nel 1375 contro l'abate di Monmaggiore ed $i$ suoi precedenti politici, "Bollettino della Società umbra di storia patria ", XXXV,1938, pp. 69-166: p. 119. 
nei due campi. Fu firmato un accordo, che garantiva l'incolumità di tutti gli assediati e consentiva loro di lasciare la fortezza portando via i propri bagagli. Così accadde, con pochissime sbavature da parte dei Perugini, grazie agli accorgimenti previsti dagli autori dell'accordo per evitare qualsiasi contatto tra la popolazione e gli occupanti della fortezza.

Ogni rivolta si differenzia dalle altre per una molteplicità di tratti specifici dovuti prima di tutto all'estrema diversità delle situazioni locali. Ciò non esime affatto lo storico dall'obbligo di mettere nella dovuta luce gli elementi e le tendenze comuni alla maggior parte di queste rivolte o perlomeno ad un significativo numero di esse. Ė quello che cercherò di fare ora, in sede di conclusione, seguendo l'ordine dei quesiti che hanno guidato la mia analisi di ciascuna delle rivolte prese in esame.

Sono davvero poche le rivolte che nascono come reazione spontanea delle «masse» o, se si preferisce, di ampie fasce della popolazione contro una situazione giudicata intollerabile, particolarmente dal punto di vista materiale. Situazioni di questo genere sono sicuramente riscontrabili nel corso del Trecento - penso in particolare alla rivolta ferrarese del 1385 e a quella padovana del 1388 - ma, nella maggior parte dei casi, si ha la certezza o il sospetto che l'iniziativa della rivolta sia partita da gruppi molto più ristretti di persone, per lo più provenienti dalle fila della nobiltà o del popolo grasso, i cui obiettivi non sempre coincidevano in toto con quelli della folla che riuscivano a trascinare dietro a loro. La rivolta fiorentina del 1343 contro il duca di Atene e le varie rivolte pisane della fine del Duecento e della prima metà del Trecento rientrano in pieno in questa categoria di rivolte nelle quali le masse sono manovrate e utilizzate da minoranze attive per fini che non corrispondono alle loro aspirazioni, ma non è affatto escluso che dietro alla rivolta perugina del 1375 e a quella viterbese del 1387 ci sia da vedere, nel primo caso, un piano dei ceti benestanti per ristabilire la loro egemonia sulla città e, nel secondo, la lunga mano di qualche grande lignaggio da sempre ostile ai di Vico in virtù di quelle inimicitiae che costituivano la sostanza dei rapporti tra lignaggi della nobiltà ${ }^{59}$. Rivolta e congiura offrono da questo punto di vista evidenti analogie anche se i promotori della rivolta, a differenza di ciò che si osserva nelle congiure, non provengono abitualmente dall'entourage più immediato del tiranno.

Discutibile e forse secondario nella fase di preparazione della rivolta, il ruolo delle masse è invece insostituibile e assolutamente determinante nella

${ }^{59}$ Sull'importanza delle inimicitiae tra famiglie della nobiltà cittadina, cfr. J.-C. Maire Vigueur, Cavalieri e cittadini. Guerra, conflitti e società nell'Italia comunale, Bologna 2004, pp. 398-406. 
fase più attiva delle operazioni, in altri termini quando si tratta di affrontare le forze armate del Signore e di sconfiggerle. Ciò non vuol dire che $\mathrm{i}$ gruppi e gli individui che hanno incitato le masse alla ribellione si tirino indietro al momento decisivo e non prendano parte ai combattimenti di strada. Anzi, gli esempi di esponenti della nobiltà e del popolo grasso che combattono con coraggio fino all'ultimo respiro o compiono prodezze non mancano, come quel Tignosi di Viterbo che non si arrese prima di aver stanato il Prefetto di Vico dal suo nascondiglio e di averlo ucciso con un colpo di spada. È chiaro però che i Signori del Trecento dispongono in generale di truppe costituite da mercenari agguerriti, disciplinati, abituati a combattere sia a piedi che a cavallo e contro i quali l'unica forza in grado di avere la meglio è quella di migliaia di persone fortemente motivate, animate da un odio incontenibile nei confronti del Signore o della sua politica. Non tutte le rivolte andarono a buon fine, lo sappiamo bene, ma tutte le rivolte di cui abbiamo parlato sono indubbiamente contrassegnate da una forte partecipazione popolare senza la quale del resto non si potrebbe, a rigore di termine, parlare di rivolta.

Tra la folla degli insorti e i piccoli gruppi che li spingono alla rivolta corre una differenza che non è solo di ordine sociale ma riguarda anche i motivi e gli obiettivi per i quali gli uni e gli altri decidono di entrare in ribellione contro la Signoria. Si tratta di un aspetto della questione sul quale le testimonianze a nostra disposizione, di natura prevalentemente cronachistica, sono sicuramente influenzate dalle opinioni personali dei loro autori e dai loro rapporti con la Signoria e dunque di un terreno sul quale lo storico deve avanzare con i piedi di piombo. Detto questo, non temo di espormi escludendo che nella maggior parte delle rivolte trecentesche il principale motivo degli insorti sia stato di cambiare la forma del regime e che il loro obiettivo fosse quindi di tornare ad un regime repubblicano giudicato intrinsecamente superiore a quello della Signoria. Motivi di matrice politico-ideologica non sono del tutto assenti, è vero, ma non sono, secondo me, riscontrabili che in alcuni segmenti della popolazione cittadina, prima di tutto in quelli tradizionalmente più coinvolti nella gestione della città comunale o culturalmente più sensibili ai richiami ideologici del repubblicanesimo: in altre parole presso le famiglie del popolo grasso e in alcuni gruppi professionali come i notai. Aggiungerei, a sostegno di questa mia interpretazione, il fatto che manca totalmente, fino ad una certa data, la percezione di una forte opposizione fra i due tipi di regimi, repubblicano e signorile: sono due possibilità, non così lontane tra di loro, tra le quali si può giocare, passando dall'una all'altra senza eccessivo trauma $\mathrm{e}$ senza che il passaggio sia percepito come qualcosa di irreversibile. Ma se non ce l'hanno il più delle volte con la forma del regime, quali sono allora 
i motivi che spingono gli insorti, e in particolare i ceti popolari - indispensabile forza d'urto di ogni rivolta - a sollevarsi contro il Signore? La risposta va cercata nella politica stessa del Signore, una politica che si caratterizza, nella maggior parte dei casi presi in esame (Ferrara, Padova, Perugia e Viterbo), dall'accrescimento costante della pressione fiscale, da una politica estera molto avventurosa, da una successione di guerre rovinose, dalla tolleranza del Signore nei confronti dei soprusi commessi dai suoi familiari e uomini d'armi e via dicendo. Ne consegue che lo studio delle rivolte non si può limitare all'unico problema, troppo astratto, della dialettica dei linguaggi politici, deve entrare nel concreto dell'operato svolto dal governo signorile e non aver paura di affrontare il problema degli indirizzi di classe della Signoria, esattamente come hanno fatto studiosi come Becker e Brucker a proposito della «dittatura» del duca di Atene, una dittatura tutto sommato piuttosto favorevole agli interessi delle classi subalterne che di fatto non hanno partecipato alla cacciata del duca, bensì hanno tentato in un primo momento di opporsi all'azione degli insorti.

Due brevi riflessioni per finire sulla questione delle violenze perpetrate dai protagonisti di ogni rivolta, la folla degli insorti da una parte, il Signore e i suoi uomini dall'altra. Come ho già detto, i Signori, che spesso sono o sono stati dei professionisti della guerra, non mancano il più delle volte di circondarsi di una forza militare costituita da mercenari agguerriti, estranei all'ambiente locale e dunque piuttosto indifferenti alla sorte dei cittadini contro i quali possono essere chiamati ad intervenire. L'esito di non poche rivolte, a Pisa, Firenze, Ferrara, Viterbo, Perugia, illustra nondimeno la fragilità intrinseca di questo tipo di forze militari di fronte a masse di manifestanti infinitamente più numerosi e animati da un «furore», come spesso dicono le fonti, che compensa la loro inevitabile inferiorità in materia di armamento, di esperienza e di conoscenza delle tecniche di combattimento. Riguardo poi alle violenze perpetrate non più nel corso ma all'indomani della rivolta, mi pare sussista, nel periodo preso in considerazione, una netta dissimmetria tra lo stile della repressione esercitata dal Signore quando le sue truppe sono riuscite a schiacciare la rivolta e la sorte riservata dai rivoltosi vittoriosi alle loro vittime. È vero che non mancano del tutto, da parte dei Signori, esempi di mutilazione o di altre pratiche infamanti compiute a danno delle vittime (Pisa 1322, Ferrara settembre 1385) ma si tratta in fin dei conti di casi isolati e le pene inflitte ai ribelli tengono conto in generale del loro livello di responsabilità e della loro condizione sociale e sono eseguite senza accanimento particolare sul corpo del sottoposto a supplizio. Niente da vedere con il trattamento riservato ad alcuni dei collaboratori del duca di Atene a Firenze, a Tommaso da Tortona a Ferrara o ancora a Francesco di Vico a 
Viterbo: lì si osservano gesti e comportamenti (messa a nudo, trascinamento, dilaniamento, dispersione dei pezzi, antropofagia) che assumono il significato di riti religiosi, come è del resto sottolineato dalla partecipazione di fanciulli, e di cui non saprei dire, allo stadio attuale delle mie conoscenze, se si ispirassero a forme anteriori di violenze tra fazioni o se fossero le prime manifestazioni di pratiche che si sarebbero moltiplicate nella fase successiva della storia delle Signorie ${ }^{60}$.

${ }^{60} \mathrm{R}$. Villard, Du bien commun au mal nécessaire : tyrannies, assassinats politiques et souveraineté en Italie, vers 1470-vers 1600, Thèse de doctorat, Université de Paris-IV, 2004, vol. 1, pp. 523-588. 


\section{POLITICHE GIUDIZIARIE E ORDINE PUBBLICO}

\section{Introduzione}

Se è possibile rilevare un elemento comune alle rivolte che animarono le città e le campagne dell'Europa negli ultimi secoli del medioevo - e assumo qui il termine "rivolta" nella sua più generica nozione operativa ${ }^{1}-$, un tratto cioè spesso presente, indipendentemente dalle caratteristiche dei movimenti di contestazione del potere, esso sembra consistere nelle repressioni che le contrastarono e che posero loro termine.

Qualche anno fa Giovanni Cherubini ne ha tracciato in modo sintetico quanto efficace la dinamica ricorrente ${ }^{2}$. Al "primo immediato successo di tutte le insurrezioni urbane o rurali" e alla "situazione critica in cui conseguentemente vengono a trovarsi sovrani e signori per un certo lasso di tempo" segue "puntuale [...], sull'onda della prima stanchezza dei rivoltosi", la repressione, che è "sempre violentissima, punteggiata di impiccagioni, decapitazioni o altre esecuzioni, tutte mirate, più che a punire, a spaventare le folle, onde riaffermare il controllo delle autorità e dei ceti dominanti". I tribunali "agiscono quasi sempre al di fuori di ogni garanzia legale, le sanzioni afflittive o pecuniarie colpiscono spesso più che gli individui interi gruppi secondo il principio della responsabilità collettiva. I beni dei condannati vengono confiscati. Nelle città italiane si moltiplicano le condanne all'esilio, che pur revocate a distanza di anni, non consentono a certi capi [...] di ritornare mai in patria”.

\footnotetext{
${ }^{1}$ Nella consapevolezza che essa è essenzialmente una costruzione storiografica: come è noto, il termine "rivolta" (e gli equivalenti nelle varie lingue) non si riscontra nelle fonti tardo medievali e la sua nozione non era stata elaborata dai contemporanei, come conferma l'assenza di una loro riflessione teorica. Aggiungo anche che prenderò qui in esame alcune "rivolte" appartenenti a contesti geografici e cronologici tra loro assai diversi, evitando di soffermarmi su casistiche particolari.

${ }^{2}$ G. Cherubini, Movimenti e sommosse popolari del XIV secolo, "Atti e relazioni dell'Accademia pugliese delle scienze», XLVIII, 1991, pp. 57-58. 
L'evidenza degli esiti repressivi delle rivolte è indubbia ${ }^{3}$. Ma tale evidenza ha finito anche con l'essere data quasi sempre per scontata nelle ricerche, al punto di trasformarsi in un luogo comune inesplorato ${ }^{4}$, in un indifferenziato meccanismo di reazione da parte delle autorità pubbliche e, pertanto, in un elemento di scarso interesse per gli storici. Quasi mai gli aspetti giudiziari sono stati oggetto di indagine, se non in qualche pagina all'interno di studi dedicati ad altri argomenti. In altri termini, non esiste letteratura in materia, e il tema appare tuttora sostanzialmente poco battuto, nonostante la messe di studi che sono stati dedicati e si continuano a dedicare alle rivolte del tardo medioevo ${ }^{5}$.

La spiegazione più ovvia di questo stato della ricerca mi sembra rinviare alle priorità che hanno caratterizzato da sempre il dibattito interpretativo sulle rivolte: la loro natura, le loro cause, i protagonisti sociali, il loro significato politico, e così via ${ }^{6}$. Questioni che sono state riprese e nuovamente discusse anche nel convegno di cui si pubblicano gli atti in questo volume ${ }^{7}$. Rispetto a esse, l'ambito dei problemi legati alla gestione dell'or-

${ }^{3}$ Cfr. i numerosi esempi rievocati anche da S.K. Cohn, Jr., Lust for liberty. The politics of social revolt in medieval Europe, 1200-1425, Cambridge (MA) 2006, pp. 147 sgg.

${ }^{4}$ Sempre Cohn, ivi, p. 152, ha calcolato che solo nel $30 \%$ circa del migliaio di "rivolte" da lui schedate (in un'accezione, peraltro, molto larga) le fonti indicano l'attivarsi della repressione.

${ }^{5}$ Pur scandagliando i principali repertori bibliografici non sono riuscito a individuare che una manciata di contributi specifici sugli aspetti giudiziari: A. Harding, The revolt against the justices, in The English rising of 1381, a cura di R. H. Hilton, T. H. Aston, Cambridge 1984, pp. 165-193 (e anche Id., The origins of the crime of conspiracy, «Transactions of the Royal Historical Society», 33, 1983, pp. 89-108); U. Andermann, Politische Justiz im Spätmittelalter. Neue Fragen zu niederdeutschen Stadtkonflikten, in Wirtschaft, Gesellschaft, Städte. Festschrift für Bernhard Kirchgässner zum 75. Geburtstag, a cura di H.-P. Becht, J. Schadt, Ubstadt-Weiher 1998, pp. 43-64 (che non sono riuscito a consultare); e ora H. E. Lacey, "Grace for the rebels": the role of the royal pardon in the peasants' revolt of 1381, "Journal of medieval history», 34, 2008, pp. 36-63.

${ }^{6} \mathrm{Mi}$ limito a ricordare come la storiografia si sia divisa tra un'interpretazione in termini di contestazione di classe, di "protesta popolare", e una visione che ne ha sottolineato viceversa la natura eversiva degli assetti di potere, di azione illegittima contro lo "stato". Della prima è una sintesi ricchissima la recente opera di Cohn, Lust for liberty cit.; della seconda sono mature espressioni le analisi di G. A. Brucker, The Ciompi revolution, in Florentine studies. Politics and society in the Renaissance Florence, a cura di N. Rubinstein, London, 1968, pp. 314-356; e M. Boone, M. R. Prak, Rulers, patricians and burghers. The great and the little traditions of urban revolt in the Low Countries, in A miracle mirrored. The Dutch Republic in European perspective, a cura di K. Davids, J. Lucassen, Cambridge 1995, pp. 99-134.

7 Rivolte urbane e rivolte contadine nell'Europa del Trecento. Un confronto, II Convegno internazionale di studi organizzato dal Centro di studi sulla civiltà comunale dell'Università degli studi di Firenze (Firenze, 30 marzo-1 aprile 2006), di cui segnalo anche il lucido resoconto di Patrick Lantschner in "Reti Medievali - Calendario", 2006, <http://www.dssg.unifi.it/rm-calendario/2006/Resoconti/Res-Rivolte_urbane.pdf>. 
dine pubblico e alle politiche giudiziarie è apparso sempre - e forse a buon diritto - di importanza minore.

Resta però un paradosso di fondo. Il nucleo documentario più importante per lo studio delle rivolte, accanto a quello cronachistico, è costituito proprio dagli atti giudiziari ${ }^{8}$ : dalle lettres de rémission dei sovrani francesi alle Friedebriefe delle città tedesche, dai registri processuali dei comuni italiani agli atti dei tribunali signorili. Queste fonti sono state utilizzate perlopiù come dei contenitori di informazioni e quasi mai analizzate di per sé stesse, come espressione, cioè, delle pratiche giudiziarie, delle strategie di conflitto, della negoziazione penale. Anche in quest'ambito, le fonti giudiziarie sembrano continuare a soffrire del sostanziale saccheggio informativo che le ha a lungo condizionate, fino a quando cioè, poco più di un terzo di secolo fa, esse hanno cominciato a essere oggetto di un'attenzione specifica da parte di studiosi che hanno contribuito a definire, come è noto, un campo di studio dedicato alla storia della giustizia e della criminalità.

\section{La contestazione della cattiva giustizia}

Si può forse dire qualcosa di più. L'interesse prevalentemente rivolto dagli studiosi a voler interpretare la maturità politica delle rivendicazioni dei rivoltosi ha curiosamente fatto cadere in secondo ordine, quando non del tutto, alcune evidenze documentarie. Mi riferisco, in particolare, a due momenti tra i più salienti delle rivolte fiorentina del 1378 e inglese del 1381.

Muoviamo dalla seconda. Sabato 15 giugno 1381, a Smithfield, a nord ovest di Londra, il re Riccardo II incontrò per la seconda volta (dopo il confronto del giorno prima a Mile End) i rivoltosi. In genere gli storici riferiscono due punti fondamentali delle richieste che il loro capo, Wat Tyler, rivolse al sovrano: l'abolizione della servitù e la spoliazione dei beni della chiesa ${ }^{9}$. Ma spesso essi tralasciano di ricordare che in realtà al primo punto delle richieste stava un'altra questione: quella della giustizia. Cito dalla fonte

Ringrazio Lantschner, che sta conducendo una promettente ricerca di dottorato su The politics of urban conflict in late medieval central Italy and northen France, c. 1350-1435: in search of a new paradigm, presso la University of Oxford, per le indicazioni, gli scambi e le sollecitazioni che mi ha generosamente fornito.

${ }^{8}$ Una riconsiderazione delle fonti per lo studio delle rivolte è ora quella, di approccio neo storicista, di S. Justice, Writing and rebellion. England in 1381, Berkeley 1994.

${ }^{9}$ Fondamentali sono gli studi di R. H. Hilton, Bond men made free. Medieval peasant movements and the English rising of 1381, London 1973; Id., Popular movements in England at the end of the fourteenth century, in Il tumulto dei Ciompi. Un momento di storia fiorentina ed europea, Firenze 1981, pp. 223-240; Id., Social concepts in the English rising of 1381, in Id., Class conflict and the crisis of feudalism. Essays in medieval social history, London 1985, pp. 142-153 e 240-241; Id., Ideology and social order in late medieval England, ivi, pp. 173-179 e 242-243. 
più autorevole, la Anonimalle Chronicle: "Then the King asked him what were the points which he wished to have revised, and he should have them freely, without contradiction, written out and sealed. Thereupon the said Walter rehearsed the points which were to be demanded; and he asked that there should be no law within the realm save the law of Winchester, and that from henceforth there should be no outlawry in any process of law, and that no lord should have lordship save civilly, and that there should be equality among all people save only the King, and that the goods of Holy Church should not remain in the hands of the religious, nor of parsons and vicars, and other churchmen"10. Solo in secondo luogo erano espresse le richieste di confisca e distribuzione dei beni della chiesa e, per ultima, la richiesta di abolizione del servaggio: la gerarchia espositiva era inequivocabile. Un'altra fonte, la Historia Anglicana di Thomas Walsingham, ci dice anche che Tyler "voluit namque, ante alia, commissione pro se et suis obtinuisse, ad decollandum omnes juridicos, escaetores, et universos, qui vel in lege docti fuere, vel cum jure, ratione officii, communicavere"11.

In altri termini, al primo posto delle richieste dei rivoltosi era la riforma della giustizia. Lo statute of Winchester di cui essi volevano la reintegrazione era quello concesso nel 1285 da Edoardo II, che conferiva al popolo il diritto di possedere le armi per organizzare l'autodifesa e l'ordine pubblico (keeping the peace) attraverso il sistema delle cosiddette "hundred", le strutture di base che erano tenute a denunciare ai giudici del re i crimini commessi nell'ambito della loro comunità. Quello che era successo nei successivi cento anni era stata l'erosione della giustizia regia da parte dei signori locali, corroborata da due leggi, lo statute of Northampton del 1328 e quello di Westminster del 1361, che avevano disposto misure contro coloro che si fossero ribellati alle leggi sul peace-keeping, e riconosciuto le giustizie amministrate dai grandi signori (i grantz), dalla gentry e dai borghesi ${ }^{12}$. Le richieste espresse da Wat Tyler chiedevano la reintegrazione

${ }^{10}$ The Anonimalle Chronicle, 1333 to 1381, a cura di V.H. Galbraith, Manchester 1927, p. 147: "Et le roy luy demanda quels furount les poyntes qil vodroit avoir et il les averoit volunters saunz contradictione escript et enseale. Et adonqes le dit Wat rehersa les poyntes queux furount a demander, et demanda qe nulle lay deveroit estre fors la lay de Wynchestre, et qe nulle ughtelarie serroit en nulle processe de laye fait de ore en avaunt, et qe nulle seignur ne averoit seignurie fors swelment estre proporcione entre toutz gentz, fors tansoulement la seignurie la roy; et qe les biens de seint esglise ne deveroient estre en mayns des gentz de religione, ne des parsons et vikeers". Il corsivo nel testo è mio.

11 Thomas de Walsingham, Historia Anglicana, a cura di H. Th. Riley, in Rerum Britannicarum medii aevi scriptores or chronicles and memorials of Great Britain and Ireland during the middle ages, 28/1,1, London 1863, p. 464. Il corsivo è sempre mio.

${ }^{12}$ Cfr. Harding, The revolt against the justices cit., pp. 165-168. 
dello status quo ante ("that there should be no law within the realm save the law of Winchester"): l'amnistia per coloro che si erano ribellati alla giustizie non regie ("and that from henceforth there should be no outlawry in any process of law"), la limitazione al solo ambito civilistico dei poteri giudiziari dei signori ("and that no lord should have lordship save civilly"), e una sostanziale uguaglianza di fronte alla legge del re ("and that there should be equality among all people save only the King"). Giustamente Alan Harding ha invitato a considerare la natura politica della rivolta inglese "in terms of the development of justice and policing over the previous hundred years" ${ }^{13}$. La rivolta inglese del 1381, cioè, non come semplice rivolta di contadini ma come un conflitto più complesso, che ebbe al centro lo scontento per l'amministrazione della giustizia e l'ostilità aperta nei confronti degli uomini di legge ${ }^{14}$.

A tale proposito non si possono non cogliere le similitudini con il fenomeno delle hermandades generales del regno di Castiglia, che si produsse proprio tra 1282 e 1325, nello stesso periodo degli statuti di Winchester e Northampton. Gli attori sono diversi: in Spagna sono i concejos delle città ad attuare le richieste, in Inghilterra è il re a formalizzare le leggi. Ma il contenuto è in larga misura lo stesso: l'esercizio della giustizia e la tutela dell'ordine. E l'avversario il medesimo: i poteri signorili, avvertiti come una minaccia dalle comunità (locali e per lo più rurali nel regno inglese, urbane in quello di Castiglia) e nei confronti dei quali l'unica garanzia appare quella della giustizia regia ${ }^{15}$. La questione del controllo della violenza e dell'equo esercizio della giustizia era dunque un aspetto centrale, se non primario, delle richieste politiche dei rivoltosi.

Da questa prospettiva, si può allora comprendere meglio anche la diffusa ostilità nei confronti degli operatori di giustizia, degli uomini di legge, degli strumenti e dei simboli del potere giudiziario che ritroviamo spesso nelle rivolte come un elemento comune ricorrente quasi quanto la loro repressione. A Bologna, per esempio, nel 1289 il "popolo senza brache" trascinò in piazza cercando poi di lapidarlo il podestà Antonio di Fissiraga, che si era inimicato molti artigiani ${ }^{16}$. A Perugia, invece, la sommossa degli artigiani del

${ }^{13}$ Ivi, p. 165.

${ }^{14}$ Il primo atto della rivolta era stata l'aggressione ai giudici regi (justices of the peace) nel villaggio di Brentwood nell'Essex, il 30 maggio 1381: cfr. Justice, Writing and rebellion cit., p. 1.

${ }^{15}$ Per un approfondimento sul caso castigliano rinvio al saggio di Hipolito Rafael Oliva in questo volume.

${ }^{16}$ Cfr. il collage delle cronache che raccontano l'episodio in Popular protest in late medieval Europe: Italy, France, and Flanders, a cura di S. K. Cohn, Jr., Manchester 2004, pp. 50-51. 
$1371 \mathrm{fu}$ rivolta immediatamente contro le case di alcuni giudici e notai particolarmente invisi ${ }^{17}$. A Firenze, tra le vittime del tumulto dei ciompi fu l'odiato bargello, ser Nuto da Città di Castello, linciato dalla folla inferocita per la voce che correva che nel palazzo dei priori "si trovonno di molti capresti, i quali havean comprati per impicchare i poveri, che havevano rubato" nei primi giorni di violenza ${ }^{18}$. E, d'altra parte, anche in periodi di ordinaria conflittualità, in una città apparentemente non turbata da sommovimenti politici come Venezia è stato calcolato che nel corso del Trecento ben il $37 \%$ delle aggressioni ebbe per vittime sbirri e forze dell'ordine ${ }^{19}$.

Ma restiamo ancora al giugno inglese del $1381^{20}$ : il giorno 2 vennero decapitati molti membri di una commissione giudiziaria (formata da baroni) dell'Essex; l'8 e il 9 numerosi castelli del Kent e dell'Essex furono distrutti, e gli archivi signorili bruciati; il 10 furono dati alle fiamme anche quelli della contea di Canterbury; tra la notte del 12 e la giornata del 13, a Londra, fu assalita la prigione di Marshalsea a Southwark, liberati i prigionieri e distrutte le case di molti giudici (jurors) e informatori giudiziari (questmongers); i rivoltosi si spostarono poi a distruggere la prigione di Fleet e quindi le stanze dei praticanti giudiziari (tenants) al Temple; fu poi data alle fiamme a Westminster la casa del vice sceriffo del Middlesex, sir John Butterwick; dalla prigione di Newgate furono liberati i prigionieri condannati (foriugez) sulla base dello statuto di Westminster del 1361; di fronte alla chiesa di St Martin-le-Grand fu decapitato Roger Legett, un giurista molto noto, giudice nelle assise (cisour) e informatore giudiziario (questmonger); la mattina del 14, mentre aveva luogo a Mile End il primo incontro tra il re e i rivoltosi, alla Torre furono uccisi, insieme con il cancelliere e il tesoriere del re, anche il serjeant-at-arms, il capo dei corpi di polizia londinesi, John Legge, e un altro juror; lo stesso giorno, fuori Londra, a Bury St Edmunds, fu riconosciuto, decapitato e messo alla

17 Cfr. V. I. Rutenburg, Popolo e movimenti popolari nell'Italia del '300 e '400, Bologna 1971, p. 120. L'autore sottolinea significativamente un'apparente contraddizione, ai suoi occhi di studioso marxista, nella strategia dei rivoltosi: essi "diressero le loro ire, prima di tutto, contro i diretti creatori delle leggi, i notai, trascurando spesso i propri padroni, che erano i responsabili principali dei loro mali", ivi, p. 151, nota 17. Nel tono pedagogico di questa posizione ideologica si può cogliere la radice di alcuni fraintendimenti della storiografia sociale sulle motivazioni che in alcune sommosse si rivelano essere essenzialmente antigiudiziarie.

${ }^{18}$ Cfr. C. Falletti-Fossati, Il tumulto dei Ciompi. Studio storico-sociale, Roma 1882, pp. 232-235, da cui anche la citazione della fonte.

${ }^{19}$ Cfr. G. Ruggiero, Patrizi e malfattori. La violenza a Venezia nel primo Rinascimento, Bologna 1982, pp. 289-294.

${ }^{20}$ Per un approfondimento degli avvenimenti, cfr. M. Mollat, Ph. Wolff, Ongles bleus, Jacques et Ciompi. Les révolutions populaires en Europe aux XIV et $X V^{e}$ siècles, Paris 1970, pp. 191 sgg.; e Harding, The revolt against the justices cit., pp. 179-180. 
gogna sir John Cavendish, il capo supremo (chief justice) del King's bench (il massimo tribunale criminale del regno), impopolare soprattutto perché ritenuto responsabile dell'applicazione del vessatorio "statuto dei lavoratori" delle contee del Suffolk e dell'Essex ${ }^{21}$; la mattina successiva, dall'abbazia di Westminster fu trascinato via per essere giustiziato a Cheapside anche sir Richard Imworth, maresciallo del King's bench, noto come un "torturatore senza pietà"; lo stesso giorno, a Smithfield, Tyler chiedeva appunto la formazione di una commissione "ad decollandum omnes juridicos, escaetores, universos, qui vel in lege docti fuere, vel cum jure, ratione officii, communicavere".

Questa sequenza impressionante di violenze dirette contro i rappresentanti della giustizia, in una sorta di vendetta sistematica da parte dei rivoltosi inglesi, richiama gli episodi di aggressione e attacco a giudici, notai, bargelli, carceri e palazzi di giustizia, che troviamo numerosi anche nelle cronache e nella documentazione per il regno di Francia e per le città italiane e fiamminghe. Nel caso inglese, però, sembra di poter cogliere lo scatenarsi di un'ostilità preordinata, maturata nel tempo, contro il ceto degli operatori giudiziari, più che l'erompere di un moto contingente. Le più tarde Chronicles di Raphael Holinshed, per esempio, attribuirono al predicatore inglese John Ball l'esortazione al popolo di "destroy first the great lords of the realm, and after, the judges and lawyers, and questmongers, and all other who have undertaken to be against the commons"22.

Non era la giustizia in sé a essere contestata, ma il suo abuso, il suo uso politico a sostegno di poteri avvertiti come vessatori: così anche la "cattiva giustizia" contro cui si scatenarono, per esempio, molte insurrezione nelle città tedesche - da Braunschweig nel 1293 a Erfurt nel 1309, a Speyer nel 1330 a Rottweil nel $1378-{ }^{23}$ o la rivolta contro il Duca d'Atene a Firenze nel 1343 , che fu accusato - si noti - dai magnati e dal "popolo grasso" anche per le numerose dispense giudiziarie viceversa accordate al "popolo minuto"24; nel 1425 a Tournai il doïen dei tessitori guidò i suoi compagni a uno sciopero e poi a un'insurrezione armata per protesta contro l'ennesimo caso di mala giustizia all'interno della corporazione ${ }^{25}$.

${ }^{21}$ Come sottolinea Ch.W. Oman, The great revolt of 1381, Oxford 1906, pp. 104-105.

${ }^{22}$ Holinshed's Chronicles, a cura di H. Ellis, London 1807, vol.2, p.749: “They might destroie first the great lords of the realme, and after the iudges and lawiers, questmoongers, and all other whom they undertooke to be against the commons".

${ }^{23} \mathrm{Cfr}$. il saggio di Pierre Monnet in questo volume.

${ }^{24}$ Cfr. M. B. Becker, Gualtieri di Brienne e l'uso delle dispense giudiziarie, «Archivio storico italiano», CXIII, 1955, pp. 245-251.

${ }^{25}$ Cfr. Chronique des Pays-Bas, de France, d'Angleterre et de Tournai, in Corpus chronicorum Flandriae, a cura di J.-J. de Smet, vol. III, Bruxelles 1856, pp. 391-394. 
Ad aiutare a comprendere meglio le implicazioni su questi temi concorrono le stesse rivendicazioni dei ciompi fiorentini. Anche in questo caso non può non colpire come quasi tutti i loro studiosi abbiano tralasciato di sottolineare come la petizione del "popolo minuto" sottoposta ai priori il 21 luglio 1378 si aprisse con richieste di carattere giudiziario ${ }^{26}$. Dei 26 punti di cui essa si compone, l'attenzione è in genere stata posta sulla rivendicazione di una propria rappresentanza corporativa e sulla riforma del sistema fiscale ${ }^{27}$. Eppure, nella gerarchia delle richieste vengono "in primis", come è nella lettera del documento, la richiesta della soppressione del tribunale dell'arte della lana, l'abrogazione della pena alla amputazione delle mani per i debitori, la proibizione di ogni arresto per debito per i successivi due anni, l'impunità per i responsabili degli incendi e dei saccheggi commessi nel corso dei moti delle settimane precedenti ${ }^{28}$. Il dato è tanto più significativo se si tiene conto che la stesura della petizione avvenne durante la notte precedente, in una concitata riunione in cui le richieste furono formulate nell'ordine stesso in cui venivano via via proposte: come ai rivoltosi inglesi anche a quelli fiorentini la cattiva giustizia apparve il primo obiettivo da colpire.

\section{La crisi del controllo sociale comunitario}

Gli esempi che abbiamo ripercorso inducono dunque a ripensare complessivamente la questione della giustizia nell'ambito delle rivolte tardo medievali. L'approccio più proficuo mi sembra essere quello che, in primo luogo, stemperi la discutibile nozione di rivolta nel clima più generale di diffusa conflittualità sociale e politica che caratterizzò nel complesso l'Occidente medievale tra la fine del secolo XIII e la metà del XV. Le profonde trasformazioni nelle pratiche e nelle rappresentazioni giudiziarie che si rilevano nel medesimo arco di tempo possono aiutare a mettere a fuoco alcune dinamiche che ridefinirono le relazioni di potere in molti contesti urbani e rurali. Dei molti aspetti relativi all'esercizio della giustizia e dell'ordine pubblico in quel lungo periodo, soffermerò in questa sede l'attenzione solo su alcuni, provando ad analizzarli sulla base di qualche esempio, non solo italiano, legato a situazioni di conflitto e di contestazione.

\footnotetext{
${ }^{26}$ Non così ora A. Stella, La révolte des Ciompi. Les hommes, les lieux, le travail, Paris 1993, pp. 62-63; e Franco Franceschi nel saggio in questo volume.

${ }^{27}$ Cfr., per esempio, N. Rodolico, I ciompi. Una pagina di storia del proletariato operaio [1945], Firenze 1971, pp. 119 sgg.; Rutenburg, Popolo e movimenti popolari cit., pp. 198 sgg.; e J. M. Najemy, "Audiant omnes artes". Corporate origins of the ciompi devolution, in Il tumulto dei Ciompi, cit., pp. 61 sgg.

${ }^{28}$ Il documento è edito in Falletti-Fossati, Il tumulto dei Ciompi cit., pp. 365-375.
} 
Un primo nucleo di questioni ruotò intorno alla trasformazione delle forme del controllo e dell'ordine pubblico. In molte aree si può infatti osservare tra XIII e XV secolo - in tempi e in modi diversi, ovviamente, a seconda dei contesti - un generale fenomeno di allentamento dei meccanismi di controllo sociale e di organizzazione dell'ordine centrati fino ad allora sull'attività delle comunità locali (vicinato, parrocchia, rione, villaggio, etc. $)^{29}$.

In Inghilterra, per esempio, il sistema che affidava alle hundreds (la citata organizzazione armata delle comunità riconosciuta con lo statuto di Winchester del 1285) la denuncia ai giudici regi dei crimini commessi al proprio interno, decadde nel corso del secolo XIV ${ }^{30}$. Lì come altrove, la crisi dei meccanismi di controllo attivi a livello vicinale, di face to face societies dove ogni membro era conosciuto e osservato, accompagnò la transizione verso assetti caratterizzati da apparati più centralizzati.

La stessa tendenza è rilevabile anche nelle città comunali italiane. A Venezia, per esempio, i "capi contrada" che sin dal XIII secolo, oltre ad altri compiti di natura amministrativa (ripartizione della fiscalità, selezione militare, etc.), erano tenuti a sorvegliare taverne e forestieri ${ }^{31}$, furono esautorati da tali competenze nel 1319 quando furono creati i "capi sestiere", nominati dal Maggior consiglio e dipendenti direttamente dal consiglio dei Dieci, che dovevano registrare i nomi degli stranieri presenti in città, espellere le persone sospette, sorvegliare alberghi e taverne.

Anche in altre città il controllo sociale si era venuto organizzando inizialmente intorno a rappresentanti attivi a livello vicinale o parrocchiale, che troviamo indicati con varie denominazioni: a Bologna, Imola e Forlì, per esempio, erano chiamati "ministeriales", a Milano e a Bergamo "an-

${ }^{29}$ È un fenomeno ormai noto agli studiosi di storia della giustizia e dell'ordine pubblico: per primi a metterlo in evidenza sono stati B. Lenman, G. Parker, The state, the community and the criminal law in early modern Europe, in Crime and the law. The social history of crime in western Europe since 1500, a cura di V. A. C. Gatrell, B. Lenman, G. Parker, London 1980, pp. 11-48. Acute osservazioni anche in M. Sbriccoli, Giustizia negoziata, giustizia egemonica. Riflessioni su una nuova fase degli studi di storia della giustizia criminale, in Criminalità e giustizia in Germania e in Italia. Pratiche giudiziarie e linguaggi giuridici tra tardo medioevo ed età moderna, a cura di M. Bellabarba, G. Schwerhoff, A. Zorzi, Bologna 2001, pp. 345-364; e X. Rousseaux, Construction et stratégies: le crime et justice entre production politique et ressources communautaires. Quelques réflexions sur l'histoire du crime et de la justice en Europe médiévale et moderne, ivi, pp. 327-343.

${ }^{30}$ Cfr. J. G. Bellamy, Crime and public order in England in the later middle ages, London 1973, pp. 90-91.

${ }^{31}$ E. Crouzet-Pavan, "Sopra le acque salse". Espaces, pouvoir et société à Venise à la fin du moyen âge, Roma 1992, pp. 267-285. 
ziani", a Siena "sindaci", a Padova, Pistoia e Firenze "cappellani"32. L'organizzazione comunitaria di cui questi ufficiali erano vitale espressione era inquadrata nell'ordinamento comunale, sin dall'obbligo di denuncia dei crimini. Questo assetto entrò in crisi nel corso del Trecento. Per esempio, a Bergamo ${ }^{33}$, ma anche a Milano, dove verso la fine del XIV secolo gli anziani delle parrocchie erano crescentemente accusati di non notificare più i crimini commessi nella propria circoscrizione ${ }^{34}$.

Personalmente ho potuto rilevare come a Firenze l'attività dei cappellani dei popoli (vale a dire delle parrocchie) si contrasse e si esaurì nei decenni centrali del XIV secolo ${ }^{35}$. Questi organi avevano rappresentato la base sociale dell'azione giudiziaria delle corti del podestà: i cappellani erano infatti tenuti alla denuncia obbligatoria dei crimini compiuti nella propria parrocchia, che aveva rappresentato la principale fonte di informazione per l'attività inquirente dei tribunali comunali. Attraverso questa rete distesa capillarmente nel tessuto sociale erano infatti passate la maggior parte delle denunce dei reati commessi in città e nel contado. Ancora negli anni 13431345 , circa la metà delle sentenze emanate dal podestà erano avviate in base alle denunce dei cappellani parrocchiali. Ma dopo la peste del 1348, la percentuale era già scesa a 1/4 del totale; nel 1368 essa toccava appena l'11\%, per poi scomparire entro l'inizio del secolo $\mathrm{XV}^{36}$. Il declino della partecipazione comunitaria al controllo sociale è testimoniata anche dall'infittirsi, nella seconda metà del Trecento, delle condanne inflitte a intere comunità per non aver assolto all'obbligo collettivo di inseguimento e cattura dei malfattori, o, per quelle rurali, per aver dato ricetto a publici et famosi latrones ${ }^{37}$.

${ }^{32}$ Cfr. G. Masi, Il popolo a Firenze alla fine del Dugento, «Archivio giuridico», XCIX, 1928, pp. 176-178.

${ }^{33}$ Cfr. C. Storti Storchi, Diritto e istituzioni a Bergamo dal comune alla signoria, Milano 1984, pp. 112 sgg. e 151 sgg.; e G. Caminiti, Problemi di difesa e sicurezza interna a Bergamo alla fine del Duecento, «Nuova rivista storica», 80, 1996, pp. 149-178.

${ }^{34} \mathrm{Cfr}$. E. Verga, Le sentenze criminali dei podestà milanesi, 1385-1429, «Archivio storico lombardo», XXVIII, 1901, p. 107.

${ }^{35} \mathrm{Cfr}$. A. Zorzi, Contrôle social, ordre public et répression judiciaire à Florence à l'époque communale: éléments et problèmes, «Annales E.S.C.», XLV, 1990, pp. 1169-1174. I cappellani dei popoli variavano nel numero, tra uno e quattro, per ogni parrocchia (tra XIV e XV secolo le parrocchie, intese come ripartizioni topografiche e universitates sociali e istituzionali oscillarono tra 56 e 65).

${ }^{36} \mathrm{Nel}$ contado l'attività di denuncia giudiziaria dei rettori dei popoli si mantenne più a lungo rispetto a quella dei cappellani cittadini, coprendo ancora nel 1400-1401 il $36 \%$ delle sentenze del podestà fiorentino, il $7 \%$ nel 1433-1435, per poi scomparire anch'essa nel pieno XV secolo: Zorzi, Contrôle social cit., p. 1173.

${ }^{37}$ Cfr. S. K. Cohn, Jr., The laboring classes in Renaissance Florence, London 1980, p. 199; e H. Manikowska, "Accorr'uomo". Il "popolo" nell'amministrazione della giustizia a Firenze durante il XIV secolo, «Ricerche storiche», XVIII, 1988, pp. 533-535. 
Tra le cause, due furono perlomeno preminenti: da un lato, i vuoti demografici provocati dalle ricorrenti crisi epidemiche che, sconvolgendo le strutture residenziali ed allentando i legami di socialità vicinale, scompaginarono gli organi di rappresentanza parrocchiale e le basi stesse del loro modo di operare; dall'altro, certamente anche la volontà dei nuovi regimi, in particolare dopo la repressione del tumulto dei ciompi, di evitare la ricostituzione di forme di organizzazione sociale potenzialmente antagoniste ${ }^{38}$.

\section{La trasformazione delle forze dell'ordine}

La crisi delle strutture comunitarie di controllo sociale si accompagnò a un analogo fenomeno di progressiva esautorazione delle milizie che assicuravano l'ordine al medesimo livello. La transizione più generale era quella verso la creazione di veri e propri corpi di "polizia", di cui assumo la nozione anche in questo caso in termini meramente operativi ${ }^{39}$.

Abbiamo visto come i rivoltosi inglesi chiesero nel 1381 la reintegrazione delle funzioni affidate sin dalla fine del XIII secolo alle hundreds, le compagnie armate di base in cui dovevano prestare servizio tutti gli uomini compresi tra i 15 e i 60 anni $^{40}$. Il caso delle città italiane consente di cogliere un aspetto ulteriore delle trasformazioni in corso nel Trecento, vale a dire il vero e proprio superamento del nesso tra strutture sociali e loro rappresentanza istituzionale ${ }^{41}$, che lasciò il campo a sempre più numerosi corpi di forze dell'ordine strettamente collegati ai nuclei di potere.

Sin dal Duecento in molte città i movimenti di "popolo" avevano organizzato, a livello rionale, proprie società armate ${ }^{42}$. Anche nei principali co-

${ }^{38}$ Cfr. ancora, su questo punto, Zorzi, Contrôle social cit., pp. 1173-1174.

${ }^{39}$ Nella consapevolezza che il termine latino politia significava ordine pubblico in quanto ordine politico e non gli organi specializzati di repressione. Su questo punto, cfr. M. Sbriccoli, Polizia (diritto intermedio), in Enciclopedia del diritto, vol. XXXIV, Milano 1985, pp. 111-120; e H. Manikowska, Il controllo sulle città. Le istituzioni dell'ordine pubblico nelle città italiane dei secoli XIV e XV, in Città e servizi sociali nell'Italia dei secoli XII-XV, Pistoia 1990, pp. 48 sgg.

${ }^{40} \mathrm{Cfr}$. ancora Bellamy, Crime and public order cit., pp. 90-91.

${ }^{41}$ Che era stato peculiare dell'esperienza comunale, come ha evidenziato G. Tabacco, Egemonie sociali e strutture del potere nel medioevo italiano, Torino $1979^{2}$, pp. 330 sgg., 350 sgg.

${ }^{42}$ Cfr. R. Davidsohn, Die Popular-Bewegung in italienischen Städten bis zur Mitte des 13. Jahrhunderts, in Id., Forschungen zur Geschichte von Florenz, vol. IV, Berlin 1908, pp. 8-29; G. De Vergottini, Arti e "popolo" nella prima metà del secolo XIII [1943], in Id., Scritti di storia del diritto italiano, a cura di G. Rossi, Milano 1977, pp. 392 sgg.; e E. Artifoni, Tensioni sociali e istituzioni nel mondo comunale, in La storia. I grandi problemi dal medioevo all'età contemporanea, vol. II, Il medioevo. 2. Popoli e strutture politiche, Torino 1986 pp. 477 sgg. 
muni toscani, come Pisa, Siena e Firenze, la mobilitazione di tali compagnie - radunate in "gonfaloni" a Firenze, o in "terzieri" a Lucca e a Siena aveva costituito il nerbo della lotta contro le violenze magnatizie ${ }^{43}$. In genere in esse dovevano prestare servizio tutti i residenti maschi di età compresa tra i 15 e i 70 anni e popolani, e non potevano farne parte i magnati e i loro servi; ogni compagnia doveva garantire un certo numero di armati di tutto punto, inquadrati dietro al proprio comandante. A segnare lo stretto legame con le istituzioni comunali e con la tutela dell'ordine politico le compagnie dovevano radunarsi agli ordini dei massimi rappresentanti politici in caso di sommosse o sedizioni: a Firenze, per esempio, dovevano seguire gli ordini del gonfaloniere di giustizia, a Siena dei Nove.

In occasione dei tumulti degli ultimi decenni del Trecento le compagnie non diedero però dimostrazione di lealtà ai propri governi comunali. A Lucca, per esempio, in occasione della fallita cospirazione di artigiani nel 1371, i gonfaloni armati erano scesi in piazza a fianco degli insorti ${ }^{44}$, e ancora, durante gli scontri tra le fazioni dei Forteguerra e dei Guinigi nel 1392, le milizie dei terzieri non si mobilitarono per difendere l'ordinamento pubblico $^{45}$. A Siena, nel 1371, membri di una compagnia, quella che prendeva nome dalla contrada del Bruco, furono addirittura tra i promotori della rivolta dei lavoratori della lana ${ }^{46}$. A Firenze, durante le giornate del tumulto dei ciompi, le compagnie del "popolo" - che ancora nel settembre 1343 , in occasione di un moto di scardassieri e "gente minuta" si erano mobilitate al seguito del podestà ${ }^{47}$ - anziché difendere le istituzioni comunali allinearono le proprie insegne dietro a quelle del popolo minuto in rivolta $^{48}$.

La reazione colpì immediatamente le organizzazioni comunitarie. A Siena, per esempio, pochi giorni dopo il tumulto del Bruco, il consiglio dei Riformatori tolse vessilli e bandiere ai capitani dei terzieri e ai capi delle

${ }^{43}$ Cfr. G. Volpe, Studi sulle istituzioni comunali a Pisa. Città e contado, consoli e podestà. Secoli XII-XIII [1902], Firenze $1970^{2}$, pp. 414 sgg.; P. Nardi, I borghi di San Donato e di San Pietro a Ovile: "populi", contrade e compagnie d'armi nella società senese dei secoli XI-XIII, «Bullettino senese di storia patria», s. III, LXXIII-LXXV, 1966-1968, pp. 39 sgg.; M. Ascheri, Dal governo di 'popolo' al governo nobiliare, in Id., Siena nel Rinascimento. Istituzioni e sistema politico, Siena 1985, pp. 21 sgg. e 71-74; Zorzi, Contrôle social cit., pp. 1176-1179.

${ }^{44}$ Cfr. Giovanni Sercambi, Le croniche lucchesi, a cura di S. Bongi, Roma 1892, vol. I, pp. 204-205.

${ }^{45}$ Cfr. ivi, vol. I, pp. 277-280.

${ }^{46} \mathrm{Cfr}$. Neri di Donato, Annales senenses, in Rerum Italicarum scriptores, [d'ora in poi RIS], XV, Milano 1729, pp. 224 e 244.

${ }^{47}$ Cfr. Marchionne di Coppo Stefani, Cronaca fiorentina, a cura di N. Rodolico, in RIS, XXX/I, Bologna $1955^{2}$, r. 593, pp. 215-216.

${ }^{48}$ Cfr. ivi, r. 795, p. 322. 
milizie corporative ${ }^{49}$, e creò una nuova forza cittadina che, pur divisa ancora per terzi, non esprimeva alcuna forma di rappresentanza e che fu subito posta a guardia della città e mobilitata per "fare a pezzi la compagnia del Bruco", come annotò il cronista Neri di Donato descrivendo la sanguinosa repressione che ebbe luogo il 30 luglio 1371 nella contrada di Ovile ${ }^{50}$. A Firenze la repressione dei ciompi e del popolo minuto del 31 agosto 1378 fu guidata nelle piazze dalle milizie delle corporazioni, a cominciare, com'è noto, da quella dei beccai ${ }^{51}$, mentre le compagnie del "popolo" furono presto ridotte a soli compiti di guardia notturna ${ }^{52}$, e sostituite da una nuova milizia civica di 2.000 cittadini di chiara fede guelfa, eletti dalla nuova magistratura sulla sicurezza, gli Otto di guardia, alla cui stretta dipendenza essi furono subito posti ${ }^{53}$. Anche a Lucca, dopo gli scontri del maggio 1392 che li videro vincitori, i Guinigi crearono un corpo di guardia di duecento "confidentes" pronto a intervenire a difesa del nuovo regime in caso di sedizioni $^{54}$.

L'esautorazione delle società armate rionali e la formazione di milizie svincolate da ogni forma di rappresentanza comunitaria, perseguivano l'evidente obiettivo strategico del disarmo delle componenti sociali e andavano nella direzione di un rafforzamento delle capacità di costrizione da parte dei poteri politici, secondo linee di sviluppo che erano comuni anche ad altre formazioni politiche europee coeve $\mathrm{e}^{55}$. Tra il XIV e il XV secolo in molte aree dell'Occidente medievale si osserva infatti un rilevante aumento delle forze dell'ordine: nelle Fiandre, per esempio, come ha rilevato David Nicholas per il caso di Ghent, nel regno d'Inghilterra, a Parigi, etc. ${ }^{56}$.

${ }^{49}$ Cfr. Neri di Donato, Annales senenses cit., p. 225.

${ }^{50}$ Ivi, pp. 225-227.

${ }^{51}$ Cfr. Cronica prima d'anonimo (1378-1387), in Il tumulto dei ciompi. Cronache e memorie, a cura di G. Scaramella, in RIS, XVIII/III, Bologna 1934, pp. 81-82; e Diario d'anonimo fiorentino dall'anno 1358 al 1389, a cura di A. Gherardi, in Cronache dei secoli XIII e XIV, in Documenti di storia italiana, VI, Firenze 1876, p. 378.

${ }^{52} \mathrm{Cfr}$. G. Guidi, Il governo della città-repubblica di Firenze del primo Quattrocento, Firenze 1981, vol. II, p. 71.

${ }^{53}$ Cfr. Zorzi, Contrôle social cit., p. 1181.

${ }^{54}$ Cfr. Ch. Meek, Lucca 1369-1400. Politics and society in an early Renaissance citystate, Oxford 1978, pp. 276-277.

${ }^{55}$ Cfr. R. Lévy, X. Rousseaux, État et justice pénale: un bilan historiographique et une relecture, «IAHCCJ Bulletin», 14, 1991, pp. 117 sgg.

${ }^{56}$ Cfr. D.M. Nicholas, Crime and punishment in fourteenth-century Ghent, «Revue belge de philologie et d'histoire», XLVIII, 1970, pp. 307-309; B. Geremek, Les marginaux parisiens aux XIV et XV siècles, Paris, 1976, pp. 26-34; Bellamy, Crime and public order cit., pp. 89-120. 
Il fenomeno si rileva anche nelle città italian $\mathrm{e}^{57}$. A Firenze, per esempio, il numero di ufficiali (bargelli, capitani di custodia e balìa, difensori del contado e distretto) che affiancarono con propri contingenti di "berrovieri" le ronde dei rettori comunali fu infoltito nel corso del Trecento ${ }^{58}$. Allo stesso modo subirono un incremento deciso anche gli organici dei corpi di polizia: il numero dei "berrovieri" quotidianamente operanti in città passò infatti dai circa 32/50 degli ultimi decenni del Duecento ai 400/420 degli ultimi anni del Trecento ${ }^{59}$, cui in determinate occasioni vennero affiancati reparti militari per controllare le piazze e i luoghi nevralgici della città: dagli anni ottanta la mobilitazione delle "vicherie" del contado fu continua in ogni occasione di tensione ${ }^{60}$. Il ricorso a masnade e truppe armate dal contado si fece frequente negli stessi anni anche a Lucca, da parte dei Guinigi, per esempio, sempre negli scontri del $1392^{61}$, o a Siena, dove nella fase cruciale della repressione della rivolta del Bruco, truppe assoldate nel contado tra le clientele signorili vennero in soccorso della milizia cittadina ${ }^{62}$.

L'aumento dei corpi di polizia determinò un sensibile mutamento del rapporto tra numero di abitanti e di poliziotti, che fu quasi ovunque imponente: a Siena, per esempio, il rapporto tra "berrovieri" e abitanti segnava 1 ogni 145 già negli anni trenta del XIV secolo ${ }^{63}$, mentre è stato calcolato come a Venezia, nel secondo Trecento, tale aliquota ammontasse a 1 ogni 250/350 abitanti ${ }^{64}$. A Firenze il rapporto passò tra l'inizio e la fine di quel secolo da 1 ogni 2.000 abitanti circa nel pieno dell'età comunale (quando la città contava 100/110.000 abitanti) a 1 ogni 150 nel momento di affermazione del regime oligarchico (quando la popolazione si era ridotta a meno di 60.000 abitanti) ${ }^{65}$.

${ }^{57}$ Riprendo qui di seguito alcuni risultati già esposti in A. Zorzi, Ordine pubblico e amministrazione della giustizia nelle formazioni politiche toscane tra Tre e Quattrocento, in Italia 1350-1450: tra crisi, trasformazione, sviluppo, Pistoia 1993, pp. 437-439.

${ }^{58}$ Cfr. Zorzi, Contrôle social cit., pp. 1179-1181; Id., Giustizia e società a Firenze in età comunale: spunti per una prima riflessione, «Ricerche storiche», XVIII, 1988, pp. 486488; e H. Manikowska, Polizia e servizi d'ordine a Firenze nella seconda metà del XIV secolo, ivi, XVI, 1986, pp. 30-36.

${ }^{59}$ Cfr. Zorzi, Contrôle social cit., pp. 1180-1181. Dati ulteriori in Manikowska, Polizia e servizi d'ordine cit., pp. 31-32 e 34.

${ }^{60}$ Cfr., per esempio, Alle bocche della piazza. Diario di anonimo fiorentino (13821401), a cura di A. Molho, F. Sznura, Firenze,1986, pp. 31-32 e, ad indicem, voce "vicherie".

${ }^{61}$ Cfr. Sercambi, Le croniche lucchesi cit., vol. I, p. 281.

${ }^{62}$ Cfr. Neri di Donato, Annales senenses cit., pp. 226-227.

${ }^{63}$ Cfr. W. M. Bowsky, Un comune italiano nel medioevo. Siena sotto il regime dei Nove, 1287-1355, Bologna 1986, p. 178.

${ }^{64}$ Cfr. Ruggiero, Patrizi e malfattori cit., p. 41.

${ }^{65}$ Cfr. Zorzi, Ordine pubblico cit., p. 438. 
Nella debolezza strutturale (in termini di dotazioni, di mezzi e di personale) degli ordinamenti giudiziari di antico regime, queste misure apparivano come le più facilmente adottabilib6 ${ }^{6}$, ed è incontestabile che esse diedero anche qualche esito: le sole ronde di polizia fiorentine, per esempio, nel primo decennio del Quattrocento effettuarono arresti in media ogni anno di 40-50 persone per porto d'armi vietate, di oltre 200 individui che violavano il coprifuoco notturno, e di oltre 400 persone colte in flagrante mentre giocavano a giochi d'azzardo proibiti ${ }^{67}$. Cifre notevoli, se si tiene conto che la popolazione di Firenze toccava in quegli anni non più di $48 / 50.000$ individui. Il rapporto tra numero di poliziotti e di abitanti era ormai sceso a 1 ogni $120 / 125^{68}$.

\section{I nuovi organi giudiziari}

Le trasformazioni dei modi del controllo sociale e dell'ordine pubblico erano solo un aspetto della più generale tendenza a rendere più stretti i rapporti tra potere politico e apparati giudiziari e repressivi. Nuove configurazioni istituzionali legarono direttamente le politiche giudiziarie all'azione dei governi negli stati europei del tardo medioevo ${ }^{69}$.

Nelle monarchie l'affermazione delle prerogative regie fu acquisita attraverso lunghi e complessi percorsi negoziali con i poteri signorili e urbani. Il processo, come è noto, fu lento e tortuoso nel regno di Inghilterra, dove le ampie autonomie giudiziarie erose dai baroni e dalla gentry nel corso del XIV secolo furono faticosamente riassorbite dalla giustizia regia, non senza esenzioni e privilegi, solo nel corso del XV secolo ${ }^{70}$. Nel regno di Francia fu invece il Parlamento di Parigi a concentrare più precocemente

${ }^{66} \mathrm{Su}$ questo punto, cfr. anche le osservazioni di Sbriccoli, Polizia cit., pp. $114 \mathrm{sgg}$.

${ }^{67}$ Ho elaborato i dati dai registri in Archivio di Stato di Firenze [d'ora in poi ASFi], Camera del Comune, Provveditori. Libri del giglio, 5-14.

${ }^{68}$ Zorzi, Ordine pubblico cit., p. xxx.

${ }^{69}$ Per uno sguardo d'insieme, cfr. Le pénal dans tous ses états. Justice, états et sociétés en Europe (XII ${ }^{e}-X X^{e}$ siècles), a cura di R. Lévy, X. Rousseaux, Bruxelles 1997; II. dd., Etats, justice pénale et histoire. Bilan et perspectives, «Droit et société», 20-21, 1992, pp. 249-279; X. Rousseaux, Genèse de l'état et justice pénale (XIII ${ }^{e}$-XVIII ${ }^{e}$ siècle). Contribution pour une histoire de la justice, in De la Res publica a los Estados modernos, a cura di V. Tamayo Salaberría, Bilbao 1992, pp. 235-259.

${ }^{70} \mathrm{Il}$ tema è stato ampiamente studiato: cfr. R.C. Palmer, The county courts of medieval England: 1150-1350, Princeton 1982; A. Musson, Public order and law enforcement. The local administration of criminal justice, 1294-1350, Woodbridge 1996; Id., W. M. Ormrod, The evolution of English justice: law, politics, and society in the fourteenth century, London 1999; E. Powell, Kingship, law, and society. Criminal justice in the reign of Henry V, Oxford 1989; e R.W. Kaeuper, War, justice, and public order. England and France in the later Middle Ages, Oxford, 1988. 
e più strettamente i poteri giudiziari intorno alle prerogative regie ${ }^{71}$, favorendo semmai lo sviluppo delle giustizie urbane a spese delle giurisdizioni signorili laiche ed ecclesiastiche ${ }^{72}$.

Anche nei principati territoriali si possono osservare dinamiche simili ${ }^{73}$. Nella contea di Provenza, per esempio, dove l'arrivo al potere della regina Giovanna d'Angiò nel 1343 fu segnato da diffusi disordini, furono proprio gli uomini di legge e l'apparato giudiziario a giocare un ruolo centrale nell'inquadramento della società, a cominciare dalle città dove essi operarono come autorevoli rappresentanti della sovranità ${ }^{74}$.

Nelle città delle Fiandre, da Gand a Bruges, a Ypres ad Arras, teatro di lotte sociali e rivolte violentissime tra la fine del XIII secolo e l'inizio del $\mathrm{XIV}^{75}$, i conti di Fiandra sostennero nello stesso periodo il passaggio da regimi urbani dominati dal patriziato delle origini a governi aperti alla partecipazione di nuovi gruppi sociali (famiglie di ricchezza mercantile recente, artigiani, etc.): sul piano giudiziario ciò significò - pur nel quadro di una pluralità di livelli giurisdizionali facenti capo al potere comitale - il passaggio dagli abusi dei giudici urbani a un'attività scabinale soggetta al controllo pubblico, con competenze meglio distribuite ${ }^{76}$.

Una cospirazione, come è noto, fu all'origine dell' istituzione a Venezia nel 1310 del consiglio dei Dieci ${ }^{77}$, una magistratura che per il suo stretto legame con il Maggior consiglio bene esprimeva la tendenza alla

${ }^{71}$ Cfr. la fondamentale indagine di C. Gauvard, "De grace especial”. Crime, état et société en France à la fin du moyen âge, Paris 1991; la raccolta di Ead., Violence et ordre public au moyen âge, Paris 2005; e una sintesi in Ead., La justice pénale du roi de France à la fin du moyen âge, in Le pénal dans tous ses états cit., pp. 81-112.

${ }_{72}$ Come mostrano, per esempio, B. Auzary-Schmaltz, J. Hilaire, Les villes et la justice d'après les archives du Parlement aux XIII et XIV ${ }^{e}$ siècles, in Pratiques sociales et politiques judiciaires dans les villes de l'Occident à la fin du moyen âge, a cura di J. Chiffoleau, C. Gauvard, A. Zorzi, Roma 2007, pp. 81-93.

${ }^{73} \mathrm{Cfr}$., per esempio, La justice dans les Etats bourguignons et les regions voisines aux $X I V^{e}-X V I^{e}$ siecles. Institutions, procedure, mentalites, a cura di J.-M. Cauchies, Neuchâtel 1990.

${ }^{74}$ Cfr. J.-L. Bonnaud, Les juges locaux du comte de Provence au XIV siècle: entre la ville, la pratique privée et l'état, in Pratiques sociales et politiques judiciaires cit., pp. 323-345.

${ }^{75} \mathrm{Cfr}$. ora il saggio di Marc Boone in questo volume.

${ }^{76} \mathrm{Cfr}$. W. Prevenier, Les sources de la pratique judiciaire en Flandre du XII ${ }^{e}$ au $X V^{e}$ siècle et leur mise en cuvre par les historiens, in Pratiques sociales et politiques judiciaires cit., pp. 105-123.

${ }^{77}$ Cfr. Ruggiero, Patrizi e malfattori cit., pp. 79-92; Id., Politica e giustizia, in Storia di Venezia cit., vol. III, Dalle origini alla caduta cit., pp. 399 sgg. Fondamentale anche G. Cozzi, Autorità e giustizia a Venezia nel Rinascimento, in Id., Repubblica di Venezia e Stati italiani. Politica e giustizia dal secolo XVI al secolo XVIII, Torino 1982, pp. $81 \mathrm{sgg}$. 
esplicita politicizzazione della funzione giudiziaria, affidata a organi legati direttamente ai governi, composti da membri eminenti dei gruppi dirigenti, e interpreti di un'attività giudiziaria e di repressione a sostegno dei nuovi, più concentrati, assetti di potere. Incaricati inizialmente in via straordinaria di riportare l'ordine in città punendo i ribelli che avevano partecipato alla congiura tramata da Baiamonte Tiepolo e Marco Querini, i Dieci furono poi confermati nelle loro funzioni investigative e giudiziarie sulle fazioni, sulle attività cospirative e sulle manifestazioni di dissenso, erodendo progressivamente le prerogative degli organi preposti fino ad allora alla giustizia penale, a cominciare dalla Quarantia criminal.

Anche in altre città italiane il trasferimento delle funzioni giudiziarie a nuove magistrature di diretta emanazione governativa, e formate da membri dei gruppi dirigenti digiuni di diritto, fu conseguente a episodi di tumulto e sedizione e si risolse nella progressiva esautorazione degli organi giudiziari di tradizione comunale affidati, si noti, a professionisti del diritto. A Siena, per esempio, al podestà comunale si affiancarono dal $1371 \mathrm{i}$ "defensores status pacifici comunis senarum" con compiti, tra gli altri, di coordinamento delle forze dell'ordine e pieni poteri giudiziari in questioni attinenti alla sicurezza ${ }^{78}$. A Lucca, nel 1374, furono istituiti i "conservatores libertatis", una magistratura composta di cittadini eletta per provvedere "ad conservandum libertatem civitatis Lucane et pacificum et bonum statum ipsius"79, che col passare degli anni pose sotto stretto controllo l'operato del podestà e intervenne direttamente in materia di sicurezza con decreti giudiziari e modifiche agli statuti cittadini ${ }^{80}$. A Firenze, la repressione dei ciompi, nel settembre del 1378, venne affidata a un nuovo organo, gli Otto di guardia, una commissione nominata dai priori col compito di coordinare l'attività "circa custodiam civitatis et attentantes aliquod contra statum in civitate vel extra" ${ }^{\text {, }}$, e presto dotata di crescenti poteri giudiziari, a cominciare, dai primi anni del 1400, dal controllo dell'operato degli stessi rettori comunali ${ }^{82}$. La repressione dei rivoltosi e dei membri delle famiglie aristocratiche che con loro si erano coalizzati, fu guidata direttamente dai

${ }^{78}$ Cfr. Ascheri, Dal governo di 'popolo' al governo nobiliare cit., p. 27; Rutenburg, Popolo e movimenti popolari cit., pp. 146-7.

${ }^{79}$ Cito da Meek, Lucca 1369-1400 cit., p. 237.

${ }^{80}$ Cfr. ivi, pp. 239-242.

${ }^{81}$ ASFi, Consulte e pratiche, 16, c. 16v. Sugli Otto di guardia, cfr. G. Antonelli, La magistratura degli Otto di guardia a Firenze, «Archivio storico italiano», XCII, 1954, pp. 3-40; e A. Zorzi, L'amministrazione della giustizia penale nella Repubblica fiorentina. Aspetti e problemi, Firenze 1988, pp. 42 sgg.

${ }^{82}$ Cfr. ivi, pp. 53 sgg. 
"difensori" a Siena e dagli Otto di guardia a Firenze, attraverso condanne, esecuzioni capitali, e provvedimenti di esilio ${ }^{83}$.

Peraltro, a Siena l'esautorazione dei giusdicenti di tradizione comunale era già stata avviata nel 1355, alla caduta del regime dei Nove, concentrando sul capitano del popolo - carica non più affidata a un forestiero ma a un cittadino di grande prestigio - l'attività di tutti i tribunali e di tutti gli ufficiali giudiziari ${ }^{84}$. A Lucca gli uffici (tutti tenuti da forestieri) del maggior sindaco, del giudice degli appelli e dell'ufficiale delle gabelle furono aboliti nel $1392 \mathrm{e} \mathrm{le} \mathrm{loro} \mathrm{competenze} \mathrm{riassunte} \mathrm{in} \mathrm{quelle} \mathrm{del} \mathrm{ristabi-}$ lito capitano del popolo ${ }^{85}$. A Firenze la progressiva esautorazione dei rettori comunali da parte degli Otto di guardia - che acquisirono de facto prima che de iure il potere di punire qualunque maleficio, di riprendere da qualsiasi tribunale le cause, di indirizzarne le sentenze, di modificarne le sanzioni - passò attraverso la riduzione della attività giudiziaria delle curie tradizionali, che si contrasse di oltre due terzi tra il 1400-01 e il 1433-35 ${ }^{86}$, e che fu prodromo della loro soppressione definitiva: il giudice degli appelli nel 1412 dal regime albizzesco, l'esecutore degli ordinamenti di giustizia nel 1435 al ritorno di Cosimo de' Medici, il capitano del popolo nel 1477 da Lorenzo il Magnifico, il podestà nell'ambito delle riforme soderiniane del $1502^{87}$.

Anche i regimi signorili promossero innovazioni analoghe. I Visconti, per esempio, istituirono nei primissimi anni del XV secolo un ufficiale, chiamato "capitaneus et executor iustitie", direttamente dipendente dal duca e con competenze in ambito penale che esautorarono quelle del podestà di Milano ${ }^{88}$. A sua volta il duca Ercole I d'Este istituì un proprio capitano di giustizia a Ferrara alla fine del XV secolo, che si configurò come la figura più potente dopo il signore ${ }^{89}$.

${ }^{83}$ Cfr., per Siena, Rutenburg, Popolo e movimenti popolari cit., p. 147; per Firenze, Brucker, The Ciompi revolution cit., pp. 79-92.

${ }^{84}$ Cfr. Ascheri, Dal governo di 'popolo’ al governo nobiliare cit., p. 32.

${ }^{85}$ Cfr. Meek, Lucca 1369-1400 cit., pp. 273-274.

${ }^{86}$ Cfr. Zorzi, L'amministrazione della giustizia penale, cit., pp. 42-45; e Manikowska, Polizia e servizi d'ordine cit., p. 37.

${ }^{87}$ Cfr. Zorzi, L'amministrazione della giustizia penale, cit., pp. 53 sgg.

${ }^{88}$ Cfr. Cfr. M. Spinelli, Il capitano di giustizia durante la prima metà del Quattrocento, in L'età dei Visconti. Il dominio di Milano fra XIII e XV secolo, a cura di L. Chiappa Mauri, L. De Angelis Cappabianca, P. Mainoni, Milano 1993, pp. 27-34; e, per l'età sforzesca, N. Covini, "La balanza drita". Pratiche di governo, leggi e ordinamenti nel ducato sforzesco, Milano 2007, pp. 45-47.

${ }^{89} \mathrm{Cfr}$. E. Guerra, Una eterna condanna. La figura del carnefice nella società italiana tardo medievale, Milano 2003, pp. 45 sgg. 


\section{L"'ordo non servatus"}

I nuovi organi giudiziari adottarono procedure che non costituivano delle innovazioni in sé, perché già in uso anche in precedenza, ma che segnarono una profonda discontinuità nell'azione inquirente e giudiziale. Usando le categorie di Mirjan Damaška, si potrebbe evidenziare come già tra XIII e XV secolo in Occidente la giustizia pubblica accentuò il suo carattere "attivo" rispetto al modello prevalentemente "reattivo" dei secoli precedenti ${ }^{90}$.

Non mi riferisco tanto al mutamento delle procedure processuali che soprattutto gli storici del diritto hanno inquadrato nel modello teorico, rispecchiato dalla trattatistica giuridica, della generale affermazione del sistema inquisitorio su quello accusatorio ${ }^{91}$. Un modello, di impianto evoluzionistico e che ascrive al processo di formazione dello stato l'affermazione di una giustizia a grado pubblico sempre maggiore (dall'accusatorio all'inquisitorio, dall'extragiudiziario al giudiziario, etc.), che è stato invalidato dagli storici delle pratiche processuali. Nelle città comunali italiane tra XII e XIV secolo, per esempio, invalse piuttosto una procedura mista, spesso deformata dalle eccezioni e dalle tensioni che si creavano intorno alla giustizia ${ }^{92}$. In quelle del regno di Francia, da Strasbourg a Laon, a Reims a Troyes, le procedure accusatoria e inquisitoria variarono nei tempi e nei luoghi tra XIII e XVI secolo e si differenziarono fortemente dallo stile processuale del Parlamento regio ${ }^{93}$. Anche in una città come Ragusa sotto il dominio veneziano fino al 1358 e poi repubblica autonoma controllata dal patriziato locale, i registri giudiziari testimoniano ancora nel XV secolo la prevalenza di una "formula mista" che consentiva il ricorso strategico all'accusa in tribunale per poi dare luogo a composizioni e risoluzioni al suo esterno ${ }^{94}$.

Più appropriato appare invece inquadrare le trasformazioni procedurali sotto il segno della crescente affermazione dell'iniziativa ex officio, che affiancò e poi finì col sovrapporre una giustizia di apparato ai pro-

${ }^{90}$ Cfr. M. R. Damaška, I volti della giustizia e del potere. Analisi comparatistica del processo, Bologna 1991, pp. 136 sgg. e 147 sgg.

${ }^{91}$ Da ultimo cfr. E. Dezza, Accusa e inquisizione dal diritto comune ai codici moderni, Milano 1989.

${ }^{92}$ Cfr. M. Vallerani, Procedura e giustizia nelle città italiane del basso medioevo (XIIXIV secolo), in Pratiques sociales et politiques judiciaires cit., pp. 439-494.

${ }^{93} \mathrm{Cfr}$. C. Gauvard, Droit et pratiques judiciaires dans les villes du nord du royaume de France à la fin du moyen âge: l'enseignement des sources, in Pratiques sociales et politiques judiciaires cit., pp. 33-79.

94 Cfr. N. Lonza, L'accusatoire et l'infrajudiciaire: la "formule mixte" à Raguse (Dubrovnik) au moyen âge, in Pratiques sociales et politiques judiciaires cit., pp. 643-658. 
cedimenti avviati su accusa o querela delle parti: un fenomeno che è rilevabile a livello continentale ${ }^{95}$. Si tratta di quell'ambito della giustizia penale che Mario Sbriccoli ha riassunto sotto la nozione di giustizia "egemonica", segnata "da uno spiccato carattere di apparato, fondata sulla sudditanza, diretta principalmente alla punizione del colpevole, regolata da norme di tipo legislativo" 96 . Fu proprio tra la fine del XIII e l'inizio del XIV secolo che al penale venne impresso "un forte carattere di pubblicizzazione" 97 , e si impose il principio che chi commetteva un delitto danneggiava la sua vittima ma offendeva anche la respublica, legittimata

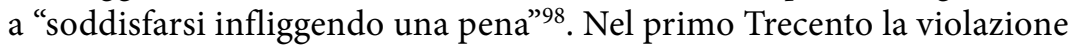
di un obbligo penale cominciò a corrispondere "sostanzialmente a una forma d'insubordinazione", una figura che cominciò a prendere forma nella normativa che fiorì intorno allo scontro tra Enrico VII e Roberto d'Angiò ${ }^{99}$. La giustizia venne così affermando il principio dell'obbedienza alla legge piuttosto che perseguire il fine della soddisfazione, allontanando la propria nozione "dalla sfera semantica del distributivo e del risarcitorio", per investire "in quella della repressione e della "lotta contro il crimine, che è azione politica" 100 . Il "paradigma del reato politico" si fece "vettore di un 'principio dell'obbedienza"'101, che venne estendendosi a tutte le tipologie dei reati ${ }^{102}$.

Nelle sue fasi di affermazione la giustizia ex officio accentuò soprattutto la flessibilità dei procedimenti. Particolarmente evidenti appaiono aspetti quali la legittimazione delle denunce segrete, la segretezza degli atti, la maggiore speditezza dell'ordo processuale.

Il ricorso crescente alle denunce segrete e anonime costituì uno degli elementi più rilevanti della trasformazione dei sistemi giudiziari nel tardo medioevo, anche in conseguenza diretta del declino delle forme comunitarie di controllo sociale e di informazione giudiziaria. Il fenomeno è stato

${ }^{95} \mathrm{Cfr}$. il quadro tracciato da X. Rousseaux, Initiative particulière et poursuite d'office. L'action pénale en Europe (XII ${ }^{e}$-XVIII ${ }^{e}$ siècles), «IAHCCJ Bulletin», 18, 1993, pp. 58-92.

${ }^{96}$ Sbriccoli, Giustizia negoziata, giustizia egemonica cit., p. 360.

${ }^{97}$ Ibidem.

${ }^{98}$ M. Sbriccoli, Giustizia criminale, in Lo Stato moderno in Europa. Istituzioni e diritto, a cura di M. Fioravanti, Laterza, Roma-Bari 2002, p. 168.

${ }^{99}$ Id., Giustizia negoziata, giustizia egemonica cit., p. 362.

${ }^{100}$ Ivi, p. 361.

${ }^{101}$ Ibidem.

${ }^{102} \mathrm{E}$ che fu poi ulteriormente corroborato dalle practicae criminales cinquecentesche: cfr. ancora M. Sbriccoli, La benda della Giustizia. Iconografia, diritto e leggi penali dal medioevo all'età moderna, in Ordo iuris. Storia e forme dell'esperienza giuridica, a cura di Id., P. Costa, M. Fioravanti e altri, Milano 2003, p. 45 e in nota. 
rilevato, per esempio, nel regno inglese ${ }^{103}$, ma è ben documentabile anche nelle città italiane. In alcune di esse la pratica entrò in uso nella prima metà del XIV secolo come strumento della lotta contro i magnati, per tutelare l'identità dei popolani che ne denunciavano i comportamenti violenti e per proteggerne l'incolumità da possibili ritorsioni: apposite cassette ove potessero essere deposte lettere di denuncia, segrete o anche anonime, furono dislocate nei luoghi pubblici (presso le chiese, le sedi dei tribunali, i palazzi della politica, etc. ${ }^{104}$. A Firenze, per esempio, nella seconda metà del Trecento la media annua di "tamburagioni" (come venivano chiamate le lettere imbucate nei cosiddetti "tamburi") contro i magnati oscillava già tra le 100 e le $200^{105}$. A differenza delle accuse formalizzate davanti al giudice nei tribunali ordinari, che comportavano l'onere di seguire le procedure di garanzia (pubblicità dell'accusa, nomina di fidejussori, etc. ${ }^{106}$, le denunce segrete non erano perseguibili per calunnia, e spesso, anzi, erano incentivate da taglie e premi in denaro ${ }^{107}$.

Fu soprattutto in seguito all' istituzione delle nuove magistrature nel primo Quattrocento che il ricorso all' informazione segreta si fece sistematico e divenne il principale modo di avvio dell'azione processuale ${ }^{108}$. A Firenze, per esempio, gli Otto di guardia agirono quasi esclusivamente in base alle notificazioni recapitate in apposite cassette e sulla scorta di informazioni attinte da spie e informatori segreti (che operavano anche all'interno del mondo corporativo ${ }^{109}$ ). I Dieci veneziani disposero dal 1382 di una cassa per le spese "secrete" di cui non dovevano rispondere ad alcun altro consiglio, e che servì loro per remunerare delazioni, taglie ed esploratori ${ }^{110}$. Anche i regimi signorili incentivarono con taglie in denaro l'afflusso di informazioni segrete: a Ferrara, per esempio, nel 1472 per fronteggiare una recrudescenza di

${ }^{103}$ Cfr. J.G. Bellamy, Criminal law and society in late medieval and Tudor England, New York 1984, pp. 8 sgg. e 90 sgg.

${ }^{104}$ Cfr. Zorzi, Ordine pubblico cit., p. 430.

${ }^{105}$ Ivi.

${ }^{106} \mathrm{Su}$ questo punto, cfr. U. Dorini, Il diritto penale e la delinquenza in Firenze nel sec. $X I V$, Lucca [s.d. ma 1923], pp. 137 sgg.

${ }^{107}$ Per qualche esempio, rinvio ancora a Zorzi, Ordine pubblico cit., pp. 431-432.

${ }^{108} \mathrm{Ne}$ ho approfondito l'analisi, al solito per il caso fiorentino, in A. Zorzi, The judicial system in Florence in the fourteenth and fifteenth centuries, in Crime society and the law in Renaissance Italy, a cura di T. Dean, K. J. P. Lowe, Cambridge 1994, pp. 4445 .

${ }^{109} \mathrm{Cfr}$. F. Franceschi, Criminalità e mondo del lavoro: il tribunale dell'arte della lana a Firenze nei secoli XIV e XV, «Ricerche storiche», XVIII, 1988, p. 571.

${ }^{110}$ Cfr. G. Cracco, Un "altro mondo". Venezia nel medioevo dal secolo XI al secolo XIV, Torino 1986, pp. 117-118; e S. Chojnacki, Crime, punishment, and the Trecento Venetian state, in Violence and civil disorder in Italian cities, 1200-1500, a cura di L. Martines, Berkeley 1972, pp. 190-191. 
"homicidi, robarie et altri gravi et enormi delicti" il duca Ercole I d'Este stanziò ben $25 \mathrm{o} 10$ ducati d'oro per chi avesse denunciato, rispettivamente, un omicidio o un furto, assicurando l'anonimato agli informatori ${ }^{111}$.

La legittimazione sociale e politica conferita all'anonimato ${ }^{112}$ era spia di nuovi assetti di potere che ricorsero crescentemente anche alla segretezza dell'azione giudiziaria. Il veneziano consiglio dei Dieci, per esempio, conduceva le indagini, assumeva le decisioni e comminava le pene nel più stretto riserbo del palazzo ducale ${ }^{113}$. Allo stesso modo procedevano anche gli Otto di guardia a Firenze, la segretezza delle cui attività si rispecchiava anche nella laconicità e nelle ellissi delle loro registrazioni documentarie, e nella facoltà di non motivare le proprie sentenze ${ }^{114}$.

La segretezza delle procedure era spesso schermata dalla mancanza o dalla vaghezza delle regole cui dovevano attenersi i nuovi organi giudicanti. Le competenze e l'attività del ricordato capitano di giustizia milanese, per esempio, non erano disciplinate dagli statuti ma rispondevano alla discrezione del duca: "non è sottoposto alli statuti et ha larga baylia"115. Dell'omonimo capitano ferrarese sappiamo come potesse operare "nullo iuris ordine servato nec servatis statutis aliquibus"116. Un "ordo non servatus" fu tipico anche del consiglio dei Dieci ${ }^{117}$, mentre i fiorentini Otto di guardia agirono in pratica per un secolo senza regolamentazione normativa delle loro competenze, e quando queste furono definite nel $1478 \mathrm{fu}$ loro comunque conferito il "pienissimo arbitrio" di giudicare e condannare "in quel modo et forma che giudicassino convenirsi"118.

L'arbitrio delle nuove magistrature non era che l'ennesima riconfigurazione dell'arbitrium di giudicare che costituiva uno degli elementi portanti del sistema giuridico del diritto comune ${ }^{119}$, e non si risolveva necessariamente in una repressione terroristica bensì in una programmatica flessibilità di intervento.

${ }^{111}$ Cfr. Guerra, Una eterna condanna cit., pp. 27 sgg.

${ }^{112} \mathrm{Su}$ questo aspetto, cfr., più in generale, le osservazioni di E. Grendi, Lettere orbe. Anonimato e poteri nel Seicento genovese, Palermo 1989, pp. 12 sgg.

${ }_{113}$ Cfr. Ruggiero, Patrizi e malfattori cit., pp. 31 sgg.

${ }^{114}$ Cfr. su questo punto Zorzi, L'amministrazione della giustizia penale cit., pp. 87-88.

${ }^{115}$ Documento citato in Covini, "La balanza drita" cit., p. 89.

${ }^{116}$ Documento citato Guerra, Una eterna condanna cit., p. 46.

${ }^{117}$ Cfr. Cozzi, Autorità e giustizia cit., pp. 81 sgg.; e Id., "Ordo est ordinem non servare": considerazioni sulla procedura penale di un detenuto dal Consiglio dei $X$, «Studi storici», XXIX, 1988, pp. 309-320.

${ }^{118}$ Come fu esplicitato in una provvisione del 18 novembre 1478: ASFi, Cento, 2, cc. 44r-46v. Su questa legge, cfr. Antonelli, La magistratura degli Otto di guardia cit., pp. 24-27.

119 Come ha mostrato M. Meccarelli, Arbitrium. Un aspetto sistematico degli ordinamenti giuridici in età di diritto comune, Milano 1998. 
Certo, in alcune situazioni l'operato di alcuni ufficiali poté risultare senza "compassione o remissione alcuna": per esempio, l'ufficiale dell'arte della lana fiorentina, cui furono lasciati crescenti poteri di investigazione e di repressione nei decenni centrali del Trecento, rischiò di finire oggetto di linciaggio da parte dei ciompi ${ }^{120}$; altri, come il ferrarese capitano di giustizia Gregorio Zampante nominato da Ercole I d'Este, finirono assassinati, tanto che il duca dovette usare le maniere forti per disperdere la folla che si era radunata per saccheggiare la casa del "grandissimo ribaldo"121. Ma la facoltà esplicitamente concessa ai fiorentini Otto di guarda nel 1478 di giudicare tenendo conto della "qualità del delicto et sue circumstanze et fine et qualità del delinquente" 122 , sanzionava in realtà una pratica in uso da anni, attraverso la quale essi avevano saputo elaborare un modo di procedere che se, da un lato, appariva inevitabilmente arbitrario agli avversari e agli oppositori medicei - colpiti infatti da bandi e confische ${ }^{123}-$, dall'altro, aveva costituito uno strumento flessibile di integrazione sociale e politica.

Non bisogna perdere di vista, infatti, che collegi come quelli dei Dieci veneziani o degli Otto fiorentini non costituivano dei veri e propri tribunali ma degli organi politici giudicanti che non istruivano processi regolari ma i cui membri discutevano collegialmente i casi in esame. Degli Otto, per esempio, non si conserva una documentazione giudiziaria di tipo tradizionale (registri di inchiesta, di escussione testimoniale e di sentenze), ma solo dei volumi di deliberazioni, che costituiscono un'eccezionale testimonianza di un modo di procedere 'politico' nella soluzione dei conflitti, fatto soprattutto di mediazioni, arbitrati e negoziazioni ${ }^{124}$.

Questa flessibilità di intervento consentì agli Otto e alle analoghe magistrature di altre città di attuare una politica sia di repressione sia di reintegrazione. Accanto a dure condanne pecuniarie, capitali o all'esilio ${ }^{125}$, la

${ }^{120}$ Cfr. Franceschi, Criminalità e mondo del lavoro cit., pp. 569 sgg.

${ }^{121}$ Come fu poi ricordato lo Zampante: le citazioni sono dal Diario Ferrarese dall'anno 1409 sino al 1502 di autori incerti, a cura di G. Pardi, in RIS, XXIV/7, Bologna 1928 , pp. $182-183$.

${ }_{122}$ ASFi, Cento, 2, c. $45 \mathrm{v}$.

${ }^{123}$ Cfr. il registro di sentenze in ASFi, Otto di guardia e balia, Repubblica, 224.

${ }^{124}$ Cfr., per vari esempi del modo di procedere degli Otto di guardia: Antonelli, $\mathrm{La}$ magistratura degli Otto di guardia cit., pp. 7-12; L. Martines, Lawyers and statecraft in Renaissance Florence, Princeton 1968, pp. 226 sgg.; Zorzi, L'amministrazione della giustizia penale cit., pp. 83-89; e O. Cavallar, Francesco Guicciardini giurista. I Ricordi degli onorari, Milano 1991, pp. 74-78, 107-108, 135-136.

${ }^{125}$ Per alcuni esempi, cfr. A. Bellinazzi, I. Cotta, Controllo sociale e repressione del dissenso. Gli Otto di guardia e balia, in Consorterie politiche e mutamenti istituzionali in età laurenziana, Milano 1992, pp. 165-166. 
maggior parte dei loro provvedimenti era costituita da ammonizioni, ordini, precetti, compromessi e assoluzioni ${ }^{126}$. Un modo di procedere, dunque, in cui prevalevano le forme di mediazione e di ricomposizione, e che in un certo senso rapportava alle istituzioni quel pluralismo di modi di risoluzione dei conflitti per via infragiudiziaria ${ }^{127}$, o comunque extraprocessuale, che costituiva pur sempre la pratica giudiziaria più comune $e$ diffusa in antico regime ${ }^{128}$. Per fare un esempio anche non italiano, basterà ricordare come nelle Fiandre i conti fecero seguire alla repressione sistematica delle rivolte urbane della prima metà del Trecento una politica giudiziaria non più centrata sull'uso brutale della forza ma aperta a un'articolata mediazione dei conflitti ${ }^{129}$.

${ }^{126}$ Ho elaborato, per esempio, i dati del quadrimestre d'ufficio settembre-dicembre 1477 (cfr. ASFi, Otto di guardia e balia, Repubblica, 46): a fronte del 33,33\% di condanne sul totale degli atti (64 casi su 192), e dell'11.98\% di assoluzioni (23/192), ben il $24,48 \%(47 / 192)$ era costituito da ordini e deliberazioni, il 17,19\%(33/192) da precetti, e il 9,90\% (19/192) da compromessi e arbitrati; dati che riprendo da Zorzi, L'amministrazione della giustizia penale cit., p. 85.

${ }^{127}$ La cui nozione qui intendo, sulla falsariga di Sbriccoli, Giustizia negoziata, giustizia egemonica cit., pp. 349-350 e 356-360 (da cui le citazioni successive), nei termini di una giustizia "negoziata" - che appare "segnata da uno spiccato carattere 'comunitario', fondata sull'appartenenza, diretta principalmente alla riparazione dell'offesa, regolata da norme e prassi condivise, in un ambito in cui domina l'oralità" - distinta dalla giustizia "egemonica" caratterizzata invece "da uno spiccato carattere di apparato". La giustizia negoziata "riposa sul consenso, prima e più che sulla certezza", in quanto "risalente, radicata, accettata e condivisa". Secondo Sbriccoli andrebbero designate "col nome di 'giustizia' vendette e ritorsioni, negoziati e accordi, transazioni e composizioni, mediazioni e paci private, patti, condiscendenze, rinunce, perdoni e remissioni. Tutto ciò non essendo l'effetto della giustizia 'statale', nel senso della giustizia di apparato, celebrata da organi pubblici a essa deputati. [...] Gli storici, riflettendo su quelle culture e su quelle mentalità, dovrebbero forse dire 'giustizia la prima, repressione la seconda', e andrebbero molto più vicini al segno".

${ }^{128}$ Sulla diffusione della giustizia non di apparato, cfr. X. Rousseaux, Entre accomodememnt local et controlle étatique: pratiques judiciaires et non-judiciaires dans le règlement des conflits en Europe médiévale et moderne, in L'infrajudiciaire du moyen âge à l'époque contemporaine, a cura di B. Garnot, Dijon 1996, p. 87-107; A. Zorzi, "Ius erat in armis". Faide e conflitti tra pratiche sociali e pratiche di governo, in Origini dello Stato. Processi di formazione statale in Italia fra medioevo ed età moderna, a cura di G. Chittolini, A. Molho, P. Schiera, Bologna 1994, pp. 609-629. La soluzione dei conflitti, d'altra parte, è una delle funzioni primarie del diritto, e - a ben vedere - la dimensione originaria dell'esercizio della giustizia: cfr. S. Roberts, The study of dispute: anthropological perspectives, in Disputes and settlements. Law and human relations in the West, ed. by J. Bossy, Cambridge 1983, pp. 1-24; Damaška, I volti della giustizia e del potere cit., pp. 173-247; N. Rouland, Aux confins du droit. Anthropologie juridique de la modernité, Paris 1991, pp. 77-119; e V. Ferrari, Funzioni del diritto. Saggio critico-ricostruttivo, Roma-Bari 1993, pp. 153-187.

${ }^{129}$ Come ha messo in evidenza Marc Boone nel saggio in questo volume. 


\section{La parenesi penale}

L'affermazione della giustizia penale ex officio si accompagnò infatti alla sua negoziazione ${ }^{130} \mathrm{e}$, dato qui più rilevante, allo sviluppo di una politica della grazia. Le politiche giudiziarie dei poteri statali tra XIII e XV secolo affinarono l'esemplarità della pena contro i nemici politici ma puntarono anche alla reintegrazione dei gruppi sociali su cui si fondava il loro consenso: usarono bilanciare, cioè, l'asprezza repressiva con la dolcezza del perdono.

Prendendo in considerazione dapprima il sistema penale, un aspetto importante fu rappresentato dallo sviluppo dei rituali giudiziari e dall'affinamento dei loro linguaggi, che fissarono nella dimensione urbana dei luoghi e dei cerimoniali il teatro privilegiato della loro rappresentazione. La parenesi penale, vale a dire il contenuto ammonitorio delle esecuzioni, fu ovviamente centrale nella repressione delle rivolte. Essa agì in primo luogo sul valore simbolico delle pene: vediamo qualche esempio.

Uno dei capi della rivolta che infiammò le Fiandre tra il 1323 e il 1328, Segher Jonssone del villaggio di Bredene fu giustiziato nel 1328. Nel 1325 egli aveva guidato le forze contadine nello scontro a Gistel, a ovest di Bruges, contro il contingente del conte di Parigi, segnando una svolta della guerra contadina ${ }^{131}$. Braccato, fu catturato con una ventina di suoi seguaci e portato a Bruges. Come racconta il Chronicon comitum Flandrensium, il "ribelle traditore" fu esemplarmente giustiziato alla presenza del conte di Parigi: legato nudo su un carro fu portato in giro per le strade della città, attanagliato con un attizzatoio rovente, e issato sul patibolo dove gli furono spezzati la schiena e gli arti e fu infine decapitato; il corpo fu messo su una ruota e sospeso a una corda da impiccati, in modo che i "suoi seguaci lo potessero fissare con timore". Il commento del cronista esprimeva una convinta adesione al valore ammonitorio della pena: "così egli ricevette una punizione uguale ai crimini che aveva commesso. Così finì questa piaga [pestis] della gente che si ribella contro i propri superiori”.

Altrettanto atroce a livello simbolico, anche se meno cruenta, fu la pena inflitta dal podestà di Firenze nel settembre 1343 a un paio di "scardassieri"

${ }^{130}$ Sulla negoziazione penale mi permetto di rinviare ad A. Zorzi, Negoziazione penale, legittimazione giuridica e poteri urbani nell'Italia comunale, in Criminalità e giustizia in Germania e in Italia cit., pp. 13-34. Cfr. anche X. Rousseaux, De la négociation au procès pénal: la gestion de la violence dans la société médiévale et moderne (500-1800), in Droit négocié, droit imposé?, a cura di Ph. Gerard, F. Ost, M. Van de Kerchove, Bruxelles 1996, pp. 273-312; e Sbriccoli, Giustizia negoziata, giustizia egemonica cit., pp. 356-359.

${ }^{131}$ Chronicon comitum Flandrensium, in Corpus chronicorum Flandriae cit., vol. I, Bruxelles 1837, p. 208. 
(cardatori di lana) che avevano partecipato al tentativo dei popolani minuti di saccheggiare il palazzo dove si riteneva che fossero ancora custoditi i beni del Duca d'Atene: per sedare la folla, i berrovieri tagliarono una mano (cioè lo strumento di lavoro) a uno di essi, mentre a un suo compagno fu amputato un piede. La folla si disperse rapidamente ${ }^{132}$. Durissima fu anche la repressione che Filippo VI ordinò a Rouen nel 1351, dove i mercanti inscenarono "una sorta di rivolta", come sottolinea il cronista, gettando nella Senna gli armadietti ("les buffés") in cui dovevano essere raccolte le nuove gabelle imposte dal re. L'attentato all'onore del sovrano fu pagato con la morte da 36 mercanti, che furono impiccati alle forche il 9 agosto, mentre tutti i cittadini furono costretti in casa fino a che la giustizia del re non fosse stata eseguita ${ }^{133}$. A Lucca, nel 1371, la rivolta armata promossa da artigiani fu rapidamente repressa dal podestà che arrestò alcuni insorti e ne mise a morte tre (un sarto, un battiloro, e un cittadino appartenente alla parte guelfa, Nuccino Sornachi) decapitandoli nella piazza del comune, mentre a un quarto (un tessitore) fu amputata la mano destra ${ }^{134}$.

In certi casi le autorità emanarono ordinanze d'urgenza per cercare di fronteggiare i disordini. Così, per esempio, a Firenze, nelle giornate dell'insurrezione dei ciompi, i priori disposero la possibilità di giustiziare senza processo ladri e razziatori di beni e mercanzie colti sul fatto: quattro membri di una banda di "certi fiamminghi ch'andavano rubando" per le case e le botteghe saccheggiate dai rivoltosi furono catturati e immediatamente impiccati; "l'un fu impiccato al Prato Ogniessanti, l'altro in sulla piazza di Santa Maria Novella a una finestra ferrata, allato a l'Ospedale de' Pinzocheri, e l'altro in Mercato Vecchio, allato a una colonna sotto un di que' tetti della loggia de' Tavernai; l'altro quarto fu [tratto] in sulla piazza di nostri Signori, ed ivi subito fu fatto un paio di forche e [...] fu impiccato". Si noti l'adesione del cronista alla funzione parenetica della pena: "Onde i ladri e rubatori, veggiendo così impiccare, si ristettono" 135 .

Nella repressione delle sommosse fu ricercata anche una discontinuità dei linguaggi penali. L'inversione delle pene e l'adozione di tipologie punitive particolari ne rappresentarono le forme più comuni.

La semantica delle tipologie penali è a questo proposito esemplare. Poena capitis per definizione, la decapitazione, riservata di norma ai colpevoli di omicidio e di crimini contro il potere, era ritenuta la forma di esecuzione più nobile anche per l'uso della spada e per i suoi echi cavalle-

${ }^{132}$ Cfr. Stefani, Cronaca fiorentina, r. 593, pp. 215-216.

${ }^{133}$ Cfr. Chronique normande de Pierre Cochon notaire apostolique à Rouen, a cura di Ch. de Robillard de Beaurepaire, Rouen 1870, pp. 75-76.

${ }^{134}$ Cfr. Sercambi, Le croniche lucchesi cit., vol. I, pp. 204-205.

${ }^{135}$ Diario d'anonimo fiorentino cit., pp. 359-360. 
reschi ${ }^{136}$. Da sempre, invece, l'impiccagione era considerata la morte più degradante, destinata agli individui di modesta condizione, per l'esposizione alla quale veniva sottoposto il cadavere: riservata in età classica alla punizione degli schiavi ${ }^{137}$, dal tardo medioevo fu intesa invece a colpire i malfattori abituali, soprattutto ladri e rapinatori. Invertirne la destinazione significava denigrare ulteriormente la dignità del giustiziato ${ }^{138}$.

Alcuni esempi fiorentini sono particolarmente espliciti. Nel 1345 lo scardassiere Ciuto Brandini, che aveva cercato di organizzare le prime forme di associazionismo tra i lavoratori sottoposti all'arte della lana, e che per questa attività contro l'ordine sociale e il "quieto e pacifico stato" avrebbe dovuto essere punito con la decapitazione, fu invece "impiccato per la gola” proprio per la sua modesta condizione sociale, come emerge dalle cronache coeve che esprimono il disprezzo del regime mercantile ${ }^{139}$. Allo stesso modo, nel 1368, uno dei popolani che avevano promosso un tumulto per il rialzo del prezzo del grano fu condannato esemplarmente (benché in contumacia) all'impiccagione ${ }^{140}$. E ancora, nel 1400, molti "publici et famosi latrones" furono giustiziati con la spada, mentre contro i protagonisti di un coevo tentativo di complotto, tra i quali erano alcuni esponenti di famiglie di rilievo, fu stabilito che fossero condotti su un carro "usque ad locum iustitie consuetum et ibidem furcis cum catena ferrea ad gulam suspendatur"141. L'inversione della pena era in questo caso inasprita

${ }^{136}$ Nella Roma repubblicana la pena del gladium era riservata ai militari e consisteva nella decapitazione eseguita manu militari: cfr. C. Ferrini, Esposizione storica e dottrinale del diritto penale romano, in Enciclopedia del diritto penale italiano, a cura di E. Pessina, Milano 1905, vol. I, p. 148. Cfr. anche H. von Hentig, La pena. Origine scopo psicologia [1932], Milano 1942, pp. 49-57; e F. Ström, On the sacral origin of the Germanic death penalties, Lund 1942, pp. 162-170.

${ }^{137}$ Cfr. Ferrini, Esposizione storica cit., pp. 145-147. La corda al collo era anche uno degli aspetti della cerimonia di sottomissione volontaria dei liberi a un senior durante l'alto medioevo: cfr. R. Boutruche, Signoria e feudalesimo. Ordinamento curtense e clientele vassallatiche [1968], Bologna 1978, p. 310. Sui significati rituali, cfr. ancora von Hentig, La pena cit., pp. 62-70; e Ström, On the sacral origin cit., pp. 115-160.

${ }^{138}$ Sulla denigrazione dei giustiziati, cfr. A. Zorzi, Dérision des corps et corps souffrants dans les exécutions en Italie à la fin du moyen âge, in La dérision au moyen âge. De la pratique sociale au rituel politique, a cura di E. Crouzet-Pavan, J. Verger, Paris 2007, pp. 225-240.

139 Cfr., per esempio, la Cronica d'Anonimo, in Donato Velluti, Cronica di Firenze. Dall'anno 1300 in circa fino al MCCCLXX, a cura di D.M. Manni, Firenze 1731, p. 148.

${ }^{140} \mathrm{Cfr}$. N. Rodolico, Il popolo minuto. Note di storia fiorentina (1343-1378), Firenze 1968, documento $n^{\circ} 11$, pp. 97-99.

${ }^{141}$ Per le sentenze dei primi, cfr. ASFi, Podestà, 3763, cc. 19r-22v; Capitano del popolo, 2146, cc. 39r-41v e 41v-45v; Esecutore degli Ordinamenti di giustizia, 1414, cc. 81r86r e 89r-94r; per quelle dei secondi, cfr. invece Podestà, 3763, cc. 9r-11v (da cui ho tratto la citazione a c. $10 \mathrm{v}), 15 \mathrm{r}-17 \mathrm{v}$ e $23 \mathrm{r}-25 \mathrm{v}$. 
dalla particolare modalità dell'impiccagione, che intendeva rimarcare l'infamia della pena.

La tipologia penale dello squartamento fu adottata, invece, in più di un'occasione per segnare il tradimento di cui si era reso colpevole il giustiziato $^{142}$. Non solo essa consentiva di esporne in modo ammonitorio le membra in più luoghi, ma evidenziava anche la volontà di non consentirne la sepoltura, impedendo la riconciliazione cristiana. La pena non colpì solo gli autori di congiure - come, per esempio, gli assassini del duca di Milano Galeazzo Maria Sforza nel 1476, che furono straziati a morte per più giorni e poi "come traditori squartati e a pezzi apiccati in diversi luoghi della terra" 143 - ma anche i partecipanti a sommosse e ad atti di insurrezione. A Tournai, per esempio, nel 1307 una sommossa dei follatori che aveva cercato di assassinare il prevosto fu duramente repressa: il suo capo fu trascinato per la città legato ad alcuni cavalli e così squartato; nei giorni successivi altri rivoltosi furono impiccati o decapitati $^{144}$. A Siena, alla fine degli anni settanta del Trecento, un comitatino che aveva tentato, insieme ad alcuni fiorentini, di bruciare la porta di San Marco, fu attanagliato sul carro e "arsegli le mani ne la detta porta", come contrappasso mimetico, e poi "squartato e sospesi i quarti alle porte" della città $^{145}$.

Una variante tipologica era anche l'affogamento. A Parigi, nel 1382, alcuni condannati a morte per un'insurrezione contro il re furono affogati nella Senna dal prevosto regio: l'esecuzione dovette avvenire segretamente perché nei giorni precedenti la folla aveva assalito le forze che stavano portando all'esecuzione uno dei condannati ${ }^{146}$. A Venezia nel 1478 , durante un'epidemia di peste, un eremita ritenuto spia del re Ferrante d'Aragona fu accusato di voler "tosegar [intossicare] i pozi [...] e le pilele di acqua santa dele chiesie": il consiglio dei Dieci lo condannò a morte e "mandato a negar, e ordinato che dove fo butado in aqua, per do mexi non si peschasse"147. Alle donne accusate di tradimento furono risparmiate le tipologie menzionate, sostituite con la pratica che le vedeva quasi

${ }^{142}$ Cfr. Ström, On the sacral origin cit., pp. 168-171.

143 Piero di Marco Parenti, Storia fiorentina, I, 1476-78 - 1492-96, a cura di A. Matucci, Firenze 1994, pp. 3-4.

${ }^{144}$ Cfr. Chronicon Aegidii Li Muisis, abbatis Sancti-Martini Tornacensis alterum, in Corpus chronicorum Flandriae cit., vol. II, Bruxelles 1841, p. 175.

${ }^{145} \mathrm{Cfr}$. Annales senenses ab anno MCCCLXXXV usque ad MCCCCXXII per anonymum scriptorem deducti, in RIS, XIX, Milano 1731, col. 389.

${ }^{146}$ Cfr. Chronique du religieux de Saint-Denys, contenant le règne de Charles VI, de 1380 à 1422, a cura di L.F. Bellaguet, Paris : Crapelet, 1852, vol. VI/1, III, IV, pp. 144-149.

${ }^{147}$ Marin Sanudo, Le vite dei dogi (1474-1494), a cura di A. Caracciolo Aricò, Padova 1989, vol. I, p. 122. 
sempre vittime: il rogo. Così, per esempio, tra i responsabili di un complotto per uccidere il legato pontificio a Bologna, Baldassarre Cossa, nel 1406, una fantesca di nome Bartolomea, "fu arsa [...] sul campo del Mercato, perché portava lettere di tradimento contro il detto legato" ${ }^{148}$.

Come è noto, gli studiosi dei rituali giudiziari sono portati a sottolineare il carattere esemplare e ammonitorio delle pene ${ }^{149}$. Tale funzione $\mathrm{fu}$ raggiunta anche attraverso la riduzione del numero delle esecuzioni e la concentrazione della loro parenesi su poche occasioni. La maggior parte degli esempi finora riportati sono ricavati da fonti cronachistiche, e dunque fortemente selettive. Solo dove si disponga degli atti giudiziari è possibile tracciare un quadro delle pene realmente eseguite. Là dove sono stati condotti, i calcoli rivelano la non ordinarietà delle esecuzioni capitali: esse furono nettamente meno rispetto a quelle irrogate, per la contumacia cui si davano gli imputati anche al fine di negoziare la pena ${ }^{150}$.

I dati disponibili relativi alla prigione parigina dello Chatelet, per esempio, indicano una diminuzione del numero delle esecuzioni tra la fine del XIV secolo e la seconda metà del XV ${ }^{151}$. Sulla spanna dei secoli XV e XVI secolo i giustiziati a Bruxelles furono in media non più di 6 all'anno ${ }^{152}$. Per Firenze, dove disponiamo di dati di lungo periodo, ho potuto calcolare che da una media di circa 11-13 esecuzioni all'anno nel terzo quarto del secolo XIV si scese a 7-8 nel secolo successivo - con anni in cui si tenne una sola esecuzione -, con un lieve incremento tra 9-10 giustizie nel Cinquecento dell'affermazione granducale, e poi un deciso crollo a 2-3 cerimonie annue nel Seicento e 1-2 nel Settecento, prima dell'abolizione leopoldina della pena $^{153}$.

Si tratta di una linea di tendenza che per l'età moderna trova conferme per le altre città di cui si disponga di statistiche. In quelle tedesche, dove il ricorso alla pena di morte divenne abituale solo nel corso del Quattrocento in seguito al consolidamento degli apparati pubblici ${ }^{154}$, l'apice esecutivo

${ }^{148}$ Cfr. Historia miscellanea bononiensis, in RIS, XVIII, Milano 1731, col. 591-592.

${ }^{149}$ Per tutti, cfr. R. Muchembled, Le temps des supplices: de l'obéissance sous les rois absolus: XVe-XVIII siècle, Paris 1992.

${ }^{150}$ Sul nesso tra contumacia e negoziazione rinvio ad A. Zorzi, Diritto e giustizia nelle città dell'Italia comunale (secoli XIII-XIV), in Stadt und Recht im Mittelalter/La ville et le droit au moyen âge, a cura di P. Monnet, O.G. Oexle, Göttingen 2003, pp. 203-204.

${ }^{151}$ Cfr. B. Geremek, Les marginaux parisiens aux XIV et XV siècles, Paris 1976, pp. 59-62; e Gauvard, "De grace especial” cit., pp. 896 sgg.

${ }^{152}$ Tra il 1404 al 1600 vi furono giustiziati 1023 individui: cfr. Lenman, G. Parker, The state, the community and the criminal law cit., pp. 13-14.

${ }^{153} \mathrm{Cfr}$. A. Zorzi, Le esecuzioni delle condanne a morte a Firenze nel tardo medioevo tra repressione penale e cerimoniale pubblico, in Simbolo e realtà della vita urbana nel tardo medioevo, Manziana (RM) 1993, pp. 153-253. 
sembra collocarsi tra XVI e XVII secolo: ad Augsburg tra 1563 e 1615; a Nuremberg tra 1561 e 1620; a Frankfurt tra 1581 e 1600; anche a Zurich la tendenza discendente si pose tra i due secoli, e così a Mechelen nelle Fiandre ${ }^{155}$; ad Amsterdam i dati disponibili indicano un declino netto nella seconda metà del Seicento ${ }^{156}$. In Inghilterra fu il regno dei Tudor a segnare l'apice della repressione più aspra, mentre il periodo tra il 1560 e il 1625 mostra un netto declino delle sentenze di morte emanate dall'Home circuit of the assizes (comprendente le contee dell'Essex, Hertfordshire, Kent, Surrey e Sussex) ${ }^{157}$; mentre i dati - i più completi in assoluto per l'Inghilterra moderna - della Court of great sessions of Cheshire indicano che, toccato l'apice di condanne a morte negli anni venti del Seicento - con oltre 16 casi l'anno -, la media precipitò nella seconda metà del XVII secolo intorno ai 2 casi l'anno ${ }^{158}$.

Per le città italiane, sappiamo per esempio che a Ferrara la media annua di esecuzioni tra 1441 e 1577 fu di 5-6, con oscillazioni a seconda dei regimi signorili estensi e dei tentativi di congiura (più benevolo quello iniziale di Leonello, più aspri quelli di Ercole I e Alfonso II) ${ }^{159}$; anche a Roma si nota un inasprimento nel secondo Cinquecento, seguito poi da un rapido decremento nei due secoli successivi ${ }^{160}$; a Milano, nel secolo di Beccaria, la media annua tra 1700 e 1767 fu di 9-10 esecuzioni ${ }^{161}$. In sostanza, nelle città di antico regime le esecuzioni furono di rado più di una al mese, molto più spesso si tennero ogni tanto nel corso dell'anno, e in certi anni l'evento fu del tutto eccezionale.

\section{La grazia}

La constatazione della relativa intensità delle esecuzioni giudiziarie potrebbe aiutare a riconsiderare anche il luogo comune della repressione incondizionata cui abbiamo fatto riferimento in apertura, e quelle generalizzazioni che hanno fatto da filtro finora a indagini specifiche su questi

${ }^{154} \mathrm{Cfr}$. P. Schuster, Le rituel de la peine capitale dans les villes allemandes à la fin $\mathrm{du}$ moyen âge: ruptures et continuités, in Pratiques sociales et politiques judiciaires cit., pp. 681-712.

${ }^{155}$ Cfr. R. van Dülmen, Theatre of horror : crime and punishment in early modern Germany, Cambridge 1990, p. 83; e anche M. Boone, La justice en spectacle. La justice urbaine en Flandre et la crise du pouvoir "bourguignon" (1477-1488), "Revue historique», 625, 2003, pp. 43-65.

${ }^{156} \mathrm{Cfr}$. P. Spierenburg, The spectacle of suffering. Executions and the evolution of repression: from a preindustrial metropolis to the European experience, Cambridge 1984, pp. 82-83.

${ }^{157}$ Cfr. J. A. Sharpe, Judicial punishment in England, London 1990, pp. 27 sgg.

${ }^{158}$ Cfr. J. Sharpe, Crime in early modern England 1550-1750, London 1984, p. 64. 
aspetti. Verificando l'intensità e le modalità delle pratiche repressive contesto per contesto, caso per caso, si potrebbe constatare così che se per le rivolte della jacquerie o dei tuchini nel sud della Francia furono scatenate delle repressioni sanguinose con esecuzioni di massa nei campi o alle forche urbane, per quella dei ciompi fiorentini, invece, come ha sottolineato di recente Samuel Cohn, la repressione non fu affatto brutale, come era ancora nella immagine di Victor Rutenburg, né diede luogo a espulsioni o a emigrazioni di massa: i ciompi condannati all'esilio nel settembre $1378 \mathrm{fu}$ rono solo 44, e molti ebbero salvacondotti per rientrare in città sin dai giorni successivi, e, alla caduta del regime delle arti minori nel 1382, solo 3 furono giustiziati e 25 inviati all'esilio ${ }^{162}$.

L'elemento più significativo è però forse un altro. Le sommosse e i tumulti offrirono ai governi anche l'occasione per attuare operazioni di indulto e di reintegrazione dei condannati su larga scala. La politica della grazia andò infatti quasi sempre di pari passo con la parenesi della pena. A condizionare tali politiche furono anche stringenti costrizioni di ordine pratico e finanziario: la difficoltà di dotarsi e di gestire efficienti apparati di polizia, e la relativa facilità a usare lo strumento penale come leva fiscale. Resta il dato che alla forca fu più spesso preferita la grazia. Le politiche della grazia sono state studiate per alcuni contesti: le Fiandre e il regno di Inghilterra, per esempio ${ }^{163}$. Esse sollecitarono anche l'aumento delle richieste individuali rivolte direttamente al sovrano o al principe, come ad esempio le suppliche, che costituirono anche in ambito giudiziario un fenomeno nuovo e rilevante tra XIV e XV secolo ${ }^{164}$.

${ }^{159}$ Cfr. W. L. Gundersheimer, Crime and punishment in Ferrara, 1440-1500, in Violence and civil disorder in Italian cities cit., pp. 110 sgg.; e M. S. Mazzi, "Gente a cui si fa notte innanzi sera". Esecuzioni capitali e potere nella Ferrara estense, Roma 2003, pp. 23-24.

${ }^{160}$ Cfr. V. Paglia, La morte confortata. Riti della paura e mentalità religiosa a Roma nell'età moderna, Roma 1982, pp. 110-111 e le statistiche alle pp. 137-155.

${ }^{161}$ Cfr. I. Mereu, La pena di morte a Milano nel secolo di Beccaria, Vicenza 1988, pp. 43-47.

${ }^{162}$ Cfr. Cohn, Lust for liberty cit., pp. 149-150.

${ }^{163}$ Cfr. J.-M. Cauchies, H. de Schepper, Justice, grâce et législation. Genèse de l'État et moyens juridiques dans les Pays-Bas, 1200-1600, Bruxelles 1994; T. S. Haskett, Access to grace: bills, justice, and governance in England, 1300-1500, in Suppliques et requêtes. Le gouvernement par la grâce en Occident (XII $-X V^{e}$ siècle), a cura di H. Millet, Roma 2003, pp. 297-317; ora anche Lacey, "Grace for the rebels" cit.

${ }^{164}$ Cfr. Suppliques et requêtes cit.; e soprattutto le importanti raccolte Suppliche e gravamina. Politica, amministrazione e giustizia in Europa (secoli XIV-XVIII), a cura di C. Nubola, A. Würgler, Bologna 2002; Forme della comunicazione politica in Europa nei secoli XV-XVIII: suppliche, gravamina, lettere, a cura degli stessi, Bologna 2004; Operare 
Mi soffermerò qui sulle rivolte francesi. Scorrendo le edizioni delle lettres de rémission ${ }^{165}$, non può non saltare agli occhi l'ampia azione di indulgenza e di revisione delle pene che fu attuata dai re, dai loro vicari e dai loro consiglieri nei confronti dei rivoltosi. Lo strumento della lettre de rémission si diffuse negli anni trenta e quaranta del Trecento in coincidenza con l'insediarsi al potere da parte della dinastia dei Valois. Attraverso di esso i re francesi svilupparono una politica giudiziaria che era costruita più sulla grazia che sugli strumenti coercitivi ${ }^{166}$. Per più motivi: la sacralizzazione del ruolo misericordioso del re, il rafforzamento dei legami di fedeltà politica al sovrano, e, preminentemente, lo scopo fiscale di fare cassa, grazie ai proventi di ogni atto, e, soprattutto, ai pagamenti che venivano richiesti in cambio dell'atto di clemenza: i ribelli tuchini della Languedoc, per esempio, pagarono 800.000 franchi al re per la remissione delle pene comminate per le violenze del 1381-1384 ${ }^{167}$.

Ecco allora che a beneficiare della grazia del re poterono essere sia singoli che gruppi o intere comunità. Fu il caso, per esempio, nella tarda estate del 1358, di Jehan de Congi, bourgeois del mercato de Meaux, incriminato per avere aiutato i rivoltosi ad assalire e conquistare la cittadina ${ }^{168}$; di Jehan Chandelier, drappiere della stessa località, bandito per avere partecipati ai tumulti ${ }^{169}$; e anche di Guillaume de Chavenoil, canonico di Meaux, accu-

la resistenza: suppliche, gravamina e rivolte in Europa (secoli XV-XIX), a cura degli stessi, Bologna 2007.

${ }^{165}$ Edite in parte in D.-F. Secousse, Recueil de pièces servant de preuves aux mémoires sur les troubles excités en France par Charles II, dit le Mauvais, roi de Navarre et comte d'Évreux, 2 voll., Paris 1755; e in S. Luce, Histoire de la Jacquerie d'après des documents inédits, Paris $1894^{2}$.

${ }^{166}$ Fondamentali sono gli studi di C. Gauvard, L'image du roi justicier en France à la fin du moyen âge d'après les lettres de rémission, in La faute, la répression et le pardon, Paris 1984, pp. 165-192; Ead., Grâce et exécution capitale, les deux visages de la justice royale française à la fin du moyen âge, «Bibliothèque de l'Ecole des Chartes», 153, 1995, pp. 275-290; Ead., Les clercs de la Chancellerie royale française et l'écriture des lettres de rémission aux $X I V^{e}$ et $X V^{e}$ siècles, in Ecrit et pouvoir dans les chancelleries médiévales. Espace français, espace anglais, a cura di K. Fianu, D.J. Guth, Louvain-la-Neuve 1997, pp. 281-291; Ead., Le roi de France et le gouvernement par la grâce à la fin du moyen âge: genèse et développement d'une politique judiciaire, in Suppliques et requêtes cit., pp. 371-404; Ead., Crimes, châtiment et grâce en France à la fin du moyen âge, in L'espai del mal, a cura di F. Sabaté Curull, Lérida 2005, pp. 33-46. Cfr. anche P. Braun, La valeur documentaire des lettres de rémission, in La faute, la répression et le pardon cit., pp. 207222; e L. De Carbonnières, Les lettres de rémission entre Parlement de Paris et chancellerie royale dans la seconde moitié $d u X I V V^{e}$ siècle, «Revue historique de droit français et étranger», 79, 2001, pp. 179-196.

${ }^{167}$ Histoire générale de Languedoc, a cura di C. Devic, J. Vaissète, Toulouse 1872, coll. 1867-1868, $\mathrm{n}^{\circ} 758$.

${ }^{168}$ Cfr. Luce, Histoire de la Jacquerie cit., p. 228.

${ }^{169}$ Cfr. ivi, pp. 230-231. 
sato del medesimo crimine ${ }^{170}$; ma anche di Hue di Sailleville, capo dei rivoltosi del villaggio di Angicourt, sempre nell'Île-de-France ${ }^{171}$; o di Jehan Herssent di Châtres-sous-Montlhéry, che diffuse nel suo villaggio l'annuncio insurrezionale (lanciato da Étienne Marcel) ${ }^{172}$; o di Jehan Morel, curato del villaggio di Blacy (nella Marne attuale), che guidò i suoi parrocchiani a un'assemblea di rivoltosi nel villaggio di Saint-Verain ${ }^{173}$; di Jehan Flageolet di Favresse, che capeggiò la rivolta in alcuni villaggi del Perthois ${ }^{174}$; di Mathieu de Leurel, muratore soggetto alla signoria del monastero di Beaulieu-les-Fontaines nella diocesi di Noyon, che finì di giustiziare Jean Bernier, un "non nobile" accusato di tradimento dai rivoltosi e condannato a morte nel villaggio di Montataire ${ }^{175}$.

La grazia fu estesa anche a intere comunità, come quelle dei villaggi di Bettancourt e di Vroil nel Perthois, condannate dal conte di Vaudemont alla pena di 2.000 scudi, per aver partecipato al terrore contro i nobili ${ }^{176}$; o agli scabini e al comune della città di Amiens per i crimini commessi durante l'insurrezione ${ }^{177}$; ma anche all'intera comunità di Parigi, vale a dire alla sua borghesia, che sotto la guida del prevosto dei mercanti, Étienne Marcel, era insorta contro i rappresentanti del re uccidendo due marescialli ${ }^{178}$. In più di un caso, l'atto di grazia disponeva l'elenco nominativo di tutti gli individui oggetto del perdono regio, come fu il caso degli abitanti di Carcassone che nell'estate del 1364 avevano attaccato un castello regio nelle vicinanze, compiendovi razzie e violenze ${ }^{179}$.

Nei casi appena menzionati si trattava di remissioni di pene inflitte a partecipanti alle rivolte. In altri, la grazia puntò a premiare chi si era opposto, o aveva cercato di farlo, alle violenze. Durante le scorrerie delle bande di tuchini nell'Auvergne, per esempio, gli abitanti di Saint-Flour avevano assalito il castello del signore di Brossadol, che era stato occupato dalla banda di Guillaume Gracia per farne la propria base di razzia, e ne avevano saccheggiati i beni: la lettera di remissione del duca di Berry e

${ }^{170}$ Cfr. ivi, pp. 228-229.

${ }^{171}$ Cfr. ivi, pp. 253-254.

${ }^{172}$ Cfr. ivi, pp. 263-264.

${ }^{173}$ Cfr. ivi, pp. 270-272.

${ }^{174}$ Cfr. ivi, pp. 293-294 (lettre concessa nel luglio 1359).

${ }^{175}$ Cfr. ivi, pp. 333-335 (lettre concessa nel marzo 1364).

${ }^{176}$ Cfr. ivi, pp. 266-268.

${ }^{177}$ Cfr. Secousse, Recueil cit., vol. I, pp. 97-99.

${ }^{178} \mathrm{Cfr}$. Ordonnances des roys de France de la troisième race, a cura di D.-F. Secousse, vol. IV, Supplement pour le règne du roy Jean, les ordonnances de Charles V. données pendant les années 1364, 1365 et 1366, Paris 1734, pp. 346-347; e Secousse, Recueil cit., vol. I, pp. 120-121 (lettre concessa nel dicembre 1358).

${ }^{179}$ Cfr. Histoire générale de Languedoc cit., coll. 1329-1331, n 511. 
Auvergne, figlio del re di Francia, emanata a Parigi nel luglio 1384, cancellò loro ogni pena ${ }^{180}$. Allo stesso modo, sempre a Saint-Flour, fu graziato Girart de Vens, guardiano del castello di Aurose, che aveva ucciso il capobanda tuchino Étienne Boutefeu, per vendicare l'assassinio del fratello Durand ${ }^{181}$.

In altri casi ancora, destinatari del perdono regio furono individui che si erano dissociati dalle violenze cui avevano partecipato. Per esempio, Colart du Four, chiamato Melin, del villaggio di Feigneux nel Beauvaisis, che era stato costretto con le minacce a seguire la compagnia di rivoltosi che si era formata in questa regione durante la Jacquerie, ma che poi era riuscito a tornare a casa senza partecipare alle violenze ${ }^{182}$; o Jean de Corneilles, scudiero figlio del defunto Raimond de Cornillan, cavaliere del villaggio di Pisserguier nella diocesi di Narbonne, che si era alleato con i tuchini della Languedoc, e che aveva partecipato all'uccisione di quattro altri scudieri senza parte attiva e - sottolinea la lettre de rémission - "senza il proprio consenso", che fu liberato dal carcere dello Châtelet di Parigi dove era stato rinchiuso nonostante avesse pagato, a suo tempo, la propria quota di riscatto per il perdono che il re aveva disposto nei confronti dei ribelli della Languedoc ${ }^{183}$.

Interessanti da analizzare si rivelano talora le motivazioni elaborate da parte del re e dei suoi consiglieri per giustificare gli atti di grazia. Nel caso, per esempio, della insurrezione di Parigi guidata da Étienne Marcel nel 1358, il comportamento dei singoli individui e della comunità nel suo insieme fu rappresentato nei termini della buona fede e della mancata consapevolezza: ricorrono, nelle lettres de rémission, espressioni come "tutto ciò che [molte buone persone e popolani fedeli] fecero fu per un buono scopo, per il riscatto e la salvezza del nostro signore [Giovanni II, allora prigioniero degli inglesi], e per il bene pubblico", e "senza l'autorità, il desiderio o il consenso del nostro signore [...] e ignari del grande tradimento e dei crimini che il prevosto [Étienne Marcel] e i suoi complici stavano attuando in segreto" 184 . Le lettres sottolineano poi la lealtà di fondo della comunità e il legame reciproco tra essa e il sovrano. L'accettazione della supplica è motivata dal sovrano "considerando l'amore fedele e la lealtà che il prevosto, i borghesi e gli abitanti di questa

${ }^{180}$ Cfr. M. Boudet, La jaquerie des Tuchins, 1363-1384, Paris 1895, pp. 129-131.

${ }^{181}$ Cfr. ivi, pp. 127-129 (lettre concessa nell'aprile 1383).

${ }^{182}$ Cfr. Luce, Histoire de la Jacquerie cit., p. 260 (lettre concessa nell'agosto 1358).

${ }^{183}$ Cfr. Histoire générale de Languedoc cit., coll. 1867-1868, ${ }^{\circ} 758$ (lettre concessa nel novembre 1395).

${ }^{184}$ Cfr. Ordonnances des roys de France cit., vol. IV, pp. 346-347; e Secousse, Recueil cit., vol. I, pp. 83-85. 
città hanno avuto sempre verso il nostro signore [...] e che è stata dimostrata dalla cattura e dalla distruzione di questi traditori, ribelli e nemici della corona di Francia"185.

\section{La riflessione dei giuristi}

Si ricorderà come il capo dei rivoltosi inglesi nel 1381, Wat Tyler, avesse richiesto, e ottenuto dal sovrano, la formazione di una commissione per giustiziare ("ad decollandum") "omnes juridicos [...] qui vel in lege docti fuere, vel cum jure, ratione officii, communicavere"186. L'attacco agli uomini di legge svelava con lucidità il loro ruolo attivo negli uffici e al servizio delle politiche giudiziarie. Non era un caso, perciò, che anche i giuristi fossero oggetto delle violenze dei rivoltosi, data la loro funzione di "intellettuali militanti" impegnati a elaborare gli strumenti dottrinali per la difesa giuridica degli ordinamenti pubblici ${ }^{187}$.

La riflessione dei giuristi legittimò infatti l'affermazione dei poteri statali nell'Occidente del XIV e XV secolo nel vortice dei "furori contadini" e "delle rivolte urbane". Ė in questo periodo - come è noto - che venne elaborandosi, attraverso il crimen rebellionis, quale espressione giurisprudenziale del problema del reato politico, il nucleo del concetto di crimen laesae maiestatis alle soglie dell'età moderna. Su questi temi rimane fondamentale lo studio condotto da Mario Sbriccoli ormai quarant'anni fa ${ }^{188}$. Difficile poter aggiungere qualcosa di originale rispetto a quella indagine ${ }^{189}: \mathrm{mi}$ limiterò pertanto a richiamarne alcuni punti aderenti al nostro discorso.

Il contesto politico in cui maturarono i percorsi della riflessione giurisprudenziale è quello delle tensioni sociali e politiche all' interno degli stati cittadini e monarchici del tardo medioevo: esse vennero elaborate nei termini di conspirationes, coniurationes e tractatus. Il tradimento, la fellonia, metteva in gioco valori come la fedeltà, la gratitudine, l'obbedienza e la de-

${ }^{185}$ Cfr. Ordonnances des roys de France cit., vol. IV, pp. 346-347.

186 Thomas de Walsingham, Historia Anglicana cit., p. 464.

187 Sul ruolo militante dei giuristi rimangono attuali le pagine di M. Sbriccoli, L'interpretazione dello statuto. Contributo allo studio della funzione dei giuristi nell'età comunale, Milano 1969, pp. 49-81.

${ }^{188}$ M. Sbriccoli, Crimen laesae maiestatis. Il problema del reato politico alle soglie della scienza penalistica moderna, Milano 1974 (a p. 43 le citazioni virgolettate poco qui sopra).

${ }^{189}$ Una variante "regionale" del discorso giuridico è analizzata da J. Dumolyn, The legal repression of revolts in the late medieval Flanders, "Tijdschrift voor rechtsgeschiedenis», LXVIII, 2000, pp. 479-521. Centrata sulla ribellione è invece la raccolta Ordnung und Aufruhr im Mittelalter. Historische und juristische Studien zur Rebellion, a cura di M.T. Fögen, Frankfurt 1995. 
vozione ${ }^{190}$. L'ossessione del tradimento, che ritornava costantemente nel linguaggio del potere, si accompagnava alla liturgia dell'obbedienza. Tradimento e obbedienza erano i presupposti ideologici fondamentali del crimen laesae maiestatis.

Ribelle era, in primo luogo, colui che non obbediva, e dunque esprimeva ingratitudine e si macchiava di un "peccato mortale"191. Nella costituzione di Enrico VII del 1312, Qui sint rebelles, furono poste le basi per la successiva definizione del comportamento ribelle: "illi omnes et singuli sunt rebelles et infideles nostri imperii, qui quomodocunque publice, vel occulte, contra nostrum honorem et fidelitatem rebellionis opera faciunt, et contra nostri imperii prosperitatem aliquid machinantur, contra nos, sive officiales nostros, in hiis quae ad commissum eis officium pertinent, rebellando"192. Su di essa si fondarono Alberico da Rosciate ("Rebellis dicitur inobediens principi circa concernentia prosperitatem imperii") e Baldo degli Ubaldi ("Nota hic dictionem rebelles et istud verbum generale est in quolibet subdito contradicente facto auctoritati superioris") per argomentare in riferimento alle pratiche politiche delle città italiane sull'"obedientia quae debetur principi" ${ }^{193}$. Mentre nel regno di Francia sarebbe stato Jean de Terrevermeille, avocat du roi nella sénéchaussée di Beaucaire, e autore del Tractatus contra rebelles suorum regum della fine del Trecento, a definire come vero rebellis colui che "inobedit regi [...] potissime in his que ad regimen regni pertinent"194.

Con la consueta lucidità fu invece Bartolo da Sassoferrato ad arricchire la qualifica della rebellio, distinguendo la seditio come "facere aliquid contra" dalla semplice infidelitas come "non facere"195. Il civis era dunque colui "qui obedit" (Alberico da Rosciate sostiene, per esempio, lo schema: "civis imperii = qui obedit imperatori"), mentre sul fronte dell' inobbedienza si ponevano la rebellio, la proditio e il crimen laesae maiestatis. Sarebbe stato in particolare Oldrado da Ponte a definire quest'ultima fattispecie in relazione all'obedientia in alcuni consilia dati a Enrico VII in un processo intentato contro Roberto d'Angiò: "ille proprie dicitur crimen laesae maiestatis committere qui, iurisdictioni et potestati imperi suppositus, ab obedientia se realiter subtrahens, hostis animum assumit, et se domino suo adversarium parat" ${ }^{\prime 196}$.

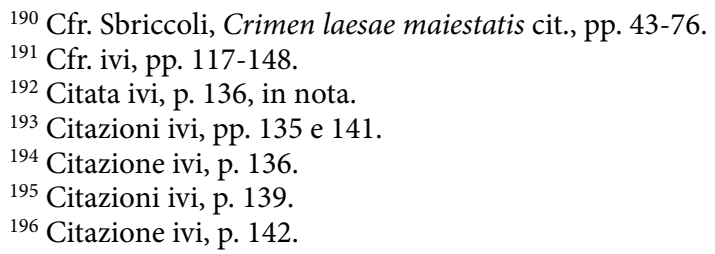


Quanto al tradimento, crimen execrandum, i giuristi tesero ad elaborarlo come una fattispecie concreta del crimen proditionis, facendolo così rientrare nel sistema del crimen laesae maiestatis ${ }^{197}$. Quest'ultimo, come ha evidenziato Sbriccoli, venne infatti connotandosi come un vero e proprio "sistema" in espansione, che tese ad allargare aree di incidenza e a moltiplicare le sue fattispecie, infiltrandosi in tutti i momenti della vita associata ${ }^{198}$. Si produsse per tal via una politicizzazione di molti reati "comuni", uno "straripamento della sfera del politico al livello di società civile"199. Questa tendenza si accompagnò alla moltiplicazione dei titolari della maiestas (come distinti dai subditi) che arrivò a comprendere gli ufficiali anche minori come gli esattori della tasse e i berrovieri ${ }^{200}$.

La tendenza alla politicizzazione dei reati comuni può essere scandita nel suo divenire: silente o dubbiosa nei giuristi di età comunale (in Alberto da Gandino, per esempio, come poi in Alberico da Rosciate o in Bartolo), essa cominciò a essere accennata in autori trecenteschi come Jacopo da Belviso e Bonifacio Vitalini per poi essere espressa apertamente, sia pure in forme ancora cautelose, da Angelo Gambiglioni nel primo Quattrocento. Le reticenze dei penalisti sarebbero scomparse del tutto tra Quattro e Cinquecento, quando il consolidamento dei poteri regi e signorili legittimò la dilatazione del crimen a tutto vantaggio dei poteri del princeps rispetto ai cittadini e ai sudditi ${ }^{201}$. La dottrina pre-cinquecentesca elaborò anche una distinzione tra il crimen rebellionis e il crimen laesae maiestatis ${ }^{202}$ : vi rifletterono sopra Bartolo, Baldo, il Gambiglioni. Fu un contemporaneo di quest'ultimo, Matteo degli Afflitti, a redigere il primo elenco dei comportamenti criminosi ascrivibili al crimen laesae maiestatis, specificando ben 45 fattispecie ${ }^{203}$.

Rimanendo alla gerarchia dei fatti di ribellione, la dottrina distinse tra il concetto di rebellio e quello di seditio ${ }^{204}$. La rebellio, il cui dato fondamentale era la disobbedienza e il potenziale tradimento, lesivi della maiestas, atteneva al comportamento individuale, e si connotava come una contestazione del potere (dello stato), perché ne negava l'autorità e ne metteva in pericolo l'esistenza: per questo motivo il ribelle era un nemico, ostile allo status reipublicae. La seditio invece definiva la rivolta di

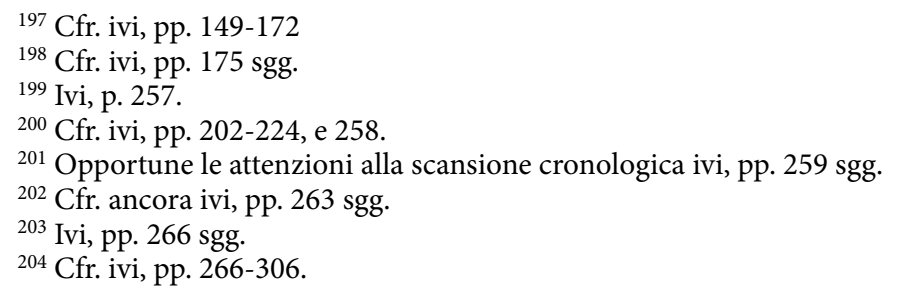


più persone, preceduta da un minimo di preparazione, sia pure spontanea: essa venne qualificata come "quietis publicae turbatio", "dissensio animorum", "turbatio status civitatis", come agitazione che tende allo scontro. Turbando la pax publica, contraddiceva la giustizia e il bene comune, e si connotava moralmente come mortale peccatum, per la atrocitas, la gravitas, l'enormitas. Attentando alla sicurezza dello stato, il seditiosus non commetteva solo un grave crimen rebellionis, né si limitava a offendere la maiestas principis, ma agiva obiettivamente a favore dei nemici esterni, presentandosi, in certa misura, come hostis e come proditor $^{205}$.

La fenomenologia della seditio fu a sua volta anatomizzata dalla dottrina ${ }^{206}$. Alle grida sediziose seguiva il turbamento dell'ordine pubblico, che era turbamento della quiete pubblica, della pax publica; la concitatio populi poteva quindi degenerare in una congregatio armatorum, tale da "frangere pacem publicam"; la sedizione si esprimeva anche nel tumultus ("confusione", "turbamento", "dissenso"), nelle factiones e nelle partialitates (cioè le divisioni interne al popolo, che rompevano il bene più prezioso dello stato, la sua unità, la sua concordia); corollari ne erano il facinus (l'azione dolosa) e la rixa.

\section{In conclusione: l'ideologia dell'ordine}

Alla sottile riflessione dei giuristi, ricca di sfumature e di tassonomie, si affiancò peraltro anche l'elaborazione di un discorso pubblico di tenore collettivo, alla cui definizione non contribuirono solo i giuristi ma anche altri intellettuali, teologi e gli stessi cittadini al governo. Mi riferisco a quella ideologia del "pacifico e quieto stato" che echeggia di continuo nei documenti pubblici coevi, come anche nelle cronache delle lotte, dei tumulti, delle sedizioni politiche, quale funzione primaria dei governi, a tutela del "bene comune"207.

La politica dell'ordine pubblico comportava infatti un'implicazione più ideologica che immediatamente amministrativa. Nella dottrina l'ordine pubblico si riassumeva nell'ordinamento politico, nell'ordo civitatis e nella pax publica. Tra i fini costitutivi del governo erano anzitutto la sicurezza e la punizione: ordine pubblico e autorità del potere politico si misuravano

${ }^{205}$ Riprendo alla lettera ivi, p. 278.

${ }^{206}$ Cfr. ivi, pp. 283-306.

${ }^{207}$ Sul "bene comune", cfr. ora De bono communi. The discourse and practice of the common good in the European city $\left(13^{\text {th }}-16^{\text {th }} c\right.$. $)$, a cura di E. Lecuppre-Desjardin, A.-L. Van Bruaene, Turnhout 2009. 
nella efficacia dell'azione di governo ${ }^{208}$. Instabilità e disordini venivano crescentemente percepiti come effetti della mancata o inadeguata punizione dei delitti.

A conclusione di questo excursus sul costante riproporsi della questione della giustizia e dell'ordine pubblico sia nelle rivendicazioni e negli attacchi violenti dei rivoltosi sia nelle politiche giudiziarie e repressive da parte dei poteri pubblici, porrò tre esempi di elaborazione del discorso pubblico che mostrano come, nei decenni centrali del XIV secolo, in contesti politici molto diversi stesse maturando un comune linguaggio dell'obbedienza all'ordine promosso dai nuovi poteri.

L'esempio celeberrimo è quello del ciclo di iconografia politica affrescato nel 1338-1339 da Ambrogio Lorenzetti nella sala del palazzo pubblico di Siena dove si riuniva il collegio governativo dei Nove ${ }^{209}$. Vi si possono rintracciare chiari elementi del linguaggio che chiamerei della ammonizione. Virtù in posizione centrale nell'affresco è - come è noto la Pax: essa però non è l'esito della concordia dei cittadini, bensì una pace armata, come rivelano le armi che spuntano da sotto il cuscino su cui è adagiata "melanconicamente" (cioè minacciata, "dubbiosa e sempre in bilico" ${ }^{210}$ ). A sua volta, la Iustitia tiene in mano una spada e nel grembo una testa mozzata. Il Buongoverno è poi assicurato dalla Securitas, che presidia le mura librando nell'aria una forca da cui pende un impiccato, e un cartiglio su cui è scritto: "Senza paura ogn'uom franco camini, / e lavorando semini ciascuno, /mentre che tal comuno / manterrà questa donna in signoria, / ch'el à levata a' rei ogni balia". Il discorso è chiaro: in città regna la pace, essa è il frutto dell'ordine armato e garantito dalla giustizia penale, e ogni tentativo di rivolta sarà domato in modo duro.

Qualche anno dopo, nel 1342, nell'isola greca di Creta il governo della repubblica veneziana represse una rivolta della popolazione locale che aveva distrutto i castelli controllati dai veneziani. La punizione si limitò a colpire i leaders, giustiziati con varie modalità (decapitazione, impiccagione e affogamento). La popolazione fu invece perdonata: il maggiore storico veneziano del secolo successivo, Marin Sanudo, sotto-

${ }^{208}$ Rinvio ancora alle osservazioni di M. Sbriccoli, Nox quia nocet. I giuristi, l'ordine e la normalizzazione dell'immaginario, in La notte. Ordine, sicurezza e disciplinamento in età moderna, a cura Id., Firenze 1991, pp. 9 e 15-16.

${ }^{209}$ Come è noto, la letteratura sul ciclo senese è estesissima: mi limito a rinviare alla recente sintesi di P. Boucheron, "Tournez les yeux pour admirer, vous qui exercez le pouvoir, celle qui est peinte ici”. Le fresque du Bon Gouvernement d'Ambrogio Lorenzetti, «Annales. Histoire, sciences sociales», 60, 2005, pp. 1137-1200.

210 Come ha finemente osservato P. Schiera, Il Buongoverno "melancolico" di Ambrogio Lorenzetti e la "costituzionale faziosità" della città, «Scienza e politica. Per una storia delle dottrine politiche», 34, 2006, pp. 93-108 (citazione alla p. 101). 
lineò come tale clemenza fosse stata disposta "affinché i greci tornassero ad essere nostri sudditi fedeli" ${ }^{211}$. In questo caso fu usato il linguaggio del perdono.

Il linguaggio della riconciliazione è invece quello adottato nella lettera che il re Giovanni II rivolse ai parigini pochi giorni dopo il suo ritorno trionfale in città nell'agosto del $1358^{212}$ : i borghesi e gli abitanti di Parigi sono appellati come "veri cari e buoni amici", ingannati da "false parole, proclami e strumenti maliziosi" per essere spinti "dalla nostra obbedienza e guida alla disobbedienza e alla ribellione". L'inganno è stato ordito da forze maligne, ma "voi avete trovato la retta via e sfidato il potere di queste", e una volta smascherato il loro "tradimento e la loro malizia" siete tornati "con lealtà e senza esitazioni alla nostra signoria e obbedienza [...], tributando il vostro rispetto a noi e alla corona di Francia, come avevano sempre fatto i vostri buoni e fedeli predecessori". Dopo avere ringraziato Dio, prosegue la lettera, "vi ringraziamo veramente di cuore per l'amore, la fedeltà, la lealtà e l'obbedienza che ci avete dimostrato [...], e desideriamo che sappiate che riconosciamo queste cose con tutto il nostro cuore". Si giunge quindi alla promessa di lealtà reciproca: "Noi e i nostri successori rimarremo sempre leali a voi e a questa buona città. Preghiamo ferventemente affinché sempre perseveriate nell'essere sempre migliori nella lealtà e nell'obbedienza verso di noi. In cambio nostro figlio $[$ Carlo $\mathrm{V}]$ vi amerà, difenderà, proteggerà e sosterrà con tutto il suo potere, come facciamo noi, contro tutti coloro che intenderanno danneggiarvi e mettervi in difficoltà". La chiusura del messaggio si concentra sul potere di giustizia: "E se qualcuno, per sua semplicità, è stato ingannato sotto l'apparenza della buona fede, noi abbiamo deciso di non applicare la lettera della legge ma di concedere la grazia e la remissione, se costui ne sarà degno".

${ }^{211}$ Marin Sanudo, Vitae Ducum Venetorum italice ab origine Urbis sive ab anno CCCCXXI usque ad annum MCCCCXCIII, in RIS, XXII, Milano 1733, col. 607.

${ }^{212}$ Secousse, Recueil cit., vol. I, pp. 87-88 (lettre concessa il 14 agosto 1358). 


\section{INDICE DEI NOMI E DEI LUOGHI}

\section{Avvertenza}

Sono stati indicizzati i nomi di persona e di luogo che compaiono nel testo e nelle note, compresi i nomi degli autori (cognome per esteso e nome puntato) salvo che non compaiano come riferimento bibliografico. Abbiamo unificato le varianti -quando possibile- alla versione italiana. Per la natura fortemente tematica del volume si è scelto inoltre di segnalare nell'indice i nomi colletivi dei rivoltosi (Es. Ciompi, Hussiti) e quelli delle fonti narrative impiegate. Non sono stati indicizzati i nomi dei poteri sovranazionali (Es. Chiesa, Impero) né quelli degli enti di governo locale (Es. Cortes, Parlamento) né i riferimenti geopolitici di carattere generale (Es. Europa, America).

Aardenburg 33

Abel, W. 341

Acaia, principe di 153, 159, 161, 162, $170,174,176,179,183,186,187$, 192

Acciaioli, Alamanno 296

Adda, fiume 202, 211

Adimari, famiglia 286, 361

Adolphe de Nassau 114

Adria 253n

Aglié 164, 165, 176, 188

Agnelino del Pian di Carpene 280

Agnola di Tura del Grasso, cronista $2 n$

Agnolo da gli Statuti, ser 280

Agreda 90

Aiguèze, castello di 70

Aimone, converso 227n

Aimone, priore 236
Alatri, 231, 233, 234, 245

Alberti, Leon Battista 306n

Alberto di Asburgo 114

Alberto, monaco, 247

Albizzi, famiglia 295n

Albornoz, Egidio cardinale 376

Alfani, G. 1

Alfonso X, re di Castiglia 74, 75, 76

Alfonso XI, re di Castiglia 79, 81, 85, 86

Algeria 140

Alighieri, Dante 367

Alma, fiume 228

Alpe del Belvedere 222, 222n

Alpe della Chiusa 239, 240n

Alpe Serpentera 222, 223n

Alpi Cozie 242

Alpi Marittime 223, 228

Alpi occidentali 221 
Alpi 156, 191, 224, 228, 248, 343n Alsazia 25, 26

Altoviti, famiglia 362,363

Amblardo, priore 227n

Amburgo 127

Amiens 53, 56, 413

Amsterdam 410

Anagni 233, 244n

Anastasi, famiglia 357

Andalusia 75, 75n, 79

Andergassen, D. X

Andreolli, B. 96, 96n, 97, 251n

Andreozzi, D. 96n, 97

Angicourt 413

Angioini vedi D'Angiò

Annales Mediolanenses 205, 211

Annales Parmenses, 206

Annali di Dunstable 14

Anomimalle Chronicle vedi Cronaca dell'Anonimalle

Antonio de Retenate 206

Antonio di Fissiraga, podestà di Bologna 385

Antonio di Mazzé 164, 165

Aosta 178, 180, 181, 184

Aquitania 56

Aragona 65, 341n

Ardicio De Ponçonasco, campario 230n

Ardua, Certosa di 224

Arduino da Dugliolo, 268, 269

Arezzo 96

Argelato 254, 263, 265, 266, 269

Aristotele 39

Armagnacchi 54, 68

Arno, fiume 368

Arona, monastero di 309

Arosio 200

Arques 36, 56n, 63n

Arras 23, 28, 53, 396

Arte della Lana 102, 288, 293, 294,
295, 295n, 297, 298, 298n, 299n, 302, 388, 403, 407

Artois 23

Arundello 177

Asburgo (Habsbourg), dinastia 47, $115,149,150$

Assisi 312

Astessanus de Marsilia 239n

Asti 236, 240, 240n

Asturie 79

Athis-sur-Orge 32

Attichy 56

Auer, famiglia 115, 117, 129

Augsburg 108, 114-117, 119, 132, $135,136,140,142,410$

Aurose, castello di 414

Auvergne 56n, 68n, 69, 413, 414

Auxerre 57, 63

Avigliana 190, 226n

Avignone 41, 41n, 244, 328

Aymo, frate 243n

Azario, Pietro cronista 156, 156n, $157,158,158 \mathrm{n}, 159,160,162$

Baciacomari, Alberto 263

Baena 90

Bagnacavallo 254

Bagni 265, 266

Bagnols sur Cèze 70

Baiamonte, Tiepolo 397

Balangero, castello di 185

Baldissero 174

Baldo degli Ubaldi 52, 351, 416

Bâle 114, 117, 134

Ball, John 6, 30, 143, 333, 334n, 387

Baratino 258

Baratonia, visconti di 226, 226n, 227n, 228

Barbania 157, 193

Barbarossa, Federico vedi Federico I

Barbero, A. 219, 317n 
Barbette, Etienne 65

Barcellona 319

Bard 153, 174, 175, 178, 179, 180, 187, 190

Bardi, famiglia 286

Bari 95

Barletta 344

Bartolo da Sassoferrato 52, 351, 416

Bartolomea, fantesca 409

Bartolomeo di Ceccarello 280

Bastari, Filippo 287

Baudana, Giacomo 239n

Baviera 320n

Baviera, duca di 144

Bazzano 260

beato Nicola, chiesa del 267

beato Dionigio, chiesa del 267

beato Giacomo de Caxadeo, convento del 268

Beaucaire 68, 416

Beauce 65

Beaulieu-les-Fontaines, monastero di 413

Beaumanoir, Philippe de 57, 58

Beauvais 61

Beccadelli, famiglia 274

Beccaria, Cesare 410

Becker, M. 364, 379

Bedfordshire 317

Belardino d'Andrucciolo 280

Belgio 23

Belvedere, castello di 264, 264n

Bene Vagienna 229

Bentivoglio, famiglia 275, 275n.

Bentivoglio, Francesco beccaio 275

Bentivoglio, Ivano beccaio 275

Benvenuto, frate 267

Berardello 280

Bercy 32n, 66n

Bergamo 201, 389

Berlino 327
Bernardo, frate 227n

Bernier, Jean 413

Beroardi, Guglielmo 242n

Berry 59, 67, 413

Bertelli, S. 296

Bertinoro 254

Bettancourt 413

Beverley, 6, 9

Béziers, 55, 56, 67, 69, 70

Bianchi, Andrea, priore 247

Biandrate, conti di 157

Billanovich, G. 17n

Billen, C. 17

Bisano 258

Blacy 413

Blickle, P. 20, 20n, 32, 137, 138, 218, 249

Bligny, B. 225

Bloch, M. 99, 305, 308, 339

Blockmans, W. 20, 21

Boca, Enriotto notaio 194

Boccadiferro, Filippo prestatore a usura 275

Bocchimpani, famiglia 369

Bocchimpani, Giovanni 369

Boemia 105, 106, 115, 132, 138, 151n, 330 n

Bois, G. 339

Bologna 3, 251-276, 313, 344, 356, 385, 389, 409

- borgo di San Mamolo 268

- piazza del comune 269

- porta Ravennate 251, 269, 270

- san Giacomo, ospedale di 267

- san Matteo Apostolo, chiesa di 268

- santa Croce di Bologna, chiesa di 273

- santa Maria in Monte, chiesa di 267

- Spirito Santo, chiesa dello 268 
- via di San Martino, 265

- via Saragozza 268

Bolzano 355

Bonaccolsi, famiglia 253, 253n

Bonaventura, Romano cardinale 232, $232 n$

Bonbologno di Bencivenne, sindaco 264

Bonifacio IX, papa 358

Bonifacio VIII, papa 254

Bonromei, famiglia 274

Bonifacius Paruçia 239n

Borbone, Bona di, contessa 153, 165, 191

Borbone, duchi di 190n

Borbone, Luigi di, duca 153

Borgogna 53, 65

Borgogna, dinastia 22, 23, 42, 42n, 47

Borgognoni, fazione 47, 54, 68

Borgomasino 164

Borgone (San Valeriano) 243n

Borgo Panigale 265

Bortolami, S. 96n, 97, 314

Bosconero 156n

Bosone Carbonello 226n

Bote, Herman cronista 109, 110, 134, 141

Botti, Francesco ufficiale delle biade 269

Boudet, M. 52n

Bourges 279, 282, 292

Bourin, M. IX, 332, 343, 345, 348

Boutefeu, Étienne 414

Bouvines 26

Brabante 18, 22, 34n, 36-39

Bracton 318

Brancaleone, famiglia 357

Brandeburgo, marchese di 355

Brandini, Ciuto, scardassiere 101, 344, 407

Braunschweig 387
Bredene 405

Bredulo 240n

Brema 108, 116, 117, 120, 135, 136, 140

Brentwood 385n

Brescia 254

Breslau 133

Bressano, signoria 239

Bretagna 61

Breydel, Jan, macellaio 30

Brianza 198, 199

Briga 235, 238

Brigida di Svezia 333n

Brione, monastero di 226n

Bristol 5, 11

Brivio 202

Broglio D’Ajano, R. 281, 294n

Brossadol, castello di 413

Brosso 182n, 177, 182

Brucker, G. A. 296, 298n, 303n, 379

Bruges 23-25, 27-33, 35, 36, 41-43, 46, 396, 405

Brun, Rudolf 115

Brunel, G. 49, 51, 52

Bruno di Colonia 217, 222, 224

Brunswick 107-111, 119, 120, 127, $128,132-134,140,141,147$

Bruxelles 17, 18, 28, 47, 409

Buggia, fiume 226

Bulst, N. 17

Buoninsegni, Domenico, cronista 146

Bury St Edmunds 6, 10, 13, 386,

Butterwick, sir John, vice sceriffo 386

Caboche 30

Cade 9

Cagnin, G. 306n

Cahors 66

Calabria 224

Calais 28, 61 
Calcara 272-74

Cambrai 28

Cambridge 6, 6n, 8, 13

Camera Apostolica 245

Caminus, vicario 237

Campania 232, 232n, 233

Canavese (Canapicio) 153-196

Canavese, conti di 157, 157n

Canavese, Torre 194

Candia 191n

Canetolo 265

Cannero 309

Canobbio 214

Canterbury 386

Cantù 198, 201, 211, 213, 214-215

Capetingi, dinastia di re Francesi 50

Capitani, O. 325

Capoccia, Angelo, vicario 332n

Capurro, Piero marinaio 3

Carcassonne, 56, 60, 67

Carle, Guillaume 53, 56

Carlo di Navarra 50, 53, 58, 68

Carlo IV di Lussemburgo, re di Boemia e imperatore) 106, 114$116,125,130$

Carlo IV, re di Francia 35, 106, 114 $116,125,130,163,330 \mathrm{n}$

Carlo V, imperatore $47,47 \mathrm{n}$

Carlo V, re di Francia 39, 42, 54, 420

Carlo VI, 'il folle', re di Francia 3, 42, $49,59,63 n, 71,332 n$

Carlo VII, re di Francia 60

Carraresi, famiglia vedi Da Carrara

Casalina 311

Casella, Giacomo, beccaio 274

Casotto, Certosa di 221, 224, 240, 240n, 248, 249n

Cassel 36

Castel San Pietro 260, 276

Castelbarco, signori di 355

Castelfranco (Castro Franco) 260,
Castellamonte 176, 177, 181

Castellamonte, conti di 174, 193

Castellar, grangia del 241

Castelseprio 204

Castenaudary 69

Castiglia, regno di 73-91, 385

Castiglione 191n, 268

Catalogna 319, 341n

Cavendish, sir John 387

Cavicciuli, famiglia 362, 363

Cazzano 265.

Cento 254,

Ceresole 178

Ceriana 308

Cesena 4, 254

Ceva, marchesi di 235, 235n, 246-248

Challet, V. 51, 54, 58, 67n, 68n, 69, 70, 70 n, 74,154

Champagne 24, 28, 54, 54n, 56, 62, 68,316

Champorcher 178

Chandelier, Jehan drappiere di Meaux 412

Chateaubriand, Francois René de 43

Châteauneuf-les-Tours 60

Chatelargent 178

Châtelet, carcere di Parigi 414

Châtres-sous-Montlhéry 413

Cheapside 387

Cherubini, G. IX, 381

Cheshire 10, 410

Chevalier, B. 50, 51, 55, 56

Chiaravalle, monastero di 203, 204

Chiavelli, Alberghetto [II] signore di Fabriano 358

Chiavelli, Battista 358

Chiavelli, Chiavello 358

Chiavelli, famiglia 358

Chiavelli, Guido 358

Chiavelli, Tomasso 358

Chinon, 60 
Chittolini, G. 96n

Chiusa di Pesio 223n, 228-230, 235, $236,238,239,239 n, 240-243,245-$ 248

Chivasso 190

Chratzer, famiglia 129

Chronicon comitum Flandrensium 405

Chronicon Estense 368, 371-373

Chronicon Parmense 356

Chy 177, 181, 193

Ciconio 186

Ciompi IX, X, 2, 3, 41, 50, 54, 94, 95, 99-104, 124, 146, 277, 287, 289291, 294, 295n, 296-300, 303, 326, $330,331,331 \mathrm{n}, 337,338 \mathrm{n}, 340$, 347, 386, 388, 391-393, 397, 406, 411

Cirié 174, 176, 183n, 183, 187, 188

Cirié, Vauda di 156n

Cistovzonov, A.H. 339

Cîteaux 220

Civitavecchia 232

Clareno, Angelo 330n

Clemente IV, papa 244

Clemente VI, papa 327, 330n

Clerkenwell 8

Clermont-l'Hérault 56, 56n, 57, 69

Cly 189

Cobbe, Geoffry 6

Cohn, S. 51, 100, 215n, 251n, 296, $344 n, 348 n, 382 n, 411$

Cola di Rienzo 30, 327, 328

Colapietra, R. 97

Collepardo, castello di 230-234

Colleretto 194

Colmar 135, 151

Cologna 253n

Colonia (Cologne) 108, 116, 126, $128,132,135,136,141,149$

Comba, R. 97, 337
Comboira 227

Como 201, 204, 205, 211-213, 215

Compiègne 62

Conscience, H. 18

Consovero, grangia del 240, 249

Cordova 85

Corgniaco vedi Cuorgné

Corio, Bernardino 186, 186n, 206, 207

Cornovaglia 9

Corpus Christi, collegio del 8

Cortonesi, A. 96, 96n, 97

Corverio, fiume 228

Coscetto da Colle da Ranieri 367, 368

Cossa, Baldassarre, legato papale 409

Costanza 107, 124, 129, 135

Courtrai 31, 32, 35, 42

Cracovia 136

Crema 201

Crespellano 260, 272

Creta 419

Crevalcore 254, 258, 260, 262, 265, 274n, 276

Crivolo, Stefano, cronista 228, 228 n, 239, 246-248

Corpus chronicorum bononiensium 251

Cronaca cittadina detta del Graziani 376

Cronaca dell'Anonimalle 7, 8

Cronaca dello Squittinatore 300

Cronaca Seconda d'Anonimo 300

Cronica di Anonimo romano 328

Cuellar 78

Cuenca 77

Cuneo 235, 235n, 237, 239, 241, 242

Cuorgné 156n, 175, 187-190, 194, 195

Czok, K. 122, 124

D’Acaia, Filippo 161, 170n, 192

D’Acaia, Giacomo 161, 170 
D'Acaia, principe 153, 159, 161, 162, 170, 174, 176, 179, 183, 187

D’Angiò, Carlo I 237, 240

D’Angiò, famiglia 237n, 315

D’Angiò, Giovanna 240, 396

D’Angiò, Luigi 164

D’Angiò, Roberto 209, 242, 400, 416

Da Belviso, Jacopo 417

Da Carrara, famiglia, signori di $\mathrm{Pa}-$ dova 306, 354, 360

Da Carrara, Francesco il Giovane 374, 375

Da Carrara, Francesco il Vecchio, Signore di Padova 374

Da Correggio, Giberto signore di Parma 356

Da Costoza, Conforto cronista 373

D'Este, Alberto IV 371, 372

D’Este, Aldovrandino 369

D’Este, Alfonso II duca di Ferrara, 410

D’Este, Azzo VIII 253, 254, 260, 261, 369

D’Este, Beatrice 206

D’Este, Ercole I, duca di Ferrara 398, 402, 403, 410

D'Este, famiglia, signori di Ferrara 253n, 275, 369, 370

D’Este, Francesco 369

D’Este, Fresco 369, 370

D'Este, Leonello 410

D’Este, Niccolò II 371, 372

D'Este, Obizzo 253, 368

D’Este, Rinaldo 369

Da Gandino, Alberto 417

Da Norcia, Simone 375

Da Rosciate, Alberico 416, 417

Da Tortona, Tommaso 371, 372, 375, 379

Dalle Fornaci, Cecco 284

Damaška, M. 399
Damme 28

Dampierre, conti di 21, 29, 30, 33, 35, 42

Dannelo 280

Danzica (Dantzig) 111

Davies, R. R. 10

De Ambrosio, Matteo 190

De Beaumanoir, Philippe 57, 58

De Brimeu, Guy 44

De Bruges, Galbert 26n

De Cassel, Robert 35

De Castro, Felipe 90

De Challant, Yblet 162, 165, 172, 174, 177, 180, 181, 183, 187

De Chavenoil, Guillaume, canonico 412

De Chignin, Barthélemy 163, 172

De Commynes, Philippe 44n

De Congi, Jehan, 412

De Corneilles, Jean, scudiero 414

De Cornillan, Raimond 414

De Deken, Willem, 'maire' 36-38

De Dinant, Henri 12

De Grandson, Othon 174, 176, 180

De La Roncière, C. M. 94, 95, 102, 103, 296, 326, 330, 331, 331n

De Lancaster, Edmond conte $64 \mathrm{n}$

De Lettenhove, K. 17, 18

De Leurel, Mathieu muratore 413

De Male, Louis conte 41, 41n

De Male, Marguerite 31

De Mendoza, Juan Hurtado 90

De Mirabello, Simon 38

De Molina, Marie 79

De Montfort, Earl Simon 13

De Montilino, Franceschinus notaio 373

De Namur, Jean 35

De Nevers, Louis conte 35, 37

De Picquigny, Jean 68

De Poitiers, Alphonse 66 
De Quixlay, Simon 6

De Roover, R. 296

De Silvesco, famiglia 190

De Terrevermeille, Jean 416

De Venette, Jean 51, 53, 61

De Vens, Durand 414

De Vens, Girart guardiano del castello di Aurose 414

Degli Afflitti, Matteo 417

Degli Arcipreti, Colino 281

Del Bosco, Ugo, priore 227n

Del Castillo, Galíndez, cronista 82

Delfinato 316, 316n

Délicieux, Bernard 60, 67

Della Faggiola, Uguccione, signore di Pisa 254, 365- 367

Della Gherardesca, Gherardo 367

Della Gherardesca, Ugolino vedi Ugolino di Donoratico

Della Scala, Cangrande 355

Della Scala, Cangrande II 354, 355

Della Scala, famiglia, signori di Verona 354

Della Scala, Fregnano, 354, 355

Della Scala, Mastino II 354

Della Torre (De la Ture), famiglia 198, 202, 207, 208, 209, 355

Della Torre, Gianfredo 209

Della Torre, Guido 208

Della Torre, Martino 208

Della Torre, Napoleone

Dentici Buccellato, R. M. 96n

Desio 198, 202

Detmar, cronista 147

Devon 9

Devroey, J.-P. 17

Di Brienne, Gualtieri (Duca d'Atene) 360-364, 377, 379

Di Cardona, Raimondo 211

Di Carpegna Falconieri, T. 328, 329n, $330 \mathrm{n}$
Di Donoratico, Fazio Novello signore di Pisa 365, 366

Di Donoratico, Gherardo, signore di Pisa 365, 366

Di Donoratico, Ranieri signore di Pisa 365, 366

Di Donoratico, Ugolino signore di Pisa 365-367

Di Rienzo, Cola 30, 327, 328

Di Sailleville, Hue 413

Di Valois, Filippo 210

Di Vico, famiglia 377

Di Vico, Francesco Signore di Viterbo 375, 376, 379

Diario del Graziani 280, 281, 291

Digione 42

Dini, B. 95

Dini, Taddeo, frate 104, 330

Dollinger, P. 124, 128

Domenico di Lano, ligrittiere, 292, 293

Domenico di Sora, abate 231

Domesday Book 318

Don Juan vedi Giovanni I, re di Castiglia

Don Pedro 79

Don Sancho vedi Sancio IV, re di Castiglia

Donati, famiglia 361,362

Donato di Neri, cronista 278, 279, 281, 284, 285, 293

Dora Baltea, fiume 156

Dora Riparia, fiume 225

Doren, Alfred 100

Doria, famiglia 3

Douai 23, 27, 28, 31

Dozza 254, 259

Drusacco 182

Du Four, Colart detto Melin 414

Dubois, J. 220

Duby, G. 339, 339n 
Durazzo 258

East Riding 9

Edoardo I, re di Inghilterra 10

Edoardo II, re di Inghilterra 13, 384

Edoardo III, re di Inghilterra 37, 38

Egen, Peter (von Argun) 115

Egidio da Argelato 263

Egitto 219

Eici, selva d' 231, 234, 243, 245

Einbeck 120

Elne 319

Engel, E. 125

Engels, F. 323, 327

Ennen, E. 125

Enrico II, re di Castiglia 90

Enrico III, re di Castiglia 90

Enrico III, re di Inghilterra 13

Enrico IV, re di Inghilterra 11

Enrico VII, re di Inghilterra 10

Enrico VII, imperatore 208-210, 400, 416,420

Enrico, visconte di Baratonia 226n

Envie 248

Erbstösser, M. 324, 325

Erfurt 108, 114, 132, 136, 139n, 147, 387

Ermenonville, castello di 53

Ernici, monti 231

Essex 6, 10, 317, 385n, 386, 410

Estella 95

Estremadura 79

Fabriano 357-359

Facius Canus 239

Faenza 254, 349n

Fasano Guarini, E. 359

Favria, signori di 164

Federico I, imperatore 199, 225

Federico II, imperatore 112, 235n

Federico di Asburgo 114
Feigneux 414

Ferdinando (o Fernando) IV, re di Castiglia 76, 78, 79, 81, 86

Ferdinando il Cattolico, re di Spagna 306,320

Ferentino 245

Feria 90

Ferrante d'Aragona, re di Napoli 408 Ferrara 254, 264, 265, 354, 360, 368, $369,371,373,374,379,398,401$, 410

Ferrour, Johanna 5, 5n

Fiandra Marittima 46, 346

Fiandre 2, 17-47, 50n, 54, 56n, 57, $63 \mathrm{n}, 103,251 \mathrm{n}, 317,345,393,396$, 404, 405, 411

Filippo, conte d'Alsazia 26

Filippo II re di Spagna 26, 38, 47

Filippo il Buono, duca di Borgogna 43 Filippo IV, il Bello re di Francia 22, 30, 31

Filippo l'Ardito, duca di Borgogna $41 \mathrm{n}, 42,42 \mathrm{n}$

Filippo VI, re di Francia 36, 406

Filippo, conte di Savoia e Borgogna $243 n$

Firenze X, 3, 15, 17, 40, 93-95, 99, $102,103,126,136,138,251 \mathrm{n}, 253$, 254, 260, 277, 278, 287, 291, 295, 299, 302, 302n, 303, 303n, 306n, $313,326,340,344,354,360,379$, 382n, 386, 387, 390, 392-395, 397, $398,401,402,405,406,409$

- Camera del Comune 287

- contrada di Camaldoli 290

- loggia de' Tavernai 406

- Mercato Vecchio 361, 406

- Prato Ognissanti 406

- Oltrarno 290

- Ospedale de' Pinzocheri 406

- palazzo dei Priori 406 
- palazzo dell'Arte della Lana 288

- palazzo del Podestà 288,362

- piazza della Signoria 290, 362, 363

- piazza San Marco 290, 300

- piazza di Santa Maria Novella 406

- Stinche 287, 362

FitzOsbert, William detto 'Longbeard' 12

Flageolet, Jehan di Favresse 413

Foglizzo 186

Fois, B. 96n, 97

Foligno 357

Forez, monti del 56, 60

Forlì 254, 389

Forteguerra, famiglia 392

Fossier, R. 50, 305

Fourquin, G. 18, 18n, 50, 325, 327, 338

Franc de Bruges 31

Franca Contea 62, 316n

Franceschi, F. 100, 332, 340n

Franceschini, G. 206, 208n

Franceschino di Guido, podestà 208

Francesco d'Agnolo detto Burbicone o Barbicone 284

Francesco D'Assisi 335

Francia IX, 2, 3, 5, 17, 18, 21-23, 25, $26,29,31,38,40,49-71,113,124$, $131 \mathrm{n}, 133,140,146,153,154$, $251 \mathrm{n}, 305,308,316,332,333$, $341 \mathrm{n}, 344,345,348,387,395,399$, 411, 414-416, 420

Francino di Naddo, Capitano del Popolo 285, 286

Francoforte 114, 117, 119, 125, 132, 151,410

Francoforte sul Meno 134

Franconia 125

Franz, G. 320

Frignano, montagna del 254
Fris, V. 43

Froissart, Jean cronista 51, 52, 317

Front 165, 174, 193

Frusinate, monti del 224

Fubini, R. 354, 354n

Gabotto, F. 155, 171n, 175, 183, 184, $184 n$

Gaggio Montano 264

Galasso di Montefeltro 254

Galbert de Bruges 26n

Galisano 272n

Galizia 75, 77, 79, 89

Galle, Anselmo 239n

Galles 10, 13

Galliani, Antonio 190

Galliani, famiglia 190

Galliera 259

Galluzzi, Paolo dottore in legge 269

Gamberini, A. 197n, 198

Gambiglioni, Angelo 417

Gand 18, 23, 24, 24n, 25-28, 30, 31, $33,35-37,37 \mathrm{n}, 39-44,47,54,56$, 393, 396

Garghi de Capraria 264

Gasconi, famiglia 371

Gassino (Gaxinum) 190

Gaston Phoebus 68

Gâtinais 65

Gauvard, C. 51n, 52, 56

Genet, J.-Ph. 20

Genova 3, 188, 306n, 308, 341n

Gerardina, domina 268

Gerbaix, Pierre tesoriere 174

Geremei, famiglia 252, 270

Germania (Allemagne) IX, 30, 47, 105-152, 320

Germania Orientale 339

Gerona 319

Gerusalemme 335

Gesso di Zola Predosa, 275 
Gesso, valle di 248, 275

Giacomo di Geri, notaio 271

Giacomo, vescovo di Ventimiglia 235

Gibertino, frate 267

Giocoli, famiglia 374

Giordano, giudice e notaio 228

Giovanna D'Arco 333, 333n

Giovanna, contessa di Costantinopoli 26

Giovanni d'Andrucciolo di Pellolo 380

Giovanni da Ferrara, 373n

Giovanni di monna Tessa 284

Giovanni di Montalenghe dei conti di

S. Martino 177

Giovanni di Salamone 263

Giovanni di Valperga 160

Giovanni Grassus 212n

Giovanni I, re di Castiglia 77, 79, 80, 85,89

Giovanni II, marchese di Monferrato 162

Giovanni II, re di Francia 414, 420

Giovanni III, duca di Brabante 37

Giovanni XXII, papa 35, 210

Girardo, marchese di Ceva 235, 235n, 246, 248

Gistel 405

Gloucester 13

Gonzaga, famiglia 354, 355

González Mínguez, C. 75n, 83

Gorreta, A. 253

Goslar 120

Göttingen 120,

Gracia, Guillaume 413

Gran Paradiso 156

Granarolo 264, 265,

Grande Chartreuse 220, 224, 227

Grangetta 204

Grassi, famiglia 212, 215

Grassi, Gaspare 211
Graus, F. 151, 349n

Grazino di Girolamo di messer Grazia 280

Gregorio XI, papa 279

Greifswald, 115

Grimbsy 13

Guadalupe 306, 320

Guant, John of, duca di Lancaster 8, $8 n$

Guastavillani, famiglia 275

Guenée, B. 1n, 51, 332

Guglielmo del fu Giacomo, frate 269

Guglielmo di Ribaldo 274

Guglielmo, dottore e giudice 280

Guglielmotti, P. 219, 236, 240, 241

Guicciardini, Francesco 352

Guicciardini, Luigi Gonfaloniere di Giustizia 288

Guido, frate 267

Guido, priore 227

Guillaume Pentecôte 64n, 66

Guillelmus Carreta 239n

Guinigi, famiglia 392-394

Günther di Schwarzburg 114

Haemers, J. 43

Halbertstatdt 120

Hales, sir Robert camerlengo 5, 334

Halle 120, 135

Hameln 120

Hanchach, John 6

Hanovre 120

Hansa 24, 107, 112, 117, 118, 120, $121,123-125,127,148,149$

Harding, A. 385

Harelle 49

Heinrich Paternostermacher, mercante 126

Helmstedt 119, 120

Henry of Bracton, giudice 318

Herssent, Jehan 413 
Hertfordshire 410

Highbury 8, 334

Hildesheim 120, 129

Hill, Ch. 326

Hilton, R. 6, 11, 83, 326, 334n, 339

Historia Anglicana 384

Historia di Perugia 281, 292

Hobsbawn, E. 83

Holinshed, Raphael, cronista 387

Hollande, contea di 23

Horn, John alderman 7

Hoshino, H. 95

Hugonet, cancelliere 44

Hurtado de Mendoza, Juan 90

Huss, Jean 60, 326n

Hussiti 2, 7, 7n, 55, 105, 113, 138, 151, $151 \mathrm{n}$

Iacobus Alfardus 239n

Ile de France 56

Imola 254, 259, 260, 389

Imworth, sir Richard, 387

Incino, pieve di 210

Inghilterra IX, 1-15, 24, 30, 40, 54, $317,326,334,343 n, 336,345,348$, $385,389,393,395,410,411$

Innocenzo III, papa 231, 232

Innocenzo IV, papa 232, 233, 235n

Inzago 200, 202

Isère 225

Italia 2, 4, 5, 24, 38, 38n, 54, 93-104, $113,115,116,155,196,198 \mathrm{n}, 217$, 251, 251n, 273, 273n, 275, 300, $305,311,315,333 \mathrm{n}, 324,332$, 338n, 340n, 341, 341n, 342, 342n, $343,343 \mathrm{n}, 344,345,346 \mathrm{n}, 348 \mathrm{n}$, $353,354,358,360,387 \mathrm{n}$

Ivrea 156, 156n, 157, 158n, 159, 161, $162,165,174,177,181,182 \mathrm{n}$, 189-192, 194
Jacquerie 2, 4, 35, 53, 56, 57, 61, 62, $73,93,95,99,332,337 \mathrm{n}, 338 \mathrm{n}$, $340,344,348,411,414$

Jobst de Moravie 114

Kaufbeuren 117

Kazmeier, Jörg, 'maire' 141

Kempten 147

Kent 5, 6, 8, 317, 386, 410

Kunzelmann, famiglia 129

Kunzelmann, Ulrich 115

L'Aquila 97

La Salle 178

La Thuile 178

Lago Maggiore 201

Lambertazzi, famiglia 251, 252, 254, 255,356

Lancaster 8

Langue d'oil 53

Languedoc 53, 59, 67-69, 154, 412, 414

Lantschner, P. 382n, 383n

Lanzo 187

Laon $28,51,53,62,63,316,399$

Lario 205

Law, J. 373

Lazio 97, 221

Lazzari, T. 251

Le Roy Ladurie, E. 60n, 61

Lecco 198, 201, 204, 205, 210, 211, 213-215

Lecuppre-Desjardin, E. 17n

Ledesma, 386

Legett, Roger giurista 386

Legge, John serjeant-at-arms 386

Lendinara $253 n$

Leningrado 99

Léon 75, 77, 79

Lessolo 177, 182

Leuci 204 
Licinio, R. 96

Liegi 12, 22, 28

Liguria 308

Lille 23, 27, 28, 31, 36

Limousin 68

Limoux, 60

Lincoln 11n, 12

Lindau 115, 132

Lione $51 \mathrm{n}, 55$

Lipsia 323

Lister, Geoffrey tintore 6

Locana 194

Locate, pieve di 209

Lodève 67

Lodi 201, 202

Loira, fiume 56

Lollardi 6, 317, 326n, 334, 334n

Lombardia 197, 198, 314

Londra 4, 6-8, 11-14, 30, 136, 138, $149,383,386$

- cattedrale di St. Paul 14

- palazzo dell'abate 14

- prigione di Fleet 386

- prigione di Marshalsea 386

- saint Mary-le-Bow, chiesa 12

- Southwark 386

- temple 386

- torre di 5

Longaruccio di S. Agnelo 280

Loranzé 174, 177, 194

Lorenzetti, Ambrogio 419

Losa, Certosa della 221, 222, 224, $225,226,227,227 \mathrm{n}$

Louneburg 107

Lubecca (Lübeck) 111, 121, 126-129, 133, 134, 136, 147, 148

Luca, marchese di Ceva 247

Lucca 314, 392-394, 397, 398, 406

Luce, S. 49

Ludovico il Bavaro, imperatore 213, 365
Lugo, 84, 87, 88

Luigi IV di Baviera 106, 114, 125

Luigi IV di Wittelsbach 114

Lunebourg 120, 127

Lupi, famiglia 356

Lusiglié 186

Lussemburgo, dinastia 115, 149

Lutero, Martin 150

Lys, valle del 35, 41

Macfarlane, A. 15

Machiavelli, Niccolò 353n, 354, 360, 363, 364

Maçincolli 264, 264n

Magdeburgo (Magdebourg) 119, 120 , $132,134,135,140,145$

Maghinardo Pagani da Susinana 254, 258

Maiella 330n

Maillotins 49, 54

Mainoni, P. 197n, 210, 214

Maire-Vigueur, J. C. 96n, 97, 328, 328n, 343n.

Malavolti, Carlo di messer Francesco 284

Malavolti, famiglia 283, 285

Malines 36

Manfredo, frate 237

Mangiavacca, Basilio notaio 264

Mantova 253n, 254

Manzolino 258

Marcel, Etienne 17, 30, 39, 49, 53, 56, $332,413,414$

Marchand, Guigues 167

Margherita di Costantinopoli, contessa 26, 27

Marin Sanudo 417

Marittima 232, 232n, 233, 244n

Marna, fiume 413

Martesana, canale 199

Marx, K. 327 
Maschke, E. 123, 128

Masino, conti di 158, 163, 164, 164n, $173,175,184,184 \mathrm{n}$

Massiccio Centrale 52n, 57

Mathi 170

Matilde, vedova di Filippo di Alsazia 26

Mayence 111, 118

Mazzé, famiglia 162, 164, 165, 175, $185,190 \mathrm{n}, 191 \mathrm{n}$

Meaux 62, 412

Meaux, abbazia di 9

Mechelen 410

Meda, monastero di 208

Medici, Cosimo dei 398

Medici, famiglia 354, 361, 362

Medici, Lorenzo il Magnifico 354, 398

Medici, Piero 354

Medici, Salvestro dei 102, 286, 287, 296n, 354n

Medicina 263, 265, 272n

Medina del Campo 76

Meisterlin, Sigismund cronista 147

Melis, F. 100

Mello, battaglia di 53

Memmingen 117, 135, 136

Menolzio (Menons, montem de) 225, 226, 226n,

Meugliano 182

Michele di Lando 288, 290, 299

Michelet, J. 17

Michelotti, famiglia 280

Middlesex 386

Midi 54, 56, 57, 66

Miglio, M. 328

Milano 159, 188, 189, 197-216, 254, $354,389,390,410$.

Mile End 7, 8, 383, 386

Minden 120, 129

Minerbio 265
Mínguez, J. M. 74n, 83

Mirabello, famiglia 38, 38n

Mirot, Léon 49

Modena 253, 253n, 254, 255, 261, 266, 272, 273, 276,

Molho, A. 95

Molina 79, 90

Mollat, M. IX, 18, 19, 41, 50, 51, 53-

$56,124,296,326,334,337,338$

Mombracco 248

Mondovì 235n, 237n, 240, 247

Monferrato 155, 157n

Monmaggiore, abate di 376

Monnet, P. 339

Monselice 314

Montagnes 90

Montalcino 96

Montalenghe, castello di 158

Montalto 177, 178, 187

Montanari, M. 96, 96n, 97

Montataire 413

Montbrison 56

Montebenedetto, Certosa di 221, 222, 224-226, 226n, 227, 227n, 227n, 242,242 n, 248

Montepessulano 56

Montereau 60n

Montestrutto 177, 178

Monteveglio, castrum di 257

Monteveglio, pieve di 273

Montpellier 67

Montréal 101

Monza 198, 208-215

Morel, Jehan, curato 413

Moreta, S. 83

Morghen, R. 324

Morigia, Bonincontro cronista 212, $212 n$

Morigia, Giovanni 211

Morimondo 204

Morini Thome 243n 
Morozzo, signori 228, 229, 235, 235n, 236

Mosa, fiume 24

Mosca, 99

Mosca, G.19

Mousnier, R. 18n

Mucciarelli, R. 96n, 97, 309

Muffel, Niklas 116

Mugello 313

Mülnheim, famiglia 128

Monaco (Munich) 133, 136, 141, 142

Mur, prigione del 60

Murcia 77

Muzza, torrente 254, 256,

Najemy, J. 286n, 296, 303n

Napoli 164, 344

Narbonne 69, 414

Navarra 64n, 95

Neri di Donato, cronista 393

Neveux, H. 337

Newgate, prigione di 386

Nicholas, D. 393

Nico Ottaviani, M.G. 96n, 97

Nicola da Monzuno, capitano 266

Nicola Marchisio, balivo 180

Nicolò da Eboli, siniscalco 242

Nicolò III, papa 252

Nîmes 56, 67, 69

Nivernais 316

Nivolet, colle del 156, 178

Nonantola 262, 265, 276,

Nordhausen 132

Nördingen 114, 117, 119

Noreña, conte di 89

Norfolk 6

Norimberga 114, 116, 117, 124, 136, $137,147,151,410$

Normandia 53, 54, 56, 339, 341, 342n

Northampton 13, 384, 385

Norwick 11
Novara 201, 207, 309

Novareglia 182

Noyon, diocesi di 413

Nuto da Città di Castello, 'bargello' 386

Oberto, vescovo 240

Odofredi, Paolo giurisperito 269

Oggiogno 309

Oldrado da Ponte 416

Onorio III, papa 231-233

Orchies 23, 31

Orense 84, 87

Oresme, Nicolas 39

Origgio 200, 208, 210

Orléans 65

Ormea 223

Orseria (o Orsiera), valle di 222, 225, 225n, 226

Owain Glyn Dŵrr 10

Oxford 12, 13

Ozegna 157

Padova 354, 360, 379, 390

Paesi Bassi IX, 17n, 21, 22, 24n, 26, 31n, 38, 38n, 47

Pagani da Susinana, Maghinardo 254, 258

Pagani, famiglia 247

Paglietta 228

Palazzago 210

Palencia 84, 87

Palmerio di Reano 226n

Panaro, fiume 253, 254, 259,271,

Panigale Vecchio 265

Panzano 256

Paolo di Berarduccio 281

Paredes de Nava 90

Parella 194

Pareto, V. 19

Parigi 15, 29, 30, 36, 37, 39, 53-57, 59, 
60, 64, 65, 103, 136, 138, 149, 335, Phoebus, Gaston 68

393, 395, 405, 408, 413, 414, $420 \quad$ Piacenza 97, 254

Parma 206, 254, 356

Parra 90

Piccardia 54, 56

Parte Guelfa 199, 286, 287, 289, 299, Piccinni, G. 95n, 96, 96n, 97 406

Pasquale II, papa 335

Passaggeri, Rolandino 252, 252n

Pastoureaux 60

Patria, L. 225n, 226n

Pavia 207, 209

Pazzi, famiglia 286, 362

Pecciolo 280

Pedagna (Pedagnie) 194

Pellini, P. 281, 291, 292

Pentecôte, Guillaume 64n, 66

Pepoli, Romeo banchiere 257, 259, 262, 274, 275, 276.

Perugia 93, 97, 99, 103, 277, 278n, 279-282, 292, 301, 340, 347, 357, 360, 376, 379, 385

- chiesa di Sant'Agostino 281

- chiesa di san Lorenzo 280

- monastero di san Pietro, monastero 311

Picco, Giacomo 187

Piccolomini, famiglia 283

Picquigny, Jean de 68

Piemonte 153, 155, 157, 162, 163, $165,167,169,172,174,177,180$, $182,183,187,189,190$ n, 196, 229, 235, 240, 242

Pieter de Coninc, tessitore 30

Pietro Cantore 335

Pietro Cavalerio, castellano 239, 239n

Pietro I re di Castiglia 348

Pietro, frate 237

Pinerolo 176

Pini, A. I. 313

Pinto, G. 96, 251n, 303n

Pintoin, Michel cronista 3, 71

Pirenne, H. 18, 22, 23n, 26n, 28, 34, $35 \mathrm{n}, 43$

Pisa 306n, 360, 365, 379, 392

Pisserguier 414

Pistoia 390

- palazzo dei Priori 288, 376, 386

- porta Santo Angelo 281, 281n

- porta San Pietro 280

- porta Sole 280, 376

Perthois 413

Pertica, castello di 160

Pesio, Chiusa 235

Pesio, fiume 236

Piumazzo 260, 273, 274n

Po, fiume 156, 161, 248

Poitiers, Alphonse de 66

Pollicino 265, 266

Poloni, A. 366, 367

Pombia, conti di 156, 156n, 157n

Pomerania, lega di 119

Pomiers, certosa di $227 \mathrm{n}$

Pesio, Santa Maria, Certosa di 219, Pons Biordon, castello di 70 221-223, 223n, 224, 228, 235n, 239, 239n, 241, 243, 245, 246

Pesio, valle del 223n, 227n, 228, 235n, 236, 247

Peste Nera 7, 9, 94, 106, 112, 114, 151, 337, 342, 346, 348

Pont, borgo di 159, 160, 168

Pontida 210

Pontoise 31, 33

Pont-Saint-Esprit 70

Poperinge 34

Praga 138

Prak, M. 21

Petrarca, Francesco 328, 328n 
Prestwich, M. 9

Prodi, P. 119n

Provana di Collegno, F. S. 242n, 248

Provenza, contea di 396

Provins 28, 55n, 56, 64-66

Puyol, J. 82

Quagliuzzo 194

Querini, Marco 397

Ragusa 399

Raimunda, prioressa 226n

Rangoni, famiglia 254

Raspanti, famiglia 279-281, 291, 292

Ratisbona 115, 129, 133, 144, 151

Ravenna 254,

Ravensbourg 117

Ravone, fiume 262, 265,

Reggio Emilia 253, 253 n., 254,

Regni, C. 96n, 97

Reims 222, 399

Renania 24, 124, 132

Reno, fiume 24, 25, 114, 118, 124, 128,133 .

Reno, fiume bolognese 259, 262, 263, 265, 266

Reposoir, certosa di $227 \mathrm{n}$

Rho 209

Riccardo II, re di Inghilterra 5, 10, 383

Riccardo, cardinale 232n

Rienoldt, patrizio 115

Riganelli, G. 96n, 97

Rimini 254

Riolo 258, ,

Riots 11

Ripaille 165, 179

Rivara, signori di 162, 164, 175, 185, 186

Rivarolo 157, 170, 171, 174, 176

Rivoli a Cirié 174
Rocca Corneta 264

Roche Bone, castello di 88

Rodano, fiume 69

Rodolfo d'Asburgo, imperatore 252

Rodolfo il Verde, prevosto 222

Rodolico, N. X, 100, 286n, 277, 296

Rolando da Lucca 313n

Roma 4, 30, 41n, 134, 251n, 323n, $344,407 n, 410$

Romagna 252, 254, 269, 276,

Romeo, R. 201

Rondinelli, Andrea 287

Roosebeke 54

Rösener, W. 320, 338

Rossi, famiglia 356

Rostock 123, 136

Roth, famiglia 129

Rothenbourg 115, 133, 136, 137

Rotonaria 231

Rottweil 132, 387

Rouen 28, 39, 53-56, 406

Rouergue 68

Rouget, Mermet 167

Roussillon

Rovigo 253n

Rubenow, Heinrich 115

Rubinstein, N. 95

Rucellai, famiglia 362

Ruggieri 280, 367

Rusca, Corrado 206

Rusca, famiglia 212

Rutenburg, V. 99, 100, 277, 278n, 280n, 296, 339, 340, 411

Saboto, Giovanni, ufficiale delle biade 269

Sacro Palazzo 228

Saint Albans 6-8

Saint-Bertin 51, 56n, 63n

Saint-Denis 51, 62n, 64, 68, 69, 71, 332 
Saint Edmund, abbazia di 13

Saint Emmeram, convento di 144

Saint-Flour 69, 413, 414

Saint-Galmier 56n

Saint-Malo 61

Saint-Martin Le Grand, chiesa 386

Saint-Omer 23, 28, 56n, 63n

Saint-Quentin 28, 61

Saint-Trond 28

Saint-Verain 413

Salimbene, Zanasio, podestà 204

Salimbeni, famiglia 282-286

Saluzzo 229.

Samoggia, fiume 263, 265

S. Carlo Canavese 156n

S. Francesco al Campo 156n

S. Giorgio, Bartolomeo di 185

S. Giorgio, borgo di 158

S. Giorgio, signori di 157, 157n, 158, $159,162,166,170,175,185,186$, 190

S. Giorio 242, 242n, 243n

S. Giovanni in Persiceto 254, 263, 265

S. Giovanni, ospedale di 8

S. Martino, signori di $157,158,158 \mathrm{n}$, 159, 160, 163-165, 167, 168, 170, $172-177,181,183,185,188,190$, 190n, 191

S. Maurizio 187

san Bartolomeo, Certosa di 231, 245

san Chierico di Calcara, chiesa di 273

san Giorgio, insegne di 8

San Giusto Canavese, 156n

san Giusto di Susa, abbazia di $227 \mathrm{n}$

San Lorenzo in Funo 272n

san Lorenzo, convento di 268

san Matteo 134

san Maurizio, monastero di 199

san Michele, grangia di 247

san Nicolò, chiesa di 273 san Paolo di Cantù, chiesa di 212n

san Pietro di Modena, monastero di 273

san Pietro di Perugia, monastero di 311

san Procolo, monastero di 267

san Salvatore, convento di 267

san Valeriano 243n

san Venanzio, chiesa di 358

San Vitale 263, 265, 266

san Zaccaria di Venezia, monastero di 314

sant' Agata 254, 256, 258, 260, 262, 265, 276

sant' Agostino di strada Maggiore, monastero di 267

Sant'Albano Stura 249

sant'Ambrogio, monastero di 199, 201, 202, 207, 210

sant'Angelo, chiesa di 232,

sant'Angelo in Pescheria, chiesa 329

sant'Antonino di Chiusa, chiesa 237

santa Maria di Castel dei Britti, monastero di 267

santa Maria di Valverde, monastero di 267

santa Maria in Trastevere, chiesa di 233

Sancio IV, re di Castiglia 74-76

Sandwich 5

Sanremo 308

Santiago di Compostella 84, 87, 88

santo Spirito in Sassia, ospedale 329

Saracini, famiglia 283

Sardegna 97, 310, 316n

Sarnow, Carsten, mercante 127

Savena, fiume 262, 263, 265, 268

Savignano sul Panaro 254, 259, 260

Savoia 62, 227, 183, 316, 316n

Savoia, Amedeo V conte di 192

Savoia, Amedeo VI conte di, detto 
Conte Verde 162-164, 164n, 165, 170, 171, 192

Savoia, Amedeo VII conte di, detto

Conte Rosso 153, 164, 164n, 165, 165n, 166-169, 171-176, 179, 184187, 189, 190, 190n, 191, 192

Savoia, Amedeo VIII conte di 248

Savoia, Carlo II, duca di 154

Savoia, famiglia 153, 155, 161, 248

Savoia, Filippo conte di 243

Savoia, Tommaso I conte di 225-227, $227 \mathrm{n}$

Savonarola, Girolamo 60

Sassonia (Saxe) 127

Sbriccoli, M. 400, 404n, 415, 417

Scarborough, 6

Schelda, valle della 24, 25, 35

Schöppenchronik de Magdebourg $139 \mathrm{n}$

Schwarz, Ulrich 115, 116

Schweidnitz 147

Scott, J. C. 4, 22

Scotti, Alberto 206

Secondotto, marchese di Monferrato 162

Segher, Jonssone 405

Segnoretus $o$ Segnorinus, sacerdote 237

Seibt, G. 328

Senna, fiume 25, 406, 408

Seprio 199, 201

Sepulveda 90

Seregno 208

Serpentera 221n, 241

Serravalle 260,

Sestan, E. X, 95

Settimo 177-179

Sforza, famiglia 354

Sforza, Galeazzo Maria, duca di Milano 408

Sicilia 345
Siena 93, 99, 103, 150, 251n, 277, 279, 282-284, 292, 294, 302, 303, 314, $340,344,347,390,392,394,397$, 398, 408

- borgo d'Ovile 285

- Compagnia del Bruco 284-286, 292, 293, 393, 394

- contrada del Bruco 392-393

- contrada di Ovile 292, 293, 295, 393

- Palazzo pubblico 284, 285, 419

- piazza del Campo 286

- porta di San Marco 408

Sigismondo di Lussemburgo, imperatore 114,117

Simoncino detto Bugigatto 296, 297

Simone Fornero di Settimo 187

Skaskin, S.D. 323

Smithfield 383, 387

Soderini, Piero 420

Soldaderii, Uguccione procuratore 260

Sorbona 326

Sornachi, Nuccino guelfo 406

Souabe 117, 119

Spagna 47, 90, 385

Speyer 387

Spira 114, 115, 118, 129, 132, 133

Spoleto 96, 357

Stade 121

Stagno 257,

Stapledon di Essex, vescovo 13

Stefano de Normandis, cardinale 233, 234

Stella, A. 100, 101, 278n, 296, 299, $302,331,332 \mathrm{n}$

Stendal 119

Stephanus, frate vedi Crivolo, Stefano

Stettin (Stettino) 121

Stoccolma 136

Stolzhirsch, Siboto 115 
Storti Storchi, C. 214

Stralsund 120, 123, 127

Strambinello 177, 194

Strambino 158, 180, 193

Strasburgo (Strasbourg) 114, 115, 124, 134-136, 399

Strickland, M. 1

Stura di Lanzo, fiume 156

Suarez de Quiñones, Pedro 90

Suárez, L. 82

Sudbury, Simon arcivescovo 5

Suffolk 387

Surrey 9,410

Susa, abate di $235 \mathrm{n}$

Sussex 9, 317, 410

Svevi, dinastia 315

Sylve Bénite (Silva Benedicta), certosa di $225,226,226 n$

Symonem Fornerii de Septimo 179n

Tabacco, G. 299, 391n

Tebaldi, Dino 274n

Tebaldi, famiglia $274,274 \mathrm{n}$

Tebaldi, Nicolò, prestatore $274 \mathrm{n}$

Tecchiena 245

Tederisi, Bonifacio giurisperito 269

Temple 3, 65, 386

Tenda 235

Teodoro II Paleologo, marchese di Monferrato 166, 184-186, 189, 190

Tettacapra, Leonardo ufficiale ai mulini 271

Thierry (Terricius), converso 225, 226, 226n

Tichtl, Ulrich 142

Tignosi, Angelo di Palino 375

Tignosi, famiglia 378

Tilly, Ch. 19, 21, 32, 32n

Toledo 77, 78

Tolomei, famiglia 283, 285
Tolosa (Toulouse) 153, 159, 160, 169

Töpfer, B. 324

Toppler, Heinrich 115

Torino 155, 156n, 161, 167, 174, 183, 185

Torre Canavese 194

Torre dell'Uccellino 264, 265

Torriani vedi Della Torre

Toscana X, 55, 284, 311

Tossignano 260

Toubert, P. 205, 244

Tournai 28, 42, 51, 387, 408

Trastámara, dinastia 89

Traversella 182

Trentino 97

Trèves 114

Treviglio 209, 213, 214

Treviso 306

Trexler, R. 296

Trezzo 211

Tribuno 329

Trinci, Corrado 357

Trinci, famiglia 357

Trinci, Nallo 357

Tripodi, C. X

Trisio da Monzuno, capitano della montagna 266

Trisulti, Certosa di 220n, 221, 230, 233- 235, 239, 243-245

Trombetti Budriesi, A.L. 251n

Troyes 68, 399

Tuchini $49,51,52 \mathrm{n}, 54,57,59,59 \mathrm{n}$, 66-70, 74, 153-196, 317, 317n, $411,412-414$

Tudor, famiglia 410

Turenne, visconte di 70

Tuscia $313 n$

Tyler, Wat 6-8, 383, 384, 387, 415

Ubaldini, Ruggeri degli, arcivescovo 367 
Ubeda, 85

Uccellino, castello dell' 264

Uchaud 69

Ugurgieri, famiglia 285

Ulm 115, 117, 118, 119, 129, 137

Ulrico, priore 228

Ülzen 120

Umbria 97, 311

Utrecht 22

Vagni detto il Priore 280

Val di Sambro 263, 265

Val sassina 204

Valdeón, J. 73n, 83

Valdigne 178

Valencia 89

Valera 203

Valladolid 78

Vallaise, signori di 178

Valle Caprina 181, 187n

Valle Chiusella 156

Valle d'Aosta 156, 161, 177, 178, 187

Valle dell'Orco 156, 178

Valle della Torre 226n

Valle di Brosso 153, 158, 182, 193, 194

Valle di Castelnuovo 194

Valle di Chy vedi Valle Caprina

Valle di Lanzo 161

Valle di Pont 165, 168, 188

Valle di Susa 161, 162

Valle San Martino 210

Valle Soana 156, 159, 160, 187, 194

Vallese 184, 187, 189

Valmadrera 204

Valois, dinastia di re francesi 42,50 , 53,412

Valperga 180, 186

Valperga, signori di 157-160, 162$168,170,172-175,180,185,186$, $188,190,191,194$
Valsavaranche 178

Van Arteveldes, famiglia 17, 30

Van Arteveldes, Jacques 37, 38, 39, $45 n$

Van Arteveldes, Philippe 41

Van de Lore, Boudin poeta 44

Vandea 19

Vanderkindere, L. 17, 18

Variolo di Monuccio, speziale 280

Vauchez, A. 333n

Vauda Canavese 156n

Vaudemont, conte di 413

Velay 60

Veneto 97, 253n, 314

Venezia 210, 212, 252, 253, 261, 306n, $314,368,386,389,394,396,408$

Ventimiglia, vescovi di 235, 235n

Verbania 309

Vercelli 201

Vermenagna, valle di 248

Verona 354, 355

Verrua 183n, 187

Via Emilia 255

Via Saragozza 268

Vic 319

Vico 4, 182, 233, 234, 245

Vigevano 214

Villafalletto 219

Villamaggiore 204

Villani, Giovanni cronista 146, 206, 275, 344, 352, 360-365.

Villani, Matteo, cronista 146

Villanova 170

Villanova di Borgone 243n

Villar Focchiardo 221, 226, 226n, $227 \mathrm{n}$

Vincennes 54

Violante, C. 324, 325

Vione 204

Vische, signori di 190n

Visconti, Azzone 205, 212, 213, 215 
Visconti, Bernabo' 355

Visconti, famiglia 159, 162, 197 197n, 198, 206, 207, 210, 211, 213, $215,216,354,355,398$

Visconti, Filippo Maria 216

Visconti, Galeazzo 197, 199, 205-207, 209-211, 213, 215

Visconti, Galeazzo II 214n

Visconti, Giangaleazzo 163, 175, 185, 188, 189, 190, 197, 216, 364, 375

Visconti, Lodrisio 211

Visconti, Matteo 199, 202-211, 213, 215, 254, 355

Visconti, Nino signore di Pisa 365, 366

Visconti, Ottone arcivescovo 197n, 202

Vitalini, Bonifacio 417

Viterbo 4, 360, 375, 378-380

Vitolo, G. 96n, 97

Vives, J. V. 320

Volta a ovest del Reno 265, 266

Von Vechelde, Hermen 141

Vroil 413

Waldmann, Hans 115

Walsingham, Thomas 384

Werner, E. 324, 324n, 325

Westminister

Westrozebeke 41, 42
Wetteravie, lega di 119

Wetzlar 133, 134

Williams, G. 13

Wiltshire 9

Winchester 9, 11, 384, 385, 389

Wittelsbach, dinastia 149

Wolff, Ph. IX, 18, 19, 41, 50, 51, 54$56,124,296,326,334,337,338$

Worms 114, 118

Wrawe, John 6

Wurtzbourg 133, 139n, 142, 147, 151

Wycliffe 334, 334n

York 6, 10-12

Yorkshire 9, 10

Ypres 23, 24, 27-29, 31-35, 37, 41, 42, 53,396

Zaccaria di Argelato, frate 269

Zafra 90

Zamora 85

Zampante, Gregorio capitano di giustizia $403,403 n$

Zanarini, M. 272,

Zarri, G. 333n

Zegher Janszone 36

Zoagli, Damiano vescovo $245 n$

Zorn, famiglia 128

Zurigo 115, 132, 134, 410

Zwin, estuario 24 


\section{AUTORI}

Alessandro Barbero, Università del Piemonte Orientale "Amedeo Avogadro".

GiUlia BARONE, Università degli Studi di Roma "La Sapienza".

Marc Boone, Universiteit Gent.

Monique Bourin, Université de Paris 1-Pantheon - Sorbonne.

VALERIA BRAIDI, Università degli Studi di Bologna.

Giovanni Cherubini, Università degli Studi di Firenze.

SAMUEL CoHn, University of Glasgow.

RINALDO COMBA, Università statale di Milano.

Franco FranCESCHI, Università degli Studi di Siena - sede di Arezzo.

PaOlo Grillo, Università Statale di Milano.

Jean-Claude Maire Vigueur, Università degli Studi di Roma 3.

Pierre Monnet, Ècole des Hautes Ètudes en Sciences Sociales, Paris.

Hipolito Rafael Oliva, Universidad de Sevilla.

Francesco Panero, Università degli Studi di Torino.

Giuliano Pinto, Università degli Studi di Firenze.

ANDREA ZorZI, Università degli Studi di Firenze. 



\section{Biblioteca di Storia}

Bertini F., La democrazia europea e il laboratorio risorgimentale italiano (1848-1860)

Bicchierai M., Una comunità rurale toscana di antico regime. Raggiolo in Casentino

Bourin M., Cherubini G., Pinto G. (a cura di), Rivolte urbane e rivolte contadine nell'Europa del Trecento. Un confronto

Corsi D., Duni M. (a cura di), «Non lasciar vivere la malefica $\gg$. Le streghe nei trattati enei processi (secoli XIV-XVII)

Lorini A., An intimate and contested relation. The United States and Cuba in the latenineteenth and early twentyeth

Zorzi A., La trasformazione di un quadro politico. Ricerche su politica e giustizia a Firenze dal comune allo Stato territoriale

Zorzi A. (a cura di), La civiltà comunale italiana nella storiografia internazionale. Atti del I convegno internazionale di studi (Pistoia, 9-10 aprile 2005) 
Finito di stampare presso

la tipografia editrice Polistampa 